\title{
nanomaterials
}

\section{Nanocolloids for Nanomedicine and Drug Delivery}

Edited by Stefano Leporatti Printed Edition of the Special Issue Published in Nanomaterials 
Nanocolloids for Nanomedicine and Drug Delivery 



\section{Nanocolloids for Nanomedicine and Drug Delivery}

Special Issue Editor

Stefano Leporatti 
Special Issue Editor

Stefano Leporatti

CNR Nanotec-Istituto di Nanotecnologia

Italy

Editorial Office

MDPI

St. Alban-Anlage 66

4052 Basel, Switzerland

This is a reprint of articles from the Special Issue published online in the open access journal Nanomaterials (ISSN 2079-4991) from 2017 to 2018 (available at: https://www.mdpi.com/journal/ nanomaterials/special_issues/Nanocolloids_Nanomedicine)

For citation purposes, cite each article independently as indicated on the article page online and as indicated below:

LastName, A.A.; LastName, B.B.; LastName, C.C. Article Title. Journal Name Year, Article Number, Page Range.

ISBN 978-3-03897-427-7 (Pbk)

ISBN 978-3-03897-428-4 (PDF)

Cover image courtesy of Stefano Leporatti.

(C) 2018 by the authors. Articles in this book are Open Access and distributed under the Creative Commons Attribution (CC BY) license, which allows users to download, copy and build upon published articles, as long as the author and publisher are properly credited, which ensures maximum dissemination and a wider impact of our publications.

The book as a whole is distributed by MDPI under the terms and conditions of the Creative Commons license CC BY-NC-ND. 


\section{Contents}

About the Special Issue Editor $\ldots \ldots \ldots \ldots \ldots \ldots \ldots$ vii

Preface to "Nanocolloids for Nanomedicine and Drug Delivery" . . . . . . . . ix

Valeria De Matteis, Mariafrancesca Cascione, Chiara Cristina Toma and Stefano Leporatti

Silver Nanoparticles: Synthetic Routes, In Vitro Toxicity and Theranostic Applications for Cancer Disease

Reprinted from: Nanomaterials 2018, 8, 319, doi:10.3390/nano8050319 . . . . . . . . . . . . .

Flavio Nucciarelli, Iria Bravo, Sergio Catalan-Gomez, Luis Vázquez, Encarnación Lorenzo and Jose Luis Pau

High Ultraviolet Absorption in Colloidal Gallium Nanoparticles Prepared from Thermal Evaporation

Reprinted from: Nanomaterials 2017, 7, 172, doi:10.3390/nano7070172 _ . . . . . . . . . . 2

Cha Yee Kuen, Sharida Fakurazi, Siti Sarah Othman and Mas Jaffri Masarudin

Increased Loading, Efficacy and Sustained Release of Silibinin, a Poorly Soluble Drug Using Hydrophobically-Modified Chitosan Nanoparticles for Enhanced Delivery of Anticancer Drug Delivery Systems

Reprinted from: Nanomaterials 2017, 7,379, doi:10.3390/nano7110379 _ . . . . . . . . . . 36

Nemany A. Hanafy, Luciana Dini, Cinzia Citti, Giuseppe Cannazza and Stefano Leporatti Inihibition of Glycolysis by Using a Micro/Nano-Lipid Bromopyruvic Chitosan Carrier as a Promising Tool to Improve Treatment of Hepatocellular Carcinoma Reprinted from: Nanomaterials 2018, 8, 34, doi:10.3390/nano8010034 . . . . . . . . . . . . . . . 53

Dominik Weber, Bernhard Torger, Karsten Richter, Michelle Nessling, Frank Momburg, Beatrice Woltmann, Martin Müller and Reinhard Schwartz-Albiez Interaction of Poly(L-lysine)/Polysaccharide Complex Nanoparticles with Human Vascular Endothelial Cells

Reprinted from: Nanomaterials 2018, 8, 358, doi:10.3390/nano8060358 . . . . . . . . . . . 65

Magdalena Osial, Paulina Rybicka, Marek Pękała, Grzegorz Cichowicz, Michał K. Cyrański and Paweł Krysiński

Easy Synthesis and Characterization of Holmium-Doped SPIONs

Reprinted from: Nanomaterials 2018, 8, 430, doi:10.3390/nano8060430 . . . . . . . . . . . . 82

Anna V. Stavitskaya, Andrei A. Novikov, Mikhail S. Kotelev, Dmitry S. Kopitsyn,

Elvira V. Rozhina, Ilnur R. Ishmukhametov, Rawil F. Fakhrullin, Evgenii V. Ivanov,

Yuri M. Lvov and Vladimir A. Vinokurov

Fluorescence and Cytotoxicity of Cadmium Sulfide Quantum Dots Stabilized on Clay Nanotubes

Reprinted from: Nanomaterials 2018, 8, 391, doi:10.3390/nano8060391 . . . . . . . . . . . . 97

Yu-Jen Lu, Pin-Yi Lin, Pei-Han Huang, Chang-Yi Kuo, K.T. Shalumon, Mao-Yu Chen and Jyh-Ping Chen

Magnetic Graphene Oxide for Dual Targeted Delivery of Doxorubicin and

Photothermal Therapy

Reprinted from: Nanomaterials 2018, 8, 193, doi:10.3390/nano8040193 . . . . . . . . . . . . 108 
Yi Teng Fong, Chih-Hao Chen and Jyh-Ping Chen

Intratumoral Delivery of Doxorubicin on Folate-Conjugated Graphene Oxide by In-Situ Forming Thermo-Sensitive Hydrogel for Breast Cancer Therapy

Reprinted from: Nanomaterials 2017, 7, 388, doi:10.3390/nano7110388 .

Jieru Qiu, Lingdan Kong, Xueyan Cao, Aijun Li, Ping Wei, Lu Wang, Serge Mignani, Anne-Marie Caminade, Jean-Pierre Majoral and Xiangyang Shi

Enhanced Delivery of Therapeutic siRNA into Glioblastoma Cells Using Dendrimer-Entrapped

Gold Nanoparticles Conjugated with $\beta$-Cyclodextrin

Reprinted from: Nanomaterials 2018, 8, 131, doi:10.3390/nano8030131 . . . . . . . . . . . . . . 152

Muhammad Sani Usman, Mohd Zobir Hussein, Sharida Fakurazi, Mas Jaffri Masarudin and Fathinul Fikri Ahmad Saad

Gadolinium-Doped Gallic Acid-Zinc/Aluminium-Layered Double Hydroxide/Gold Theranostic Nanoparticles for a Bimodal Magnetic Resonance Imaging and Drug Delivery System

Reprinted from: Nanomaterials 2017, 7, 244, doi:10.3390/nano7090244 . . . . . . . . . . . . 163

Yuge Feng, Chengliang Wang, Fei Ke, Jianye Zang and Junfa Zhu

MIL-100(Al) Gels as an Excellent Platform Loaded with Doxorubicin Hydrochloride for pH-Triggered Drug Release and Anticancer Effect

Reprinted from: Nanomaterials 2018, 8, 446, doi:10.3390/nano8060446 . . . . . . . . . . . . . 179

Rohini Atluri, Rahul Atmaramani, Gamage Tharaka, Thomas McCallister, Jian Peng,

David Diercks, Somesree GhoshMitra and Santaneel Ghosh

Photo-Magnetic Irradiation-Mediated Multimodal Therapy of Neuroblastoma Cells Using a

Cluster of Multifunctional Nanostructures

Reprinted from: Nanomaterials 2018, 8,774, doi:10.3390/nano8100774 . . . . . . . . . . . . . 190

Michael Evangelopoulos, Alessandro Parodi, Jonathan O. Martinez and Ennio Tasciotti

Trends towards Biomimicry in Theranostics

Reprinted from: Nanomaterials 2018, 8, 637, doi:10.3390/nano8090637 _ . . . . . . . . . . . 207

Nikita A. Navolokin, Sergei V. German, Alla B. Bucharskaya, Olga S. Godage,

Viktor V. Zuev, Galina N. Maslyakova, Nikolaiy A. Pyataev, Pavel S. Zamyshliaev,

Mikhail N. Zharkov, Georgy S. Terentyuk, Dmitry A. Gorin and Gleb B. Sukhorukov

Systemic Administration of Polyelectrolyte Microcapsules: Where Do They Accumulate and

When? In Vivo and Ex Vivo Study

Reprinted from: Nanomaterials 2018, 8, 812, doi:10.3390/nano8100812 . . . . . . . . . . . . 227

Antonio Lopalco, Annalisa Cutrignelli, Nunzio Denora, Angela Lopedota, Massimo Franco and Valentino Laquintana

Transferrin Functionalized Liposomes Loading Dopamine $\mathrm{HCl}$ : Development and Permeability Studies across an In Vitro Model of Human Blood-Brain Barrier

Reprinted from: Nanomaterials 2018, 8, 178, doi:10.3390/nano8030178 . . . . . . . . . . . . . 241

Agostina Grillone, Tianshu Li, Matteo Battaglini, Alice Scarpellini, Mirko Prato,

Shinji Takeoka and Gianni Ciofani

Preparation, Characterization, and Preliminary In Vitro Testing of

Nanoceria-Loaded Liposomes

Reprinted from: Nanomaterials 2017, 7, 276, doi:10.3390/nano7090276 _ . . . . . . . . . . . 251 


\section{About the Special Issue Editor}

Stefano Leporatti, PhD, received his Master's Degree in Physics at University of Genoa, and obtained his PhD in Solid State Physics at Max Planck Institute of Colloids and Interface Science with Prof. Dr. Helmuth Mohwald in 1999. From 2001 to 2006, he has been Research Scientist at the Institute of Medical Physics \& Biophysics, Universität Leipzig, Leipzig (Germany). From 2006 to 2008 he has been CNR Senior Researcher (University Associate Professor Equivalent) at the National Nanotechnology Laboratory (NNL) of CNR-INFM in Lecce, Italy (NanoBioMolecular Division of Prof. R. Rinaldi) and, since 2008, he has been their NanoCarriers and BioMechanics Group Leader. Since 2015, he has worked at the newly constituted CNR Institute of Nanotechnology, CNR Nanotec in Lecce (Italy) as Primo Ricercatore CNR (Research Professor). Web: http://nanotec.cnr.it/user/stefano.leporatti/. 



\section{Preface to "Nanocolloids for Nanomedicine and Drug Delivery"}

This Special Issue of Nanomaterials, "Nanocolloids for Nanomedicine and Drug Delivery", focuses on the new development of tailored nano-systems for targeted drug delivery. Nanomedicine is an interdisciplinary field in which nanotechnology, nanoscience, and nanoengineering interact with life sciences. It is expected to lead to the development of novel nanosystems, drugs, and other applications for diagnosis and therapy. Furthermore, nanoparticulates drug delivery is a new, attractive vehicle for transporting and releasing drugs to a targeted site.

Stefano Leporatti

Special Issue Editor 



\title{
Review \\ Silver Nanoparticles: Synthetic Routes, In Vitro Toxicity and Theranostic Applications for Cancer Disease
}

\author{
Valeria De Matteis ${ }^{1, *}$, Mariafrancesca Cascione ${ }^{2}$, Chiara Cristina Toma ${ }^{1}$ \\ and Stefano Leporatti ${ }^{3, *}$ \\ 1 Dipartimento di Matematica e Fisica "E. De Giorgi", Università del Salento, Via Monteroni, 73100 Lecce, \\ Italy; chiara.toma@unisalento.it \\ 2 Dipartimento di Scienze Biomediche e Oncologia Umana, Università degli Studi di Bari "Aldo Moro", \\ p.zza G. Cesare, 70124 c/o Policlinico Bari, Italy; mariafrancesca.cascione@unisalento.it \\ 3 CNR Nanotec-Istituto di Nanotecnologia, c/o Campus Ecotekne, Via Monteroni, 73100 Lecce, Italy \\ * Correspondence: valeria.dematteis@unisalento.it (V.D.M.); stefano.leporatti@nanotec.cnr.it (S.L.)
}

Received: 24 April 2018; Accepted: 8 May 2018; Published: 10 May 2018

\begin{abstract}
The large use of nanomaterials in many fields of application and commercial products highlights their potential toxicity on living organisms and the environment, despite their physico-chemical properties. Among these, silver nanoparticles (Ag NPs) are involved in biomedical applications such as antibacterial agents, drug delivery vectors and theranostics agents. In this review, we explain the common synthesis routes of Ag NPs using physical, chemical, and biological methods, following their toxicity mechanism in cells. In particular, we analyzed the physiological cellular pathway perturbations in terms of oxidative stress induction, mitochondrial membrane potential alteration, cell death, apoptosis, DNA damage and cytokines secretion after Ag NPs exposure. In addition, their potential anti-cancer activity and theranostic applications are discussed.
\end{abstract}

Keywords: silver nanoparticles; synthetic routes; toxicity; theranostics

\section{Introduction}

The unique physico-chemical properties of silver nanoparticles (Ag NPs) have attracted increasing interest from the scientific community [1] due to their high thermal conductivity, plasmonic properties, chemical stability and antibacterial ability [2]. The use of Ag is not new; it dates to the times of Hippocrates, who used it as antibacterial to manage ulcers [3]. Nowadays, Ag NPs are used in many commercial products including soaps, plastics, food, textiles, catheters, and bandages. It is calculated that around 383 products are based on nano Ag globally, corresponding to $24 \%$ of all nano-products in use. For this reason, researchers are attempting to understand the adverse effects on living organisms: numerous in vitro and in vivo studies have demonstrated their toxicity occurring by means of cellular pathway perturbations [4]; nevertheless, their mechanism of action is still unclear. A lot of factors (size, shape, morphology, surface chemistry, charge, coating/capping agents, agglomeration, purity) influence the biological activity of Ag NPs and as consequence the adverse effects are different in different cell types [5].

Another important feature of Ag NPs is their involvement in cancer treatment. Cancer is a disease characterized by uncontrolled cellular growth and spread, during which cells become unresponsive to the usual check-points, leading to tumor growth and metastasis [6]. However, chemotherapy does not specifically target drugs to cancerous sites, therefore exposing healthy cells to undesirable effects. Moreover, a large dose is required owing to its rapid elimination and nonspecific distribution [7]. For these reasons, the goal of nanomedicine is to identify cost-effective molecules that have high 
specificity and sensitivity in cells [8]. With this in mind, Ag NPs are a promising tool as anticancer agents in diagnostics and probing [9], with strong effects against different cancer cell lines offering many advantages [10]. Their better penetration, and the possibility to track Ag NPs in the body make them a more efficient tool in cancer treatment with less risk compared to standard therapeutic procedures [11]. The unique Ag NP properties, such as easy surface functionalization, optical properties, reproducible synthetic routes and high surface: volume ratio, makes them suitable for cancer treatment [12]. The optical properties can be tuned to have an absorption at specific wavelengths that is useful for imaging and photothermal applications in tissue [13]. Ag NPs can also be functionalized with different molecules such as DNA/RNA to selectively target different cells [14] and antibodies or polymers [15]. These last agents are important to extend the half-life time for in vivo circulation that is critical in drug and gene delivery applications [16]. In addition, Ag NPs are used as an ablation tool for cancer cells due their ability to convert radiofrequencies into heat [17].

Starting from these assumptions, in this review we focused on the synthetic routes used for the synthesis of Ag NPs (physical, chemical and green methods), the mechanism of their toxicity in cells and their potential applications in theranostics for cancer.

\section{Principal Routes of Ag NPs Synthesis}

Engineering nanoparticles (NPs) can be synthetized by different approaches: "top-down", and "bottom-up". The first means the nanoparticle synthesis comes from a bulk system, while bottom-up means they are obtained from nanoscaled materials starting from atomic level. The top-down is exploited in synthesis based on physical methods, whereas the bottom-up approach is useful for chemical or green procedures, and it is more suitable for obtaining monodispersed nanostructures with fewer defects [18].

\subsection{Physical Synthesis}

The use of physical methods allows the synthesis of nanoparticles in the absence of solvent, permitting the uniformity of Ag NPs size distribution compared to chemical routes [19].

The main routes of synthesis are listed below:

- Evaporation-condensation

One of the common physical routes is the evaporation-condensation method, using a tube furnace at atmospheric pressure, where the source material is centered in a furnace and vaporized into a carrier gas. Many types of NPs are synthetized using this technique, including Ag NPs [20]. However, this procedure presents many limitations, among them high consumption of energy, large time to achieve the operating temperature. Together with bulky shape instrumentation, this makes this technique of little use.

- Laser ablation

Ag NPs can be produced by laser ablation method, which permits the obtaining of uncontaminated colloids, even if the control of size is difficult. This method uses a laser beam as the energy source to induce ablation on a solid target material, which vaporizes into atoms and clusters, and successively the NPs are assembled in ambient media (gas or liquid) [21]. Pyatenko et al. [22] synthetized Ag NPs by a laser ablation, irradiating a bulk Ag with a $532 \mathrm{~nm}$ laser beam in pure water. They obtained 2-5 nm Ag NPs after use of high laser power and small spot sizes. Tsuji et al. [23] used focused and unfocused laser beam irradiation with two intensities (12 and $900 \mathrm{~mJ} / \mathrm{cm}^{2}$ respectively). They demonstrated a reduction in terms of NP diameter (from $29 \mathrm{~nm}$ to $12 \mathrm{~nm}$ ) with the decrease of laser wavelength. Amendola et al. [24] obtained stable solutions of Ag NPs in pure acetonitrile and $\mathrm{N}, \mathrm{N}$-dimethylformamide by laser ablation of the bulk metal with a size of $(1.9 \pm 1.5) \mathrm{nm}$ and $(2.2 \pm 2.5) \mathrm{nm}$ respectively (Figure 1a). 


\section{- Thermal decomposition}

Thermal decomposition is an endothermic chemical reaction induced by heat. The substances have a specific thermal decomposition that cause chemical decomposition. Therefore, the process permits the break-up of large molecules into smaller ones due to heat in an oxygen-restricted environment [25]. Ag NPs have also been synthesized using thermal decomposition method by Lee and Kang [26], using a solution of $\mathrm{AgNO}_{3}$ and sodium oleate. The synthesis of spherical Ag NPs with a size ranging from $9.5 \mathrm{~nm}$ to $0.7 \mathrm{~nm}$ was obtained by changing the temperature from room temperature to $290{ }^{\circ} \mathrm{C}$ for $1 \mathrm{~h}$. Navaladian et al. achieved [27] spherical crystalline Ag NPs (10 $\mathrm{nm}$ ) by thermal decomposition of Ag oxalate in water and in ethylene glycol, using polyvinyl-alcohol (PVA) as a capping agent, which reduces Ag oxalate. The Ag NPs became smaller when the PVA concentration increased.

\section{- Ultrasonic spray pyrolysis}

Another physical approach is ultrasonic spray pyrolysis, which allows the obtaining of NPs with a controlled size through the production of aerosol from a dilute aqueous metal salt solution. Pluym et al. [28] produced pure and monodispersed micron-sized Ag NPs by spray pyrolysis with an ultrasonic generator at $600{ }^{\circ} \mathrm{C}$ (using $\mathrm{N}_{2}$ carrier gas), and above $900{ }^{\circ} \mathrm{C}$ (using air carrier gas). Pingali et al. [29] proposed a one-step synthesis of Ag NPs with a diameter ranging from $20 \mathrm{~nm}$ to $300 \mathrm{~nm}$, by pyrolysis of ultrasonically atomized spray of $\mathrm{AgNO}_{3}$ solution, maintaining a temperature of $650{ }^{\circ} \mathrm{C}$ with a tube furnace. Different sizes were obtained tuning the concentration of $\mathrm{AgNO}_{3}$ solution and ultrasound power.

\section{- Arc discharge method}

Arc discharge method is mostly used to synthetize carbon nanotubes (CNTs): a current arc voltage is applied between two graphite electrodes that vaporize carbon in the presence of a catalyst immersed in an inert gas (helium or argon) [30]. Recently, this method is used for synthesis of metallic NPs such as Ag NPs.

Arc discharge method requires vacuum apparatus with an efficient cooling system. Tien et al. [31] used it to produce Ag NPs into ultrapure water. They adopted two Ag electrodes that, after melting at high temperature, were converted into Ag NPs with a size ranging from $5 \mathrm{~nm}$ to $45 \mathrm{~nm}$. Another study [32] described the production of spherical Ag NPs (3-5) nm by direct metal sputtering into propane-1,2,3-triol (glycerol).

Although physical methods were consistent for obtaining good Ag NPs without the use of hazardous chemicals, their use is often unfeasible due to the limitations of large energy consumption and long times required to reach thermal stability [33].

\subsection{Chemical Approach}

\section{- Chemical reduction}

The most used chemical approach is chemical reduction, which permits synthesis of Ag NPs in solution (water or organic solvents) in presence of (i) metal precursors, (ii) reducing agents sodium citrate, ascorbate, sodium borohydride $\left(\mathrm{NaBH}_{4}\right)$, elemental hydrogen, polyol process, Tollens reagent, $\mathrm{N}, \mathrm{N}$-dimethylformamide (DMF), poly(ethyleneglycol) — block co polymer (PLGA-PEG-PLGA), and (iii) stabilizing/capping agents poly(vinyl alcohol) (PVA), poly(vinyl pyrrolidone) (PVP), poly(ethyleneglycol) PEG, poly(methacrylic acid) (PMAA), poly(methyl methacrylate) (PMMA) [31].

The reduction of $\mathrm{Ag}$ salts induces the formation of colloidal solutions: this process occurs in two steps (nucleation and growth) that strongly influence the shape and the size of Ag NPs. These two critical steps are controlled by $\mathrm{pH}$, temperature, stabilizing agents and reduction agents $[34,35]$. Dadosh [36] developed a one-step synthesis of Ag NPs using tannic acid as reducing agent together with sodium citrate. The modification of tannic acid concentrations induced the formation of different sized (from $18 \mathrm{~nm}$ to $30 \mathrm{~nm}$ ) Ag NPs. Based on this procedure, De Matteis et al. [37] 
optimized the synthetic route, in terms of $\mathrm{AgNO}_{3}$ concentration and temperature. Zhang et al. [38] used a hyper-branched poly(methylene bisacrylamide aminoethyl piperazine) with terminal dimethylamine groups (HPAMAM-N $\left(\mathrm{CH}_{3}\right)_{2}$ ) to produce Ag NPs. Wang et al. [39] proposed the generation of Ag NPs using a solution of PVP and $\mathrm{AgNO}_{3}$ with glucose as reducing agent. The solution was completed with $\mathrm{NaOH}$ to increase the speed of reaction. The stability of solution took placed when the mole ratio of $\mathrm{NaOH}$ and $\mathrm{AgNO}_{3}$ varied between 1.4 and 1.6, without $\mathrm{Ag}^{+}$. Suriati et al. [40] obtained $\mathrm{Ag}$ NPs $(35-80 \mathrm{~nm})$ using trisodium citrate and ascorbic acid as surfactants. The increase of ascorbic concentration induced the formation of polygonal NPs with a large size while the size was reduced increasing the trisodium citrate amount, and the shape was quasi-spherical. The use of gallic acid as reducing and stabilizing agent was adopted to obtain 7, 29, and $89 \mathrm{~nm}$ of $\mathrm{Ag} \mathrm{NPs}$ from $\mathrm{AgNO}_{3}$ [41]. The authors used two $\mathrm{pH}$ values (11 and 10) to obtain 7 and $29 \mathrm{~nm}$ respectively. Also, another method allowed the synthesis of Ag NPs (24 nm) by exploiting hydrazine hydrate and sodium citrate as reducing agents [42] and sodium dodecyl sulphate as stabilizing agent in presence of $\mathrm{AgNO}_{3} 8 \%(w / w)$. In other routes, tri-sodium citrate and $\mathrm{NaBH}_{4}$ acted as stabilizer and the reducing agent respectively, in presence of $\mathrm{AgNO}_{3}$ [43,44]. Agnihotri et al. [45] synthetized monodispersed Ag NPs (5, 7, 10, 15, 20 , $30,50,63,85$, and $100 \mathrm{~nm})$ with a co-reduction employing sodium borohydride $\left(\mathrm{NaBH}_{4}\right)$ as a primary reductant and trisodium citrate (TSC), as secondary reductant and a stabilizing agent. $\mathrm{NaBH}_{4}$ allowed to form instant nuclei generation, while TSC was important to control the particles size (Figure 1b).

- Microemulsion

Microemulsion method is a reproducible technique that allows the obtaining of uniform size NPs and it is based on the use of three precursors: (i) polar phase that commonly is water, (ii) non-polar phase as hydrocarbon liquid or oil, and (iii) surfactant [46]. The two phases are separated by the presence of surfactant, which forms an interfacial layer, reducing the interfacial tension between the microemulsion, and inhibiting the coalescence of the droplets. This technique (water-in-oil (w/o) or oil-in-water $(\mathrm{o} / \mathrm{w})$ depending on the surfactant) allows the obtaining of monodispersed and stable $\mathrm{Ag}$ NPs using two microemulsions: one with water core of $\mathrm{AgNO}_{3}$ (as $\mathrm{Ag}^{+}$source) and the other water core with hydrazine hydrate (as reducing agent) [47,48]. The reaction starts with the addition of non-toxic dodecane (oil phase) and sodium bis (2-ethylhexyl) sulfosuccinate (AOT, surfactant). Pileni et al. [49] used w/o droplets to tune the size of Ag NPs that were extracted from reverse micelles and mixed in nonpolar solvent. They found that the diameter of NPs changed from $2 \mathrm{~nm}$ to $7 \mathrm{~nm}$, after increasing the size of water drops. Chen et al. [50] reduced $\mathrm{AgNO}_{3}$ with $\mathrm{AOT}$, obtaining cubic shaped Ag NPs, with diameters less of $10 \mathrm{~nm}$.

\section{- Sonochemical method}

Many NPs of different materials were synthetized by sonochemical method, which have the advantages of eliciting rapidity of reaction time and formation of small NPs. The method includes three steps: formation, growth and implosive collapse of microcavities [51]. Ultrasound waves perturb chemical reactions derived from high temperature (5000 K) and pressure (1000 atm), inducing the collapse of microscopic bubbles (cavities), which expand during the decompression step and implode in the compression phase [52,53]. Gutierrez et al. [54] used this method to produce Ag NPs from a solution of $\mathrm{Ag}^{+}$by sonication at $1 \mathrm{MHz}$ under argon-hydrogen atmosphere. Wani and co-workers [55] synthetized Ag NPs using two reducing agents (sodium borohydride and sodium citrate) in two separate reactions irradiated with the same $20 \mathrm{KHz}$ ultrasound waves. Spherical Ag NPs $\left(10 \mathrm{~nm}\right.$ ) were obtained using $\mathrm{NaBH}_{4}$, while smaller NPs $(3 \mathrm{~nm})$ were formed in the presence of sodium citrate.

- Sol-gel

The sol-gel process is a colloidal chemistry technology, which is widely applied to synthetized metal and metal oxide NPs at low temperature. In the first phase, the monomers of materials are converted into a colloidal solution (sol), which represents the precursor (metal alkoxides or chlorides) 
for gel formation, which in turn formed particles or polymers. To obtain colloids, the precursors are hydrolysed and polycondensed [56].

Zhai et al. [57] used a sol-gel route to synthetize Ag NPs embedding hybrid materials with organicosilica precursors (tetraethoxysilane, mercaptopropyltrimethoxysilane and polymethyl hydrosiloxane) in alcoholic conditions. The three precursors act as framework constructor, a complexing agent toward metal ions and an in situ reducing agent for $\mathrm{Ag}^{+}$. Lkhagvajav et al. [58] prepared $\mathrm{Ag}$ NPs using $\mathrm{AgNO}_{3}$ and glucose as a reducing agent, which were first mixed in distilled water. The formation of NPs was showed when the solution become transparent.

- Electrochemical synthetic method

Electrochemical synthetic method is used to synthetize Ag NPs with a controllable size. In fact, the size can vary by electrolysis parameters modifications, while the monodispersion grade depends on the electrolytic compositions [31]. The detailed protocol of this method was described by Reetz and Helbig [59]. The authors reported Ag NPs synthesis in which a metal sheet was anodically dissolved, thus the formed metal was reduced at the cathode, giving rise to metallic particles stabilized by tetra alkylammonium salts. Ma et al. [60] obtained spherical Ag NPs $(10-20 \mathrm{~nm})$ in aqueous solution, choosing PVP to stabilize the Ag clusters and to reduce agglomerations. The application of rotating platinum cathode permitted the obtaining of a high monodispersity route, while the sodium dodecyl benzene sulfonate enhanced particle size distribution. This method was also adopted for the synthesis of the Ag NPs in acetonitrile containing tetrabutylammonium salts [61].

The possibility of obtaining monodisperse NPs with a tunable size is an advantage in the use of chemical methods, together with low cost and rapidity of steps [33]. However, the disadvantages of these methods are the hazardous and toxic elements employed in the synthetic routes and difficulty in purification. Although chemical and physical methods are considered suitable methods to synthetize well-defined nanoparticles, the scientific community is moving towards green synthesis of NPs.

\subsection{Green Synthesis}

The use of natural products as a source of reagents for NP synthesis is defined as green synthesis [62]. The natural source useful for synthetized Ag NPs can be divided in three categories:

(a) microorganisms (fungi, yeasts, bacteria, and actinomycetes),

(b) plants and plant extract,

(c) membranes, viruses' DNA, and diatoms.

Microorganisms are able to produce metallic NPs by enzymes that contribute to physiological cellular activities. Depending on the NPs localization, the synthesis can take place intracellularly or extracellularly [62]. The intracellular synthesis of Ag NPs are due to the transfer of metal ions into the microorganism, while the extracellular route includes the localization of metal ions onto the cell surface. The enzymes, functional groups, proteins and enzymes are designated to reduce ions [63].

\section{- Bacteria}

Bacillus licheniformis was used to synthetized $50 \mathrm{~nm}$ Ag NPs by Kalimuthu et al. [64] in the presence of an aqueous solution of $\mathrm{AgNO}_{3}$, with enzyme nitrate as a stabilizer. Culture supernatants of Staphylococcus aureus as well as supernatants derived from Enterobacteriaceae were exploited to synthetize Ag NPs [65]. Many lactic acid bacteria (Lactobacillus spp., Pediococcus pentosaceus and Enterococcus faecium) have the ability to produce glucose, galactose, mannose and fructose, thus they are involved in redox reactions to obtain Ag NPs [66]. Ag NPs with different physico-chemical properties were also synthetized from Escherichia coli [67], Klebsiella pneumonia [68], Pseudomonas stutzeri [69], Brevibacterium casei [70], Bacillus megaterium [71], Proteus mirsabilis [72], Plectonema boryanum [73], and Enterobacter cloacae [74]. 


\section{- Fungi}

Fungi are considered useful tools for Ag NPs synthesis, due to their ability to quickly collect and uptake metals as well as the easy set-up equipment in the laboratory compared to bacteria. The large number of enzymes produced by fungi allow the reduction of $\mathrm{AgNO}_{3}$ solution on their surface [75]. Bhangale et al. [76] used biomass derived from Aspergillus flavus for the synthesis of spherical Ag NPs with a size of $7.13 \mathrm{~nm}$. Vigneshwaran and co-workers [77] reported a similar synthesis of NPs with a size of $(8.92 \pm 1.61) \mathrm{nm}$. Penicillium fellutanum produces the enzyme nitrate reductase in culture filtrate, which was involved in reduction of $\mathrm{Ag}^{+}$[78]. At the same time, the fungus Aspergillus niger was used to produce Ag NPs extracellularly [79]. In this case, the combination of reductase enzyme and quinine induced a transfer of electrons extracellularly [80]. In some cases, Ag NPs are not obtained in the solution, but on the surface of fungus where Ag+ are confined. This phenomenon is probably induced by the presence of wall proteins with carboxylate groups that have negative charge. In addition, the proteins contributed to the Ag nuclei formation that increase flowing the $\mathrm{Ag}^{+}$ reduction [81]. Ag NPs are also derived from fungi as Aspergillus terreus [82], Bryophilous rhizoctoni [83], Pleurotus ostreatus [84], Aspergillus flavus [77].

- Plants

The non-toxic and eco-friendly method of synthetizing NPs is biosynthesis, which includes the reduction of $\mathrm{Ag}^{+}$by biomolecules (saponins, proteins, tannins, amino polysaccharides, enzymes, alkaloids, vitamins, etc.) from plant extracts [85]. In general, adding plant extracts to $\mathrm{AgNO}_{3}$ solution induces the reduction of $\mathrm{Ag}^{+}$, and this phenomenon can be visualized with Ultra-violet Visible (UV-VIS) spectroscopy in time points. Many portions of flora are employed to obtain Ag NPs. Extracts of Alternanthera dentate have permitted the rapid obtaining of spherical Ag NPs with a size ranging from $50 \mathrm{~nm}$ to $100 \mathrm{~nm}$, with antibacterial activity [86]. Dried roasted Coffea arabica seed extract in the presence of $\mathrm{AgNO}_{3}$ induced a reduction of $\mathrm{Ag}^{+}$showing a color changing from yellow to dark brown. By this approach, the nano Ag exhibited spherical $(20 \mathrm{~nm})$ and ellipsoidal $(30 \mathrm{~nm})$ shape [87]. Tribulus terrestris was used to obtain spherical Ag NPs $\left(16-28 \mathrm{~nm}\right.$ ) due to the mix of extracts and $\mathrm{AgNO}_{3}$. Also, in this case, the NPs have strong antibacterial properties against Escherichia coli, Staphylococcus aureus, Pseudomonas aeruginosa and Bacillus subtilis [88]. Krishnaraj et al. synthetized spherical Ag NPs $(15-50 \mathrm{~nm})$ from the leaf extract of Acalypha indica [89]. Some researchers exploited orange peel (Citrussinensis) to obtain nanomaterials derived from food waste. They obtained spherical NPs with an average size of $6 \mathrm{~nm}$ [90]. Khalil et al. [91] used olive leaf to reduce $\mathrm{AgNO}_{3}$ in order to obtain $\mathrm{Ag}$ NPs. The authors observed a significant synthetic route with the increase of $\mathrm{pH}$ and temperature that contributed to spherical Ag NPs with a size of (20-25) nm. A concentration of $(0.03-0.07) \mathrm{mg} / \mathrm{mL}$ of NPs induced several toxic effects against Staphylococcus aureus, Pseudomonas aeruginosa, and Escherichia coli. In a recent work, Rashid et al. [92] employed Ferula latisecta leaf extract and $1 \mathrm{mM}$-aqueous $\mathrm{AgNO}_{3}$ to obtain Ag NPs with a diameter of about $20 \mathrm{~nm}$ (Figure 1c). Green synthesis is a promising route for synthesis of biocompatible and stable nanoparticles that minimizes the waste and energy costs and reduces the toxicity in comparison with physical and chemical methods [93]. Indeed, this method is environmentally friendly, easily scaled up for large-scale syntheses of nanoparticles, and is low cost. In addition, in the synthetic routes do not involve high temperatures, pressures, energy or toxic chemicals [94]. However, some disadvantages should be considered: for example, in the case of plants, they produce low yield of secreted proteins, which decreases the synthetic rate [95], while the manipulation of bacteria presupposes the use of specific set-up that, in many cases, is expensive. Representative Transmission electron microscopy (TEM) images of Ag NPs obtained with different methods were showed in Figure 2a-d. 


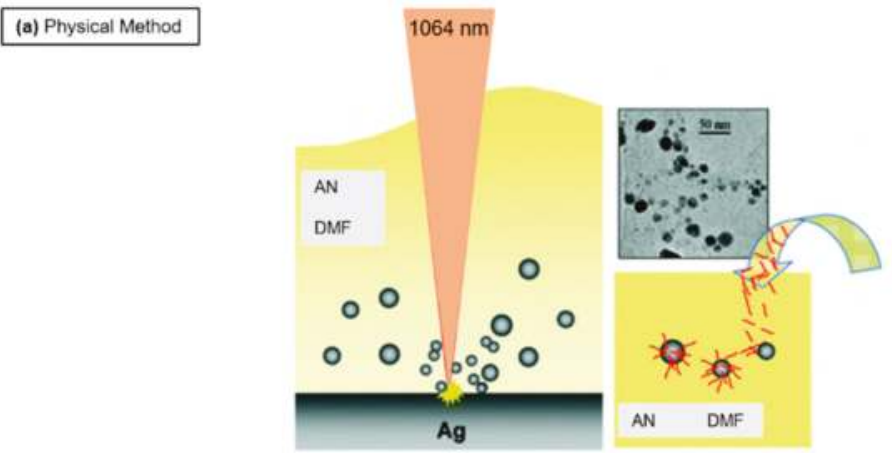

(b) Chemical Method
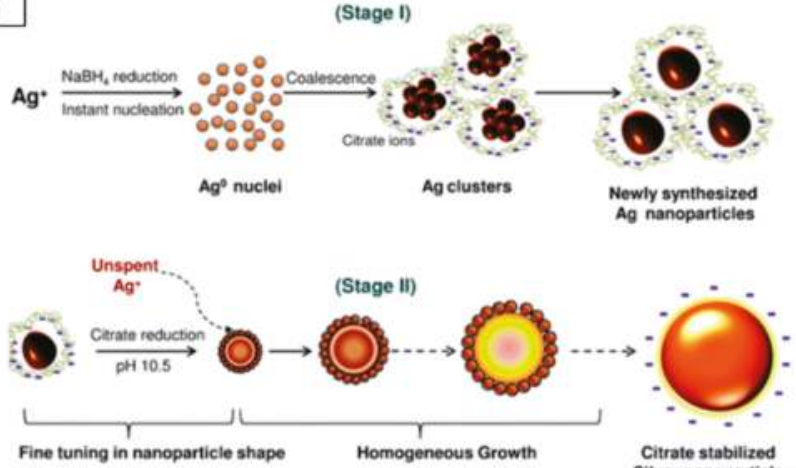

(c) Green Method

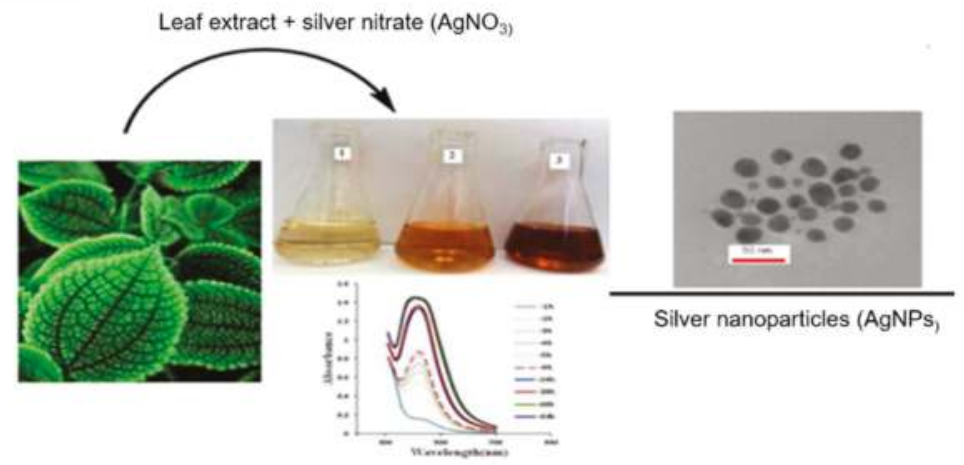

Figure 1. Schematic representation of common routes to synthetize Ag NPs with different approaches: (a) physical approach (laser ablation) adapted from [24] with permission from American Chemical Society, Copyright 2007: a laser pulses of $1064 \mathrm{~nm}$ focused with a $10 \mathrm{~cm}$ focus lens on Ag plate in pure acetonitrile (AN) and N,N-dimethylformamide (DMF) was used in order to obtain Ag NPs with a size of $5 \mathrm{~nm}$, (b) chemical approach (chemical reduction), adapted from [45] with permission from The Royal Society of Chemistry, 2014: Ag NPs were obtained from a solution of $\mathrm{AgNO}_{3}$ using $\mathrm{NaBH}_{4}$ as a primary reductant and trisodium citrate, both as secondary reductant as well as stabilizing agent, and (c) green approach (plant extract) adapted from [92] with permission from The Royal Society of Chemistry, 2016: Ag NPs (20-30 nm) were synthetized by adding Ferula latisecta leaves extract to $1 \mathrm{mM}$ aqueous $\mathrm{AgNO}_{3}$ solution. The solution turned from yellow to dark brown. 


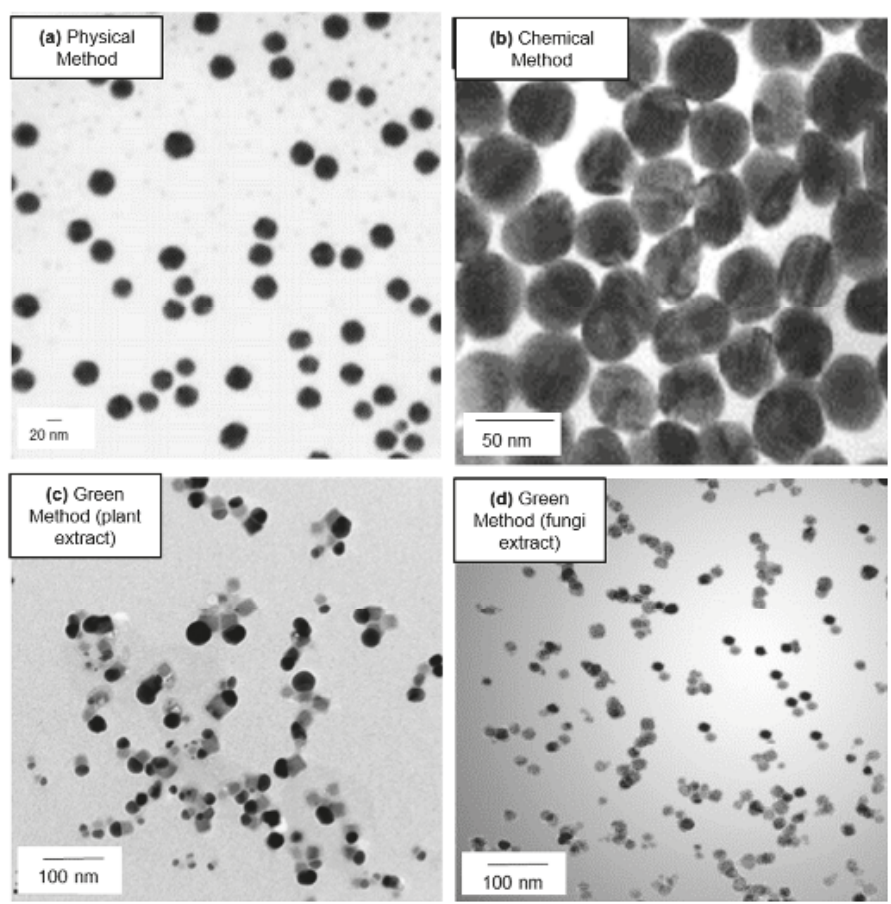

Figure 2. Representative TEM images of Ag NPs synthetized by different synthetic routes: (a) Ag NPs $(9.4 \pm 5.9) \mathrm{nm}$ obtained by $532 \mathrm{~nm}$ laser ablation of a Ag rod using $60 \mathrm{~mJ} /$ pulse at $1.0 \times 10^{-3} \mathrm{M}$ of CTAB. Adapted/reprinted from [96], Copyright (2002), with permission from Elsevier; (b) Ag NPs (130 nm) produced by chemical method with ascorbic acid reduction at $\mathrm{pH}$ 10. Adapted/reprinted from [97], Copyright (2010), with permission from Elsevier; (c) Ag NPs (from $3 \mathrm{~nm}$ to $44 \mathrm{~nm}$ ) synthesized from fresh Codium capitatum extract. Adapted from [98], Creative Commons Attribution License (CC BY) (d) Ag NPs (5-25) nm obtained from Penicillium fellutanum Biourge. Adapted from [78] with permission of Elsevier, 2009.

\section{In Vitro Cytotoxicity Mechanism Induced by Ag NPs}

The level of cytotoxicity relating to the rate of internalized NPs was influenced by their size; this evidence was confirmed in the Ag NPs case [99-101]. In particular, Liu and co-workers demonstrated the size-dependent cytotoxicity of Ag NPs (approximately 5, 20 and $50 \mathrm{~nm}$ ) in terms of cell morphology, cell viability, cellular membrane integrity, oxidative stress and cell cycle progression, in four human cell lines (A549, SGC-7901, HepG2 and MCF-7). The obtained results, with quantified EC50 values, ensured a greater cytotoxic response to the nano Ag size [99]. Furthermore, as obtained by Hsin et al. [100], the decreased viability in $\mathrm{NIH}_{3} \mathrm{~T}_{3}$ mouse fibroblast, A10 rat vascular smooth muscle and HCT116 human colon cancer cells was induced only from Ag particles having a size smaller than a $100 \mathrm{~nm}$. Several studies reported in the literature suggest how the Ag NP toxicity occurs in sequential steps. When the Ag NPs were endocitated, they undergo a degradation process that induce a release of $\mathrm{Ag}^{+}$causing Reactive Oxygen Species (ROS) generation and glutathione (SGH) level reduction. The augmentation of cellular superoxide radicals triggers the alterations in the transmembrane potential of mitochondria and influences the signal transduction pathways, which play an important role in apoptosis program activation and cell death [102] (Figure 3a). Carlson et al. evaluated alterations, in terms of mitochondrial and cell membrane viability, in alveolar macrophages cells after $24 \mathrm{~h}$ of exposure to Ag NPs (NPs, Ag-15 nm, Ag-30 nm, and Ag-55 nm), quantifying ROS production [103]. 
In this work, MTT and LDH analysis indicated the size-dependent cytotoxic effects following Ag NPs exposure demonstrating how only Ag-15nm induced a significant increase of ROS level. The authors suggested different hypothesis to justify the experimental evidence: the reduction of the macrophages abilities to protect themselves from ROS caused by the total cell -SH reactive nature, the stronger ROS generation due to the possible unquenching of $\mathrm{Ag}-15 \mathrm{~nm}$ by glutathione (GSH), or the activation of apoptosis pathways. Previously, Hussain et al. demonstrated how cytotoxicity of $\mathrm{Ag}(15,100 \mathrm{~nm})$ in BRL 3A rat liver cells is likely to be mediated through oxidative stress: increase in ROS levels is related to a significant depletion of GSH level and reduced mitochondrial membrane potential [101]. In vitro effects provoked by exposure to PVP-coated $\mathrm{Ag}$ NPs $(\sim 70 \mathrm{~nm})$ and $\mathrm{Ag}^{+}$ions released by solution of $\mathrm{AgNO}_{3}$ were evaluated by Foldbjerg et al. on two different human cells line: monocytic cell line (THP-1) and alveolar cell line (A549) [104,105]. Study on THP-1, conducted by flow cytometric assay, showed how the induction of cell apoptosis and necrosis depended on concentration and exposure time. In addition, the drastic increase in ROS production, detected after 6-24 h, highlighted that oxidative stress plays an important role in cytotoxicity induced by Ag NPs and $\mathrm{Ag}^{+}$[104]. The dose-dependent cellular toxicity caused by Ag NPs and $\mathrm{Ag}^{+}$was also confirmed in A549 cells, and a strictly correlation between the levels of reactive oxygen species (ROS) and mitochondrial dysfunctions or apoptosis was demonstrated. In addition, the role of Ag compounds as ROS-induced genotoxicity was suggested by increased bulky DNA adduct amount after Ag exposure [105]. Hsin et al. [100] showed that the apoptotic effect induced by nano Ag exposure was a mitochondria-dependent mechanism. Specifically, this effect was reported for NIH3T3 mouse fibroblast, A10 rat vascular smooth muscle and HCT116 human colon cancer cells treated with Ag NPs ( $<100 \mathrm{~nm}$ ) for $72 \mathrm{~h}$ at increasing concentration (from $0.5 \mathrm{ng} / \mathrm{mL}$ to $0.5 \mathrm{mg} / \mathrm{mL}$ ). The key role played by oxidative stress in cytoxicity induced by nano Ag was also demonstrated in human hepatoma HepG2 cells [106]. Kim and co-workers investigated the toxicity events due to $24 \mathrm{~h}^{\prime}$ exposure to $\mathrm{Ag}^{+}$and Ag NPs (from $\sim 5 \mathrm{~nm}$ to $10 \mathrm{~nm}$ ). The most cytotoxic effect was shown for free $\mathrm{Ag}^{+}$ions in comparison with $\mathrm{Ag} \mathrm{NPs}$, as suggested by metal-responsive metallothionein $1 \mathrm{~b}$ (MT1b) mRNA expression. Nevertheless, intracellular oxidative stress level was increased also following Ag NPs treatment. However, the use of the antioxidant $N$-acetyl-L-cysteine (NAC) prevented Ag toxicity and DNA-damage in HepG2 cells. The authors concluded that the oxidative stress was the first phenomena involved in Ag NPs cytotoxicity and it was independent of Ag+ ions adverse effects. Avalos et al. [107] investigated cytotoxicity induced to Ag NPs, having two different size: $4.7 \mathrm{~nm}$ and $42 \mathrm{~nm}$, on normal human dermal fibroblasts. Smaller particles were more toxic than larger ones, as confirmed by MTT and lactate dehydrogenase (LDH) assays. In both case, the preventive addition of NAC strongly reduced the adverse effects of nano Ag exposure. Foldbjerg et al. [108] performed a systematic study by microarray technique on altered A549 cell transcriptome upon $12.1 \mu \mathrm{g} / \mathrm{mL} \mathrm{Ag}$ $\mathrm{NPs}$ and $1.3 \mu \mathrm{g} / \mathrm{mL} \mathrm{Ag}+$ stimulation at two different time points ( $24 \mathrm{~h}$ and $48 \mathrm{~h}$ ). They found that $\mathrm{Ag}$ NP altered the regulation of more than 1000 genes, whereas Ag+ only 133: different gene members of the metallothionein, heat shock protein, and histone families were upregulated. In addition, Ag+ and Ag NP treatment influenced cell cycle progression and ROS production. The authors concluded by suggesting that the cellular response to $\mathrm{Ag}^{+}$was faster but less stable than Ag NP treatment. At the same time, Piao et al. [109] demonstrated that the Ag-induced toxicity in human Chang liver cells was higher after free $\mathrm{Ag}^{+}$compared with NPs, having size of ranging from $5 \mathrm{~nm}$ to $10 \mathrm{~nm}$. After $24 \mathrm{~h}$ of Ag exposure, ROS level increased and concurrently the GSH decreased. This elicited damage against various cellular components, such as DNA breaks, lipid membrane peroxidation, and protein carbonylation. In addition, alteration of mitochondrial membrane potential was detected by cytochrome $\mathrm{c}$ release from the mitochondria, resulting in the activation of caspases 9 and 3. Finally, the apoptotic effect was exerted via the activation of c-Jun $\mathrm{NH}(2)$-terminal kinase (JNK) causing the formation of apoptotic bodies and DNA fragmentation. The DNA damage, cell cycle arrest and apoptosis events were observed in human Jurkat $\mathrm{T}$ cells by Eom et al. [110]. These effects were induced by activation of p38 mitogen-activated protein kinase through nuclear factor-E2-related factor-2 and nuclear factor- $\mathrm{kB}$ signaling pathways. Nishanth et al. [111] examined the inflammatory responses 
of RAW 264.7 mouse macrophages due to exposure at different time points of many kinds of NPs, such as Ag at concentrations of $5 \mu \mathrm{g} / \mathrm{mL}$, having different size $(\sim 15 \mathrm{~nm}, \sim 40 \mathrm{~nm})$. This study reveals the high propensity of Ag NPs in inflammation induction, suggested by a significant increase in IL-6, reactive oxygen species (ROS) generation, nuclear translocation of nuclear factor- $\mathrm{kB}(\mathrm{NF}-\mathrm{\kappa B})$, and tumor necrosis factor-alpha (TNF- $\alpha$ ) expression. AshaRani and colleagues [112] explored the potential molecular mechanisms involved in Ag NPs toxicity in normal human lung cells (IMR-90) and human brain cancer cells (U251). In their work, it was demonstrated that nano Ag interacts with cytosolic proteins, which were adsorbed on nanoparticle surfaces, influencing the gene and protein expression profiles. In particular, in the two cell lines, Ag NP exposure provoked downregulation of both cyclin B and cyclin E, which were involved in cell cycle progression, and many DNA damage response/repair factors (XRCC1 and 3, FEN1, RAD51C, RPA1). Moreover, apoptosis pathway was activated by down regulation of p53 and caspase 3 cleavage. Finally, the Ag NPs triggered an inflammatory response through IL-8 and IL- 6 cytokines secretions, and macrophages stimulations. Many studies suggest that surface modifications of Ag NPs influenced their interactions with cellular components. Ahamed et al. [113] reported that polysaccharide-coated and -uncoated Ag NPs induced genotoxic effects in two mammalian cell lines: mouse embryonic stem (mES) cells and mouse embryonic fibroblasts (MEF). The different chemical surface functionalization induced a different effect in terms of toxicity: a major damage of DNA was obtained in coated nanoparticles. Even so, the annexin V protein expression and MTT assay showed a decrease of cell viability in both NPs types. Chichova and co-workers [114] analyzed the effects on rat liver mitochondrial oxidative phosphorylation due to exposure to Ag NPs coated with polysaccharide starch (Ag NPs/Starch, Dav = $15.4 \pm 3.9 \mathrm{~nm}$ ) and trisaccharide raffinose (Ag NPs/Raff, Dav $=24.8 \pm 6.8 \mathrm{~nm}$ ). Both types of Ag NPs showed decoupling effects on intact mitochondria through the alteration of ATP synthase and ATPase activities, suggesting their ability to cross the inner mitochondrial membrane. De Matteis et al. [37] investigated the mechanism of toxicity induced by citrate-capped Ag NPs with a hydrodynamic diameter of around $20 \mathrm{~nm}$ in HeLa and A549 cells at concentrations of 0.06, 0.3 and $0.6 \mathrm{nM}$ after 48 and $96 \mathrm{~h}$. The authors firstly confirmed the negative effects on cell viability, ROS production, apoptotic pathway stimulation and DNA damage and after, they investigated the in situ degradation of Ag NPs using a fluorescent probe. They found an intracellular "heavy metal type" mechanism due to ionization of NPs in $\mathrm{Ag}^{+}$in lysosomes and the consecutive release in the cytosol, which explains the stronger toxicity behavior of Ag NPs. In addition, the activation of metallothioneins upon Ag NPs demonstrated a link between ions and cell death (Figure 3b,c).

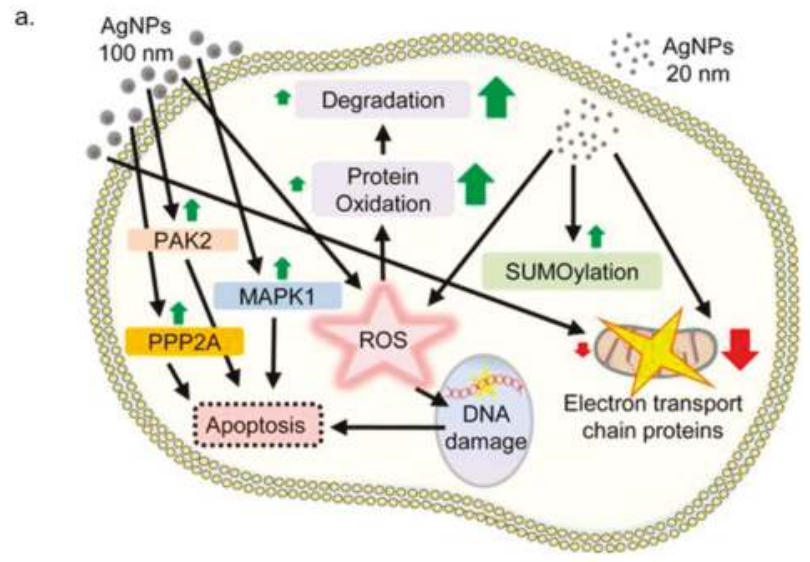

Figure 3. Cont. 


\section{b.}

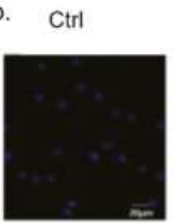

3 hours 24 hours
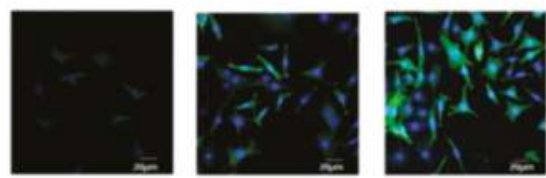

c.

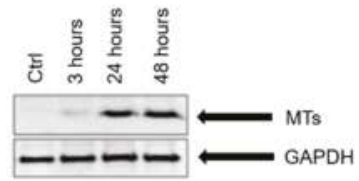

Figure 3. (a) Schematic representation mechanism of toxicity induced by AgNPs in cell. Reprinted/adapted with permission from [102], Copyright (2014) American Chemical Society (b) Representative images of Hela cell lines exposed to AgNPs at different time points and immunostained to detect metallothionein expression. Nuclei are stained by DAPI staining and metallothioneins with a primary anti-metallothioneins antibody coupled with a FITC-labeled secondary antibody. The expression of metallothioneins in cells is dependent on time. (c) Western blot analysis of metallothionein expression in HeLa cells treated with AgNPs. Adapted from [37] with permission from Elsevier, 2015.

\section{AgNPs and Theranostics}

While the early efforts in nanomedicine were focused on improving the properties of already available therapeutic and diagnostic modalities, more novel strategies have emerged through the supramolecular assembly of simpler components, by means of nanoscale engineering $[115,116]$. Theranostics is a new technological field which develops molecular diagnostics integrated with targeted therapeutics. It comprises nanosize structures, combining targeting properties, i.e., control of the spatial and temporal release of therapeutic agents, and monitoring modalities for the response to the treatment, and assessing the effectiveness of these agents [116]. Because of its properties, theranostics increases drug efficacy and safety, and therefore it is of great interest in cancer research, becoming one of the key topics in this field [117-120]. Nowadays, much research effort has been made in order to synthetize anticancer drugs and design proper vehicles, guiding them more precisely to tumor cells and away from sites of toxicity, optimizing drug concentration and limiting size-adverse effects [117]. Moreover, an imaging function is often added to delivery vehicles by attaching contrast agents for use in non-invasive methods of imaging, including X-ray-based computer-assisted tomography (CT), positron emission tomography (PET), single photon emission tomography and magnetic resonance imaging (MRI) [121]. With respect to conventional modalities, nanoscale particles and nanovehicles are increasingly being tested for their effects on cancer cells [122]. Multifunctional nanomaterials are used as drug-delivery agents and diagnostic tools, because they offer the possibility to deliver and release drugs, targeting cancer cells in a regulated manner and at the same time allow the detection of cancer cells with enormous specificity and sensitivity [123]. Ag NPs exhibit unique physical and chemical features that make them suitable for cancer theranostic applications. As other metallic NPs, Ag NPs have a larger surface area and area:volume ratio, which in turn enhance their catalytic activity. Owing to their nanosize, they can be vehiculated to the tumor site either by passive targeting (exploiting the enhanced permeability and retention effect), or by active targeting (by means of proper ligand surface functionalization) [124]. Ag NPs are reported to have anticancer property; furthermore, Ag NPs elicit various damaging effects on structures and functions of cells, which finally induce cytotoxicity, genotoxicity, immunological responses, and even cell death. Gonipanath et al. [125] demonstrated the cytotoxic effect of Ag NPs exerted on living cells; in fact, they found that Ag NPs induced apoptosis on cancerous HT29 as well as non-cancerous BHK21 cells. Interestingly, they observed a synergistic 
effect on apoptosis using uracil phosphoribosyltransferase (UPRT)-expressing cells and non-UPRT expressing cells in the presence of the drug fluorouracil (5-FU), suggesting that Ag NPs, combined with traditional cancer treatment modalities, enhanced their performance. By means of biotechnology and nanotechnology, nanomaterials could be properly bioconjugated, exhibiting new features in tumor treatment $[126,127]$. Proper functionalized nanomaterials could affect cell growth and viability based on the size, capping or coating materials, color, surface chemistry, and dose [128]. Starting from these observations, Ag NPs were often used in combination with polymers for the delivery to cancer cells. Sanpui et al. reported the synthesis of a chitosan (CS) nanocarrier (NC)-based delivery of Ag NPs able to induce apoptosis at very low concentrations of the NPs in human colon cancer cells (HT 29) [129]. They demonstrated that Ag CS NCs induced the production of intracellular ROS also at low concentration, compared to the use of free Ag NPs.

Other experimental research has proved the synergistic effect of Ag NPs and polymers concerning cancer treatment. For example, PVP-coated Ag NPs inhibited the growth of acute myeloid leukemia (AML), inducing a cytotoxic effect due to the production of reactive oxygen species (ROS), losses of mitochondrial membrane potential and DNA damage [130]. The same molecular mechanisms were reported for starch-coated Ag NPs, which were studied in normal human lung fibroblast cells (IMR-90), and human glioblastoma cells (U251) showing anticancer properties [131]. In a recent study, Liang et al., investigated the effect of Ag NPs on human glioma U251 cells and its role in the combinational use with Temozolomide (TMZ), an imidazotetrazine derivative of the alkylating agent dacarbazine, against glioma cells. They found that Ag NPs could have a potential application in enhancing chemotherapy for glioma. In fact, Ag NPs showed dose-dependent cytotoxicity on U251 cells owing to their ability to enhance the drug-sensitivity of TMZ on U251 cells [132]. Protein-conjugated Ag sulfide nano-particles, nano-rods and nano-wires were reported to inhibit the C6 glioma cells and human hepatocellular carcinoma Bel-7402 cells significantly; moreover, the effect of nano-crystals on tumor cells was crystal size-dependent [128]. Among the modalities used for reached tumor sites, targeted therapy has recently become the most attractive strategy for cancer treatment. Locatelli et al. synthetized multifunctional nanocomposites consisting of polymeric nanoparticles (PNPs) containing two cytotoxic agents (the drug alisertib and Ag NPs), conjugated with a chlorotoxin, an active targeting 36-amino acid-long peptide that specifically binds to MMP-2, a receptor overexpressed by brain cancer cells. They demonstrated the strong toxicity ability of these composite nanostructures in a human glioblastoma-astrocytoma epithelial-like cell line (U87MG) [133]. Not only chemistry synthetized Ag NPs elicited cytotoxic effects on cancer cells, but also biologically derived Ag NPs showed anticancer properties [134]. In fact, the anticancer property of bacterial (B-Ag NPs) and fungal extract-produced Ag NPs (F-Ag NPs) was demonstrated in human breast cancer MDA-MB-231 and MCF-7 cells [135-137]. Plant extract-mediated synthesis of Ag NPs exhibited more pronounced toxic effects in human lung carcinoma cells (A549) compared to non-cancer cells such as human lung cells, indicating that Ag NPs could target cell-specific toxicity. This mechanism could be due to the typical acidic $\mathrm{pH}$ value in cancer cells [138]. The interesting ability of Ag NPs to selectively affect cell viability was also confirmed by other experimental evidenc. Zureberek et al. [139] investigated the role of respiration in Ag NP-induced oxidative stress. Considering that cancer cells rely on glucose as the main source of energy supply, the authors demonstrated that glucose availability was strictly related to NP toxicity. They found that Ag NPs induced dose-dependent generation of $\mathrm{H}_{2} \mathrm{O}_{2}$. In addition, $\mathrm{Ag} \mathrm{NP}$ toxicity for the cells maintained in the low-glucose medium was significantly lower compared to cells growing in the high-glucose concentration. This result indicated that scarceness of glucose supply resulted in upregulation of the endogenous antioxidant defense mechanisms, which in turn affected ROS generation and toxicity induced by Ag NPs. Moreover, because hydrogen peroxide is continuously formed at micromolar levels and participates in redox homeostasis [140], He and co-workers [141] studied the interaction between $\mathrm{H}_{2} \mathrm{O}_{2}$ and $\mathrm{Ag} \mathrm{NPs}$, examining the effects of Ag NPs upon generation of ROS and oxygen over a physiologically relevant $\mathrm{pH}$ range. Their results demonstrated the alteration of the balance between hydroxyl radicals, oxygen 
and hydrogen peroxide influenced the effects of Ag NPs. In addition, Ag NPs [142] are known to strongly interact with electromagnetic radiation (i.e., photons) $[143,144]$ resulting in a localized surface plasmonic resonance (LSPR) $[145,146]$ (Figure 4a). The local electric fields generated on the NP surfaces are the product of enhanced light-matter interaction, occurring only at specific resonant frequencies $[147,148]$. The elevated fields raise a high number of electron-hole pairs, which in turn can induce photochemical transformations [149]. However, the plasmonic resonance of conventionally spherical Ag NPs is restricted only in the visible range of the spectrum (400-550 nm) [150], and its employment in biological tissues is thus rather limited because of the high tissue-mediated visible light absorption [151]. Ag exhibits the highest efficiency of plasmonic excitation among the three metals displaying plasmonic resonance $(\mathrm{Ag}, \mathrm{Au}$, and $\mathrm{Cu})$ [152]. In addition, the plasmonic peak can be tuned, varying the shape and sizes of Ag-based nanomaterials (Figure $4 b$ ).

a.
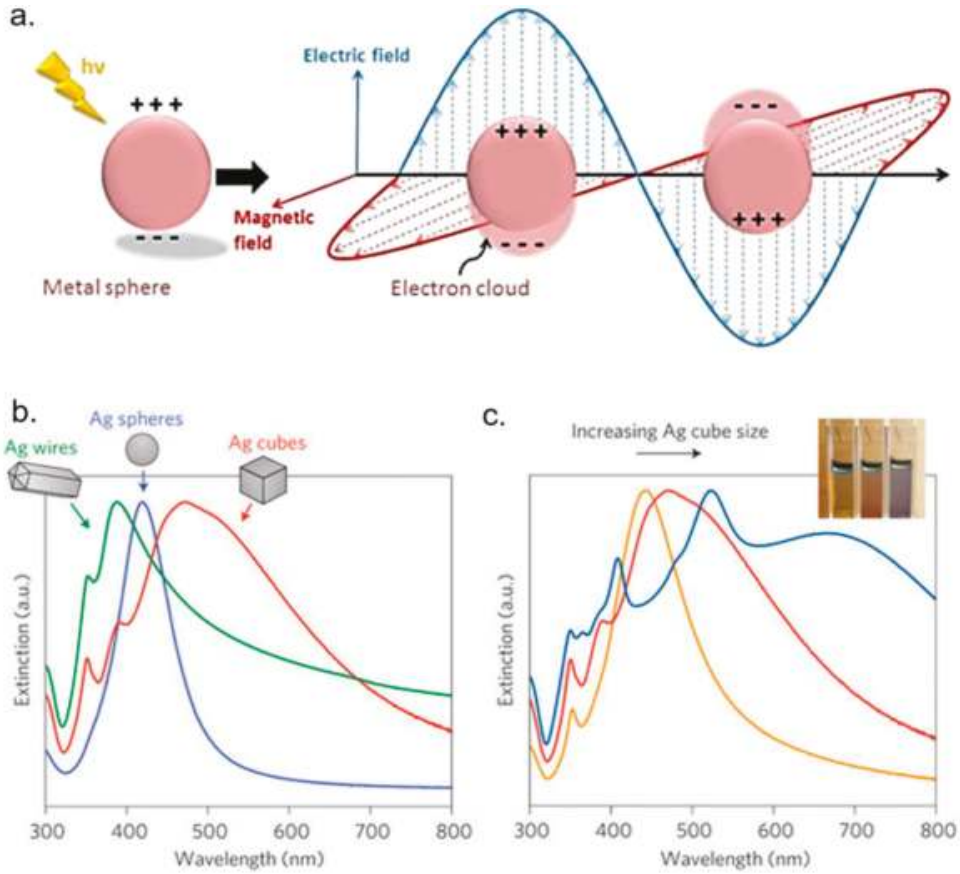

Figure 4. (a) Schematic representation of a localized surface plasmon resonance (LSPR), reproduced from [153] with permission of The Royal Society of Chemistry. (b,c) The change of shape and size exhibited different extinction properties. Adapted from [154] with permission from Macmillan Publishers (Nature Materials), 2015.

Mukherjee et al. developed green synthesized Ag NPs with multifunctional activities, using Olaz scandens leaf extracts. Ag NPs exhibited anticancer activity against different cancer cells (A549: human lung cancer cell lines, B16: mouse melanoma cell line and MCF7: human breast cancer cells). In addition to that, they were biocompatible to rat cardiomyoblast normal cell line (H9C2), human umbilical vein endothelial cells (HUVEC) and Chinese hamster ovary cells (CHO). At the same time, Ag NPs showed bright red fluorescence, which could be used to detect the localization of drug molecules inside cancer cells. For these reasons, Ag NPs could act not only as anticancer drugs but also as drug delivery vehicle and imaging facilitator [155]. Farrag et al. [156] functionalized Ag NPs with PVP and antitumoral drug Doxorubicin (DOX) to quickly track by ${ }^{125}$ I isotope their localization in the tumor site. They showed the double use of this Ag vector, which is both diagnostic and 
therapeutic (Figure 5a). In another study, Boca-Farcau et al. [157] developed newly synthesized chitosan-coated Ag nanotriangles (Chit-Ag NTs) with strong resonances in near infrared (NIR), investigating their ability to operate as photothermal agents against a line of human non-small lung cancer cells (NCI-H460). By the hyperthermia experiments, they found that the rate of cell mortality in the presence of Chit-AgNTs was higher than in the presence of thiolated poly(ethylene) glycol capped gold nanorods (PEG-AuNRs) (a common hyperthermia agent used as reference). No destructive effects were detected on the control sample (cells without nanoparticles) under identical irradiation conditions. Kovács et al. [158] synthetized Ag NPs (5 and $35 \mathrm{~nm})$ to test their ability to kill tumor suppressor-deficient osteosarcoma cancer cells. They found that NPs induced apoptosis in wild-type p53-containing U2Os and p53-deficient Saos-2 cells demonstrating the potential novel chemotherapeutic approaches based on Ag NPs (Figure 5b). Schrand et al. examined the chemical and biological properties of Ag NPs of similar sizes, differing in their surface chemistry (hydrocarbon versus polysaccharide), for their potential use as biological labels in neuroblastoma cells. We observed strong optical labelling of the cells in high-illumination light microscopy. Ag NPs were able to bind to plasma membrane and be uptaken and localized into intracellular vacuoles, suggesting that they could be involved in a cell labelling procedure. The major drawbacks of this approach relied on the induction of ROS, the degradation of mitochondrial membrane integrity, and the disruption of the actin cytoskeleton system after $24 \mathrm{~h}$ of Ag NPs exposure [159]. The large use of Ag NPs for cancer diagnosis and treatment raises concerns over their potential short- and long-term toxicity, above all in view of the application into clinical practice. Nevertheless, information about the mechanism of cytotoxicity derived mainly from in vitro studies and the impact of Ag NPs on animal models is still unclear. As reviewed elsewhere, Ag NPs elicited many toxicological responses (including effects on circulatory, respiratory, central nervous and hepatic systems) in laboratory rodents exposed to Ag NPs [160]. Results showed that the cytotoxic and genotoxic effect of Ag NPs was strictly linked to their concentration, size, surface-coating, exposure time and environmental factors [161]. Adult male C57BL/6N mice exposed to Ag NPs exhibited oxidative stress-induced neurotoxicity in brain regions [162] and other experimental evidence reported that liver and bile ducts are accumulation sites for Ag NPs [163]. Another study in zebrafish embryos suggested that the toxicity of Ag NPs was associated with bioavailable $\mathrm{Ag}^{+}$[164]. More recently, Munger et al. orally administered Ag NPs in healthy volunteers and they evaluated human biodistribution, bioprocessing and possible toxicity of Ag NPs. They demonstrated that in vivo oral exposure to Ag NPs solutions did not produce clinically severe changes in human metabolic, hematologic, urine, physical findings or imaging morphology [165]. This work opened a new scenario for the use of Ag NPs in cancer theranostics in the near future.

a.

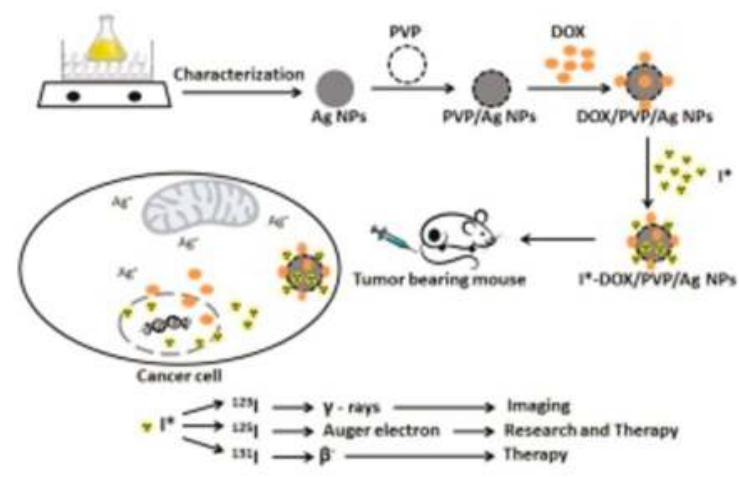

Figure 5. Cont. 
b.

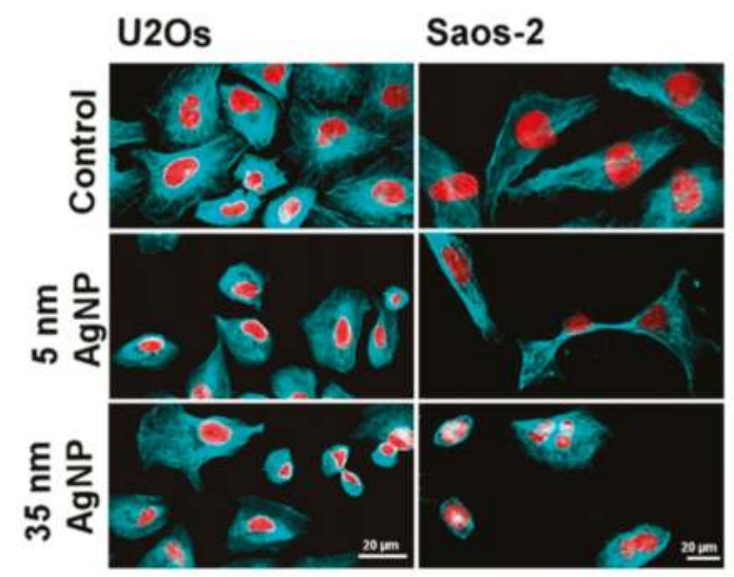

Figure 5. (a) AgNPs with PVP coating and Doxorubicin (DOX) loaded polymeric NPs (DOX/PVP/Ag NPs) AND iodine-125 isotope to tracking in vivo the NPs after intravenously injection in normal and solid tumor bearing mice. NPs specifically targeted tumor site for a long period of time making Ag-based NPs as tumor-specific agents for both diagnostic and therapeutic applications. Reprinted from Publication [156] with permission from Elsevier, 2017. (b) Confocal images showed the effect of AgNPs on tubulin by apoptotic events induction in U2Os and Saos-2 cells. Adapted from [158] with permission of Springer Nature, 2016.

\section{Conclusions}

In this work, we have first studied the main methods (physical, chemical and green) to synthetize Ag NPs by using bottom-up and top-down approaches. These methods are aimed at obtaining Ag NPs in a reproducible manner and with specific physico-chemical properties, suitable for various applications. We also analyzed the most recent literature concerning the toxicity mechanisms at the cellular level of Ag NPs, which makes it useful as an anti-cancer tool, combining a good intracellular and intra-tissue tracking with a therapeutic effect. Future challenges are finalized to develop Ag-based anti-tumor nanomaterials for personalized medicine treatment.

Conflicts of Interest: The authors declare no conflict of interest.

\section{References}

1. Beyene, H.D.; Werkneh, A.A.; Bezabh, H.K.; Ambaye, T.G. Synthesis paradigm and applications of silver nanoparticles (Ag NPs), a review. Sustain. Mater. Technol. 2017, 13, 18-23.

2. Chen, X.; Schluesener, H.J. Nanosilver: A nanoproduct in medical application. Toxicol. Lett. 2008, 176, 1-12. [CrossRef] [PubMed]

3. Alexander, J.W. History of the medical use of silver. Surg. Infect. 2009, 10, 289-292. [CrossRef] [PubMed]

4. Bhattacharya, S.; Zhang, Q.; Carmichael, P.L.; Boekelheide, K.; Andersen, M.E. Toxicity testing in the 21 century: Defining new risk assessment approaches based on perturbation of intracellular toxicity pathways. PLoS ONE 2011, 6, e20887. [CrossRef] [PubMed]

5. Jo, D.H.; Kim, J.H.; Lee, T.G.; Kim, J.H. Size, surface charge, and shape determine therapeutic effects of nanoparticles on brain and retinal diseases. Nanomed. Nanotechnol. Biol. Med. 2015, 11, 1603-1611. [CrossRef] [PubMed]

6. Rai, M.; Kon, K.; Ingle, A.; Duran, N.; Galdiero, S.; Galdiero, M. Broad-spectrum bioactivities of silver nanoparticles: The emerging trends and future prospects. Appl. Microbiol. Biotechnol. 2014, 98, 1951-1961. [CrossRef] [PubMed] 
7. Jurj, A.; Braicu, C.; Pop, L.A.; Tomuleasa, C.; Gherman, C.D.; Berindan-Neagoe, I. The new era of nanotechnology, an alternative to change cancer treatment. Drug Des. Dev. Ther. 2017, 11, 2871-2890. [CrossRef] [PubMed]

8. Riehemann, K.; Schneider, S.W.; Luger, T.A.; Godin, B.; Ferrari, M.; Fuchs, H. Nanomedicine-challenge and perspectives. Angew. Chem. 2009, 48, 872-897. [CrossRef] [PubMed]

9. Huang, Y.; Fan, C.Q.; Dong, H.; Wang, S.M.; Yang, X.C.; Yang, S.M. Current applications and future prospects of nanomaterials in tumor therapy. Int. J. Nanomed. 2017, 12, 1815-1825. [CrossRef] [PubMed]

10. Conde, J.; Doria, G.; Baptista, P. Noble metal nanoparticles applications in cancer. J. Drug Deliv. 2012, 2012, 751075. [CrossRef] [PubMed]

11. Bhattacharyya, S.; Kudgus, R.A.; Bhattacharya, R.; Mukherjee, P. Inorganic nanoparticles in cancer therapy. Pharm. Res. 2011, 28, 237-259. [CrossRef] [PubMed]

12. Sau, T.K.; Rogach, A.L.; Jackel, F.; Klar, T.A.; Feldmann, J. Properties and applications of colloidal nonspherical noble metal nanoparticles. Adv. Mater. 2010, 22, 1805-1825. [CrossRef] [PubMed]

13. Lee, K.S.; El-Sayed, M.A. Gold and silver nanoparticles in sensing and imaging: Sensitivity of plasmon response to size, shape, and metal composition. J. Phys. Chem. B 2006, 110, 19220-19225. [CrossRef] [PubMed]

14. Sperling, R.A.; Parak, W.J. Surface modification, functionalization and bioconjugation of colloidal inorganic nanoparticles. Philos. Trans. Ser. A Math. Phys. Eng. Sci. 2010, 368, 1333-1383. [CrossRef] [PubMed]

15. Pelaz, B.; del Pino, P.; Maffre, P.; Hartmann, R.; Gallego, M.; Rivera-Fernandez, S.; de la Fuente, J.M.; Nienhaus, G.U.; Parak, W.J. Surface functionalization of nanoparticles with polyethylene glycol: Effects on protein adsorption and cellular uptake. ACS Nano 2015, 9, 6996-7008. [CrossRef] [PubMed]

16. Nishiyama, N. Nanomedicine: Nanocarriers shape up for long life. Nat. Nanotechnol. 2007, 2, $203-204$. [CrossRef] [PubMed]

17. Day, E.S.; Morton, J.G.; West, J.L. Nanoparticles for thermal cancer therapy. J. Biomech. Eng. 2009, 131, 074001. [CrossRef] [PubMed]

18. De Matteis, V.; Rinaldi, R. Toxicity assessment in the nanoparticle era. Adv. Exp. Med. Biol. 2018, 1048, 1-19. [PubMed]

19. Iravani, S.; Korbekandi, H.; Mirmohammadi, S.V.; Zolfaghari, B. Synthesis of silver nanoparticles: Chemical, physical and biological methods. Res. Pharm. Sci. 2014, 9, 385-406. [PubMed]

20. Gurav, A.S.; Kodas, T.T.; Wang, L.-M.; Kauppinen, E.I.; Joutsensaari, J. Generation of nanometer-size fullerene particles via vapor condensation. Chem. Phys. Lett. 1994, 218, 304-308. [CrossRef]

21. Kim, M.; Osone, S.; Kim, T.; Higashi, H.; Seto, T. Synthesis of nanoparticles by laser ablation: A review. KONA Powder Part. J 2017, 80-90. [CrossRef]

22. Pyatenko, A.; Shimokawa, K.; Yamaguchi, M.; Nishimura, O.; Suzuki, M. Synthesis of silver nanoparticles by laser ablation in pure water. Appl. Phys. A 2004, 79, 803-806. [CrossRef]

23. Tsuji, T.; Iryo, K.; Watanabe, N.; Tsuji, M. Preparation of silver nanoparticles by laser ablation in solution: Influence of laser wavelength on particle size. Appl. Surf. Sci. 2002, 202, 80-85. [CrossRef]

24. Amendola, V.; Polizzi, S.; Meneghetti, M. Free silver nanoparticles synthesized by laser ablation in organic solvents and their easy functionalization. Langmuir ACS J. Surf. Colloids 2007, 23, 6766-6770. [CrossRef] [PubMed]

25. Balboul, B.A. Thermal decomposition study of erbium oxalate hexahydrate. Thermochim. Acta 2000, 351, 55-60. [CrossRef]

26. Lee, D.K.; Kang, Y.S. Preparation and characterization of magnetic nanoparticles by $\gamma$-irradiation. Mater. Sci. Eng. C 2004, 24, 107-111. [CrossRef]

27. Navaladian, S.; Viswanathan, B.; Viswanath, R.; Varadarajan, T. Thermal decomposition as route for silver nanoparticles. Nanoscale Res. Lett. 2006, 2, 44-48. [CrossRef] [PubMed]

28. Pluym, T.; Powell, Q.; Gurav, A.; Ward, T.; Kodas, T.; Wang, L.; Glicksman, H. Solid silver particle production by spray pyrolysis. J. Aerosol Sci. 1993, 24, 383-392. [CrossRef]

29. Pingali, K.C.; Rockstraw, D.A.; Deng, S. Silver nanoparticles from ultrasonic spray pyrolysis of aqueous silver nitrate. Aerosol Sci. Technol. 2005, 39, 1010-1014. [CrossRef]

30. Sharma, R.; Sharma, A.K.; Sharma, V. Synthesis of carbon nanotubes by Arc discharge and chemical vapor deposition method with analysis of its morphology, dispersion and functionalization characteristics. Cogent Eng. 2015, 2, 1094017. [CrossRef] 
31. Tien, D.-C.; Tseng, K.-H.; Liao, C.-Y.; Huang, J.-C.; Tsung, T.-T. Discovery of ionic silver in silver nanoparticle suspension fabricated by Arc discharge method. J. Alloys Compd. 2008, 463, 408-411. [CrossRef]

32. Siegel, J.; Kvítek, O.; Ulbrich, P.; Kolská, Z.; Slepička, P.; Švorčík, V. Progressive approach for metal nanoparticle synthesis. Mater. Lett. 2012, 89, 47-50. [CrossRef]

33. Zhang, X.-F.; Liu, Z.-G.; Shen, W.; Gurunathan, S. Silver nanoparticles: Synthesis, characterization, properties, applications, and therapeutic approaches. Int. J. Mol. Sci. 2016, 17, 1534. [CrossRef] [PubMed]

34. Chen, S.-F.; Zhang, H. Aggregation kinetics of nanosilver in different water conditions. Adv. Nat. Sci. Nanosci. Nanotechnol. 2012, 3, 035006. [CrossRef]

35. Dang, T.M.D.; Le, T.T.T.; Fribourg-Blanc, E.; Dang, M.C. Influence of surfactant on the preparation of silver nanoparticles by polyol method. Adv. Nat. Sci. Nanosci. Nanotechnol. 2012, 3, 035004. [CrossRef]

36. Dadosh, T.; Sperling, J.; Bryant, G.W.; Breslow, R.; Shegai, T.; Dyshel, M.; Haran, G.; Bar-Joseph, I. Plasmonic control of the shape of the raman spectrum of a single molecule in a silver nanoparticle dimer. ACS Nano 2009, 3, 1988-1994. [CrossRef] [PubMed]

37. De Matteis, V.; Malvindi, M.A.; Galeone, A.; Brunetti, V.; De Luca, E.; Kote, S.; Kshirsagar, P.; Sabella, S.; Bardi, G.; Pompa, P.P. Negligible particle-specific toxicity mechanism of silver nanoparticles: The role of $\mathrm{Ag}^{+}$ ion release in the cytosol. Nanomedicine Nanotechnol. Biol. Med. 2015, 11, 731-739. [CrossRef] [PubMed]

38. Zhang, Y.; Peng, H.; Huang, W.; Zhou, Y.; Yan, D. Facile preparation and characterization of highly antimicrobial colloid Ag or Au nanoparticles. J. Colloid Interface Sci. 2008, 325, 371-376. [CrossRef] [PubMed]

39. Wang, H.; Qiao, X.; Chen, J.; Ding, S. Preparation of silver nanoparticles by chemical reduction method. Colloids Surf. A Physicochem. Eng. Asp. 2005, 256, 111-115. [CrossRef]

40. Suriati, G.; Mariatti, M.; Azizan, A. Synthesis of silver nanoparticles by chemical reduction method: Effect of reducing agent and surfactant concentration. Int. J. Autom. Mech. Eng. 2014, 10, 1920. [CrossRef]

41. Martinez-Castanon, G.; Nino-Martinez, N.; Martinez-Gutierrez, F.; Martinez-Mendoza, J.; Ruiz, F. Synthesis and antibacterial activity of silver nanoparticles with different sizes. J. Nanopart. Res. 2008, 10, 1343-1348. [CrossRef]

42. Guzmán, M.G.; Dille, J.; Godet, S. Synthesis of silver nanoparticles by chemical reduction method and their antibacterial activity. Int. J. Chem. Biomol. Eng. 2009, 2, 104-111.

43. Pinto, V.V.; Ferreira, M.J.; Silva, R.; Santos, H.A.; Silva, F.; Pereira, C.M. Long time effect on the stability of silver nanoparticles in aqueous medium: Effect of the synthesis and storage conditions. Colloids Surf. A Physicochem. Eng. Asp. 2010, 364, 19-25. [CrossRef]

44. Jana, N.R.; Gearheart, L.; Murphy, C.J. Wet chemical synthesis of high aspect ratio cylindrical gold nanorods. J. Phys. Chem. B 2001, 105, 4065-4067. [CrossRef]

45. Agnihotri, S.; Mukherji, S.; Mukherji, S. Size-controlled silver nanoparticles synthesized over the range 5-100 $\mathrm{nm}$ using the same protocol and their antibacterial efficacy. RSC Adv. 2014, 4, 3974-3983. [CrossRef]

46. Dhand, C.; Dwivedi, N.; Loh, X.J.; Ying, A.N.J.; Verma, N.K.; Beuerman, R.W.; Lakshminarayanan, R.; Ramakrishna, S. Methods and strategies for the synthesis of diverse nanoparticles and their applications: A comprehensive overview. RSC Adv. 2015, 5, 105003-105037. [CrossRef]

47. Solanki, J.N.; Murthy, Z.V.P. Controlled size silver nanoparticles synthesis with water-in-oil microemulsion method: A topical review. Ind. Eng. Chem. Res. 2011, 50, 12311-12323. [CrossRef]

48. Zhang, W.; Qiao, X.; Chen, J. Synthesis of nanosilver colloidal particles in water/oil microemulsion. Colloids Surf. A Physicochem. Eng. Asp. 2007, 299, 22-28. [CrossRef]

49. Pileni, M.; Taleb, A.; Petit, C. Silver metal nanosized particles: Control of particle size, self assemblies in 2d and 3d superlattices and optical properties. J. Dispers. Sci. Technol. 1998, 19, 185-206. [CrossRef]

50. Chen, D.-H.; Wu, S.-H. Synthesis of nickel nanoparticles in water-in-oil microemulsions. Chem. Mater. 2000, 12, 1354-1360. [CrossRef]

51. Zhanjiang, Z.; Jinpei, L. Synthesis and characterization of silver nanoparticles by a sonochemical method. Rare Met. Mater. Eng. 2012, 41, 1700-1705. [CrossRef]

52. Okitsu, K.; Yue, A.; Tanabe, S.; Matsumoto, H.; Yobiko, Y. Formation of colloidal gold nanoparticles in an ultrasonic field: Control of rate of gold (iii) reduction and size of formed gold particles. Langmuir ACS J. Surf. Colloids 2001, 17, 7717-7720. [CrossRef]

53. Zhu, J.; Palchik, O.; Chen, S.; Gedanken, A. Microwave assisted preparation of CdSe, PbSe, and $\mathrm{Cu}_{2-x} \mathrm{Se}$ nanoparticles. J. Phys. Chem. B 2000, 104, 7344-7347. [CrossRef] 
54. Gutierrez, M.; Henglein, A.; Dohrmann, J.K. Hydrogen atom reactions in the sonolysis of aqueous solutions. J. Phys. Chem. 1987, 91, 6687-6690. [CrossRef]

55. Wani, I.A.; Ganguly, A.; Ahmed, J.; Ahmad, T. Silver nanoparticles: Ultrasonic wave assisted synthesis, optical characterization and surface area studies. Mater. Lett. 2011, 65, 520-522. [CrossRef]

56. Brinker, C.J.; Scherer, G.W. Sol-Gel Science: The Physics and Chemistry of Sol-Gel Processing; Academic Press: New York, NY, USA, 2013.

57. Zhai, S.-R.; Shao, X.; Zhou, D.; Zhai, B.; An, Q.-D. Sol-gel synthesis of nanosilver embedded hybrid materials using combined organosilica precursors. J. Sol-Gel Sci. Technol. 2012, 62, 281-286. [CrossRef]

58. Lkhagvajav, N.; Yasa, I.; Celik, E.; Koizhaiganova, M.; Sari, O. Antimicrobial activity of colloidal silver nanoparticles prepared by sol-gel method. Dig. J. Nanomater. Biostruct. 2011, 6, 149-154.

59. Reetz, M.T.; Helbig, W. Size-selective synthesis of nanostructured transition metal clusters. J. Am. Chem. Soc. 1994, 116, 7401-7402. [CrossRef]

60. Ma, H.; Yin, B.; Wang, S.; Jiao, Y.; Pan, W.; Huang, S.; Chen, S.; Meng, F. Synthesis of silver and gold nanoparticles by a novel electrochemical method. ChemPhysChem 2004, 5, 68-75. [CrossRef] [PubMed]

61. Rodriguez-Sanchez, L.; Blanco, M.; Lopez-Quintela, M. Electrochemical synthesis of silver nanoparticles. J. Phys. Chem. B 2000, 104, 9683-9688. [CrossRef]

62. Rafique, M.; Sadaf, I.; Rafique, M.S.; Tahir, M.B. A review on green synthesis of silver nanoparticles and their applications. Artif. Cells Nanomed. Biotechnol. 2017, 45, 1272-1291. [CrossRef] [PubMed]

63. Zhang, X.; Yan, S.; Tyagi, R.; Surampalli, R. Synthesis of nanoparticles by microorganisms and their application in enhancing microbiological reaction rates. Chemosphere 2011, 82, 489-494. [CrossRef] [PubMed]

64. Kalimuthu, K.; Babu, R.S.; Venkataraman, D.; Bilal, M.; Gurunathan, S. Biosynthesis of silver nanocrystals by bacillus licheniformis. Colloids Surf. B Biointerfaces 2008, 65, 150-153. [CrossRef] [PubMed]

65. Nanda, A.; Saravanan, M. Biosynthesis of silver nanoparticles from staphylococcus aureus and its antimicrobial activity against mrsa and mrse. Nanomed. Nanotechnol. Biol. Med. 2009, 5, 452-456. [CrossRef] [PubMed]

66. Saravanan, C.; Rajesh, R.; Kaviarasan, T.; Muthukumar, K.; Kavitake, D.; Shetty, P.H. Synthesis of silver nanoparticles using bacterial exopolysaccharide and its application for degradation of azo-dyes. Biotechnol. Rep. 2017, 15, 33-40. [CrossRef] [PubMed]

67. El-Shanshoury, A.E.-R.R.; ElSilk, S.E.; Ebeid, M.E. Extracellular biosynthesis of silver nanoparticles using escherichia coli ATCC 8739, bacillus subtilis atcc 6633, and streptococcus thermophilus esh1 and their antimicrobial activities. ISRN Nanotechnol. 2011, 2011, 385480. [CrossRef]

68. Mokhtari, N.; Daneshpajouh, S.; Seyedbagheri, S.; Atashdehghan, R.; Abdi, K.; Sarkar, S.; Minaian, S.; Shahverdi, H.R.; Shahverdi, A.R. Biological synthesis of very small silver nanoparticles by culture supernatant of klebsiella pneumonia: The effects of visible-light irradiation and the liquid mixing process. Mater. Res. Bull. 2009, 44, 1415-1421. [CrossRef]

69. Klaus, T.; Joerger, R.; Olsson, E.; Granqvist, C.-G. Silver-based crystalline nanoparticles, microbially fabricated. Proc. Natl. Acad. Sci. USA 1999, 96, 13611-13614. [CrossRef] [PubMed]

70. Kalishwaralal, K.; Deepak, V.; Pandian, S.R.K.; Kottaisamy, M.; BarathManiKanth, S.; Kartikeyan, B.; Gurunathan, S. Biosynthesis of silver and gold nanoparticles using brevibacterium casei. Colloids Surf. B Biointerfaces 2010, 77, 257-262. [CrossRef] [PubMed]

71. Fu, J.-K.; Zhang, W.; Liu, Y.-Y.; Lin, Z.-Y.; Yao, B.-X.; Weng, S.-Z.; Zeng, J.-L. Characterization of adsorption and reduction of noble metal ions by bacteria. Chem. J. Chin. Univ. 1999, 20, 1452-1454.

72. Samadi, N.; Golkaran, D.; Eslamifar, A.; Jamalifar, H.; Fazeli, M.R.; Mohseni, F.A. Intra/extracellular biosynthesis of silver nanoparticles by an autochthonous strain of proteus mirabilis isolated fromphotographic waste. J. Biomed. Nanotechnol. 2009, 5, 247-253. [CrossRef] [PubMed]

73. Lengke, M.F.; Fleet, M.E.; Southam, G. Biosynthesis of silver nanoparticles by filamentous cyanobacteria from a silver (i) nitrate complex. Langmuir ACS J. Surf. Colloids 2007, 23, 2694-2699. [CrossRef] [PubMed]

74. Minaeian, S.; Shahverdi, A.; Nouhi, A.A.; Shahverdi, H.R. Extracellular biosynthesis of silver nanoparticles by somebacteria. J. Sci. I. U. A. (JSIAU) 2008, 17, 66.

75. Kowshik, M.; Ashtaputre, S.; Kharrazi, S.; Vogel, W.; Urban, J.; Kulkarni, S.K.; Paknikar, K. Extracellular synthesis of silver nanoparticles by a silver-tolerant yeast strain mky3. Nanotechnology 2002, 14, 95. [CrossRef] 
76. Bhangale, H.; Sarode, K.; Patil, A.; Patil, D. Microbial Synthesis of Silver Nanoparticles Using Aspergillus Flavus and Their Characterization; Techno-Societal 2016, International Conference on Advanced Technologies for Societal Applications; Springer: Berlin, Germany, 2016; pp. 463-470.

77. Vigneshwaran, N.; Ashtaputre, N.; Varadarajan, P.; Nachane, R.; Paralikar, K.; Balasubramanya, R. Biological synthesis of silver nanoparticles using the fungus Aspergillus Flavus. Mater. Lett. 2007, 61, 1413-1418. [CrossRef]

78. Kathiresan, K.; Manivannan, S.; Nabeel, M.; Dhivya, B. Studies on silver nanoparticles synthesized by a marine fungus, penicillium fellutanum isolated from coastal mangrove sediment. Colloids Surf. B Biointerfaces 2009, 71, 133-137. [CrossRef] [PubMed]

79. Kathiresan, K.; Alikunhi, N.M.; Pathmanaban, S.; Nabikhan, A.; Kandasamy, S. Analysis of antimicrobial silver nanoparticles synthesized by coastal strains of Escherichia Coli and aspergillus niger. Can. J. Microbiol. 2010, 56, 1050-1059. [CrossRef] [PubMed]

80. Gade, A.; Bonde, P.; Ingle, A.; Marcato, P.; Duran, N.; Rai, M. Exploitation of Aspergillus Niger for synthesis of silver nanoparticles. J. Biobased Mater. Bioenergy 2008, 2, 243-247. [CrossRef]

81. De Souza, A.O.; Rodrigues, A.G. Biosynthesis of silver nanoparticles by fungi. Fungal Biomol. Sources Appl. Recent Dev. 2015, 115-135. [CrossRef]

82. Li, G.; He, D.; Qian, Y.; Guan, B.; Gao, S.; Cui, Y.; Yokoyama, K.; Wang, L. Fungus-mediated green synthesis of silver nanoparticles using Aspergillus terreus. Int. J. Mol. Sci. 2011, 13, 466-476. [CrossRef] [PubMed]

83. Raudabaugh, D.B.; Tzolov, M.B.; Calabrese, J.P.; Overton, B.E. Synthesis of silver nanoparticles by a bryophilous rhizoctonia species. Nanomater. Nanotechnol. 2013, 3, 2. [CrossRef]

84. Devika, R.; Elumalai, S.; Manikandan, E.; Eswaramoorthy, D. Biosynthesis of silver nanoparticles using the fungus Pleurotus Ostreatus and their antibacterial activity. Open Access Sci. Rep. 2012, 1, 557.

85. Kulkarni, N.; Muddapur, U. Biosynthesis of metal nanoparticles: A review. J. Nanotechnol. 2014, 2014, 510246. [CrossRef]

86. Kumar, D.A.; Palanichamy, V.; Roopan, S.M. Green synthesis of silver nanoparticles using alternanthera dentata leaf extract at room temperature and their antimicrobial activity. Spectrochim. Acta Part A Mol. Biomol. Spectrosc. 2014, 127, 168-171. [CrossRef] [PubMed]

87. Dhand, V.; Soumya, L.; Bharadwaj, S.; Chakra, S.; Bhatt, D.; Sreedhar, B. Green synthesis of silver nanoparticles using coffea arabica seed extract and its antibacterial activity. Mater. Sci. Eng. C 2016, 58, 36-43. [CrossRef] [PubMed]

88. Gopinath, V.; MubarakAli, D.; Priyadarshini, S.; Priyadharsshini, N.M.; Thajuddin, N.; Velusamy, P. Biosynthesis of silver nanoparticles from tribulus terrestris and its antimicrobial activity: A novel biological approach. Colloids Surf. B Biointerfaces 2012, 96, 69-74. [CrossRef] [PubMed]

89. Krishnaraj, C.; Jagan, E.; Rajasekar, S.; Selvakumar, P.; Kalaichelvan, P.; Mohan, N. Synthesis of silver nanoparticles using acalypha indica leaf extracts and its antibacterial activity against water borne pathogens. Colloids Surf. B Biointerfaces 2010, 76, 50-56. [CrossRef] [PubMed]

90. Veeraputhiran, V. Bio-catalytic synthesis of silver nanoparticles. Int. J. ChemTech Res. 2013, 5, 255-2562.

91. Khalil, M.M.; Ismail, E.H.; El-Baghdady, K.Z.; Mohamed, D. Green synthesis of silver nanoparticles using olive leaf extract and its antibacterial activity. Arab. J. Chem. 2014, 7, 1131-1139. [CrossRef]

92. Rashid, Z.; Moadi, T.; Ghahremanzadeh, R. Green synthesis and characterization of silver nanoparticles using ferula latisecta leaf extract and their application as a catalyst for the safe and simple one-pot preparation of spirooxindoles in water. New J. Chem. 2016, 40, 3343-3349. [CrossRef]

93. Roy, N.; Gaur, A.; Jain, A.; Bhattacharya, S.; Rani, V. Green synthesis of silver nanoparticles: An approach to overcome toxicity. Environ. Toxicol. Pharmacol. 2013, 36, 807-812. [CrossRef] [PubMed]

94. Ahmed, S.; Ahmad, M.; Swami, B.L.; Ikram, S. A review on plants extract mediated synthesis of silver nanoparticles for antimicrobial applications: A green expertise. J. Adv. Res. 2016, 7, 17-28. [CrossRef] [PubMed]

95. Makarov, V.V.; Love, A.J.; Sinitsyna, O.V.; Makarova, S.S.; Yaminsky, I.V.; Taliansky, M.E.; Kalinina, N.O. "Green" nanotechnologies: Synthesis of metal nanoparticles using plants. Acta Nat. 2014, 6, 35-44.

96. Chen, Y.-H.; Yeh, C.-S. Laser ablation method: Use of surfactants to form the dispersed ag nanoparticles. Colloids Surf. A Physicochem. Eng. Asp. 2002, 197, 133-139. [CrossRef]

97. Qin, Y.; Ji, X.; Jing, J.; Liu, H.; Wu, H.; Yang, W. Size control over spherical silver nanoparticles by ascorbic acid reduction. Colloids Surf. A Physicochem. Eng. Asp. 2010, 372, 172-176. [CrossRef] 
98. Kannan, R.; Stirk, W.; Van Staden, J. Synthesis of silver nanoparticles using the seaweed Codium Capitatum P.C. Silva (Chlorophyceae). S. Afr. J. Bot. 2013, 86, 1-4. [CrossRef]

99. Liu, W.; Wu, Y.; Wang, C.; Li, H.C.; Wang, T.; Liao, C.Y.; Cui, L.; Zhou, Q.F.; Yan, B.; Jiang, G.B. Impact of silver nanoparticles on human cells: Effect of particle size. Nanotoxicology 2010, 4, 319-330. [CrossRef] [PubMed]

100. Hsin, Y.H.; Chen, C.F.; Huang, S.; Shih, T.S.; Lai, P.S.; Chueh, P.J. The apoptotic effect of nanosilver is mediated by a ROS- and JNK-dependent mechanism involving the mitochondrial pathway in NIH3T3 cells. Toxicol. Lett. 2008, 179, 130-139. [CrossRef] [PubMed]

101. Hussain, S.M.; Hess, K.L.; Gearhart, J.M.; Geiss, K.T.; Schlager, J.J. In Vitro toxicity of nanoparticles in BRL 3a rat liver cells. Toxicology In Vitro 2005, 19, 975-983. [CrossRef] [PubMed]

102. Verano-Braga, T.; Miethling-Graff, R.; Wojdyla, K.; Rogowska-Wrzesinska, A.; Brewer, J.R.; Erdmann, H.; Kjeldsen, F. Insights into the cellular response triggered by silver nanoparticles using quantitative proteomics. ACS Nano 2014, 8, 2161-2175. [CrossRef] [PubMed]

103. Carlson, C.; Hussain, S.M.; Schrand, A.M.; Braydich-Stolle, L.K.; Hess, K.L.; Jones, R.L.; Schlager, J.J. Unique cellular interaction of silver nanoparticles: Size-dependent generation of reactive oxygen species. J. Phys. Chem. B 2008, 112, 13608-13619. [CrossRef] [PubMed]

104. Foldbjerg, R.; Olesen, P.; Hougaard, M.; Dang, D.A.; Hoffmann, H.J.; Autrup, H. PVP-coated silver nanoparticles and silver ions induce reactive oxygen species, apoptosis and necrosis in THP-1 monocytes. Toxicol. Lett. 2009, 190, 156-162. [CrossRef] [PubMed]

105. Foldbjerg, R.; Dang, D.A.; Autrup, H. Cytotoxicity and genotoxicity of silver nanoparticles in the human lung cancer cell line, a549. Arch. Toxicol. 2011, 85, 743-750. [CrossRef] [PubMed]

106. Kim, S.; Choi, J.E.; Choi, J.; Chung, K.H.; Park, K.; Yi, J.; Ryu, D.Y. Oxidative stress-dependent toxicity of silver nanoparticles in human hepatoma cells. Toxicology In Vitro 2009, 23, 1076-1084. [CrossRef] [PubMed]

107. Avalos, A.; Haza, A.I.; Mateo, D.; Morales, P. Interactions of manufactured silver nanoparticles of different sizes with normal human dermal fibroblasts. Int. Wound J. 2016, 13, 101-109. [CrossRef] [PubMed]

108. Foldbjerg, R.; Irving, E.S.; Hayashi, Y.; Sutherland, D.S.; Thorsen, K.; Autrup, H.; Beer, C. Global gene expression profiling of human lung epithelial cells after exposure to nanosilver. Toxicol. Sci. 2012, 130, 145-157. [CrossRef] [PubMed]

109. Piao, M.J.; Kang, K.A.; Lee, I.K.; Kim, H.S.; Kim, S.; Choi, J.Y.; Choi, J.; Hyun, J.W. Silver nanoparticles induce oxidative cell damage in human liver cells through inhibition of reduced glutathione and induction of mitochondria-involved apoptosis. Toxicol. Lett. 2011, 201, 92-100. [CrossRef] [PubMed]

110. Eom, H.J.; Choi, J. P38 mapk activation, DNA damage, cell cycle arrest and apoptosis as mechanisms of toxicity of silver nanoparticles in jurkat $t$ cells. Environ. Sci. Technol. 2010, 44, 8337-8342. [CrossRef] [PubMed]

111. Nishanth, R.P.; Jyotsna, R.G.; Schlager, J.J.; Hussain, S.M.; Reddanna, P. Inflammatory responses of raw 264.7 macrophages upon exposure to nanoparticles: Role of ROS-NFkB signaling pathway. Nanotoxicology 2011, 5, 502-516. [CrossRef] [PubMed]

112. Asharani, P.; Sethu, S.; Lim, H.K.; Balaji, G.; Valiyaveettil, S.; Hande, M.P. Differential regulation of intracellular factors mediating cell cycle, DNA repair and inflammation following exposure to silver nanoparticles in human cells. Genome Integr. 2012, 3, 2. [CrossRef] [PubMed]

113. Ahamed, M.; Karns, M.; Goodson, M.; Rowe, J.; Hussain, S.M.; Schlager, J.J.; Hong, Y. DNA damage response to different surface chemistry of silver nanoparticles in mammalian cells. Toxicol. Appl. Pharmacol. 2008, 233, 404-410. [CrossRef] [PubMed]

114. Chichova, M.; Shkodrova, M.; Vasileva, P.; Kirilova, K.; Doncheva-Stoimenova, D. Influence of silver nanoparticles on the activity of rat liver mitochondrial atpase. J. Nanopart. Res. 2014, 16, 1-14. [CrossRef]

115. Lee, D.Y.; Li, K.C. Molecular theranostics: A primer for the imaging professional. AJR Am. J. Roentgenol. 2011, 197, 318-324. [CrossRef] [PubMed]

116. Svenson, S. Theranostics: Are we there yet? Mol. Pharm. 2013, 10, 848-856. [CrossRef] [PubMed]

117. Lim, E.K.; Kim, T.; Paik, S.; Haam, S.; Huh, Y.M.; Lee, K. Nanomaterials for theranostics: Recent advances and future challenges. Chem. Rev. 2015, 115, 327-394. [CrossRef] [PubMed]

118. Bardhan, R.; Lal, S.; Joshi, A.; Halas, N.J. Theranostic nanoshells: From probe design to imaging and treatment of cancer. Acc. Chem. Res. 2011, 44, 936-946. [CrossRef] [PubMed] 
119. Cole, A.J.; Yang, V.C.; David, A.E. Cancer theranostics: The rise of targeted magnetic nanoparticles. Trends Biotechnol. 2011, 29, 323-332. [CrossRef] [PubMed]

120. Davis, M.E.; Chen, Z.G.; Shin, D.M. Nanoparticle therapeutics: An emerging treatment modality for cancer. Nat. Rev. Drug Discov. 2008, 7, 771-782. [CrossRef] [PubMed]

121. Ferrari, M. Cancer nanotechnology: Opportunities and challenges. Nat. Rev. Cancer 2005, 5, 161-171. [CrossRef] [PubMed]

122. Verma, S.K.; Mani, P.; Sharma, N.R.; Krishnan, A.; Kumar, V.V.; Reddy, B.S.; Chaudhuri, A.; Roy, R.P.; Sarkar, D.P. Histidylated lipid-modified sendai viral envelopes mediate enhanced membrane fusion and potentiate targeted gene delivery. J. Biol. Chem. 2005, 280, 35399-35409. [CrossRef] [PubMed]

123. Acharya, S.; Sahoo, S.K. PLGA nanoparticles containing various anticancer agents and tumour delivery by EPR effect. Adv. Drug Deliv. Rev. 2011, 63, 170-183. [CrossRef] [PubMed]

124. Sharma, H.; Mishra, P.K.; Talegaonkar, S.; Vaidya, B. Metal nanoparticles: A theranostic nanotool against cancer. Drug Discov. Today 2015, 20, 1143-1151. [CrossRef] [PubMed]

125. Gopinath, P.; Gogoi, S.K.; Chattopadhyay, A.; Ghosh, S.S. Implications of silver nanoparticle induced cell apoptosis for in vitro gene therapy. Nanotechnology 2008, 19, 075104. [CrossRef] [PubMed]

126. Kerr, S.L.; Sharp, B. Nano-particle labelling of nucleic acids for enhanced detection by inductively-coupled plasma mass spectrometry (ICP-MS). Chem. Commun. 2007, 4537-4539. [CrossRef] [PubMed]

127. Whaley, S.R.; English, D.S.; Hu, E.L.; Barbara, P.F.; Belcher, A.M. Selection of peptides with semiconductor binding specificity for directed nanocrystal assembly. Nature 2000, 405, 665-668. [CrossRef] [PubMed]

128. Wang, H.J.; Yang, L.; Yang, H.Y.; Wang, K.; Yao, W.G.; Jiang, K.; Huang, X.L.; Zheng, Z. Antineoplastic activities of protein-conjugated silver sulfide nano-crystals with different shapes. J. Inorg. Biochem. 2010, 104, 87-91. [CrossRef] [PubMed]

129. Sanpui, P.; Chattopadhyay, A.; Ghosh, S.S. Induction of apoptosis in cancer cells at low silver nanoparticle concentrations using chitosan nanocarrier. ACS Appl. Mater. Interfaces 2011, 3, 218-228. [CrossRef] [PubMed]

130. Guo, D.; Zhu, L.; Huang, Z.; Zhou, H.; Ge, Y.; Ma, W.; Wu, J.; Zhang, X.; Zhou, X.; Zhang, Y. Anti-leukemia activity of PVP-coated silver nanoparticles via generation of reactive oxygen species and release of silver ions. Biomaterials 2013, 34, 7884-7894. [CrossRef] [PubMed]

131. AshaRani, P.V.; Low Kah Mun, G.; Hande, M.P.; Valiyaveettil, S. Cytotoxicity and genotoxicity of silver nanoparticles in human cells. ACS Nano 2009, 3, 279-290. [CrossRef] [PubMed]

132. Liang, P.; Shi, H.; Zhu, W.; Gui, Q.; Xu, Y.; Meng, J.; Guo, X.; Gong, Z.; Chen, H. Silver nanoparticles enhance the sensitivity of temozolomide on human glioma cells. Oncotarget 2017, 8, 7533-7539. [CrossRef] [PubMed]

133. Locatelli, E.; Naddaka, M.; Uboldi, C.; Loudos, G.; Fragogeorgi, E.; Molinari, V.; Pucci, A.; Tsotakos, T.; Psimadas, D.; Ponti, J.; et al. Targeted delivery of silver nanoparticles and alisertib: In vitro and in vivo synergistic effect against glioblastoma. Nanomedicine 2014, 9, 839-849. [CrossRef] [PubMed]

134. Ortega, F.G.; Fernandez-Baldo, M.A.; Fernandez, J.G.; Serrano, M.J.; Sanz, M.I.; Diaz-Mochon, J.J.; Lorente, J.A.; Raba, J. Study of antitumor activity in breast cell lines using silver nanoparticles produced by yeast. Int. J. Nanomed. 2015, 10, 2021-2031.

135. Gurunathan, S.; Han, J.W.; Eppakayala, V.; Jeyaraj, M.; Kim, J.H. Cytotoxicity of biologically synthesized silver nanoparticles in MDA-MB-231 human breast cancer cells. BioMed Res. Int. 2013, 2013, 535796. [CrossRef] [PubMed]

136. Gurunathan, S.; Park, J.H.; Han, J.W.; Kim, J.H. Comparative assessment of the apoptotic potential of silver nanoparticles synthesized by bacillus tequilensis and calocybe indica in MDA-MB-231 human breast cancer cells: Targeting p53 for anticancer therapy. Int. J. Nanomed. 2015, 10, 4203-4222. [CrossRef] [PubMed]

137. Gurunathan, S.; Han, J.W.; Dayem, A.A.; Eppakayala, V.; Park, J.H.; Cho, S.-G.; Lee, K.J.; Kim, J.-H. Green synthesis of anisotropic silver nanoparticles and its potential cytotoxicity in human breast cancer cells (MCF-7). J. Ind. Eng. Chem. 2013, 19, 1600-1605. [CrossRef]

138. Gurunathan, S.; Jeong, J.K.; Han, J.W.; Zhang, X.F.; Park, J.H.; Kim, J.H. Multidimensional effects of biologically synthesized silver nanoparticles in helicobacter pylori, helicobacter felis, and human lung (1132) and lung carcinoma a549 cells. Nanoscale Res. Lett. 2015, 10, 35. [CrossRef] [PubMed]

139. Zuberek, M.; Wojciechowska, D.; Krzyzanowski, D.; Meczynska-Wielgosz, S.; Kruszewski, M.; Grzelak, A. Glucose availability determines silver nanoparticles toxicity in HEPG2. J. Nanobiotechnol. 2015, 13, 72. [CrossRef] [PubMed] 
140. Halliwell, B.; Clement, M.V.; Ramalingam, J.; Long, L.H. Hydrogen peroxide. Ubiquitous in cell culture and in vivo? IUBMB Life 2000, 50, 251-257. [CrossRef] [PubMed]

141. He, W.; Zhou, Q.; Yu, S.; Cai, D.; Wang, Q.; Zhang, X.; Huang, W.Q. Mechanism on atrial natriuretic peptide receptor in anti-anxiety with acupuncture based on its tranquilizing effect. Zhongguo Zhen Jiu 2015, 35, 101-104. [PubMed]

142. Hao, E.; Schatz, G.C. Electromagnetic fields around silver nanoparticles and dimers. J. Chem. Phys. 2004, 120, 357-366. [CrossRef] [PubMed]

143. Bohren, C.F.; Huffman, D.R. Absorption and Scattering by a Sphere; Wiley Online Library: New York, NY, USA, 1983.

144. Kreibig, U.; Vollmer, M. Optical Properties of Metal Clusters; Springer Science \& Business Media: New York, NY, USA, 2013; Volume 25.

145. Hutter, E.; Fendler, J.H. Exploitation of localized surface plasmon resonance. Adv. Mater. 2004, 16, 1685-1706. [CrossRef]

146. Hecht, B.; Bielefeldt, H.; Novotny, L.; Inouye, Y.; Pohl, D. Local excitation, scattering, and interference of surface plasmons. Phys. Rev. Lett. 1996, 77, 1889. [CrossRef] [PubMed]

147. Jain, P.K.; Huang, X.; El-Sayed, I.H.; El-Sayed, M.A. Noble metals on the nanoscale: Optical and photothermal properties and some applications in imaging, sensing, biology, and medicine. Acc. Chem. Res. 2008, 41, 1578-1586. [CrossRef] [PubMed]

148. Schasfoort, R.B. Handbook of Surface Plasmon Resonance; Royal Society of Chemistry: Cambridge, UK, 2017.

149. Brongersma, M.L.; Halas, N.J.; Nordlander, P. Plasmon-induced hot carrier science and technology. Nat. Nanotechnol. 2015, 10, 25. [CrossRef] [PubMed]

150. Amendola, V.; Bakr, O.M.; Stellacci, F. A study of the surface plasmon resonance of silver nanoparticles by the discrete dipole approximation method: Effect of shape, size, structure, and assembly. Plasmonics 2010, 5, 85-97. [CrossRef]

151. Jacques, S.L. Optical properties of biological tissues: A review. Phys. Med. Biol. 2013, 58, R37. [CrossRef] [PubMed]

152. Evanoff, D.D.; Chumanov, G. Synthesis and optical properties of silver nanoparticles and arrays. ChemPhysChem 2005, 6, 1221-1231. [CrossRef] [PubMed]

153. Peiris, S.; McMurtrie, J.; Zhu, H.-Y. Metal nanoparticle photocatalysts: Emerging processes for green organic synthesis. Catal. Sci. Technol. 2016, 6, 320-338. [CrossRef]

154. Linic, S.; Aslam, U.; Boerigter, C.; Morabito, M. Photochemical transformations on plasmonic metal nanoparticles. Nat. Mater. 2015, 14, 567-576. [CrossRef] [PubMed]

155. Mukherjee, S.; Chowdhury, D.; Kotcherlakota, R.; Patra, S. Potential theranostics application of bio-synthesized silver nanoparticles (4-in-1 system). Theranostics 2014, 4, 316-335. [CrossRef] [PubMed]

156. Farrag, N.S.; El-Sabagh, H.A.; Al-mahallawi, A.M.; Amin, A.M.; AbdEl-Bary, A.; Mamdouh, W. Comparative study on radiolabeling and biodistribution of core-shell silver/polymeric nanoparticles-based theranostics for tumor targeting. Int. J. Pharm. 2017, 529, 123-133. [CrossRef] [PubMed]

157. Boca, S.C.; Potara, M.; Gabudean, A.M.; Juhem, A.; Baldeck, P.L.; Astilean, S. Chitosan-coated triangular silver nanoparticles as a novel class of biocompatible, highly effective photothermal transducers for in vitro cancer cell therapy. Cancer Lett. 2011, 311, 131-140. [CrossRef] [PubMed]

158. Kovács, D.; Igaz, N.; Keskeny, C.; Bélteky, P.; Tóth, T.; Gáspár, R.; Madarász, D.; Rázga, Z.; Kónya, Z.; Boros, I.M. Silver nanoparticles defeat p53-positive and p53-negative osteosarcoma cells by triggering mitochondrial stress and apoptosis. Sci. Rep. 2016, 6, 27902. [CrossRef] [PubMed]

159. Schrand, A.M.; Braydich-Stolle, L.K.; Schlager, J.J.; Dai, L.; Hussain, S.M. Can silver nanoparticles be useful as potential biological labels? Nanotechnology 2008, 19, 235104. [CrossRef] [PubMed]

160. Stensberg, M.C.; Wei, Q.; McLamore, E.S.; Porterfield, D.M.; Wei, A.; Sepulveda, M.S. Toxicological studies on silver nanoparticles: Challenges and opportunities in assessment, monitoring and imaging. Nanomedicine 2011, 6, 879-898. [CrossRef] [PubMed]

161. Tran, Q.H.; Le, A.-T. Silver nanoparticles: Synthesis, properties, toxicology, applications and perspectives. Adv. Nat. Sci. Nanosci. Nanotechnol. 2013, 4, 033001. [CrossRef]

162. Rahman, M.; Wang, J.; Patterson, T.; Saini, U.; Robinson, B.; Newport, G.; Murdock, R.; Schlager, J.; Hussain, S.; Ali, S. Expression of genes related to oxidative stress in the mouse brain after exposure to silver-25 nanoparticles. Toxicol. Lett. 2009, 187, 15-21. [CrossRef] [PubMed] 
163. Sung, J.H.; Ji, J.H.; Park, J.D.; Yoon, J.U.; Kim, D.S.; Jeon, K.S.; Song, M.Y.; Jeong, J.; Han, B.S.; Han, J.H. Subchronic inhalation toxicity of silver nanoparticles. Toxicol. Sci. 2008, 108, 452-461. [CrossRef] [PubMed]

164. Van Aerle, R.; Lange, A.; Moorhouse, A.; Paszkiewicz, K.; Ball, K.; Johnston, B.D.; de-Bastos, E.; Booth, T.; Tyler, C.R.; Santos, E.M. Molecular mechanisms of toxicity of silver nanoparticles in zebrafish embryos. Environ. Sci. Technol. 2013, 47, 8005-8014. [CrossRef] [PubMed]

165. Munger, M.A.; Radwanski, P.; Hadlock, G.C.; Stoddard, G.; Shaaban, A.; Falconer, J.; Grainger, D.W.; Deering-Rice, C.E. In Vivo human time-exposure study of orally dosed commercial silver nanoparticles. Nanomed. Nanotechnol. Biol. Med. 2014, 10, 1-9. [CrossRef] [PubMed]

(c) 2018 by the authors. Licensee MDPI, Basel, Switzerland. This article is an open access article distributed under the terms and conditions of the Creative Commons Attribution (CC BY) license (http:/ / creativecommons.org/licenses/by/4.0/). 
Article

\title{
High Ultraviolet Absorption in Colloidal Gallium Nanoparticles Prepared from Thermal Evaporation
}

\author{
Flavio Nucciarelli ${ }^{1,2, *}$, Iria Bravo ${ }^{3,4}$, Sergio Catalan-Gomez ${ }^{2}$, Luis Vázquez ${ }^{5}$, \\ Encarnación Lorenzo ${ }^{3,4,6}$ and Jose Luis Pau ${ }^{2}$ \\ 1 Physics Department, Lancaster University, Lancaster LA1 4YB, UK \\ 2 Grupo de Electrónica y Semiconductores, Departamento de Física Aplicada, Universida Autónoma de \\ Madrid, 28049 Madrid, Spain; sergio.catalan@uam.es (S.C.-G.); joseluis.pau@uam.es (J.L.P.) \\ 3 Departamento de Química Analítica y Análisis Instrumental, Universidad Autónoma de Madrid, \\ Cantoblanco, 28049 Madrid, Spain; iria.bravo@uam.es (I.B.); encarnacion.lorenzo@uam.es (E.L.) \\ 4 Instituto Madrileño de Estudios Avanzados en Nanociencia (IMDEA-Nanociencia), Faraday, 9, \\ Campus UAM, Cantoblanco, 28049 Madrid, Spain \\ 5 Materials Science Factory, Instituto de Ciencia de Materiales de Madrid, CSIC, 28049 Madrid, Spain; \\ lvb@icmm.csic.es \\ 6 Institute for Advanced Research in Chemical Sciences (IAdChem), Universidad Autónoma de Madrid, \\ 28049 Madrid, Spain \\ * Correspondence: nccflv@gmail.com; Tel.: +34-91-497-8607
}

Received: 9 June 2017; Accepted: 30 June 2017; Published: 6 July 2017

\begin{abstract}
New methods for the production of colloidal Ga nanoparticles (GaNPs) are introduced based on the evaporation of gallium on expendable aluminum zinc oxide (AZO) layer. The nanoparticles can be prepared in aqueous or organic solvents such as tetrahydrofuran in order to be used in different sensing applications. The particles had a quasi mono-modal distribution with diameters ranging from $10 \mathrm{~nm}$ to $80 \mathrm{~nm}$, and their aggregation status depended on the solvent nature. Compared to common chemical synthesis, our method assures higher yield with the possibility of tailoring particles size by adjusting the deposition time. The GaNPs have been studied by spectrophotometry to obtain the absorption spectra. The colloidal solutions exhibit strong plasmonic absorption in the ultra violet (UV) region around $280 \mathrm{~nm}$, whose width and intensity mainly depend on the nanoparticles dimensions and their aggregation state. With regard to the colloidal GaNPs flocculate behavior, the water solvent case has been investigated for different $\mathrm{pH}$ values, showing UV-visible absorption because of the formation of NPs clusters. Using discrete dipole approximation (DDA) method simulations, a close connection between the UV absorption and NPs with a diameter smaller than $\sim 40 \mathrm{~nm}$ was observed.
\end{abstract}

Keywords: gallium; nanoparticle; colloid; AZO; tetrahydrofuran; thermal evaporation; DDA simulation

\section{Introduction}

Insulating, metal and semiconducting nanoparticles (NPs) have played a crucial role in the development of nanotechnology during the last two decades. The driving force in the field comes from the large surface-to-volume ratio and the manifestation of quantum effects that make the physical and chemical properties of these particles different from those found in bulk materials. Due to their applicability in different areas such as drug delivery [1], disinfection [2], photovoltaics [3], (bio)sensing [4,5], and catalysis [6,7], many studies have addressed the need for reproducible and reliable methods for the preparation of NPs. One of the main goals has been the production of colloidal suspensions in a liquid medium to ease the manipulation, storage, chemical modification and administration of the NPs in many practical cases. 
Metal nanoparticles can be prepared as colloidal suspensions following bottom-up or top-down approaches. After Turkevich's work in the early fifties on the synthesis of gold NPs in aqueous solution at boiling temperature, one of the most popular bottom-up methods for producing metal NPs became the reduction of metal salts solved in a liquid phase [8,9]. Other liquid-phase methods commonly used for the fabrication of metal NPs have been magnetic-microwave heating [10], template synthesis [11] and electrodeposition [12]. They typically require the use of toxic reagents, which remain adsorbed on the surface after the NP synthesis and have potential adverse effects on human health [13]. On the other hand, gas phase methods are based on the nucleation and condensation of the gas molecules after supersaturation [14]. Examples of these methods are laser ablation, spray pyrolysis and furnace evaporation. Generally, size-selective precipitation is needed in liquid and gas phase methods to produce narrow size distributions [15].

Metal NPs are highly soluble in nonpolar organic solvents where, due to the low dielectric constant of the medium, the solvent molecules are not able to screen the surface charges around the particle, keeping a repulsive force between the NPs [16]. However, in polar solvents, the electrostatic surface interactions between the particles tend to produce their condensation and precipitation, giving rise to disordered aggregates that are not easily resoluble [17]. Those interactions are dominated by Van der Waals forces that increase inversely with the sixth power of distance between them [18]. The light-cluster interaction will depend on the number of agglomerated NPs, their special arrangement and the surface-environment interplay [19]. For that reason, the aqueous colloids must be stabilized to reduce surface interactions between NPs through the formation of self-assembled monolayers, polymeric coating or the use of ionic liquids $[20,21]$. The stabilization of the NPs is therefore considered a key task in the preparation of NPs, and the steps followed to achieve this are intimately involved in the fabrication process.

Gallium $(\mathrm{Ga})$ is a low melting point metal whose interesting properties have attracted much attention in recent years. Colloidal NPs of this material with sizes lower than $50 \mathrm{~nm}$ have been characterized, exhibiting strong plasmonic absorption bands in the ultraviolet region [22,23], which makes them very attractive for surface-enhanced Raman scattering and fluorescence spectroscopy under UV excitation. They are in liquid state at room temperature surrounded by a thin gallium oxide layer that keeps them stable for months at ambient conditions [23]. The NPs have also shown a large charge storage capacity, fostering their investigation as one of the components in lithium ion batteries. Thanks to their fast reaction in the acidic environment found around tumors, they have also performed optimally for drug delivery purposes in cancer treatment [24]. Indeed, in vivo experiments in mice have demonstrated the reduction of tumors through the release of doxorubicin in the affected area without clear signs of toxicity. For this application, the size of the NPs must be very specific to allow surpassing of the cell barrier and delivery of the drug inside the cell to provoke the apoptosis of the tumoral cells.

Monodisperse colloidal Ga NPs have been synthesized using Ga alkylamides precursors in liquid-phase chemistry [23]. Another method based on the co-deposition of Ga atoms and solvent molecules at $77 \mathrm{~K}$ has been reported, yielding colloidal NPs in different organic solvents like tetrahydrofuran (THF), 2-propanol and acetone [22]. Furthermore, taking advantage of the liquid state of the Ga-In eutectic alloy, ultrasound sonication of bulk pieces has also enabled the production of large concentrations of NPs in a controlled manner [24]. In this work, we propose a bottom-up method for the production of GaNP colloids from the physical vapor deposition (PVD) of Ga under vacuum conditions on a solid substrate that contains a metal oxide expendable layer. The method provides a coating layer of self-assembled NPs without photolithographic steps.

The fabrication process enables the synthesis of colloids with a quite uniform NP size in polar protic and aprotic solvents after etching the oxide layer in an acidic solution. The aggregation of the NPs in THF and aqueous solutions is investigated through ultraviolet/visible spectrophotometry. The Ga NPs absorbance spectrum is usually found in the UV range [2] and it has its origin in the high plasmon frequency of the material. When a photon with the resonance energy impinges on the particle, 
a localized surface wave is built and the resultant energy can be absorbed or reemitted as scattered light. Additionally, the wave gives rise to a near-field enhancement around the structure. The nanoparticle size distribution can be tuned by changing the evaporation time of the gallium target. Furthermore, the use of physical vapor deposition methodologies reduces the cost, improves the reproducibility of the NP preparation, and enables pre-functionalization and size tuning separately from the selected solvent. The method can be easily scaled to large coverage areas to increase the fabrication yield. Moreover, in comparison to other methods, it produces a minimum amount of contaminant wastes.

\section{Results and Discussion}

\subsection{Colloidal Synthesis Optimization}

A colloidal solution of gallium nanoparticles was prepared following the procedure as shown in Figure 1. The step-by-step process will be analyzed in the methods and materials section, while the technological problems and the colloid opto-chemical features are presented here.

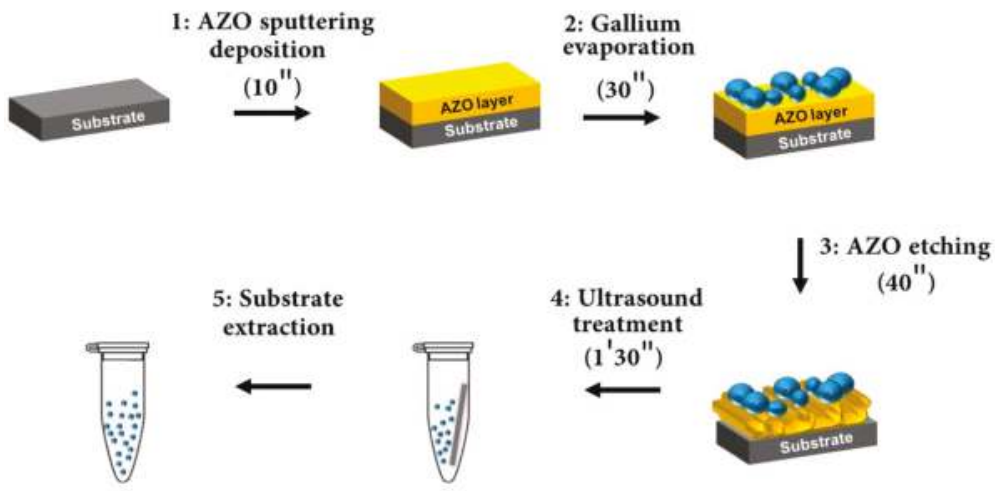

Figure 1. Colloidal Ga NPs synthesis. Step 1: about $300 \mathrm{~nm}$ of AZO expendable layer deposition on silicon substrate; Step 2: Ga NPs evaporation on the AZO layer; Step 3: the expendable layer is etched until NPs almost detached from the surface; Step 4: by means of ultrasound treatment, the NPs are transfer into the solution; Step 5: extraction of the substrate from the as-synthetized colloidal solution.

The endurance of the Ga nanoparticles in acidic environments was studied after their evaporation on a bare glass substrate. The substrates were immersed in a phosphoric acid/acetic acid/deionized water (1:1:75) bath for various times, ranging from $1 \mathrm{~min}$ to $8 \mathrm{~h}$. The NP size distribution of each SEM image was determined and compared, in order to study the etching rate of the NPs. After a 1 min etch (Figure $2 b$ ) the NPs size did not change significantly, revealing a similar distribution as the un-etched sample (Figure 2a). This is a remarkable result, considering that the AZO layer has a total etching time of less than $1 \mathrm{~min}$. Clearly, after $2 \mathrm{~h}$ (Figure 2c) small NPs started to disappear, as the biggest ones reduced their dimension, showing an increase of the number of NPs with an average size of $90 \mathrm{~nm}$. After $8 \mathrm{~h}$ (not shown), all the NPs dissolved completely, leaving no residual of Ga on the glass surface.

In acidic medium, the NPs' oxide shell did not endure more than a few minutes [25,26], provoking the exposure of the gallium to the chemical solution. As time passed, the metal kept oxidizing slowly, and the new oxide layers were quickly dissolved until all the inner metal gallium disappeared. The comparison between histograms of $1 \mathrm{~min}$ and $2 \mathrm{~h}$ etched samples (Figure 2d) shows a decrease in the smaller NP population. For this reason, the etching process in our synthesis has been kept under $1 \mathrm{~min}$, to avoid changes in the NPs' morphology. 


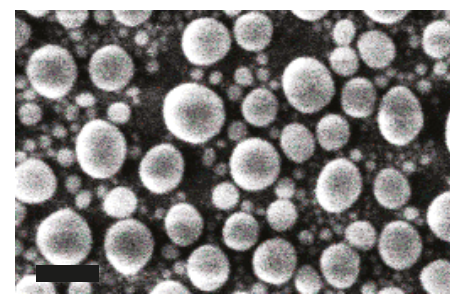

(a)

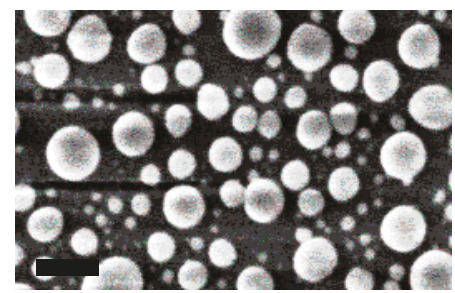

(c)

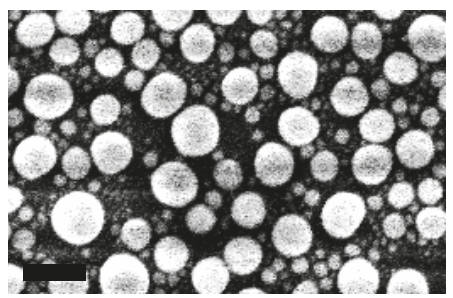

(b)

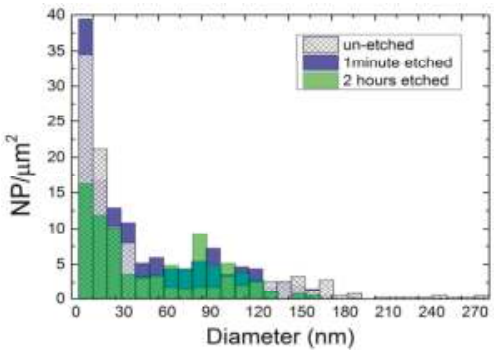

(d)

Figure 2. (a) Ga NPs evaporated on a glass substrate and immersed in an acidic bath for (b) 1 min; (c) $2 \mathrm{~h}$. After $2 \mathrm{~h}$, many of the smallest NPs have disappeared and the biggest ones have reduced their dimensions. (d) Histograms obtained from the SEM images. Scale bars are all $200 \mathrm{~nm}$ in length.

The AZO expendable layer in the preparation scheme (Figure 1) was deposited at room temperature (RT) and $300{ }^{\circ} \mathrm{C}$ in order to compare possible structural differences of the two surfaces and find the best conditions for the Ga NP deposition. As atomic force microscopy (AFM) analysis shows (Figure 3), the room temperature (RT) sample exhibited a mean surface roughness of $6 \mathrm{~nm}$, while, for high-temperature growth, this value doubled to $13.6 \mathrm{~nm}$. The images clearly show a smaller grain size for the RT layer, compared to the $300{ }^{\circ} \mathrm{C}$ sample.

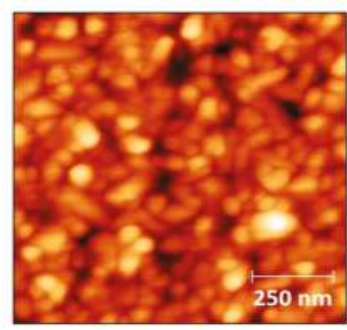

(a)

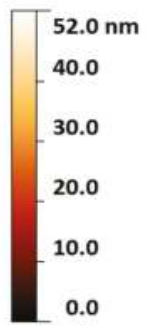

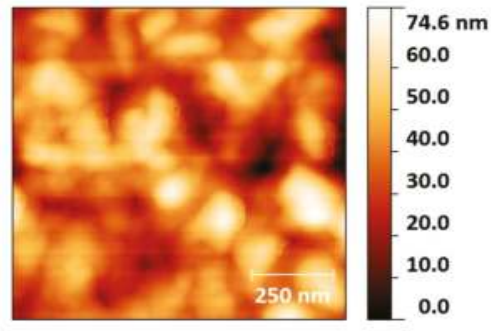

(b)

Figure 3. AFM images of the surface of AZO layer deposited at (a) RT and (b) $300{ }^{\circ} \mathrm{C}$.

In order to identify the most suitable candidate for our process, Ga was evaporated on both AZO surfaces. Figure $4 \mathrm{a}$,b show the as-evaporated distributions, where the first column is centered at a diameter of $12 \mathrm{~nm}$ with a width of $\pm 6 \mathrm{~nm}$, and includes the largest number of NPs in both cases. Comparing the RT and $300{ }^{\circ} \mathrm{C}$ histograms, the NPs' dimensions are not affected by the deposition temperature of the $\mathrm{AZO}$, but their concentration is. In particular, the higher the $\mathrm{AZO}$ grown temperature, the higher the number of particles obtained per square micron. This increase in 
the number of particles might be related to the faceting of the AZO surface upon growth at higher temperature, and the larger surface to volume ratio in those samples.

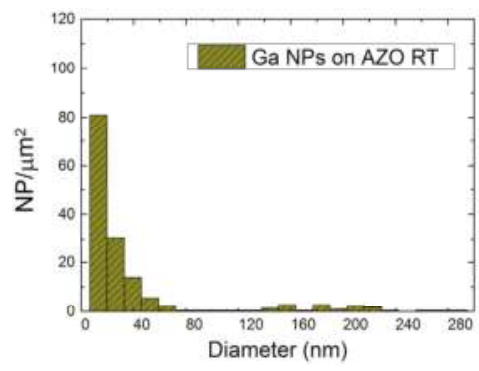

(a)

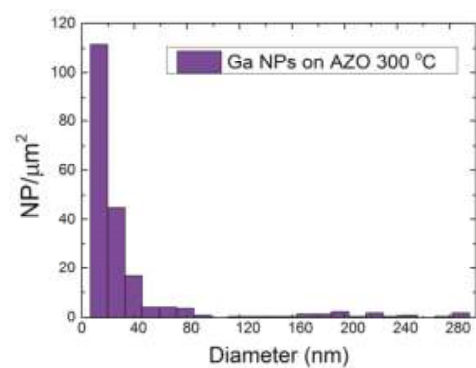

(b)

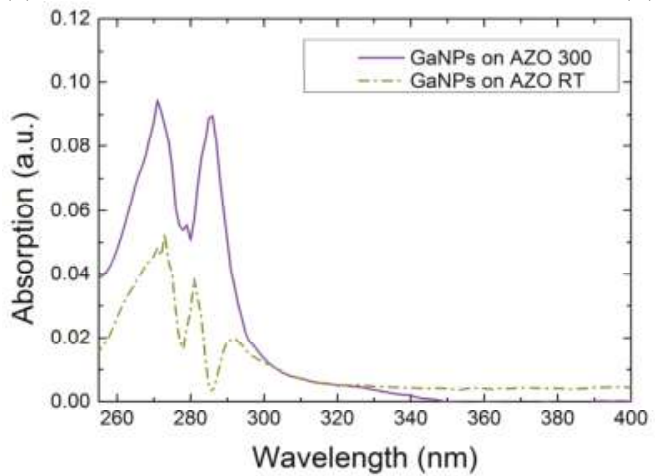

(c)

Figure 4. As-evaporated distributions of Ga NPs on (a) an AZO layer deposited at RT and (b) AZO layer deposited at $300^{\circ} \mathrm{C}$. (c) Absorption spectra in THF solvent.

In addition, the entire colloidal synthesis for both types of expendable layers was performed in order to study possible changes in the optical characteristics. For that aim, the absorption spectroscopy analysis between $200 \mathrm{~nm}$ and $1000 \mathrm{~nm}$ was carried out in THF solvent. A larger absorption in the UV spectra was observed for both samples (Figure 4c) and similar experiments have been conducted in sets of different AZO thickness. As expected, higher reproducibility and larger absorption was obtained in the solution prepared from the layers grown at $300{ }^{\circ} \mathrm{C}$.

The expendable layer etching rate was also determined for AZO layers deposited at $300^{\circ} \mathrm{C}$. Layers of $300 \mathrm{~nm}$ were grown on silicon for that purpose. By measuring the etching depth as a function of time, the etching rate was found to be $18 \mathrm{~nm} / \mathrm{s}$. Similar samples with evaporated Ga NPs were also investigated, and the etching rate in this case was estimated to be $6 \mathrm{~nm} / \mathrm{s}$, three times slower than the uncovered case.

Further investigations of the evaporated Ga NPs on AZO layers grown at RT and $300{ }^{\circ} \mathrm{C}$ were carried out. The samples were etched in a phosphoric acid/acetic acid/deionized water (1:1:75) solution for $5 \mathrm{~s}, 15 \mathrm{~s}$ and $20 \mathrm{~s}$ (Figure 5). Scanning electron microscopy was performed to study the etching evolution of the expendable layer in order to obtain information on the minimum time to assure the NPs detachment from the hard support. As the AZO layer gradually disappears (dark zone indicated by arrows) the particles have higher probability to be dispersed in the solution by means of ultrasound treatment. After $5 \mathrm{~s}$ etching (Figure $5 \mathrm{a}, \mathrm{d}$ ), the layer was not dissolved and no significant changes were produced. Between 15 and $20 \mathrm{~s}$, the NPs were less bonded to the expendable layer, and 
significant void areas are found between the largest NPs. Thus, the etching time for colloidal synthesis was chosen to be $40 \mathrm{~s}$, in order to assure the highest NP detachment rate while preserving the NP size obtained after the evaporation.

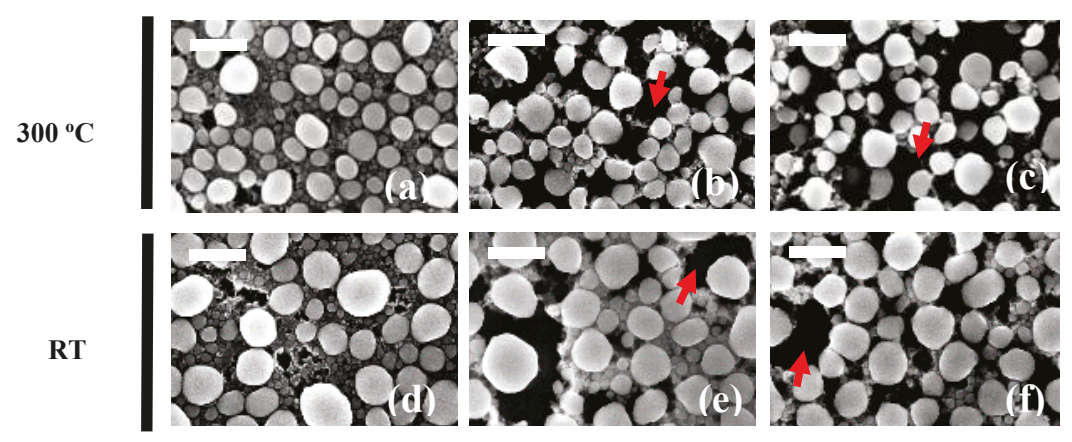

Figure 5. Ga NP/AZO/Si sample immersed in water/phosphoric acid/acetic acid bath for (a,d) $5 \mathrm{~s}$ (b,e) $15 \mathrm{~s}$ and (c,f) $20 \mathrm{~s}$. Scale bar is $500 \mathrm{~nm}$ in length in all the pictures.

\subsection{Optical Characteristics of $\mathrm{Ga}$ NPs}

In order to study the interactions between the nanoparticles and the surrounding environment, two different solvents were used to prepare the Ga NPs colloids: deionized water (DIW) and tetrahydrofuran (THF). By means of aqueous solution, we studied how colloidal Ga NPs behave at different $\mathrm{pH}$ levels, while tetrahydrofuran was used to test the sample in a polar aprotic environment. Table 1 shows their chemical and optical features, which have also been used to study and simulate the developed samples. The protic and aprotic nature of the solvents influences the Ga NPs agglomeration status, as will be discussed later. The refractive index values were used to simulate the stand-alone and cluster nanoparticle status in both solvents with the use of the discrete dipole approximation (DDA) method. Finally, considering that both solvents heavily absorb light in the UV range, only the data obtained above their cut-off wavelength were analyzed.

Table 1. Solvent properties. Optical characteristics were extracted from [27].

\begin{tabular}{cccc}
\hline Solvent & Class & Refractive Index @ 270 nm & Solvent $\boldsymbol{\lambda}$ Cut-Off (nm) \\
\hline Water & Polar protic & 1.33 & 190 \\
THF & Polar aprotic & 1.40 & 212 \\
\hline
\end{tabular}

The stability of NPs in a solution depends on the interface between the surrounding media and the nanoparticle. In the case of colloids, the force balance between close particles may be expressed in consideration of different contributions such as gravitational, inertial, electrical and chemical reactivity [28]. Since the first two may be neglected for nanoparticles smaller than $0.5 \mu \mathrm{m}[28,29]$, according to the Derjaguin, Landau, Vervey, and Overbeek (DLVO) theory $[30,31]$ the electrostatic (repulsive) and Van der Waals (attractive) forces have a primary role in the inter-particle interaction. Recently, an extended DLVO theory (XDLVO) [32] demonstrated that the colloid's stability also takes into account other parameters, such as the ion concentration in the solution and the NP's hydrophobicity, which are relevant to our case of study.

\subsubsection{Ga NPs in THF Solvent}

The Ga NPs colloids in THF solution were prepared and optically characterized in the UV/visible range. Different NPs' size distributions were found using $30 \mathrm{~s}, 45 \mathrm{~s}$ and $60 \mathrm{~s}$ evaporation time. Figure 6 
shows the related histograms of the three samples obtained from scanning electron microscopy (SEM) images. In the case of $30 \mathrm{~s}$ evaporation, a quasi-unimodal distribution was obtained, where the density of NPs with diameters lower than $40 \mathrm{~nm}$ density was higher than in the other two samples. Furthermore, SEM investigation of the tilt drop-cast sample shows that our colloidal Ga NPs have a hemispherical structure similar to that obtained by other authors [33,34]. During the Ga thermal evaporation, the NP's shape strongly depends of the nucleation process, which is related to the surface wettability of the substrate material. When the NPs' outer surface meets oxygen, an oxide shell covers the metal core and preserves the obtained geometry. The NPs also keep this geometry after being transferred to the solvent.

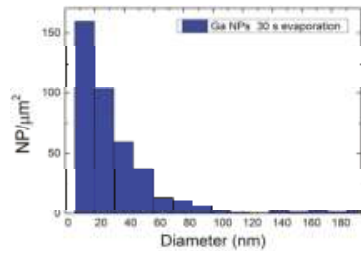

(a)

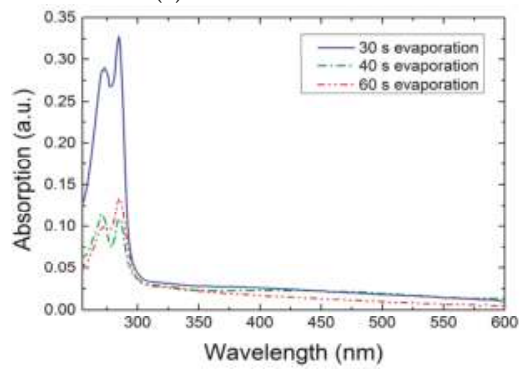

(d)

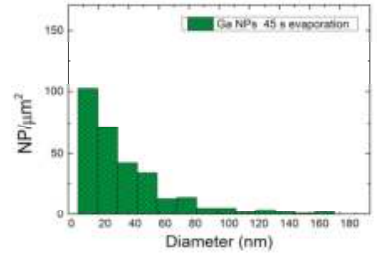

(b)

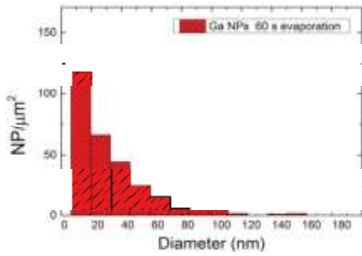

(c)

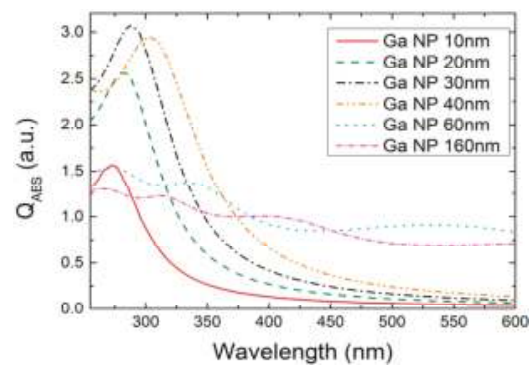

(e)

Figure 6. Ga NP distributions for (a) $30 \mathrm{~s}$; (b) $45 \mathrm{~s}$ and (c) $60 \mathrm{~s}$ evaporation time; (d) The optical absorption was measured after colloidal preparation in THF; (e) Numerical simulation of the absorption efficiency (QABS) in structures with different diameters was carried out in order to find a relationship between the measured spectra and the NPs distributions.

The experimental absorption spectra of the three samples are shown in Figure $6 \mathrm{~d}$. As already discussed, THF has a cut-off absorbance wavelength of $212 \mathrm{~nm}$, and the measurements were considered reliable only for data above that value. The curves have a similar shape, and exhibit a main absorption band between 260-300 nm with peaks centered at $273 \mathrm{~nm}$ and $285 \mathrm{~nm}$. According to the Beer-Lambert's law, the measured optical signal is strictly related with the concentration of the smallest Ga NPs in the solution, which scales well for the exhibited distributions. Bigger NPs may contribute to the broad band between 300-600 $\mathrm{nm}$.

In order to further understand the relationship between the experimental absorption and the Ga NP distribution, the light-matter interaction was theoretically studied through discrete-dipole approximation implemented by DDSCAT software (Department of Astrophysical Sciences, Princeton University, U.S.) [35]. The simulations consisted of hemispherical NPs of liquid gallium, with a $2 \mathrm{~nm}$ native oxide shell in THF solvent. The liquid gallium and gallium oxide permittivities were extracted from Knight et al. [34] and Rebiena et al. [36], respectively, whereas solvent refractive index refers to the value in Table 1. In order to reproduce the experimental conditions, the diameter of the NPs varies between 10 and $160 \mathrm{~nm}$. Their optical behavior was studied for wavelengths ranging from 255 to $800 \mathrm{~nm}$. In addition, a circular polarized light beam was set to emulate the un-polarized beam from the spectrophotometer source. Interaction cut-off and 
error tolerance parameters were set as high as possible, with values of $3 \times 10^{3}$ and $10^{-4}$, respectively. The simulation results were expressed in terms of absorption efficiency $\left(\mathrm{Q}_{\mathrm{ABS}}\right)$ and scattering efficiency ( $\mathrm{QSCAT}_{\mathrm{SC}}$, both of which depend on the target cross-sectional area. Note that the absorption coefficient is directly proportional to the particle diameter, while the scattering is proportional to the fourth power of it. Figure 6e shows $Q_{A B S}$ for different NP diameters, where $30 \mathrm{~nm}$ has the highest value in the UV region. Thus, the experimental absorption band is likely related to absorption NPs of smaller diameters $(10-40 \mathrm{~nm})$. The biggest NPs contribute less to the absorption at low wavelengths, but they can be responsible for the absorption at higher wavelengths, according to the simulations.

It is believed that the stability of the Ga NPs is high, and does not show agglomeration effects. The outer gallium oxide shell may confer hydrophobic behavior, preventing agglomerative clustering. Similar results have been found by Vasiliev [37] during the investigation of polymer-coated Ag nanoparticles, where different agglomeration statuses for $\mathrm{Ag}$ - functionalized and unfunctionalized colloidal—were verified both in water and THF.

\subsubsection{Ga NPs in Aqueous Solution}

The behavior of the Ga NP colloids was also studied in the case of aqueous solution under different $\mathrm{pH}$ conditions. The acid/base level of the sample was achieved by adding $\mathrm{NaOH} 10^{-1} \mathrm{M}$ and $\mathrm{HCl} 10^{-1} \mathrm{M}$ solutions to reach the target acidity. Generally, the NPs' flocculation behavior is related to their surface charge, estimated from the zeta potential $(\zeta)$ measurement. The latter calculates the electrokinetic potential of the colloid and the further the value is from zero, the less the NPs aggregate. In the case of Ga oxide NPs, the zeta potential zero value - the so-called point of zero charge (PZC) - is set between $\mathrm{pH} 7.5-8.5$ [38], and because of the Ga NPs oxide shell, it was assumed that our colloidal nanoparticles would have the same PZC value.

Figure 7a shows the comparison of colloidal absorption spectra for different $\mathrm{pHs}$. The experiment was carried out on $3 \mathrm{~mL}$ of colloidal solution ranging in $\mathrm{pH}$ from 2.8 to 8.5 , as described in the methods section. As the $\mathrm{pH}$ shifts from acidic to basic, the absorption decreases when the $\mathrm{pH}$ approaches 7.5 (near the PZC of the Ga oxide particle), and it starts rising again at a value of 8.5. The signal tends to decrease, getting close to the $\mathrm{PZC} \mathrm{pH}$ value because of cluster formation, which reduces the colloidal absorption in the observed range. All the curves show a characteristic absorption band between $250 \mathrm{~nm}$ and $300 \mathrm{~nm}$, which is related to the colloidal Ga NP size distribution as in the THF case.

Further simulation on NP agglomeration and comparison between the aqueous and the THF case absorption peak were investigated. To evaluate the Ga NPs cluster absorption trend in aqueous solution, different structures made from 8 to 64 sphere nanoparticles were simulated by the DDA method (Figure 7b,c) [39]. Usually, the light interaction with an NP cluster generates a higher scattering contribution than absorption according to the Mie theory and both contributions are red-shifted compared to the single particle characteristic. When more than 16 nanoparticles of $20 \mathrm{~nm}$ diameter agglomerate, the absorption decreases drastically, as shown in Figure $7 \mathrm{~b}$. A similar result was found for the $30 \mathrm{~nm}$ nanoparticle cluster, where the maximum agglomeration level before the absorption falls was $16 \mathrm{NPs}$, as well. For this reason, the decreasing trend of the absorption for the $\mathrm{pH}$ change may be explained by the agglomeration theory. The closer the $\mathrm{pH}$ is to the $\mathrm{PZC}$, the higher the agglomeration occurring between NPs, which leads to a lower absorption signal. In addition, the NP plasmon resonance condition for the aqueous and THF solutions was compared. As expected, the nanoparticle absorption peak shifts in value depending on the medium permittivity (Figure 7d). The comparison of $30 \mathrm{~nm}$ Ga hemisphere with $2 \mathrm{~nm}$ oxide shell in THF $(n=1.4)$ and aqueous solution $(n=1.33)$ shows a red-shifted curve in the case of the higher refractive index solution, with absorption peaks displayed at $285 \mathrm{~nm}$ and $273 \mathrm{~nm}$, respectively. Later, these results were compared with the measured absorption band and good agreement was observed.

In conclusion, the Ga NPs' oxide shell likely acts as a hydrophilic material in water, provoking the agglomeration phenomenon. Also, by means of different $\mathrm{pH}$, the ion concentration around the colloidal NPs can be varied and the cluster formation may change because of it. 


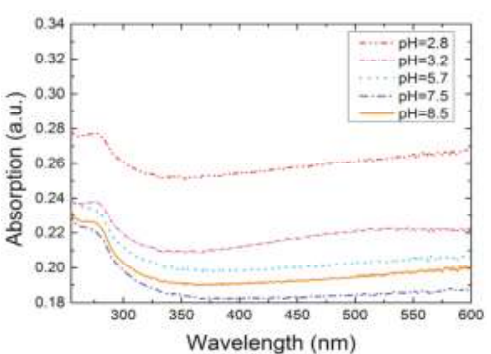

(a)

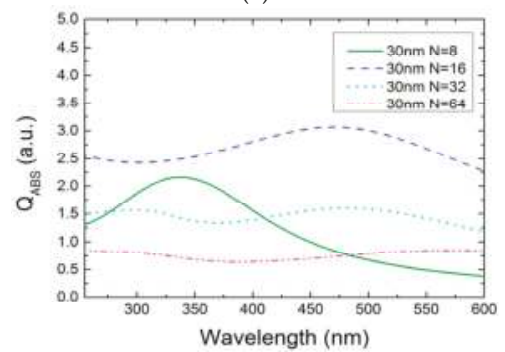

(c)

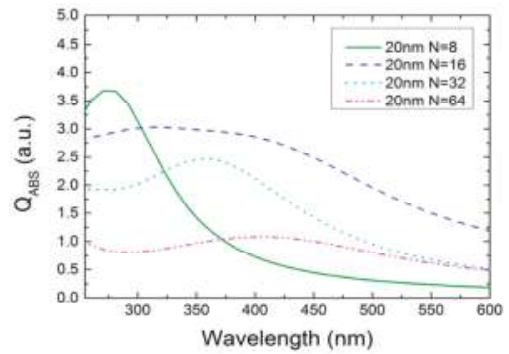

(b)

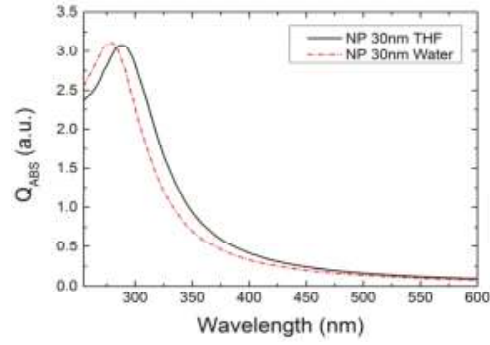

(d)

Figure 7. (a) Absorption measurements of aqueous colloidal solutions for different $\mathrm{pH}$ levels ranging from 2.8 to 8.5. Results of the simulations for NP clusters made of N number of agglomerated spheres with (b) $20 \mathrm{~nm}$ and (c) $30 \mathrm{~nm}$ diameter. (d) Calculated QABS of NPs in THF and aqueous solution.

\section{Materials and Methods}

\subsection{Ga NPs Synthesis}

A colloidal solution of gallium nanoparticles was prepared following the procedure as shown in Figure 1. First, a substrate of silicon with an area of $0.5 \mathrm{~cm} \times 2 \mathrm{~cm}$ was cleaved and cleaned using an aqueous solution of $40 \%$ hydrofluoric acid in order to remove the native oxide. The AZO [40] expendable layer was deposited using an Alcatel A450 radio frequencies (RF) sputtering system. For the sake of comparison, the layers were prepared depositing at room temperature and $300{ }^{\circ} \mathrm{C}$. The system comprises an RF source set at $150 \mathrm{~W}$ and a $50 \mathrm{sccm}$ Ar flow to generate the plasma that sputters the AZO target (Kurt J. Lesker $\mathrm{ZnO} / \mathrm{Al}_{2} \mathrm{O}_{3}, 2 \%$ Standard Doping). Prior to deposition, the target was sputtered for $1 \mathrm{~min}$ to remove impurities. The deposition time for the AZO layer was 10 min under a pressure of $10^{-2}$ mbar to obtain a $300 \mathrm{~nm}$ thick layer. The AZO was chosen taking into account its fast etching in moderately acidic solutions.

Gallium was evaporated [41] on the expendable layer using a Joule-effect Edwards E306 evaporation system (Moorfield, Knutsford, UK). For our process, $0.28 \mathrm{~g}$ of solid Ga (99.9999\%) was heated for $30 \mathrm{~s}$ with a $50 \mathrm{~W}$ power under $10^{-6}$ Torr pressure. The distance from the material heater to the sample was set at $20 \mathrm{~cm}$. An ice cooling system was employed to keep the substrate temperature as low as possible, in order to limit the metal surface mobility during the nucleation process. During the growth, the lower the substrate temperature the less NPs coarsening occurs.

To prepare the colloidal solutions, several vials of $3 \mathrm{~mL}$ volume were filled with the following solvents: DIW and THF. After Ga deposition and extraction from the thermal evaporation system, the sample was immersed in a phosphoric acid/acetic acid/deionized water (1:1:75) bath for $40 \mathrm{~s}$ to partially etch the AZO layer and weaken the structural support of the NPs. Later, it was rinsed in water and promptly inserted into the selected solvent. To allow the NPs transfer from the sample to the solution, an ultrasound treatment of $1^{\prime} 30^{\prime \prime}$ was used. 


\subsection{Scanning Electron Microscopy (SEM)}

The SEM investigation was carried out using a Philips XL30 S-FEG microscope (Philips, Amsterdam, The Netherlands) under a $10^{-3}$ bar pressure at room temperature. The colloidal solution was drop cast on a clean silicon substrate, and promptly analyzed in order to avoid possible contamination effects. After the investigation, images were post-processed by Gwyddion open-source software to estimate nanoparticle size and distribution [42].

\subsection{Atomic Force Microscopy (AFM)}

In order to characterize the sputtered AZO layer surface, an Agilent PicoPlus 5500 AFM (Agilent Technologies Inc., Santa Clara, CA, USA) was used operating in dynamic mode. The analyzed samples comprised a $300 \mathrm{~nm}$ thick AZO layer grown on a silicon substrate at room temperature and $300{ }^{\circ} \mathrm{C}$. Images were analyzed and post-processed by Gwyddion open source software to investigate the surface morphology of both samples.

\section{4. $\mathrm{pH}$ Measurement}

Colloidal sample $\mathrm{pH}$ was varied by adding $\mathrm{NaOH} 10^{-1} \mathrm{M}$ and $\mathrm{HCl} 10^{-1} \mathrm{M}$ solutions to achieve the target acidity. The total added liquid did not exceed $0.1 \%$ of the original volume $(3 \mathrm{~mL})$, in order to avoid changes of the colloid concentration and, therefore, the optical absorption signal. For all solutions, the $\mathrm{pH}$ was measured before and after the spectrophotometry analysis to rule out $\mathrm{pH}$ changes during measurement due to rearrangement of ions in the solution.

\subsection{UV-Visible Spectrophotometry}

UV-visible spectra of the different colloidal samples were acquired using a Thermo Scientific GO spectrophotometer. For the analysis, differential optical absorption was measured on the colloidal solution poured in a $1.0 \mathrm{~cm}$ quartz cuvette using the same colloidal solvent as reference. By means of the equipment, temperature was fixed at $25^{\circ} \mathrm{C}$ and exposed to a light ranging from $200 \mathrm{~nm}$ to $1000 \mathrm{~nm}$ in wavelength, with a system resolution of $1 \mathrm{~nm}$.

\section{Conclusions}

We investigated the properties of the colloidal Ga NPs in THF and aqueous solvents with the use of SEM, AFM and UV spectrophotometer. The colloidal solutions were prepared from the evaporation of nanoparticles on an expandable layer, which gave plenty of possible solutions (such as ion implantation or thermal annealing) for the modification of physico-chemical properties. The AZO expandable layer growth was optimized in order to achieve the highest yield and reproducibility of the synthesis. The NPs' endurance during the etch step of the process was also proved. The colloidal Ga NPs were surrounded by $\mathrm{GaOx}$, and had different agglomeration status depending on the solvent. In the aqueous solution case, the oxide shell had a hydrophilic behavior and NPs tended to agglomerate promptly, depending on the $\mathrm{pH}$. A broad absorption along the UV-visible spectrum due to cluster formation was observed. In the THF solvent, the gallium oxide shell instead acted as a hydrophobic interface, and colloidal flocculation was mostly prevented. In that case, a strong and quite narrow UV absorption band was measured. Later, colloidal absorption bands were explained by DDA numerical simulations. Jointly with the use of the centrifugation process, it will be possible to select different absorption bands, depending on the evaporated nanoparticles' dimensions. Future works may use these results to investigate and develop new medical and innovative applications based on Ga NPs.

Acknowledgments: The authors would to thank Eduardo Ruiz Martin for helping with the clean room processes and for fruitful discussions. We are also grateful to the international PROMIS project, framed in the Horizon 2020 research and innovation program under the Marie Sklodowska-Curie grant agreement No. 641899. This research is supported by the MINECO (CTQ2014-53334-C2-2-R, MAT2014-54231-C4-1-P and MAT2016-80394-R) and Comunidad de Madrid (NANOAVANSES ref. S2013/MIT-3029) project. I.B. gratefully acknowledges the FPI-2012 Grant from Spanish Ministerio de Economía y Competitividad. 
Author Contributions: F.N. and J.L.P. conceived and designed the experiments; F.N. performed the experiments; F.N. and J.L.P. analyzed the data; S.C.-G., I.B., L.V., and E.L. contributed reagents/materials/analysis tools; F.N. wrote the paper.

Conflicts of Interest: The authors declare no conflict of interest. The founding sponsors had no role in the design of the study; in the collection, analyses, or interpretation of data; in the writing of the manuscript, and in the decision to publish the results.

1. Dreaden, E.C.; Austin, L.A.; Mackey, M.A.; El-Sayed, M.A. Size matters: Gold NPs in targeted cancer drug delivery. Ther. Deliv. 2012, 3, 457-478. [CrossRef] [PubMed]

2. Yuan, Z.; Chen, Y.; Li, T.; Yu, C.-P. Reaction of silver NPs in the disinfection process. Chemosphere 2013, 93, 619-625. [CrossRef] [PubMed]

3. Wang, P.H.; Millard, M.; Brolo, A.G. Optimizing Plasmonic Silicon Photovoltaics with Ag and Au Nanoparticle Mixtures. J. Phys. Chem. 2014, 118, 5889-5895. [CrossRef]

4. Doria, G.; Conde, J.; Veigas, B.; Giestas, L.; Almeida, M.; Assunção, M.; Rosa, J.; Baptista, P.V. Noble Metal NPs for Biosensing Applications. Sensors 2012, 12, 1657-1687. [CrossRef] [PubMed]

5. Tiwari, P.M.; Vig, K.; Dennis, V.A.; Singh, S.R. Functionalized Gold Nanoparticles and Their Biomedical Applications. Nanomaterials 2011, 1,31-63. [CrossRef] [PubMed]

6. Corti, C.W.; Holliday, R.J.; Thompson, D.T. Progress towards the commercial application of gold catalysts. Top. Catal. 2007, 44, 331-343. [CrossRef]

7. Hudson, R.; Hamasaka, G.; Osako, T.; Yamada, Y.M.A.; Li, C.-J.; Uozumi, Y.; Moores, A. Highly efficient iron(0) nanoparticle-catalyzed hydrogenation in water in flow. Green Chem. 2013, 15, 2141-2148. [CrossRef]

8. Kimling, J.; Maier, M.; Okenve, B.; Kotaidis, V.; Ballot, H.; Plech, A. Turkevich Method for Gold Nanoparticle Synthesis Revisited. J. Phys. Chem. 2006, 110, 15700-15707. [CrossRef] [PubMed]

9. Turkevich, J.; Stevenson, P.C.; Hillier, J. A study of the nucleation and growth processes in the synthesis of colloidal gold. Discuss. Faraday Soc. 1951, 11, 55-75. [CrossRef]

10. Chikan, V.; McLaurin, E.J. Rapid Nanoparticle Synthesis by Magnetic and Microwave Heating. Nanomaterials 2016, 6, 85. [CrossRef] [PubMed]

11. McCaffrey, R.; Long, H.; Jin, Y.; Sanders, A.; Park, W.; Zhang, W. Template Synthesis of Gold NPs with an Organic Molecular Cage. J. Am. Chem. Soc. 2014, 136, 1782-1785. [CrossRef] [PubMed]

12. Hezard, T.; Fajerwerg, K.; Evrard, D.; Collière, V.; Behra, P.; Gros, P. Gold NPs electrodeposited on glassy carbon using cyclic voltammetry: Application to $\mathrm{Hg}$ (II) trace analysis. J. Electroanal. Chem. 2012, 664, 46-52. [CrossRef]

13. Bhau, B.S.; Ghosh, S.; Puri, S.; Borah, B.; Sarmah, D.K.; Khan, R. Green synthesis of gold NPs from the leaf extract of Nepenthes khasiana and antimicrobial assay. Adv. Mater. Lett. 2015, 6, 55-58. [CrossRef]

14. Kruis, F.E.; Fissan, H.; Peled, A. Synthesis of NPs in the gas phase for electronic, optical and magnetic applications-A review. J. Aerosol Sci. 1998, 29, 511-535. [CrossRef]

15. Kowalczyk, B.; Lagzi, I.; Grzybowski, B.A. Nanoseparations: Strategies for size and/or shape-selective purification of NPs. Curr. Opin. Colloid Interface Sci. 2011, 16, 135-148. [CrossRef]

16. Markovich, G.; Collier, C.P.; Henrichs, S.E.; Remacle, F.; Levine, R.D.; Heath, J.R. Architectonic Quantum Dot Solids. Acc. Chem. Res. 1999, 32, 415-423. [CrossRef]

17. Collier, C.P.; Vossmeyer, T.; Heath, J.R. Nanocrystal superlattices. Annu. Rev. Phys. Chem. 1998, 49, 371-404. [CrossRef] [PubMed]

18. Fendler, J.H. Colloid Chemical Approach to Nanotechnology. Korean J. Chem. Eng. 2001, 18, 1-13. [CrossRef]

19. Tomalia, D.A.; Khanna, S.N. A Systematic Framework and Nanoperiodic Concept for Unifying Nanoscience: Hard/Soft Nanoelements, Superatoms, Meta-Atoms, New Emerging Properties, Periodic Property Patterns, and Predictive Mendeleev-like Nanoperiodic Tables. Chem. Rev. 2016, 116, 2705-2774. [CrossRef] [PubMed]

20. Ulman, A. Formation and structure of self-assembled monolayers. Chem. Rev. 1996, 96, 1533-1554. [CrossRef] [PubMed]

21. Sakai, T.; Alexandridis, P. Single-Step Synthesis and Stabilization of Metal NPs in Aqueous Pluronic Block Copolymer Solutions at Ambient Temperature. Langmuir 2004, 20, 8426-8430. [CrossRef] [PubMed]

22. Meléndrez, M.F.; Cárdenas, G.; Arbiol, J. Synthesis and characterization of gallium colloidal NPs. J. Colloid Interface Sci. 2010, 346, 279-287. [CrossRef] [PubMed] 
23. Yarema, M.; Wörle, M.; Rossell, M.D.; Erni, R.; Caputo, R.; Protesescu, L.; Kravchyk, K.V.; Dirin, D.N.; Lienau, K.; von Rohr, F.; et al. Monodisperse Colloidal Gallium NPs: Synthesis, Low Temperature Crystallization, Surface Plasmon Resonance and Li-Ion Storage. J. Am. Chem. Soc. 2014, 136, 12422-12430. [CrossRef] [PubMed]

24. Lu, Y.; Hu, Q.; Lin, Y.; Pacardo, D.B.; Wang, C.; Sun, W.; Ligler, F.S.; Dickey, M.D.; Gu, Z. Transformable liquid-metal nanomedicine. Nat. Commun. 2014, 136, 12422-12430. [CrossRef] [PubMed]

25. Ohira, S.; Arai, N. Wet chemical etching behavior of $\beta-\mathrm{Ga}_{2} \mathrm{O}_{3}$ single crystal. Phys. Status Solidi C 2008, 5, 3116-3118. [CrossRef]

26. Junga, Y.; Ahna, J.; Baikb, K.H.; Kimc, D.; Peartond, S.J.; Rene, F.; Kima, J. Chemical Etch Characteristics of N-Face and Ga-Face GaN by Phosphoric Acid and Potassium Hydroxide Solutions. J. Electrochem. Soc. 2012, 159, H117-H120. [CrossRef]

27. Snyder, L.R.; Kirkland, J.J.; Glajch, J.L. Practical HPLC Method Development, 2nd ed.; John Wiley \& Sons: Hoboken, NJ, USA, 1997.

28. Ring, T.A. Fundamentals of Ceramic Powder Processing and Synthesis; Academic Press Inc.: New York, NY, USA, 1996.

29. Tsuda, A.; Henry, F.S.; Butler, J.P. Particle transport and deposition: Basic physics of particle kinetics. Compr. Physiol. 2013, 3, 1437-1471. [PubMed]

30. Verwey, E.J.; Overbeek, J.T.G. Theory of the Stability of Lyophobic Colloids; Elsevier: Amsterdam, The Netherlands, 1948.

31. Derjaguin, B.V.; Lanadau, L. Theory of the stability of strongly charged lyophobic sols and of the adhesion of strongly charged particles in solution of electrolytes. Acta Physicochim. USSR 1941, 14, 633-662. [CrossRef]

32. Hotze, E.M.; Phenrat, T.; Lowry, G.V. Nanoparticle Aggregation: Challenges to Understanding Transport and Reactivity in the Environment. J. Environ. Qual. 2010, 39, 1909-1924. [CrossRef] [PubMed]

33. Losurdo, M.; Suvorova, A.; Rubanov, S.; Hingerl, K.; Brown, A.S. Thermally stable coexistence of liquid and solid phases in gallium nanoparticles. Nat. Mater. 2016, 15, 995-1002. [CrossRef] [PubMed]

34. Knight, M.W.; Coenen, T.; Yang, Y.; Brenny, B.J.M.; Losurdo, M.; Brown, A.S.; Everitt, H.O.; Polman, A. Gallium Plasmonics: Deep Subwavelength Spectroscopic Imaging of Single and Interacting Gallium Nanoparticles. ACS Nano 2015, 9, 2049-2060. [CrossRef] [PubMed]

35. Draine, B.T.; Flatau, P.J. Discrete dipole approximation for scattering calculations. J. Opt. Soc. Am. A 1994, 11, 1491-1499. [CrossRef]

36. Rebiena, M.; Henrion, W.; Hong, M.; Mannaerts, J.P.; Fleischer, M. Optical properties of gallium oxide thin films. Appl. Phys. Lett. 2002, 81, 250. [CrossRef]

37. Vasiliev, A.N.; Gulliver, E.A.; Khinast, J.G.; Riman, R.E. Highly dispersible polymer-coated silver Nanoparticle. Surf. Coat. Technol. 2009, 203, 2841-2844. [CrossRef]

38. Kosmulski, M. Pristine Points of Zero Charge of Gallium and Indium Oxides. J. Colloid Interface Sci. 2001, 238, 225-227. [CrossRef] [PubMed]

39. Shen, Y.; Draine, B.T.; Johnson, E.T. Modeling Porous Dust Grains with Ballistic Aggregates. I. Geometry and Optical Properties. Astrophys. J. 2008, 689, 260-275. [CrossRef]

40. Minami, T.; Nanot, H.; Takata, S. Highly Conductive and Transparent Aluminum Doped Zinc Oxide Thin Films Prepared by RF Magnetron Sputtering. Jpn. J. Appl. Phys. 1984, 23, 776-779. [CrossRef]

41. Marín, A.G.; Hernández, M.J.; Ruiz, E.; Abad, J.M.; Lorenzo, E.; Piqueras, J.; Pau, J.L. Immunosensing platform based on gallium nanoparticle arrays on silicon substrates. Biosens. Bioelectron. 2015, 74, 1069-1075. [CrossRef] [PubMed]

42. Nečas, D.; Klapetek, P. Gwyddion: An open-source software for SPM data analysis. Cent. Eur. J. Phys. 2012, 10, 181-188. [CrossRef]

(c) 2017 by the authors. Licensee MDPI, Basel, Switzerland. This article is an open access article distributed under the terms and conditions of the Creative Commons Attribution (CC BY) license (http:/ / creativecommons.org/licenses/by/4.0/). 
Article

\title{
Increased Loading, Efficacy and Sustained Release of Silibinin, a Poorly Soluble Drug Using Hydrophobically-Modified Chitosan Nanoparticles for Enhanced Delivery of Anticancer Drug Delivery Systems
}

\author{
Cha Yee Kuen ${ }^{1,2}$, Sharida Fakurazi ${ }^{3}$, Siti Sarah Othman ${ }^{1}$ and Mas Jaffri Masarudin ${ }^{1,2, *}$ \\ 1 Department of Cell and Molecular Biology, Faculty of Biotechnology and Biomolecular Sciences, \\ Universiti Putra Malaysia, 43400 Serdang, Selangor, Malaysia; yeekuen_91@hotmail.com (C.Y.K.); \\ sarahothman@upm.edu.my (S.S.O.) \\ 2 Cancer Research Laboratory, Institute of Biosciences, Universiti Putra Malaysia, 43400 Serdang, Selangor, Malaysia \\ 3 Department of Human Anatomy, Faculty of Medicine and Health Sciences, Universiti Putra Malaysia, \\ 43400 Serdang, Selangor, Malaysia \\ * Correspondence: masjaffri@upm.edu.my; Tel.: +60-3-89471970
}

Received: 19 October 2017; Accepted: 30 October 2017; Published: 8 November 2017

\begin{abstract}
Conventional delivery of anticancer drugs is less effective due to pharmacological drawbacks such as lack of aqueous solubility and poor cellular accumulation. This study reports the increased drug loading, therapeutic delivery, and cellular accumulation of silibinin (SLB), a poorly water-soluble phenolic compound using a hydrophobically-modified chitosan nanoparticle (pCNP) system. In this study, chitosan nanoparticles were hydrophobically-modified to confer a palmitoyl group as confirmed by 2,4,6-Trinitrobenzenesulfonic acid (TNBS) assay. Physicochemical features of the nanoparticles were studied using the TNBS assay, and Attenuated total reflectance Fourier transform infrared spectroscopy (ATR-FTIR) analyses. The FTIR profile and electron microscopy correlated the successful formation of pCNP and pCNP-SLB as nano-sized particles, while Dynamic Light Scattering (DLS) and Field Emission-Scanning Electron Microscopy (FESEM) results exhibited an expansion in size between PCNP and PCNP-SLB to accommodate the drug within its particle core. To evaluate the cytotoxicity of the nanoparticles, a Methylthiazolyldiphenyl-tetrazolium bromide (MTT) cytotoxicity assay was subsequently performed using the A549 lung cancer cell line. Cytotoxicity assays exhibited an enhanced efficacy of SLB when delivered by CNP and pCNP. Interestingly, controlled release delivery of SLB was achieved using the PCNP-SLB system, conferring higher cytotoxic effects and lower $\mathrm{IC}_{50}$ values in 72-h treatments compared to CNP-SLB, which was attributed to the hydrophobic modification of the CNP system.
\end{abstract}

Keywords: chitosan nanoparticles; hydrophobically-modified CNP; slibinin; nanobiotechnology

\section{Introduction}

Over the last decade, radiation, chemotherapy and surgery have become important methods to treat cancer patients. Among these methods, chemotherapy remains the most significant treatment, with synthetic drugs being the most potent chemotherapeutic drugs used [1]. The main obstacle faced by current treatments is the inefficient delivery of drugs to target cells. Thus, conventional treatment often leads to side effects in patients due to non-specific interaction of the drugs with non-cancerous cells in the body. Silibinin, also known as silybin, is a major active constituent obtained from the seeds of the milk thistle plant, Silybum marianum. It exists as a polyphenolic flavonolignan with hepatoprotective 
and antioxidant activity. Substantial evidence from current research has demonstrated its clinical use in medical therapies especially in Asia, Europe, and the USA [2-4]. It has been suggested that silibinin is an extremely utilizable natural compound for cancer studies [5,6]. Additionally, there have been increasing research endeavors conducted to elucidate the potential anticancer properties of silibinin against numerous cancer models, including lung [7,8], skin [9,10], prostate [11,12], colon [13], and bladder [14]. Silibinin is preferentially advantageous for development as a candidate therapeutic agent as it is considered remarkably safe in cytotoxicity studies, as it confers low toxicity even in acute administration dosages in both humans and animals, and there are no $\mathrm{LD}_{50}$ values for the flavonolignan reported in laboratory studies. However, its widespread application in medical therapy has been marred by its low bioavailability due to low solubility in water $(0.4 \mathrm{mg} / \mathrm{mL})$ [15-18]. This restriction was due to its multiple ring structure, which is too large to be absorbed by simple diffusion, which leads to poor water solubility, poor bioavailability and thus poor intestinal absorption [19].

In order to circumvent such a disadvantage, numerous methods for its synthesis have been proposed in order to increase the solubility and bioavailability of silibinin. This has included the implementation of solid lipid nanoparticles via encapsulation [20], incorporation in solid dispersion systems [21], and complexation with phospholipids [22]. A previous study by Zhang et al. utilized stearic acid as a colloidal carrier for the encapsulation of silibinin. This modification successfully incorporated silibinin into solid lipid nanoparticles with anticipated shape, size and entrapment efficiency. However, the systemic adoption of solid lipid nanoparticles for the encapsulation of silibinin is currently limited to the inherent rapid in vivo clearance by the reticuloendothelial system (RES) which decreases the persistence of the silibinin-nanoparticle complex from blood circulation. Considering the nano-scale dimensions of nanoparticles, they can be adapted to utilize the enhanced permeability and retention effects (EPR) of tumor vasculatures to increase the accumulation of chemotherapeutic drugs. Nanoparticles have been demonstrated to exhibit 200 times higher drug accumulation in tumor cells compared to normal tissues, such as kidney, muscle and heart [23].

Chitosan (CS) is a linear polysaccharide linked by a $\beta-(1-4)$-linked-D-glucosamine backbone with randomly acetylated amine groups. It is a product of the partial deacetylation of chitin and can be acquired from numerous sources including the exoskeleton of crustaceans [24]. CS is known for its superior features such as biocompatibility, biodegradable and non-toxicity, which makes it an excellent candidate to be utilized in agriculture, biomedicine, food industries and many other fields. A previous study by Kang et al. [25] has successfully synthesized chitosan nanoparticles (CNP) loaded with albendazole, a poorly water-soluble but extremely permeable anthelmintic drug, where a stable nanoparticle system was established. Besides this, Chai et al. [26] also demonstrated that CNP can function as a drug delivery system for Doxorubicin, an anticancer drug. The study showed that Doxorubicin was successfully coated by chitosan and alginate with a good combination and showed controlled release properties. Thus, CNP can be hydrophobically-modified to incur hydrophobic-hydrophobic interactions with drugs to encapsulate them into the nanoparticles, which can potentially increase the solubility of low bioavailability drugs, and protect and stabilize the drugs from the surrounding environment.

This study demonstrates the enhanced encapsulation efficiency of silibinin in hydrophobically-modified chitosan nanoparticles as compared with traditional chitosan nanoparticles, in order to enhance the therapeutic efficacy in the A549 human lung cancer cell line. Based on the background and objectives, perhaps novel, effective and safe hydrophobically-modified chitosan nanoparticles for the enhanced therapeutic delivery of silibinin is proposed. Findings from this study can perhaps be used to further increase the efficacy of silibinin in anti-cancer applications. 


\section{Results and Discussion}

\subsection{Particle Size and Polydispersity of Nanoparticle Samples}

The formation of CNP occurred through ionic crosslinking between protonated amine groups of CS and anionic phosphate groups of the cross linker, Sodium Tripolyphosphate (TPP) [27,28]. When cross linking occurs, the protonated amine groups will associate with the anionic phosphate groups of TPP to form nanoparticles where the CS polymer will start to form spherical, nano-scaled particles. Figures 1 and 2 depict the particle size distribution (PSD) and polydispersity index (PDI) of nanoparticles formed by the crosslinking of $600 \mu \mathrm{L}$ CS with different volumes of TPP. The graph suggested that the formation of nanoparticles occurred at the minimal addition of $100 \mu \mathrm{L}$ TPP for pCNP and $150 \mu \mathrm{L}$ for CNP. Figures 1 and 2 show where the size of the pCNP experienced a noticeable drop from $4583.00 \pm 244.62 \mathrm{~nm}$ to $228.11 \pm 119.06 \mathrm{~nm}$, while the PDI dropped from $0.577 \mathrm{~nm}$ to $0.113 \mathrm{~nm}$ with the addition of $50 \mu \mathrm{L}$ and $100 \mu \mathrm{L}$ of TPP; the size of the CNP decreased from $761.40 \pm 399.73 \mathrm{~nm}$ to $49.14 \pm 3.98 \mathrm{~nm}$, while the PDI decreased from $0.71 \pm 0.18 \mathrm{~nm}$ to $0.36 \pm 0.07 \mathrm{~nm}$ with the addition of $100 \mu \mathrm{L}$ and $150 \mu \mathrm{L}$ of TPP. This observation was similar to the earlier study of Masarudin et al. (2015), where a $50 \mu \mathrm{L}$ addition of TPP was suggested as the minimal volume required to form CNP.

The smallest size of nanoparticles was obtained using $150 \mu \mathrm{L}$ of TPP for CNP $(49.14 \pm 3.98 \mathrm{~nm})$ and $200 \mu \mathrm{L}$ for pCNP $(77.08 \pm 6.50 \mathrm{~nm})$, respectively. The lowest PDI of nanoparticles was obtained using $250 \mu \mathrm{L}$ of TPP for CNP $(0.15 \pm 0.07)$ and $200 \mu \mathrm{L}$ for $\mathrm{pCNP}(0.14 \pm 0.08)$, respectively. The PDI was used as an indication of nanoparticle homogeneity, which depicts the stability of the samples in the colloidal suspension [29]. The PDI showed a similar trend as PSD, where the value dropped at the TPP ranges of 50-150 $\mu \mathrm{L}$. Both the PSD and PDI data suggested that a decrease in nanoparticle size occurred with an increase of the cross linker, while in turn increasing the monodispersity of the nanoparticles up to $200 \mu \mathrm{L}$ of TPP addition. This trend was most probably contributed to by the increased volumes of TPP that provided more anionic phosphate groups to form electrostatic interactions with the protonated CS chain [30]. As more TPP was added, the cross-linking degree of the nanoparticles was augmented to where a compact particle structure is thought to occur, leading to the production of smaller-sized nanoparticles [31].

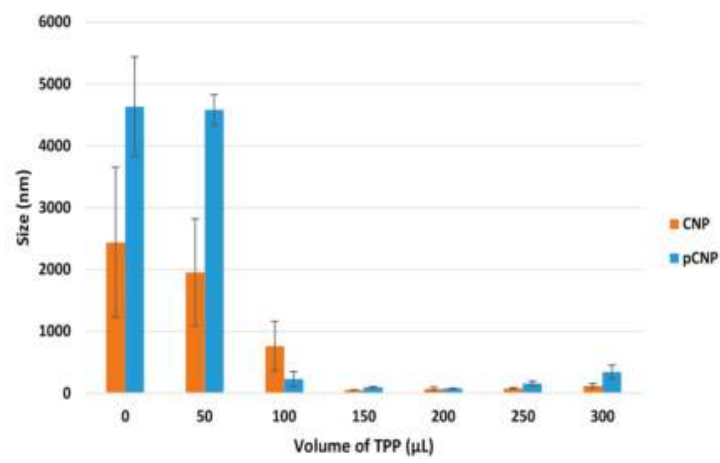

Figure 1. The PSD of nanoparticles at different TPP volumes. The smallest size of nanoparticles was obtained with the addition of $150 \mu \mathrm{L}$ TPP for CNP and $200 \mu \mathrm{L}$ for pCNP. Error bars represent the SEM averaged from three independent replicates of the experiment. The one-way analysis of variance (ANOVA) was performed with a $p$ value of the particle size at 0.0002 and $<0.0001$ for CNP and pCNP, indicating that there was a significant effect of TPP volume on the particle size formed. 
1.2

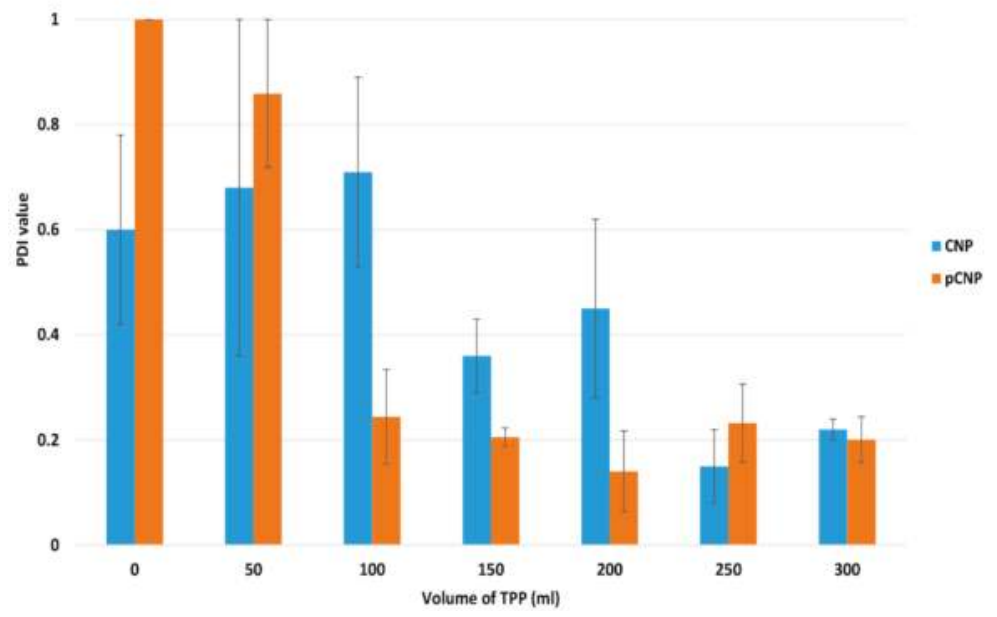

Figure 2. PDI of nanoparticles at different TPP volumes. The lowest PDI of nanoparticles was obtained with the addition of $250 \mu \mathrm{L}$ TPP for CNP and $200 \mu \mathrm{L}$ for pCNP. Error bars represent the SEM averaged from three independent replicates of the experiment. The one-way analysis of variance (ANOVA) was performed with $p$ value of particle size $<0.0001$ for both CNP and $\mathrm{pCNP}$ indicating that there was a significant effect of TPP volume on the PDI of the nanoparticles formed.

Interestingly, when the TPP volume exceeded $200 \mu \mathrm{L}$, both the particle size and PDI increased to above $100 \mathrm{~nm}$ and 0.2 , respectively. It possibly indicates that agglomeration between the nanoparticles occurred. The addition of anionic TPP beyond the optimum volume will attract more CS chains due to the increase in the degree of cross-linking, and will possibly attract the neighboring nanoparticles causing agglomeration [32], which suggests that $200 \mu \mathrm{L}$ of TPP and $600 \mu \mathrm{L}$ of pCS can form nanoparticles of optimum size and PDI.

\subsection{Utilization of the Free Amine Group by Nanoparticles Formation}

The formation of CNP and pCNP was suggested to be due to the ionic crosslinking interactions between protonated free amine group of CS/pCS and the anionic phosphate group of TPP. When the amount of cross-linker added was increased, the amount of amine groups being utilized will also increase, which in turn decreases the amount of free amine group available in a constant volume of CS/pCS. Figure 3 shows that the percentage of utilized amine groups of chitosan increased in direct proportion to the increased volume of TPP added to the CS/pCS, from 0 up to $22.20 \pm 1.02$ and $37.17 \pm 1.397$ for CNP and pCNP, respectively, and upon addition of $300 \mu \mathrm{L}$ of TPP. The data suggested that cross-linking occurred between CS/PCS and TPP on the formation of CNP and pCNP. This increases postulates that CNP and pCNP were successfully constructed, which is similar to the observation reported by a previous study [29]. A higher percentage of utilized amine groups was detected in the pCNP compared to CNP, probably due to the interaction of palmitic acid with the CS prior to the TPP. The palmitic acid will conjugate to the amine group of the CS to form pCS, where utilization of the amine group occurs, and is then only further cross-linked with TPP to form pCNP, which explains the higher percentage of utilization compared to CNP. 


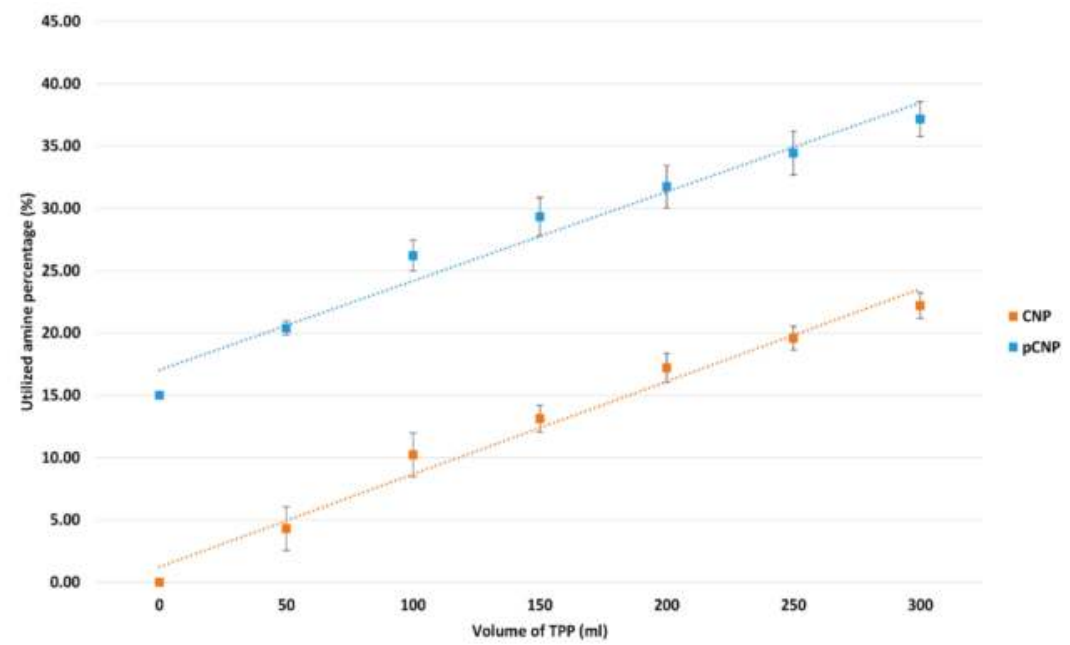

Figure 3. Utilized amine percentage at different volumes of TPP. The utilized amine percentage increased with the addition of TPP volume for both CNP and $\mathrm{pCNP}$. The graph data are presented as mean \pm SEM from three independent experiments. A paired $t$-test was performed with a $p$ value below 0.0001, which indicates that CNP and pCNP have extremely significant differences on the percentage of free $\mathrm{NH}_{2}$ group.

\subsection{Formation of $p C N P$ and $p C N P-S L B$}

The encapsulation efficiency (\% E.E) of pCNP were approximately $49.33 \pm 1.45 \%$, which suggests that when approximately $50 \%$ of the SLB had been loaded into the pCNP, there was about a 2.5 -fold increase of the particle size increment. Anyway, the \% E.E of CNP were approximately only $24.58 \pm 2.06 \%$, which suggests that only half of the SLB will be loaded into the CNP compared to the pCNP. A higher \% E.E was achieved by the pCNP compared with the CNP, probably due to the hydrophobic anchor possessed by the palmitic acid that conjugated with the CS, forming a hydrophobic core, where the SLB will associate with the core instead of the hydrophilic surface. It suggested that the pCNP system is a great carrier candidate that can increase the loading of hydrophobic load. The study of Marchiori et al. [33], performed nanoencapsulation by using interfacial deposition of the preformed polymer method with pomegranate oil as an oil core for the encapsulation of SLB. In their study, a high \% E.E was achieved, credited to the higher affinity of SLB with the oil core than the aqueous phase. These results was similar to the findings of our study, where higher \% E.E was obtained in pCNP compared to CNP, as the SLB is suggested to have associated with the pCNP by hydrophobic-hydrophobic interaction.

On the other hand, the study of Shankar and Argawal successfully encapsulated SLB by using polymeric micelles. Polymeric micelles are self-assembled, amphiphilic copolymers where the hydrophilic part usually forms the shell and hydrophobic part forms the core, which is similar to the structure of $\mathrm{pCNP}$. The study also achieved a high \% E.E, suggesting that amphiphilic nanoparticles are a great candidate for hydrophobic SLB [34]. The size and PDI of the pNCP-SLB are shown in Figure 4. It is important to optimally obtain small-size nanoparticles as well as encapsulated nanoparticles, because the nano-scaled particles are able to extravasate through the endothelium in the epithelium, inflammatory sites, and tumors, or penetrate the microcapillaries. This possesses an advantageous effect in which the nanoparticles permit efficient uptake by many different cell types in addition to selective drug accumulation at target sites [35].

Particle size date showed an expansion of about $270 \%$, from $77.08 \pm 6.50 \mathrm{~nm}$ to $208.43 \pm 12.02 \mathrm{~nm}$, upon SLB loading $(300 \mu \mathrm{M})$. Similarly, the PDI of the pCNP increased from $0.14 \pm 0.08$ to $0.30 \pm 0.02$ 
after encapsulation, suggesting the successful encapsulation of SLB in pCNP. The expansion in size indicated the successful incorporation of SLB within the core of the nanoparticles. The slight changes in PDI occurred due to the decrease of the uniformity in the size of the nanoparticles following encapsulation, which consist of a population of free pCNPs of smaller size $(<100 \mathrm{~nm})$ and pCNP-SLBs of larger size $(>100 \mathrm{~nm})$. The expansion in size was correlated with the encapsulation efficiency $(\%$ E.E) of the nanoparticles shown in Table 1.
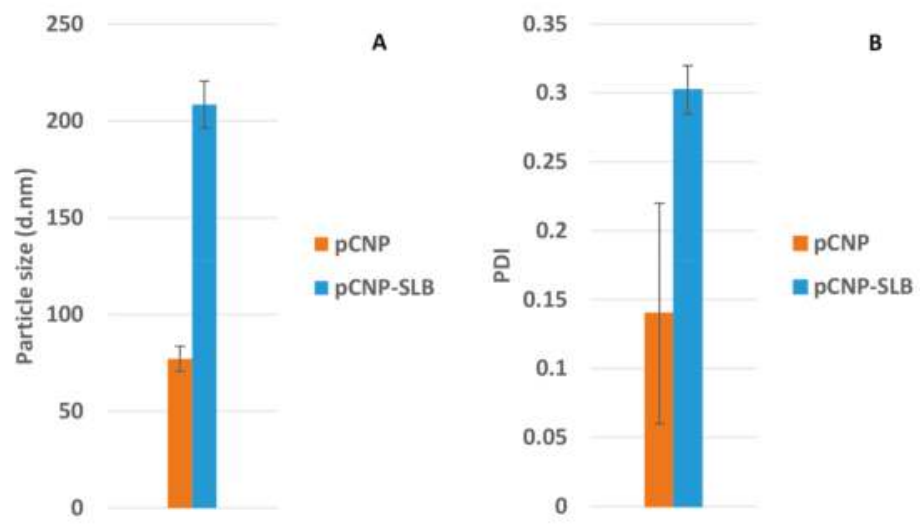

Figure 4. (A) PSD and (B) PDI of pCNP after SLB encapsulation. The particle size and PDI of pCNP increased after the encapsulation of SLB. The graph data is presented as mean \pm SEM from three independent experiments. A $p$ value below 0.05 was obtained, indicating significant differences in particle size between $\mathrm{pCNP}$ and $\mathrm{pCNP}-\mathrm{SLB}$ as measured by paired $t$-test.

Table 1. \% E.E of CNP-SLB and pCNP-SLB at $300 \mu \mathrm{M}$ SLB. The results show that the $\%$ E.E of pCNP-SLB is about two-fold higher that CNP-SLB. The graph data are presented as mean \pm SEM from three independent experiments.

\begin{tabular}{ccc}
\hline Sample & \% E.E CNP-SLB & \% E.E pCNP-SLB \\
\hline 1 & 22.46 & 50.12 \\
2 & 28.70 & 51.35 \\
3 & 22.58 & 46.51 \\
Average & $24.58 \pm 2.06$ & $49.33 \pm 1.45$ \\
\hline
\end{tabular}

\subsection{Morphological Analysis of Nanoparticles by FESEM}

A morphological analysis was performed using FESEM to ascertain the structure, size and polydispersity of CNP, pCNP and pCNP-SLB. As shown in Figure 5, the nanoparticles are generally spherical in shape, with a size ranging from below $100 \mathrm{~nm}$ before encapsulation and up to 200-300 $\mathrm{nm}$ post-encapsulation. As described in the study of Ariff et al., the CS or pCS in this study appeared to have an irregular shape when they stood alone, and to form spherically-shaped nanoparticles with the addition of TPP, indicating the success of the CNP/pCNP formation [36]. Blank CNP particles conferred sizes in the range of $64.1 \mathrm{~nm}$ to $84.7 \mathrm{~nm}$, whilst pCNP was slightly larger at $87.9 \mathrm{~nm}$ to $110.0 \mathrm{~nm}$ diameter.

When SLB was encapsulated into the nanoparticles, the expansion in size detected from the DLS was made morphologically evident using FESEM. The pCNP-SLB samples existed as larger particles with sizes approximately $215.8 \mathrm{~nm}$ to $243.3 \mathrm{~nm}$. It was postulated that the increase in size of pCNP was attributed to the incorporation of palmitic acid within its core, which led to a significant expansion after the encapsulation of SLB in pCNP. This result was similar to the results observed previous by 
Ariff et al., where the size of nanoparticles expanded post-encapsulation [34]. A previous study by Leena et al. [18], utilized chitosan nanoparticles loaded with different concentrations of SLB and incorporated alginate/gelatin scaffolds for bone formation in vitro. The particle size of CNP-SLB obtained from the study was about $264 \pm 51 \mathrm{~nm}$ post-encapsulation with $100 \mu \mathrm{M}$ of SLB. Regarding the pCNP-SLB in this study, where an initial SLB concentration of $300 \mu \mathrm{M}$ was used for encapsulation, a smaller size of nanoparticles with a higher \% E.E was obtained in our study. This further suggests that pCNP is a better nano-carrier for SLB. Anyway, some agglomeration was observed in Figure 5, which can possibly be attributed to the drying process used while preparing the samples for FESEM imaging [37].

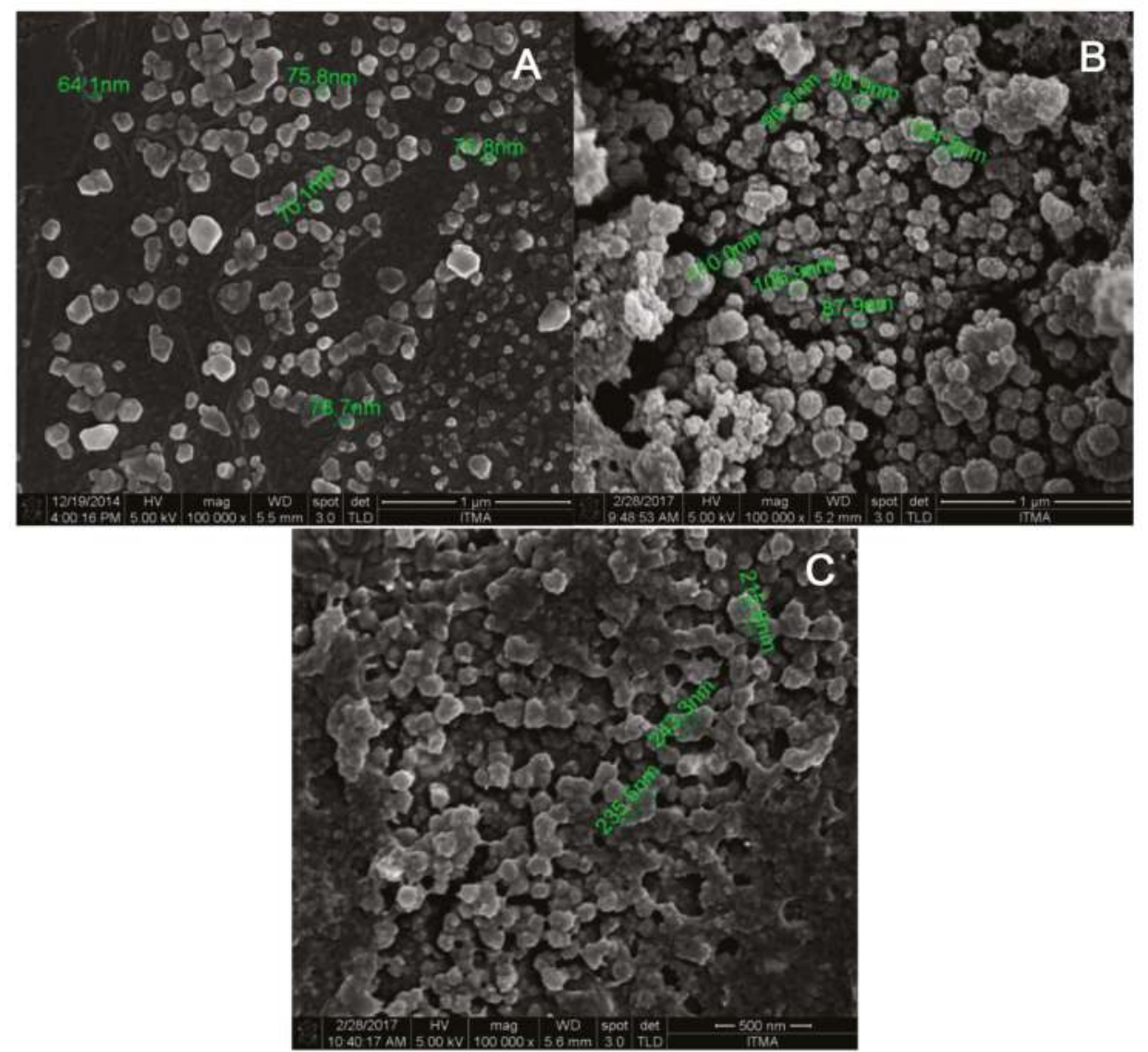

Figure 5. The figure shows the morphological structure of (A) CNP, (B) pCNP and (C) pCNP-SLB. The CNP shows a particle size of $64.1 \mathrm{~nm}$ to $84.7 \mathrm{~nm}$, the pCNP shows a particle size of $87.9 \mathrm{~nm}$ to $110.0 \mathrm{~nm}$, and the pCNP-SLB shows a particle size ranging from $215.8 \mathrm{~nm}$ to $243.3 \mathrm{~nm}$.

\subsection{Identification of Characteristic Functional Groups in Nanoparticle Samples}

In order to study the formation of drug-encapsulated pCNP-SLB, an FTIR analysis was performed to study the presence of important functional groups belonging to SLB and pCNP that occurred in pCNP-SLB. According to Coates [38] every single molecule has a unique vibrational spectrum which can be utilized as a fingerprint to be compared between an "unknown" and a "known" spectra. 
Thus, by comparing the peaks of the "known" spectra of SLB and pCNP with the "unknown" spectra of pCNP-SLB, we can deduce the formation of pCNP-SLB. The infrared spectra for SLB, pCNP, and PCNP-SLB is as shown in Figure 6, while a summary of the important characteristic functional groups detected is depicted in Table 2.

There are several characteristic peaks shown by pCNP: a broad peak at $3353 \mathrm{~cm}^{-1}$, corresponding to the hydrogen-bonded $\mathrm{O}-\mathrm{H}$ stretching vibration and $\mathrm{N}-\mathrm{H}$ stretching from the primary amine overlapped in the same region; a peak at $1632 \mathrm{~cm}^{-1}$, corresponding to the amide II carbonyl stretch; and a peak at $1067 \mathrm{~cm}^{-1}$, corresponding to the inorganic phosphate group of TPP [39]. Besides this, several characteristic peaks are also possessed by SLB: at $3446 \mathrm{~cm}^{-1}$, due to $-\mathrm{OH}$ stretching; at $2936 \mathrm{~cm}^{-1}$, due to $-\mathrm{CH}$ stretching; at $1626 \mathrm{~cm}^{-1}$, due to $-\mathrm{C}=\mathrm{O}$ stretching; at 1507 and $1461 \mathrm{~cm}^{-1}$, due to $-\mathrm{C}=\mathrm{C}$ skeleton vibrations of aromatic ring stretching; and at $1268 \mathrm{~cm}^{-1}$, due to $-\mathrm{C}-\mathrm{O}-\mathrm{C}$ stretching. From the table, the percentage of transmittance at the peak of $3353 \mathrm{~cm}^{-1}$ of pCNP and SLB was $49.62 \%$ and $49.98 \%$, respectively, but this increased to $85.97 \%$ after encapsulation, indicating a decrease in the primary amine group. It shows that upon encapsulation, the free primary amine group was utilized and led to the shift in the peak from $3353 \mathrm{~cm}^{-1}$ in pCNP to $3416 \mathrm{~cm}^{-1}$ in pCNP-SLB. A similar observation was shown by the study of Kafshgari et al. [40] where the amine group of CS was shifted from the wavenumber of $3413 \mathrm{~cm}^{-1}$ to $3395 \mathrm{~cm}^{-1}$ upon encapsulation of bovine serum albumin due to the utilization of amine groups.

However, the inorganic phosphate group of pCNP detected at wavenumber of $1067 \mathrm{~cm}^{-1}$ and $1081 \mathrm{~cm}^{-1}$ for $\mathrm{pCNP}-\mathrm{SLB}$, with increased transmittance after encapsulation, indicated the utilization of the functional group. The characteristic peak for alkyl groups at $2888 \mathrm{~cm}^{-1}$ and $2936 \mathrm{~cm}^{-1}$ was detected in pCNP and SLB, respectively. After encapsulation, this peak appeared at $2851 \mathrm{~cm}^{-1}$, with a decrease of transmittance, indicating that more active alkyl groups are present upon encapsulation, possibly due to the introduction of SLB in the pCNP [41]. Meanwhile, the peaks attributed to carbonyl groups of pCNP and SLB were detected at the $1632 \mathrm{~cm}^{-1}$ and $1626 \mathrm{~cm}^{-1}$ wavenumber, respectively, and shifted to $1635 \mathrm{~cm}^{-1}$ after encapsulation, also with an increase of transmittance, which shows the interaction between pCNP and SLB that utilized the $\mathrm{C}=\mathrm{O}$ bond; these results were similar to the previous study of Tan et al. [42]. The C-O-C stretching that happened only in SLB was also observed in PCNP-SLB, with an increase in transmittance from 10 to $67.95 \%$, indicating the utilization of the functional group after encapsulation.

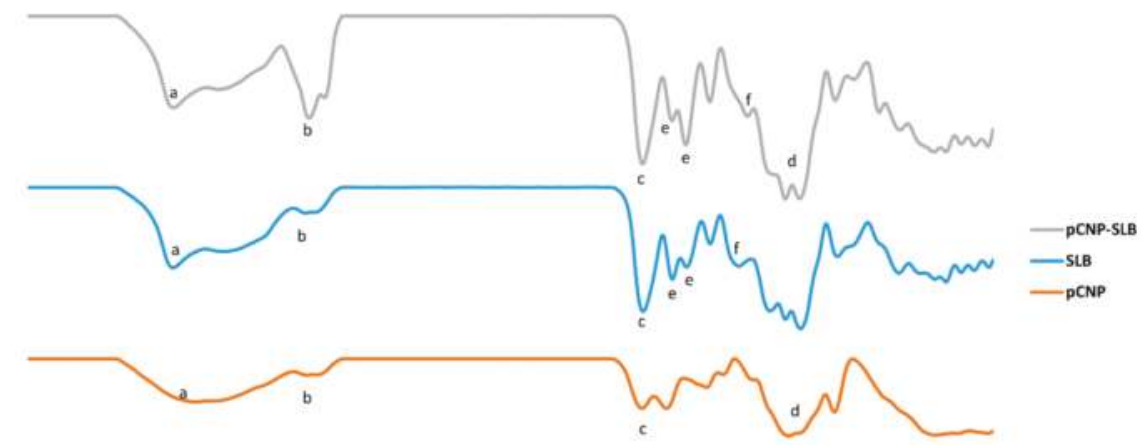

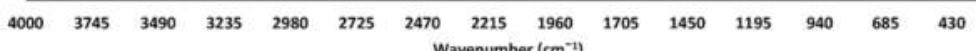

Figure 6. FTIR spectra of pCNP, SLB and pCNP-SLB. The characteristic functional groups are labeled for (a) amine group, (b) alkyl group, (c) carbonyl group, (d) inorganic phosphate group, (e) aromatic ring and (f) ether group. 
Table 2. The functional groups present in PCNP, SLB and pCNP-SLB. All the characteristic functional groups of pCNP, SLB and pCNP-SLB are listed in the table at their respective wavenumber and percentage of transmittance.

\begin{tabular}{cccc}
\hline Functional Group & Wavelength & Percentage Transmittance & Sample \\
\hline Amine $(\mathrm{a})$ & 3353 & 49.62 & pCNP \\
$(\mathrm{N}-\mathrm{H})$ & 3446 & 49.98 & SLB \\
& 3416 & 85.97 & pCNP-SLB \\
Alkyl group $(\mathrm{b})$ & 2888 & 80.94 & pCNP \\
$\left(-\mathrm{CH}, \mathrm{CH}_{2}\right)$ & 2936 & 88.91 & SLB \\
& 2851 & 24.92 & pCNP-SLB \\
Carbonyl group (c) & 1632 & 42.10 & pCNP \\
$(\mathrm{C}=\mathrm{O})$ & 1626 & 12.62 & SLB \\
& 1635 & 71.46 & pCNP-SLB \\
Inorganic Phosphate $(\mathrm{d})$ & 1067 & 10 & pCNP \\
$(\mathrm{P}=\mathrm{O})$ & 1081 & 40.15 & pCNP-SLB \\
Aromatic ring $(\mathrm{e})$ & $1507 \& 1461$ & $38.53 \& 30.42$ & SLB \\
$(\mathrm{C}=\mathrm{C})$ & $1536 \& 1465$ & $81.63 \& 41.83$ & pCNP-SLB \\
Ether (f) & 1268 & 10 & SLB \\
$(\mathrm{C}-\mathrm{O}-\mathrm{C})$ & 1223 & 67.95 & pCNP-SLB \\
\hline
\end{tabular}

The characteristic functional groups are labeled for (a) amine group, (b) alkyl group, (c) carbonyl group, (d) inorganic phosphate group, (e) aromatic ring and (f) ether group.

\subsection{CNP and $p$ CNP Cytotoxicity in A549 Cell Lines}

CNP is generally considered as non-cytotoxic to cells, due to its proven biodegradable and biocompatible properties [43]. In order to assess the effectiveness of its hydrophobically-modified counterpart, pCNP as a safe carrier for SLB delivery, an MTT cytotoxicity assay was performed in the A549 cell line against the nanoparticle system. MTT is used to assess initial cytotoxicity because we need to ensure that that vectors itself do not exert cytotoxicity effects. After incubation, those metabolically-active viable cells will produce purple formazon salts and can be read at $570 \mathrm{~nm}$ by using a spectrophotometer as an indicator for viable cells [44].

Figure 7 shows the viability of A549 cells after being treated by CNP and pCNP to compare the cytotoxicity of pCNP after hydrophobic modification, and the results demonstrate a similar cytotoxicity effect by both carriers where no $\mathrm{IC}_{50}$ was found. As mentioned in the previous study of Masarudin [45] there is no significant deviation between $\mathrm{CNP}$ and $\mathrm{pCNP}$ in term of size, morphology and also content. Thus, we also assumed that there is no substantial difference in terms of the cytotoxicity effect, and this was postulated by the results. It is important to verify the non-toxic effects of pCNP so that the delivery efficacy of SLB will not be affected by the vector in the later assay. The previous study of Zhang et al. [46] utilized hydrophobically-modified oleoyl-chitosan $(\mathrm{OCH})$ as carriers for doxorubicin, and the vector did not confer cytotoxicity effects to A549 cell lines, which is similar to our results. Besides this, the study of Chiu et al. [47], also revealed that N-palmitoyl chitosan nanoparticles with different degrees of substitution had no significant cytotoxicity effect in HT1080 cells, which further indicated that $\mathrm{pCNP}$ is a good candidate for a delivery vector. 


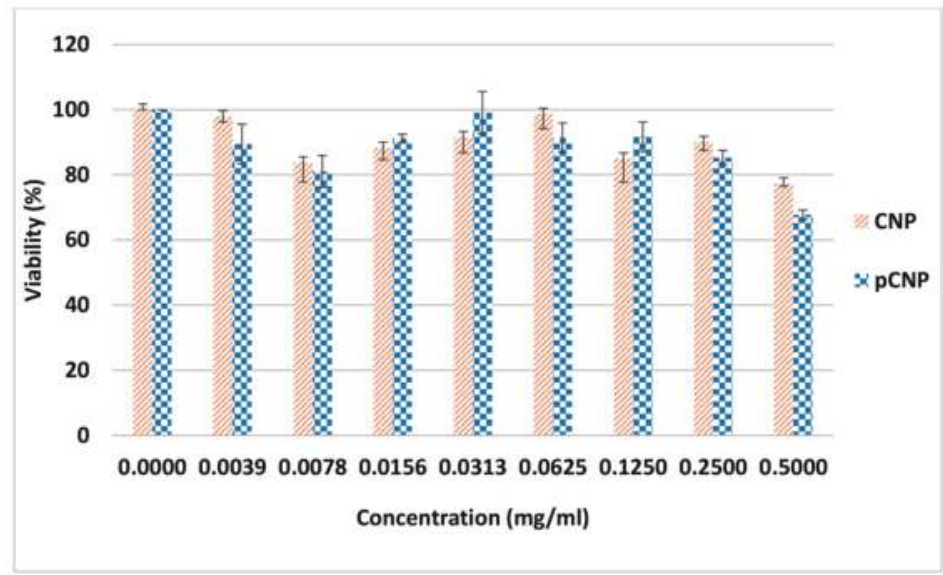

Figure 7. The percentage of viability assessed by CNP and pCNP using an MTT assay. CNP and pCNP have similar cytotoxicity effects where no $\mathrm{IC}_{50}$ was found. Data are presented as mean $\pm \mathrm{SEM}$ from three independent experiments. One-way ANOVA was performed with $p=0.1097$, which indicated that both CNP and pCNP had no significant difference in cytotoxicity effect in A549 cell lines. The experiment was not conducted with a further time point study because it showed no cytotoxicity effects in the $24 \mathrm{~h}$ study.

\subsection{Nanoparticle-Mediated Cell Cytotoxicity of SLB CNP-SLB and pCNP-SLB in A549 Cell Lines}

The MTT assay was repeated to assess the efficacy of SLB in A549 cells using CNP-SLB and pCNP-SLB systems to discern whether a nanoparticle-mediated delivery system can augment its in vitro efficiency. Approximately $300 \mu \mathrm{M}$ of SLB was used for the encapsulation of CNP and pCNP to form CNP-SLB and pCNP-SLB, as suggested by the study of Mateen et al. [48], where 10-75 $\mu \mathrm{M}$ of SLB was able to inhibit the cell growth of non-small cell lung cancer (NSCLC) [49]. Based on the E.E data obtained from Table 1, both CNP-SLB and pCNP-SLB contained approximately $75 \mu \mathrm{M}$ (24.57\% E.E) and $150 \mu \mathrm{M}(49.34 \%$ E.E) of SLB respectively, and the final concentration for cell treatment was $37.5 \mu \mathrm{M}$. Figure 8 shows the percentage of cell viability for cells treated with SLB, CNP-SLB, and $\mathrm{pCNP}-\mathrm{SLB}$, which generally revealed a substantial improvement in efficacy for SLB delivered using CNP and $\mathrm{pCNP} 48 \mathrm{~h}$ post treatment. Since the concentration of SLB encapsulated in pCNP was two-fold greater compared to CNP, it was initially thought that a lower IC50 would be obtained $48 \mathrm{~h}$ post-treatment. The $\mathrm{IC}_{50}$ calculated was $18.36 \mu \mathrm{M}$ and $18.69 \mu \mathrm{M}$ for CNP-SLB and PCNP-SLB, respectively. At this time point, the difference is thought to be less significant between CNP and its hydrophobically-modified version.

Interestingly, after $72 \mathrm{~h}$ of treatment, the $\mathrm{IC}_{50}$ for pCNP-SLB decreased to $6.058 \mu \mathrm{M}$, and that of CNP-SLB decreased to $12.77 \mu \mathrm{M}$, which is about $211 \%$ difference, as shown in Figure 9. This change was postulated to demonstrate the effectiveness of using PCNP as a controlled-release carrier, where the SLB was shown to be released slowly from the nanoparticle core upon treatment. Consequently, the efficacy of SLB for the first $48 \mathrm{~h}$ post-treatment was similar for both CNP and pCNP systems, but significantly differed for treatment of $72 \mathrm{~h}$. This was most probably due to the fact that most of the SLB encapsulated in CNP was fully released at $48 \mathrm{~h}$ post-treatment, compared to $\mathrm{pCNP}$, due to a greater association of SLB to the hydrophobic core in pCNP. This suggests that $\mathrm{pCNP}$ is great candidate for controlled-release properties, coupled with a higher \% E.E for SLB. A previous study by Mateen et al. [48] demonstrated that an SLB treatment of $10-75 \mu \mathrm{M}$ will cause growth inhibition in large cell carcinoma cells (H1299 and H460) and a bronchioalveolar carcinoma cell line (H322), which is similar to the findings 
of our study. However, the results of SLB delivery was improved by using pCNP, which shown by the low $\mathrm{IC}_{50}$.

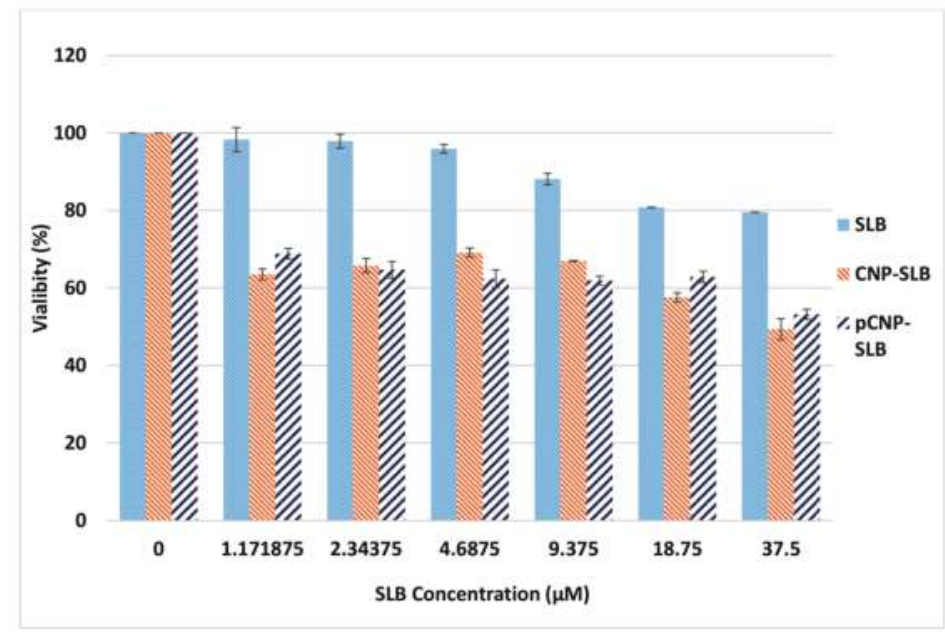

Figure 8. Cytotoxic effect of SLB, CNP-SLB and pCNP-SLB after $48 \mathrm{~h}$ of treatment. A similar SLB efficacy for CNP-SLB and PCNP-SLB was observed where both are significantly higher than SLB alone. Data are presented as mean \pm SEM from three independent experiments. One-way ANOVA was performed with a $p$ value below 0.05 for both between SLB and CNP-SLB and between SLB and pCNP-SLB, which indicated a significant difference of efficacy between SLB alone and SLB delivered by vector, and $p=0.9995$ between CNP-SLB and PCNP-SLB, which indicated no significant difference of efficacy between them.

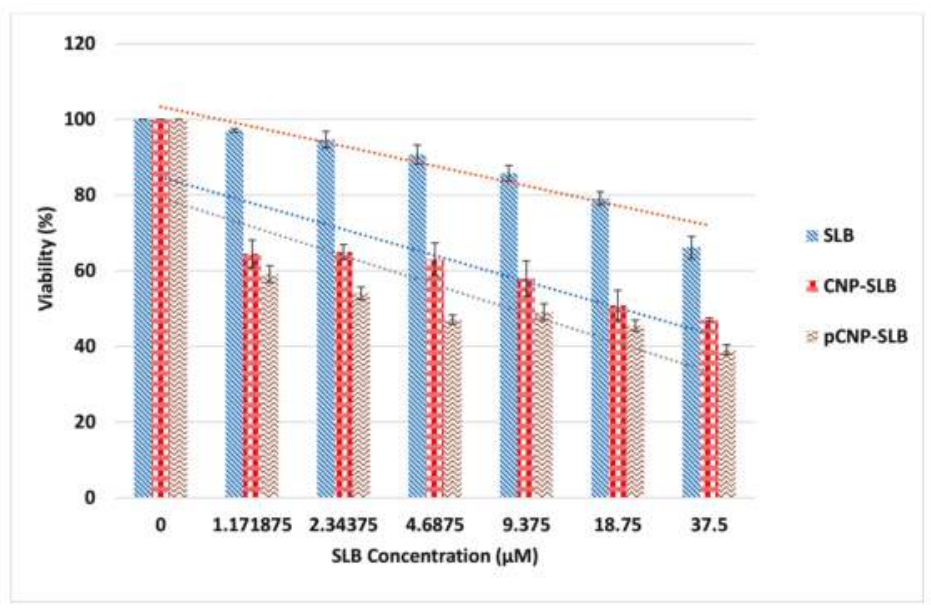

Figure 9. Cytotoxic effect of SLB, CNP-SLB and PCNP-SLB after $72 \mathrm{~h}$ of treatment. The highest efficacy was shown by PCNP-SLB, followed by CNP-SLB and SLB alone. Data are presented as mean \pm SEM from three independent experiments. A one-way ANOVA was performed and a $p$ value below 0.05 indicated a significant difference of efficacy between them. 
The incorporation of palmitic acid into CNP formed pCNP, which provides a hydrophobic anchor to associate with SLB through a hydrophobic-hydrophobic interaction. As proposed by Masarudin [45], a higher drug efficacy was obtained when $\left[{ }^{14} \mathrm{C}\right]$-doxorubicin was delivered using $\mathrm{pCNP}$ compared to CNP as a carrier, which is comparable with the results in this study. The pCNP was able to achieve a higher \% E.E when more SLB was encapsulated into the hydrophobic core, attributed to the hydrophobic-hydrophobic interaction and then delivered and released in a slower manner for longer duration compared to CNP. This explained why the efficacy of SLB for the first $48 \mathrm{~h}$ post treatment was similar, but differed considerably for the treatment of $72 \mathrm{~h}$.

\section{Materials and Methods}

Chitosan (CS, low molecular weight), sodium tripolyphosphate (TPP), palmitic acid N-hydroxy-succinimide ester (NHS-palmitate), silibinin and dimethyl sulfoxide (DMSO) were acquired in powder form from Sigma-Aldrich (St. Louis, MO, USA). Roswell Park Memorial Institute-1640 medium (RPMI-1640), fetal bovine serum (FBS), 0.25\% trypsin-EDTA (1 $\times$ ) and Antibiotic-Antimycotic $(100 \times)$ were purchased from Gibco Life Technologies (Grand island, NY, USA). Glacial acetic acid, sodium hydroxide and hydrochloric acid (analytical grade) were obtained from Friendemann Schmidt Chemicals (Parkwood, Western Australia). Absolute ethanol was purchased from Nacalai Tesque, Inc. (Kyoto, Japan). All reagents, unless otherwise stated, were used without further purification.

\subsection{Synthesis of Chitosan Nanoparticles (CNP) and Palmitoyl Chitosan Nanoparticles ( $p$ CNP)}

\subsubsection{Chitosan Nanoparticles (CNP)}

CNPs were synthesized by ionic gelation methods as described by Masarudin et al. (2015) [29]. CS and TPP were prepared to a concentration of $1.0 \mathrm{mg} / \mathrm{mL}$ in $50 \mathrm{~mL}$ centrifuge tubes before subsequently diluted to $0.5 \mathrm{mg} / \mathrm{mL}$ and $0.7 \mathrm{mg} / \mathrm{mL}$ respectively, and adjusted to $\mathrm{pH} 5$ and $\mathrm{pH}$ 2 using $1 \mathrm{M} \mathrm{NaOH}$ and $1 \mathrm{M} \mathrm{HCl}$. The CNPs were formed by adding increasing volumes of TPP solution $(0 \mu \mathrm{L}$ to $300 \mu \mathrm{L})$ to $600 \mu \mathrm{L}$ of CS solution. The CNPs were then purified by centrifugation at $13,000 \mathrm{rpm}$ for $20 \mathrm{~min}$. After centrifugation, $40 \%$ of the total CNP supernatant volume were mixed with $60 \%$ of deionized water $\left(\mathrm{dH}_{2} \mathrm{O}\right)$ corresponding to the $40 \%$ supernatant volume and utilized for further analyses.

\subsubsection{Hydrophobically-Modified Chitosan Nanoparticles (pCNP)}

The $1.0 \mathrm{mg} / \mathrm{mLCS}$ was prepared as mentioned above and adjusted to $\mathrm{pH}$ 6. Separately, NHS-palmitate was prepared in absolute ethanol to a concentration of $0.9 \mathrm{mg} / \mathrm{mL}$. NHS-palmitate was then added to the CS solution through dropwise addition at a 2:1 volume ratio, before being left to react for $20 \mathrm{~h}$ at $50{ }^{\circ} \mathrm{C}$. Following incubation, the hydrophobically-modified chitosan (pCS) was precipitated from the solution by adjusting the $\mathrm{pH}$ to $\mathrm{pH}$ 9. The precipitate was subsequently separated from the solution by centrifugation at $4000 \mathrm{rpm}$ for $45 \mathrm{~min}$. The precipitate was washed once with a solution of acetone: ethanol (50:50) and then thrice with $\mathrm{dH}_{2} \mathrm{O}$, and left to dry in the oven. The pCS was then used to prepare pCNP using similar methods as previously described for CNP.

\subsubsection{Synthesis of Silibinin-Encapsulated pCNP (pCNP-SLB)}

$5 \mathrm{mg}$ of Silibinin was dissolved in 50\% DMSO and $50 \% \mathrm{dH}_{2} \mathrm{O}$ to prepare a $10 \mathrm{mM}$ master stock. It was then further diluted by mixing $100 \mu \mathrm{L}$ of master stock with $100 \mu \mathrm{L}$ of $\mathrm{dH}_{2} \mathrm{O}$ until it became $5 \mathrm{mM}$ and was added dropwise to $600 \mu \mathrm{L}$ of pCS with continuous mixing until a final concentration of $300 \mu \mathrm{M}$ was then added with $200 \mu \mathrm{L}$ of TPP. 


\subsection{Physicochemical Characterization of Nanoparticle Samples}

\subsubsection{Analysis of Particle Size Distribution and Polydispersity}

The size and distribution of synthesized CNPs, pCNPs, CNP-SLB and pCNP-SLB were ascertained using dynamic light scattering on a Malvern Zetasizer Nano S Instrument (Malvern Instruments, Worcestershire, UK). About $1000 \mu \mathrm{L}$ of samples was loaded into a disposable cuvette, and the particle size was measured in triplicate readings for each sample to ensure the stability of the sample. All data were recorded as mean \pm standard error of mean (SEM). The significant alteration of particle sizes between the CNP and pCNP samples was subsequently evaluated by one way analysis of variance (ANOVA), with a $p$ value $<0.05$ considered as significant.

\subsubsection{Morphological and Surface Topological Analyses}

The surface morphologies and size of pCNP and pCNP-SLB were further examined using field-emission scanning electron microscopy (FESEM) analysis. Nanoparticles were diluted prior to analysis by mixing $100 \mu \mathrm{L}$ of samples with $500 \mu \mathrm{L}$ of $\mathrm{dH}_{2} \mathrm{O}$. A drop of each diluted samples was then placed onto an aluminum stub and left to dry in an oven for three days. The sample-loaded stubs were then gold-coated in a vacuum before being observed under an electron microscope (FEI NOVA nanoSEM 230, Thermo Fisher, Hillsboro, OR, USA).

\subsubsection{Fourier Transform Infrared (FTIR) Analysis with Attenuated Total Reflectance (ATR-FTIR)}

FTIR analysis was performed for SLB, pCNP and pCNP-SLB samples. Prior to analysis, the samples were freeze dried using a Coolsafe 95-15 PRO freeze drier (ScanVac, Lynge, Denmark) for $48 \mathrm{~h}$. Next, the samples in powder form was analyzed using a Spectrum 100 (Perkin Elmer, Waltham, MA, USA) using the attenuated total reflectance (ATR) method at an infrared frequency range of 200 to $4000 \mathrm{~cm}^{-1}$.

\subsection{Determination of Free Amine Groups in Nanoparticle Samples Using the 2,4,6-Trinitrobenzene} Sulfonic Assay

Prior to the assay, $0.05 \%(v / v)$ TNBS reagent, $0.1 \mathrm{M} \mathrm{NaHCO}_{3}, 10 \%(w / v)$ SDS and $1.0 \mathrm{M} \mathrm{HCl}$ were prepared in a $15 \mathrm{~mL}$ centrifuge tube. CS standards were prepared by serially diluting $50 \mu \mathrm{L}$ of $0.5 \mathrm{mg} / \mathrm{mL}$ CS solution using $0.1 \mathrm{M} \mathrm{NaHCO}_{3}$. Approximately $50 \mu \mathrm{L}$ of $0.05 \%(v / v)$ TNBS solution was then added to each sample in Eppendorf tubes. pCS standards were subsequently prepared using similar methods as for CS. Next, $100 \mu \mathrm{L}$ of nanoparticle samples at different TPP volume additions were aliquoted into Eppendorf tubes and mixed with $100 \mu \mathrm{L} 0.05 \%(v / v)$ TNBS solution. All the standard and sample tubes were then incubated for $3 \mathrm{~h}$ at $37^{\circ} \mathrm{C}$. Following incubation, $100 \mu \mathrm{L}$ of the standard/samples were transferred into a 96-well plate. Approximately $100 \mu \mathrm{L}$ of $10 \%$ SDS and $75 \mu \mathrm{L}$ of $1 \mathrm{M} \mathrm{HCl}$ were added into each well and mixed, and the absorbance was read at a wavelength of $405 \mathrm{~nm}$. The utilized amine percentage was then calculated using the following equation:

$$
\text { Free amine percentage }(\%)=\frac{A_{405} \text { of } \mathrm{CNP} / \mathrm{pCNP}}{A_{405} \text { of } \mathrm{CS} / \mathrm{pCS}} \times 100 \%
$$

The significant alteration of utilized amine percentage of CNP and pCNP samples was subsequently evaluated by paired $t$-test, with a $p$ value $<0.05$ considered as significant.

\subsection{Encapsulation Efficiency of Silibinin in Nanoparticle Samples}

The encapsulation efficiency (\% EE) was calculated by comparing the difference in absorbance at $288 \mathrm{~nm}$ between free SLB and the supernatant of encapsulated SLB. The CNP-SLB and pCNP-SLB samples were centrifuged at 13,000 rpm for $20 \mathrm{~min}$. The supernatant was then collected and the absorbance at 
$288 \mathrm{~nm}$ was read using a UV/VIS spectrophotometer (NP80, Implen, München, Germany). The \% EE was then calculated using the following equation:

$$
\% \mathrm{EE}=\frac{\mathrm{A}_{288} \text { of free SLB }-\mathrm{A}_{288} \text { of SLB in supernatant }}{\mathrm{A}_{288} \text { of free SLB }} \times 100 \%
$$

The absorbance of free SLB at $288 \mathrm{~nm}$ was used to deduct the absorbance of SLB that remained in the supernatant post-encapsulation and divided by the absorbance of free SLB, then multiplied by 100 percent to get the percentage of encapsulation (\% E.E).

\subsection{Determination of In Vitro Cellular Efficacy Using Nanoparticle-Mediated Delivery of Silibinin}

The A549 cell line was established by culturing in a T-25 flask with growth media consisting of $90 \%$ of $1 \times$ RPMI medium 1640 and $10 \%$ FBS. Approximately $100 \mu \mathrm{L}$ of cells were seeded into a 96-wells plate. Cells were seeded at a density of $7 \times 10^{3}$ cells per well for 48 -h treatments and $4 \times 10^{3}$ for 72-h treatment, whilst cells were treated with $100 \mu \mathrm{L}$ of CNP, pCNP, SLB, CNP-SLB and pCNP-SLB. At the end of each time point, the wells were decanted and replaced with $170 \mu \mathrm{L}$ fresh growth media. Separately, $5 \mathrm{mg} / \mathrm{mL}$ MTT solution was prepared in $1 \times$ PBS and sterilely filtered with $0.22 \mu \mathrm{m}$ nylon filter. Approximately $30 \mu \mathrm{L}$ of the MTT solution was then added into each well, mixed and incubated for a further $4 \mathrm{~h}$. Following incubation, $150 \mu \mathrm{L}$ of solution was removed and $100 \mu \mathrm{L}$ of DMSO was added to each well. The absorbance was then read at $570 \mathrm{~nm}$ using a Bio-Rad iMark ${ }^{\mathrm{TM}}$ Microplate Absorbance Reader (Bio-Rad, Hercules, CA, USA). Cell viability was determined using the following equation:

$$
\% \text { viability }=\frac{A_{570} \text { of treated cells }}{A_{570} \text { of untreated cells }} \times 100 \%
$$

The significant efficacy of nanoparticles, SLB and SLB-encapsulated nanoparticles was subsequently evaluated by one way analysis of variance (ANOVA), with a $p$ value $<0.05$ considered as significant.

\section{Conclusions}

The present study showed the successful hydrophobic-modification of CNP and encapsulation of SLB. In addition, pCNP was found to be a better delivery vector compared to CNP due to the incorporation of NHS-palmitic acid, which is non-toxic and possesses a hydrophobic-hydrophobic interaction with SLB, achieving a higher encapsulation efficiency and higher efficacy effect in the A549 cell line compared to CNP. Hence, the pCNP system established in this study shows great potential for imminent customization and studies as a delivery vector, especially for low bioavailability drugs for cancer therapeutics.

Acknowledgments: The author Cha Yee Kuen would like to acknowledge Universiti Putra Malaysia (UPM) for provisions of a Graduate Research Fellowship. The author Mas Jaffri Masarudin would like to acknowledge Universiti Putra Malaysia for research funding under the UPM-IPB funds Vot No. 9425801 to conduct this research.

Author Contributions: Cha Yee Kuen and Mas Jaffri Masarudin conceived and designed the experiments; Cha Yee Kuen performed the experiments; Sharida Fakurazi, Siti Sarah Othman and Mas Jaffri Masarudin analyzed the data and contributed reagents/materials/analysis tools; Cha Yee Kuen wrote the paper. All authors read and edited the paper before submission.

Conflicts of Interest: The authors declare no conflict of interest.

\section{References}

1. Chalasani, S.; Prakash, K.V.; Pulla, R.P.; Tekula, R.; Manasa, E.; Umasankar, B. Development and validation of doxorubicin hcl in bulk and its pharmaceutical dosage form by visible spectrophotometry. Int. J. Pharm. Sci. 2013, 3, 216-218.

2. Wellington, K.; Jarvis, B. Silymarin: A review of its clinical properties in the management of hepatic disorders. BioDrugs 2001, 15, 465-489. [CrossRef] [PubMed] 
3. Kim, N.C.; Graf, T.N.; Sparacino, C.M.; Wani, M.C.; Wall, M.E. Complete isolation and characterization of silybins and isosilybins from milk thistle (Silybum marianum). Org. Biomol. Chem. 2003, 1, 1684-1689. [CrossRef] [PubMed]

4. Tyagi, N.; De, R.; Begun, J.; Popat, A. Cancer therapeutics with epigallocatechin-3-gallate encapsulated in biopolymeric nanoparticles. Int. J. Pharm. 2017, 518, 220-227. [CrossRef] [PubMed]

5. Ramasamy, K.; Agarwal, R. Multitargeted therapy of cancer by silymarin. Cancer Lett. 2008, 269, 352-362. [CrossRef] [PubMed]

6. Mateen, S.; Raina, K.; Agarwal, R. Chemopreventive and Anti-cancer Efficacy of Silibinin against Growth and Progression of Lung Cancer. Nutr. Cancer 2013, 65, 3-11. [CrossRef] [PubMed]

7. Sharma, G.; Singh, R.P.; Chan, D.C.; Agarwal, R. Silibinin induces growth inhibition and apoptotic cell death in human lung carcinoma cells. Anticancer Res. 2003, 23, 2649-2655. [PubMed]

8. Chu, S.C.; Chiou, H.L.; Chen, P.N.; Yang, S.F.; Hsieh, Y.S. Silibinin inhibits the invasion of human lung cancer cells via decreased productions of urokinase-plasminogen activator and matrix metalloproteinase- 2 . Mol. Carcinog. 2004, 40, 143-149. [CrossRef] [PubMed]

9. Mohan, S.; Dhanalakshmi, S.; Mallikarjuna, G.U.; Singh, R.P.; Agarwal, R. Silibinin modulates UVB-induced apoptosis via mitochondrial proteins, caspases activation, and mitogen-activated protein kinase signaling in human epidermoid carcinoma A431 cells. Biochem. Biophys. Res. Commun. 2004, 320, 183-189. [CrossRef] [PubMed]

10. Dhanalakshmi, S.; Mallikarjuna, G.U.; Singh, R.P.; Agarwal, R. Dual efficacy of silibinin in protecting or enhancing ultraviolet B radiation-caused apoptosis in HaCaT human immortalized keratinocytes. Carcinogenesis 2004, 25, 99-106. [CrossRef] [PubMed]

11. Deep, G.; Agarwal, R. Anti-metastatic Efficacy of Silibinin: Molecular Mechanisms and Therapeutic Potential against Cancer. Cancer Metastasis Rev. 2010, 29, 447-463. [CrossRef] [PubMed]

12. Ting, H.; Deep, G.; Agarwal, R. Molecular Mechanisms of Silibinin-Mediated Cancer Chemoprevention with Major Emphasis on Prostate Cancer. AAPS J. 2013, 15, 707-716. [CrossRef] [PubMed]

13. Kumar, S.; Raina, K.; Agarwal, C.; Agarwal, R. Silibinin strongly inhibits the growth kinetics of colon cancer stem cell-enriched spheroids by modulating interleukin 4/6-mediated survival signals. Oncotarget 2014, 5, 4972-4989. [CrossRef] [PubMed]

14. Wu, K.; Ning, Z.; Zeng, J.; Fan, J.; Zhou, J.; Zhang, T.; Zhang, L.; Chen, Y.; Gao, Y.; Wang, B.; et al. Silibinin inhibits $\beta$-catenin/ZEB1 signaling and suppresses bladder cancer metastasis via dual-blocking epithelial-mesenchymal transition and stemness. Cell Signal. 2013, 25, 2625-2633. [CrossRef] [PubMed]

15. Morazzoni, P.; Bombardelli, E. Silybum marianum (Carduus marianus). Fitoterapia 1995, 66, 3-42.

16. Basaga, H.; Poll, G.; Tekkaya, C.; Aras, I. Free radical scavenging and antioxidative properties of "silibin" complexs on microsomal lipid peroxidation. Cell Biochem. Funct. 1997, 15, 27-33. [CrossRef]

17. Skottov, N.; Kreeman, V.; Vaoa, R.; Chmela, Z.; Ulrichov, J.; Simanek, V. Effect of silymarin and silibinin-phosphatidylcholine complex on plasma and lipoprotein cholesterol, and oxidation of LDL in rats fed on high cholesterol diet supplemented with current oil. Acta Univ. Palacki. Olomuc. Fac. Med. 2000, 144, 55-58. [CrossRef]

18. Leena, R.S.; Vairamani, M.; Selvamurugan, N. Alginate/Gelatin scaffolds incorporated with Silibinin-loaded Chitosan nanoparticles for bone formation in vitro. Colloids Surf. B Biointerfaces 2017, 158, 308-318. [CrossRef] [PubMed]

19. Kidd, P.; Head, K. A review of the bioavailability and clinical efficacy of milk thistle phytosome: A silybin-phosphatidylcholine complex (Siliphos). Altern. Med. Rev. 2005, 10, 193-203. [PubMed]

20. Zhang, J.Q.; Liu, X.; Li, X.L.; Jasti, B.R. Preparation and Characterization of Solid Lipid Nanoparticles Containing Silibinin. Drug Deliv. 2007, 14, 381-387. [CrossRef] [PubMed]

21. Yang, G.; Zhao, Y.; Feng, N.; Zhang, Y.; Liu, Y.; Dang, B. Improved dissolution and bioavailability of silymarin delivered by a solid dispersion prepared using supercritical fluids. Asian J. Pharm. Sci. 2015, 10, 194-202. [CrossRef]

22. Yanyu, X.; Yunmei, S.; Zhipeng, C.; Qineng, P. The preparation of silybin-Phospholipid complex and the study on its pharmacokinetics in rats. Int. J. Pharm. 2006, 307, 77-82. [CrossRef] [PubMed]

23. Greish, K. Enhanced permeability and retention (EPR) effect for anticancer nanomedicine drug targeting. Cancer Nanotechnol. 2010, 624, 25-37.

24. Hirano, S. Chitin and chitosan as novel biotechnological materials. Polym. Int. 1999, 48, 732-734. [CrossRef] 
25. Kang, B.S.; Lee, S.E.; Ng, C.L.; Kim, J.K.; Park, J.S. Exploring the Preparation of Albendazole-Loaded Chitosan-Tripolyphosphate Nanoparticles. Materials 2015, 8, 486-498. [CrossRef] [PubMed]

26. Chai, F.; Sun, L.; He, X.; Li, J.; Liu, Y.; Xiong, F.; Ge, L.; Webster, T.J.; Zheng, C. Doxorubicin-loaded poly (lactic-co-glycolic acid) nanoparticles coated with chitosan/alginate by layer by layer technology for antitumor applications. Int. J. Nanomed. 2017, 12, 1791-1802. [CrossRef] [PubMed]

27. Shu, X.Z.; Zhu, K.J. The influence of multivalent phosphate structure on the properties of ionically cross-linked chitosan films for controlled drug release. Eur. J. Pharm. Biopharm. 2012, 54, 235-243. [CrossRef]

28. Hassan, U.A.; Hussein, M.Z.; Masarudin, M.J. Synthesis of a nanoparticle system for the enhanced accumulation of fluorescently-labelled amino acids encapsulated in monodispersed chitosan nanoparticle system. Malays. Appl. Biol. 2017, 46, 171-175.

29. Masarudin, M.J.; Cutts, S.M.; Evison, B.J.; Phillips, D.R.; Pigram, P.J. Factors determining the stability, size distribution, and cellular accumulation of small, monodisperse chitosan nanoparticles as candidate vectors for anticancer drug delivery: Application to the passive encapsulation of $\left[{ }^{14} \mathrm{C}\right]$-doxorubicin. Nanotechnol. Sci. Appl. 2015, 8, 67-80. [CrossRef] [PubMed]

30. Ravikumara, N.R.; Madhusudhan, B. Chitosan nanoparticles for tamoxifen delivery and cytotoxicity to MCF-7 and Vero cells. Pure Appl. Chem. 2011, 83, 2027-2040. [CrossRef]

31. Liu, H.; Gao, C. Preparation and properties of ionically crosslinked chitosan nanoparticles. Polym. Adv. Technol. 2009, 20, 613-619. [CrossRef]

32. Fan, W.; Yan, W.; Xu, Z.; Ni, H. Formation mechanism of monodisperse, low molecular weight chitosan nanoparticles by ionic gelation technique. Colloids Surf. B Biointerfaces 2012, 90, 21-27. [CrossRef] [PubMed]

33. Marchiori, M.C.L.; Rigon, C.; Copetti, P.M.; Sagrillo, M.R.; Cruz, L. Nanoencapsulation Improves Scavenging Capacity and Decreases Cytotoxicity of Silibinin and Pomegranate Oil Association. AAPS PharmSciTech 2017, 18, 3236-3246. [CrossRef] [PubMed]

34. Shankar, G.; Agrawal, Y.K. Formulation and evaluation of polymeric micelles for a poorly absorbed drug. Res. J. Pharm. Biol. Chem. Sci. 2015, 6, 1314-1321.

35. Singh, R.; Lillard, J.W. Nanoparticle-based targeted drug delivery. Exp. Mol. Pathol. 2009, 86, $215-223$. [CrossRef] [PubMed]

36. Ariff, S.A.Y.; Yusoff, K.; Masarudin, M.J. Encapsulation of mirna in chitosan nanoparticles as a candidate for an anti-metastatic agent in cancer therapy. Malays. Appl. Biol. 2017, 46, 165-170.

37. Gomathi, T.; Prasad, P.S.; Sudha, P.N.; Anil, S. Size optimization and in vitro biocompatibility studies of chitosan nanoparticles. Int. J. Biol. Macromol. 2017, 104, 1794-1806.

38. Sahu, S.K.; Maiti, S.; Maiti, T.K.; Ghosh, S.K.; Pramanik, P. Hydrophobically modified carboxymethyl chitosan nanoparticles targeted delivery of paclitaxel. J. Drug Target. 2010, 19, 104-113. [CrossRef] [PubMed]

39. Mohammadpour, D.N.; Eskandari, R.; Avadi, M.R.; Zolfagharian, H.; Mir Mohammad Sadeghi, A.; Rezayat, M. Preparation and in vitro characterization of chitosan nanoparticles containing Mesobuthus eupeus scorpion venom as an antigen delivery system. J. Venom. Anim. Toxins Incl. Trop. Dis. 2012, 18, 44-52.

40. Kafshgari, M.H.; Khorram, M.; Khodadoost, M.; Khavari, S. Reinforcement of Chitosan Nanoparticles Obtained by and Ionic Cross-Linking Process. Iran. Polym. J. 2011, 20, 445-456.

41. Gomathi, T.; Govindarajan, C.; Rose, H.R.M.H.; Sudha, P.N.; Imran, P.K.; Venkatesan, J.; Kim, S.K. Studies on drug-polymer interaction, in vitro release and cytotoxicity from chitosan particles excipient. Int. J. Pharm. 2014, 468, 214-222. [CrossRef] [PubMed]

42. Tan, J.M.; Karthivashan, G.; Gani, S.A.; Fakurazi, S.; Hussein, M.Z. In vitro drug release characteristic and cytotoxic activity of silibinin-loaded single walled carbon nanotubes functionalized with biocompatible polymers. Chem. Cent. J. 2016, 10, 81. [CrossRef] [PubMed]

43. Nagpal, K.; Singh, S.K.; Mishra, D.N. Chitosan Nanoparticles: A Promising System in Novel Drug Delivery. Chem. Pharm. Bull. 2010, 58, 1423-1430. [CrossRef] [PubMed]

44. Riss, T.L.; Moravec, R.A.; Niles, A.L.; Duellman, S.; Benink, H.A.; Worzella, T.J.; Minor, L. Cell Viability Assays. In Assay Guidance Manual; Eli Lilly \& Company and the National Centre for Advancing Translational Sciences: Bethesda, MD, USA, 2013.

45. Masarudin, M.J. Chitosan Nanoparticles as a Delivery Vehicle for $\left[{ }^{14} \mathrm{C}\right]$-Doxorubicin and the Formaldehyde Releasing Prodrug AN-250. Ph.D. Thesis, La Trobe University, Bundoora, Australia, 2012.

46. Zhang, J.; Chen, X.G.; Li, Y.Y.; Liu, C.S. Self-assembled nanoparticles based on hydrophobically modified chitosan as carriers for doxorubicin. Nanomed. Nanotechnol. Biol. Med. 2007, 3, 258-265. [CrossRef] [PubMed] 
47. Chiu, Y.L.; Ho, Y.C.; Chen, Y.M.; Peng, S.F.; Ke, C.J.; Chen, K.J.; Mi, F.L.; Sung, H.W. The characteristics, cellular uptake and intracellular trafficking of nanoparticles made of hydrophobically-modified chitosan. J. Control. Release 2010, 146, 152-159. [CrossRef] [PubMed]

48. Mateen, S.; Tyagi, A.; Agarwal, C.; Singh, R.P.; Agarwal, R. Silibinin inhibits human nonsmall cell lung cancer cell growth through cell-cycle arrest by modulating expression and function of key cell-cycle regulators. Mol. Carcinog. 2010, 49, 247-258. [CrossRef] [PubMed]

49. Wang, Y.; Li, P.; Truong-Dinh Tran, T.; Zhang, J.; Kong, L. Manufacturing Techniques and Surface Engineering of Polymer Based Nanoparticles for Targeted Drug Delivery to Cancer. Nanomaterials 2016, 6, 26. [CrossRef] [PubMed]

(C) 2017 by the authors. Licensee MDPI, Basel, Switzerland. This article is an open access article distributed under the terms and conditions of the Creative Commons Attribution (CC BY) license (http:/ / creativecommons.org/licenses/by/4.0/). 


\title{
Inihibition of Glycolysis by Using a Micro/Nano-Lipid Bromopyruvic Chitosan Carrier as a Promising Tool to Improve Treatment of Hepatocellular Carcinoma
}

\author{
Nemany A. Hanafy ${ }^{1,2, t, \ddagger}$, Luciana Dini $^{3}$, Cinzia Citti ${ }^{1,3}$, Giuseppe Cannazza ${ }^{3,4}$ and \\ Stefano Leporatti ${ }^{1, *}$ \\ 1 CNR NANOTEC-Istituto di Nanotecnologia, 73100 Lecce, Italy; nemany.hanafy@nanotec.cnr.it (N.A.H.); \\ cinzia.citti@gmail.com (C.C.) \\ 2 Department of Mathematics and Physics "E. De Giorgi", University of Salento, 73100 Lecce, Italy \\ 3 Department of Biological and Environmental Sciences and Technologies (DiSTeBA), University of Salento, \\ 73100 Lecce, Italy; luciana.dini@unisalento.it (L.D.); giuseppe.cannazza@unimore.it (G.C.) \\ 4 Life Science Department, University of Modena e Reggio Emilia, 41121 Modena, Italy \\ * Correspondence: stefano.leporatti@nanotec.cnr.it; Tel.: +39-0832-319829 \\ + Present Address: Sohag Cancer Center, 82511 Sohag, Egypt. \\ $\ddagger$ Present Address: Institute of Nanoscience and Nanotechnology, Kafrelsheikh University, \\ 33516 Kafr ElSheikh, Egypt.
}

Received: 15 December 2017; Accepted: 8 January 2018; Published: 10 January 2018

\begin{abstract}
Glucose consumption in many types of cancer cells, in particular hepatocellular carcinoma (HCC), was followed completely by over-expression of type II hexokinase (HKII). This evidence has been used in modern pharmacotherapy to discover therapeutic target against glycolysis in cancer cells. Bromopyruvate (BrPA) exhibits antagonist property against HKII and can be used to inhibit glycolysis. However, the clinical application of BrPA is mostly combined with inhibition effect for healthy cells particularly erythrocytes. Our strategy is to encapsulate BrPA in a selected vehicle, without any leakage of BrPA out of vehicle in blood stream. This structure has been constructed from chitosan embedded into oleic acid layer and then coated by dual combination of folic acid (FA) and bovine serum albumin (BSA). With FA as specific ligand for cancer folate receptor and BSA that can be an easy binding for hepatocytes, they can raise the potential selection of carrier system.
\end{abstract}

Keywords: nanocarrier; glycolysis; hepatocellular carcinoma (HCC); bromopyruvate

\section{Introduction}

Increase of glucose consumption in many types of cancer cells is supported mostly by overexpression of type II hexokinase (HKII) [1]. Hence, Hexokinase (ATP: D-hexose 6-phosphotransferase) is a key enzyme that catalyzes the first step in the glycolysis pathway. This enzyme transfers a phosphate group from ATP to glucose to form glucose-6-phosphate [2]. Moreover, HKII interacts with the outer membrane protein voltage dependent anion channel (VDAC). It blocks mitochondrial inter-membrane space protein release and prevents activation of the apoptotic process [3]. This unique property has gained attention from researchers to develop new chemotherapeutic strategies targeting the glycolysis pathway in cancer cells [4]. Various inhibitors affecting the key enzymes of the glycolysis pathway have been identified. Among the glycolytic inhibitors, bromopyruvate (BrPA) shows promising anticancer activity both in vitro and in vivo. Indeed, BrPA causes regression of solid tumors by ATP depletion [5]. It has, furthermore, been shown to be effective and, indeed, curative, as a single agent against hepatic tumors in animal models [5]. 
The crucial problem for using BrPA in clinical application is related to its interaction with normal cells, especially erythrocytes [6]. Thus, there is an urgent need to encapsulate BrPA inside smart carriers having efficient strategies from size, shape, and targeted for cancer cells. In our previous report, BrPA attached Poly(allylamine) hydrochloride was entrapped inside $\mathrm{CaCO}_{3}$ rods during their fabrication. Encapsulated BrPA was absorbed by cancer cells and, furthermore, was released gradually with time as demonstrated by confocal microscopy and MTT assay [7]. However, non-specific, passive, targeting carriers can result in uptake by healthy cells. This can be minimized by the active targeting of the therapy, which has not been explored previously by this team. In our recent work, targeted hybrid lipid polymer is fabricated as an alternate assembly structure instead of liposomes. Their positive attributes (such as their tunable size, surface charge, high drug loading yield, sustained drug release profile, favorable stability in serum, good cellular targeting ability) make them a promising drug delivery vehicle for further in vivo tests. Hybrid polymeric protein carriers (HPPNCs) were assembled by using chitosan, oleic acid, and BSA-FA to produce a core-shell structure.

Chitosan is a copolymer of $\beta$-(1 $\rightarrow 4)$-linked-2-acetamido-2-deoxy-D-glucopyranose and 2-amino-2-deoxy-D-glucopyranose [8]. Its unique properties, such as biodegradability, biocompatibility, nontoxicity, positively-charged, and rigid linear molecular structure make this macromolecule ideal as a drug carrier and delivery material [9]. Chitosan is soluble in aqueous solutions of various acids, but chitosan molecules have no amphiphilic property and cannot produce micelles in water. Thus, there are many reports on hydrophobic changes of chitosan, for example, palmitoyl glycol chitosan [10], deoxycholic acid-modified chitosan, [11], poly( $N$-isopropylacrylamide)-chitosan [12], linoleic acid-modified chitosan [13], linolenic acid modified chitosan [14], $\mathrm{N}$-alkyl-O-sulfate chitosan [15], chitosanpolylactide graft copolymer [16], $\mathrm{N}$-acetylchitosan, $\mathrm{N}$-propionylchitosan, and $\mathrm{N}$-butyrylchitosan, butanoylchitosan, hexanoy-chitosan, and benzoyl-chitosan [17]. Bovine serum albumin (BSA) is biodegradable, biocompatible, nontoxic, and not immunogenic [18], making it an ideal delivery carrier for drugs. In particular, BSA-based nanoparticles (NPs) might cause natural abundance in plasma, relative stability and inertness in biochemical pathways, availability, and a relatively benign in vivo biological fate [19]. A tumor-targeting agent, folic acid, was linked to BSA to increase the selective targeting ability of the conjugate [20]. Folic acid has been widely used as a ligand for folate receptor-mediated selective targeting and delivery of drugs into tumor cells [21]. The folate receptor has been found to be overexpressed in a wide range of tumors, and is known as a high-affinity membrane folate-binding protein, which mediates uptake of the vitamin by receptor-mediated endocytosis [22]. Recently, maximum entrapment efficiency investigation of similar systems was also performed [23] and use of SiRNA for following oral administration of chitosan/SiRNA nanoparticles was further investigated [24]. In a previous paper, we have investigated conjugation of folic acid with BSA. Whereas prior to the conjugation to BSA, FA was activated by using 1-ethyl-3-(3-dimethylaminopropyl) carbodiimide (EDAC) and NHS to trigger the binding of the carboxyl group (specifically the gamma-COOH) of FA to the free amino moieties of BSA [25]. The novelty of this work is to obtain nucleus made up of chitosan-oleic acid. Since the hydrophobic modification of chitosan that was done by coupling with fatty acid, can result in product with an amphiphilic behavior and self-aggregation. Then oleic acid grafted chitosan was inserted into a layer of albumin-FA to achieve higher drug levels in tumor tissue and to minimize side effects.

\section{Results and Discussion}

\subsection{Characterization}

Oleic acid is a mono-unsaturated fatty acid. It is able to generate reactive oxygen species (ROS) inside cells because it has free fatty acids with anti-neoplastic properties against cancer cells [26]. In this study, the active site of free fatty acid was blocked by dissolving oleic acid in alcohol [27] (e.g., in this study, ethanol was used). It was then heated for $2 \mathrm{~h}$ at $60^{\circ} \mathrm{C}$. Afterwards EDAC was added to activate the carboxylic group of oleic acid (see Figure 1) resulting in a homogenous esterified 
suspension [28]. Oleic acid (OA) was coupled to chitosan by the formation of amide linkages through the EDAC-mediated reaction with different degrees of amino substitution (DS) as described in a previous study [29] (see Figure 1, Step 1). Although chitosan molecules present no amphiphilic property and, therefore, cannot form micelles in water, chitosan chains can be modified by oleic acid by means of the introduction of carboxylic acid groups in the presence of water-soluble carbodiimide, which react with carboxyl groups of fatty acids, forming active ester intermediates. Consequently, the intermediates can react with primary amine groups of chitosan to create an amide bond. The final product of this assembly is a nano-sized self-aggregation in aqueous media [30]. These nuclei were made up of self-aggregated chitosan and oleic acid was coated by FA conjugated with BSA to target cancer cells and to minimize side effects [22].

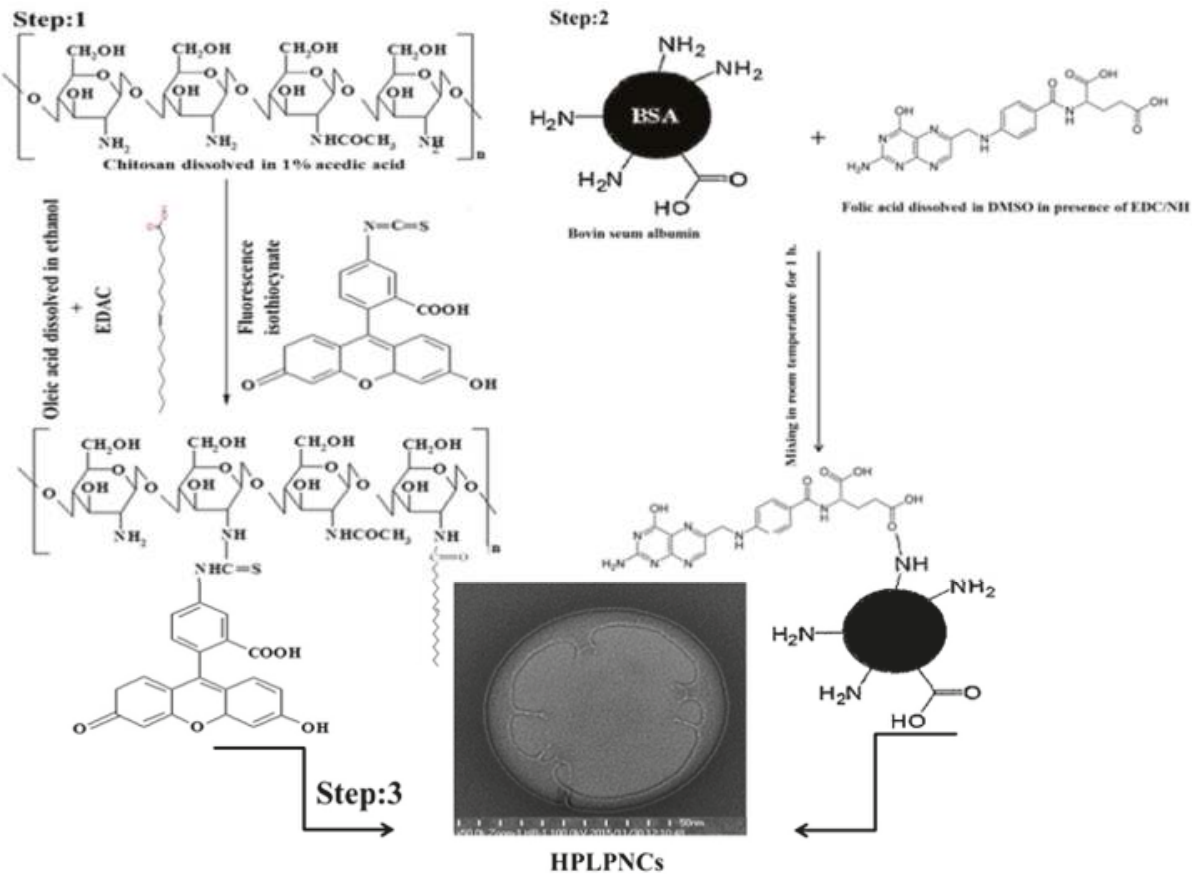

Figure 1. Scheme of hybrid polymer lipid protein nanocarrier structure. Step 1: self-assembly Structure of chitosan and oleic acid; step 2: conjugation folic acid with bovine serum albumin; and step 3: functionalization of chitosan grafted oleic acid surface by using BSA-FA.

The zeta potential of nanoparticles assembled by oleic acid-grafted chitosan showed good adsorption $(81 \pm 1.5 \mathrm{mV}$ ) (see Figure $2 \mathrm{C}$ ) compared to chitosan alone and oleic acid alone. The results show a significant reduction of the potential surface of NPs after their fabrication, indicating that BSA-FAwas assembled up to surface of OA-grafted chitosan.

This result confirms the stability of this colloidal suspension for biological and environmental applications [31]. Additionally, it is a real indication for the combination of these dual structures compared to the zeta potential of both chitosan alone and oleic acid alone (see Figure 2A,B). Dynamic light scattering (DLS) investigation was also performed to gain evidence of the differences in the size of the materials used (see Figure S1 in the Supplementary Materials).

The distribution of used materials such as chitosan alone, oleic acid alone, oleic acid-grafted chitosan, and hybrid polymeric lipid protein micro/nano-particles on a scale bar were studied by DLS to describe the modification of the material size that was used during the experiment. The given 
result indicates that chitosan and oleic acid have high distributions before assembling and their complexes improve their uniformity. Hence, the polydispersity value (PDI) reflects the nanoparticle size distribution. In our study, PDI mostly ranged from 0.6 to 1 . This wide range of values is closely related to the number of carboxyl groups of OA and the primary amino group of chitosan assembled together.

For the purpose of targeted delivery, the surface of NPs was also functionalized with FA conjugated to BSA. Their potential surface was modified after conjugation and measured at $18.6 \pm 0.8 \mathrm{mV}$ (see Figure 2D). This result indicates that the surface of OA-integrated chitosan was actually coated by a BSA-FA layer. Data of the BSA functionalized with FA was already published [25].
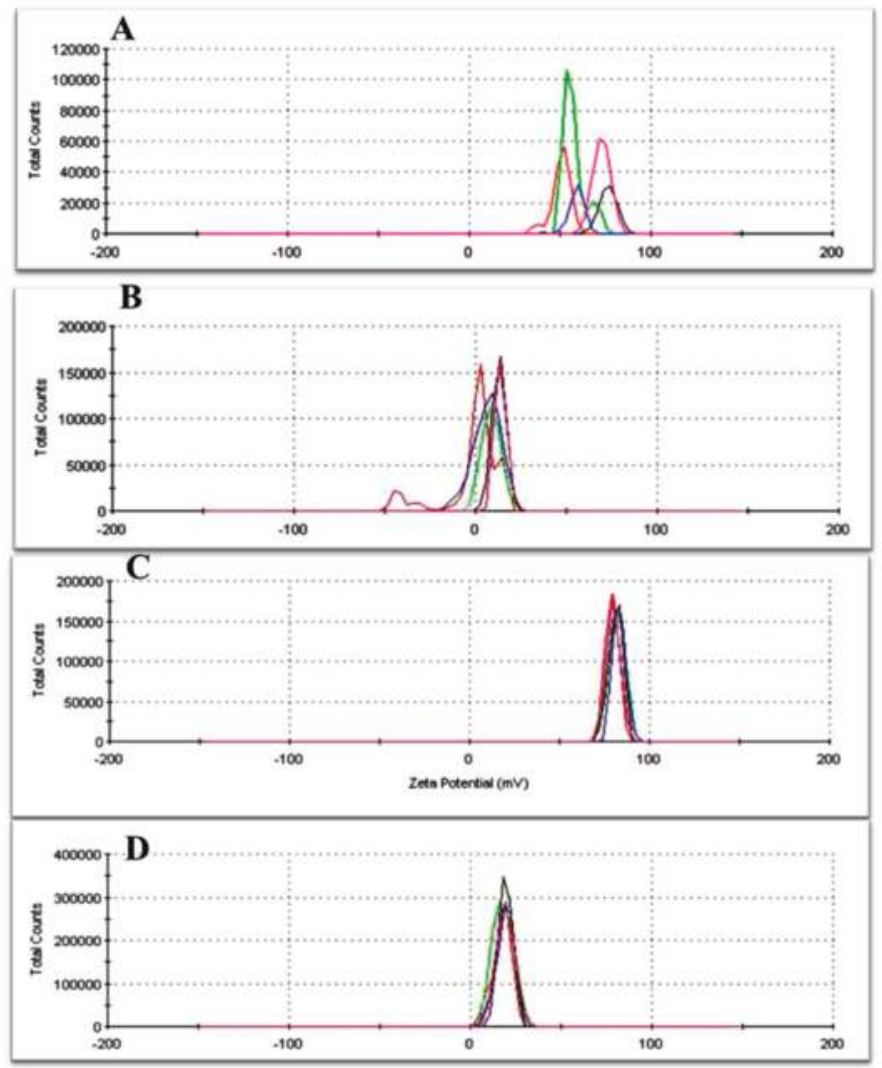

Figure 2. Zeta potential measurement: (A) chitosan solution alone; (B) oleic acid suspension alone; (C) chitosan grafted oleic acid; and (D) Hybrid Polymeric Lipid Protein Nanocarriers (HPLPNCs).

In order to characterize the structure of the hybrid nano-lipid, NPs were stained by uranyl acetate to enhance OA electron density and then imaged by Transmission Electron Microscopy (TEM). The results show a dim ring structure surrounding the core (see Figure 3) and three or four layers were completely attached having diameters of 30-60 nm [27]. These results indicated that the hydrophobic modified chitosan was well dispersed in aqueous media, with an increase in the amide linkage between chitosan and OA, and a denser hydrophobic core was formed [32]. These modifications can introduce hydrophobic groups into chitosan and form amphiphilic chitosan polymers. Some of these amphiphilic chitosan polymers can generate nano-sized self-aggregation in aqueous media [30]. In this 
study chitosan chains were modified by oleic acid through the introduction of the carboxylic acid group in the presence of water-soluble carbodiimide, which reacts with the carboxyl groups of fatty acids forming active ester intermediates. Consequently, the intermediates can react with primary amine groups of chitosan to form an amide bond (see scheme Figure 1).

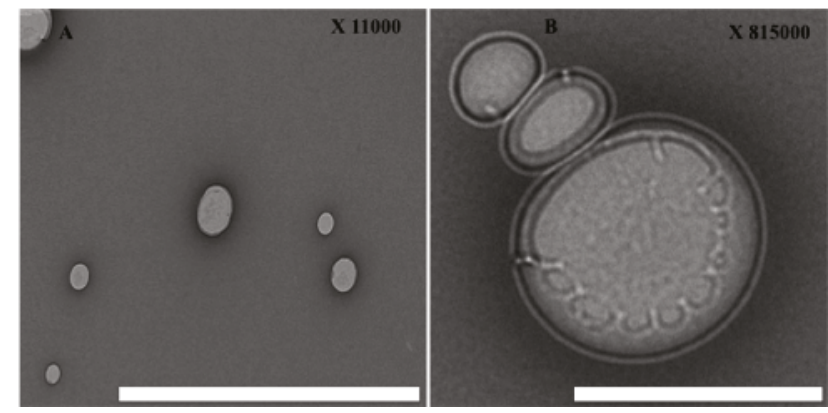

Figure 3. Transmission Electron Microscopy (TEM) characterization: (A) low magnification of HPLPNCs; and (B) high magnification view of HPLPNCs. Scale bars: $250 \mathrm{~nm}$.

The NP furthermore comprises three distinct functional components: (i) a hydrophobic polymeric core where chitosan was successfully entrapped inside the core and it was the main place for drug encapsulation; (ii) a hydrophilic BSA-FA shell with a delivery targeting purpose and for good liver cell binding; and (iii) a lipid monolayer at the interface of the core and the shell that acts as a molecular fence to prevent drug leakage, thereby enhancing drug encapsulation efficiency, increasing drug loading yield, and controlling drug release [33]. Moreover, the fluorescein isothiocyanate (FITC) marker integrated inside carrier moieties shows good fluorescein intensity (see Figure 4A,B). However, the intensity of FITC-labeled HPPNCs was observed by fluorescence spectroscopy showing a peak at $520 \mathrm{~nm}$. Similarly, the peak emerged by FITC integrated chitosan-oleic acid moieties. Figure 4C shows that intracellular nanoparticle uptake occurred after post-cell treatment. Hence, FITC-HPPNC was visualized as a green color distributed inside the cytoplasm. Cellular uptake study using FITC-labeled HPPNCs showed that cancer cells readily accumulate the nanoparticles within cells for up to $24 \mathrm{~h}$ post treatment. According to Equation (1), high-resolution mass spectrometry shows good results for the encapsulation of BrPA (see Figure 5) into the NPs. Quantitative calculations provide a loading efficiency of about $0.45 \mathrm{mg} / \mathrm{mL}$ and a percentage of loading of about $45 \%$.
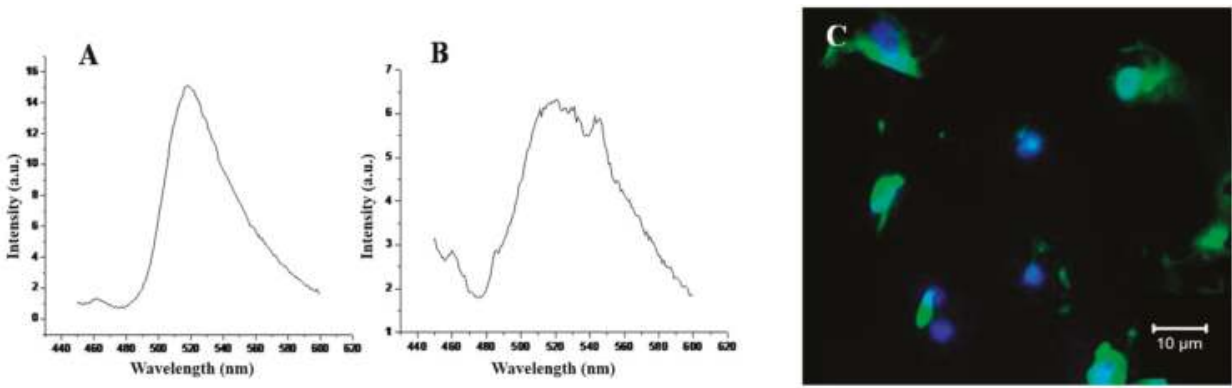

Figure 4. Fluorescence characterization: (A) Chitosan grafted oleic acid; (B) assembled structure of Hybrid Polymeric Lipid Protein Nano-carriers (HPLPNCs); and (C) cellular uptake. 


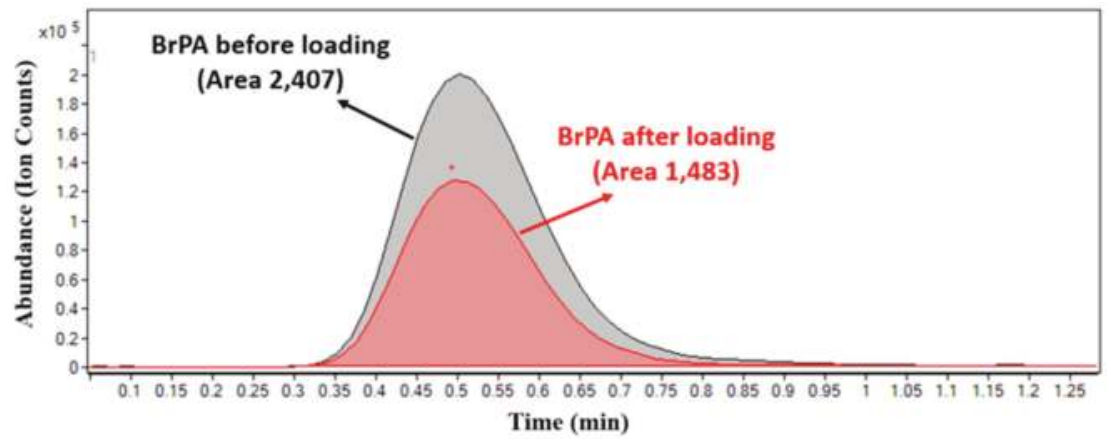

Figure 5. Overlapped high-resolution liquid chromatography coupled to mass spectrometry HPLC-HRMS chromatograms of BrPA before (black) and after (red) loading. The peak area was obtained from the extracted ion chromatogram (EIC) with $m / z 164.9193$ corresponding to the molecular ion $[\mathrm{M}-\mathrm{H}]^{-}$of BrPA. The peak obtained after loading refers to BrPA concentration in the supernatant after centrifugation.

\subsection{Cellular Experiments}

The cellular internalization of hybrid polymeric lipid protein carriers was measured by fluorescence microscopy. Hence, FITC-labeled carriers are successfully localized inside cytoplasm and emitted green color (see Figure 4C). The optical density measurements give an indication of the relative viable cells present at the time the dye is added.

In this study, crystal violet was used to investigate the morphological characterization for all experimental conditions. Ethidium bromide was also used to show hyperchromatism and apoptotic bodies. Crystal violet (CV) is a triphenylmethane dye known as gentian violet, utilized widely to measure cell viability [34] or cell proliferation [35] under different conditions. Crystal violet can enter the cell membrane and reacts with cytoplasmic protein structures, distinguish between cytoskeleton and nuclear morphology. The morphological structure of either HLF cells incubated in normal conditions or that were incubated with free Hybrid Polymeric Lipid Protein Nanocarriers HPLPNCs appeared in well-organized structures with intact nuclei (see Figure 6). Most of the HLF cells incubated with free BrPA or encapsulated BrPA exhibited round and condensed structures with apoptotic morphology.

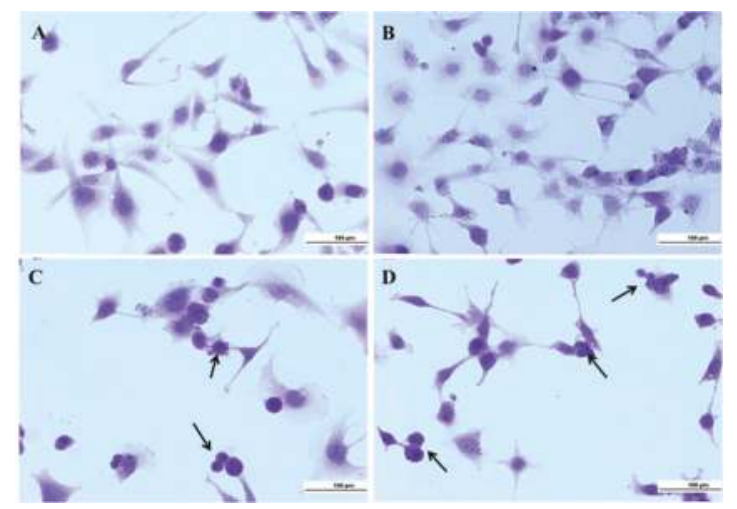

Figure 6. Crystal violet shows morphological characterization: (A) control HLF; (B) free HPLPNCs; (C) free BrPA; and (D) encapsulated BrPA. Arrows indicate apoptotic cells. 
Ethidium bromide, a DNA binding dye, stains those cells that have lost their nuclear membrane integrity [36]. It is commonly used to visualize nuclear membrane disintegration and apoptotic body formations that are characteristic of apoptosis.

In Figure 7 control HLF cells and free HPLPNC showed rounded nucleus with one or more nucleoli. On the other side, hyper chromatic cells were characterized by the condensed yellow color in both free BrPA and encapsulated BrPA groups, in addition to apoptotic bodies, were seen in encapsulated BrPA slides.

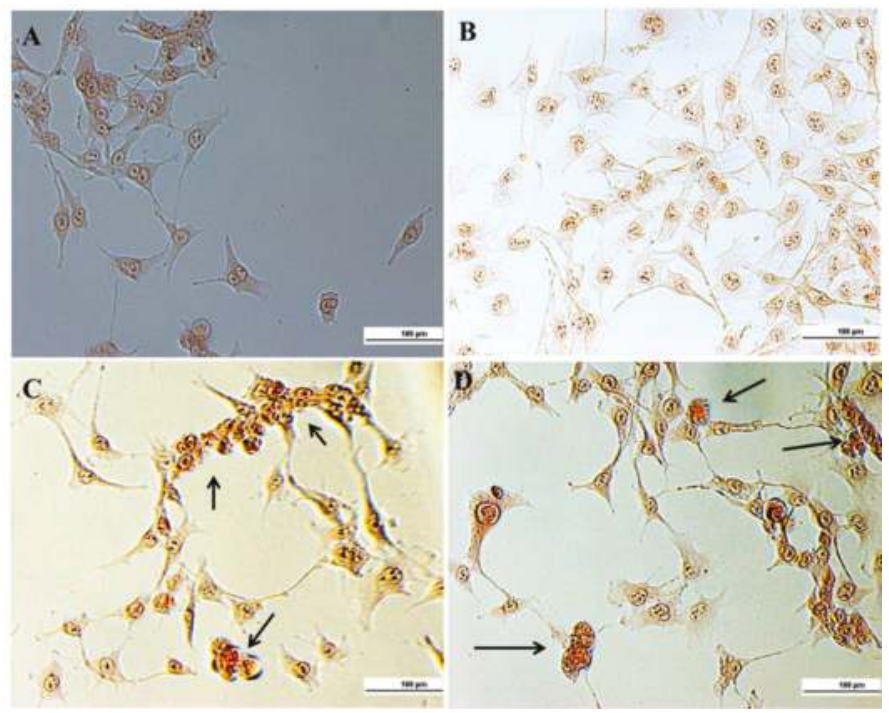

Figure 7. Hyperchromatism and apoptotic bodies: (A) control HLF; (B) free HPLPNCs; (C) free BrPA; and (D) encapsulated BrPA. Arrows indicate apoptotic bodies.

Trypan blue is one of the most commonly used methods for assessment of viability in a given cell population [37,38]. It is used in our study to quantify dead cells by spectrophotometry at $570 \mathrm{~nm}$ [31]. Optical analysis of the cultures revealed an admixture of live (trypan blue negative) and dead (trypan blue positive) in experimental condition. In Figure 8 the cell mortality measured by trypan blue assay was increased in case of free BrPA and also encapsulated BrPA, compared to control HLF cells and cells treated by free HPLPNC (capsules). Furthermore, upon increasing the treatment time (from 3 to 6 to $24 \mathrm{~h}$ ) there is also a clear increase in cell death. In our previous work [25], and in this study, are reported the potential therapeutic effectiveness of targeted nanoparticles against cancer cells since they can allow smart chemotherapeutics to be accumulated in specific tumor sites, in order to minimize the potential side effects of chemotherapies on healthy cells, too. These advantages have received significant attention due to the overexpression of specific receptors, antigens, and molecules on cancer cell membrane. These molecules can be recognized by nanoparticles that were designed by folic acid [25], transferrin [39], short oligonucleotides of RNA or DNA that can fold into various conformations and engage in ligand binding [40], specific antibodies [41], and peptides [42]. 


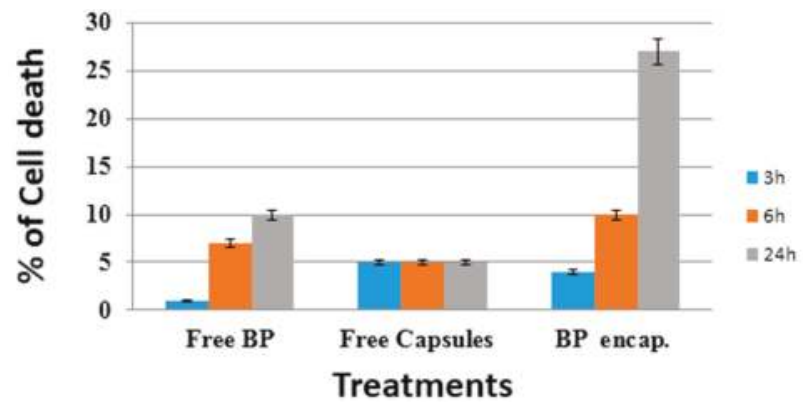

Figure 8. Trypan blue spectrophotometrical viability analysis against HLF cells. Percentage of dead cells upon increasing time (3-6-24 h) after treatment with free HPLPNC, free BrPA and encapsulated $\mathrm{BrPA}$ are reported. Data showed is an averaged value of three successive measurements with standard deviation (S.D.).

\section{Materials and Methods}

\subsection{Chemicals}

Chitosan oligosaccharide (Molecular Weight (MW) 5kDa), oleic acid, and 1-ethyl-3-(3-dimethylaminopropyl) carbodiimide (EDAC), dimethyl sulfoxide (DMSO), bromopyruvate, bovine serum albumin, folic acid, trypan blue, crystal violet, and ethiduim bromide were purchased from Sigma-Aldrich (Milan, Italy).

\subsection{Carrier Fabrication}

Step 1: $1 \mathrm{~mL}$ of oleic acid was dissolved in $10 \mathrm{~mL}$ of ethanol under sonication for $15 \mathrm{~min}$, then heated in water bath at $60{ }^{\circ} \mathrm{C}$ for $2 \mathrm{~h}$ in the presence of EDAC and fluorescence isothiocyanate. Afterwards $0.5 \mathrm{mg}$ chitosan was dissolved in $50 \mathrm{~mL}$ of $1 \%$ acetic acid. Then $5 \mathrm{~mL}$ of oleic acid was mixed with $25 \mathrm{~mL}$ of chitosan under rotation for $15 \mathrm{~min}$.

Step 2: $65 \mathrm{mg}$ of folic acid was dissolved in $2.5 \mathrm{~mL}$ of DMSO for $30 \mathrm{~min}$. Then $30 \mathrm{mg}$ of EDAC and $38 \mathrm{mg}$ of NHS were added, completing rotation for $1 \mathrm{~h}$. Afterwards $4 \mathrm{mg}$ of BSA were dissolved in $50 \mathrm{~mL}$ of distilled water in the presence of EDAC for $30 \mathrm{~min}$. At the end $0.5 \mathrm{~mL}$ of activated FA mixed with $25 \mathrm{~mL}$ of activated BSA under rotation for $30 \mathrm{~min}$.

Step 3: Chitosan integrated oleic acid was coated by BSA conjugated with FA under rotation for $30 \mathrm{~min}$. Then the mixture was centrifuged at $5000 \mathrm{rpm}$ for $30 \mathrm{~min}$ at $20{ }^{\circ} \mathrm{C}$. Afterwards the upper layer was separated and dissolved in $10 \mathrm{~mL}$ Milli Q water and the mixture was dialyzed against milli Q water overnight.

\subsection{Characterization}

\subsubsection{Transmission Electron Microscopy (TEM)}

Samples for TEM analysis were obtained by drop-casting a few microliters of solution onto standard TEM carbon-coated Cu-grids, and by allowing the solvent to fully evaporate. Samples were imaged by using a JEOL JEM 1011 TEM microscope (JEOL, Inc., Peabody, MA, USA) operating at $100 \mathrm{kV}$.

\subsubsection{Fluorescence Spectrophotometry}

The intensity of fluorescence markers was detected by Cary Eclipse fluorescence spectrophotometer (Agilent, Santa Clara, CA, USA). The analysis was performed on the following: chitosan integrated oleic acid-FITC and free hybrid assembly. 


\subsubsection{Zeta Potential Measurements}

The zeta potential surface of carrier fabrication was measured by using a Malvern Nano ZS90 (Malvern Instruments, Malvern, UK). An average of five successful runs was considered for analysis.

\subsubsection{Quantification of BrPA loaded HPLPNCs by Using HPLC-Mass Spectrometry (HPLC-MS)}

Briefly, BrPA solution of known concentration was incubated overnight with HPLPNCs. Then, the supernatant was removed by centrifugation and it was analyzed by high-resolution liquid chromatography coupled to mass spectrometry (HPLC-HRMS). The loading percentage was defined as the residual BrPA moles in solution after loading divided by the moles of BrPA in solution before loading. In particular the encapsulation efficiency (\% loading) was calculated as the relative difference between 3-BrPA concentrations before and after the incubation experiment (see Equation (1)).

$$
\% \text { Loading }=100 \times([\mathrm{BrPA}] \mathrm{i}-[\mathrm{BrPA}] \mathrm{f}) /[\mathrm{BrPA}] \mathrm{i}
$$

[BrPA] i is defined as the initial concentration of BrPA, [BrPA]f is defined as the final concentration of BrPA. HPLC-HRMS experiments were performed with an Agilent 6540 quadruple time-of-flight (QToF) mass spectrometer (Agilent, Santa Clara, CA, USA) equipped with an electrospray ionization (ESI) source and interfaced to an Agilent 1200 modular high-performance liquid chromatograph consisting of a binary pump, a vacuum degasser, a thermostated autosampler, and a thermostated column compartment. The following general conditions were adopted: ESI source operating in negative mode; solvent: $80 \%$ water $\left(0.1 \%\right.$ formic acid) and $20 \%$ acetonitrile; flow rate: $0.2 \mathrm{~mL} \cdot \mathrm{min}^{-1}$; drying gas $\left(\mathrm{N}_{2}\right)$ : $11 \mathrm{~L} \cdot \mathrm{min}^{-1}$; nebulizer pressure: $45 \mathrm{psi}$; drying gas temperature: $350{ }^{\circ} \mathrm{C}$; capillary voltage: $4000 \mathrm{~V}$; fragmentor: $150 \mathrm{~V}$; mass range: $50-1600 \mathrm{~m} / \mathrm{z}$. Mass spectrometry chromatograms were acquired and analyzed using Agilent Mass Hunter Qualitative Analyses version B.01.04 data processing software (Agilent, Santa Clara, CA, USA). A four non-zero point calibration curve was built for BrPA by plotting the concentration of the analytical standard in aqueous solution $(0.1,0.2,0.5$, and $1.0 \mathrm{mg} / \mathrm{mL})$ against and the peak area of the $m / z 164.9193$ corresponding to the extracted ion chromatogram (EIC) of BrPA. The calibration equation was: $y=5 \cdot 106 x+495,851$ with a coefficient of determination $R^{2}=0.9979$.

\subsection{Cellular Experiments}

\subsubsection{Cellular Studies}

HLF cell lines were purchased as described in $[43,44]$ and were maintained in DMEM medium supplemented with FBS (10\%), penicillin (100 U.mL ${ }^{-1}$ culture medium), streptomycin $\left(100 \mathrm{mg} \cdot \mathrm{mL}^{-1}\right.$ culture medium), and glutamine (5\%). Cells were grown in an incubator at $37^{\circ} \mathrm{C}$, under $5 \% \mathrm{CO}_{2}$, and at $95 \%$ relative humidity. Cell lines were serum-starved for $24 \mathrm{~h}$ before any test.

\subsubsection{Cellular Uptake}

HLF Cell lines were seeded on sterilized glass coverslips into petri dishes, with a density of 2000 cells. They were grown under normal condition as previously described. After $24 \mathrm{~h}, 100 \mu \mathrm{L}$ of hybrid assembly were added. Cellular uptake was measured after the next $24 \mathrm{~h}$ incubation by fluorescence microscopy.

\subsubsection{Crystal Violet}

Ten thousand HLF cells were seeded in 24 multi-wells and grown as previously described. After $24 \mathrm{~h}$, cells were added with $100 \mu \mathrm{L}$ of free hybrid lipid nanoparticles, or with free BrPA or with encapsulated BrPA and incubated for additional $24 \mathrm{~h}$. Then, DMEM was discharged and cells were washed three times with phosphate buffered saline PBS ( $\mathrm{pH} 7.2)$. Cells were fixed for 15 min with buffered formalin (3.7\%), extensively washed with PBS ( $\mathrm{pH} 7.3$ ), and finally stained with $0.01 \%$ crystal violet in PBS. After removing excess stain, cells were incubated at PBS (pH 7.3). Optical images 
were captured in the bright field by using a fluorescence microscope (TCS SP5; Leica, Microsystem $\mathrm{GmbH}$, Mannheim, Germany) equipped with a digital camera (Leica, Microsystem GmbH, Mannheim, Germany).

\subsubsection{Ethidium Bromide (EB)}

Cells were washed with $1 \times$ PBS buffer ( $\mathrm{pH} 7.4$ ), fixed with absolute methanol for $10 \mathrm{~min}$, and washed again with $1 \times$ PBS buffer ( $\mathrm{pH} 7.4)$. Cells were stained with $50 \mu \mathrm{L}$ of EB $(100 \mu \mathrm{g} / \mathrm{mL})$ for 10-15 min and then they were immediately washed with PBS and observed under a light microscope.

\subsubsection{Trypan Blue}

According to procedure used by Uliasz and Hewett, 2007 [12], $50 \mathrm{~mL}$ of sterile $0.4 \%$ trypan blue solution (final concentration $0.05 \%$ ) was added to each culture well and the plate placed back into the incubator $\left(37^{\circ} \mathrm{C}\right)$ for $15 \mathrm{~min}$. Then dye-containing media was gently removed by washing $(3 \times 750 \mathrm{~mL})$ with ice-cold phosphate buffered saline (0.01 M PBS). A slow, steady wash prevents loss of injured cells that may originate from mechanical handling. Visual analysis of the cultures showed a mixture of live (trypan blue negative) and dead (trypan blue positive) cells in each experimental condition. Cells were then lysed with $200 \mathrm{~mL}$ of sodium dodecyl sulfate (SDS; $1 \% w / v$ ) and the contents gently fractured taking care not to introduce air bubbles. At the end, $175 \mathrm{~mL}$ of the SDS: trypan blue solution was transferred to a 96-well culture dish and measured spectrophotometrically at $590 \mathrm{~nm}$.

\section{Conclusions}

Chitosan-grafted OA was used as a vehicle to encapsulate BrPA through electrostatic reaction of amino-hydroxyl groups. Hence, the OA layer acts as a molecular fence to prevent drug release. Finally HPLPNCs were fabricated with smart properties, such as nano-sized diameter, spherical shape, control drug release properties, good drug capacity, and dual combination targeting. Crystal violet and ethidium bromide results confirm efficiency of encapsulated BrPA, compared to HPLPNCs alone.

Supplementary Materials: The following are available online at http://www.mdpi.com/2079-4991/8/1/34/s1.

Acknowledgments: This work was supported by the REA research grant no. PITN-GA-2012-316549 (IT-LIVER) from the People Programme (Marie Curie Actions) of the European Union's Seventh Framework Programme (FP7/2007-2013).

Author Contributions: Nemany A. Hanafy designed and performed most of experiments, analyzed the results, generated the figures and tables, and wrote the manuscript; Luciana Dini performed and analyzed the SEM experiments and critically revised the manuscript; Cinzia Citti performed the HPLC-MS experiments and revised the manuscript; Giuseppe Cannazza analyzed HPLC-MS experiments and revised the manuscript; and Stefano Leporatti designed the experiments, supervised the study, discussed the data, and revised the manuscript. All authors read and approved the final manuscript.

Conflicts of Interest: The authors declare no conflict of interest.

\section{References}

1. Chen, Z.; Zhang, H.; Lu, W.; Huang, P. Role of mitochondria-associated hexokinase II in cancer cell death induced by 3-bromopyruvate. Biochim. Biophys. Acta 2009, 1787, 553-560. [CrossRef] [PubMed]

2. Macchioni, L.; Davidescu, M.; Sciaccaluga, M.; Marchetti, C.; Migliorati, G.; Coaccioli, S.; Roberti, R.; Corazzi, L.; Castigli, E. Mitochondrial dysfunction and effect of antiglycolytic bromopyruvic acid in GL15 glioblastoma cells. J. Bioenerg. Biomembr. 2011, 43, 507-518. [CrossRef] [PubMed]

3. Pastorino, J.G.; Hoek, J.B.; Shulga, N. Activation of Glycogen Synthase Kinase $3 \beta$ Disrupts the Binding of Hexokinase II to Mitochondria by Phosphorylating Voltage-Dependent Anion Channel and Potentiates Chemotherapy-Induced Cytotoxicity. Cancer Res. 2005, 65, 10545-10554. [CrossRef] [PubMed]

4. Chen, Z.; Lu, W.; Garcia-Prieto, C.; Huang, P. The Warburg effect and its cancer therapeutic implications. J. Bioenerg. Biomembr. 2007, 39, 267-274. [CrossRef] [PubMed] 
5. Ko, Y.H.; Pedersen, P.L.; Geschwind, J.F. Glucose catabolism in the rabbit VX2 tumor model for liver cancer: Characterization and targeting hexokinase. Cancer Lett. 2001, 173, 83-91. [CrossRef]

6. Sadowska-Bartosz, I.; Soszynski, M.; Ulaszewski, S.; Ko, Y.; Bartosz, G. Transport of 3-bromopyurvate across the human erytherocyte membrane. Cell. Mol. Biol. Lett. 2014, 19, 201-214. [CrossRef] [PubMed]

7. Hanafy, N.A.N.; De Giorgi, M.L.; Nobile, C.; Cascione, M.F.; Rinaldi, R.; Leporatti, S. $\mathrm{CaCO}_{3}$ rods as chitosan-polygalacturonic acid carriers for bromopyruvic acid delivery. Sci. Adv. Mater. 2016, 8, 514-523. [CrossRef]

8. Rinaudo, M. Chitin and chitosan: Properties and applications. Prog. Polym. Sci. 2006, 31, 603-632. [CrossRef]

9. Li, F.; Liu, W.G.; Yao, K.D. Preparation of oxidized glucose-crosslinked $N$-alkylated chitosan membrane and in vitro studies of $\mathrm{pH}$-sensitive drug delivery behavior. Biomaterials 2002, 23, 343-347. [CrossRef]

10. Martin, L.; Wilson, C.G.; Koosha, F.; Tetley, L.; Gray, A.I.; Senel, S.; Uchegbu, I.F. The release of model macromolecules may be controlled by the hydrophobicity of palmitoyl glycol chitosan hydrogels. J. Control. Release 2002, 80, 87-100. [CrossRef]

11. Kim, Y.H.; Gihm, S.H.; Park, C.R.; Lee, K.Y.; Kim, T.W.; Kwon, I.C.; Chung, H.; Jeong, S.Y. Structural characteristics of size-controlled self-aggregates of deoxycholic acid-modified chitosan and their application as a DNA delivery carrier. Bioconjug. Chem. 2001, 12, 932-938. [CrossRef] [PubMed]

12. Wang, M.Z.; Fang, Y.; Hu, D.D. Preparation and properties of chitosan-poly( $N$-isopropylacrylamide) full-IPN hydrogels. React. Funct. Polym. 2001, 48, 215-221. [CrossRef]

13. Chen, X.G.; Lee, C.M.; Park, H.J. O/W emulsification for the selfaggregation and nanoparticle formation of linoleic acid-modified chitosan in the aqueous system. J. Agric. Food Chem. 2003, 51, 3135-3139. [CrossRef] [PubMed]

14. Liu, C.G.; Desai, K.G.H.; Chen, X.G.; Park, H.J. Linolenic acidmodified chitosan for formation of self assembled nanoparticles. J. Agric. Food Chem. 2005, 53, 437-441. [CrossRef] [PubMed]

15. Zhang, C.; Ping, Q.N.; Zhang, H.J.; Shen, J. Preparation of $\mathrm{N}$-alkyl-O-sulfate chitosan derivatives and micellar solubilization of taxol. Carbohydr. Polym. 2003, 54, 137-141. [CrossRef]

16. Wu, Y.; Zheng, Y.L.; Yang, W.L.; Wang, C.C.; Hu, J.H.; Fu, S.K. Synthesis and characterization of a novel amphiphilic chitosan-polylactide graft copolymer. Carbohydr. Polym. 2005, 59, 165-171. [CrossRef]

17. Lee, D.W.; Powers, K.; Baney, R. Physicochemical properties and blood compatibility of acylated chitosan nanoparticles. Carbohydr. Polym. 2004, 58, 371-377. [CrossRef]

18. Xiao, J.B.; Wu, M.X.; Kai, G.Y.; Wang, F.J.; Cao, H.; Yu, X.B. ZnO-ZnS QDs interfacial heterostructure for drug/food delivery application: Enhancement of the binding affinities of flavonoid aglycones to bovine serum albumin. Nanomedicine 2011, 7, 850-858. [CrossRef] [PubMed]

19. Wang, G.; Uludag, H. Recent developments in nanoparticle-based drug delivery and targeting systems with emphasis on protein-based nanoparticles. Expert Opin. Drug Deliv. 2008, 5, 499-515. [CrossRef] [PubMed]

20. Du, C.; Deng, D.; Shan, L.; Wan, S.; Cao, J.; Tian, J.; Achilefu, S.; Gu, Y. A pH-sensitive doxorubicin prodrug based on folate-conjugated BSA for tumor-targeted drug delivery. Biomaterials 2013, 34, 3087-3097. [CrossRef] [PubMed]

21. Gruner, B.A.; Weitman, S.D. The folate receptor as a potential therapeutic anticancer target. Investig. New Drugs 1999, 16, 205-219. [CrossRef]

22. Sabharanjak, S.; Mayor, S. Folate receptor endocytosis and trafficking. Adv. Drug Deliv. Rev. 2004, 56, 1099-1109. [CrossRef] [PubMed]

23. Gandham, S.K.; Talekar, M.; Amit Singh, A.; Amiji, M.M. Inhibition of hexokinase-2 with targeted liposomal 3-bromopyruvate in an ovarian tumor spheroid model of aerobic glycolysis. Int. J. Nanomed. 2015, 10, 4405-4423.

24. Ballarín-González, B.; Dagnaes-Hansen, F.; Fenton, R.A.; Gao, S.; Hein, S.; Dong, M.; Kjems, J.; Howard, K.A. Protection and Systemic Translocation of siRNA Following Oral Administration of Chitosan/siRNA Nanoparticles. Mol. Ther. Nucleic Acids 2013, 5, e76. [CrossRef] [PubMed]

25. Hanafy, N.A.N.; Quarta, A.; Di Corato, R.; Dini, L.; Nobile, C.; Tasco, V.; Carallo, S.; Cascione, M.F.; Malfettone, A.; Soukupova, J.; et al. Hybrid Polymeric-Protein Nano-Carriers (HPPNC) for Targeted Delivery of TGF $\beta$ Inhibitors to Hepatocellular Carcinoma Cells. J. Mater. Sci. Mater. Med. 2017, 28, 120. [CrossRef] [PubMed]

26. Liu, J.; Shimizu, K.; Kondo, R. Anti-androgenic activity of fatty acids. Chem. Biodivers. 2009, 6, 503-512. [CrossRef] [PubMed] 
27. Huang, L.; Cheng, X.; Liu, C.; Xing, K.; Zhang, J.; Sun, G.; Li, X.; Chen, X. Preparation, characterization, and antibacterial activity of oleic acid-grafted chitosan oligosaccharide nanoparticles. Front. Biol. China 2009, 4, 321-327. [CrossRef]

28. Marchetti, J.M.; Errazu, A.F. Esterification of free fatty acids using sulfuric acid as catalyst in the presence of triglycerides. Biomass Bioenergy 2008, 32, 892-895. [CrossRef]

29. Zhang, J.; Chen, X.G.; Huang, L.; Han, J.T.; Zhang, X.F. Self-assembled polymeric nanoparticles based on oleic acid-grafted chitosan oligosaccharide: Biocompatibility, protein adsorption and cellular uptake. J. Mater. Sci. Mater. Med. 2012, 23, 1775-1783. [CrossRef] [PubMed]

30. Janes, K.A.; Fresneau, M.P.; Marazuela, A.; Fabra, A.; Alonso, M.J. Chitosan nanoparticles as delivery systems for doxorubicin. J. Control. Release 2001, 73, 255. [CrossRef]

31. Uliasz, T.F.; Hewe, S.J. A microtiter trypan blue absorbance assay for the quantitative determination of excitotoxic neuronal injury in cell culture. J. Neurosci. Methods 2000, 100, 157-163. [CrossRef]

32. Esquenet, C.; Terech, P.; Boue, F.; Buhler, E. Structural and rheological properties of hydrophobically modified polysaccharide associative networks. Langmuir 2004, 20, 3583-3592. [CrossRef] [PubMed]

33. Chan, J.M.; Zhang, L.; Yuet, K.P.; Liao, G.; Rhee, J.W.; Langer, R.; Farokhzad, O.C. PLGA-lecithin-PEG core-shell nanoparticles for controlled drug delivery. Biomaterials 2009, 30, 1627-1634. [CrossRef] [PubMed]

34. Thomas, M.; Finnegan, C.E.; Rogers, K.M.; Purcell, J.W.; Trimble, A.; Johnston, P.G.; Boland, M.P. STAT1: A modulator of chemotherapy-induced apoptosis. Cancer Res. 2004, 64, 8357-8364. [CrossRef] [PubMed]

35. Zivadinovic, D.; Gametchu, B.; Watson, C.S. Membrane estrogen receptor-alpha levels in MCF-7 breast cancer cells predict cAMP and proliferation responses. Breast Cancer Res 2005, 7, R101-R112. [CrossRef] [PubMed]

36. Shukla, S.; Jadaun, A.; Arora, V.; Sinha, R.K.; Biyani, N.; Jain, V.K. In vitro toxicity assessment of chitosan oligosaccharidecoated iron oxide nanoparticles. Toxicol. Rep. 2015, 2, 27-39. [CrossRef] [PubMed]

37. Pappenheimer, A.J. Experimental studies upon lymphocytes: The reactions of lymphocytes under various experimental conditions. J. Exp. Med. 1917, 25, 25-31. [CrossRef]

38. Patterson, M.K., Jr. Measurement of growth and viability of cells in culture. Methods Enzymol. 1979, 58, 141-152. [PubMed]

39. Sahoo, S.K.; Ma, W.; Labhasetwar, V. Efficacy of transferrin-conjugated paclitaxel-loaded nanoparticles in a murine model of prostate. Int. J. Cancer 2004, 112, 335-340. [CrossRef] [PubMed]

40. Gu, F.X.; Karnik, R.; Wang, A.Z.; Alexis, F.; Levy-Nissenbaum, E.; Hong, S.; Langer, R.S.; Farokhzad, O.C. Targeted nanoparticles for cancer therapy. Nano Today 2007, 2, 14-21. [CrossRef]

41. Weiner, L.M.; Surana, R.; Wang, S. Monoclonal antibodies: Versatile platforms for cancer immunotherapy. Nat. Rev. Immunol. 2010, 10, 317-327. [CrossRef] [PubMed]

42. Pasqualini, R.; Ruoslahti, E. Organ targeting in vivo using phage display peptide libraries. Nature 1996, 380, 364-366. [CrossRef] [PubMed]

43. Giannelli, G.; Bergamini, C.; Fransvea, E.; Marinosci, F.; Quaranta, V.; Antonaci, S. Human hepatocellular carcinoma (HCC) cells require both $\alpha 3 \beta 1$ integrin and matrix metalloproteinases activity for migration and invasion. Lab. Investig. 2001, 81, 613-627. [CrossRef] [PubMed]

44. Hanafy, N.A.; Ferraro, M.M.; Gaballo, A.; Dini, L.; Tasco, V.; Nobile, C.; De Giorgi, M.L.; Carallo, S.; Rinaldi, R.; Leporatti, S. Fabrication and characterization of ALK1fc-loaded fluoro-magnetic nanoparticles for inhibiting TGF $\beta 1$ in hepatocellular carcinoma. RSC Adv. 2016, 6, 48834-48842. [CrossRef]

(C) 2018 by the authors. Licensee MDPI, Basel, Switzerland. This article is an open access article distributed under the terms and conditions of the Creative Commons Attribution (CC BY) license (http:/ / creativecommons.org/licenses/by/4.0/). 
Article

\title{
Interaction of Poly(L-lysine)/Polysaccharide Complex Nanoparticles with Human Vascular Endothelial Cells
}

\author{
Dominik Weber ${ }^{1}$, Bernhard Torger ${ }^{2}$, Karsten Richter ${ }^{3}$, Michelle Nessling ${ }^{3}$, Frank Momburg ${ }^{1}$, \\ Beatrice Woltmann ${ }^{4}$, Martin Müller ${ }^{5,6, *}$ and Reinhard Schwartz-Albiez ${ }^{1}$ \\ 1 Deutsches Krebsforschungszentrum (DKFZ), Clinical Cooperation Unit Applied Tumor Immunology, \\ D-69120 Heidelberg, Germany; weberdominik@hotmail.de (D.W.); f.momburg@dkfz-heidelberg.de (F.M.); \\ r.s-albiez@dkfz-heidelberg.de (R.S.-A.) \\ 2 Institute of Plant and Wood Chemistry, Technische Universität Dresden, D-01737 Tharandt, Germany; \\ bernhard.torger@tu-dresden.de \\ 3 Deutsches Krebsforschungszentrum (DKFZ), Central Unit Electron Microscopy, D-69120 Heidelberg, \\ Germany; k.richter@dkfz.de (K.R.); m.nessling@dkfz-heidelberg.de (M.N.) \\ 4 Institute of Physiological Chemistry, Faculty of Medicine Carl Gustav Carus, Technische Universität \\ Dresden, 01307 Dresden, Germany; beatrice.woltmann@mailbox.tu-dresden.de \\ 5 Department Polyelectrolytes and Dispersions, Leibniz-Institut für Polymerforschung Dresden e.V., \\ Hohe Straße 6, D-01069 Dresden, Germany \\ 6 Department of Chemistry and Food Chemistry, Technische Universität Dresden, D-01062 Dresden, Germany \\ * Correspondence: mamuller@ipfdd.de; Tel.: +49-351-4658-405; Fax: +49-351-4658-284
}

Received: 17 April 2018; Accepted: 15 May 2018; Published: 22 May 2018

\begin{abstract}
Angiogenesis plays an important role in both soft and hard tissue regeneration, which can be modulated by therapeutic drugs. If nanoparticles (NP) are used as vectors for drug delivery, they have to encounter endothelial cells (EC) lining the vascular lumen, if applied intravenously. Herein the interaction of unloaded polyelectrolyte complex nanoparticles (PECNP) composed of cationic poly(L-lysine) (PLL) and various anionic polysaccharides with human vascular endothelial cells (HUVEC) was analyzed. In particular PECNP were tested for their cell adhesive properties, their cellular uptake and intracellular localization considering composition and net charge. PECNP may form a platform for both cell coating and drug delivery. PECNP, composed of PLL in combination with the polysaccharides dextran sulfate (DS), cellulose sulfate (CS) or heparin (HEP), either unlabeled or labeled with fluorescein isothiocyanate (FITC) and either with positive or negative net charge were prepared. PECNP were applied to human umbilical cord vein endothelial cells (HUVEC) in both, the volume phase and immobilized phase at model substrates like tissue culture dishes. The attachment of PECNP to the cell surface, their intracellular uptake, and effects on cell proliferation and growth behavior were determined. Immobilized PECNP reduced attachment of HUVEC, most prominently the systems PLL/HEP and PLL/DS. A small percentage of immobilized PECNP was taken up by cells during adhesion. PECNP in the volume phase showed no effect of the net charge sign and only minor effects of the composition on the binding and uptake of PECNP at HUVEC. PECNP were stored in endosomal vesicles in a cumulative manner without apparent further processing. During mitosis, internalized PECNP were almost equally distributed among the dividing cells. Both, in the volume phase and immobilized at the surface, PECNP composed of PLL/HEP and PLL/DS clearly reduced cell proliferation of HUVEC, however without an apparent cytotoxic effect, while PLL/CS composition showed minor impairment. PECNP have an anti-adhesive effect on HUVEC and are taken up by endothelial cells which may negatively influence the proliferation rate of HUVEC. The negative effects were less obvious with the composition PLL/CS. Since uptake and binding for PLL/HEP was more efficient than for PLL/DS, PECNP of PLL/HEP may be used to deliver growth factors to endothelial cells during vascularization of bone reconstitution material, whereas those of PLL/CS may have an advantage for substituting biomimetic bone scaffold material.
\end{abstract}


Keywords: poly(L-lysine); cellulose sulfate; dextran sulfate; heparin; polyelectrolyte complex nanoparticle (PECNP); vascular endothelial cells; cell attachment; cellular uptake; proliferation

\section{Introduction}

Angiogenesis plays an important role in both soft and hard tissue regeneration, which can be modulated by therapeutic drugs. Dispersed nanoparticles (NP) can be used to deliver drugs, growth factors or genes to distinct tissues, or NP immobilized at given implants or bone substitution materials (BSM) can be used to increase their biophysical stability, biocompatibility, and cell adherence [1]. When incorporated into scaffold matrices they may additionally support their mechanical stability and enhance biocompatibility of the implanted scaffold material [2]. For both modes of application, vascular endothelial cells represent the prime cellular target as they are port of entry for drugs from the blood circulation into tissue and are essential for the vascularization of tissue reconstitution material [3]. When used as soluble carriers for e.g., anti-cancer drugs, nanoparticles coated with distinct protein ligands for specific cell surface receptors can be directed to the respective tumor tissue thereby improving the pharmacokinetics and pharmacodynamics of the respective cytotoxic drug [4,5]. In particular, encapsulation of these drugs in nanoparticles may increase their half-life in the blood circulation and enhance their concentration in the tumor tissue [6,7]. In order to reach tumor cells, nanoparticles have to overwhelm barriers of the tumor microenvironment which are represented, as one of the first steps, by the endothelial layer of blood vessels during the extravasation of the drug delivery system.

A possible strategy to enhance migration and settlement of vascular endothelial cells, thereby initiating neo-angiogenesis, could be to integrate modified nanoparticles into scaffolds. For instance, attempts have been described to stabilize and controllably release the endothelial chemokine VEGF (vascular endothelial growth factor) by binding to polysaccharide-conjugated polyelectrolyte complexes [8].

In order to find an effective nanoparticle vehicle for delivery of growth factors, cytotoxic drugsor adhesion proteins to vascular endothelial cells, several factors such as composition, size, and charge of nanoparticles with regard to their endothelial binding, uptake, and possible cytotoxicity have to be analyzed $[9,10]$. Various nanoparticle systems composed of charged polysaccharides, polypeptides or synthetic polyelectrolytes have been used as drug delivery systems [11-13] and may also support cellular ingrowth into a scaffold material [14-16].

Nanoparticles containing biopolymers such as polysaccharides can support controlled release of drugs and cellular adhesion within scaffold material [17,18]. Heparin based nanoparticles have been shown to improve biocompatibility of nanoparticles in various applications [19].

In our study, we applied polyelectrolyte complex nanoparticles (PECNP), composed of the polycation poly(L-lysine) (PLL) combined with the three anionic polysaccharides dextran sulfate (DS), cellulose sulfate (CS) or heparin (HEP), to human umbilical cord vein endothelial cells in vitro (HUVEC) and investigated their effect on cell binding, uptake, intracellular localization, proliferation, as well as on cellular attachment to surfaces and subsequent migration. We analyzed the influence of the composition, namely the effect of the anionic polysaccharides CS, DS, HEP within PECNP, both in the volume phase and immobilized at a model substrate. As an additional feature we used PECNP with either positive or negative net charge, which can be achieved by mixing polycation and polyanion solutions in defined ratios [11]. The potential of these PECNP with regard to directed sizing (20-500 $\mathrm{nm}$ ), shaping (spheres, rods), and controlled charge of their surfaces has been outlined previously [11].

Adhesive coatings of PECNP were previously investigated for their loading and retarded release of distinct drugs such as bisphosphonates $[12,20]$ and for the effect of their composition on the viability of human mesenchymal stromal cells (hMSC) [21] in the context of bone healing and remodeling. To go further, their interaction to human vascular endothelial cells (HUVEC) is now addressed in the context of angiogenesis during bone healing. 


\section{Materials and Methods}

\subsection{Preparation of Polyelectrolyte Complex Nanoparticles (PECNP)}

Polyelectrolyte complex nanoparticles (PECNP) composed of the polycation poly(L-lysine) (PLL, $\mathrm{M}_{\mathrm{W}}=50,000 \mathrm{~g} / \mathrm{mol}$, (Sigma-Aldrich, Schnelldorf, Germany), in combination with the polyanions cellulose sulfate (CS, degree of substitution $d_{S}=2.8, M_{W}=1,200,000 \mathrm{~g} / \mathrm{mol}$, Janssen, Beerse, Belgium), dextran sulfate (DS, $\mathrm{d}_{\mathrm{S}}=3.0, \mathrm{M}_{\mathrm{W}}=500,000 \mathrm{~g} / \mathrm{mol}$, Carl Roth $\mathrm{GmbH}$, Germany) or heparin (HEP, $\mathrm{M}_{\mathrm{W}}=20,000 \mathrm{~g} / \mathrm{mol}$, Carl Roth $\mathrm{GmbH}$, Karlsruhe, Germany) and the fluorescein isothiocyanate (FITC) labeled PECNP species were prepared as described in detail elsewhere [11,21,22]. Briefly summarized, $2 \mathrm{mM}$ clear solutions of cationic PLL and anionic CS, DS or HEP were mixed at $\mathrm{pH}=7.0$ and more or less turbid (milky) dispersions resulted. According to their molar number of charged repeating units ( $\mathrm{n}+$ : molar number of cationic repeating units; $\mathrm{n}-$ : molar number of anionic repeating units) two molar mixing ratios denoted $n-/ n+$ were applied, which were $n-/ n+=0.9$ and $n-/ n+=1.1$. These two molar mixing ratios resulted in PECNP, which had a slightly positive net charge (PECNP-0.9, $\mathrm{n}-/ \mathrm{n}+=0.9$, cationic excess) or slightly negative net charge (PECNP-1.1, $\mathrm{n}-/ \mathrm{n}+=1.1$, anionic excess), which was proven by zeta-potential measurements (see below). Furthermore, sizes i.e., hydrodynamic radii $R_{H}$ of these PECNP were determined by dynamic light scattering (see below). The particle sizes of the herein used PECNP can be found in the Table 1.

Table 1. Hydrodynamic radius $\left(\mathrm{R}_{\mathrm{H}}\right)$, zeta-potential at $\mathrm{pH}=7.4$, PLL conformation and morphology (dry spin coated state at poly(styrene) (PS) film) of the PECNP samples used in this work. Numbers of individual measurements are given in brackets. The data have been partly already given in [21], whereby slight deviations within the error range might prevail.

\begin{tabular}{ccccc}
\hline PECNP Sample & $\mathbf{R}_{\mathbf{H}} / \mathbf{n m}$ & Zeta-Potential/mV & PLL Conformation & Morphology \\
\hline PLL/CS-0.9 & $106 \pm 7(\# 9)$ & $+45+5 \mathrm{mV}$ & $\alpha$-helical & granular, spherical \\
PLL/DS-0.9 & $69 \pm 12(\# 14)$ & $+45+5 \mathrm{mV}$ & $\alpha$-helical & - \\
PLL/HEP-0.9 & $62 \pm 8(\# 3)$ & - & $\alpha$-helical & - \\
PLL/CS-1.1 & $101 \pm 10(\# 13)$ & $-43+5 \mathrm{mV}$ & $\alpha$-helical & granular, spherical \\
PLL/DS-1.1 & $88 \pm 17(\# 8)$ & $-44+5 \mathrm{mV}$ & $\alpha$-helical & granular, spherical \\
PLL/HEP-1.1 & $67 \pm 7(\# 6)$ & - & $\alpha$-helical & granular, spherical \\
\hline
\end{tabular}

\subsection{Dynamic Light Scattering (DLS)}

Hydrodynamic radii $\left(\mathrm{R}_{\mathrm{H}}\right)$ of PECNP were determined by DLS using Jianke Portable Particle Sizer (Jianke Instruments Co. Ltd., Wuhu, China). A scattering angle of $89.3^{\circ}$ was applied. Two mL of PECNP dispersions were filled in cuvettes with a circular bottom $(\mathrm{D}=10 \mathrm{~mm})$. The autocorrelation function was recorded for $180 \mathrm{~s}$ and $\mathrm{R}_{\mathrm{H}}$ values were calculated from values of the translational diffusion coefficient $\mathrm{D}$ using the Stokes-Einstein equation $\mathrm{R}_{\mathrm{H}}=\mathrm{k}_{\mathrm{B}} \mathrm{T} /\left(\mathrm{D} 6 \pi \eta\right.$ ) (Boltzmann constant $\mathrm{k}_{\mathrm{B}}$; temperature $\mathrm{T}=298 \mathrm{~K}$; and viscosity $\eta$ ). The ALV-5000/E/EPP-Software (ALV GmbH, Langen, Germany) was used for the computation of DLS parameters applying the "Simple Fit" tool. Intensity weighted size distributions were computed and plotted. Error values of $R_{H}$ given in Table 1 were related to the standard deviation of (3-14) individual but equally prepared PECNP samples.

\subsection{Zeta-Potential}

The Zeta-potential measurements on PECNP dispersions in order to determine the net charge of PECNP were performed at neutral $\mathrm{pH}$ values $(\mathrm{pH}=7.4)$ using a Zetasizer 3000 (Malvern Instruments Ltd., Worchestershire, UK).

\subsection{Cells}

HUVEC (human umbilical cord vein endothelial cells, PromoCell, Heidelberg, Germany) were cultivated in endothelial cell basal media full medium (ECBM-FM; PromoCell) consisting of endothelial 
cell basal media supplemented with 10\% fetal bovine serum (FBS) and endothelial cell growth medium supplement (PromoCell). Cells were cultured at $37^{\circ} \mathrm{C}, 5 \% \mathrm{CO}_{2}$ atmosphere and $95 \%$ relative humidity. HUVEC were split before reaching confluence and were used up to cell culture passage 6 for functional assays. HUVEC were detached using the Detach Kit (PromoCell) according to the manufacturers' protocol. In detail, cells were washed with HEPES (4-(2-hydroxyethyl)-1-piperazineethanesulfonic acid) and subsequently with trypsin/EDTA (Ethylenediaminetetraacetic acid) for a few seconds. Cells were then detached by applying fresh trypsin/EDTA to the cells. As soon as cells started to detach the cell culture flask was gently tapped to detach the remaining adherent cells. The enzymatic reaction was stopped using trypsin neutralizing solution (PromoCell). All cells were cultured under sterile conditions at $37^{\circ} \mathrm{C}, 5 \%$ $\mathrm{CO}_{2}$ atmosphere, and $95 \%$ relative humidity. Fresh media exchanges were performed twice a week.

\subsection{Growth Pattern of HUVEC on PECNP}

PECNP (100 $\mu \mathrm{L} / \mathrm{cm}^{2}$ of a $2 \mathrm{mM}$ PECNP dispersion) were immobilized on the bottom of an 8-well- $\mu$-slide, ibiTreat (Ibidi, Martinsried, Germany) on a waving platform shaker under sterile conditions overnight at room temperature. HUVEC $\left(4 \times 10^{4}\right.$ cells in $300 \mu \mathrm{L}$ basal ECBM medium $)$ were seeded into the wells and photographic microscopy images were acquired after 0,10 , and $20 \mathrm{~h}$ of incubation using a ZEISS cell observer. (Carl Zeiss, Oberkochen, Germany).

\subsection{Cellular Uptake of Immobilized PECNP (Light Microscopy)}

Fluorescein isothiocyanate (FITC)-labeled PECNP $\left(52.6 \mu \mathrm{L} / \mathrm{cm}^{2}\right.$ of a $2 \mathrm{mM}$ dispersion) were immobilized under motion on a 24-well plate overnight. Then, wells were washed with phosphate buffered saline (PBS), $4 \times 10^{4}$ HUVEC were seeded on the PECNP layer in $1 \mathrm{~mL}$ basal ECBM and incubated at $37{ }^{\circ} \mathrm{C}$ and $5 \% \mathrm{CO}_{2}$ and $95 \%$ relative humidity for $24 \mathrm{~h}$. The media were then replaced with fresh basal ECBM and cells were incubated for another $24 \mathrm{~h}$. For further analysis, cells were detached and transferred to an 8-well- $\mu$-slide-ibiTreat. After $24 \mathrm{~h}$ of incubation in ECBM-FM, cells were fixed as indicated below.

For fluorescence microscopic analysis of the cellular uptake of dispersed PECNP, $2.3 \times 10^{4}$ cells were seeded on an 8-well $\mu$-slide-ibiTreat and FITC-labeled PECNP were added to the attached cells for $1 \mathrm{~h}$, $4 \mathrm{~h}$, and $24 \mathrm{~h}$ after exchange of culture media to ECBM. The uptake of PECNP was stopped by washing the cells with $\mathrm{Ca}^{2+} / \mathrm{Mg}^{2+}$-containing PBS followed by fixation with $4 \%$ paraformaldehyde (PFA) in PBS $(v / v)$ for $10 \mathrm{~min}$ at room temperature. After 3 washing steps in PBS, 4 drops of iTFx Signal Enhancer (Thermo Fisher, Dreieich, Germany) were applied for $30 \mathrm{~min}$ to block unspecific binding. HUVEC were then incubated with biotinylated anti-CD31 mouse mAb (PECAM-1, platelet/endothelial cell adhesion molecule 1; Becton\&Dickenson (B\&D), Heidelberg, Germany) for $30 \mathrm{~min}$ followed by a Cy3-coupled streptavidin antibody (Dianova, Hamburg, Germany) for $30 \mathrm{~min}$. Cell nuclei were stained with Hoechst 33342 (Biotium, Fremont, CA, USA) for 10 min. For preservation, fluorescent mounting media (Dako, Hamburg, Germany) was added to the cells. Cells were analyzed using a widefield microscope (Zeiss Cell Observer Z1; Carl Zeiss, Oberkochen, Germany) and a confocal microscope (Leica TCS SP5 II, Wetzlar, Germany).

\subsection{Analysis of Cellular Interactions with PECNP (Transmission Electron Microscopy, TEM)}

ACLAR film slides (Redding, CA, USA) were placed in 24-well plates and $1 \times 10^{5} \mathrm{HUVEC}$ were seeded on top in $1 \mathrm{~mL}$ media and incubated for $24 \mathrm{~h}$ at $37^{\circ} \mathrm{C}, 5 \% \mathrm{CO}_{2}$, and $95 \%$ relative humidity. A volume of $25 \mu \mathrm{L}$ of a $2 \mathrm{mM}$ PECNP dispersion was added to the media (final dilution 1:40) for $4 \mathrm{~h}$. Incubation was stopped by the addition of a primary fixative ( $4 \%$ formaldehyde, $2 \%$ glutaraldehyde and $1 \mathrm{mM} \mathrm{MgCl}$, in $100 \mathrm{mM}$ sodium phosphate buffer at $\mathrm{pH}$ 7.2). Following two post-fixations steps, buffered $\mathrm{OsO}_{4}(1 \%)$ and ethanolic uranyl acetate $(0.5 \%)$, respectively, samples were flat-embedded in epoxy resin (Serva, Heidelberg, Germany) for ultrathin sectioning. Sections were post-stained with uranyl and lead and investigated by TEM (EM912, Carl Zeiss, Oberkochen, Germany). 


\subsection{Analysis of Cellular Interactions with Fluorescent PECNP (Flow Cytometry)}

Detached HUVEC were incubated with PE-conjugated mouse antibodies against CD31 on ice for $30 \mathrm{~min}$ in the dark. For setting parameters of live-dead discrimination, HUVECs were incubated in parallel with $4 \%$ PFA in another reaction tube. After two washing steps, cells were resuspended in $100 \mu \mathrm{L}$ of basal culture medium (i.e., ECBM) containing FITC-labeled PECNP (1:40 dilution of a $2 \mathrm{mM}$ stock suspension) and incubated for $1 \mathrm{~h}$. After careful washing, cells were resuspended in a 1:15 dilution of BD-via probe ${ }^{\mathrm{TM}}$ (B\&D, Heidelberg, Germany) for exclusion of dead cells. Flow cytometric analysis was performed using a BD FACS Canto ${ }^{\mathrm{TM}}$ II (BD Biosciences, San Jose, CA, USA), analyzing 50.000 cells/sample, and data were analyzed by the FlowJo ${ }^{\text {TM }}$ software (Version 10, Ashland, OR, USA). Background values for PE- and FITC-fluorescence were calculated using unstained cells. In order to analyze PECNP internalization, cells incubated with FITC-labeled PECNP were analyzed for their fluorescence signal intensity. Then, trypan blue was added to the samples and the signal intensity was re-analyzed resulting only in the excitation of the internalized PECNP as the signal of PECNP on the surface was quenched [23]. For analysis of uptake kinetic, HUVEC were incubated with FITC-labeled PECNP for 5, 30, 60, or $120 \mathrm{~min}$. HUVECs were first analyzed for the total amount of cell-associated FITC-label (PECNP signal). Then, $120 \mu \mathrm{L}$ of a $0.4 \mathrm{mg} / \mathrm{mL}$ solution of trypan blue was added to the cells and samples were immediately measured again. Unlabeled HUVEC were used as negative control (threshold value for FITC-signal). Each measurement was performed for 10,000 cells.

\subsection{Analysis of Cell Proliferation ([ $\left.{ }^{3} H\right]$-Thymidine Incorporation Assay)}

PECNP in several concentrations $\left(2.5,5,10,50 \mu \mathrm{L} / \mathrm{cm}^{2}\right.$ of a $2 \mathrm{mM}$ PECNP stock dispersion, diluted in sterile water) were immobilized on a 96-well tissue culture plate. For this, PECNP were applied to the bottom of the wells of a tissue culture plate under sterile conditions, and incubated overnight under motion on a waving platform shaker at room temperature. HUVEC were seeded in triplicates in media without heparin (Promocell culture media supplement DM2, PromoCell, Heidelberg, Germany) on PECNP-coated 96-well plates at a cell density of $3.5 \times 10^{3}$ cells/well. Cells were allowed to adhere for $2-4 \mathrm{~h}$ and then $1 \mu \mathrm{Ci}\left[{ }^{3} \mathrm{H}\right]$-thymidine/well was applied. For analyzing the influence of dispersed PECNP on proliferation, HUVEC were seeded into 96 -well plates, incubated at $37{ }^{\circ} \mathrm{C}$ and $5 \% \mathrm{CO}_{2}$ and $95 \%$ relative humidity for $1 \mathrm{~h}$ and $10 \mu \mathrm{L}$ of PECNP solution in the concentrations as indicated above was added to the culture media. Then, $1 \mu \mathrm{Ci}\left[{ }^{3} \mathrm{H}\right]$-thymidine was added to the media. All tissue culture plates were incubated under cell culture condition for 24-26 h. The incubation was stopped as cells were detached and frozen. For this, the cell media was carefully removed and $200 \mu \mathrm{L}$ of a solution of trypsin-EDTA (Detach kit, PromoCell) was applied to the well. The plates were incubated at $37^{\circ} \mathrm{C}$ for $5-10 \mathrm{~min}$ and the cells were subsequently frozen at $-20^{\circ} \mathrm{C}$. An additional thawing-freezing step was applied and the cell debris (including the cellular DNA) was transferred to a printed filter mat A (PerkinElmer, Waltham, MA, USA) using a TomTec harvester (TomTec, Hamden, CT, USA). The dried filters were transferred to a sample bag (PerkinElmer) and the $\left[{ }^{3} \mathrm{H}\right]$-thymidine incorporated into DNA was measured using a Betaplate scintillator and a MicroBeta TriLux scintillator counter (both PerkinElmer).

\section{Results and Discussion}

We analyzed the influence of composition and net charge of biorelated polyelectrolyte complex nanoparticles (PECNP) on human umbilical cord vein endothelial cells (HUVEC) with regard to their effect on cell adhesion, uptake, and cytotoxicity. Biorelated cationic poly(L-lysine) (PLL) was combined with the three biorelated anionic polysaccharides cellulose sulfate (CS), dextran sulfate (DS), and heparin (HEP) resulting in the PECNP of PLL/CS, PLL/DS, and PLL/HEP. The interaction to HUVEC was studied for PECNP in the volume phase as well as bound at model substrates such as tissue culture plates. In the following, first colloidal properties of the used PECNP systems are introduced (Section 3.1), second, results on the interfacial interaction between HUVEC and immobilized PECNP coatings (Section 3.2), and third 
interaction between HUVEC and PECNP in the volume phase (Section 3.3) are shown. Finally, proliferation of HUVEC in contact to PECNP in both states will be screened (Section 3.4).

\subsection{Colloidal Properties of PECNP}

Six PECNP systems composed of PLL/CS, PLL/DS, and PLL/HEP with positive and negative net charge, indicated as PLL/polysaccharide- $0.9(n-/ n+=0.9)$ or PLL/polysaccharide- $1.1(n-/ n+=1.1)$, respectively, were prepared. Their colloidal parameters hydrodynamic radius $\left(\mathrm{R}_{\mathrm{H}}\right)$, from dynamic light scattering (DLS) measurements, as well as net charge from zeta-potential measurements are summarized in Table 1.

Generally, the $\mathrm{R}_{\mathrm{H}}$ values (sizes) of all PECNP ranged between 62-106 nm, where PECNP of PLL/CS (101-106 nm) were considerably larger, and those of PLL/DS (69-88 nm) and PLL/HEP (62-67 nm) smaller. However, given the obvious molecular weight $\left(\mathrm{M}_{\mathrm{W}}\right)$ differences of the polyanions (see Materials and Methods section) no correlation between $\mathrm{M}_{W}(\mathrm{CS}>\mathrm{DS}>\mathrm{HEP})$ and PECNP size (CS > DS > HEP) should be drawn within the given error range. Hence for all compositions HUVEC should encounter PECNP with diameters $\mathrm{D}_{\mathrm{H}}=2 \mathrm{R}_{\mathrm{H}}$ between $\approx 120-210 \mathrm{~nm}$. Expectedly, PECNP with slight excess of polycation $(\mathrm{n}-/ \mathrm{n}+=0.9$, PEC-0.9) featured positive, while those with slight excess of polyanion $(\mathrm{n}-/ \mathrm{n}+=1.1$, PEC-1.1) featured anionic net charge at $\mathrm{pH}=7.4$, which was detected by zeta-potential measurements. The extended zeta-potential courses versus $\mathrm{pH}$ are given in the Supplementary Material (SM, Figure SM1a-d) for PLL/CS and PLL/DS (data on PLL/HEP not shown). Obviously, for all compositions the cationic PECNP $(\mathrm{n}-/ \mathrm{n}+=0.9)$ showed a drop of positive zeta-potential beginning at around $\mathrm{pH}=9$, which is due to the deprotonation of PLL primary amino groups having isoelectrical point IEP $\approx 9.5$. Whereas, anionic PECNP $(\mathrm{n}-/ \mathrm{n}+=1.1)$ kept their negative zeta-potential for the whole $\mathrm{pH}$ range at values in the range -50 to $-40 \mathrm{mV}$.

Furthermore, the conformation state of PLL within PECNP was studied both in the volume phase by circular dichroism (CD) spectroscopy and bound to polystyrene (PS) films relevant for the cell culture experiments by attenuated total reflection Fourier transform infrared (ATR-FTIR) spectroscopy. In Figure SM2 CD spectra on 0.002 M dispersions of PLL/CS-1.1, PLL/DS-1.1 and PLL/HEP-1.1 are given, which all show a doublet at 208/225 nm with negative intensity as well as a positive signal at $195 \mathrm{~nm}$, both diagnostic for the $\alpha$-helical secondary structure (similar data for PLL/CS-0.9, PLL/DS-0.9, and PLL/HEP-0.9 is not shown). Additionally, in the Figure SM3 ATR-FTIR spectra on respective PECNP samples bound to PS films show Amide I and Amide II maxima at 1653 and $1546 \mathrm{~cm}^{-1}$, which are also diagnostic for the $\alpha$-helical secondary structure of PLL (similar data for PLL/DS-0.9 and PLL/HEP-0.9 is not shown). The PLL conformation state for all six PECNP samples is included in the Table 1.

Finally, scanning force microscopy (SFM) images of spin-coated PECNP at poly(styrene) (PS) films after rinsing in HEPES buffer given in the Figure SM4 of the SM show dense coverage and granular morphology of merged and single PECNP, which is summarized in the Table 1. Interestingly, for PLL/CS-0.9 (Figure SM4a) the presence of both microparticles and nanoparticles can be identified, where the microparticle seems to be composed of nanoparticles ("blackberry model") as was also claimed for complexes between synthetic polyelectrolytes earlier [24].

Conclusively, all three PECNP compositions PLL/CS, PLL/DS, and PLL/HEP for both positive $(\mathrm{n}-/ \mathrm{n}+=0.9)$ and negative $(\mathrm{n}-/ \mathrm{n}+=1.1)$ net charge did not show substantial differences in their colloidal behavior with respect to size and net charge magnitude and also on the secondary structure as well as morphology level there were no significant differences. Hence in the following in-vitro experiments on the PECNP interaction with HUVEC, argumentation on a chemical level should be justified.

\subsection{Cell Growth on Immobilized PECNP Coatings}

In order to see what impact these PECNP in immobilized state have on the growth behavior of HUVECs, surfaces of various cell culture dishes and microscopic slides were coated with PECNP, modified by CS, DS, and HEP. Additionally, for fluorescence microscopy and flow cytometric analysis also PECNP labeled with FITC were applied. Light microscopy of immobilized PECNP on slides 
revealed, that even under constant motion during coating, PECNP did not spread and attach homogeneously on the bottom of 8-well ibiTreat slides, coated with $100 \mu \mathrm{L} / \mathrm{cm}^{2}$ of a $0.4 \mathrm{mM}$ dispersion of the respective PECNP, which can be obtained from Figure 1A and 1B. HUVEC seemed to avoid areas coated with high concentrations of PECNP. This was also demonstrated by coating the slides with a higher concentration of PECNP $\left(100 \mu \mathrm{L} / \mathrm{cm}^{2}\right.$ of a $2 \mathrm{mM}$ dispersion). Cell attachment in areas with high concentration of PECNP (ring-shaped areas) was less dense as compared to those with lower concentration of PECNP, which is shown in kinetics of cell growth on these slides (Figure 1C). This effect was most prominent for PECNP composed of PLL/HEP and PLL/DS (Figure 1C, black dashed line), which grew in a web-shaped manner. As compared to control cultures without PECNP-coating, cells grew in a looser, reticular pattern on PLL/CS PECNP (Figure 1C, dashed red line).

A

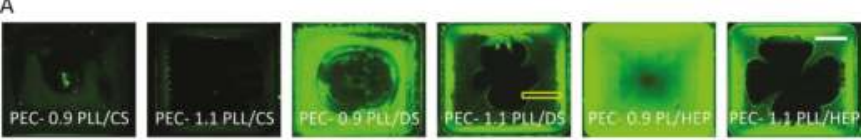

B

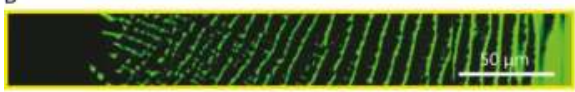

C

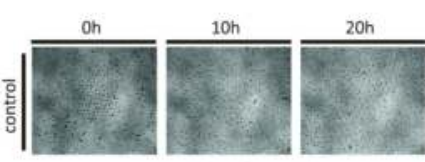

PEC- 0.9 PLL (cationic)

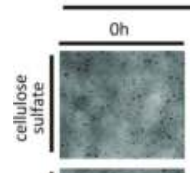

$10 \mathrm{~h}-1-20 \mathrm{~h}$

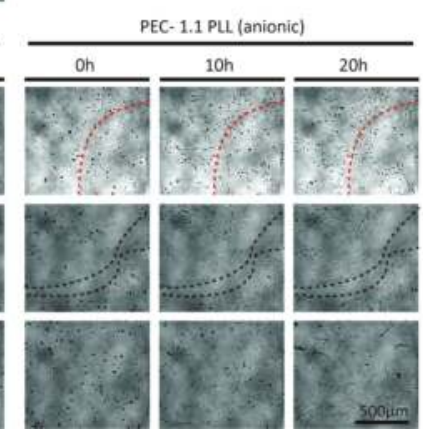

Figure 1. Influence of immobilized polyelectrolyte complex nanoparticles (PECNP) on human umbilical cord vein endothelial cells (HUVEC) seeding. Microscopic images of PECNP distribution on various areas of slide surface (scale bar: $250 \mu \mathrm{m}$ ). Cationic (0.9) or anionic (1.1) PECNP composed of poly(L-lysine) (PLL) and either cellulose sulfate (CS), dextran sulfate (DS) or heparin (HEP) were used. (A) PECNP in some cases attached to the surface during the drying process in ring-shaped patterns which entailed areas of high and low PECNP concentration (Scale bar: $250 \mu \mathrm{m}$ ); (B) Magnification of PEC-1.1 PLL/DS from A -ring-shaped pattern of dried PECNP; (C) PECNP immobilized on Ibidi-slides at high concentrations $\left(100 \mu \mathrm{L} / \mathrm{cm}^{2}\right.$ of a $2 \mathrm{mM}$ PECNP dispersion). PECNP distributed inhomogeneously on the surface of the 8 -well $\mu$-slide-ibiTreat slides during the drying process. HUVEC cells $\left(4 \times 10^{4}\right.$ cells) were seeded onto the slides and photos were taken at times indicated. Depending on the modification and concentration of PECNP applied, alterations in cell growth and adhesion patterns were observed. Cells avoided areas with higher concentrations of PECNP as outlined by black dashed lines. This effect was most prominent for PECNP composed of PLL/DS-1.1 and of PLL/HEP-0.9. Cells grew in a looser, web-shaped pattern on PECNP of PLL/CS. High concentrations of PLL/CS (red dashed line) had less effect than PLL/DS or PLL/HEP PECNP. 


\subsection{Cell Growth on Dispersed PECNP in the Volume Phase}

\subsubsection{Cell Surface Attachment of PECNP}

The next issues to be studied were whether and to what extent PECNP in the volume phase attach to the cell surface and are further taken up by HUVECs. The attachment process was quantified by flow cytometric analysis using fluorescein isothiocyanate (FITC)-labeled PECNP in dispersion. For measuring cell surface attachment, HUVEC were incubated with FITC-labeled PECNP on ice for $1 \mathrm{~h}$ and the amount of PECNP on the cell surface of live cells was estimated (Figure 2). Apparently, cell surface attachment of PECNP of PLL/HEP, regardless of net charge was slightly better than that of PLL/CS and PLL/DS. An obvious reason for this may be that heparin is an endogenous molecule of mammalian physiology and that heparin may interfere with surface receptors on HUVEC like VEGF-R2 or the hyaluronic acid receptor for endocytosis (HARE) [25]. Thus the charge of interfering particles with, as a rule, slightly negatively charged cell surfaces is less decisive than functional interaction with a specific cell surface receptor for binding efficacy.

A

B

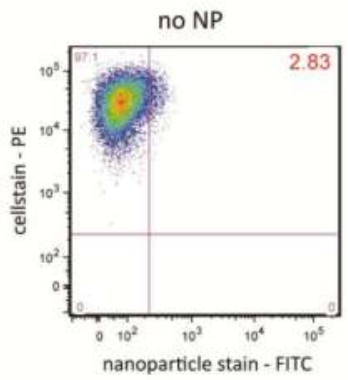

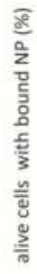

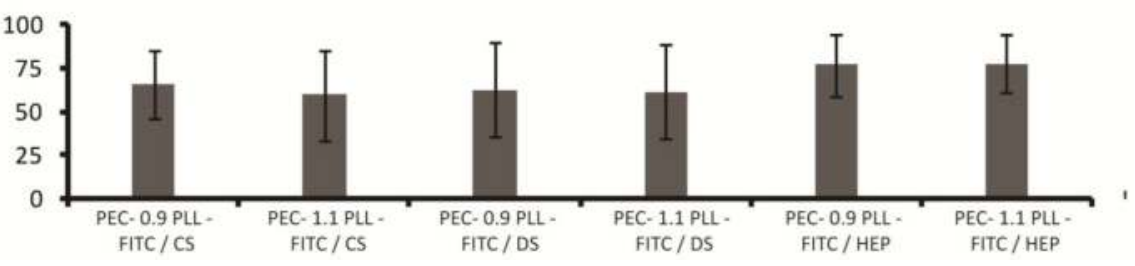

Figure 2. Interaction of polyelectrolyte complex nanoparticles (PECNP) with the cell surface of human umbilical cord vein endothelial cells (HUVEC). HUVEC were incubated on ice for $1 \mathrm{~h}$ with fluorescein isothiocyanate (FITC)-labeled PECNP, cells were stained with an anti-CD31 monoclonal antibody conjugated to PE and subjected to flow cytometric analysis. (A) Cells were live-gated by VIA-probe and gated according to CD31-PE surface staining ( $y$-axis) and FITC staining ( $x$-axis). As negative control, cells without FITC-labeled PECNP were taken and gates set accordingly. Cells with bound FITC-labeled PECNP were counted in comparison to negative control (percentage of positive cells given for each analysis, right upper quadrant); (B) Percentage of cells with surface-bound PECNP compared to control without PECNP set as $100 \%$, mean \pm SD, number of experiments: $n=4$. CS = cellulose sulfate, DS = dextran sulfate, HEP = heparin-containing PECNP.

\subsubsection{Cellular Uptake of PECNP}

In a next step, the uptake of PECNP was measured in comparison to cell surface attachment in a kinetic experiment (Figure 3). In this experiment, PECNP composed of PLL/CS were picked out and incubated for up to $120 \mathrm{~min}$ with HUVECs under cell culture conditions. The cell surface attachment was distinguished from uptake by quenching the FITC signal on the cell surface by trypan blue. 
A
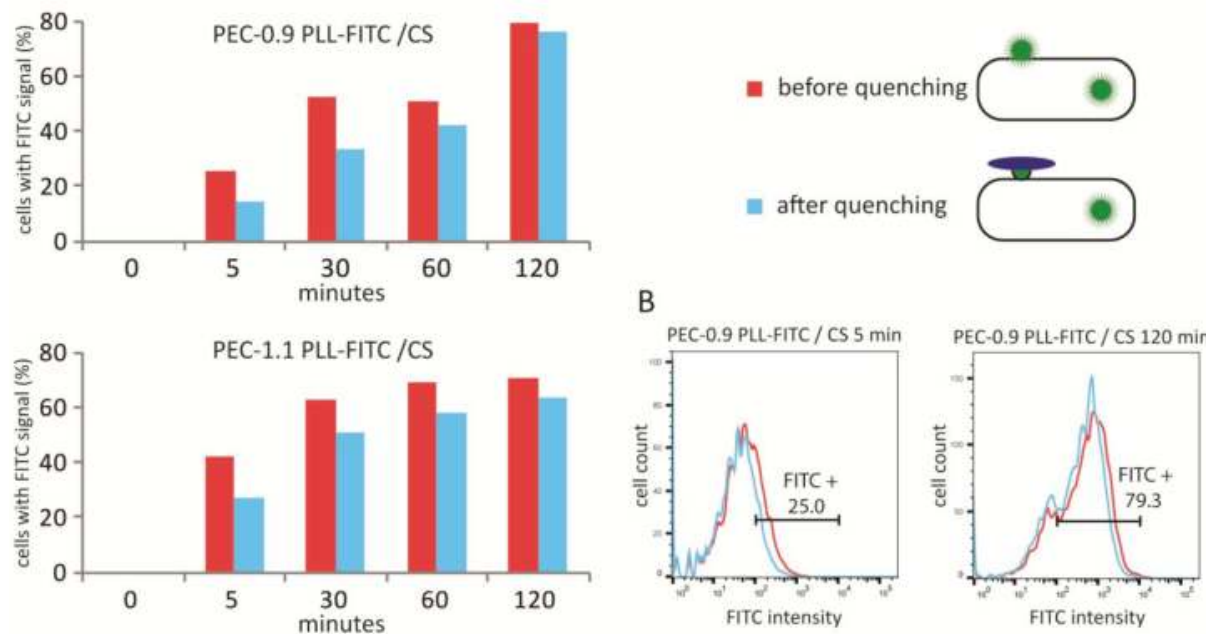

Figure 3. Analysis of polyelectrolyte complex nanoparticles (PECNP) internalization into human umbilical cord vein endothelial cells (HUVEC). FITC-labeled PECNP were incubated with HUVEC for 5 to $120 \mathrm{~min}$, HUVEC were detached and immediately prepared for flow cytometric analysis. Cells were live-gated (VIA-probe) and further gated according to their scatter signals (forward (FSC) vs. sideward scatter signal (SSC)). Cells without PECNP incubation were taken as controls to set the background threshold for PECNP-FITC interaction. Cells were measured and the percentage of cells with bound PECNP in relation to the controls was determined (red bars in (A) histograms, red lines in (B) flow cytometric diagrams). By the addition of trypan blue, the cell surface attached FITC signal was quenched and flow cytometric analysis was repeated, measuring only the FITC signal within the cells (blue bars in (A), blue lines in (B) and as exemplified in the upper right scheme).

Uptake of PECNP for all three combinations PLL/CS, PLL/DS and PLL/HEP was also observed in confocal microscopy using both PECNP in the volume phase and immobilized on a model substrate (Figure 4). In a time range of $1 \mathrm{~h}$ to $24 \mathrm{~h}$ it became apparent, that for all compositions and net charges PECNP were taken up by HUVEC. However, the composition influenced the uptake rate of soluble PECNP. PECNP of PLL/HEP were taken up very early and fast, leading to big clusters already after $1 \mathrm{~h}$ incubation. This result was in accordance with our observations shown in Figure 2, where PLL/HEP attached on live cells already after $1 \mathrm{~h}$ of incubation. Remarkably, after $24 \mathrm{~h}$ of incubation the fluorescence signal of internalized PECNP of PLL/HEP faded in contrast to that of PLL/DS and PLL/DS, which may be due to degradation of the PLL/HEP PECNP by endogenous heparinases of endothelial cells [26] while PLL/CS and PLL/DS PECNP may be non-digestible by endothelial cells. After $24 \mathrm{~h}$ incubation, the PECNP signal strength, regardless of net charge and composition, was concentrated to the largest extent in the perinuclear area of the cells. The PECNP were exclusively situated in this endo-lysosomal compartment but none in the cytosol or in the nucleus which was reported for charged polystyrene based nanoparticles [27]. Also, surface-immobilized PECNP were taken up by the cells though to a much smaller extent than of soluble PECNP and within a longer time frame (Figure 4). 


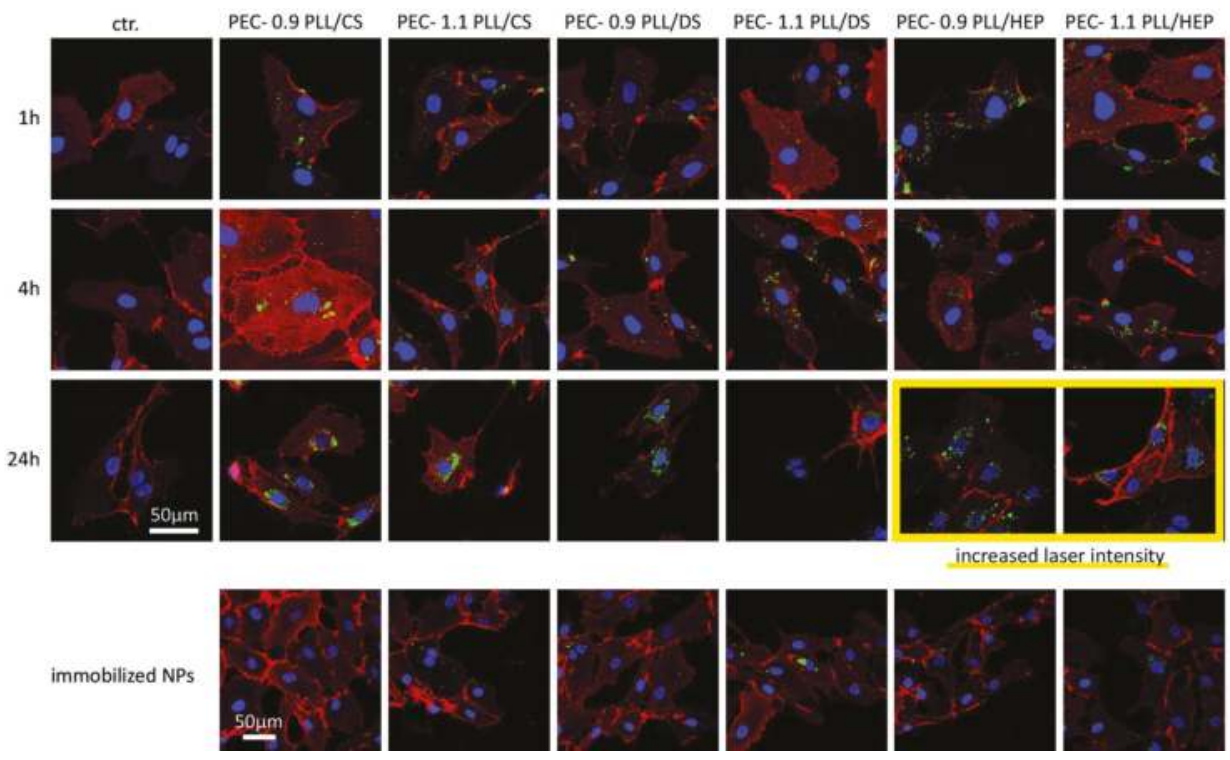

Figure 4. Uptake of polyelectrolyte complex nanoparticles (PECNP) into human umbilical cord vein endothelial cells (HUVEC). HUVEC were investigated for their uptake of PECNP-FITC (fluorescein isothiocyanate), either from the volume phase or from the immobilized state, demonstrated by confocal microscopy. Cells were cultivated either with PECNP in endothelial medium (volume phase) for times indicated or in contact with immobilized PECNP (surface) for $48 \mathrm{~h}$ cultivation time (bottom row). After cultivation, cells were detached and transferred to Ibidi slides and stained with Hoechst 33342 (cell nuclei) and an anti-CD31 (PECAM-1) monoclonal antibody conjugated to biotin, followed by incubation with an anti-mouse antibody conjugated to $\mathrm{Cy} 3 /$ streptavidin.

In more detail, transmission electron microscopy (TEM) showed neat attachment of PECNP to the plasma membrane of cells, preferentially in clustered form, and internalized PECNP in vesicles. PECNP in plasma membrane transit had not been seen unambiguously. In particular, none of the many coated vesicles abundant in HUVEC cell periphery ever contained PECNP indicating that internalization is not receptor-mediated in contrast to previously published data on charged nanoparticles which were taken up via the clathrin-mediated pathway [28]. This observation may also be in contrast to another report which describes that differently composed polyelectrolyte nanoparticles have an affinity to caveolae during endothelial cell uptake [29]. No apparent cell surface damage by binding and uptake of PECNP was observed by TEM. The observed vesicles increased with time of incubation, indicating that newly internalized PECNP-containing vesicles fuse with older ones. After long-time incubation, e.g., $72 \mathrm{~h}$, huge vesicles occupied a great portion of the cytoplasmic space. Stuffed with PECNP, they also included stacked membranes, while both components appeared segregated within the same membrane-bound space (Figure 5). 


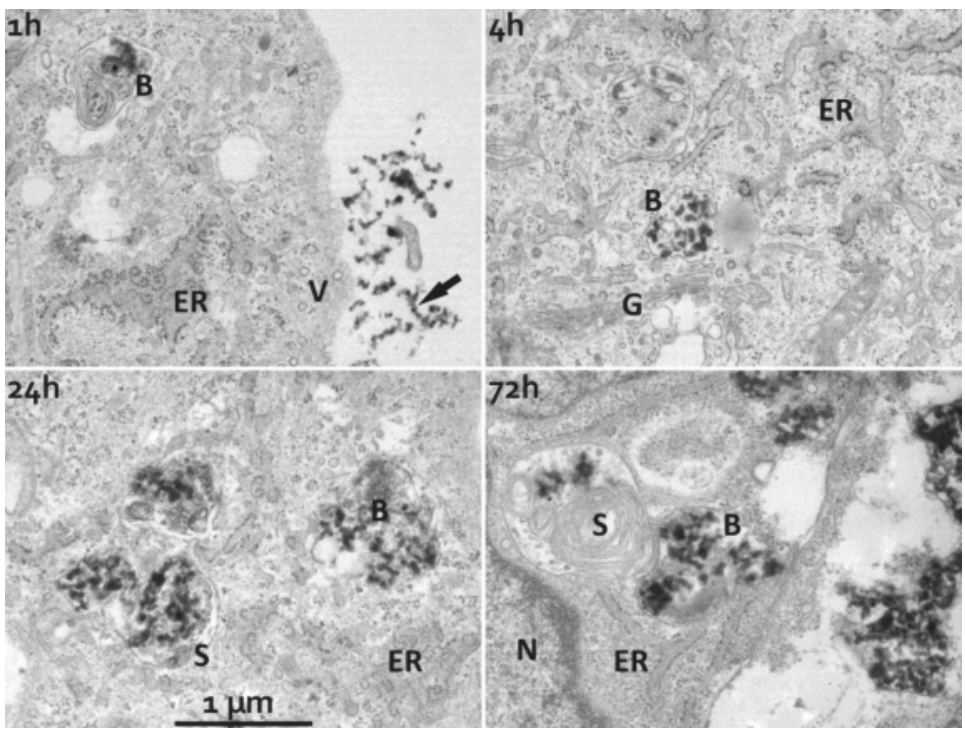

Figure 5. Ultrastructural demonstration of the polyelectrolyte complex nanoparticle PECNP compartment in human umbilical cord vein endothelial cells (HUVEC). HUVEC cell cultures admixed with PECNP composed of positively charged poly(L-lysine)/cellulose sulfate (PLL/CS-0.9) in the volume phase were fixed for TEM measurements after incubation times as indicated $(1 \mathrm{~h} / 4 \mathrm{~h} / 24 \mathrm{~h} / 72 \mathrm{~h})$. $1 \mathrm{~h} / 4 \mathrm{~h}$ incubation (upper row): disperse clusters of bead-like PECNP are in contact with the cells. Individual beads are compact, of variable shape and of typically $40 \mathrm{~nm}$ size. They frequently connect to each other into short chains (arrow). Close contact with the cell surface does not involve particular cell-surface coats. Internalized beads (B), i.e., PECNP, are rarely seen after $1 \mathrm{~h}$ incubation, more readily within the $4 \mathrm{~h}$-samples, and always within membrane-enclosed vesicles. These vesicles differ in size from the typical endothelial vesicles of HUVEC. $24 \mathrm{~h} / 72 \mathrm{~h}$ incubation (bottom row): vesicles with internalized PECNP grew beyond $1 \mu \mathrm{m}$-size. This "nanobead compartment" now occupied an essential volume of the cell cytoplasm. The PECNP-vesicles also feature inclusions of stacked membranes (S) which appear segregated from the bead-clusters. These membrane convolutions get more prominent with increasing time. B: (nano)beads/PECNP; ER: rough endoplasmatic reticulum; N: cell nucleus, G: Golgi apparatus, V: endosomal vesicles, all four images at same magnification.

The observation that PECNP accumulated with time in large endosomal vesicles indicates that lysosomal digest did not efficiently take place. Distinct endothelial proteins, such as PECAM, integrated into vesicles may be crucial for further intracellular processing [30]. Thus, it may be that the PLL/polysaccharide composition of PECNP does not suffice for further intracellular processing of nanoparticles, at least in endothelial cells, but additionally requires specific cell-specific proteins integrated into the PECNP as mentioned above. Also, it has to be considered that incubation with PECNP for several days, which may not occur under physiological conditions, represents an extreme situation and was performed to clearly demonstrate the intracellular localization and showed that lysosomal degradation did not take place. As has been shown by light microscopy and flow cytometry, uptake happened in shorter times (5-120 min).

In contrast to physical measurement of particle size (Table 1), size estimation by TEM revealed somewhat smaller sizes for single PECNP (extracellular: $39 \pm 9 \mathrm{~nm}$; intracellular after $4 \mathrm{~h}$ incubation: $50 \pm 8 \mathrm{~nm}$; intracellular after $24 \mathrm{~h}$ incubation: $42 \pm 7 \mathrm{~nm}$ ). Interestingly, the incorporated FITC-labeled PECNP were equally distributed during mitosis (Figure 6). 

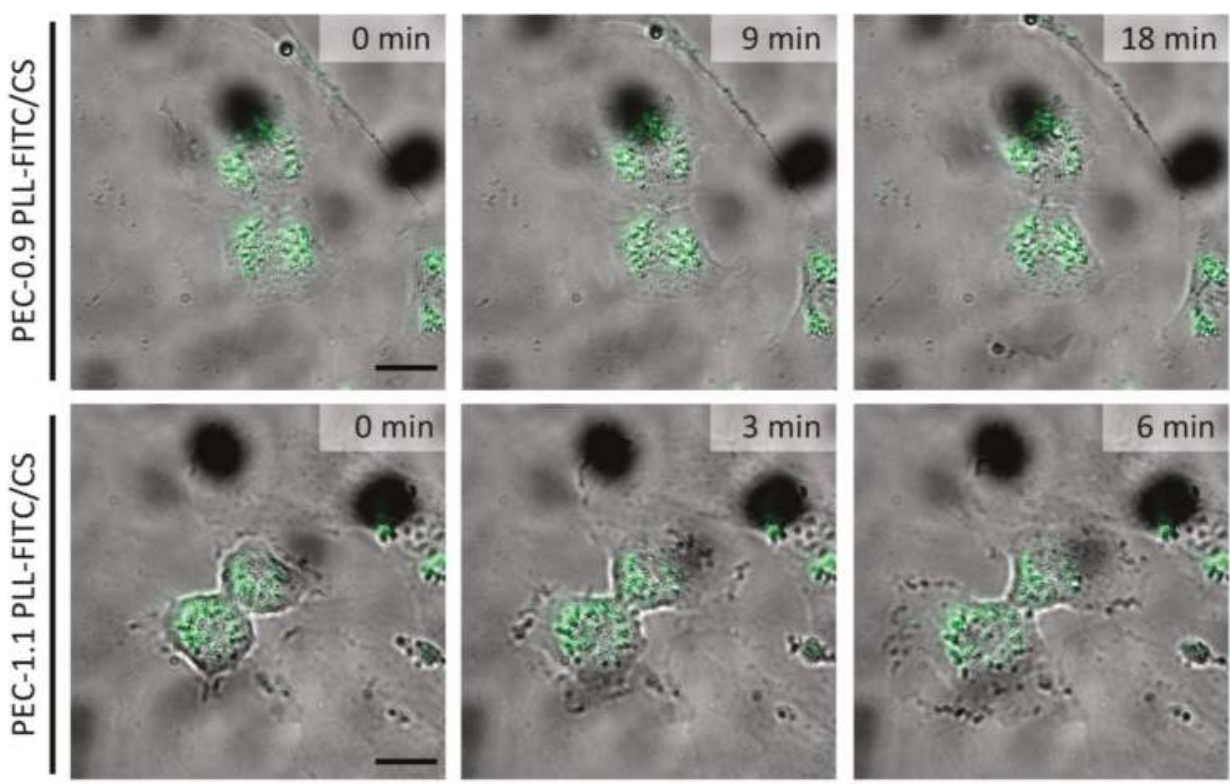

Figure 6. Distribution of internalized polyelectrolyte complex nanoparticles (PECNP) during cell division. Human umbilical cord vein endothelial cells (HUVEC) were incubated with $300 \mu \mathrm{L}$ each of $50 \mu \mathrm{M}$ fluorescein isothiocyanate (FITC)-labelled PECNP dispersed in endothelial culture medium for $24 \mathrm{~h}$ as described in Materials and Methods. After 3 washing steps, cells carrying PECNP were analyzed in the telophase of cell division by widefield microscopy. Images show separation of cells loaded with PECNP at time points indicated. The number of PECNP within cells apparently was split in approximately equal portions during cell division. PEC: polyelectrolyte complex; PEC-1.1: negatively charged PECNP; PEC-0.9: positively charged PECNP; PLL: (poly-L)lysine; CS: cellulose sulfate; (Scale bar: $20 \mu \mathrm{m}$ ).

\subsection{Effect of PECNP on Cell Proliferation in the Volume Phase and Immobilized State}

Since PECNP were taken up in large amounts, it was analyzed whether they may influence cell proliferation both in the volume phase and attached on a surface. To this end, the influence of PECNP on proliferation of HUVEC was tested by their $\left[{ }^{3} \mathrm{H}\right]$-thymidine uptake during a cultivation time of $24 \mathrm{~h}$ (Figure 7). All PECNP samples reduced proliferation in a dose-dependent fashion which was evident both for the immobilized as well as for the volume phase state though the negative influence was stronger for the immobilized PECNP (black bars Figure 7B). PLL/HEP and PLL/DS PECNP had significant anti-proliferative effects at medium and high concentration (20 and $50 \mu \mathrm{L} / \mathrm{cm}^{2}$, respectively). Negatively charged PLL/CS PECNP (PEC-1.1), especially in lower concentrations (5 and $10 \mu / \mathrm{cm}^{2}$ ), had the lowest anti-proliferative effect. Reflected in reduced proliferation rates after PECNP uptake, the time-dependently high endosomal accumulation of PECNP may have caused stress for the cells. We did not find a significant difference with regard to uptake and intracellular localization between negatively and positively charged nanoparticles as has been reported [26]. However, as estimated by analysis of TEM images it appeared, that positively charged PECNP showed a larger number of vesicles with particles than negatively charged PECNP after 24 and $72 \mathrm{~h}$ incubation (data not shown), which may be due to the slightly negatively charged cell membrane. It was suggested that charged nanoparticles of various materials are more cytotoxic than uncharged ones which may however not apply for polysaccharide based nanoparticles as for instance those containing chitosan [10]. 
A
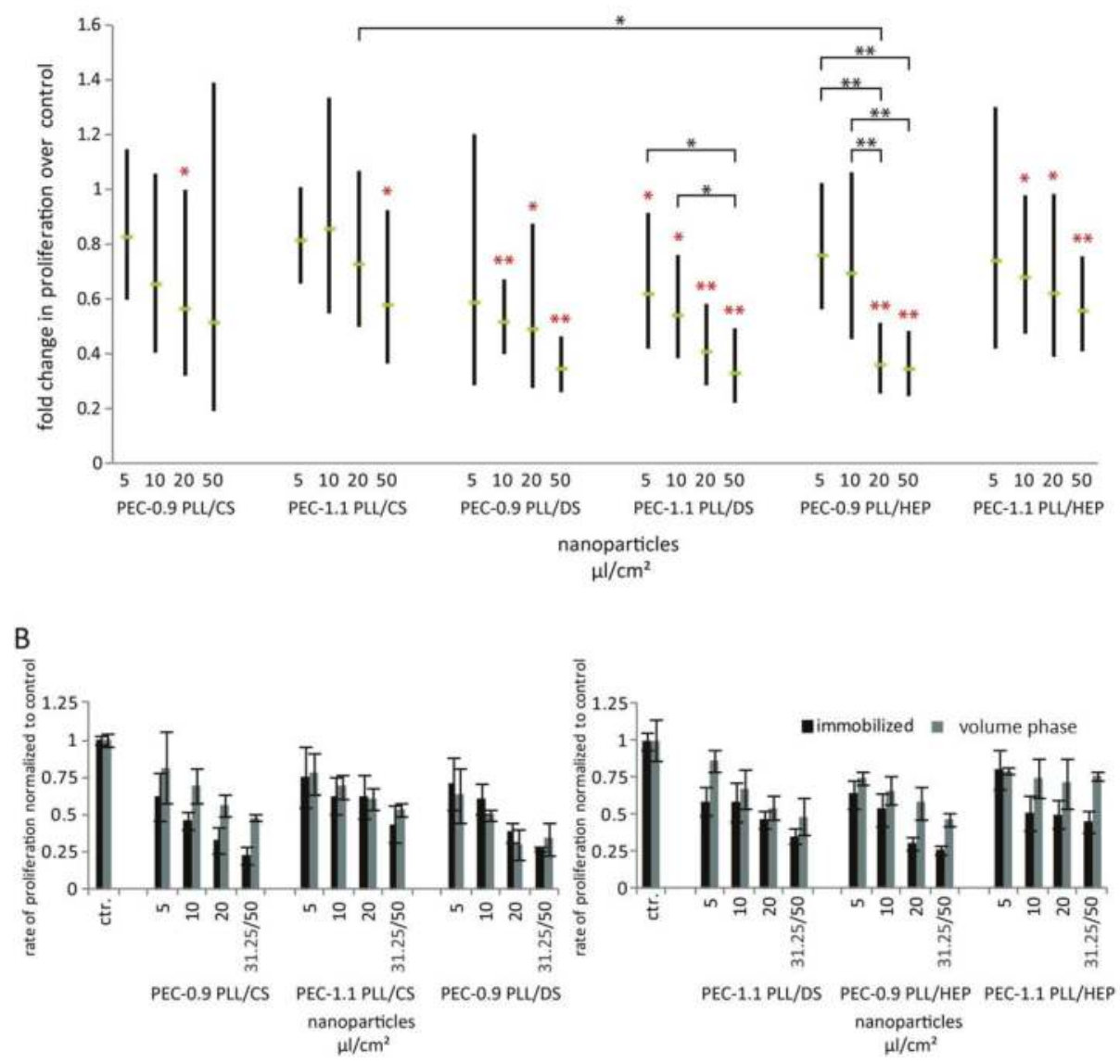

Figure 7. The influence of polyelectrolyte complex nanoparticles PECNP on cell proliferation. The influence of PECNP on proliferation of human umbilical cord vein endothelial cells (HUVEC) was assayed by [3H] thymidine incorporation as described in Materials and Methods. (A) Influence on proliferation, shown as fold change for each PECNP preparation compared to untreated (i.e., without PECNP addition) control HUVEC cultures. HUVECs were seeded on culture plates coated with PECNP. Black bars indicate $95 \%$ confidence interval (number of experiments: $n=4$ ), red * indicate significant changes in proliferation using a two-tailed, paired $t$-test. Horizontal bars and black * indicate significant differences between various concentrations of the same PECNP applied or between various PECNP of same concentration (ANOVA, one way analysis of variance), ${ }^{*} p<0.05,{ }^{* *} p<0.01$ ) (B) Direct comparison of HUVEC proliferation rates affected by PECNP in the immobilized state (black bars) and in the volume phase (grey bars). Proliferation rates were normalized to those of control cultures (ctr). The highest concentration of PECNP in fluid state was $31 \mu \mathrm{L} / \mathrm{cm}^{2}$, and for immobilized PECNP $50 \mu \mathrm{L} / \mathrm{cm}^{2}$. The other concentrations of PECNP were as indicated. Error bars indicate standard deviation of at least triplicates/assay.

In our study, all PECNP, in the volume phase and in an immobilized state reduced cell proliferation in HUVECs in a concentration-dependent manner albeit to various extents. In another study cytotoxic effects of iron oxide nanoparticles on human endothelial cells were reported [31]. Although in our 
study the proliferation rate was reduced by addition of PECNP, it has to be stressed that this did not entail a higher cytotoxicity. Flow cytometric analysis of dead versus live cells after application of PECNP did not show a higher propensity for dead cells (data not shown). Also, the fact that mitosis was not influenced by internalized PECNP supports this finding. As the intracellular load of PECNP is apparently bisected after each cell division the non-digestible PECNP will gradually be diminished. In another study uptake of modified polystyrene nanoparticles by mesenchymal stem cells did not affect the viability of these cells [13].

Immobilized PECNP can be used as an integrative part of a scaffold material and hence it is important to know how endothelial cells are able to adhere to and migrate on a PECNP coated surface. Application of PECNP to surfaces of culture dishes or microscopic slides resulted in heterogeneous spreading of nanoparticles. Under these conditions PECNP had generally an anti-adhesive effect. This repulsive effect was lowest with PECNP of PLL/CS, which suggests these nanoparticles are more appropriate for coating of scaffold surfaces. A further advantage for in-vivo application may be that both, HEP and CS have anti-coagulant activities [32,33]. In an earlier study we investigated the interaction between PECNPs and human mesenchymal stromal cells (hMSC) and found, similar to the findings of this study, that net charge did not significantly influence adhesion and uptake, while PECNP composition affected e.g., metabolic activity of hMSC [21]. It has also been shown that PECNP can be applied as drug delivery system when cast as particle films [12,20,34,35]. In our study we found differential effects of PECNP on endothelial cell adhesion. Therefore, when applying PECNP in cast form for surface mediated drug delivery the possible anti-adhesive effect of several PECNP has to be considered and certainly those with lowest anti-adhesive effect have to be preferred for this purpose.

\section{Conclusions}

Our study showed that PLL/polysaccharide based PECNP attached to the cell surface of vascular endothelial cells and were taken up into the vesicular compartment in a cumulative manner. Among the three PECNP compositions used here, PLL/HEP seemed to be the ideal vehicle for transport of drugs or growth factors to endothelial cells, because (i) attachment and uptake was faster than for the other modifications, (ii) PLL/HEP seemed to be digested in the lysosomal compartment by endogeneous glycosidases and (iii) possibly sulfatases, and (iii) interactions with growth factors, important for vascularization, such as vascular endothelial growth factor (VEGF) and basic fibroblast growth factor (bFGF), have a high binding capacity for heparin, and thus PECNP of PLL/HEP may be helpful for supporting the presentation of these growth factors [36] to vascular endothelial cells and may also reduce release of the growth factors during cellular regeneration for example of bone tissue within scaffolds [14] (iii). On the other side, PECNP of PLL/CS may be better suited for coating surfaces of scaffold material since its anti-adhesive effects and its anti-proliferative impact were much smaller compared to PECNP composed of PLL/HEP or PLL/DS. Depending on the specific requirements for nanoparticle application, mixing of HEP and CS in ternary complexes of PLL/CS/HEP in appropriate fractions may be advantageous to design specific properties for several applications as mentioned here. Finally, the net charge of the PECNP, which can be modulated by the excess of either cationic PLL or one of the three anionic polysaccharides, did not play an essential role in our experimental approach, which is in line with former results on the interaction of PECNP with comparable compositions with human mesenchymal stromal cells (hMSC) [21].

Our study has yielded basic insights into the biocompatibility of PECNP for vascular endothelial cells. In future experiments, using PECNP, the influence of shear stress and stretched conditions has to be taken into account, since it is known that under flow conditions, equivalent to the physiological condition in the blood stream [37], uptake of nanoparticles may be different [38,39]. In an earlier study, by measuring uptake of silica nanoparticles into human endothelial cells it was found, that cytotoxicity was not increased (i) and endocytosis was decreased as compared to maintenance of cells under static conditions (ii) [40]. So far, we were able to show interactions with endothelial cells in the volume phase via the comparatively harsh shear stress conditions of flow cytometry confirming data of other 
groups [23]. Therefore, adhesion and uptake may be lower under dynamic than under static conditions and thereby anti-proliferative effects may also be diminished in the in-vivo situation. Also, in-vivo studies have to clarify the potential clearance of PECNP from the body with time.

Supplementary Materials: The following are available online at http://www.mdpi.com/2079-4991/8/6/358/s1, Figure SM1: Zeta-potential/pH profiles of PECNP, Figures SM2 and SM3: PLL conformation in PECNP samples, Figure SM4. Morphology of PECNP at poly(styrene) (PS) found by scanning force microscopy (SFM).

Author Contributions: R.S.A. and M.M. initiated this cooperative research work. D.W. and R.S.A. designed all cell experiments. M.M. and B.T. selected and prepared appropriate PECNP samples. K.R. and M.N. performed TEM analysis. R.S.A. and M.M. drafted and with the help of B.T. and B.W. iteratively refined the manuscript. F.M. assisted with the fluorescent microscopy and cytometric analysis. All authors approved the final manuscript.

Funding: This research was funded by Deutsche Forschungsgemeinschaft (DFG), in the framework of Sonderforschungsbereich/Transregio 79 (Materials for Tissue Regeneration within Systemically Altered Bone).

Conflicts of Interest: The authors report no conflict of interest in this work.

\section{References}

1. Tautzenberger, A.; Kovtun, A.; Ignatius, A. Nanoparticles and their potential for application in bone. Int. J. Nanomed. 2012, 7, 4545-4557. [CrossRef] [PubMed]

2. Hartig, S.M.; Greene, R.R.; Dikov, M.M.; Prokop, A.; Davidson, J.M. Multifunctional nanoparticle polyelectrolyte complexes. Pharm. Res. 2007, 24, 2353-2369. [CrossRef] [PubMed]

3. Baiguera, S.; Ribatti, D. Endothelization approaches for viable engineered tissues. Angiogenesis 2013, 16, 1-14. [CrossRef] [PubMed]

4. Asai, T. Nanoparticle-mediated delivery of anticancer agents to tumor angiogenic vessels. Biol. Pharm. Bull. 2012, 35, 1855-1861. [CrossRef] [PubMed]

5. Zhao, G.; Rodriguez, B.L. Molecular targeting of liposomal nanoparticles to tumor microenvironment. Int. J. Nanomed. 2013, 8, 61-71. [CrossRef] [PubMed]

6. He, C.; Hu, Y.; Yin, L.; Tang, C.; Yin, C. Effects of particle size and surface charge on cellular uptake and biodistribution of polymeric nanoparticles. Biomaterials 2010, 31, 3657-3666. [CrossRef] [PubMed]

7. Pastorino, F.; Brignole, C.; Loi, M.; Di Paolo, D.; Di Fiore, A.; Perri, P.; Pagnan, G.; Ponzoni, M. Nanocarrier-mediated targeting of tumor and tumor vascular cells improves uptake and penetration of drugs into neuroblastoma. Front. Oncol. 2013, 3, 190. [CrossRef] [PubMed]

8. Huang, M.; Vitharana, S.N.; Peek, L.J.; Coop, T.; Berkland, C. Polyelectrolyte complexes stabilize and controllably release vascular endothelial growth factor. Biomacromolecules 2007, 8, 1607-1614. [CrossRef] [PubMed]

9. Alexis, F.; Pridgen, E.; Molnar, L.K.; Farokhzad, O.C. Factors affecting the clearance and biodistribution of polymeric nanoparticles. Mol. Pharm. 2008, 5, 505-515. [CrossRef] [PubMed]

10. Fröhlich, E. The role of surface charge in cellular uptake and cytotoxicity of medical nanoparticles. Int. J. Nanomed. 2012, 7, 5577-5591. [CrossRef] [PubMed]

11. Müller, M. Sizing, shaping and pharmaceutical applications of polyelectrolyte complex nanoparticles. Adv. Polym. Sci. 2014, 256, 197-260.

12. Müller, M.; Torger, B.; Vehlow, D.; Urban, B.; Wehrum, D.; Woltmann, B.; Hempel, U. Drug delivery and cell interaction of adhesive poly(ethylenimine)/sulfated polysaccharide complex particle films. Biointerphases 2015, 10, 011001. [CrossRef] [PubMed]

13. Baldwin, A.D.; Kiick, K.L. Polysaccharide-modified synthetic polymeric biomaterials. Biopolymers 2010, 94, 128-140. [CrossRef] [PubMed]

14. Knaack, S.; Lode, A.; Hoyer, B.; Rösen-Wolff, A.; Gabrielyan, A.; Roeder, I.; Gelinsky, M. Heparin modification of a biomimetic bone matrix for controlled release of VEGF. J. Biomed. Mater. Res. A 2014, 102, 3500-3511. [CrossRef] [PubMed]

15. Nagahata, M.; Nakaoka, R.; Tramoto, A.; Abe, K.; Tsuchiya, T. The response of normal osteoblasts to anionic polysaccharide polyelectrolyte complexes. Biomaterials 2005, 26, 5138-5144. [CrossRef] [PubMed]

16. Lemarchand, C.; Gref, R.; Passirani, C.; Garcion, E.; Petri, B.; Müller, R.; Costantini, D.; Couvreur, P. Influence of polysaccharide coating on the interactions of nanoparticles with biological systems. Biomaterials 2005, 27, 108-118. [CrossRef] [PubMed] 
17. Rodriguez-Velazquez, E.; Alatorre-Meda, M.; Mano, J.F. Polysaccharide-based nanobiomaterials as controlled release systems for tissue engineering applications. Curr. Pharm. Des. 2015, 21, 4837-4850. [CrossRef] [PubMed]

18. Kim, D.H.; Termsarasab, U.; Cho, H.J.; Yoon, I.S.; Lee, J.Y.; Moon, H.T.; Kim, D.D. Preparation and characterization of self-assembled nanoparticles based on low-molecular-weight heparin and stearylamine conjugates for controlled delivery of docetaxel. Int. J. Nanomed. 2014, 9, 5711-5727. [CrossRef] [PubMed]

19. Kemp, M.M.; Linhardt, R.J. Heparin-based nanoparticles. Wiley Interdiscip. Rev. Nanomed. Nanobiotechnol. 2010, 2, 77-87. [CrossRef] [PubMed]

20. Müller, M.; Keßler, B. Release of pamidronate from poly(ethyleneimine)/cellulose sulphate complex nanoparticle films: An in situ ATR-FTIR study. J. Pharm. Biomed. Anal. 2012, 66, 183-190. [CrossRef] [PubMed]

21. Woltmann, B.; Torger, B.; Müller, M.; Hempel, U. Interaction between immobilized polyelectrolyte complex nanoparticles and human mesenchymal stromal cells. Int. J. Nanomed. 2014, 9, 2205-2215.

22. Kokesch-Himmelreich, J.; Woltmann, B.; Torger, B.; Rohnke, M.; Arnhold, S.; Hempel, U.; Müller, M.; Janek, J. Detection of organic nanoparticles in human bone marrow-derived stromal cells using ToF-SIMS and PCA. Anal. Bioanal. Chem. 2015, 407, 4555-4565. [CrossRef] [PubMed]

23. Hartig, S.M.; Greene, R.R.; Carlesso, G.; Higginbotham, J.N.; Khan, W.N.; Prokop, A.; Davidson, J.M. Kinetic analysis of nanoparticulate polyelectrolyte complex interactions with endothelial cells. Biomaterials 2007, 28, 3843-3855. [CrossRef] [PubMed]

24. Starchenko, V.; Müller, M.; Lebovka, N. Sizing of PDADMAC/PSS complex aggregates by polyelectrolyte and salt concentration and PSS molecular weight. J. Phys. Chem. B 2012, 116, 14961-14967. [CrossRef] [PubMed]

25. Pandey, M.S.; Harris, E.N.; Weigel, P.H. HARE-mediated endocytosis of hyaluronan and heparin is targeted by different subsets of three endocytic motifs. Int. J. Cell Biol. 2015, 2015, 524707. [CrossRef] [PubMed]

26. Hammond, E.; Khurana, A.; Shridhar, V.; Dredge, K. The role of heparanase and sulfatases in the modification of heparan sulfate proteoglycans within the tumor microenvironment and opportunities for novel cancer therapeutics. Front. Oncol. 2014, 4, 195. [CrossRef] [PubMed]

27. Lorenz, M.R.; Holzapfel, V.; Musyanovych, A.; Nothelfer, K.; Walther, P.; Frank, H.; Landfester, K.; Schrezenmeier, H.; Mailänder, V. Uptakte of functionalized, fluorescent-labeled polymeric particles in different cell lines and stem cells. Biomaterials 2006, 27, 2820-2828. [CrossRef] [PubMed]

28. Harush-Frenkel, O.; Debotton, N.; Benita, S.; Altschuler, Y. Targeting of nanoparticles to the clathrin-mediated endocytic pathway. Biochem. Biophys. Res. Commun. 2007, 353, 26-32. [CrossRef] [PubMed]

29. Voigt, J.; Christensen, J.; Shastri, V.P. Differential uptake of nanoparticles by endothelial cells through polyelectrolytes with affinity for caveolae. Proc. Natl. Acad. Sci. USA 2014, 111, 2942-2947. [CrossRef] [PubMed]

30. Garnacho, C.; Albelda, S.M.; Muzykantov, V.R.; Muro, S. Differential intra-endothelial delivery of polymer nanocarriers targeted to distinct PECAM-1 epitopes. J. Control. Release 2008, 130, 226-233. [CrossRef] [PubMed]

31. Wu, X.; Tan, Y.; Mao, H.; Zhang, M. Toxic effects of iron oxide nanoparticles on human umbilical vein endothelial cells. Int. J. Nanomed. 2010, 5, 385-399. [CrossRef]

32. Lane, D.A.; Denton, J.; Flynn, A.M.; Thunberg, L.; Lindahl, U. Anticoagulant activities of heparin oligosaccharides and their neutralization by platelet factor 4. Biochem. J. 1984, 218, 725-732. [CrossRef] [PubMed]

33. Wagenknecht, W.; Nehls, I.; Philipp, B. Studies on the regioselectivity of cellulose sulfation in an $\mathrm{N}_{2} \mathrm{O}_{4}-\mathrm{N}, \mathrm{N}$-dimethylformamide-cellulose system. Carbohydr. Res. 1993, 240, 245-252. [CrossRef]

34. Torger, B.; Vehlow, D.; Urban, B.; Salem, S.R.; Appelhans, D.; Müller, M. Cast polyelectrolyte complex particle films of unmodified or maltose-modified poly(ethyleneimine) and cellulose sulphate: Fabrication, film stability and retarded release of zoledronate. Biointerphases 2013, 8, 25. [CrossRef] [PubMed]

35. Vehlow, D.; Schmidt, R.; Gebert, A.; Siebert, M.; Lips, K.S.; Müller, M. Polyelectrolyte complex based interfacial drug delivery system with controlled loading and improved release performance for bone therapeutics. Nanomaterials 2016, 6, 53. [CrossRef] [PubMed] 
36. Friedel, M.; André, S.; Goldschmidt, H.; Gabius, H.J.; Schwartz-Albiez, R. Galectin-8 enhances adhesion of multiple myeloma cells to vascular endothelium and is an adverse prognostic factor. Glycobiology 2016, 26, 1048-1058. [CrossRef] [PubMed]

37. Han, J.; Zern, B.J.; Shuvaev, V.V.; Davies, P.F.; Muro, S.; Muzykantov, V. Acute and chronic shear stress differently regulate endothelial internalization of nanocarriers targeted to platelet-endothelial cell adhesion molecule-1. ACS Nano 2012, 6, 8824-8836. [CrossRef] [PubMed]

38. Han, J.; Shuvaev, V.V.; Davies, P.F.; Eckmann, D.M.; Muro, S.; Muzykantov, V.R. Flow shear stress differentially regulates endothelial uptake of nanocarriers targeted to distinct epitopes of PECAM-1. J. Control. Release 2015, 210, 39-47. [CrossRef] [PubMed]

39. Freese, C.; Schreiner, D.; Anspach, L.; Bantz, C.; Maskos, M.; Unger, R.E.; Kirkpatrick, C.J. In vitro investigation of silica nanoparticle uptake into human endothelial cells under physiological cyclic stretch. Part. Fibre Toxicol. 2014, 11, 68. [CrossRef] [PubMed]

40. Folkman, J.; Shing, Y. Control of angiogenesis by heparin and other sulfated polysaccharides. Adv. Exp. Med. Biol. 1993, 313, 355-364.

(C) 2018 by the authors. Licensee MDPI, Basel, Switzerland. This article is an open access article distributed under the terms and conditions of the Creative Commons Attribution (CC BY) license (http:/ / creativecommons.org/licenses/by/4.0/). 
Article

\title{
Easy Synthesis and Characterization of Holmium-Doped SPIONs
}

\author{
Magdalena Osial, Paulina Rybicka, Marek Pękała, Grzegorz Cichowicz, Michał K. Cyrański and \\ Paweł Krysiński *
}

Faculty of Chemistry, University of Warsaw, Pasteura 1 Street, 02-093 Warsaw, Poland; magdalena@osial.eu (M.O.); p.rybicka@student.uw.edu.pl (P.R.); pekala@chem.uw.edu.pl (M.P.); gcichowicz@chem.uw.edu.pl (G.C.); mkc@chem.uw.edu.pl (M.K.C.)

* Correspondence: pakrys@chem.uw.edu.pl; Tel.: +48-22-55-26-404

Received: 21 May 2018; Accepted: 8 June 2018; Published: 13 June 2018

\begin{abstract}
The exceptional magnetic properties of superparamagnetic iron oxide nanoparticles (SPIONs) make them promising materials for biomedical applications like hyperthermia, drug targeting and imaging. Easy preparation of SPIONs with the controllable, well-defined properties is a key factor of their practical application. In this work, we report a simple synthesis of Ho-doped SPIONs by the co-precipitation route, with controlled size, shape and magnetic properties. To investigate the influence of the ions ratio on the nanoparticles' properties, multiple techniques were used. Powder X-ray diffraction (PXRD) confirmed the crystallographic structure, indicating formation of an $\mathrm{Fe}_{3} \mathrm{O}_{4}$ core doped with holmium. In addition, transmission electron microscopy (TEM) confirmed the correlation of the crystallites' shape and size with the experimental conditions, pointing to critical holmium content around 5\% for the preparation of uniformly shaped grains, while larger holmium content leads to uniaxial growth with a prism shape. Studies of the magnetic behaviour of nanoparticles show that magnetization varies with changes in the initial $\mathrm{Ho}^{3+}$ ions percentage during precipitation, while below $5 \%$ of $\mathrm{Ho}$ in doped $\mathrm{Fe}_{3} \mathrm{O}_{4}$ is relatively stable and sufficient for biomedicine applications. The characterization of prepared nanoparticles suggests that co-precipitation is a simple and efficient technique for the synthesis of superparamagnetic, Ho-doped SPIONs for hyperthermia application.
\end{abstract}

Keywords: superparamagnetic iron oxide nanoparticles; SPIONs; rare-earth doping; holmium; endoradiotherapy

\section{Introduction}

In recent years, magnetic nanoparticles like magnetite $\left(\mathrm{Fe}_{3} \mathrm{O}_{4}\right)$ have allowed for significant progress in the field of drug delivery and cancer treatment [1,2]. Efforts focused on the rapid development and study of magnetic iron-oxide-based nanoparticles have drastically increased, especially in the case of their applications in oncology [3], where highly efficient carcinogenic cell destruction is needed.

Nanosized iron oxide exhibits a wide range of magnetic properties depending on the shape, size and chemical composition of the particles. Magnetite nanoparticles ranging from a few nanometers up to $100 \mathrm{~nm}$ are very attractive in a wide array of modern scientific fields, such as nanotechnology [4-6] biotechnology [7], MRI contrast agents [8], magnetic separation and immobilization [9] etc. These nanomaterials can also be effective for medical applications including bioimaging [10] and biosensing in diagnostics (theranostics) [11,12], controlled drug delivery and cancer therapeutics [13-16]. Several excellent reviews have been published on the synthesis, functionalization and application of magnetic nanoparticles $[17,18]$. 
Much of the literature focuses on the medical application of nanoparticles based on the superparamagnetic iron oxide nanoparticles SPIONs because of their easy synthesis, stability and biocompatibility [19-21]. Due to their biocompatibility, they are already used in clinical trials $[22,23]$. A very interesting prospect is to enhance their size-dependent properties like low toxicity, facile synthesis [24], surface-to-volume ratio, superparamagnetism $[25,26]$ and affect the magnetic interactions through doping the core of nanoparticles with different metal ions. Usually transition metals are effective dopants, changing the magnetic properties of iron oxide nanoparticles [27,28]. Whilst doping of magnetite with lanthanides such as $\mathrm{Ho}, \mathrm{Gd}, \mathrm{Tb}$, as well as other metals, e.g., $\mathrm{Re}, \mathrm{Y}$, is common and simple in principle, establishing the synthesis procedure with controlled shape, size and magnetic properties is difficult $[10,15,16]$. Lanthanide-doped nanoparticles can be directed to the tumour tissues with the help of an external magnet. Thus, they can serve not only as drug carriers in targeted drug delivery or magnetic hyperthermia, but also in so-called endoradiotherapy. The latter feature can be easily implemented by replacing the "cold" atoms of lanthanides in the superparamagnetic core with their "hot" nuclei, emitting soft $\beta(-)$ radiation suitable for the internal radiotherapy, localized directly within the tumour. Thus, these nanoparticles can be used simultaneously in targeted drug delivery, hyperthermia and endoradiotherapy. Moreover, the amount of radionuclides per single nanoparticle greatly exceeds the amount of radionuclides per single molecule found in radiopharmaceuticals being currently used in radiotherapies. Therefore, such multifunctional nanoparticles may become indispensable in many areas of modern medicine. For that application the lanthanides of ionic radius matching the SPIONs crystal lattice and high magnetic moment have to be chosen. The spinel structure in magnetite-based nanoparticles of formula $\mathrm{MFe}_{2} \mathrm{O}_{4}$, where $\mathrm{Fe}^{3+}$ ions occupy octahedral sites [29] and divalent metal ions $\mathrm{M}$ such as $\mathrm{Fe}^{2+}, \mathrm{Ni}^{2+}$, etc. occupy the tetrahedral positions in the crystal [30], can be modified through the substitution of the $\mathrm{Fe}^{3+}$ with different trivalent ions. Substitution with ions with an ionic radius similar to $\mathrm{Fe}^{3+}(0.785 \AA)$ [31] does not affect the magnetic behaviour of the doped SPIONs significantly, while the incorporation of lanthanide ions like $\mathrm{Ho}^{3+}\left(1.01 \AA\right.$ ) [32] with a large radius, ca. 30\% larger than $\mathrm{Fe}^{3+}$, may lead to core anisotropy, crystallographic lattice alterations and a decrease in the magnetic properties due to the $\mathrm{Fe}(\mathrm{III})$ and $\mathrm{Ho}(\mathrm{III})$ ionic radii mismatch [33,34].

The influence of the incorporation of lanthanide ions into the core of SPIONs is still poorly understood. We are aware of the fact that the largest, octahedral site of the magnetite lattice can accommodate cations up to ca. 85-90 pm radius, and there is a large ionic radii mismatch for $\mathrm{Ho}^{3+}$ (104 pm) as compared to $\mathrm{Fe}^{3+}(78.5 \mathrm{pm})$ ions that are to be replaced in this lattice. However, the literature data [35] and our results for SPIONs modified with Tb (106 pm) [33] indicate that such replacement is possible, at least for terbium cations, requiring local lattice distortion and favouring incorporation of these ions into octahedral and surface sites. On the other hand, most ferrites are ferrimagnetic, i.e., part of magnetic moments of the constituent ions are antiparallel, partially compensating for the overall magnetic moment of SPIONs. Therefore, the introduction of lanthanide metal ions of different ionic radii than $\mathrm{Fe}^{3+}$ may alter the crystallographic structure, resulting in an increase of unpaired spins and enhancing the saturation magnetization. This behaviour would be very advantageous for a drug delivery system based on SPIONs.

Since the properties of magnetic nanoparticles are strongly related to their shape and size, various methods and synthetic conditions are directed towards control over their chemical composition, morphology of formed crystallites, degree of agglomeration and magnetic properties.

The literature refers to co-precipitation, the microemulsions polyol process, solvothermal and sonochemical techniques as suitable solutions for the preparation of iron-oxide-based nanoparticles dispersed in water [36-38]. Among the many SPIONs synthetic procedures, co-precipitation is a promising technique due to its simplicity and productivity. The conditions of synthesis like ion concentration, $\mathrm{pH}$ of the solution as well as duration of synthesis and heat treatment are crucial to determine the physicochemical properties of SPIONs. 
In this paper, we report on the morphology and magnetic and structural properties of Ho-doped iron oxide magnetic nanoparticles synthesized by the co-precipitation method from a solution containing different molar concentrations of all ions forming the nanoparticle core. To avoid elimination by clearance organs, the hydrodynamic diameter of the nanoparticles should remain in the range of 10-100 nm [16]. Therefore, we focused on nanoparticles that were uniform in size, with a hydrodynamic diameter below $100 \mathrm{~nm}$. Holmium dopant was chosen since it can be easily replaced by its ${ }^{166} \mathrm{Ho}$ radionuclide emitting $\beta(-)$ "soft radiation suitable for targeted endoradiotherapy" and due to its high magnetic moment $\left(\sim 10.6 \mu_{\mathrm{B}}\right)$ [39], which is expected to enhance a magnetization of ferrites studied. On the other hand, the atomic size mismatch is found to distort the atomic lattice and weaken the magnetic properties.

\section{Materials and Methods}

Iron (II) chloride tetrahydrate $\mathrm{FeCl}_{2} \cdot 4 \mathrm{H}_{2} \mathrm{O}$ puriss p.a. $\geq 99 \%$ (RT), iron (III) chloride hexahydrate $\mathrm{FeCl}_{3} \cdot 6 \mathrm{H}_{2} \mathrm{O}$ Aldrich ACS reagent 97\% were supplied from Sigma-Aldrich, Germany, holmium (III) chloride hexahydrate $\mathrm{HoCl}_{3} \cdot 6 \mathrm{H}_{2} \mathrm{O} 99.9 \%$ trace metals was obtained from Sigma-Aldrich, $25 \%$ ammonia solution $\mathrm{NH}_{4} \mathrm{OH}$ was supplied from CHEMPUR, Poland. All chemicals were of analytical grade standards and used as received. Deionized water with resistivity $18.2 \mathrm{M} \Omega \mathrm{cm}$ at $25^{\circ} \mathrm{C}$ was obtained using the Milli-Q ultra-pure water filtering system (Merck, Darmstadt, Germany). Successfully prepared SPIONs were modified with 3-phosphonopropionic acid obtained from Sigma-Aldrich with $94 \%$ grade acid with the use of analytical-grade $\mathrm{NaOH}$ from CHEMPUR, Poland.

SPIONs were synthesized by the co-precipitation technique in aqueous media containing different batches of ions having a molar percentage of $\mathrm{Ho}(\mathrm{III})$ vs. total iron content of $1 \%, 2.5 \%, 5 \%, 7.5 \%$ and $10 \%$. The required amounts of salts were dissolved in a beaker to reach the complete dissolution of $87.5 \mathrm{~mL}$ solution with $\mathrm{pH}$ around 1.9 and molarity $0.1 \mathrm{M}$ of the $\mathrm{FeCl}_{2} \cdot 4 \mathrm{H}_{2} \mathrm{O}, 0.1 \mathrm{M}$ of the $\mathrm{FeCl}_{3} \cdot 6 \mathrm{H}_{2} \mathrm{O}$ and $\mathrm{HoCl}_{3} \cdot 6 \mathrm{H}_{2} \mathrm{O}$ in amounts from $1-10 \%$ instead of $\mathrm{Fe}^{3+}$ ions. The solution was stirred mechanically for $10 \mathrm{~min}$ at a rate of $500 \mathrm{rpm}$ (chosen as the minimum to obtain a stable vortex), and after that the ammonia was added drop by drop to the solution, and stirred for an additional $30 \mathrm{~min}$. During the addition of ammonia the solution turned black, indicating the formation of a suspension with nanoparticles (see Figure 1). The schematic reaction taking place during synthesis is presented as follows:

$$
x \mathrm{Fe}^{3+}+(2-x) \mathrm{Ho}^{3+}+\mathrm{Fe}^{2+}+8 \mathrm{OH}^{-} \rightarrow \mathrm{Ho}_{(2-x)} \mathrm{Fe}_{x} \mathrm{FeO}_{4}+4 \mathrm{H}_{2} \mathrm{O} .
$$

After $30 \mathrm{~min}$ the beaker with suspension was left on the magnet for an additional $30 \mathrm{~min}$ for sedimentation, and suspended nanoparticles were washed with water and acetone alternatively to remove the residual $\mathrm{NH}_{4} \mathrm{OH}$ and all unreacted compounds.

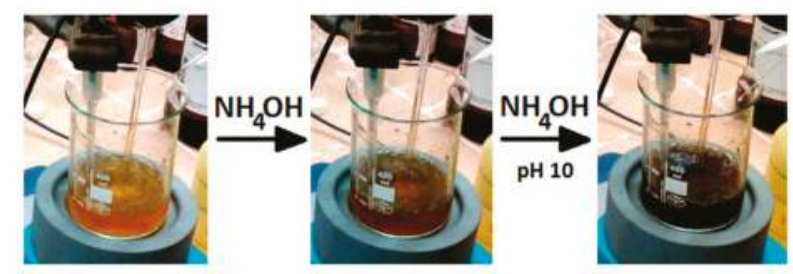

Figure 1. Image of the co-precipitation of Ho-doped ferrite nanoparticles under $\mathrm{NH}_{3}$ addition.

Nanoparticles were stabilized with 3-phosphonopropionic acid (CEPA), where $20 \mathrm{mg}$ of CEPA were used per $1 \mathrm{mg}$ of nanoparticles. The SPIONs were suspended in water, and then a CEPA solution with a $\mathrm{pH}$ of $\sim 5$ (set by the addition of an appropriate amount of $0.1 \mathrm{M} \mathrm{NaOH}$ ) was added dropwise with mechanical stirring. After CEPA addition into the SPIONs suspension, the solution was 
continuously stirred for the next $30 \mathrm{~min}$ and the suspension of nanoparticles stabilized with CEPA was washed several times with water to remove any unreacted products.

Transmission electron microscopy images were recorded using EF-TEM, Zeiss Libra 120 Plus, Stuttgart, Germany microscope operating at $120 \mathrm{kV}$. Samples were prepared from the sonicated aqueous suspensions and a drop was placed on the copper grid covered with formvar/carbon layer and dried in air. Dynamic light scattering (DLS) was used as a complementary technique to analyse the size of nanoparticles. Measurements were carried out with Malvern Instruments Zetasizer Nano ZS, Malvern, United Kingdom. The powder X-ray diffraction patterns were recorded with a powder diffraction X-ray diffractometer (PXRD) Bruker D8 Discover, Massachusets, USA operating with Debye-Scherrer geometry with $\mathrm{Cu} K \alpha$ radiation with line $\lambda=1.540598 \AA$ and a scan rate of $1^{\circ}$ per minute in $0.012^{\circ}$ steps covering the $2 \theta$ angle range from $20^{\circ}$ to $130^{\circ}$. Measurements were performed at RT. The X-ray photoelectron spectroscopy (XPS) measurements were performed using PHI 5000 VersaProbe (ULVAC-PHI) spectrometer, Gothenburg, Sweden with monochromatic $\mathrm{Al} \mathrm{K} \alpha$ radiation $(\mathrm{h} v=1486.6 \mathrm{eV})$ from $\mathrm{X}$-ray source operating at $100 \mu \mathrm{m}$ spot size, $25 \mathrm{~W}$ and $15 \mathrm{kV}$. XPS data were analysed with CasaXPS software ver. 2.3.16, Wimslow, United Kingdom. The binding energy values were calibrated and normalized to the $\mathrm{C} 1 \mathrm{~s}$ peak at $284.8 \mathrm{eV}$. The magnetic behaviour of samples was verified with a QD vibrating sample magnetometer VSM over the magnetic field range from $-2.0 \mathrm{~T}$ to $+2.0 \mathrm{~T}$ in the temperature from $100 \mathrm{~K}$ to $300 \mathrm{~K}$ stabilized to accuracy of about $0.01 \mathrm{~K}$. Magnetization and coercive fields were measured with accuracy better than $1 \%$. Thermogravimetric analysis (TGA) was performed with TGA Q50 (TA Instruments), New Castle, USA, under nitrogen.

\section{Results}

SPIONs were synthesized through the co-precipitation method, which is a widely used technique for the preparation of SPIONs from aqueous solutions [40,41]. To verify how changes in the holmium doping affect the shape, size, crystallinity and magnetic properties of the synthesized SPIONs, multiple techniques were used. The magnetic properties of the superparamagnetic core are affected by size and shape. Smaller SPIONs with a high surface area to volume ratio yield smaller mass magnetization than larger SPIONs due to the increased contribution of the surface anisotropic layer decreasing the overall magnetization. This is usually explained in terms of a core-shell model, where the magnetically dead layer, strains and distortions at the surface are claimed to be responsible for the particle size effects [42]. Therefore, in order to elucidate only the effects of holmium doping on the magnetic behaviour of SPIONs, we have chosen a synthetic procedure yielding SPIONs of low size distributions and good crystallinity. The controlled size distribution is also beneficial from the point of view of their prospective medical applications, as discussed in Section 1.

\subsection{Morphology Studies}

The changes of morphology of SPIONs under Ho doping were studied with TEM. The images obtained by TEM reveal the differences in the morphology for nanoparticles with various concentrations of $\mathrm{Ho}^{3+}$ vs. $\mathrm{Fe}^{3+}$ used during the synthesis. The high level of aggregation observed on the presented images is caused by sample preparation for TEM analysis: the ethanol suspension is placed on the TEM grids and during the solvent evaporation the nanoparticles aggregate (the Marangoni effect). The literature attributes the dependence of morphology to the experimental conditions, indicating the formation of nanoparticles (SPIONs) having spherical [43], quasi-spherical [44], and even octahedral [45] shapes. As can be seen in Figure 2, the aggregates of undoped nanoparticles (a), doped with $1 \%$ (b), and 2.5\% (c) of holmium have a spherical shape with an average diameter of about 10-15 $\mathrm{mm}$, whereas higher doping results in an irregular axial growth of the crystals and an increase of the grain size up to $30-40 \mathrm{~nm}$. Spherical particles, similar to pristine magnetite nanoparticles (Figure 2a), are formed when holmium doping does not exceed $2.5 \%$, only slightly affecting the crystal structure of nanoferrites. Exceeding the critical value of the holmium dopant in the ferrite lattice stimulates the crystal growth in one direction. Particles shown in 
Figure 2a,b appear to be monodispersed, and of similar morphology. Typical histogram exemplifying the size distribution of nanoparticles for $\mathrm{Fe}_{3} \mathrm{O}_{4} @ 2.5 \% \mathrm{Ho}$, is shown in Figure 3, below.

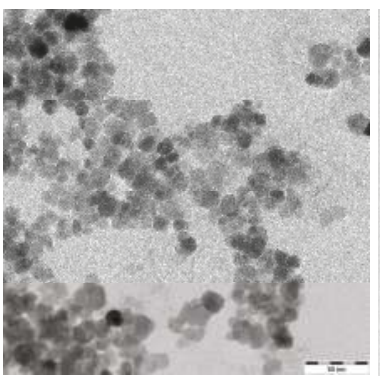

(a)

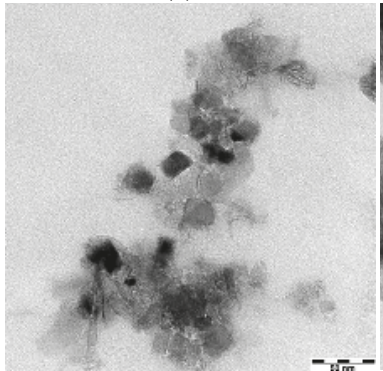

(d)

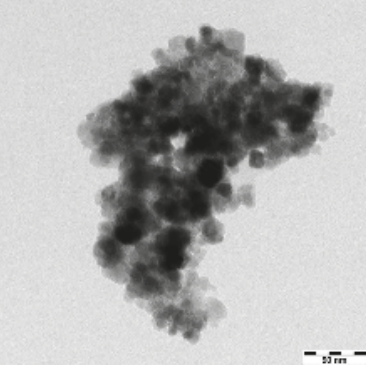

(b)

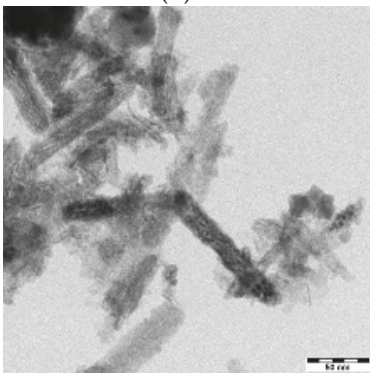

(e)

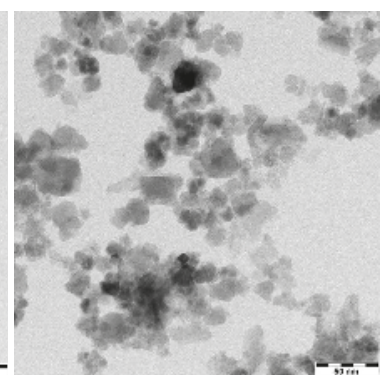

(c)

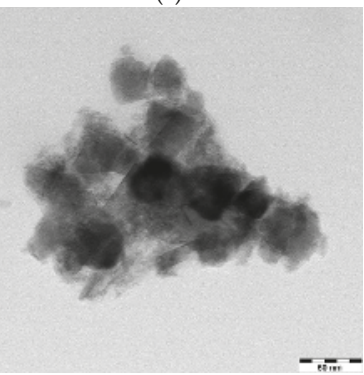

(f)

Figure 2. TEM images of (a) undoped iron oxide SPIONs, and doped with (b) $1 \%$; (c) $2.5 \%$; (d) $5 \%$; (e) $7.5 \%$; (f) $10 \%$ of holmium obtained by co-precipitation (scale bar: $50 \mathrm{~nm}$ ).

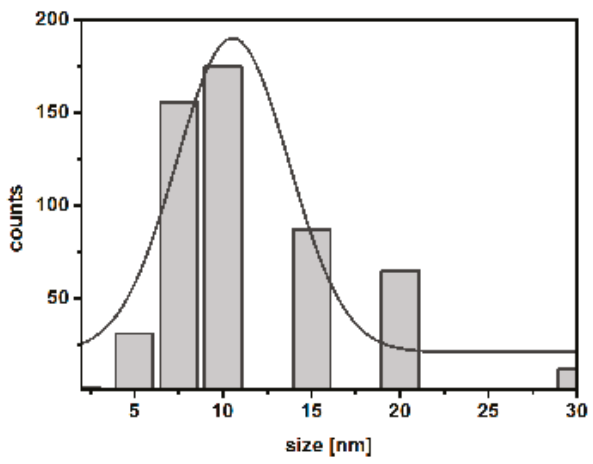

Figure 3. Histogram for $\mathrm{Fe}_{3} \mathrm{O}_{4} @ 2.5 \%$ Ho.

\subsection{Size Distribution and Zeta Potential Studies}

The size distribution of all samples was also investigated by means of dynamic light scattering (DLS) in an aqueous dispersion. Likewise assessed from the TEM analysis, the size of the investigated SPIONs is similar; however, SPIONs are not stabilized with any organic shell, and therefore they tend to precipitate spontaneously within a few minutes. Therefore, we stabilized them with a CEPA shell.

As can be seen in Figure 4, the size of the unmodified SPIONs containing $2.5 \%$ of holmium is ca. $89 \mathrm{~nm}$ in diameter, while after modification of their surface with CEPA this value is lower by ca. 
$20 \mathrm{~nm}$. A lower diameter of SPIONs covered with CEPA suggests that they are more dispersed than the unmodified ones. In comparison to the TEM analysis, the diameter value for uncovered SPIONs is higher because DLS reports the hydrodynamic diameter including the solvation shell of SPIONs agglomerate, whereas TEM images show only the solid core of nanoparticles. To confirm if unmodified SPIONs agglomerate, the zeta potential corresponding to the surface potential was measured. The zeta potential value for uncovered SPIONs suspended in water is about $-2.7 \mathrm{mV}$, while after covering with CEPA the zeta potential value is about $-32.5 \mathrm{mV}$. SPIONs covered with CEPA are stable at $\mathrm{pH} 7$ for more than a week, while non-covered tend to aggregate spontaneously.

This behaviour suggests the presence of strong electric charges on the SPIONs covered with CEPA, keeping all SPIONs away from each other.

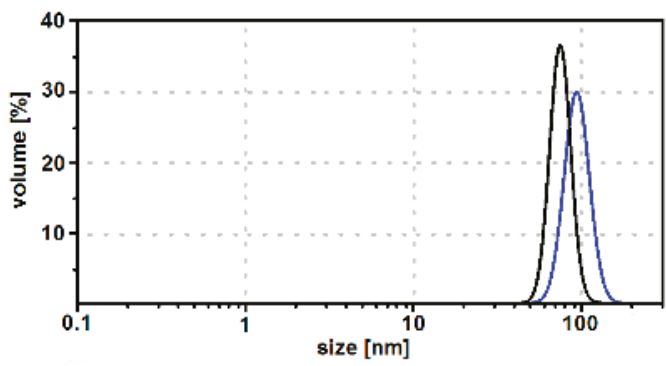

Figure 4. Size distribution by volume for $\mathrm{Fe}_{3} \mathrm{O}_{4} @ 2.5 \%$ Ho unmodified (blue curve) and modified with CEPA (black curve).

\subsection{Thermogravimetric Analysis}

The TGA analysis of nanoparticles doped with $1 \%$ and $2.5 \%$ of holmium and surface-modified with 3-phosphoropropionic acid was carried out in the range from ambient temperature to $600{ }^{\circ} \mathrm{C}$ with a heating rate of $10{ }^{\circ} \mathrm{C} / \mathrm{min}$ under the nitrogen atmosphere. The TG curves indicate a total weight loss of $\mathrm{Fe}_{3} \mathrm{O}_{4} @ 2.5 \%$ Ho nanoparticles due to the decomposition of the organic material from the surface of nanoparticles. On the basis of the thermograms presented in Figure 5, the quantity of 3-phosphoropropionic acid was evaluated. The organic shell constitutes ca. 7.5\% for $\mathrm{Fe}_{3} \mathrm{O}_{4} @ 1 \% \mathrm{Ho}$ and $9 \%$ for $\mathrm{Fe}_{3} \mathrm{O}_{4} @ 2.5 \% \mathrm{Ho}$ of the conjugate mass, which gives $0.075 \mathrm{mg}\left(4.9 \cdot 10^{-7} \mathrm{~mol}\right)$ per $1 \mathrm{mg}$ of $\mathrm{Fe}_{3} \mathrm{O}_{4} @ 1 \% \mathrm{Ho}$ SPIONs, and $0.09 \mathrm{mg}\left(5.8 \cdot 10^{-7} \mathrm{~mol}\right)$ per $1 \mathrm{mg}$ of $\mathrm{Fe}_{3} \mathrm{O}_{4} @ 2.5 \%$ Ho SPIONs. Based on the zeta potential studies, it is seen that such an amount of CEPA is sufficient to stabilize SPIONs.

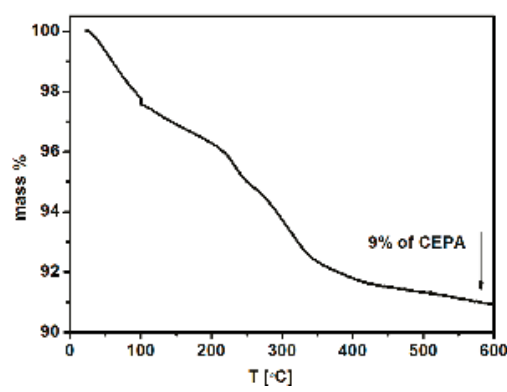

(a)

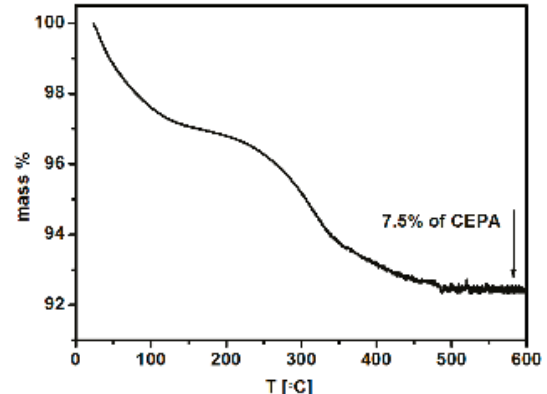

(b)

Figure 5. Thermograms of the SPIONs modified with 3-phosphoropropionic acid: (a) $\mathrm{Fe}_{3} \mathrm{O}_{4} @ 1 \% \mathrm{Ho@CEPA}$, and (b) $\mathrm{Fe}_{3} \mathrm{O}_{4} @ 2.5 \% \mathrm{Ho@CEPA.}$ 


\subsection{Crystallographic Structure}

Powder diffraction patterns were recorded with a powder diffraction X-ray diffractometer (PXRD) operating with Debye-Scherrer geometry and $\mathrm{Cu} \mathrm{K} \alpha$ radiation with line $\lambda=1.540598 \AA$. Measurements were performed at RT and a scan rate of $1^{\circ}$ per minute in $0.012^{\circ}$ steps, covering the $2 \theta$ angle range from $20^{\circ}$ to $130^{\circ}$. For nanoparticles containing 1-10 at. \% of holmium, the diffraction patterns consist of a series of peaks, whose positions reveal the $\mathrm{Fe}_{3} \mathrm{O}_{4}$ phase (JCPDS file, No. 19-0629 for magnetite) (see Figure 6). Due to the high iron content in the crystals, the $\mathrm{X}$-ray fluorescence is revealed as a noisy background in all recorded patterns. Synthesized nanoparticles have a high surface-to-volume ratio, crystal strains and surface defects, which contributes to the full width at half maximum (FWHM) of the reflexes. Their small size also correlates to the relatively broad shape of these patterns. According to the literature, the experimental conditions influence the crystal structure of prepared nanoparticles as well as other properties [46].

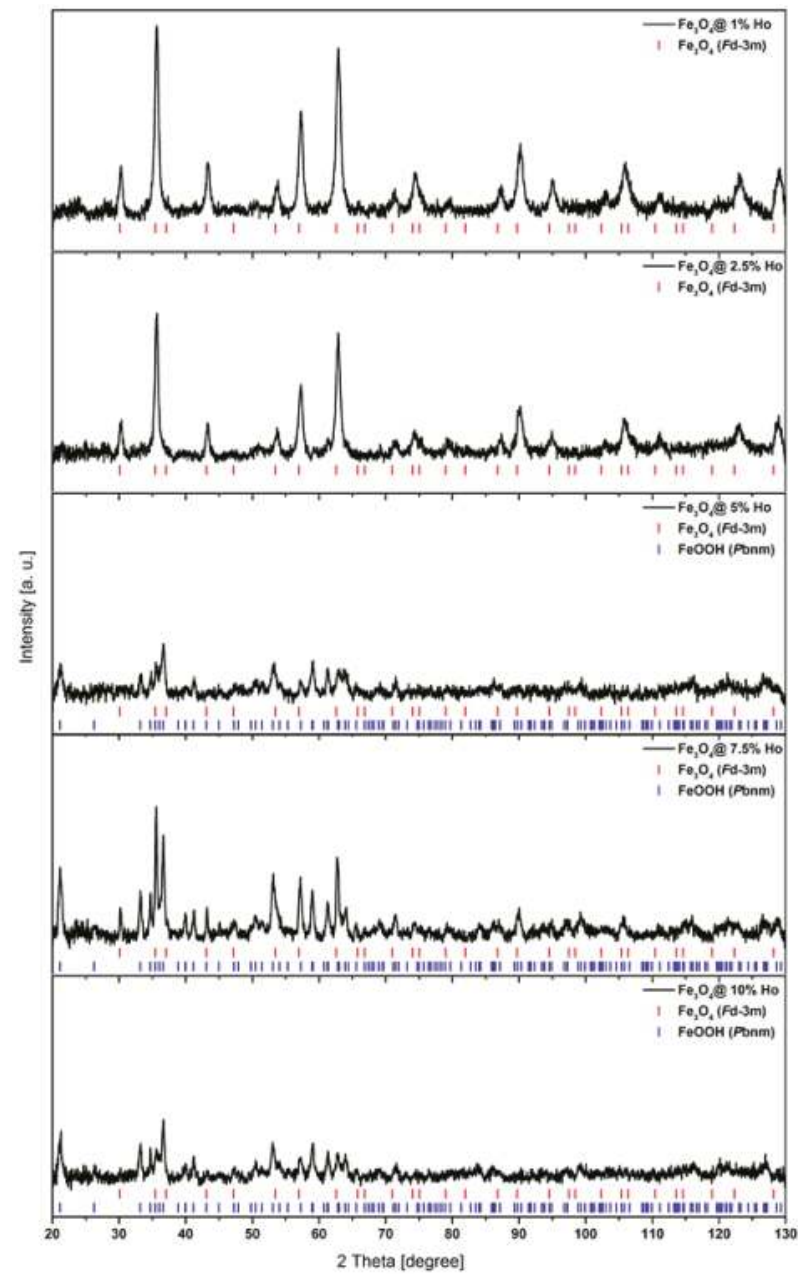

Figure 6. PXRD patterns of undoped and Ho-doped nanoferrite crystallites. 
Samples doped with 1 at. \% and 2.5 at. \% holmium reveal reflexes characteristic of the $\mathrm{Fd}-3$ $\mathrm{m}$ space group with single phase composition, while increasing holmium doping leads to poorer crystallinity and the additional formation of $P$ bnm space group of goethite: $\alpha$-FeOOH. The PXRD patterns explain the sudden change of crystal shape presented in the TEM images (see Figure 2), where crystallites with irregular shape appear. Line broadening in the recorded XRD patterns enables the calculation of the crystal size based on the Scherrer formula [47] and subsequent comparison to the TEM results. The average crystallite size in pure $\mathrm{Fe}_{3} \mathrm{O}_{4}$ is about $10 \mathrm{~nm}$, while the size of the doped SPIONs increases to ca. $17 \pm 2 \mathrm{~nm}$ (below 5\% doping), which correlates with the TEM studies. The appearance of goethite with a $5-10 \%$ doping level leads to the poorer crystallinity and increasing amorphism of the obtained precipitate. Additionally, the shape of SPIONs is elongated due to the presence of $\mathrm{FeOOH}$, which appears within this doping in the crystallites and, contrary to $\mathrm{Fe}_{3} \mathrm{O}_{4}$, crystallizes as a rhombic structure. [48]. In accordance with the literature [39], we do not observe a separate phase of $\mathrm{Ho}_{2} \mathrm{O}_{3}$.

The literature [35] suggests that lanthanide ions are incorporated into the octahedral sites of the crystallographic lattice, while such a replacement of $\mathrm{Fe}^{3+}$ with larger ions can cause a distortion of the lattice. Within this work we replaced $\mathrm{Fe}^{3+}$ having an ionic radius about $78.5 \mathrm{p}$, with $\mathrm{Ho}^{3+}$ ions, which are around $30 \%$ larger $(\sim 101 \mathrm{pm})$. The diffraction patterns show that the crystallinity is poorer for samples with the highest holmium content. Doping above $5 \%$ leads to polycrystallinity, and randomly distributed vacancies in the spinel structure appear. Drastic lattice deformation occurs with $5 \%$ holmium doping at $\mathrm{Fe}_{3} \mathrm{O}_{4}$ crystal. It is obvious that within such changes of the structure, the morphology of formed nanoparticles and magnetic properties should also change. We are inclined to assign the observed changes to the fact that at this doping level the amount of Ho is too large to be accommodated within the $F \mathrm{~d}-3 \mathrm{~m}$ space group. As a consequence, this may lead to the observed polycrystallinity of SPIONs. Nevertheless, these results show that, up to a given doping level, $\mathrm{Ho}^{3+}$ ions can be incorporated within magnetite crystallites and not merely adsorb onto the surface of SPIONs. Such adsorption will not lead to lattice distortions. However, we cannot exclude at least partial adsorption on $\mathrm{Ho}^{3+}$ ions onto a well-developed surface of SPIONs.

\subsection{XPS Analysis}

In addition to the XRD studies, X-ray photoelectron spectroscopy was applied to investigate the chemical composition of the formed nanoparticles with $2.5 \%$ holmium doping. For this purpose, the analysis of the binding energy of Ho $4 \mathrm{~d}$ and Fe $2 \mathrm{p}$ regions was carried out. The overall survey spectrum of the holmium-doped iron oxide nanoparticles is presented in Figure 7.

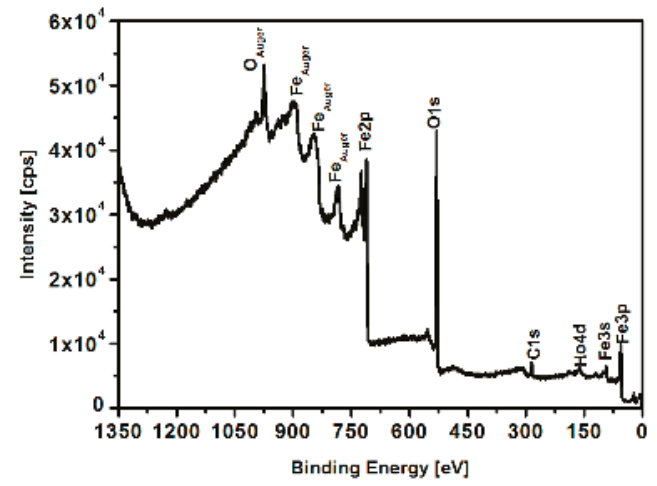

Figure 7. XPS survey spectrum of $\mathrm{Fe}_{3} \mathrm{O}_{4} @ 2.5$ at. \% Ho nanoparticles. 
Figure $8 \mathrm{a}, \mathrm{b}$ shows the indicative regions of Fe $2 \mathrm{p}$ and Ho $4 \mathrm{~d}$ binding energies, respectively, with deconvolution. As can be seen in Figure 8a, the spectrum can be fit to the doped iron oxide, where the peak positions of the $\mathrm{Fe} 2 \mathrm{p}_{3 / 2}$ and $\mathrm{Fe} 2 \mathrm{p}_{1 / 2}$ corresponding to the $\mathrm{Fe}^{3+}$ octahedral species [49] are located at binding energy $710.4 \mathrm{eV}$ and $723.9 \mathrm{eV}$, respectively. The peak at $710.4 \mathrm{eV}$ can be deconvoluted into two peaks: $\mathrm{Fe}^{2+} 2 \mathrm{p}_{3 / 2}$ and $\mathrm{Fe}^{3+} 2 \mathrm{p}_{3 / 2}$, respectively, ascribed to magnetite, but the precise deconvolution depends largely upon the model used [50]. The presence of satellite peaks at $718.7 \mathrm{eV}$ and $732.5 \mathrm{eV}$ may originate from the high-spin $\mathrm{Fe}^{2+} 2 \mathrm{p}_{3 / 2}$ shake-up. [50].

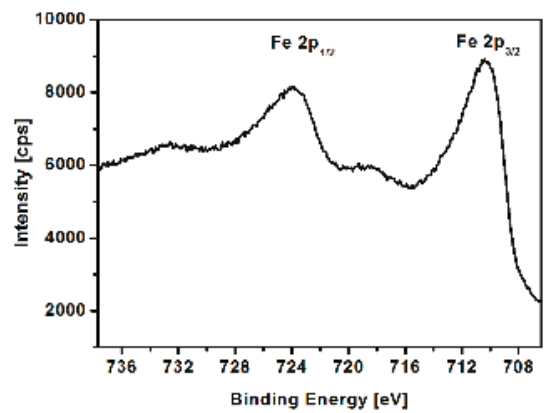

(a)

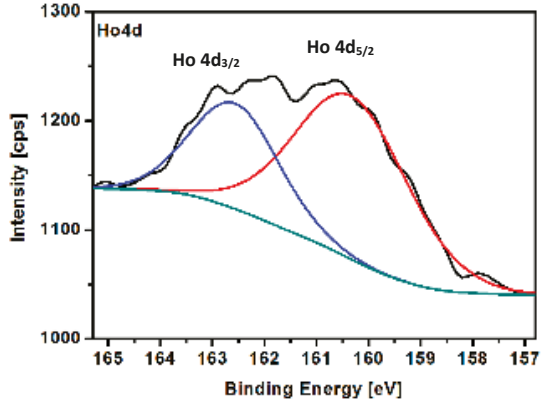

(b)

Figure 8. XPS spectra of (a) Fe 2p and (b) Ho 4d region for $\mathrm{Fe}_{3} \mathrm{O}_{4} @ 2.5 \% \mathrm{Ho}$ SPIONs.

The experimental results are similar to the literature data for iron at different oxidation states [51]. Figure $8 \mathrm{~b}$ presents the peaks at binding energies $160.5 \mathrm{eV}$ and $162.7 \mathrm{eV}$, characteristic to $\mathrm{Ho}^{3+} 4 \mathrm{~d}_{5 / 2}$ / and $4 \mathrm{~d}_{3 / 2}$, indicating that holmium has been incorporated into the crystal lattice of iron oxide [52]. Due to the low amount of holmium in our samples, these peaks are of low intensity; therefore, their further analysis can be inaccurate.

\subsection{Magnetic Analysis}

Magnetic measurements of the ferrite-based nanoparticles were performed in a broad range of the applied magnetic field. Magnetization of the SPIONs studied increases abruptly in magnetic fields up to about $300 \mathrm{Oe}$ and then approaches saturation at both $100 \mathrm{~K}$ and $300 \mathrm{~K}$ (Figure 9). The corresponding values of magnetization are lower for the $300 \mathrm{~K}$ isotherm than for the $100 \mathrm{~K}$ one. This magnetization decrease is consistent with a magnetization description given by the Brillouin function, which predicts magnetization suppression caused by the rising temperature [42,53,54]. The saturation magnetization $\mathrm{M}_{\mathrm{S}}$ measured at $100 \mathrm{~K}$ for the pure $\mathrm{Fe}_{3} \mathrm{O}_{4}$ nanoparticles is found to be $83 \mathrm{emu} / \mathrm{g}$, which is close to the value obtained for the undoped bulk magnetite. The magnetization value of nanoparticles depends on the experimental conditions during synthesis [54,55]. The $\mathrm{M}_{\mathrm{S}}$ magnetization decreases down to $65 \mathrm{emu} / \mathrm{g}$ with the rise in temperature from 100 to $300 \mathrm{~K}$ (see Figure 9). The magnetization at both $100 \mathrm{~K}$ and $300 \mathrm{~K}$ decreases gradually when Ho doping rises from $1 \%$ to $10 \%$. For $1 \%$ of Ho doping, only a slight $\mathrm{M}_{\mathrm{s}}$ reduction is observed. The saturation magnetization, $\mathrm{M}_{\mathrm{s}}$, of SPIONs doped with $2.5 \%$ being about $50 \mathrm{emu} / \mathrm{g}$ at $300 \mathrm{~K}$ is sufficient for magnetic separation under the applied external magnetic field (see Figure 9); however, subsequent doping above $2.5 \%$ of holmium leads to a decrease in the magnetization and degradation of the superparamagnetic properties, which is not satisfactory from a biomedical point of view.

The more detailed inspection of magnetization hysteresis loops in weak fields (Figure 10) allows us to determine the coercive field $\mathrm{H}_{\mathrm{c}}$. At a temperature of $300 \mathrm{~K}$, the coercive fields are equal $15 \mathrm{Oe}$ and 10 Oe for the pure magnetite and SPIONs with $1 \%$ of Ho, respectively. Such a low coercive field $\left(\mathrm{H}_{\mathrm{c}}\right)$ as well as the shape of the magnetization curve are the characteristic features of superparamagnetic 
materials. The coercive field also remains low for the $2.5 \%$ and $5 \%$ doping, whereas $\mathrm{H}_{\mathrm{c}}$ increases for $7.5 \%$ and $10 \%$ doping (Figure 11). On the other hand, one may notice the remarkably larger $\mathrm{H}_{\mathrm{c}}$ values ranging between about 60 and 120 Oe, when the SPIONs studied become ferromagnetic at $100 \mathrm{~K}$ (Figure 11) [56].

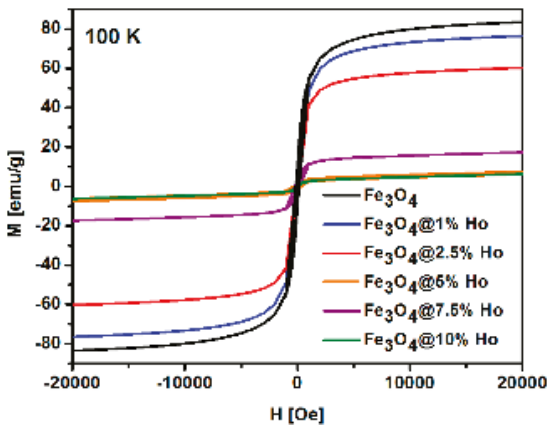

(a)

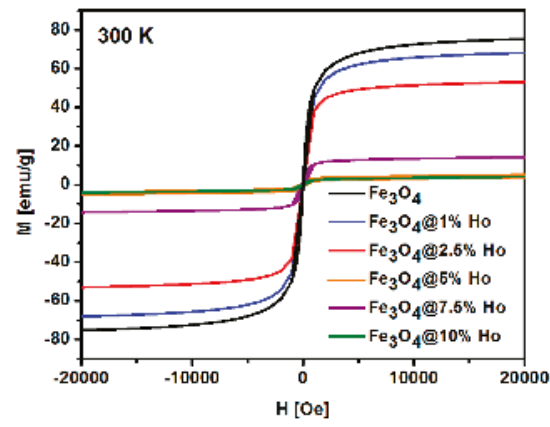

(b)

Figure 9. Magnetization isotherms for SPIONs with different Ho content measured at (a) $100 \mathrm{~K}$ and (b) $300 \mathrm{~K}$.

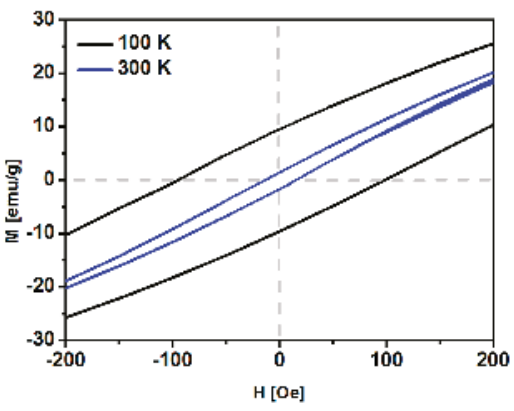

(a)

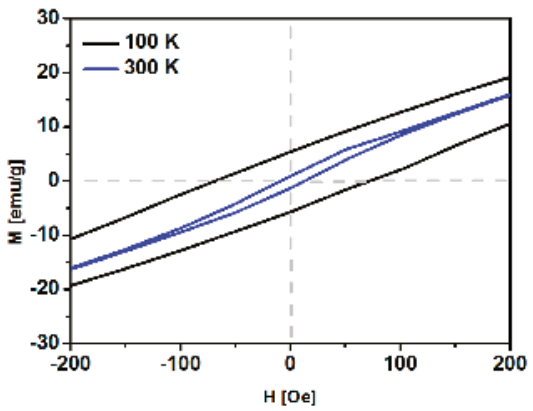

(b)

Figure 10. Magnetization loops $\mathrm{K}$ for $(\mathbf{a}) \mathrm{Fe}_{3} \mathrm{O}_{4},(\mathbf{b}) \mathrm{Fe}_{3} \mathrm{O}_{4} @ 1 \%$ Ho registered at $100 \mathrm{~K}$ and $300 \mathrm{~K}$ from -200 Oe to 200 Oe.

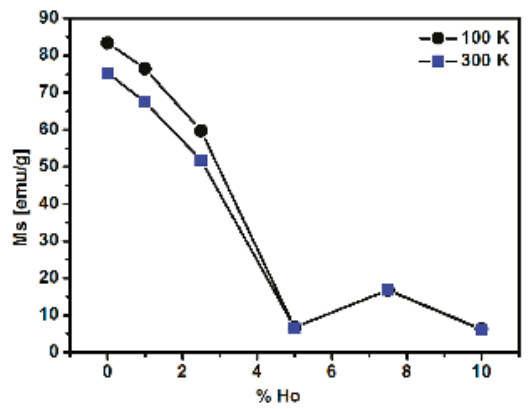

(a)

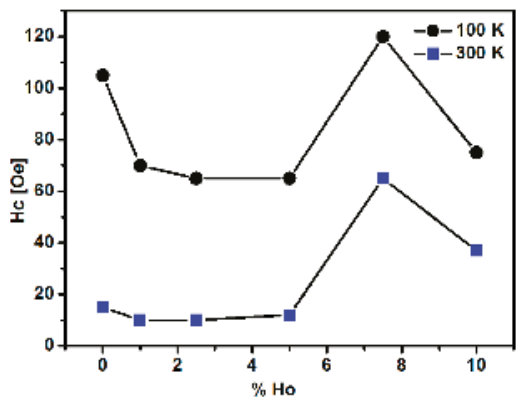

(b)

Figure 11. Values of (a) saturation magnetization at 20.000 Oe and (b) coercive field as a function of holmium content in SPIONs measured at $100 \mathrm{~K}$ and $300 \mathrm{~K}$. Error bars are smaller than the data symbols. 
A depletion of magnetic properties is observed for the higher holmium content. The saturation magnetization $\mathrm{M}_{\mathrm{S}}$ drops when Ho doping is above $2.5 \%$ (Figure 11). This is accompanied by an increase in the coercive field $\mathrm{H}_{\mathrm{c}}$ above $5 \%$ of Ho. The observed changes may be due to several reasons. The crystallographic lattice is found to be distorted at an Ho content exceeding $2.5 \%$, as discussed in chapter 3.4. Crystallographic Structure.

It is also observed that the grains start to deviate from a spherical shape. Moreover, the doped ferrites become multiphasic as the additional $\alpha$-FeOOH goethite phase appears in the NPs. This goethite phase is known to contain vacancies, which enhance the coercivity fields [57]. Thus, the magnetization results correlate well with the crystallographic data (vide supra).

The observed degradation of magnetic properties of studied ferrites is consistent with a two-phase approach of the so-called core-shell model, which is commonly used in analysis of fine structured materials [54]. The magnetic and electrical properties of transition-metal-based oxides are known to be strongly affected by various types of structural and chemical disorder [54,58-60]. The level of disorder may be accounted for by the volume fraction of disordered phase contained in the solid. In the polycrystalline and nanocrystalline solids a mean size of grains/crystallites is on the order of micrometers or tens of nanometers, respectively.

The surface layer/shell of grains and crystallites contains a material that is strongly structurally disordered as compared to the inner core of crystallites, which preserves the long-range translational symmetry characteristic of the bulk material. The thickness of the surface layer/shell extends from one to about a few nanometers and weakly depends on preparation method [43]. Thus, the volume fraction of a surface shell is known to increase abruptly when grain sizes are reduced down to the nanometer range $[48,49,54]$. In a rough approximation, the surface shell is often assumed to be nonmagnetic or weakly magnetic. Therefore, the magnetization of a nanostructured solid becomes suppressed as compared to the bulk material of the same chemical composition. In order to enhance their magnetization, materials like magnetite are doped with e.g., rare earth ions bearing a large magnetic moment. This approach may be successful to some extent since the atomic size mismatch between $\mathrm{Fe}$ and rare earth atoms starts to distort the atomic lattice and deplete the magnetic parameters. Finally, the magnetic properties of the doped ferrites studied in this work result from two competing factors: the atomic size mismatch and the high magnetic moment of Ho ions.

The magnetic properties of prepared SPIONs are stable. The dependence of magnetization in the Zero-Field-Cooled (ZFC) and Field-Cooled (FC) modes in the applied DC field of 100 Oe was measured versus temperature range from 60 to $350 \mathrm{~K}$ (Figure 12). The FC magnetization varies only weakly in the temperature range studied. The ZFC magnetization is a monotonically increasing function of temperature; however, the ZFC maximum related to the blocking temperature $\mathrm{T}_{\mathrm{B}}$, may be located above $350 \mathrm{~K}$. The shape of the ZFC curve may be due to the relatively broad grain size distribution.

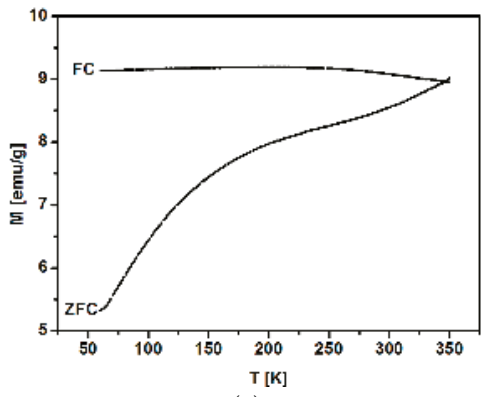

(a)

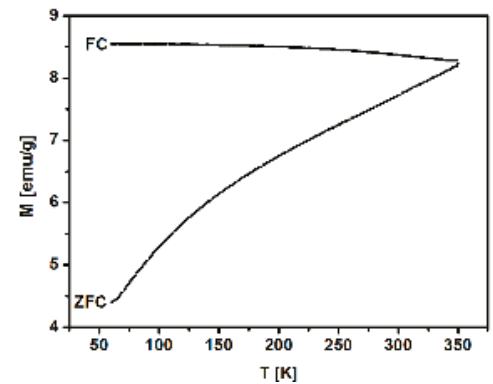

(b)

Figure 12. Temperature dependence of ZFC and FC magnetization at 100 Oe for nanoparticles doped with (a) $1 \%$ and (b) $2.5 \%$ of holmium. 


\section{Discussion}

The aim of this work was to introduce a simple approach to incorporate the lanthanide, $\mathrm{Ho}^{3+}$, ions into the ferrite oxide nanoparticles through the co-precipitation synthesis at room temperature, forming Ho-doped multifunctional SPIONs for their further modifications for biomedical applications. SPIONs doped with holmium were successfully synthesized in conditions enabling us to control their properties, such as shape, size, magnetization and structure. We have found that $2.5 \%$ molar of holmium in the ferrite-based SPIONs is maximal value yielding SPIONs with homogeneous phase and high magnetization above $60 \mathrm{emu} / \mathrm{g}$. Undoped and 1-2.5\% Ho-doped samples have a size ranging from a few to $20 \mathrm{~nm}$ in diameters, whereas further increase in the holmium content causes the growth of their size and irregular shape of the grains. We also observed an unusual drop in the magnetic properties at $5 \%$ of holmium in SPIONs, which we are inclined to assign to the size mismatch of $\mathrm{Ho}^{3+}$ and $\mathrm{Fe}^{3+}$ ions, leading to crystal lattice strain, defects in the structure and the formation of the goethite phase. The conclusion on the formation of $\alpha-\mathrm{FeOOH}$ in the synthesized nanoparticles is additionally supported by the appearance of coercivity under the influence of an external magnetic field. XPS analysis confirmed the presence of holmium-doped iron oxide SPIONs. In contrast to the heterogeneous samples, SPIONs doped with 1-2.5\% reveal superparamagnetic behaviour at room temperature and XRD patterns confirm that they maintain a homogeneous phase with well-formed crystallites. As they are synthesized, SPIONs tend to aggregate in the aqueous media. Subsequent modification with a CEPA organic shell stabilizes the suspension due to the electrostatic repulsion of negatively charged carboxylic groups of 3-phosphoropropionic acid shell. Further studies will attempt to implement the replacement of "cold" atoms of Ho in the superparamagnetic core with its ${ }^{166} \mathrm{Ho}$ radionuclide, emitting "soft" $\beta(-)$ radiation limited only to the distance of several millimeters, for the multiplied therapeutic effect of endoradiotherapy and magnetic hyperthermia.

\section{Conclusions}

In summary, using an efficient co-precipitation technique we obtained and characterized SPIONs doped with holmium. Taking into account their physicochemical properties, the superparamagnetic SPIONs doped with 1-2.5\% holmium can be used for biomedical applications. The incorporation of such an amount of lanthanide is optimal for maintaining high magnetization and the homogeneous crystal structure of SPIONs, as a core SPIONs for modification with organic linkers and antitumor drugs. SPIONs prepared via the proposed route have great potential application in the biomedical field.

\section{Patents}

Application no. P-424901.

Author Contributions: M.O. and P.K. conceived and designed the experiments; M.O. and P.R. synthesized nanoparticles and performed DLS measurements/analysis, M.O. measured TGA and modified nanoparticles, M.P. performed/interpreted magnetometry experiments, G.C. and M.K.C. performed/interpreted XRD experiments, M.O. and P.K. analysed the data and wrote the paper.

Funding: This research was funded by [National Science Centre (NCN)] grant number [UMO-2016/21/B/ ST4/02133-OPUS].

Acknowledgments: Thanks to Marcin Pisarek, PhD (Polish Academy of Science in Warsaw), for carrying out the XPS measurements and analysis.

Conflicts of Interest: The authors declare no conflict of interest. The founding sponsors had no role in the design of the study; in the collection, analyses, or interpretation of data; in the writing of the manuscript, and in the decision to publish the results.

\section{References}

1. Wu, M.; Huang, S. Magnetic nanoparticles in cancer diagnosis, drug delivery and treatment (Review). Mol. Clin. Oncol. 2017, 7, 738-746. [CrossRef] [PubMed] 
2. Brzozowska, M.; Krysinski, P. Synthesis and functionalization of magnetic nanopartciles with covalently bound electroactive compound doxorubicine. Electrochim. Acta 2009, 54, 5065-5070. [CrossRef]

3. Banobre-López, M.; Teijeiro, A.; Rivas, J. Magnetic nanoparticles-based hyperthermia for cancer treatment. Rep. Pract. Oncol. Radiother. 2013, 18, 397-400. [CrossRef] [PubMed]

4. Tsuotoaka, T. Frequency dispersion of complex permeability in Mn-Zn and Ni-Zn spinel ferrites and their composite materials. J. Appl. Phys. 2003, 93, 2789-2796. [CrossRef]

5. Hartshorne, H.; Backhouse, C.J.; Lee, W.E. Ferrofluid-based microchip pump and valve. Sens. Actuators $B$ 2004, 99, 592-600. [CrossRef]

6. Condomitti, U.; Almeida, S.N.; Silveira, A.T., Jr.; de Melo, F.; Toma, H.E. Green Processing of Strategic Elements Based on Magnetic Nanohydrometallurgy. J. Baz. Chem. Soc. 2018, 29, 948-959. [CrossRef]

7. Bucak, S.; Jones, D.A.; Laibinis, P.E.; Hatton, T.A. Protein separations using colloidal magnetic nanoparticles. Biotechnol. Prog. 2003, 19, 477-484. [CrossRef] [PubMed]

8. Li, Z.; AdYi, P.W.; Sun, Q.; Lei, H.; Zhao, H.L.; Zhu, H.Z.; Smith, S.C.; Lan, M.B.; Lu, G.Q. Ultrasmall Water-Soluble and Biocompatible Magnetic Iron Oxide Nanoparticles as Positive and Negative Dual Contrast Agents. Funct. Mater. 2012, 22, 2387-2393. [CrossRef]

9. Zhou, L.; He, B.; Zhang, F. Facile one-pot synthesis of iron oxide nanoparticles cross-linked magnetic poly(vinyl alcohol) gel beads for drug delivery. ACS Appl. Mater. Interfaces 2012, 4, 192-199. [CrossRef] [PubMed]

10. Kim, J.; Piao, Y.; Hyeon, T. Multifunctional nanostructured materials for multimodal imaging, and simultaneous imaging and therapy. Chem. Soc. Rev. 2009, 38, 372-390. [CrossRef] [PubMed]

11. Zhang, W.; Li, X.; Zou, R.; Wu, H.; Shi, H.; Yu, S.; Liu, Y. Multifunctional glucose biosensors from $\mathrm{Fe}_{3} \mathrm{O}_{4}$ nanoparticles modified chitosan/graphene nanocomposites. Sci Rep. 2015, 5, 11129. [CrossRef] [PubMed]

12. Li, X.; Wen, F.; Creran, B.; Jeong, Y.; Zhang, X.; Rotello, V.M. Colorimetric protein sensing using catalytically amplified sensor arrays. Small 2012, 8, 3589-3592. [CrossRef] [PubMed]

13. Zhang, Q.; Liu, J.; Yuan, K.; Zhang, Z.; Zhang, X.; Fang, X. A multi-controlled drug delivery system based on magnetic mesoporous $\mathrm{Fe}_{3} \mathrm{O}_{4}$ nanopaticles and a phase change material for cancer thermo-chemotherapy. Nanotechnology 2017, 28, 405101. [CrossRef] [PubMed]

14. Chen, F.H.; Gao, Q.; Ni, J.Z. The grafting and release behavior of doxorubincine from $\mathrm{Fe}_{3} \mathrm{O}_{4} @ \mathrm{SiO}_{2}$ core-shell structure nanoparticles via an acid cleaving amide bond: the potential for magnetic targeting drug delivery. Nanotechnology 2008, 19, 165103. [CrossRef] [PubMed]

15. Pugazhendhi, A.; Edison, T.; Nesakumar, J.I.; Karuppusamy, I.; Brindhadevi, K. Inorganic nanoparticles: A potential cancer therapy for human welfare. Int. J. Pharm. 2018, 539, 104-111. [CrossRef] [PubMed]

16. Kievit, F.M.; Zhang, M. Surface engineering of iron oxide nanoparticles for targeted cancer therapy. Acc. Chem. Res. 2011, 44, 853-862. [CrossRef] [PubMed]

17. Safarik, I.; Baldikova, E.; Prochazkova, J.; Safarikova, M.; Pospiskova, K. Magnetically Modified Agricultural and Food Waste: Preparation and Application. J. Agric. Food Chem. 2018, 66, 2538-2552. [CrossRef] [PubMed]

18. Cardoso, V.F.; Francesko, A.; Ribeiro, C.; Bañobre-López, M.; Martins, P.; Lanceros-Mendez, S. Advances in Magnetic Nanopartciles for Biomedical Applications. Adv. Healthc. Mater. 2017, 7, 1-35. [CrossRef]

19. Cortajarena, A.L.; Ortega, D.; Ocampo, S.M.; Gonzalez-García, A.; Couleaud, P.; Miranda, R.; Belda-Iniesta, C.; Ayuso-Sacido, A. Engineering iron oxide nanoparticles for clinical settings. Nanobiomedicine 2014, 1, 2. [CrossRef]

20. Stamopoulos, D.; Manios, E.; Gogola, V.; Niarchos, D.; Pissas, M. On the biocompatibility of $\mathrm{Fe}_{3} \mathrm{O}_{4}$ ferromagnetic nanoparticles with human blood cells. J. Nanosci. Nanotechnol. 2010, 10, 6110-6115. [CrossRef] [PubMed]

21. Li, L.; Jiang, W.; Luo, K.; Song, H.; Lan, F.; Wu, Y.; Gu, Z. Superparamagnetic iron oxide nanoparticles as MRI contrast agents for non-invasive stem cell labeling and tracking. Theranostics 2013, 3, 595-615. [CrossRef] [PubMed]

22. Maier-Hauff, K.; Ulrich, F.; Nestler, D.; Niehoff, H.; Wust, P.; Thiesen, B.; Orawa, H.; Budach, V.; Jordan, A. Efficacy and safety of intratumoral thermotherapy using magnetic iron-oxide nanoparticles combined with external beam radiotherapy on patients with recurrent glioblastoma multiforme. J. Neuro-Oncol. 2011, 103, 317-324. [CrossRef] [PubMed] 
23. Maier-Hauff, K.; Rothe, R.; Scholz, R.; Gneveckow, U.; Thiesen, B.; Feussner, A.; Deimling, A.; Waldoefner, N.; Felix, R.; Jordan, A. Intracranial thermotherapy using magnetic nanoparticles combined with external beam radiotherapy: Results of a feasibility study on patients with glioblastoma multiforme. J. Neuro-Oncol. 2007, 81, 53-60. [CrossRef] [PubMed]

24. Hasany, S.; Ahmed, I.; Rajan, J.; Rehman, A. Systematic review of the preparation techniques of iron oxide magnetic nanoparticles. Nanosci. Nanotechnol. 2012, 2, 148-158. [CrossRef]

25. Huber, D.L. Synthesis, properties, and applications of iron nanoparticles. Small 2005, 1, 482-501. [CrossRef] [PubMed]

26. De Cuyper, M.; Joniau, M. Magnetoliposomes. Formation and structural characterization. Eur. Biophys. J. 1988, 15, 311-319. [CrossRef] [PubMed]

27. De Silva, C.R.; Smith, S.; Shim, I.; Pyun, J.; Gutu, T.; Jiao, J.; Zheng, Z. Lanthanide(III)-Doped Magnetite Nanoparticles. J. Am. Chem. Soc. 2009, 131, 6336-6337. [CrossRef] [PubMed]

28. Petran, A.; Radu, T.; Borodi, G.; Nan, A.; Suciu, M.; Turcu, R. Effects of rare earth doping on multi-core iron oxide nanoparticles properties. Appl. Surf. Sci. 2018, 428, 492-499. [CrossRef]

29. Kanasamy, G.; Maity, D. Recent advances in superparamagnetic iron oxide nanoparticles (SPIONs) for in vitro and in vivo cancer nanotheranostics. Int. J. Pharm. 2015, 496, 191-218. [CrossRef] [PubMed]

30. Raana, G.; Johri, U.C. A study on structural and magnetic properties of Ni-substituted magnetite nanopartciles. J. Alloys Compd. 2013, 577, 376-381. [CrossRef]

31. Mariotto, G.; Murphy, S.; Berdunov, N.; Ceballos, S.F.; Shvets, I.V. Influence of Ca and K on the reconstruction of the $\mathrm{Fe}_{3} \mathrm{O}_{4}(001)$ surface. Surf. Sci. 2004, 564, 79-86. [CrossRef]

32. Webelements. Available online: https://www.webelements.com/holmium/atom_sizes.html (accessed on 16 May 2018).

33. Rekorajska, A.; Cichowicz, G.; Cyranski, M.K.; Grden, M.; Pekala, M.; Blanchard, G.J.; Krysinski, P. Synthesis and Characterization of Tb-Doped Nanoferrites. ChemNanoMat 2018, 4, 231-242. [CrossRef]

34. Chaturvedi, S.; Rabindranath, B.; Sathe, V.; Kulkarni, S.; Singh, S. Holmium induced enhanced functionality at room temperature and structural phase transition at high temperature in bismuth ferrite nanopartciles. J. Mater. Chem. C 2016, 4, 780-792. [CrossRef]

35. Rice, K.P.; Russek, S.E.; Geiss, R.H.; Shaw, J.M.; Usselman, R.J.; Evarts, E.R.; Silva, T.J.; Nembach, H.T.; Arenholtz, E.; Idzerda, Y.U. Temperature-dependent structure of Tb-doped magnetite nanoparticles. Appl. Phys. Lett. 2015, 106, 062409. [CrossRef]

36. Wu, W.; He, Q.; Jiang, C. Magnetic Iron Oxide Nanoparticles: Synthesis and Surface Functionalization Strategies. Nanoscale Res. Lett. 2008, 3, 397-415. [CrossRef] [PubMed]

37. Laurent, S.; Forge, D.; Port, M.; Roch, A.; Robic, C.; Elst, L.V.; Muller, R.N. Magnetic Iron Oxide Nanoparticles: Synthesis, Stabilization, Vectorization, Physicochemical Characterizations, and Biological Applications. Chem. Rev. 2008, 108, 2064-2110. [CrossRef] [PubMed]

38. Mamani, J.B.; Costa-Filho, A.J.; Cornejo, D.R.; Vieira, E.D.; Gamarra, L.F. Synthesis and characterization of magnetite nanoparticles coated with lauric acid. Mater. Charact. 2013, 81, 28-36. [CrossRef]

39. Bloemen, M.; Vandendriessche, S.; Goovaerts, V.; Brullot, W.; Vanbel, M.; Carron, S.; Geukens, N.; Parac-Vogt, T.; Verbiest, T. Synthesis and characterization of holmium-doped iron oxide nanopartciles. Materials 2014, 7, 1154-1164. [CrossRef] [PubMed]

40. Thanh, N.T.K.; Maclean, N.; Mahiddine, S. Mechanisms of nucleation and growth of nanoparticles in solution. Chem. Rev. 2014, 114, 7610-7630. [CrossRef] [PubMed]

41. Vikram, S.; Dhakshnamoorthy, M.; Vasanthakumari, R.; Rajamani, A.R.; Rangarajan, M.; Tsuzuki, T. Tuning the magnetic properties of iron oxide nanoparticles by a room-temperature. J. Nanosci. Nanotechnol. 2015, 15, 3870-3878. [CrossRef] [PubMed]

42. Baaziz, H.; Tozri, A.; Dhahri, E.; Hlil, E.K. Effect of particle size reduction on the structural, magnetic properties and the spin excitations in ferromagnetic insulator $\mathrm{L}_{0.9} \mathrm{Sr}_{0.1} \mathrm{MnO}_{3}$ nanoparticles. Ceram Int. 2015, 41, 2955-2962. [CrossRef]

43. Ozel, F.; Kockar, H. Growth and characterizations of magnetic nanoparticles under hydrothermal conditions: Reaction time and temperature. J. Magn. Mater. 2015, 373, 213-216. [CrossRef]

44. Klein, S.; Sommer, A.; Distel, L.V.R.; Hazemann, J.-L.; Kröner, W.; Neuhuber, W.; Müller, P.; Proux, O.; Kryschi, C. Superparamagnetic iron oxide nanoparticles as novel X-ray enhancer for low-dose radiation therapy. J. Phys. Chem. B 2014, 118, 6159-6166. [CrossRef] [PubMed] 
45. Li, W.P.; Liao, P.Y.; Su, C.H.; Yeh, C.S. Formation of oligonucleotide-gated silica shell-coated $\mathrm{Fe}_{3} \mathrm{O}_{4}-\mathrm{Au}$ core-shell nanotrisoctahedra for magnetically targeted and near-infrared light-responsive theranostic platform. J. Am. Chem. Soc. 2014, 136, 10062-10075. [CrossRef] [PubMed]

46. Serna, C.J.; Bødker, F.; Mørup, S.; Morales, M.P.; Sandiumenge, F.; Veintemillas Verdaguer, S. Spin frustration in maghemite nanoparticles. Solid State Commun. 2001, 118, 437-440. [CrossRef]

47. Hummer, D.H.; Heaney, P.J.; Post, J.E. In situ observations of particles size evolution during the hydrothermal crystallization of $\mathrm{TiO}_{2}$ : A time-resolved synchrotron SAXS and WAXS study. J. Cryst. Growth 2012, 344, 51-58. [CrossRef]

48. Li, D.; Hu, X.; Sun, Y.; Su, S.; Xia, A.; Ge, H. Geothite $(\alpha-\mathrm{FeOOH})$ nanopowders synthesized via a surfactant-assisted hydrothermal method: Morphology, magnetic properties and conversion to rice-like $\alpha-\mathrm{Fe}_{2} \mathrm{O}_{3}$ after annealing. RSC Adv. 2015, 5, 27091-27096. [CrossRef]

49. Wilson, D.; Langell, M.A. XPS analysis of oleylamine/oleic acid capped $\mathrm{Fe}_{3} \mathrm{O}_{4}$ nanoparticles as a function of temperature. Surf. Sci. 2014, 303, 6-13. [CrossRef]

50. Grosvenor, A.P.; Kobe, B.A.; Biesinger, M.C.; McIntyre, N.S. Investigation of multiplet splitting of Fe 2p XPS spectra and bonding in iron compounds. Surf. Interface Anal. 2004, 36, 1564-1574. [CrossRef]

51. Yamashita, T.; Hayes, P. Analysis of XPS spectra of $\mathrm{Fe}^{2+}$ and $\mathrm{Fe}^{3+}$ ions in oxide materials. Appl. Surf. Sci. 2008, 254, 2441-2449. [CrossRef]

52. Fan, Z.; Wu, T.; Xu, X. Synthesis of reduced grapheme oxide as a platform for loading $\beta-\mathrm{NaYF}_{4}: \mathrm{Ho}^{3+} @ \mathrm{TiO}_{2}$ based on an advanced visible light-driven photocatalyst. Sci. Rep. 2017, 7, 13833. [CrossRef] [PubMed]

53. Coey, J.M.D. Magnetism and Magnetic Materials; Cambridge University Press: Cambridge, UK, 2010.

54. Baaziz, W.; Pichon, B.P.; Fleutot, S.; Liu, Y.; Lefevre, C.; Greneche, J.M.; Toumi, M.; Mhiri, T.; Begin-Colin, S. Magnetic iron oxide nanoparticles: reproducible tuning of the size and nanosized-dependent composition, defects, and spin canting. J. Phys. Chem. C 2014, 118, 3795-3810. [CrossRef]

55. Ho, D.; Sun, X.; Sun, S. Monodisperse magnetic nanoparticles for theranostic applications. Acc. Chem. Res. 2011, 44, 875-882. [CrossRef] [PubMed]

56. Köferstein, R.; Walther, T.; Hesse, D.; Ebbinghaus, S.G. Preparation and characterization of nanosized magnesium ferrite powders by starch-gel process and corresponding ceramics. J. Mater. Sci. 2013, 48, 6509-6518. [CrossRef]

57. Lee, G.H.; Kim, S.H.; Choi, B.J.; Huh, S.H. Magnetic Properties of needle-like $\alpha$-FeOOH and $\gamma$-FeOOH nanopartciles. J. Korean Phys. Soc. 2004, 45, 1019-1024. [CrossRef]

58. Veverka, P.; Kaman, O.; Knížek, K.; Novák, P.; Maryško, M.; Jirák, Z. Magnetic properties of rare-earth-doped $\mathrm{La}_{0.7} \mathrm{Sr}_{0.3} \mathrm{MnO}_{3}$. J. Phys. Condensed Matter 2017, 29, 035803. [CrossRef] [PubMed]

59. Markovich, V.; Fita, I.; Wisniewski, A.; Mogilyansky, D.; Puzniak, R.; Titelman, L.; Martin, C.; Gorodetsky, G. Size effect on the magnetic properties of antiferromagnetic $\mathrm{La}_{0.2} \mathrm{Ca}_{0.8} \mathrm{MnO}_{3}$ nanoparticles. Phys. Rev. B 2010, 81, 094428. [CrossRef]

60. Curiale, J.; Granada, M.; Troiani, H.E.; Sánchez, R.D.; Leyva, A.G.; Levy, P.; Samwer, K. Magnetic dead layer in ferromagnetic manganite nanoparticles. Appl. Phys. Lett. 2009, 95, 043106. [CrossRef]

(C) 2018 by the authors. Licensee MDPI, Basel, Switzerland. This article is an open access article distributed under the terms and conditions of the Creative Commons Attribution (CC BY) license (http:/ / creativecommons.org/licenses/by/4.0/). 


\title{
Fluorescence and Cytotoxicity of Cadmium Sulfide Quantum Dots Stabilized on Clay Nanotubes
}

\author{
Anna V. Stavitskaya ${ }^{1}$, Andrei A. Novikov ${ }^{1, *}$, Mikhail S. Kotelev ${ }^{1}$, Dmitry S. Kopitsyn ${ }^{1}$, \\ Elvira V. Rozhina ${ }^{2}$, Ilnur R. Ishmukhametov ${ }^{2}$, Rawil F. Fakhrullin ${ }^{2}$, Evgenii V. Ivanov ${ }^{1}$, \\ Yuri M. Lvov ${ }^{1,3, *}$ and Vladimir A. Vinokurov ${ }^{1}$ \\ 1 Functional Aluminosilicate Nanomaterials Lab, Gubkin University, Moscow 119991, Russia; \\ stavitsko@mail.ru (A.V.S.); kain@inbox.ru (M.S.K.); kopicin.d@inbox.ru (D.S.K.); ivanov166@list.ru (E.V.I.); \\ vinok_ac@mail.ru (V.A.V.) \\ 2 Bionanotechnology Lab, Institute of Fundamental Medicine and Biology, Kazan Federal University, \\ Kazan, Republic of Tatarstan, Russian Federation, 420008; rozhinaelvira@gmail.com (E.V.R.); \\ sal.ilnur@gmail.com (I.R.I.); kazanbio@gmail.com (R.F.F.) \\ 3 Institute for Micromanufacturing, Louisiana Tech University, Ruston, LA 71272, USA \\ * Correspondence: novikov.a@gubkin.ru (A.A.N.); ylvov@latech.edu (Y.M.L.); \\ Tel.: +7-499-507-8692 (A.A.N.); +1-318-257-5144 (Y.M.L.)
}

Received: 8 May 2018; Accepted: 28 May 2018; Published: 31 May 2018

\begin{abstract}
Quantum dots (QD) are widely used for cellular labeling due to enhanced brightness, resistance to photobleaching, and multicolor light emissions. $\mathrm{CdS}$ and $\mathrm{Cd}_{\mathrm{x}} \mathrm{Zn}_{1-\mathrm{x}} \mathrm{S}$ nanoparticles with sizes of 6-8 nm were synthesized via a ligand assisted technique inside and outside of $50 \mathrm{~nm}$ diameter halloysite clay nanotubes (QD were immobilized on the tube's surface). The halloysite-QD composites were tested by labeling human skin fibroblasts and prostate cancer cells. In human cell cultures, halloysite-QD systems were internalized by living cells, and demonstrated intense and stable fluorescence combined with pronounced nanotube light scattering. The best signal stability was observed for QD that were synthesized externally on the amino-grafted halloysite. The best cell viability was observed for $\mathrm{Cd}_{\mathrm{x}} \mathrm{Zn}_{1-\mathrm{x}} \mathrm{S}$ QD immobilized onto the azine-grafted halloysite. The possibility to use QD clay nanotube core-shell nanoarchitectures for the intracellular labeling was demonstrated. A pronounced scattering and fluorescence by halloysite-QD systems allows for their promising usage as markers for biomedical applications.
\end{abstract}

Keywords: bioimaging; nanoarchitectures; halloysite; intracellular labeling

\section{Introduction}

Nanomaterials show great promise when it comes to targeted drug delivery, diagnostics, and controlled-release drug treatment. In recent years, formulations based on halloysite clay nanotubes have attracted attention in biology and medicine as a drug delivery vehicle [1-6], in implants and tissue engineering [7], and in chemical- and bio-sensing [8,9]. Halloysite nanotubes can be employed as encapsulation containers due to their tubular structure, mesoporous 10-15 $\mathrm{nm}$ diameter lumen, and site-dependent chemistry with positively $\left(\mathrm{Al}_{2} \mathrm{O}_{3}\right)$ and negatively $\left(\mathrm{SiO}_{2}\right)$ charged inner and outer tube surfaces [10-13].

Halloysite has been proposed as a template for synthesis and stabilization of various nanoparticles following a core-shell nanoarchitecture strategy. Halloysite-metal nanoparticle composites have been employed in heterogeneous catalysis [14,15]. Antibacterial Ag [16,17], as well as plasmonic Au nanoparticles [18], were synthesized into and onto halloysite tubes to form new nanosystems with enhanced biological activity. Metal chalcogenide halloysite-based formulations have already been tested in photocatalysis and bioimaging $[19,20]$. Metal chalcogenide quantum dots (QD) are 
semiconductor nanoparticles with a size of up to $10 \mathrm{~nm}$ that emit light with a wavelength that can be finely tuned from ultraviolet to infrared, depending on sizes, structure, and composition; among them, cadmium containing QDs are one of the most useable [21]. QDs are favorable for intracellular labeling because of the easily tunable light emission, wide absorption band, high resistance to photobleaching, and possibilities of surface modification by conjugation with proteins [22].

One of the main problems with nanomaterial applications in living organisms is the toxicity of such tiny objects. For example, QD for bioimaging are often synthesized using complicated stabilization techniques to make them less cytotoxic and better dispersible in water, and this is especially important for cadmium-containing QDs [23]. Halloysite clay encapsulation could help dispersing the quantum dots in water, as well as decrease the toxicity of QD via the tube surface immobilization and decreasing amounts of free CdSe or CdS. These natural alumosilicate clay rolled structures, named halloysite, are known to be biocompatible [24]. One of the first reports on halloysite exposition for HeLa and MCF-7 mammal cell lines demonstrated that halloysite has low toxicity at concentrations up to $100 \mu \mathrm{g} / \mathrm{mL}$. Although halloysite can be easily taken up by the cultured cells, its toxicity was reported to be very low, both for cell cultures and in vivo for animals [25]. Even at higher concentrations (up to $1500 \mu \mathrm{g} / \mathrm{mL}$ ), halloysite nanotubes conjugated with noble metal nanoparticles, which have low toxicity for plants, as was reported for radish seeds [26].

Here, we report that site-selective immobilization of cadmium-containing QDs on halloysite nanotubes opens the way to obtain new fluorescent materials with broad emission spectra, good stability, and low in vitro toxicity. To reduce the cadmium content, a solid solution of cadmium-zinc sulfide was also used as fluorescent nanoparticle shells on core clay nanotubes.

\section{Materials and Methods}

Halloysite nanotubes (HNT), (3-Aminopropyl)triethoxysilane (APTES), furfural, hydrazine hydrate, cadmium nitrate tetrahydrate $\left(\mathrm{Cd}\left(\mathrm{NO}_{3}\right)_{2} \cdot 4 \mathrm{H}_{2} \mathrm{O}\right)$, zinc nitrate hexahydrate $\left(\mathrm{Zn}\left(\mathrm{NO}_{3}\right)_{2} \cdot 6 \mathrm{H}_{2} \mathrm{O}\right)$, thioacetamide (TAA), ethylenediaminetetraacetic acid (EDTA), ammonium hydroxide solution $\left(\mathrm{NH}_{4} \mathrm{OH}\right)$, and ethanol 96\% were all purchased from Sigma-Aldrich (Rushim, Moscow, Russia).

\subsection{QDs Stabilization on Halloysite}

Cadmium sulfide and cadmium-zinc sulfide QDs were stabilized on halloysite using the two following synthesis strategies.

In first case, APTES was used as a grafting agent. The halloysite salinization was performed using $0.2 \mathrm{~g}$ of APTES per $1 \mathrm{~g}$ of halloysite dispersed in ethanol and stirred at $60{ }^{\circ} \mathrm{C}$ for $24 \mathrm{~h}$ (modified from [27]). After the reaction, the dispersion was washed several times with ethanol. The resulting precipitate was dried for $12 \mathrm{~h}$ at $60{ }^{\circ} \mathrm{C}$. Afterwards, the resulting $\mathrm{HNT}-\mathrm{NH}_{2}$ was dispersed in a $\mathrm{Cd}\left(\mathrm{NO}_{3}\right)_{2}$ solution and stirred for $30 \mathrm{~min}$ using sonication. Then a TAA solution was added in the cadmium-containing mixture, and $\mathrm{pH}$ was adjusted to 10 using $\mathrm{NH}_{4} \mathrm{OH}$. After 5 min, the yellow precipitate was centrifuged, washed with ethanol several times, and dried at $60{ }^{\circ} \mathrm{C}$ for $24 \mathrm{~h}$. The obtained sample was labeled as $\mathrm{HNT}-\mathrm{NH}_{2}-\mathrm{CdS}$ (see Scheme 1).

In second case, azine produced from furfural and hydrazine hydrate was used as a ligand to form stable $\mathrm{CdS}$ and $\mathrm{Cd}_{\mathrm{x}} \mathrm{Zn}_{\mathrm{y}} \mathrm{S}$ QD on halloysite nanotubes. The procedure for HNT-Azine synthesis is described elsewhere [20,28]. The synthesis of CdS QDs was performed according to the same procedure described above. The obtained sample was labeled as HNT-Azine-CdS. The same HNT-Azine was used to stabilize $\mathrm{Cd}_{0.7} \mathrm{Zn}_{0.3} \mathrm{~S} \mathrm{QD}$, where a solution of $\mathrm{Cd}\left(\mathrm{NO}_{3}\right)_{2}$ and $\mathrm{Zn}\left(\mathrm{NO}_{3}\right)_{2}$ with Cd: $\mathrm{Zn}$ molar ratio of 0.7:0.3 was taken as a metal precursor solution. The procedure of QD synthesis was the same as for HNT-NH $H_{2}-\mathrm{CdS}$ and HNT-Azine-CdS. The sample was labeled as HNT-Azine-Cd ${ }_{0.7} \mathrm{Zn}_{0.3} \mathrm{~S}$.

To compare the photostability of synthesized HNT-QD materials with commonly used fluorescent dyes, we prepared rhodamine 6G (R6G) and fluorescein (Fluor) dyes that were adsorbed onto the halloysite nanotubes. Dyes were adsorbed on the halloysite surfaces from concentrated ethanol solutions, using a vacuum for better loading. After soaking the halloysite in dye solution for $30 \mathrm{~min}$, 
the ethanol was evaporated under vacuum, and obtained composites (HNT-R6G and HNT-Fluor) were washed with ethanol and dried overnight.

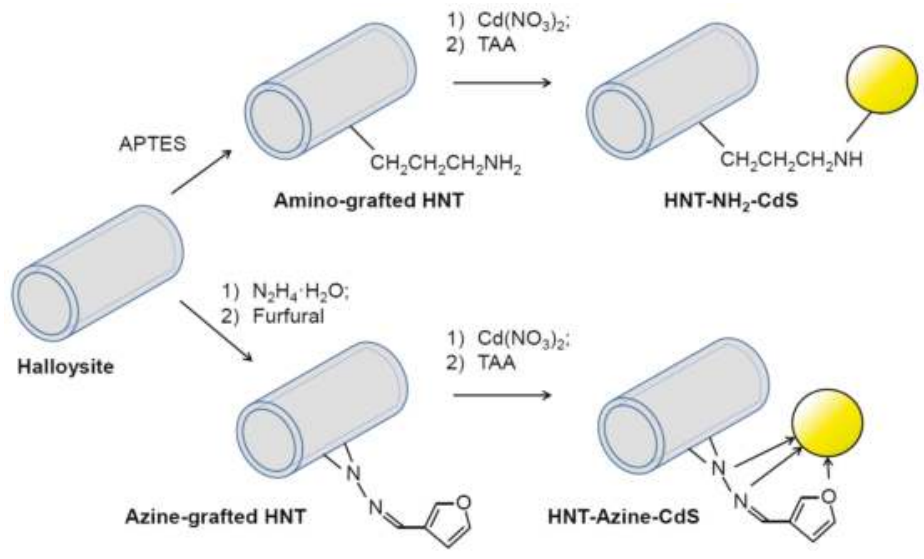

Scheme 1. Synthesis of halloysite-CdS composites.

\subsection{Cell Cultures}

Epithelial human prostate cell line (PC-3) was obtained from the American Type Culture Collection (ATCC, Manassas, VA, USA). The cells were seeded in a sterile culture flask with a growth area of $75 \mathrm{~cm}^{2}$ (Corning Inc., Corning, NY, USA), and contained $12 \mathrm{~mL}$ of Dulbecco's Modified Eagle's Medium (DMEM), supplemented with 10\% fetal bovine serum (PAA laboratories, Dartmouth, MA, USA), 100 $\mathrm{IU} / \mathrm{mL}$ of penicillin, and $100 \mathrm{ng} / \mathrm{mL}$ of streptomycin. The cells were cultivated at $37^{\circ} \mathrm{C}$ in a humidified atmosphere containing $5 \% \mathrm{CO}_{2}$, and sub-cultured by trypsinization every three days at $80 \%$ confluency.

\subsection{Characterization}

Fluorescent materials' morphology evaluation and elemental analysis were performed with a JEM-2100 transmission electron microscope (Jeol, Tokyo, Japan), equipped with a JED-2300 X-ray fluorescence spectrometer (Jeol, Tokyo, Japan). Size distributions of QD were estimated by measuring the diameters of electron-dense particles in transmission electron microscopy (TEM) images with ImageJ v1.50i suite (National Institutes of Health, Bethesda, MD, USA). Reflectance spectra of the synthesized materials were registered in $45^{\circ} / 45^{\circ}$ geometry using a $150 \mathrm{~W}$ xenon arc lamp (LOT Oriel, Darmstadt, Germany) and QE65000 spectrometer (Ocean Optics, Dunedin, FL, USA). Elemental analysis was performed using an ARL TM PERFORM'X Sequential X-ray Fluorescence Spectrometer (Thermo Scientific, Waltham, MA, USA).

For the study of cells' morphology and cytoskeleton structure, $1 \times 10^{5}$ cells were added to the six-well plate re-suspended in medium $(1 \mathrm{~mL})$ on coverslips $(10 \mathrm{~mm})$, where the plate was previously at the bottom of each well. The cells were grown for $24 \mathrm{~h}$, the HNT-QD (100 mg/mL) was added, and cells were cultured for $24 \mathrm{~h}\left(37^{\circ} \mathrm{C}\right.$ and $\left.5 \% \mathrm{CO}_{2}\right)$. Then, the cells were washed with phosphate-buffered saline (PBS) and stained with 4',6-diamidino-2-phenylindole (DAPI) solution (1 mg/mL) and Phalloidin Alexa Fluor ${ }^{\circledR} 488$ (Thermo Fisher Scientific Inc., Waltham, MA, USA), according to the standard protocols. The slides were observed with laser scanning microscope Carl Zeiss LSM-780 (Jena City, Germany) with $543 \mathrm{~nm}, 488 \mathrm{~nm}$, and $405 \mathrm{~nm}$ lasers, and images were processed using ZEN Black software (Carl Zeiss MicroImaging GmbH, Göttingen, Germany). Enhanced dark-field microscopy images were obtained using an Olympus BX51 upright microscope (Tokyo, Japan) equipped with a CytoViva ${ }^{\circledR}$ oil immersion dark-field condenser (Auburn, AL, USA). 


\subsection{Cell Viability}

To measure the cell viability while incubated with HNT-QD, they were seeded in a sterile culture flask with growth area of $75 \mathrm{~cm}^{2}$ (Corning Inc., Corning, NY, USA) until the confluence reached $\sim 80 \%$. Cells were rinsed with PBS and then were detached from the substrate by trypsinization. Then, the cells were grown in a six-well plate for $24 \mathrm{~h}$ and HNT-QD were added. After $24 \mathrm{~h}$ of incubation in standard conditions, we assessed cell death induction using ReadyProbes ${ }^{\circledR}$ Cell Viability Imaging Kit (Blue/Green) (Thermo Fisher Scientific Inc., Waltham, MA, USA) according to the standard protocol. The nuclei of all cells were analyzed with a standard DAPI filter (excitation/emission maxima: $360 / 460 \mathrm{~nm}$ ), and the nuclei of dead cells with compromised plasma membranes were detected with standard FITC/GFP (green) filter set (excitation/emission maxima: 504/523 nm) on a flow cytometer FACS (BD Biosciences, San Jose, CA, USA).

\section{Results}

\subsection{Fluorescent Materials Morphology and Composition}

Halloysite nanotubes (HNT) that were used varied in length from $300 \mathrm{~nm}$ to $1 \mu \mathrm{m}$, with an average length of $600 \mathrm{~nm}$, inner diameter of $15-20 \mathrm{~nm}$, and their chemical formula is similar to kaolinite $\left(\mathrm{Al}_{2} \mathrm{Si}_{2} \mathrm{O}_{5}(\mathrm{OH})_{4} \cdot \mathrm{nH}_{2} \mathrm{O}\right)$. The outer surface of halloysite is negatively charged at $\mathrm{pH}$ above 4 and was comprised of silica [29]. Surface modification of halloysite with silane is a common method that allows nanoparticles to bind to halloysite surface and to prevent their detachment from the tubes and aggregate [30-32]. In the case of cadmium containing QD (CdS or $\left.\mathrm{Cd}_{0.7} \mathrm{Zn}_{0.3} \mathrm{~S}\right)$, it is preferable to have complexation agents that cover QD to prevent cadmium release. Therefore, we have chosen an organic azine as a ligand for chalcogenide nanoparticle formation. This technique makes it possible to load nanoparticles inside the lumen of halloysite nanotubes [15], preventing QD nanoparticles from aggregating.

Figure 1 shows TEM images of halloysite nanotubes before modification (A), and after synthesis of fluorescent nanomaterials (B-D). The content of CdS in the samples, as evaluated by X-ray fluorescence elemental analysis, was 3.2, 3.5, and $2.9 \mathrm{wt} \%$ for cadmium sulfide quantum dots immobilized onto the amino-grafted halloysite HNT- $\mathrm{NH}_{2}$-CdS (Figure 1B), cadmium sulfide quantum dots immobilized onto the azine-grafted halloysite HNT-Azine-CdS (Figure 1C), and cadmium-zinc sulfide quantum dots immobilized onto the azine-grafted halloysite HNT-Azine- $\mathrm{Cd}_{0.7} \mathrm{Zn}_{0.3} S$ (Figure 1D), respectively.

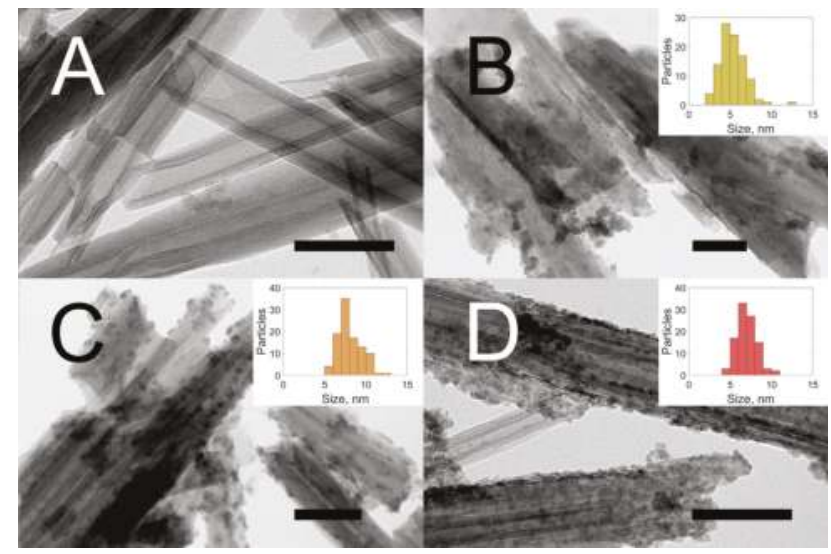

Figure 1. TEM images of pristine HNT (A); HNT-NH ${ }_{2}-\mathrm{CdS}$ (B); HNT-Azine-CdS (C); and HNT-Azine$\mathrm{Cd}_{0.7} \mathrm{Zn}_{0.3} \mathrm{~S}$ (D). Particle size distributions derived from measurements of 100 particles for each sample are shown in insets (B-D), (see also Table S1 in Supplementary Materials). 
As shown above, the particle location on the tubes was different in every case. In the case of amino-grafted halloysite, the clusters were distributed all over the nanotubes. The particle size varied in a wide range from 2 to $13 \mathrm{~nm}$ (Figure 1B, inset). The concentration of nanoparticles in case of amino-grafted halloysite (Figure 1B) was lower than that of azine-grafted QD (Figure 1C,D). HNTs-Azine-CdS materials contained QD with better monodispersity; the majority of QD have size within 6 to $8 \mathrm{~nm}$ (Figure 1C,D, insets). There were no large Cd-clusters observed separate from the nanotubes. HNTs-Azine- $\mathrm{Cd}_{0.7} \mathrm{Zn}_{0.3} \mathrm{~S}$ had densely located particles with size from 5 to $10 \mathrm{~nm}$. Such a difference in the nanoparticle size distributions caused a variation in the material's spectral properties.

The synthesized cadmium QD materials had a bright yellow color, which is associated with their strong light absorption in blue spectral range (Figure 2). The positions of absorption peaks imply that these nanomaterials might demonstrate fluorescence when excited by a laser in the 400-500 nm range.
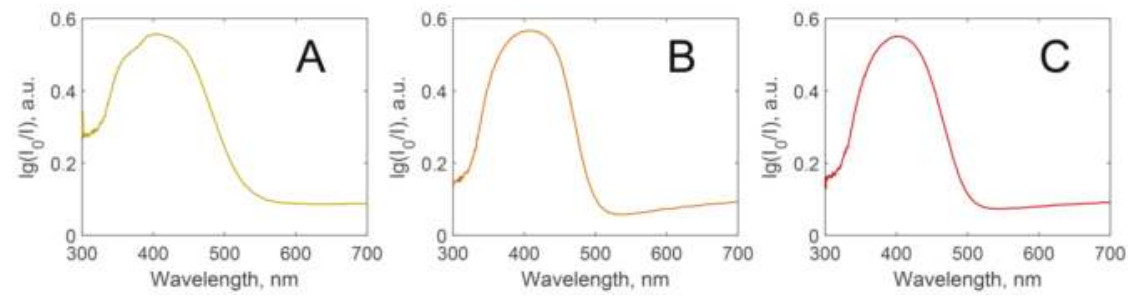

Figure 2. Diffusive reflectance spectra of $\mathrm{HNT}-\mathrm{NH}_{2}-\mathrm{CdS}(\mathbf{A})$; $\mathrm{HNT}-\mathrm{Azine}-\mathrm{CdS}(\mathbf{B})$; and HNT-Azine- $\mathrm{Cd}_{0.7} \mathrm{Zn}_{0.3} \mathrm{~S}$

(C). Spectra were registered using pristine halloysite as a reference.

\subsection{Laser Scanning and Dark Field Microscopy}

We applied the halloysite-QD composites to label human cells in vitro to demonstrate the optical effects of these materials within live cells. Figure 3 presents the laser scanning microscopy (LSM) images of different Cd-composites with QD stabilized on halloysite nanotubes. Bright and well-resolved fluorescence was observed in all cases. It can be seen that every material had different emission spectra ranging from green (HNTs-Azine-CdS), to yellow-red (HNTs-Azine-Cd $\mathrm{d}_{0.7} \mathrm{Zn}_{0.3} \mathrm{~S}$ ), to red (HNT-NH $\mathrm{N}_{2}-\mathrm{CdS}$ ). Figure $3 \mathrm{C}$ shows the confocal microscopy image of the sample that had been stored for nine months. Cell nuclei were stained with DAPI, and were visible as large blue spots. Smaller red, yellow-red, and green spots around the nuclei correspond to HNT-QD composites, and imply that these composites are well-distributed on the cells' surfaces or inside them. These images confirm the effective uptake of QD-modified halloysite; apparently the uptake occurs in the same way as with dextrin-coated clay nanotubes [6].
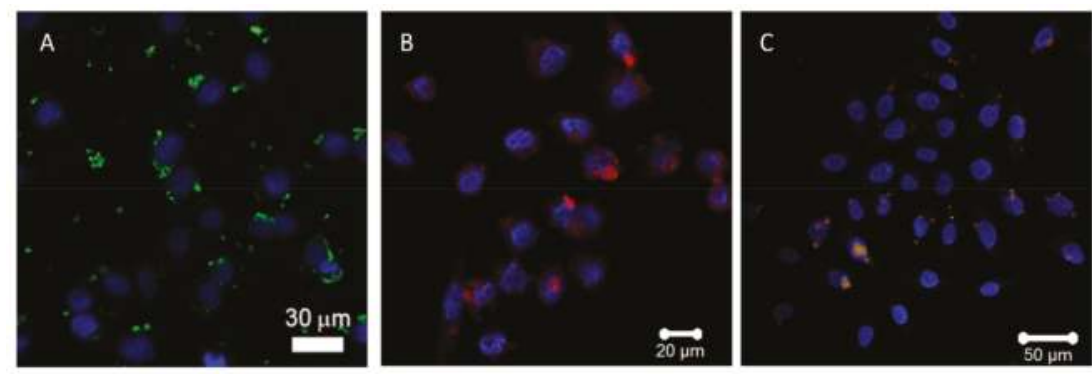

Figure 3. Laser scanning microscopy (LSM) images of PC-3 cells that were QD-labeled with HNTs-Azine-CdS (A), HNTs-NH $-\mathrm{CdS}(\mathbf{B})$, and HNTs-Azine-Cd ${ }_{0.7} \mathrm{Zn}_{0.3} \mathrm{~S}(\mathbf{C})$. The nuclei were stained with DAPI (blue channel, 405-nm laser), QD are shown in green (488-nm laser) and red channel (543-nm laser). 
More detailed distributions of the QD-nanotubes within the PC-3 cell are presented in Figure 4, demonstrating the correlative microscopy images taken using dark-field and epifluorescence microscopy. When observed using enhanced darkfield microscopy (Figure 4A), halloysite nanotubes appear as bright spots due to their good light-scattering properties. The cell membrane and cytoplasm can also be seen; however, at the same illumination intensity, the halloysite-lacking regions of the cell appeared to be faint. The corresponding fluorescence image of the same cell (Figure 4B) was stained with ReadyProbes ${ }^{\circledR}$ viability dye, while HNT- $\mathrm{NH}_{2}-\mathrm{CdS}$ appeared as red spots, and their locations correspond to the brightest spots in Figure 4A, allowing us to correlate the QD fluorescence with halloysite light scattering.

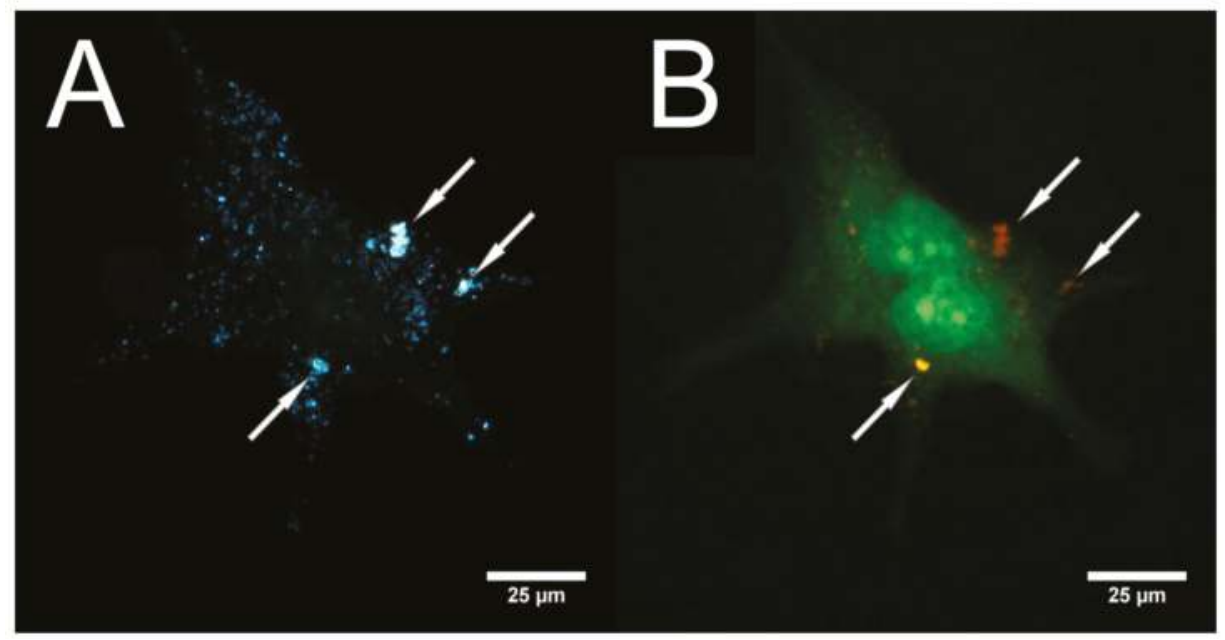

Figure 4. Visualization of PC-3 cell labeled with $\mathrm{HNT}_{-} \mathrm{NH}_{2}-\mathrm{CdS}$ : dark-field microscopy image of PC-3 with HNT- $\mathrm{NH}_{2}-\mathrm{CdS}$ (A) and fluorescence image of cells stained with ReadyProbes ${ }^{\circledR}$ Cell Viability Imaging Kit (Blue/Green) (ThermoFisher) (B). HNT-NH $\mathrm{H}_{2}$-CdS appeared as bright white spots (A, marked by arrows), or yellow and red spots (B), (marked by arrows).

\subsection{Luminescence Stability}

Time-dependent change of the intensity of QD fluorescence was observed using a laser confocal microscope equipped with a 405-nm diode laser in time-series mode. The signal intensity was recorded every $30 \mathrm{~min}$ for $4 \mathrm{~h}$, and is shown in Figure 5. In Figure 5, the photostability of synthesized materials is shown, along with the photostability of fluorescent dyes rhodamine 6G and fluorescein immobilized onto the halloysite (HNT-R6G and HNT-Fluor, respectively). It is known that photobleaching of fluorescent dyes follows pseudo-first-order kinetics [33,34], so experimental points (circles and crosses in Figure 5) were approximated by first-order kinetics fits (lines in Figure 5). The highest luminescence signal stability was observed for the HNTs-NH $2-C d S\left(k=0.00086 \mathrm{~min}^{-1}\right)$, which is comparable with the photostability of rhodamine $6 \mathrm{G}\left(k=0.0012 \mathrm{~min}^{-1}\right)$. Azine-grafted materials (HNT-Azine-CdS and HNT-Azine-Cd $\mathrm{d}_{0.7} \mathrm{Zn}_{0.3} \mathrm{~S}$ ) and halloysite-fluorescein composite (HNT-Fluor) showed a decreasing fluorescence intensity with time $\left(k=0.0139,0.0057\right.$, and $0.0045 \mathrm{~min}^{-1}$, respectively). 


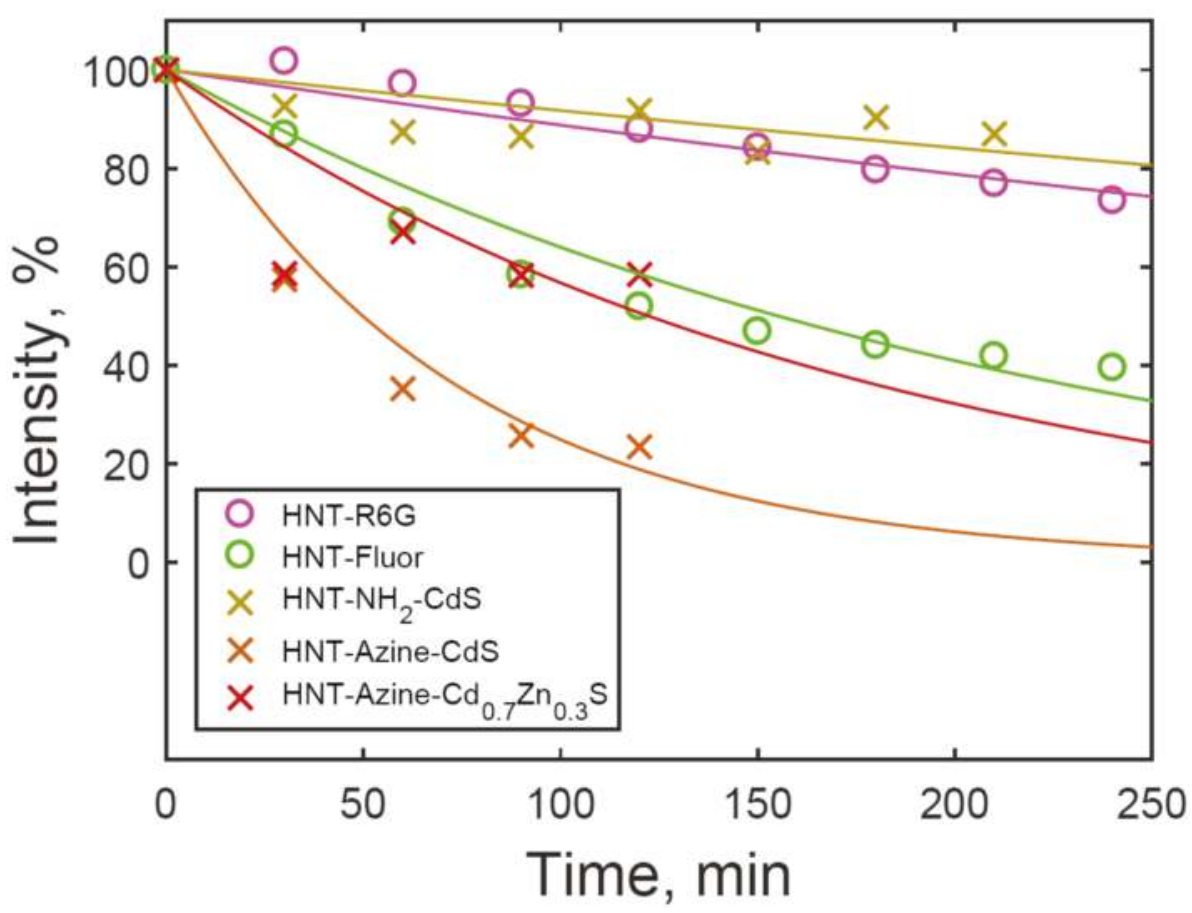

Figure 5. Time-dependent luminescence intensity of the synthesized materials (lines are first-order kinetics fits; see also Table S2 in Supplementary Materials).

\subsection{Cytotoxicity}

Earlier, we have shown the lack of toxic effects of halloysite-QD on cells with colorimetric assays and flow cytometry [20]. The toxicity of quantum dots depends on their size, chemical structure, and coating used $[35,36]$. We developed QDs that have a wide range of fluorescence, which is crucial for in vivo visualization. The toxicity of quantum dots was measured using the flow cytometry method. As one can see, viability of the cell is high in all cases as compared to the control (Figure 6). The percentage of live cells is higher when the HNT-Azine- $\mathrm{Cd}_{0.7} \mathrm{Zn}_{0.3} \mathrm{~S}$ was used in cell cultivation. 


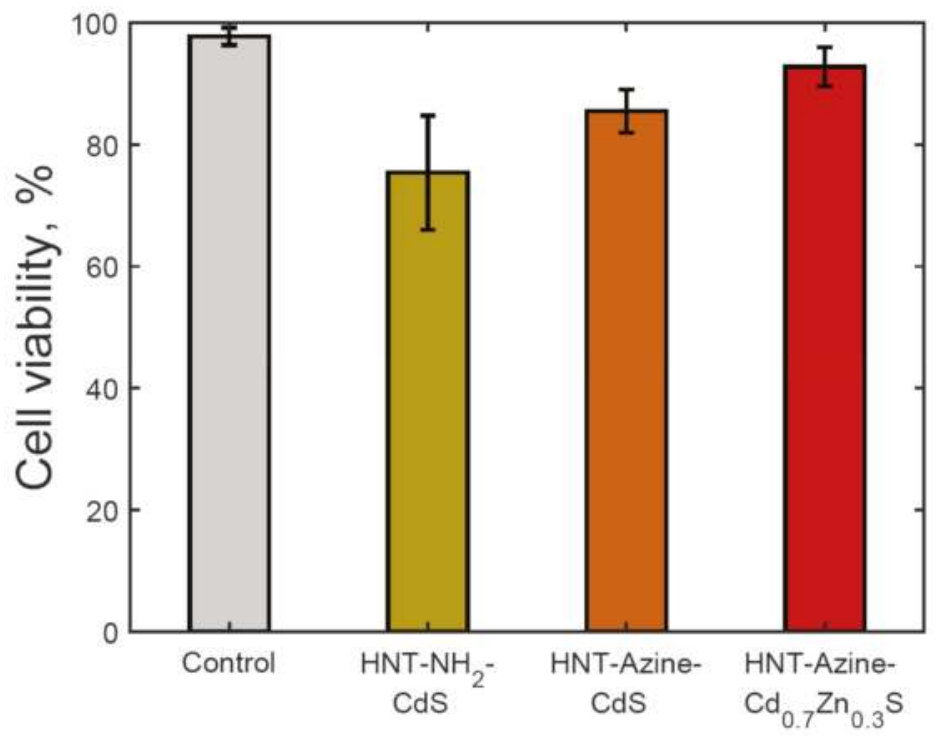

Figure 6. Flow cytometry data on viability of PC-3 cells exposed to halloysite-QD composites. Error bars are sample standard deviations (see also Figures S5-S8 in Supplementary Materials).

\section{Discussion}

The synthesis of halloysite with grafted nitrogen-containing electron donating groups leads to the formation of fluorescent core-shell materials, which are comprised of QDs immobilized onto the surface of the clay nanotubes. The nature of the grafted groups affects the particle organization, size distribution, and spectral properties of the formed QD systems. Generally, azine-grafted materials provide a higher surface coverage of halloysite nanotubes with QDs and a narrower cadmium-containing nanoparticle size distribution. The immobilization of QDs onto the halloysite nanotubes prevents the aggregation of QD and ensures their good dispersibility in water. This immobilization approach is suitable even for nanoparticles without hydrophilic ligands or an amphiphilic polymer coating employed for the surfactant-stabilized nanoparticles [37].

One of the known problems of QD bioimaging applications is their blinking behavior, namely the transition between a photoluminescent "on" state and the Auger-recombination "off" state [38]. The halloysite-QD composites with high surface QD coverage provide a simple and robust workaround of the blinking problem because the luminescence is provided by many QD, thus making the blinking by individual QD negligible.

The produced halloysite-QD tubular nanocomposites demonstrate the affinity towards living cells; PC-3 cells were contrasted by the designed nanosystems, and no free fluorescent particles were detected. The remarkable differences in the fluorescence signal stability show that better particle size distribution and higher concentration of QD do not guarantee the stability of composites. HNTs- $\mathrm{NH}_{2}-\mathrm{CdS}$ formulations show higher photobleaching resistance, probably because of more sparsely distributed particles that are resistant to aggregation. The high photobleaching stability is crucial for real-life applications, such as study of the dynamics of intracellular processes, or prolonged diagnostics of organism malfunctions.

As one can see in Figures 3 and 4, halloysite-QD composites are either taken up by human cells or adsorbed onto the cell membranes. The underlying mechanism is not clear yet, but based on earlier observations [39], we assume that uptake of halloysite occurs via endocytosis, and depends on proliferation rate of different cell cultures. 
The surface modification of halloysite affects not only the synthesis and immobilization of cadmium chalcogenide nanoparticles, but also the cytotoxicity of the halloysite-QD composites. The HNTs- $\mathrm{NH}_{2}-\mathrm{CdS}$ formulations were most resistant to photobleaching, but at the same time demonstrated the highest cytotoxicity. Cadmium-containing QD are known to be cytotoxic because of $\mathrm{Cd}^{2+}$ ion emissions and direct interaction of QD with cell surface [40]. Thus, the immobilization of QD onto the surface of halloysite nanotubes may lower the cytotoxicity induced by the latter mechanism. Interestingly, among the azine-grafted halloysite composites, HNTs-Azine-Cd $\mathrm{C}_{0.7} \mathrm{Zn}_{0.3} \mathrm{~S}$ showed the lowest cytotoxicity together with moderate photobleaching resistance. The lower cytotoxicity of HNTs-Azine- $\mathrm{Cd}_{0.7} \mathrm{Zn}_{0.3} \mathrm{~S}$ is probably due to the lower emission of $\mathrm{Cd}^{2+}$ ions from mixed cadmium-zinc sulfide, combined with the immobilization of QD.

We conclude that cadmium-zinc sulfide QD azine-grafted onto the halloysite clay nanotubes are the most promising materials for bioimaging.

Supplementary Materials: The following materials are available online at http://www.mdpi.com/2079-4991/ 8/6/391/s1. Figure S1: Source TEM image of pristine HNT (Figure 1A); Figure S2: Source TEM image of HNT-NH $\mathrm{N}_{2}$-CdS (Figure 1B); Figure S3: Source TEM image of HNT-Azine-CdS (Figure 1C); Figure S4: Source TEM image of HNT-Azine-Cd $\mathrm{C}_{0.7} \mathrm{Zn}_{0.3} \mathrm{~S}$ (Figure 1D); Figure S5: Flow cytometry graphs of the control sample of PC-3 cells; Figure S6: Flow cytometry graphs of PC-3 cells exposed to the $\mathrm{HNTs}_{\mathrm{NH}}-\mathrm{CdS}$ sample; Figure S7: Flow cytometry graphs of PC-3 cells exposed to the HNT-Azine-CdS sample; Figure S8: Flow cytometry graphs of PC-3 cells exposed to the HNTs-Azine-Cd $\mathrm{Cd}_{0.7} \mathrm{Zn}_{0.3} \mathrm{~S}$ sample; Table S1: Measured diameters of electron-dense particles found in TEM images; Table S2: Photostability data for the synthesized nanomaterials.

Author Contributions: Conceptualization, Y.M.L. and V.A.V.; Data curation, A.V.S., A.A.N., M.S.K., D.S.K., E.V.R., and I.R.I.; Funding acquisition, Y.M.L. and V.A.V.; Investigation, A.V.S., M.S.K., D.S.K., and E.V.R.; Project administration, Y.M.L.; Resources, R.F.F., E.V.I., Y.M.L., and V.A.V.; Supervision, R.F.F., Y.M.L., and V.A.V.; Visualization, A.V.S., A.A.N., M.S.K., E.V.R., and I.R.I.; Writing—original draft, A.V.S.; Writing-review and editing, A.V.S., A.A.N., E.V.R., R.F.F., Y.M.L., and V.A.V.

Funding: This work was supported by the Ministry of Education and Science of the Russian Federation (Grant 14.Z50.31.0035). Work on design of halloysite composites was supported by grant FSA3-18-64013-0 U.S. Civilian Research \& Development Foundation (CRDF Global). Any opinions, findings, or recommendations expressed in this material do not necessarily reflect the views of CRDF Global. This study was performed according to the Russian Government Program of Competitive Growth of Kazan Federal University.

Acknowledgments: Authors thank Sergey Egorov (A.V. Topchiev Institute of Petrochemical Synthesis, RAS) for elemental analysis of fluorescent nanomaterials.

Conflicts of Interest: The authors declare no conflict of interest. The funding sponsors had no role in the design of the study; in the collection, analyses, or interpretation of data; in the writing of the manuscript, or in the decision to publish the results.

\section{References}

1. Yendluri, R.; Otto, D.P.; De Villiers, M.M.; Vinokurov, V.; Lvov, Y.M. Application of halloysite clay nanotubes as a pharmaceutical excipient. Int. J. Pharm. 2017, 521, 267-273. [CrossRef] [PubMed]

2. Lvov, Y.M.; DeVilliers, M.M.; Fakhrullin, R.F. The application of halloysite tubule nanoclay in drug delivery. Expert Opin. Drug Deliv. 2016, 13, 977-986. [CrossRef] [PubMed]

3. Cavallaro, G.; Lazzara, G.; Milioto, S.; Parisi, F.; Evtugyn, V.; Rozhina, E.; Fakhrullin, R. Nanohydrogel Formation within the Halloysite Lumen for Triggered and Sustained Release. ACS Appl. Mater. Interfaces 2018, 10, 8265-8273. [CrossRef] [PubMed]

4. Cavallaro, G.; Danilushkina, A.; Evtugyn, V.; Lazzara, G.; Milioto, S.; Parisi, F.; Rozhina, E.; Fakhrullin, R. Halloysite Nanotubes: Controlled Access and Release by Smart Gates. Nanomaterials 2017, 7, 199. [CrossRef] [PubMed]

5. Lazzara, G.; Riela, S.; Fakhrullin, R.F. Clay-based drug-delivery systems: What does the future hold? Ther. Deliv. 2017, 8, 633-646. [CrossRef]

6. Yendluri, R.; Lvov, Y.; de Villiers, M.M.; Vinokurov, V.; Naumenko, E.; Tarasova, E.; Fakhrullin, R. Paclitaxel encapsulated in halloysite clay nanotubes for intestinal and intracellular delivery. J. Pharm. Sci. 2017, 106, 3131-3139. [CrossRef] [PubMed]

7. Abdullayev, E.; Lvov, Y. Halloysite clay nanotubes as a ceramic "skeleton" for functional biopolymer composites with sustained drug release. J. Mater. Chem. B 2013, 1, 2894-2903. [CrossRef] 
8. Ghanei-Motlagh, M.; Taher, M.A. A novel electrochemical sensor based on silver/halloysite nanotube/molybdenum disulfide nanocomposite for efficient nitrite sensing. Biosens. Bioelectron. 2018, 109, 279-285. [CrossRef] [PubMed]

9. Yang, M.; Xiong, X.; He, R.; Luo, Y.; Tang, J.; Dong, J.; Lu, H.; Yu, J.; Guan, H.; Zhang, J.; et al. Halloysite Nanotube-Modified Plasmonic Interface for Highly Sensitive Refractive Index Sensing. ACS Appl. Mater. Interfaces 2018, 10, 5933-5940. [CrossRef] [PubMed]

10. Prishchenko, D.A.; Zenkov, E.V.; Mazurenko, V.V.; Fakhrullin, R.F.; Lvov, Y.M.; Mazurenko, V.G. Molecular dynamics of the halloysite nanotubes. Phys. Chem. Chem. Phys. 2018, 20, 5841-5849. [CrossRef] [PubMed]

11. Cavallaro, G.; Lazzara, G.; Konnova, S.; Fakhrullin, R.; Lvov, Y. Composite films of natural clay nanotubes with cellulose and chitosan. Green Mater. 2014, 2, 232-242. [CrossRef]

12. Hillier, S.; Brydson, R.; Delbos, E.; Fraser, T.; Gray, N.; Pendlowski, H.; Phillips, I.; Robertson, J.; Wilson, I. Correlations among the mineralogical and physical properties of halloysite nanotubes (HNTs). Clay Miner. 2016, 51, 325-350. [CrossRef]

13. Massaro, M.; Cavallaro, G.; Colletti, C.G.; D’Azzo, G.; Guernelli, S.; Lazzara, G.; Pieraccini, S.; Riela, S. Halloysite nanotubes for efficient loading, stabilization and controlled release of insulin. J. Colloid Interface Sci. 2018, 524, 156-164. [CrossRef] [PubMed]

14. Massaro, M.; Colletti, C.G.; Lazzara, G.; Milioto, S.; Noto, R.; Riela, S. Halloysite nanotubes as support for metal-based catalysts. J. Mater. Chem. A 2017, 5, 13276-13293. [CrossRef]

15. Vinokurov, V.A.; Stavitskaya, A.V.; Glotov, A.P.; Novikov, A.A.; Zolotukhina, A.V.; Kotelev, M.S.; Gushchin, P.A.; Ivanov, E.V.; Darrat, Y.; Lvov, Y.M. Nanoparticles Formed Onto/Into Halloysite Clay Tubules: Architectural Synthesis and Applications. Chem. Rec. 2018. [CrossRef] [PubMed]

16. Jana, S.; Kondakova, A.V.; Shevchenko, S.N.; Sheval, E.V.; Gonchar, K.A.; Timoshenko, V.Y.; Vasiliev, A.N. Halloysite nanotubes with immobilized silver nanoparticles for anti-bacterial application. Colloids Surf. B 2017, 151, 249-254. [CrossRef] [PubMed]

17. Shu, Z.; Zhang, Y.; Yang, Q.; Yang, H. Halloysite nanotubes supported Ag and ZnO nanoparticles with synergistically enhanced antibacterial activity. Nanoscale Res. Lett. 2017, 12, 135. [CrossRef] [PubMed]

18. Zieba, M.; Hueso, J.L.; Arruebo, M.; Martínez, G.; Santamaría, J. Gold-coated halloysite nanotubes as tunable plasmonic platforms. New J. Chem. 2014, 38, 2037-2042. [CrossRef]

19. Vinokurov, V.A.; Stavitskaya, A.V.; Ivanov, E.V.; Gushchin, P.A.; Kozlov, D.V.; Kurenkova, A.Y.; Kolinko, P.A.; Kozlova, E.A.; Lvov, Y.M. Halloysite nanoclay based CdS formulations with high catalytic activity in hydrogen evolution reaction under visible light irradiation. ACS Sustain. Chem. Eng. 2017, 5, 11316-11323. [CrossRef]

20. Micó-Vicent, B.; Martínez-Verdú, F.M.; Novikov, A.; Stavitskaya, A.; Vinokurov, V.; Rozhina, E.; Fakhrullin, R.; Yendluri, R.; Lvov, Y. Stabilized Dye-Pigment Formulations with Platy and Tubular Nanoclays. Adv. Funct. Mater. 2017. [CrossRef]

21. Hoshino, A.; Hanada, S.; Yamamoto, K. Toxicity of nanocrystal quantum dots: The relevance of surface modifications. Arch. Toxicol. 2011, 85, 707-720. [CrossRef] [PubMed]

22. Mal, J.; Nancharaiah, Y.V.; van Hullebusch, E.D.; Lens, P.N.L. Metal chalcogenide quantum dots: Biotechnological synthesis and applications. RSC Adv. 2016, 6, 41477-41495. [CrossRef]

23. Li, J.; Zhu, J.-J. Quantum dots for fluorescent biosensing and bio-imaging applications. Analyst 2013, 138, 2506-2015. [CrossRef] [PubMed]

24. Lvov, Y.M.; Shchukin, D.G.; Möhwald, H.; Price, R.R. Halloysite clay nanotubes for controlled release of protective agents. ACS Nano 2008, 2, 814-820. [CrossRef] [PubMed]

25. Vergaro, V.; Abdullayev, E.; Lvov, Y.M.; Zeitoun, A.; Cingolani, R.; Rinaldi, R.; Leporatti, S. Cytocompatibility and uptake of halloysite clay nanotubes. Biomacromolecules 2010, 11, 820-826. [CrossRef] [PubMed]

26. Bellani, L.; Giorgetti, L.; Riela, S.; Lazzara, G.; Scialabba, A.; Massaro, M. Ecotoxicity of halloysite nanotube-supported palladium nanoparticles in Raphanus sativus L. Environ. Toxicol. Chem. 2016, 35, 2503-2510. [CrossRef] [PubMed]

27. Carli, L.N.; Daitx, T.S.; Soares, G.V.; Crespo, J.S.; Mauler, R.S. The effects of silane coupling agents on the properties of PHBV/halloysite nanocomposites. Appl. Clay Sci. 2014, 87, 311-319. [CrossRef] 
28. Vinokurov, V.A.; Stavitskaya, A.V.; Chudakov, Y.A.; Ivanov, E.V.; Shrestha, L.K.; Ariga, K.; Darrat, Y.A.; Lvov, Y.M. Formation of metal clusters in halloysite clay nanotubes. Sci. Technol. Adv. Mater. 2017, 18, 147-151. [CrossRef] [PubMed]

29. Lvov, Y.; Wang, W.; Zhang, L.; Fakhrullin, R. Halloysite Clay Nanotubes for Loading and Sustained Release of Functional Compounds. Adv. Mater. 2016, 28, 1227-1250. [CrossRef] [PubMed]

30. Kumar-Krishnan, S.; Hernandez-Rangel, A.; Pal, U.; Ceballos-Sanchez, O.; Flores-Ruiz, F.J.; Prokhorov, E.; Arias de Fuentes, O.; Esparza, R.; Meyyappan, M. Surface functionalized halloysite nanotubes decorated with silver nanoparticles for enzyme immobilization and biosensing. J. Mater. Chem. B 2016, 4, 2553-2560. [CrossRef]

31. Zhang, H.; Ren, T.; Ji, Y.; Han, L.; Wu, Y.; Song, H.; Bai, L.; Ba, X. Selective modification of halloysite nanotubes with 1-pyrenylboronic acid: A novel fluorescence probe with highly selective and sensitive response to hyperoxide. ACS Appl. Mater. Interfaces 2015, 7, 23805-23811. [CrossRef] [PubMed]

32. Zhang, H. Selective modification of inner surface of halloysite nanotubes: A review. Nanotechnol. Rev. 2017, 6, 573-581. [CrossRef]

33. Eggeling, C.; Volkmer, A.; Seidel, C.A.M. Molecular photobleaching kinetics of Rhodamine 6G by oneand two-photon induced confocal fluorescence microscopy. ChemPhysChem 2005, 6, 791-804. [CrossRef] [PubMed]

34. Song, L.; Hennink, E.J.; Young, I.T.; Tanke, H.J. Photobleaching kinetics of fluorescein in quantitative fluorescence microscopy. Biophys. J. 1995, 68, 2588-2600. [CrossRef]

35. Guo, G.; Liu, W.; Liang, J.; He, Z.; Xu, H.; Yang, X. Probing the cytotoxicity of CdSe quantum dots with surface modification. Mater. Lett. 2007, 61, 1641-1644. [CrossRef]

36. Cho, S.J.; Maysinger, D.; Jain, M.; Röder, B.; Hackbarth, S.; Winnik, F.M. Long-term exposure to CdTe quantum dots causes functional impairments in live cells. Langmuir 2007, 23, 1974-1980. [CrossRef] [PubMed]

37. Pellegrino, T.; Manna, L.; Kudera, S.; Liedl, T.; Koktysh, D.; Rogach, A.L.; Keller, S.; Rädler, J.; Natile, G.; Parak, W.J. Hydrophobic nanocrystals coated with an amphiphilic polymer shell: A general route to water soluble nanocrystals. Nano Lett. 2004, 4, 703-707. [CrossRef]

38. Efros, A.L.; Nesbitt, D.J. Origin and control of blinking in quantum dots. Nat. Nanotechnol. 2016, 11, 661-671. [CrossRef] [PubMed]

39. Dzamukova, M.R.; Naumenko, E.A.; Lvov, Y.M.; Fakhrullin, R.F. Enzyme-activated intracellular drug delivery with tubule clay nanoformulation. Sci. Rep. 2015, 5, 10560. [CrossRef] [PubMed]

40. Kirchner, C.; Liedl, T.; Kudera, S.; Pellegrino, T.; Javier, A.M.; Gaub, H.E.; Stölzle, S.; Fertig, N.; Parak, W.J. Cytotoxicity of colloidal CdSe and CdSe/ZnS nanoparticles. Nano Lett. 2005, 5, 331-338. [CrossRef] [PubMed]

(C) 2018 by the authors. Licensee MDPI, Basel, Switzerland. This article is an open access article distributed under the terms and conditions of the Creative Commons Attribution (CC BY) license (http:/ / creativecommons.org/licenses/by/4.0/). 


\title{
Magnetic Graphene Oxide for Dual Targeted Delivery of Doxorubicin and Photothermal Therapy
}

\author{
Yu-Jen Lu ${ }^{1}$, Pin-Yi Lin ${ }^{2}$, Pei-Han Huang ${ }^{1}$, Chang-Yi Kuo ${ }^{2}$, K.T. Shalumon ${ }^{2}$, Mao-Yu Chen ${ }^{1}$ \\ and Jyh-Ping Chen $2,3,4,5, *$ \\ 1 Department of Neurosurgery, Chang Gung Memorial Hospital Linkuo Medical Center and College of \\ Medicine, Chang Gung University, Taoyuan 33305, Taiwan; alexlu0416@gmail.com (Y.-J.L.); \\ giselle.huang@gmail.com (P.-H.H.); mailtomaxi@gmail.com (M.-Y.C.) \\ 2 Department of Chemical and Materials Engineering, Chang Gung University, Taoyuan 33302, Taiwan; \\ arrow06280@hotmail.com (P.-Y.L.); onesky1997@gmail.com (C.-Y.K.); shalumon@gmail.com (K.T.S.) \\ 3 Department of Plastic and Reconstructive Surgery and Craniofacial Research Center, Chang Gung Memorial \\ Hospital, Linkou, Kwei-San, Taoyuan 33305, Taiwan \\ 4 Research Center for Food and Cosmetic Safety, Research Center for Chinese Herbal Medicine, College of \\ Human Ecology, Chang Gung University of Science and Technology, Kwei-San, Taoyuan 33302, Taiwan \\ 5 Department of Materials Engineering, Ming Chi University of Technology, Tai-Shan, \\ New Taipei City 24301, Taiwan \\ * Correspondence: jpchen@mail.cgu.edu.tw; Tel.: +886-3-2118800 (ext. 5298)
}

Received: 2 March 2018; Accepted: 23 March 2018; Published: 27 March 2018

\begin{abstract}
To develop a $\mathrm{pH}$-sensitive dual targeting magnetic nanocarrier for chemo-phototherapy in cancer treatment, we prepared magnetic graphene oxide (MGO) by depositing $\mathrm{Fe}_{3} \mathrm{O}_{4}$ magnetic nanoparticles on graphene oxide (GO) through chemical co-precipitation. MGO was modified with polyethylene glycol (PEG) and cetuximab (CET, an epidermal growth factor receptor (EGFR) monoclonal antibody) to obtain MGO-PEG-CET. Since EGFR was highly expressed on the tumor cell surface, MGO-PEG-CET was used for dual targeted delivery an anticancer drug doxorubicin (DOX). The physico-chemical properties of MGO-PEG-CET were fully characterized by dynamic light scattering, transmission electron microscopy, X-ray diffraction, Fourier transform Infrared spectroscopy, thermogravimetric analysis, and superconducting quantum interference device. Drug loading experiments revealed that DOX adsorption followed the Langmuir isotherm with a maximal drug loading capacity of $6.35 \mathrm{mg} / \mathrm{mg}$, while DOX release was $\mathrm{pH}$-dependent with more DOX released at $\mathrm{pH} 5.5$ than $\mathrm{pH}$ 7.4. Using quantum-dots labeled nanocarriers and confocal microscopy, intracellular uptakes of MGO-PEG-CET by high EGFR-expressing CT-26 murine colorectal cells was confirmed to be more efficient than MGO. This cellular uptake could be inhibited by pre-incubation with CET, which confirmed the receptor-mediated endocytosis of MGO-PEG-CET. Magnetic targeted killing of CT-26 was demonstrated in vitro through magnetic guidance of MGO-PEG-CET/DOX, while the photothermal effect could be confirmed in vivo and in vitro after exposure of MGO-PEG-CET to near-infrared (NIR) laser light. In addition, the biocompatibility tests indicated MGO-PEG-CET showed no cytotoxicity toward fibroblasts and elicited minimum hemolysis. In vitro cytotoxicity tests showed the half maximal inhibitory concentration (IC50) value of MGO-PEG-CET/DOX toward CT-26 cells was $1.48 \mu \mathrm{g} / \mathrm{mL}$, which was lower than that of MGO-PEG/DOX $(2.64 \mu \mathrm{g} / \mathrm{mL})$. The IC50 value could be further reduced to $1.17 \mu \mathrm{g} / \mathrm{mL}$ after combining with photothermal therapy by NIR laser light exposure. Using subcutaneously implanted CT-26 cells in BALB/c mice, in vivo anti-tumor studies indicated the relative tumor volumes at day 14 were 12.1 for control (normal saline), 10.1 for DOX, 9.5 for MGO-PEG-CET/DOX, 5.8 for MGO-PEG-CET/DOX + magnet, and 0.42 for MGO-PEG-CET/DOX + magnet + laser. Therefore, the dual targeting MGO-PEG-CET/DOX could be suggested as an effective drug delivery system for anticancer therapy, which showed a 29-fold increase in therapeutic efficacy compared with control by combining chemotherapy with photothermal therapy.
\end{abstract}


Keywords: graphene oxide; magnetic nanoparticles; doxorubicin; cetuximab; photothermal therapy

\section{Introduction}

Claiming the lives of 8.8 million people in 2015 alone, cancer is always a serious leading cause of death worldwide [1]. Currently, there are several different treatment techniques, including surgery, radiation, chemotherapy, targeted therapy, and immunotherapy [2]. Among these, chemotherapy has remained as one of the most common therapy methods for the treatment of different kinds of cancers. However, to be successful, chemotherapy may be dependent on several factors, including optimization of drug delivery to a specific targeting site, hence minimizing undesirable side effects to normal cells [3].

Advanced drug delivery systems are able to overcome the problems in conventional chemotherapy by offering carrier systems the possibility to hold sufficient amount of drug, prolong the circulation time, and provide controlled release of drug within tumor cells [4]. In particular, the application of nanotechnology in chemotherapeutics has huge potential to overcome the problems faced in drug delivery, and also provides a platform for the development of a multi-functional drug delivery nano-system for theranostic nanomedicine [5]. Although several nanomaterial-based chemotherapeutics have been successfully translated to clinical applications, the successful clinical translation of promising nanotherapy from benchside to bedside still faces plenty of hurdles. The inconsistency between the pre-clinical and clinical studies and the heterogeneity found in tumors may be suggested as two of the major challenges that nanomaterial-based anti-tumor therapies are facing for translational medicine [6].

Nanoparticles provide ample means of enforcing targeted therapy via passive targeting that refers to efficient localization of nanoparticles within the tumor microenvironment, as well as active targeting that represents the active uptake of nanoparticles by tumor cells. The miniscule size of nanoparticles not only enables far greater intracellular uptake as compared with micron-sized particles [7], it also allows for an inherent passive targeting by means of the enhanced permeability and retention (EPR) effect across tumor tissue's leaky microvasculature [8-10]. Furthermore, new classes of carbon-based nanomaterials, such as carbon nanotube [11] and graphene [12], augment the passive targeting mechanism by releasing their therapeutic moieties in response to a given external environment $\mathrm{pH}$. As epidermal growth factor receptor (EGFR) is highly expressed on the surface of tumor cells, active targeting could be achieved through the surface modification of nanoparticles with a targeting ligand, the EGFR monoclonal antibody (cetuximab, CET), to increase the bindings of drug-loaded nanocarriers with surface receptors of cancer cells and to significantly enhance their intracellular uptake by targeted cancer cells $[13,14]$. On the other hand, there have been numerous studies exploring the conjugation of magnetic nanoparticles with chemotherapeutic agents, which can then be specifically targeted to localized tumors by guidance with an external magnetic field, hence further increasing the efficiency of anti-cancer therapy through magnetic targeting [15-17].

Graphene is currently the thinnest material in existence with a thickness of only $0.35 \mathrm{~nm}$ [18]. It has a two-dimensional planar structure composed of a sp ${ }^{2}$ mixed-layer orbital with a considerably large specific surface area, making it suitable for carrying large quantities of substances (e.g., metal, biomolecules, and drugs) [19]. When used as a drug carrier, graphene is typically converted into graphene oxide (GO) to increase hydrophilicity by the introduction of oxygen-containing functional groups and bind with chemotherapeutic drugs, such as doxorubicin (DOX), by physical adsorption [20,21]. With loading capacities of up to $2.35 \mathrm{mg} / \mathrm{mg}$ of DOX, GO has a substantially greater loading capacity than other conventional drug carriers, such as polymeric micelle, hydrogel microparticles, and liposomes [22]. Furthermore, the adsorption between GO and DOX is pH-sensitive, which offers controlled drug release after intracellular uptake of DOX-loaded GO by cancer cells through endocytosis into the endosomes for release of its cargo in the low $\mathrm{pH}(\sim 5)$ endosomal 
environment. Indeed, the blood's physiological $\mathrm{pH}(\mathrm{pH}$ 7.4) is expected to prevent burst DOX release in the circulation after intravenous injection of DOX-loaded GO, whereas the lower $\mathrm{pH}$ environment after endocytosis into cancer cells would trigger the release of the drug intracellularly for enhanced chemotherapeutic efficacy [22-24].

It should be noted that current literature proposes that GO may induce the generation of reactive oxygen species in target cancer cells, which was deemed as one of the most important nanotoxicity mechanisms of GO [25]. Nonetheless, the nanotoxicity depends on the number of layers, size, surface properties, and methods of the synthesis of GO, in addition to the dose, time of exposure, cell type, and administration method [26]. Thus, generalizations of GO nanotoxicity should be avoided due to the presence of several parameters affecting the toxicity profile of GO. For cellular responses to sheet-like GO, discrepancies were reported for different cell types [27]. However, GO of greatly different sizes ( $350 \mathrm{~nm}$ vs. $2200 \mathrm{~mm}$ ) was selectively internalized by two macrophages by phagocytosis and showed equal uptake amount in macrophages [28].

Another advantage that is offered by GO is its strong optical absorption in the near-infrared (NIR) tissue transparency window that may allow its potential use as a photothermal therapy agent. Photothermal therapy involves the use of light absorbents so as to absorb $808 \mathrm{~nm}$ NIR light and convert the light energy into thermal energy for the killing of cancer cells and the ablation of tumor tissue [29,30]. In recent years, researchers have successfully demonstrated that GO exposed to NIR could destroy cancer cells in vitro and shrink tumor size from animal experiments [31]. Thus, irradiating GO with NIR light after its intracellular uptake by cancer cells could be employed as a noninvasive method for cancer treatment in conjunction with its advantages as a nanocarrier for DOX.

Taken together, all of the considerations mentioned above, we aim to utilize GO's unique properties, $\mathrm{pH}$-sensitive drug release, high drug loading, and strong optical NIR absorption, to develop a multi-functional DOX-carrying drug delivery system that incorporates dual-targeting drug delivery with photothermal therapy. We focus on using magnetic graphene oxide (MGO) by chemical co-precipitation of $\mathrm{Fe}_{3} \mathrm{O}_{4}$ magnetic nanoparticles on $\mathrm{GO}$ nano-platelets [32], which was further modified with polyethylene (PEG) and CET (MGO-PEG-CET), for magnetic and the receptor-mediated dual targeted delivery of DOX. We thoroughly characterize the properties of the nanocarriers and evaluate the anti-cancer therapeutic efficacy both in vitro and in vivo using high EGFR-expressing CT-26 murine colorectal cells.

\section{Results and Discussion}

\subsection{Preparation and Characteriazation of $M G O, M G O-P E G-C E T$ and MGO-PEG-CET/DOX}

The nanocarriers were synthesized according to the scheme in Figure 1. Modification using $\mathrm{ClCH}_{2} \mathrm{COOH}$ introduced abundant $-\mathrm{COOH}$ groups on $\mathrm{MGO}$ surface, which reacted with the $-\mathrm{NH}_{2}$ groups of avidin through carbodiimide-mediated amide bond formation catalyzed by 1-(3-dimethylaminopropyl)-3-ethylcarbodiimide hydrochloride (EDC) and N-hydroxysuccinimide (NHS). Using biotin-PEG-NHS that has a terminal -NHS groups to react spontaneously with the $-\mathrm{NH}_{2}$ groups of CET (or quantum dots, QDs), we prepared biotinylated PEG-CET (or PEG-QDs). Finally, MGO-PEG-CET (or MGO-PEG-CET-QDs) could be facially prepared by taking advantage of the high affinity of avidin toward biotin $\left(K_{d}=10^{-15} \mathrm{M}\right)$ and the capacity to bind up to four biotin molecules per avidin [33]. Also, as the bond formation between avidin and biotin is very rapid and is not unaffected by $\mathrm{pH}$ and temperature, which further facilitate the approach adopted here to conjugate CET to PEGylated MGO.

This method also provides a simple method for PEGylation of MGO, which is expected to decrease the aggregation of MGO by diminishing its interaction with serum proteins to modulate the EPR effect, reduce the reticuloendothelial system (RES) uptake, and increase the circulation time of MGO-PEG [34]. It was demonstrated that after coating with PEG, drug-loaded nanocarriers could accumulate less in the liver to result in higher tumor accumulation than unmodified ones 
without PEGylation [35]. From chemical analysis, the toluidine blue $\mathrm{O}$ (TBO) dye adsorption assay confirmed that each milligram of MGO contained $2.38 \times 10^{-4} \pm 5.04 \times 10^{-5} \mathrm{mmol}$ of $-\mathrm{COOH}$ for conjugation with avidin. Quantitative analysis with protein assays indicated that the amount of avidin and CET conjugated to MGO is $1.938 \pm 0.102 \mathrm{mg}$ of avidin and $2.52 \pm 0.212 \mathrm{mg}$ of CET per $\mathrm{mg}$ of MGO, respectively.

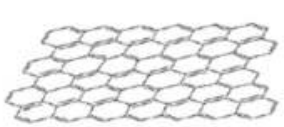

Graphene

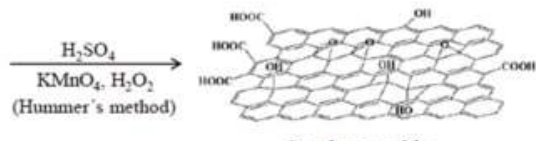

Graphene oxide
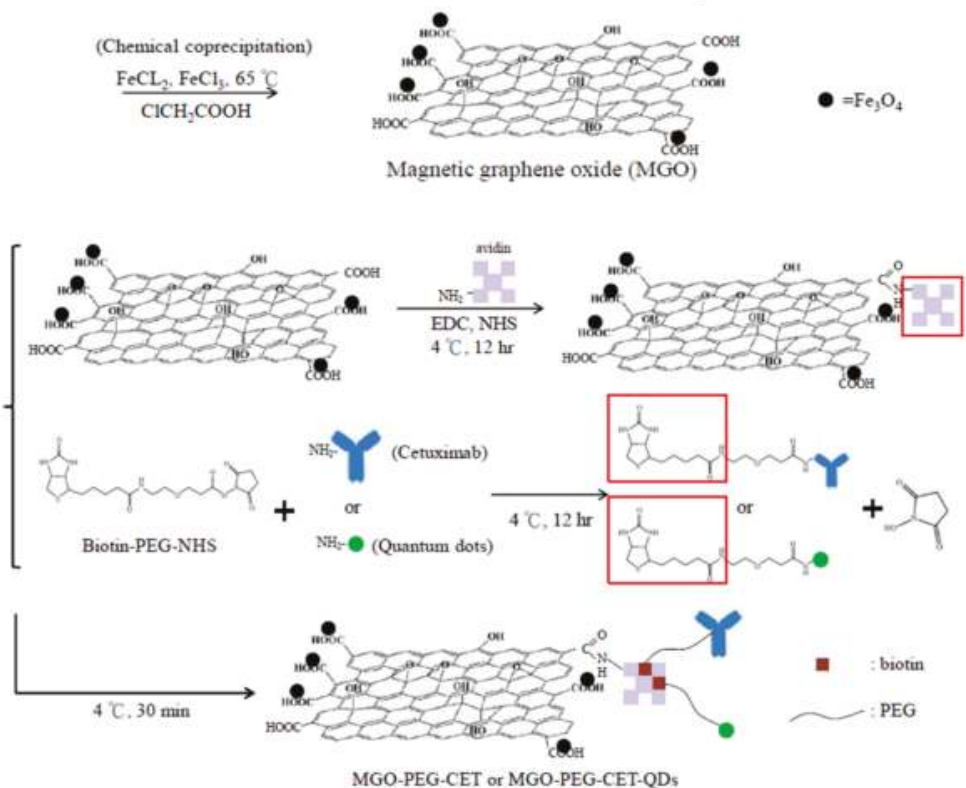

MGO-PEG-CET or MGO-PEG-CET-QDs

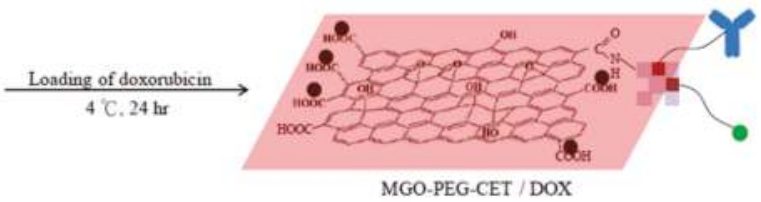

Figure 1. The flow diagram for producing doxorubicin (DOX)-loaded Magnetic Graphene Oxide (MGO)-polyethylene glycol (PEG)-cetuximab (CET) (MGO-PEG-CET/DOX). $\mathrm{Fe}_{3} \mathrm{O}_{4}$ magnetic nanoparticles were deposited on GO by chemical co-precipitation to prepare MGO. Avidin was bound to MGO by covalent binding while biotin-PEG N-hydroxysuccinimide (NHS) was conjugated to cetuximab (CET) or quantum dots (QDs). Mixing of avidin-modified MGO with biotin-PEG-CET and biotin-PEG-QDs could produce MGO-PEG-CET and MGO-PEG-CET-QDs for doxorubicin (DOX) loading and fluorescent tracking after intracellular uptake.

The structure of GO, MGO and MGO-PEG-CET were observed under transmission election microscope (TEM). Figure 2a shows the laminar stacking form of GO with size less than $300 \mathrm{~nm}$, while Figure $2 \mathrm{~b}$ depicts the appearance of black nanoparticles in MGO from the electron dense magnetite after chemical co-precipitation of $\mathrm{Fe}_{3} \mathrm{O}_{4}$ magnetic nanoparticles. After negative staining with $2 \%$ phosphotungstic acid that selectively binds to the basic groups (lysine and arginine residues) 
of proteins [36], magnetic nanoparticles appeared black while the light grey zones revealed the presence of avidin and CET in the TEM image of MGO-PEG-CET (Figure 2c). Figure 2d illustrates the crystal lattices of $\mathrm{Fe}_{3} \mathrm{O}_{4}$ on the MGO detected through selected area electron diffraction of the circled area of MGO, which further confirms the presence of well-crystallized $\mathrm{Fe}_{3} \mathrm{O}_{4}$ magnetic nanoparticles in MGO. For suspension stability, 1\% MGO is stable in deionized (DI) water for $24 \mathrm{~h}$, but not in phosphate buffered saline (PBS) (Figure 2e). Consistent with a previous report that surface modification with PEG and proteins (avidin and CET) could substantially improve the stability of GO [37], MGO-PEG-PET was confirmed to be free from agglomeration and sedimentation in PBS and cell culture medium after $24 \mathrm{~h}$ (Figure 2e).

Form Table 1, the average hydrodynamic diameter obtained from dynamic light scattering (DLS) indicated that the particle size was significantly increased from GO to MGO after decorating $\mathrm{GO}$ with $\mathrm{Fe}_{3} \mathrm{O}_{4}$. However, the particle size showed no significant difference between MGO and MGO-PEG-CET after grafting with soft polymer chains. As nanoparticles with hydrophilic surfaces and threshold size $\sim 200 \mathrm{~nm}$ will show improved EPR effect by increasing residence time in blood [38], MGO-PEG-CET falls within this size range and is expected to reach the tumor and endocytosed by cancer cells. For zeta potentials, GO showed a highly negative value due to the presence of abundant oxygen-containing functional groups on GO surface. The zeta potential of MGO slightly increased to $-35.1 \mathrm{mV}$ as $\mathrm{Fe}_{3} \mathrm{O}_{4}$ showed a positive zeta potential $(28.8 \pm 0.3 \mathrm{mV})$ from the $-\mathrm{NH}_{2}$ groups in ammonia used during chemical co-precipitation. When CET was conjugated to MGO, the zeta potential of MGO-PEG-CET further increased to $\sim 20 \mathrm{mV}$ as CET is a chimeric antibody with an isoelectric point of about 8.5 [39]. Nonetheless, the zeta potential is still high enough to confer dispersion stability by resisting aggregation.
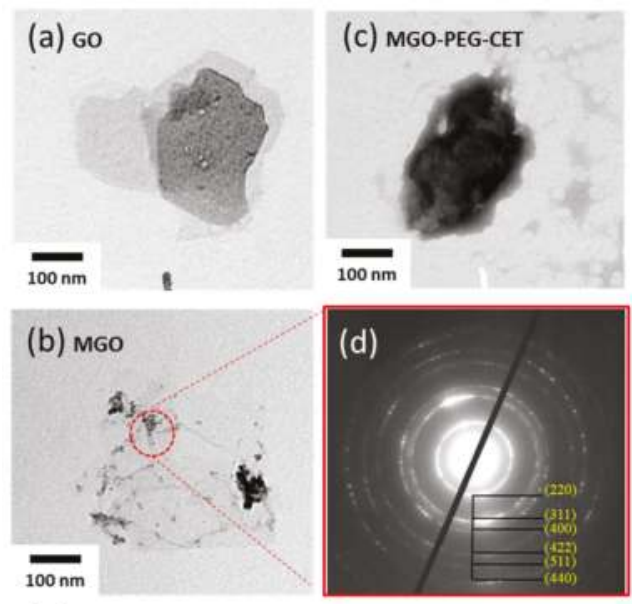

(e)

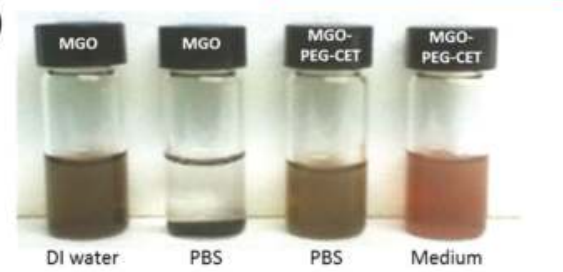

Figure 2. Transmission electron images of graphene oxide (GO) (a); MGO (b); and, MGO-PEG-CET after staining with $2 \%$ phosphotungstic acid (c); (d) The selected area electron diffraction patterns of MGO in the circled area in (b); (e) The suspension stability of $0.1 \mathrm{mg} / \mathrm{mL}$ MGO and MGO-PEG-CET in deionized (DI) water, phosphate buffered saline (PBS) and cell culture medium after $24 \mathrm{~h}$. 
Table 1. The particle size and polydispersity index (PDI) by dynamic light scattering (DLS) and zeta potential of different nanocarriers.

\begin{tabular}{cccc}
\hline Sample & Particle Size $(\mathbf{n m})$ & Polydispersity Index & Zeta Potential $(\mathbf{m V})$ \\
\hline GO & $136.4 \pm 5.7$ & $0.18 \pm 0.05$ & $-44.3 \pm 2.8$ \\
MGO & $205.5 \pm 19.9 *$ & $0.28 \pm 0.03^{*}$ & $-35.1 \pm 0.9^{*}$ \\
MGO-PEG-CET & $215.7 \pm 18.4^{*}$ & $0.29 \pm 0.03^{*}$ & $-19.8 \pm 0.4^{*}$, \\
\hline \multicolumn{4}{r}{${ }^{*} p<0.05$ compared with GO; ${ }^{*} p<0.05$ compared with MGO. }
\end{tabular}

Figure 3a shows X-ray diffraction (XRD) patterns of $\mathrm{Fe}_{3} \mathrm{O}_{4}$ and MGO. GO will show a typical diffraction peak at $2 \theta=11.6^{\circ}$ due to the $(002)$ reflection with spacing $\mathrm{d}=0.91 \mathrm{~nm}[40,41]$. For MGO, new diffraction peaks were found at $2 \theta=30.1^{\circ}, 35.4^{\circ}, 43.1^{\circ}, 53.2^{\circ}, 56.9^{\circ}$, and $62.5^{\circ}$, and identified as the cubic spinel crystal planes of $\mathrm{Fe}_{3} \mathrm{O}_{4}$ from JCPDS database [42]. In addition, the crystallite size of $\mathrm{Fe}_{3} \mathrm{O}_{4}$ could be estimated to be $10.9 \mathrm{~nm}$ from the strongest (31 1) reflection using the Debye-Scherrer equation [43].

From Fourier transform infrared (FTIR) analysis in Figure 3b, GO reveals characteristic bands at 1265 and $1074 \mathrm{~cm}^{-1}$ due to $\mathrm{C}-\mathrm{OH}$ and $\mathrm{C}-\mathrm{O}$ stretching vibrations, while the characteristic bands at 1623 and $3400 \mathrm{~cm}^{-1}$ are due to $\mathrm{C}=\mathrm{C}$ and $-\mathrm{OH}$ [44]. In addition, the band at $1725 \mathrm{~cm}^{-1}$ could be assigned to $\mathrm{C}=\mathrm{O}$ stretching vibrations from carbonyl and carboxylic groups in $\mathrm{GO}$. MGO shows an additional characteristic peak at $572 \mathrm{~cm}^{-1}$ from the stretching vibration of $\mathrm{Fe}-\mathrm{O}$ bond, suggesting that $\mathrm{Fe}_{3} \mathrm{O}_{4}$ is bound to $\mathrm{GO}$ successfully. For MGO-PEG-CET, additional peaks at 843,947 , and $1106 \mathrm{~cm}^{-1}$ could be assigned to PEG [45].
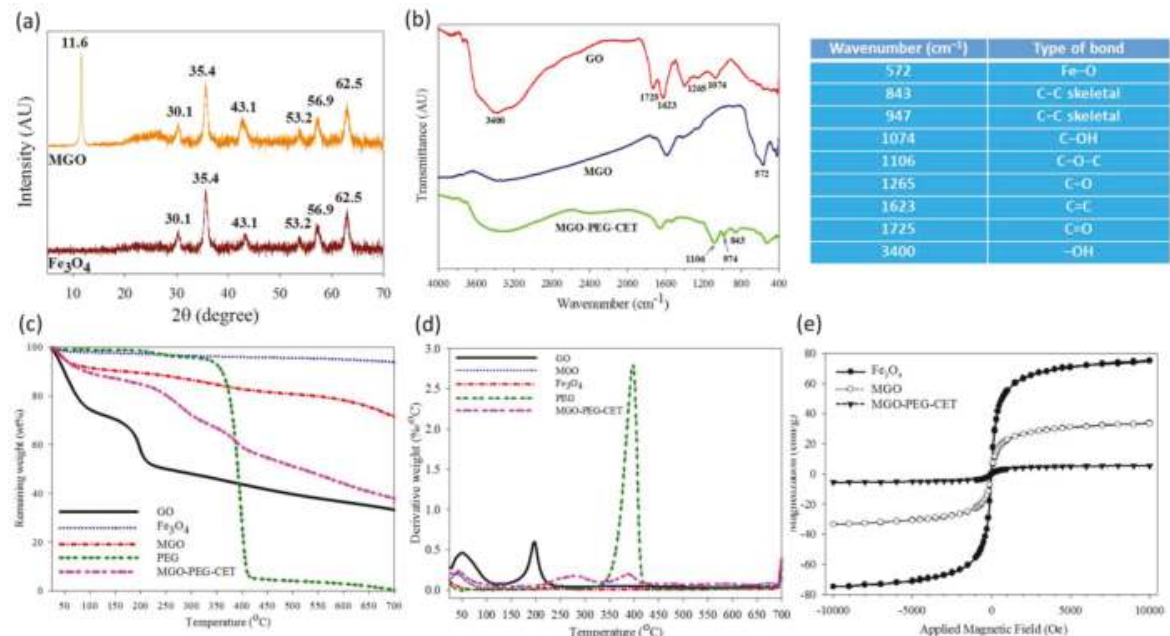

(e)

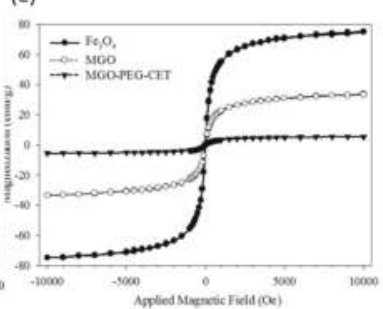

Figure 3. Characterization of MGO and MGO-PEG-CET by X-ray diffraction (XRD) (a); Fourier transform infrared (FTIR) (b); thermogravimetric analysis (TGA) (c); differential thermal analysis (DTA) (d); and superconducting quantum interference device (SQUID) (e). The table lists the wavenumbers of characteristic peak found in the FTIR spectra in (b).

Thermogravimetric analysis (TGA) was conducted on GO, $\mathrm{Fe}_{3} \mathrm{O}_{4}, \mathrm{MGO}$, and MGO-PEG-CET (Figure 3c). After initial weight loss due to water, substantial weight loss ( 21\%) was shown by GO when heated from 130 to $250{ }^{\circ} \mathrm{C}$ with the decomposition of its oxygen-containing functional groups, which gave a peak decomposition temperature of $200^{\circ} \mathrm{C}$ and $33 \%$ residual weight at $700{ }^{\circ} \mathrm{C}[46,47]$. $\mathrm{Fe}_{3} \mathrm{O}_{4}$ had minimal weight loss of $\sim 3 \%$ at $700{ }^{\circ} \mathrm{C}$, corresponding to the loss of surface $-\mathrm{OH}$ functional groups [48]. PEG underwent $\sim 90 \%$ weight loss between $330^{\circ} \mathrm{C}$ and $420^{\circ} \mathrm{C}$ with a peak decomposition 
temperature at $\sim 400{ }^{\circ} \mathrm{C}$ from the differential thermal analysis (DTA) curve in Figure $3 \mathrm{~d}$, to give zero residual weight at $700{ }^{\circ} \mathrm{C}$, as expected for an organic polymer [49]. For MGO, thermal decomposition was delayed and more residual weight $(\sim 72 \%)$ than GO was found at $700{ }^{\circ} \mathrm{C}$. The difference in the residual weight between $\mathrm{GO}$ and MGO was used to calculate the mass percentage of $\mathrm{Fe}_{3} \mathrm{O}_{4}$ in MGO, which was $\sim 42 \%$ after considering the weight loss of $\mathrm{Fe}_{3} \mathrm{O}_{4}$. When considering the TGA curve of PEG, MGO-PEG-CET showed additional weight loss from 340 to $440{ }^{\circ} \mathrm{C}$ and a peak decomposition temperature at $\sim 400{ }^{\circ} \mathrm{C}$, which correspond to the thermal decomposition of PEG and confirms the presence of PEG in the nanocarrier. The final residual weight was also consistent with MGO-PEG-CET $(38 \%)<$ MGO $(72 \%)$, as grafted PEG, in addition to avidin and CET, will contribute to additional weight loss. Using inductively coupled plasma-optical emission spectroscopy (ICP-OES), the weight percentage of $\mathrm{Fe}_{3} \mathrm{O}_{4}$ in $\mathrm{MGO}$ could be also confirmed to be $43 \%$.

A superconducting quantum interference device (SQUID) magnetic field intensity analysis was conducted to obtain the hysteresis curves of the nanocarriers (Figure 3e). The saturation magnetization was $75.1 \mathrm{emu} / \mathrm{g}$ for $\mathrm{Fe}_{3} \mathrm{O}_{4}, 33.4 \mathrm{emu} / \mathrm{g}$ for MGO, and $5.5 \mathrm{emu} / \mathrm{g}$ for MGO-PEG-CET. The reduced $\mathrm{Fe}_{3} \mathrm{O}_{4}$ weight percentage in the nanocarriers may lead to reduced saturation magnetization [50]. Thus, the saturation magnetization of MGO calculated from the saturation magnetization is $44 \%$ that of GO, which is close to the values from TGA $(42 \%)$ and ICP-OES $(43 \%)$. Further grafting with high molecular weight proteins (avidin molecular weight $=\sim 67 \mathrm{kDa}$ and CET molecular weight $=\sim 152 \mathrm{kDa}$ ), and PEG is expected to substantially decrease the weight percentage of $\mathrm{Fe}_{3} \mathrm{O}_{4}$ in MGO-PEG-CET and influence the saturation magnetization. Nonetheless, calculation based on SQUID saturation magnetization indicated that MGO-PEG-CET contained 7\% $\mathrm{Fe}_{3} \mathrm{O}_{4}$, which is less than that predicted by ICP-OES (12\%). Thus, the reduced saturation magnetization value may originate from the diamagnetic natures of avidin, CET, and PEG on the MGO surface [50,51]. From the magnetization curve, the residue magnetization (remanence) was close to zero without applied external magnetic field $\left(0.13 \mathrm{emu} / \mathrm{g}\right.$ for $\mathrm{Fe}_{3} \mathrm{O}_{4}, 0.6 \mathrm{emu} / \mathrm{g}$ for MGO, and $0.1 \mathrm{emu} / \mathrm{g}$ for MGO-PEG-CET) and no hysteresis loop was observed. Taken together, MGO-PEG-CET could be confirmed to be superparamagnetic from the SQUID magnetization curve, an important property for magnetic targeted delivery of DOX.

\subsection{Drug Loading and Release}

Figure 4a shows the effect of initial DOX concentration on the loading content (weight of DOX loaded per unit weight of MGO-PEG-CET) and the loading efficiency (weight percentage of DOX loaded) of DOX. As initial DOX concentration increased eight-fold from 0.05 to $0.4 \mathrm{mg} / \mathrm{mL}$, the loading efficiency decreased only slightly from 89.8 to $82.1 \%$, indicating high loading capacity of DOX on MGO-PEG-CET. However, the loading content increased continuously with increasing DOX concentration, in close to linear manner, and reached $3.26 \mathrm{mg} / \mathrm{mg}$. With continuously increasing loading capacity, we also modeled the adsorption DOX to MGO-PEG-CET with the Langmuir adsorption isotherm, assuming MGO-PEG-CET to be an ideal adsorbent composed of series of distinct sites capable of binding DOX. Figure $4 \mathrm{~b}$ indicated that the adsorption could be modeled satisfactory by the Langmuir adsorption isotherm with $\left(R^{2}=0.99\right)$ and the maximal adsorption capacity could be obtained at $6.35 \mathrm{mg} / \mathrm{mg}$ [52]. Though initial DOX concentration could be theoretically increased to approach the maximum drug loading, the corresponding increase in solution viscosity hindered recovery of MGO by magnetic separation; therefore, the concentration ratio between MGO-PEG-CET and DOX was set at 1:4 $(0.1 \mathrm{mg} / \mathrm{mL}$ MGO-PEG-CET with $0.4 \mathrm{mg} / \mathrm{mL} \mathrm{DOX)} \mathrm{for} \mathrm{future} \mathrm{studies.}$

The release of DOX from MGO-PEG-CET/DOX was investigated from the cumulative percentage of DOX released at $37^{\circ} \mathrm{C}$ in $\mathrm{pH} 7.4$ or $\mathrm{pH} 5.7 \mathrm{PBS}$ to simulate the extracellular and the intracellular environment (Figure 4c). Sustained release of DOX from MGO-PEG-CET/DOX was observed and the percentage of DOX released at pH $5.7(54.6 \%)$ is about twice that released at pH $7.4(29 \%)$ within one week, thus confirming the $\mathrm{pH}$-sensitive $\mathrm{DOX}$ release. Moreover, the initial slope of the release curve at $\mathrm{pH} 5.7$ demonstrates the effective and rapid release of drug in an acidic environment, fulfilling 
the requirement for intracellular DOX release in the endosome after intracellular uptake [53,54]. GO could adsorb DOX through $\pi-\pi$ stacking and by hydrogen bonds between $-\mathrm{OH}(-\mathrm{COOH})$ groups of MGO-PEG-CET and -OH group of DOX [55]. Therefore, the $\mathrm{pH}$-sensitive drug release may be due to the weakening of those hydrogen bonds when $\mathrm{H}^{+}$weakens hydrogen bond interactions and promotes drug release. By releasing its drug cargo in the acidic endosomal environment $(\mathrm{pH}<6)$ after intracellular uptake, the cytotoxicity of MGO-PEG-CET/DOX toward cancer cells could be enhanced.
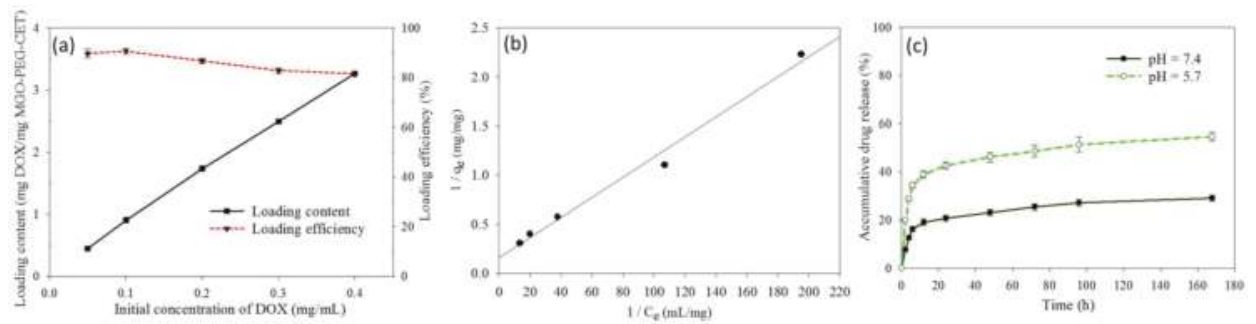

Figure 4. (a) Drug loading content and loading efficiency when a DOX solution with different initial concentration was mixed with an equal volume of $0.1 \mathrm{mg} / \mathrm{mL}$ MGO-PEG-CET; (b) The drug loading was satisfactorily modeled with the Langmuir adsorption isotherm where $C_{e}$ is the equilibrium DOX concentration in the solution and $q_{e}$ is the adsorbed DOX amount; and, (c) The release of DOX from MGO-PEG-CET/DOX in $\mathrm{pH} 7.4$ and $5.7 \mathrm{PBS}$ at $37^{\circ} \mathrm{C}$.

\subsection{Intracelular Uptake}

The high expression of EGFR on CT-26 surface is expected to facilitate ligand-targeting of CT-26 cancer cells using CET, an EGFR antibody [56]. This targeting effect could manifest itself through intracellular uptake of quantum dots (QDs)-tagged nanocarriers observed under a confocal microscope. Indeed, the confocal images in Figure 5 confirmed that CT-26 cells showed more intracellular uptake of MGO-PEG-CET than MGO-PEG from the signal intensity of QDs. Furthermore, the intracellular uptake of MGO-PEG-CET was inhibited when CT-26 cells were pre-treated with CET, thus confirming the receptor-mediated endocytosis of MGO-PEG-CET, as EGFR on cell surface could be blocked with excess CET. Therefore, we could confirm the enhanced intracellular uptake of CET-conjugated nanocarrier is governed by the binding of CET in MGO-PEG-CET to EGFR on CT-26 surface, which could provide an active targeting mechanism for targeted drug delivery.

The process of endocytosis was further confirmed by TEM. The TEM micrographs in Figure 6 clearly identified aggregates of MGO-PEG-CET within the endosomes after intracellular uptake, which are located in the cell cytoplasm and in close proximity to the cell nucleus. The endocytosis of MGO-PEG-CET is consistent with a previous report that studied the size-dependent intracellular uptake of protein-coated GO [57]. The authors reported that small GO (420 nm equivalent diameter) enter cells mainly through clathrin-mediated endocytosis, while large GO (860 nm equivalent diameter) enter through both phagocytosis and endocytosis.

Visualization of QDs-tagged MGO-PEG-CET/DOX after contacting with CT-26 cells revealed the green fluorescence of QDs-labeled MGO-PEG-CET in the cell cytoplasm, while the red fluorescence of DOX could only be identified in cell nuclei and merged with the blue fluorescence from the DAPI-stained cell nuclei (Figure 5). This implied DOX could be released from MGO-PEG-CET/DOX in the acidic intracellular environment after endocytosis, followed by releasing DOX into the nucleus to chelate with DNA molecules and exert cytotoxicity toward cancer cells [58]. Taken together, the confocal microscopy and TEM results strongly suggested that the cytotoxicity effects of DOX toward CT-26 could be facilitated by endocytosis of MGO-PEG-CET/DOX, followed by drug release at low endosomal $\mathrm{pH}$ value to enhance the anticancer activity of the drug. 


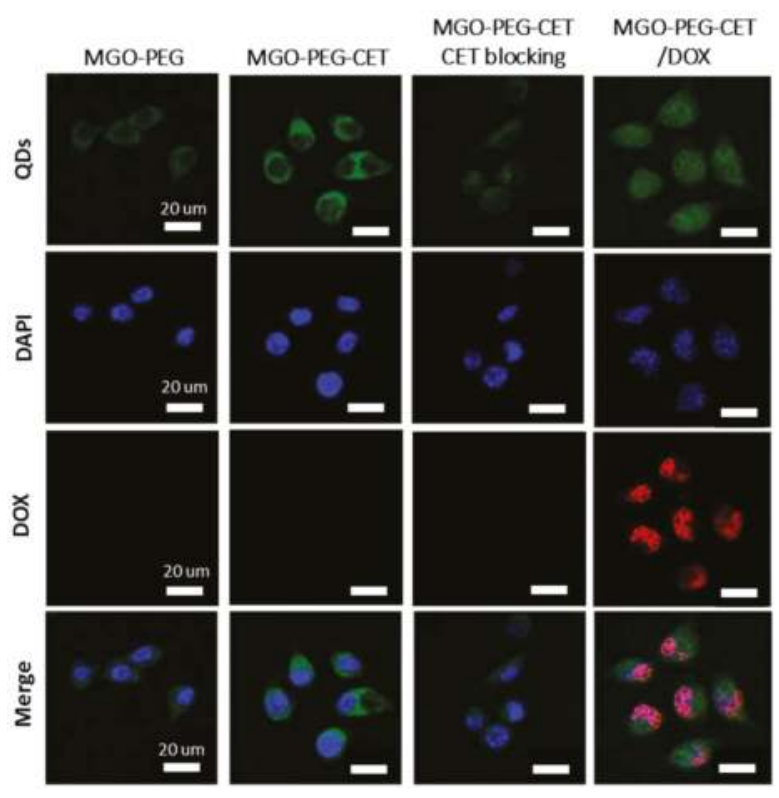

Figure 5. The confocal microscopy images of CT-26 cells after incubated with MGO-PEG, MGO-PEG-CET or MGO-PEG-CET/DOX for $1 \mathrm{~h}$. Blocking of interaction between EGFR and CET (MGO-PEG-CET CET blocking) was carried out by pre-incubating CT-26 cells with CET (1 mg / $\mathrm{mL}$ ) for $1 \mathrm{~h}$ to block EGFR receptors on cell surface followed by incubating with MGO-PEG-CET for $1 \mathrm{~h}$. Bar $=20 \mu \mathrm{m}$.

(a)

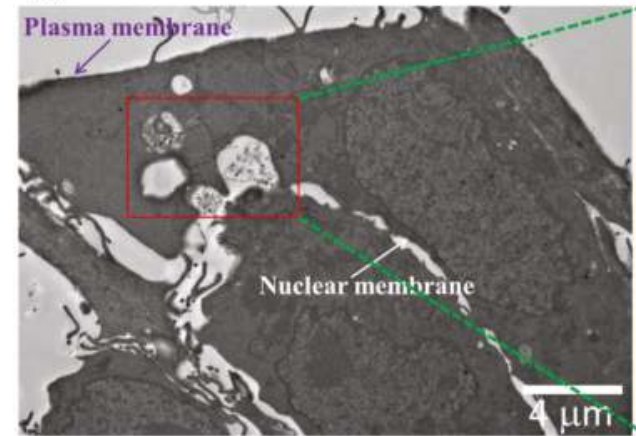

(b)

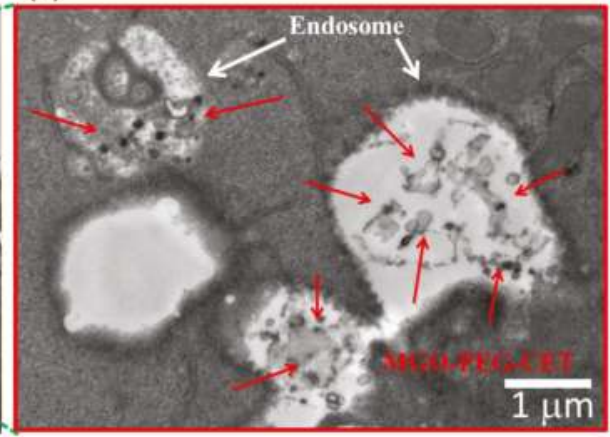

Figure 6. The transmission electron microscope (TEM) micrographs of CT-26 cells after contacting with MGO-PEG-CET for $1 \mathrm{~h}$, bar $=4 \mu \mathrm{m}$. (b) is the magnified image of the red square shown in (a), bar $=1 \mu \mathrm{m}$.

\subsection{Magnetic Targeting and Laser-Induced Hyperthermia}

Through Live/Dead cell viability staining, we verified that an applied magnetic field in vitro could successfully guide MGO-PEG-CET/DOX to the magnetic targeting zone created by a magnet under the well in the cell culture dish. Within the magnetic targeting zone, there were hardly any live cells, while dead cells within this zone were likely to be detached from the well surface and removed during rinsing (Figure 7a). In contrast, abundant live cells (stained green) were detected outside the 
magnetic targeting zone, endorsing the possibility to magnetically guide MGO-PEG-CET/DOX to the tumor site in vivo using a magnetic field for magnetic targeting [58].

The photothermal effect was studied in vitro by measuring the temperature rise of solutions containing nanocarriers after irradiating with NIR laser at $2.5 \mathrm{~W} / \mathrm{cm}^{2}$ for $3 \mathrm{~min}$ (Figure $7 \mathrm{~b}$ ). Both GO and MGO showed a temperature rise, but the temperature increase was more pronounced for MGO. This is consistent with previous reports that both GO [59] and $\mathrm{Fe}_{3} \mathrm{O}_{4}$ magnetic nanoparticles [60] showed photothermal effects after absorbing light in the NIR region. The introduction of polymer and protein, such as PEG, avidin, and CET, may partially hamper the absorption of NIR light by MGO, resulting in a lower temperature rise for MGO-PEG-CET.

To observe the photothermal effect in vivo, MGO-PEG-CET was injected into healthy BALB/c mice (Figure 7c) or tumor-bearing BALB/c mice with CT-26 cells implanted subcutaneously (Figure 7d). Magnets were attached to the tumor for $2 \mathrm{~h}$ and both of the mice were exposed to NIR laser for $5 \mathrm{~min}$ at $2.5 \mathrm{~W} / \mathrm{cm}^{2}$. The regional temperature of the healthy mouse only rose to $42.5^{\circ} \mathrm{C}$, whereas the regional temperature of the tumor-bearing mouse rose to $60.1^{\circ} \mathrm{C}$. These results verified that MGO-PEG-CET is suitable for photothermal therapy in vivo [30].

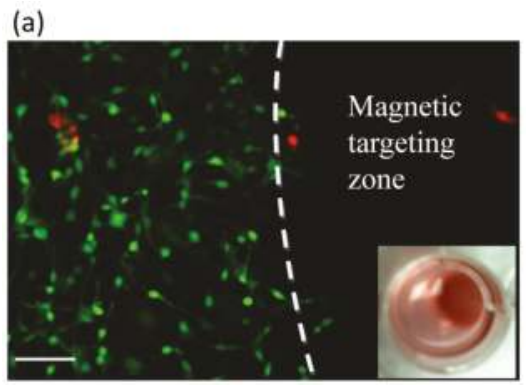

(c)

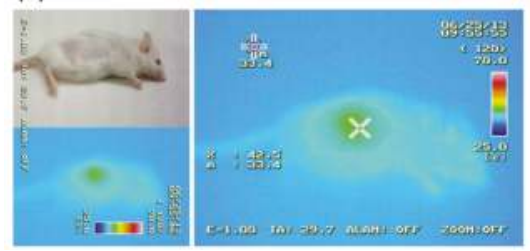

(b)
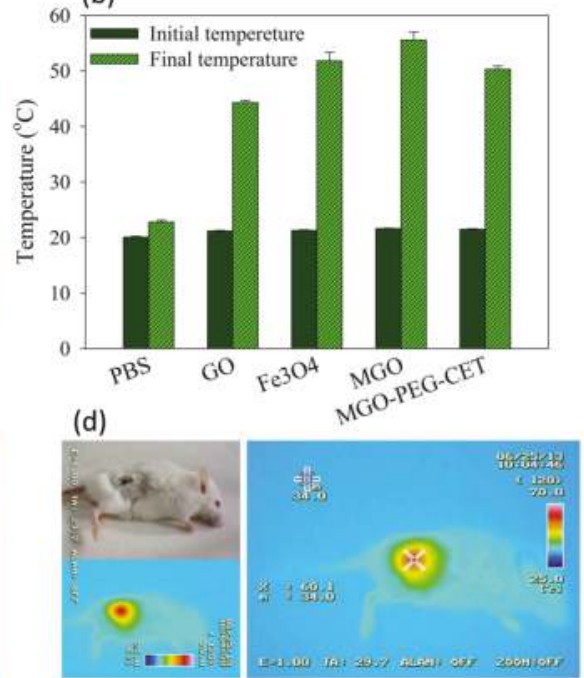

Figure 7. (a) Live/Dead staining of CT-26 cells after contacting with MGO-PEG-CET/DOX in a cell culture dish with a magnetic targeting zone created in a well of a culture dish by placing a magnet at the bottom of the well. The insert shows that MGO-PEG-CET/DOX was guided to the right corner of the well in the culture dish. Green: live cells; red: dead cells. Bar $=100 \mu \mathrm{m}$; (b) Temperature changes in vitro after exposure different nanocarriers $\left(1 \mathrm{mg} / \mathrm{mL}\right.$ in $0.2 \mathrm{~mL}$ of PBS) to NIR light at $2.5 \mathrm{~W} / \mathrm{cm}^{2}$ for $3 \mathrm{~min}$. The in vivo temperature rise from thermal imaging of healthy BALB/c mouse (c) and tumor-bearing mouse (d) after intravenous injection of MGO-PEG-CET $(7 \mathrm{mg} / \mathrm{kg})$, followed by guidance with a magnetic field (1400 Gauss) for $2 \mathrm{~h}$ and exposure to NIR light $\left(2.5 \mathrm{~W} / \mathrm{cm}^{2}\right.$ for $5 \mathrm{~min}$ ).

\subsection{Biocompatibility of Nanocarriers}

Biocompatibility tests were performed to assess the safety of the nanocarriers, including the cell viability test and hemolysis assay. The cell viability test was conducted on $3 \mathrm{~T} 3$ fibroblast and CT-26 cells, which was incubated with different concentrations of MGO-PEG and MGO-PEG-CET. Both MGO-PEG and MGO-PEG-CET were non-toxic to fibroblasts in the concentration studies (Figure 8a). For CT-26, MGO-PEG was also biocompatible up to $100 \mu \mathrm{g} / \mathrm{mL}$ (Figure 8b). In contrast, MGO-PEG-CET shows 
mild toxicity from 10 to $100 \mu \mathrm{g} / \mathrm{mL}$, and the relative cell viability was significantly significant different from those of MGO-PEG. It is well-documented that CET causes cytotoxicity to EGFR-expressing cancer cells, which renders CET to be a FDA approved drug for treating colon and head/neck cancers $[61,62]$. This feature is advantageous when considering that CET in the drug-free nanocarrier (MGO-PEG-CET) may also contribute to the killing of CT-26 cells.

An in vitro hemolysis assay was conducted to verify blood biocompatibility of MGO-PEG-CET. The absorption spectra (Figure 8c) of the supernatant of MGO-PEG-CET (31.25 250 $\mu \mathrm{g} / \mathrm{mL}$ in PBS) after incubation with red blood cells (RBCs) at $37^{\circ} \mathrm{C}$ for $2 \mathrm{~h}$ were conducted, with deionized (DI) water and PBS being, respectively, designated as the positive and negative controls. The osmotic pressure of DI water caused RBCs to rupture; thus, the absorbance spectrum of the DI water group showed absorbance values significantly higher than that of other groups. No visible hemolysis effect was observed after incubation with MGO-PEG-CET. The solution absorbance at $540 \mathrm{~nm}\left(\mathrm{OD}_{540}\right)$ was the lowest for PBS, but slightly increased with increasing MGO-PEG-CET concentration, indicating that the nanocarrier caused slight but acceptable RBC damage (Figure 8d). That both of the solution colors and the absorbance of the MGO-PEG-CET solution were similar to that of the PBS endorsed minimum hemolysis due to MGO-PEG-CET and its safety for in vivo application as a drug carrier.
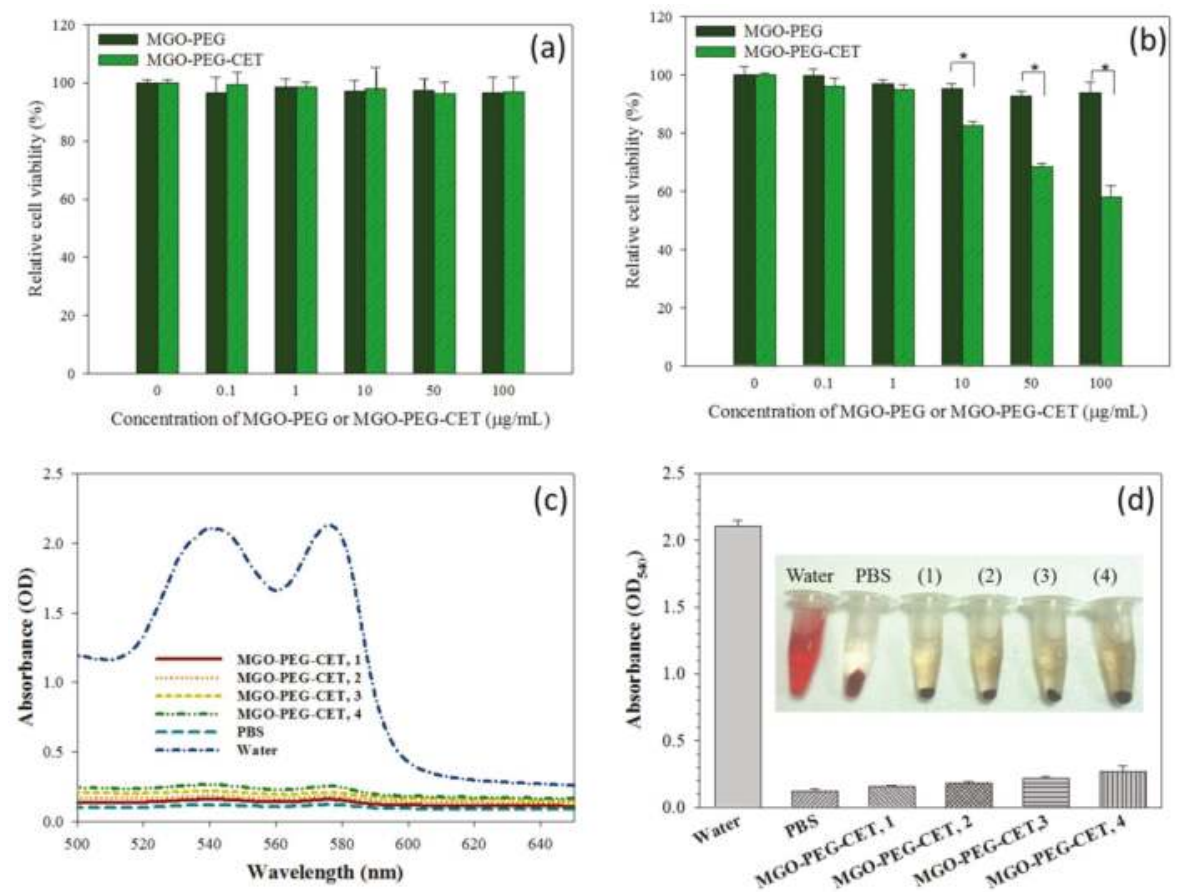

Figure 8. The biocompatibility of MGO-PEG and MGO-PEG-CET toward 3T3 fibroblasts (a) and CT-26 (b) by incubating cells with nanocarrier at different concentrations for $24 \mathrm{~h}$ and the relative cell viability was determined by MTT assays relative to culture medium ( $\left.{ }^{*} p 0.05\right)$; The hematological compatibility of MGO-PEG-CET was determined from the absorption spectra of the supernatant of MGO-PEG-CET after incubation with red blood cells in PBS for $2 \mathrm{~h}$ (c) for hemolytic assay and the optical density at $540 \mathrm{~nm}\left(\mathrm{OD}_{540}\right)$ of the supernatant of MGO-PEG-CET was determined (d). Water and PBS were used as the positive and the negative controls, respectively. The temperature was at $37^{\circ} \mathrm{C}$. The concentrations of MGO-PEG-CET were $100 \mu \mathrm{g} / \mathrm{mL}$ (1), $200 \mu \mathrm{g} / \mathrm{mL}$ (2), $400 \mu \mathrm{g} / \mathrm{mL}$ (3) and $800 \mu \mathrm{g} / \mathrm{mL}$ (4) in (d). 


\subsection{The Efficacy of Combined Therapy In Vitro and In Vivo}

Cell cytotoxicity assay was performed to assess the half maximal inhibitory concentration (IC50) of DOX after $24 \mathrm{~h}$ incubation with CT-26 cells in order to compare the efficacy of different treatments in vitro (Figure 9). The IC50 of DOX, MGO-PEG/DOX, MGO-PEG-CET/DOX, and MGO-PEG-CET/DOX + laser were 5.64, 2.64, 1.48, and $1.17 \mu \mathrm{g} / \mathrm{mL}$, respectively. The results showed that MGO-PEG/DOX showed higher cytotoxicity than DOX, owing to the cellular uptake of MGO-PEG/DOX. The cytotoxicity could be further enhanced using MGO-PEG-CET/DOX with CET ligand-targeting to enhance the intracellular uptake of the nanocarrier and increase intracellular DOX concentration (Figure 5). Most importantly, MGO-PEG-CET/DOX treatment, followed by laser irradiation showed the highest cytotoxicity toward CT-26 cells with only one-fifth the IC50 of DOX, supporting the synergistic effects of chemotherapy and photothermal therapy.

The antitumor efficacy of MGO-PEG-CET/DOX was studied in vivo in a xenograft tumor model in mice. BALB/c mice with subcutaneous CT-26 tumors of $60-100 \mathrm{~mm}^{3}$ were subjected to treatment with normal saline (control) and DOX in different ways. Gross images of the tumor-bearing mice taken on day 0 and 14 demonstrated the apparent tumor size differences in each group and the tumor removed from the animal on day 14 supported the anti-tumor effects with each treatment, but to a different degree (Figure 10a). Based on results of H\&E staining of tumor tissue on day 14, necrosis of the cancer cells was most substantial in MGO-PEG-CET/DOX + magnet and MGO-PEG-CET/DOX + magnet + laser groups [59], but cell growth was observed in control, DOX and MGO-PEG-CET/DOX groups (Figure 10a).

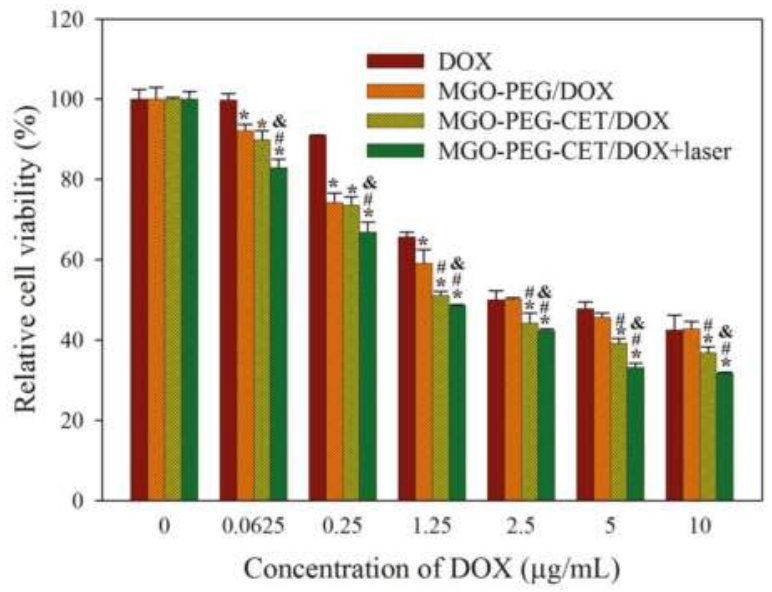

Figure 9. In vitro cytotoxicity of DOX, MGO-PEG/DOX, MGO-PEG-CET/DOX and MGO-PEG-CET/DOX + laser after contacted with CT-26 cells for $24 \mathrm{~h}$. The laser group was subject to $2.5 \mathrm{~W} / \mathrm{cm}^{2}$ NIR light exposure for $3 \mathrm{~min}$ after treating with MGO-PEG-CET/DOX. * $p<0.05$ compared with DOX. ${ }^{\#} p<0.05$ compared with MGO-PEG/DOX. \& $p<0.05$ as compared with MGO-PEG-CET/DOX.

The tumor volumes were recorded every other day up to 14 days and were expressed as relative tumor volume after normalizing the tumor volume at each time point with the tumor volume at day 0 . At day 14, the average values of relative tumor volumes were 12.1 (control), 10.1 (free DOX), 9.5 (MGO-PEG-CET/DOX), 5.8 (MGO-PEG-CET/DOX + magnet) and 0.42 (MGO-PEG-CET/DOX + magnet + laser) (Figure 10b). When compared to the control, only MGO-PEG-CET/DOX + magnet and MGO-PEG-CET/DOX + magnet + laser groups showed substantial tumor suppression throughout the observation period (* $p<0.05)$. Although both free DOX and MGO-PEG-CET/DOX groups showed a 
general trend of tumor volume reduction as compared with the control with MGO-PEG-CET/DOX consistently performed better than DOX, both of the groups did not show significant difference in tumor volume from the control throughout the experiment. This underscores the importance of dual targeting with magnetic guidance in addition to ligand-targeting at the tumor site (MGO-PEG-CET/DOX + magnet) to bring about a significant difference from the control group in tumor volume. Nonetheless, the MGO-PEG-CET/DOX + magnet treatment failed to suppress tumor growth after day 8 with a rapid increase of tumor volume. This uncontrolled increase in tumor size could be alleviated by combining with photothermal therapy using laser light. Indeed, Only the MGO-PEG-CET/DOX + magnet + laser treatment could continuously suppress tumor growth and shrank the tumor size to a value less than the original value throughout the 14-day observation period. Undoubtedly, the significance of local hyperthermia for photothermal tumor ablation could be inferred for this remarkable enhancement in treatment efficacy [63]. As shown in Figure 10c, the mouse's body weight did not exhibit any significant difference between groups. However, mice in the control group showed a trend of better weight gain when compared to other groups under DOX treatment, which could be ascribed to the common adverse effect from chemotherapy. However, we did not observe any changes in appetite and behavior throughout the observation period for all of the mice under treatment.

(a)

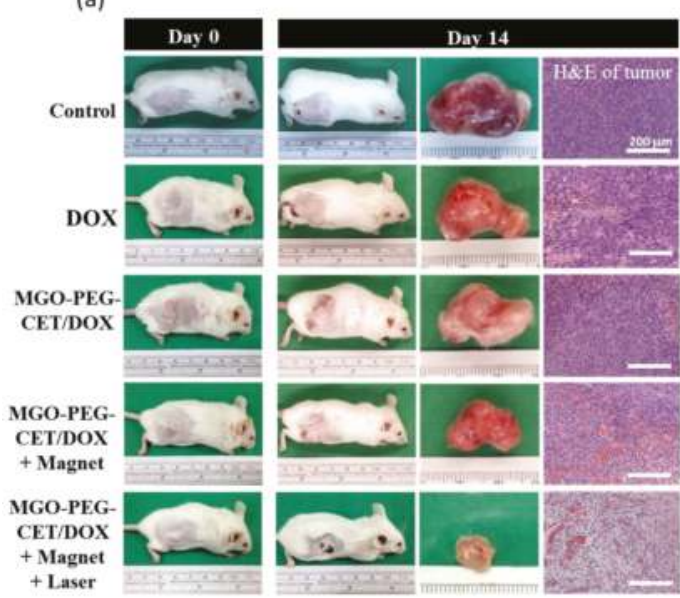

(b)

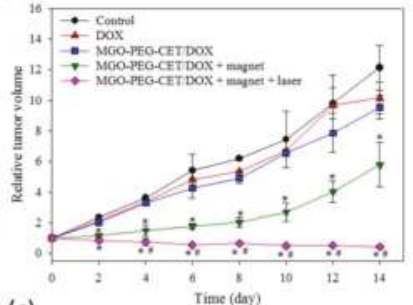

(c)

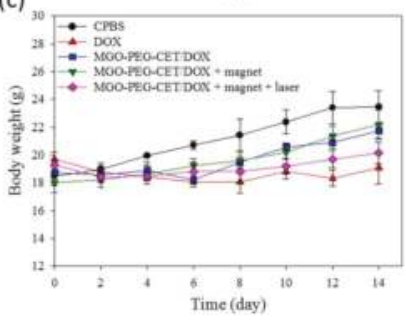

Figure 10. The anti-tumor efficacy in vivo with tumor-bearing BALB/C mice. BALB/c mice were subcutaneously implanted with CT-26 cells and were given different treatment by intravenous injection of normal saline (control), DOX, MGO-PEG-CET/DOX, MGO-PEG-CET/DOX + magnet, and MGO-PEG-CET/DOX + magnet + laser (30 mg/kg DOX). (a) The gross observation of tumor-bearing BALB/c mice on day 0 and 14, the gross view of incised tumor and the H\&E staining of the incised tumor on day $14(\mathrm{bar}=200 \mu \mathrm{m})$; The relative tumor volume $(\mathbf{b})$ and body weight $(\mathrm{c})$ were recorded. ${ }^{*} p<0.05$ compared with control, DOX, and MGO-PEG-CET/DOX, ${ }^{\#} p<0.05$ as compared with MGO-PEG-CET/DOX + magnet.

\section{Materials and Methods}

\subsection{Materials}

Graphene oxide (N002-PDE) powder was obtained from Angstron Materials Inc. (Dayton, OH, USA). Potassium bromide (KBr) was purchased from Showa Chemical Co. (Tokyo, Japan). 1-(3-dimethylaminopropyl)-3-ethylcarbodiimide hydrochloride (EDC), and N-hydroxysuccinimide (NHS) were purchased from Acros Organics (Geel, Belgium). Avidin and cetuximab (CET) was 
purchased from Calbiochem (San Diego, CA, USA) and Merck (Darmstadt, Germany), respectively. Biotin-PEG-NHS (molecular weight $=3400 \mathrm{Da}$ ) was purchased from Nanocs Inc. (New York, NY, USA). Doxorubicin (DOX), 3-(4,5-Dimethyl-2-thiazolyl)-2,5-diphenyl-2H-tetrazolium bromide (MTT), 4',6-diamidine-2'-phenylindole dihydrochloride (DAPI), and RPMI-1640 medium for cell culture were all purchased from Sigma (St Louis, MO, USA). Live/Dead viability/cytotoxicity kit was purchased from Invitrogen (Carlsbad, CA, USA). Fetal bovine serum (FBS) purchased from Hyclone, GE Healthcare (Logan, UT, USA) was used for cell culture. All of the reagents were of analytical grade.

\subsection{Preparation of Magnetic Graphene Oxide (MGO)}

GO nano-platelets was prepared by a modified Hummers' method, as reported before [20]. Chemical co-precipitation was used to deposit $\mathrm{Fe}_{3} \mathrm{O}_{4}$ on $\mathrm{GO}$ surface by dispersing $25 \mathrm{mg}$ of GO, $108 \mathrm{mg}$ of $\mathrm{FeCl}_{3} \cdot 6 \mathrm{H}_{2} \mathrm{O}$ and $40 \mathrm{mg}$ of $\mathrm{FeCl}_{2} \cdot 4 \mathrm{H}_{2} \mathrm{O}$ (mole ratio of $\mathrm{Fe}^{2+}: \mathrm{Fe}^{3+}=1: 2$ ) in $50 \mathrm{~mL}$ of deionized (DI) water by sonication for $30 \mathrm{~min}$. The solution was purged with $\mathrm{N}_{2}$ for $30 \mathrm{~min}$ (to prevent oxidation of $\mathrm{Fe}_{3} \mathrm{O}_{4}$ ) and was heated to $65^{\circ} \mathrm{C}$. Next, $1 \mathrm{~g}$ of $\mathrm{ClCH}_{2} \mathrm{COOH}$ was added to the solution to convert $-\mathrm{OH}$ to $-\mathrm{COOH}$. After $1 \mathrm{~h}, 2 \mathrm{~g}$ of $\mathrm{NaOH}$ was added to the solution for reaction at a basic environment for an additional $30 \mathrm{~min}$. A magnet was used to collect magnetic graphene oxide (MGO) from the solution, followed by washing with copious DI water. The amount of - $\mathrm{COOH}$ groups on MGO surface was determined by the toluidine blue $\mathrm{O}$ (TBO) assays.

\subsection{Preparation of $M G O-P E G-C E T$ and $M G O-P E G-C E T-Q D s$}

$0.05 \mathrm{~mL}$ of $60 \mathrm{mM}$ 1-ethyl-3-(3-dimethylaminopropyl) carbodiimide (EDC) and $0.05 \mathrm{~mL}$ of $60 \mathrm{mM}$ $\mathrm{N}$-hydroxysuccinimide (NHS) were prepared in phosphate-buffered saline (PBS, $\mathrm{pH}=7.4$ ) and mixed with $0.5 \mathrm{~mL}$ of $\mathrm{MGO}(1 \mathrm{mg} / \mathrm{mL})$ solution prepared above at $4{ }^{\circ} \mathrm{C}$ for $30 \mathrm{~min}$ for activation of the $-\mathrm{COOH}$ groups of MGO. $1 \mathrm{mg}$ of avidin was then added and the solution was left to react for $12 \mathrm{~h}$ at $4{ }^{\circ} \mathrm{C}$ for formation of amide bond between - $\mathrm{COOH}$ of $\mathrm{MGO}$ and $-\mathrm{NH}_{2}$ of avidin (MGO-avidin). MGO-avidin was recovered from the solution with a magnet and washed with PBS. The amount of avidin in MGO-avidin was quantified from the amount of unbound avidin in the solution using the Coomassie (Bradford) Protein Assay Kit (Thermo Fisher Scientific, Waltham, MA, USA).

To synthesized biotin-PEG-CET and biotin-PEG-QDs, $0.2 \mathrm{mg}$ of biotin-PEG-NHS was reacted with $4.2 \mathrm{mg}$ of CET or $20 \mu \mathrm{L}$ of quantum dots (QDs, QSA-490, with amine group from Ocean Nanotech, San Diego, CA, USA) in $1 \mathrm{~mL}$ PBS for $12 \mathrm{~h}$ at $4{ }^{\circ} \mathrm{C}$ through a spontaneous covalent bond formation between NHS esters and $-\mathrm{NH}_{2}$ groups in CET or QDs. Biotin-PEG-CET was reacted with MGO-avidin prepared above and incubated at $4{ }^{\circ} \mathrm{C}$ for $30 \mathrm{~min}$ for binding between avidin and biotin to from MGO-PEG-CET. MGO-PEG-CET was separated from the solution with a magnet and its CET content was determined from the unbound CET in the supernatant using Coomassie (Bradford) Protein Assay Kit. Biotin-PEG-QDs were used to bind empty biotin binding sites of avidin on MGO-PEG-CET to prepare fluorescently labelled MGO-PEG-CET-QDs. MGO-PEG and MGO-PEG-QDs were prepared similarly by replacing CET with glycine to react with biotin-PEG-NHS.

\subsection{Physico-Chemical Properties of Nanocarriers}

The particles size, polydispersity (PDI) and zeta potential of nanocarriers were determined by dynamic light scattering (DLS) using a Nano ZA90 Zetasizer (Malvern Instruments Ltd., Worcestershire, UK) with particle suspensions that were prepared in DI water. For transmission electron microscopy (TEM), the particles was diluted to $0.01 \mathrm{mg} / \mathrm{mL}$ in DI water and then dropped onto a 200 mesh carbon-coated copper grid, followed by drying at $25{ }^{\circ} \mathrm{C}$ for one day before loading into the microscope. MGO-PEG-CET was stained with $2 \%$ phosphotungstic acid for $30 \mathrm{~s}$ before drying. The morphology and size of particle were observed by TEM (JEOL JEM-1230, Tokyo, Japan) at $100 \mathrm{kV}$. For Fourier transform infrared (FTIR) spectroscopy, the samples were blended with $\mathrm{KBr}$, compressed to form a pellet and analyzed with a TENSOR II FTIR Spectrometer (Bruker Optics Inc., Billerica, MA, USA). The transmission spectra were obtained from 400 to $4000 \mathrm{~cm}^{-1}$ at $2.5 \mathrm{~mm} / \mathrm{s}$ with a resolution 
of $4 \mathrm{~cm}^{-1}$. The iron contents of samples were analyzed by inductively coupled plasma optical emission spectroscopy (ICP-OES, Optima 2100 DV, Perkin Elmer, Waltham, MA, USA). For X-ray diffraction (XRD) analysis of the crystal structures of samples, a D2 PHASER X-ray powder diffractometer (Bruker AXS Inc., Madison, WI, USA) was used by scanning dried power in the $2 \theta$ range of $5^{\circ}-70^{\circ}$. The step size was $0.04^{\circ}$ and measurement time was $2 \mathrm{~s}$ per step. The phases were compared with the JCPDS database for identification. The crystallite size was determined using the Debye-Scherrer equation. Thermogravimetric analysis (TGA) was conducted with $8 \sim 10 \mathrm{mg}$ of powder sample in nitrogen atmosphere from 25 to $750^{\circ} \mathrm{C}$, with a heating rate of $10^{\circ} \mathrm{C} / \mathrm{min}$ using a Q50 TGA from TA Instruments (New Castle, DE, USA). The magnetization curves were obtained with a superconducting quantum interference device (SQUID) magnetometer (MPMS XL-7, Quantum Design, San Diego, CA, USA) at $25^{\circ} \mathrm{C}$ and applied magnetic field of $10,000 \mathrm{G}$.

\subsection{Drug Loading and Release}

Doxorubicin (DOX) loading onto MGO-PEG-CET was accomplished by mixing $0.1 \mathrm{mg}$ MGO-PEG-CET with different amount of DOX in $1 \mathrm{~mL}$ PBS (pH 7.4) at $4{ }^{\circ} \mathrm{C}$ for $24 \mathrm{~h}$. After separating MGO-PEG-CET/DOX by a strong magnet, the concentration of DOX in the supernatant was determined by a UV/Vis spectrophotometer (U3010, Hitachi, Tokyo, Japan) at $490 \mathrm{~nm}$. The amount of DOX on MGO-PEG-CET/DOX was calculated from mass balance with the drug loading content $(\mathrm{mg} / \mathrm{mg})$ being defined as weight of DOX loaded/weight of MGO-PEG-CET and the drug loading efficiency $(\%)$ defined as (weight of DOX loaded/weight of DOX initially added) $\times 100$.

For drug release, MGO-PEG-CET/DOX was placed in $1 \mathrm{~mL}$ of PBS (pH 5.7 or $\mathrm{pH}$ 7.4) and shaken at $120 \mathrm{rpm}$ and $37^{\circ} \mathrm{C}$ in dark. A magnet was used to separate MGO-PEG-CET/DOX at predetermined time points and the precipitate was re-suspended with $1 \mathrm{~mL}$ of fresh $\mathrm{PBS}$ of the same $\mathrm{pH}$. The amount of DOX released from PEG-MGO-CET/DOX was determined from DOX concentration in the supernatant using a UV/Vis spectrophotometer at $490 \mathrm{~nm}$ in a cumulative manner with drug release (\%), defined as (weight of DOX released/weight of DOX loaded) $\times 100$.

\subsection{Intracellular Uptake}

CT-26 murine colonic carcinoma cells were obtained from Professor Chia-Rui Shen at the Graduate Institute of Medical Biotechnology of Chang Gung University, Taiwan. To observe the intracellular uptake of nanocarriers by CT-26 cells, $5 \times 10^{4}$ cells were seeded to $15-\mathrm{mm}$ glass slides placed in a 24-well plate. After adding cell culture medium (RPMI-1640 with 10\% FBS) and cultured for $24 \mathrm{~h}$, MGO-PEG-QDs, MGO-PEG-CET-QDs, or MGO-PEG-CET-QDs/DOX was separately added to each well and incubated for another $1 \mathrm{~h}$. After removing the cell culture medium and washing with PBS, cells was fixed with $4 \%$ paraformaldehyde for $15 \mathrm{~min}$ and were stained with $1 \mu \mathrm{g} / \mathrm{mL}$ DAPI for $10 \mathrm{~min}$. To further confirm that the interaction between CET and EGFR molecules was the mechanism for enhancing the targeting efficacy of CET-conjugated nanocarriers, CT-26 cells were pre-treated with $1 \mathrm{mg} / \mathrm{mL}$ of CET for $1 \mathrm{~h}$ to block the EGFR molecules on cell surface before incubating with MGO-PEG-CET-QDs. The slides were observed under a confocal laser scanning microscope (Zeiss LSM 510 Meta, Oberkochen, Germany). The uptake of MGO and release of DOX could be visualized by the green fluorescence of QDs-labelled MGO-PEG or MGO-PEG-CET and the red fluorescence of DOX. The excitation wavelength is Red/Green/Blue $=543 / 488 / 364 \mathrm{~nm}$ and the emission wavelength is Red $/$ Green $/$ Blue $=550-650 / 500-550 / 407-482 \mathrm{~nm}$.

The phenomenon of cell uptake was also observed through transmission electron microscope (TEM), where $5 \times 10^{4}$ CT-26 cells were grown on ThermoNox (Nunc, Thermo Fisher Scientific, Waltham, MA, USA) coverslips and were treated with MGO-PEG-CET for $24 \mathrm{~h}$. After fixing with a mixture of $2 \%$ glutaraldehyde and $2.5 \%$ paraformaldehyde for $2 \mathrm{~h}, 0.1 \mathrm{M}$ sodium cacodylate buffer ( $\mathrm{pH} 7.4$ ) was used to rinse the cells followed by post-fixing $30 \mathrm{~min}$ in $1.0 \%$ osmium tetroxide. Graded ethanol series $(30 \%, 50 \%, 70 \%, 80 \%, 95 \%$, and $100 \%)$ were used to dehydrate the cells for $10 \mathrm{~min}$ at each concentration, followed by two rinses in 100\% propylene oxide. With infiltration and embedding in epoxy resins for 
$48 \mathrm{~h}$ at $60^{\circ} \mathrm{C}, \sim 80 \mathrm{~nm}$ ultrathin specimen were sectioned and examined under a FEI/Philips CM 120 TEM (FEI, Hillsboro, OR, USA).

\subsection{Photothermla Effect}

In vitro photothermal effect was determined in $0.2 \mathrm{~mL}$ suspensions of GO, MGO, and MGO-PEG-PET ( $1 \mathrm{mg} / \mathrm{mL}$ in PBS) in 96-well cell culture plates by irradiating with an $808 \mathrm{~nm}$ continuous-wave near infrared (NIR) laser at a power of $2.5 \mathrm{~W} / \mathrm{cm}^{2}\left(0.4 \mathrm{~cm}^{2}\right.$ laser area) for $3 \mathrm{~min}$. The temperature of the solution before and after exposure to NIR light was determined with a K-Type thermal couple thermometer (Hanna Instruments, Woonsocket, RI, USA).

In vivo photothermal effect was from thermal imaging of a tumor-bearing BALB/c mouse after the intravenous injection of MGO-PEG-CET. The tumor-bearing mouse was injected with MGO-PEG-CET $(7 \mathrm{mg} / \mathrm{kg})$, followed by guidance with a magnetic field (1400 Gauss) for $2 \mathrm{~h}$ and exposure to NIR light at $2.5 \mathrm{~W} / \mathrm{cm}^{2}\left(0.4 \mathrm{~cm}^{2}\right.$ laser area) for $5 \mathrm{~min}$. Thermal images were captured with an infrared thermal imaging camera (Thermo GEAR G100EX, Avio, Tokyo, Japan) to measure the temperature distribution around the tumor area. A healthy BALB/c mouse was used as a control after exposure to the same NIR light for 5 min at similar same location.

\subsection{Magnetic Guidance In Vitro}

To examine the effect of magnetic guidance of MGO-PEG-CET, $0.5 \mathrm{~mL}$ cell culture medium containing CT-26 cells $\left(5 \times 10^{4}\right)$ was added to each well of a 24-well plate and was cultured for $24 \mathrm{~h}$. After adding MGO-PEG-CET / DOX to each well to reach a final concentration of $0.1 \mathrm{mg} / \mathrm{mL}$, the culture plate was placed on a magnetic separator, which had $7.5 \mathrm{~mm}$ diameter permanent magnets glued to the center of each well, followed by $24 \mathrm{~h}$ cell culture. After washing with PBS, a Live/Dead cell viability assay was conducted by examining with an inverted fluorescence microscope to determine live and dead cells around the magnetic targeting zone created by the magnet.

\subsection{Blood Compatibility Analysis}

The hemolysis assay was conducted to evaluate the whole blood compatibility of MGO-PEG-CET. The red blood cells (RBCs) from Sprague-Dawley (SD) rats (BioLASCO, Taipei, Taiwan) were obtained by removing the serum from the whole blood after centrifugation at $3500 \mathrm{rpm}$ at $4{ }^{\circ} \mathrm{C}$ for $10 \mathrm{~min}$. All of the animal experiments were conducted according to protocols approved by the Chang Gung University's Institutional Animal Care and Use Committee (IACUC Approval No.: CGU15-168). Following wash with PBS five times, the cells were diluted to ten times of the original volume with PBS. The diluted RBC $(0.3 \mathrm{~mL})$ suspension was mixed with $1.2 \mathrm{~mL}$ of DI water (positive control), $1.2 \mathrm{~mL}$ of PBS (negative control), or $1.2 \mathrm{~mL}$ of different concentration of MGO-PEG-CET in PBS. The mixtures were incubated at $37^{\circ} \mathrm{C}$ for $30 \mathrm{~min}$ and centrifuged. The absorbance values of the supernatants were recorded from 500 to $650 \mathrm{~nm}$ using an ultraviolet-visible (UV/Vis) Spectrophotometer and compared at $540 \mathrm{~nm}\left(\mathrm{OD}_{540}\right)$ for all the samples.

\subsection{In Vitro Cytotoxicity}

Approximately $5 \times 10^{3}$ CT-26 cells in $200 \mu \mathrm{L}$ cell culture medium were placed in each well of a 96-well culture plate and cultured for $24 \mathrm{~h}$. After removing the spent culture medium, different concentrations of DOX (free DOX, MGO-PEG/DOX, or MOG-PEG-CET/DOX) in $200 \mu \mathrm{L}$ cell culture medium was added to each well and incubated at $37^{\circ} \mathrm{C}$ for $24 \mathrm{~h}$. The medium in each well was removed and each well was washed with PBS, followed by adding $200 \mu \mathrm{L}$ diluted MTT solution $\left(1 \mathrm{mg} / \mathrm{mL}\right.$ in culture medium) and incubated for $2 \mathrm{~h}$ at $37^{\circ} \mathrm{C}$ in dark. The MTT solution was removed and purple formazan crystals in each well was dissolved with $200 \mu \mathrm{L}$ dimethyl sulfoxide and the solution absorbance was measured with a microplate reader at $570 \mathrm{~nm}\left(\mathrm{OD}_{570}\right)$. The cytotoxicity to CT-26 cells was determined from the relative cell viability (\%) relative to cells cultured in cell culture medium. 


\subsection{Mouse Subcutaneous Tumor Model}

Female BALB/c mice weighing approximately 15-20 g (4-6 weeks old) were purchased from BioLASCO (Taipei, Taiwan). All of the animal experiments were conducted according to protocols that were approved by the Chang Gung University's Institutional Animal Care and Use Committee (IACUC Approval No.: CGU15-168). CT-26 cells were harvested by $0.1 \%$ trypsin-EDTA, washed once with PBS, re-suspended in serum-free RPMI-1640 $\left(1 \times 10^{7}\right.$ cells in $\left.100 \mu \mathrm{L}\right)$ and were subcutaneously injected into the right flank of each mouse. When the tumors had grown to approximately $60-100 \mathrm{~mm}^{3}$ (about 14 days), the tumor-bearing mice were randomized into five groups ( $n=6$ in each group): group 1 (control) received $200 \mu \mathrm{L}$ intravenous (IV) injection of normal saline; group 2 received $200 \mu \mathrm{L}$ IV injection of DOX solution (30 mg/kg); group 3 received $200 \mu \mathrm{L}$ IV injection of $9.2 \mathrm{mg} / \mathrm{kg}$ MGO-PEG-CET/DOX (containing $30 \mathrm{mg} / \mathrm{kg}$ DOX); group 4 was treated as in groups 3, but the tumor was exposed to a magnetic field of 1400 Gauss with a magnet for $2 \mathrm{~h}$ after IV injection; group 5 was treated as in group 4 but the tumor was exposed to additional NIR irradiation ( $808 \mathrm{~nm}$ wavelength, $2.5 \mathrm{~W} / \mathrm{cm}^{2}$ ) for $5 \mathrm{~min}$ every two days. Injections were carried out over $2 \mathrm{~min}$ through the tail vein, with withdrawal of needle over $1 \mathrm{~min}$ to prevent back leak. The animal body weight and tumor volume were continuously monitored on alternate days for two weeks post treatment [64]. For ethical reasons, animals were euthanized when the volume of the implanted tumor reached $2 \mathrm{~cm}^{3}$. The tumor size was measured using a caliper and defined as: tumor volume $=($ length $\times$ width $\times$ width $) / 2$. Tumors were collected on day 14 of the treatment, fixed in $10 \%$ buffered formalin, followed by paraffin-embedment and sectioning to $2-3 \mu \mathrm{m}$ thickness for hematoxylin and eosin (H\&E) staining.

\subsection{Statistical Analyses}

All data were reported as mean \pm standard deviation (SD) and subject to one-way analysis of variance (ANOVA) analysis. Tukey's post-hoc test was used to determine the difference between any two groups with $p$-value $<0.05$ considered to be statistically significant.

\section{Conclusions}

We presented a dual-targeting nanomedicine approach for cancer therapy using MGO-PEG-CET/DOX that combines co-precipitated $\mathrm{Fe}_{3} \mathrm{O}_{4}$ magnetic nanoparticles and CET (an EGFR antibody) for magnetic and receptor-mediated ligand-targeting of malignant CT-26 mouse colon carcinoma. The combinatory chemo-photothermal therapy comprises the antitumor drug DOX and laser-induced hyperthermia with contribution from the EGFR-specific antibody (CET). Through this comprehensive design, the MGO-PEG-CET/DOX showed enhanced cytotoxicity toward CT-26 in vitro and inhibited tumor propagation in vivo. The anti-tumor effects could be augmented using an NIR laser for photothermal therapy in vitro and in vivo. From the proof-of-concept report using magnetic targeting plus NIR laser irradiation, which successfully shrunk tumors to $42 \%$ of its original volume in 14 days, this study provides a new paradigm to evolve traditional chemotherapeutic drug (DOX) and to overcome its side effects. The dual targeting MGO-PEG-CET drug delivery system could be implied to offer an extraordinary platform in promoting the success of cancer therapy.

Acknowledgments: We would like to express our appreciation of financial supports provided by Change Gung Memorial Hospital (CMRPD2G0081, CMRPD2G0082, CMRPG3F1742 and BMRP249) and the Ministry of Science and Technology (MOST-106-2221-E-182-056-MY3). The authors thank the Microscopy Center at Chang Gung University and the Microscope Core Laboratory in Change Gung Memorial Hospital Linkuo Medical Center for technical assistance.

Author Contributions: Yu-Jen Lu and Jyh-Ping Chen conceived and designed the experiments; Yu-Jen Lu and Pin-Yi Lin performed the experiments; Pin-Yi Lin, Chang-Yi Kuo and Mao-Yu Chen analyzed the data; Yu-Jen Lu, Pei-Han Huang, K.T. Shalumon and Jyh-Ping Chen wrote the paper.

Conflicts of Interest: The authors declare no conflict of interest. 


\section{References}

1. Organization, W.H. Cancer. Available online: http://www.who.int/cancer/en/ (accessed on 19 October 2017).

2. Feng, S.S.; Chien, S. Chemotherapeutic engineering: Application and further development of chemical engineering principles for chemotherapy of cancer and other diseases. Chem. Eng. Sci. 2003, 58, 4087-4114. [CrossRef]

3. Skalickova, S.; Loffelmann, M.; Gargulak, M.; Kepinska, M.; Docekalova, M.; Uhlirova, D.; Stankova, M.; Fernandez, C.; Milnerowicz, H.; Ruttkay-Nedecky, B.; et al. Zinc-modified nanotransporter of doxorubicin for targeted prostate cancer delivery. Nanomaterials 2017, 7, 435. [CrossRef] [PubMed]

4. Au, J.L.; Jang, S.H.; Zheng, J.; Chen, C.T.; Song, S.; Hu, L.; Wientjes, M.G. Determinants of drug delivery and transport to solid tumors. J. Controll. Release 2001, 74, 31-46. [CrossRef]

5. Lammers, T.; Aime, S.; Hennink, W.E.; Storm, G.; Kiessling, F. Theranostic nanomedicine. Acc. Chem. Res. 2011, 44, 1029-1038. [CrossRef] [PubMed]

6. Quader, S.; Kataoka, K. Nanomaterial-enabled cancer therapy. Mol. Ther. 2017, 25, 1501-1513. [CrossRef] [PubMed]

7. Goldberg, M.; Langer, R.; Jia, X. Nanostructured materials for applications in drug delivery and tissue engineering. J. Biomater. Sci. Polym. Ed. 2007, 18, 241-268. [CrossRef] [PubMed]

8. Duncan, R. The dawning era of polymer therapeutics. Nat. Rev. Drug Discov. 2003, 2, 347-360. [CrossRef] [PubMed]

9. Maeda, $\mathrm{H}$. The enhanced permeability and retention (EPR) effect in tumor vasculature: The key role of tumor-selective macromolecular drug targeting. Adv. Enzyme Regul. 2001, 41, 189-207. [CrossRef]

10. Matsumura, Y.; Maeda, H. A new concept for macromolecular therapeutics in cancer chemotherapy: Mechanism of tumoritropic accumulation of proteins and the antitumor agent smancs. Cancer Res. 1986, 46, 6387-6392. [PubMed]

11. Lu, Y.J.; Wei, K.C.; Ma, C.C.; Yang, S.Y.; Chen, J.P. Dual targeted delivery of doxorubicin to cancer cells using folate-conjugated magnetic multi-walled carbon nanotubes. Colloids Surf. B Biointerfaces 2012, 89, 1-9. [CrossRef] [PubMed]

12. McCallion, C.; Burthem, J.; Rees-Unwin, K.; Golovanov, A.; Pluen, A. Graphene in therapeutics delivery: Problems, solutions and future opportunities. Eur. J. Pharm. Biopharm. 2016, 104, 235-250. [CrossRef] [PubMed]

13. Hong, S.; Leroueil, P.R.; Majoros, I.J.; Orr, B.G.; Baker, J.R.; Holl, M.M.B. The binding avidity of a nanoparticle-based multivalent targeted drug delivery platform. Chem. Biol. 2007, 14, 107-115. [CrossRef] [PubMed]

14. Montet, X.; Funovics, M.; Montet-Abou, K.; Weissleder, R.; Josephson, L. Multivalent effects of rgd peptides obtained by nanoparticle display. J. Med. Chem. 2006, 49, 6087-6093. [CrossRef] [PubMed]

15. Mejias, R.; Perez-Yague, S.; Gutierrez, L.; Cabrera, L.I.; Spada, R.; Acedo, P.; Serna, C.J.; Lazaro, F.J.; Villanueva, A.; Morales, M.P.; et al. Dimercaptosuccinic acid-coated magnetite nanoparticles for magnetically guided in vivo delivery of interferon gamma for cancer immunotherapy. Biomaterials 2011, 32, 2938-2952. [CrossRef] [PubMed]

16. Sanson, C.; Diou, O.; Thevenot, J.; Ibarboure, E.; Soum, A.; Brulet, A.; Miraux, S.; Thiaudiere, E.; Tan, S.; Brisson, A.; et al. Doxorubicin loaded magnetic polymersomes: Theranostic nanocarriers for mr imaging and magneto-chemotherapy. ACS Nano 2011, 5, 1122-1140. [CrossRef] [PubMed]

17. Yang, C.L.; Chen, J.P.; Wei, K.C.; Chen, J.Y.; Huang, C.W.; Liao, Z.X. Release of doxorubicin by a folate-grafted, chitosan-coated magnetic nanoparticle. Nanomaterials 2017, 7, 85. [CrossRef] [PubMed]

18. Shang, N.G.; Papakonstantinou, P.; McMullan, M.; Chu, M.; Stamboulis, A.; Potenza, A.; Dhesi, S.S.; Marchetto, H. Catalyst-free efficient growth, orientation and biosensing properties of multilayer graphene nanoflake films with sharp edge planes. Adv. Funct. Mater. 2008, 18, 3506-3514. [CrossRef]

19. Yang, X.Y.; Zhang, X.Y.; Ma, Y.F.; Huang, Y.; Wang, Y.S.; Chen, Y.S. Superparamagnetic graphene oxide-Fe $\mathrm{Fe}_{3} \mathrm{O}_{4}$ nanoparticles hybrid for controlled targeted drug carriers. J. Mater. Chem. 2009, 19, 2710-2714. [CrossRef]

20. Sun, X.; Liu, Z.; Welsher, K.; Robinson, J.T.; Goodwin, A.; Zaric, S.; Dai, H. Nano-graphene oxide for cellular imaging and drug delivery. Nano. Res. 2008, 1, 203-212. [CrossRef] [PubMed]

21. Liu, J.; Cui, L.; Losic, D. Graphene and graphene oxide as new nanocarriers for drug delivery applications. Act. Biomater. 2013, 9, 9243-9257. [CrossRef] [PubMed] 
22. Li, Y.M.; Jiang, T.; Lv, Y.; Wu, Y.; He, F.; Zhuo, R.X. Amphiphilic copolymers with pendent carboxyl groups for high-efficiency loading and controlled release of doxorubicin. Colloids Surf. B Biointerfaces 2015, 132, 54-61. [CrossRef] [PubMed]

23. Felber, A.E.; Dufresne, M.H.; Leroux, J.C. Ph-sensitive vesicles, polymeric micelles, and nanospheres prepared with polycarboxylates. Adv. Drug Deliv. Rev. 2012, 64, 979-992. [CrossRef] [PubMed]

24. Simoes, S.; Moreira, J.N.; Fonseca, C.; Duzgunes, N.; de Lima, M.C. On the formulation of ph-sensitive liposomes with long circulation times. Adv. Drug Deliv. Rev. 2004, 56, 947-965. [CrossRef] [PubMed]

25. Yan, T.; Zhang, H.; Huang, D.; Feng, S.; Fujita, M.; Gao, X.D. Chitosan-functionalized graphene oxide as a potential immunoadjuvant. Nanomaterials 2017, 7, 59. [CrossRef] [PubMed]

26. Seabra, A.B.; Paula, A.J.; de Lima, R.; Alves, O.L.; Durán, N. Nanotoxicity of graphene and graphene oxide. Chem. Res. Toxicol. 2014, 27, 159-168. [CrossRef] [PubMed]

27. Huang, J.; Zong, C.; Shen, H.; Liu, M.; Chen, B.; Ren, B.; Zhang, Z. Mechanism of cellular uptake of graphene oxide studied by surface-enhanced raman spectroscopy. Small 2012, 8, 2577-2584. [CrossRef] [PubMed]

28. Yue, H.; Wei, W.; Yue, Z.; Wang, B.; Luo, N.; Gao, Y.; Ma, D.; Ma, G.; Su, Z. The role of the lateral dimension of graphene oxide in the regulation of cellular responses. Biomaterials 2012, 33, 4013-4021. [CrossRef] [PubMed]

29. Yang, K.; Wan, J.M.; Zhang, S.; Tian, B.; Zhang, Y.J.; Liu, Z. The influence of surface chemistry and size of nanoscale graphene oxide on photothermal therapy of cancer using ultra-low laser power. Biomaterials 2012, 33, 2206-2214. [CrossRef] [PubMed]

30. Zhang, W.; Guo, Z.; Huang, D.; Liu, Z.; Guo, X.; Zhong, H. Synergistic effect of chemo-photothermal therapy using pegylated graphene oxide. Biomaterials 2011, 32, 8555-8561. [CrossRef] [PubMed]

31. Ma, X.X.; Tao, H.Q.; Yang, K.; Feng, L.Z.; Cheng, L.; Shi, X.Z.; Li, Y.G.; Guo, L.; Liu, Z. A functionalized graphene oxide-iron oxide nanocomposite for magnetically targeted drug delivery, photothermal therapy, and magnetic resonance imaging. Nano Res. 2012, 5, 199-212. [CrossRef]

32. Huang, Y.S.; Lu, Y.J.; Chen, J.P. Magnetic graphene oxide as a carrier for targeted delivery of chemotherapy drugs in cancer therapy. J. Magn. Magn. Mater. 2017, 427, 34-40. [CrossRef]

33. Park, J.W.; Mok, H.; Park, T.G. Epidermal growth factor (EGF) receptor targeted delivery of pegylated adenovirus. Biochem. Bioph. Res. Commun. 2008, 366, 769-774. [CrossRef] [PubMed]

34. Jokerst, J.V.; Lobovkina, T.; Zare, R.N.; Gambhir, S.S. Nanoparticle pegylation for imaging and therapy. Nanomedicine 2011, 6, 715-728. [CrossRef] [PubMed]

35. Gref, R.; Minamitake, Y.; Peracchia, M.T.; Trubetskoy, V.; Torchilin, V.; Langer, R. Biodegradable long-circulating polymeric nanospheres. Science 1994, 263, 1600-1603. [CrossRef] [PubMed]

36. Höög, J.L.; Gluenz, E.; Vaughan, S.; Gull, K. Chapter 8-Ultrastructural investigation methods for trypanosoma brucei. In Methods in Cell Biology; Müller-Reichert, T., Ed.; Academic Press: Camgridge, MA, USA, 2010; Volume 96, pp. 175-196.

37. Jokar, S.; Pourjavadi, A.; Adeli, M. Albumin-graphene oxide conjugates; carriers for anticancer drugs. RSC Adv. 2014, 4, 33001-33006. [CrossRef]

38. Acharya, S.; Sahoo, S.K. PLGA nanoparticles containing various anticancer agents and tumour delivery by epr effect. Adv. Drug Deliv. Rev. 2011, 63, 170-183. [CrossRef] [PubMed]

39. Tseng, S.H.; Chou, M.Y.; Chu, I.M. Cetuximab-conjugated iron oxide nanoparticles for cancer imaging and therapy. Int. J. Nanomed. 2015, 10, 3663-3685.

40. Mahmoud, W.E. Morphology and physical properties of poly(ethylene oxide) loaded graphene nanocomposites prepared by two different techniques. Eur. Polym. J. 2011, 47, 1534-1540. [CrossRef]

41. Murugan, A.V.; Muraliganth, T.; Manthiram, A. Rapid, facile microwave-solvothermal synthesis of graphene nanosheets and their polyaniline nanocomposites for energy strorage. Chem. Mater. 2009, 21, 5004-5006. [CrossRef]

42. Liang, R.P.; Liu, C.M.; Meng, X.Y.; Wang, J.W.; Qiu, J.D. A novel open-tubular capillary electrochromatography using beta-cyclodextrin functionalized graphene oxide-magnetic nanocomposites as tunable stationary phase. J. Chromatogr. A 2012, 1266, 95-102. [CrossRef] [PubMed]

43. He, H.; Gao, C. Supraparamagnetic, conductive, and processable multifunctional graphene nanosheets coated with high-density $\mathrm{Fe}_{3} \mathrm{O}_{4}$ nanoparticles. ACS Appl. Mater. Interfaces 2010, 2, 3201-3210. [CrossRef] [PubMed]

44. Zhu, Y.; Murali, S.; Cai, W.; Li, X.; Suk, J.W.; Potts, J.R.; Ruoff, R.S. Graphene and graphene oxide: Synthesis, properties, and applications. Adv. Mater. 2010, 22, 3906-3924. [CrossRef] [PubMed] 
45. Kolhe, P.; Kannan, R.M. Improvement in ductility of chitosan through blending and copolymerization with peg: Ftir investigation of molecular interactions. Biomacromolecules 2003, 4, 173-180. [CrossRef] [PubMed]

46. Shen, J.F.; Shi, M.; Ma, H.W.; Yan, B.; Li, N.; Ye, M.X. Hydrothermal synthesis of magnetic reduced graphene oxide sheets. Mater. Res. Bull. 2011, 46, 2077-2083. [CrossRef]

47. Xu, L.Q.; Wang, L.; Zhang, B.; Lim, C.H.; Chen, Y.; Neoh, K.G.; Kang, E.T.; Fu, G.D. Functionalization of reduced graphene oxide nanosheets via stacking interactions with the fluorescent and water-soluble perylene bisimide-containing polymers. Polymer 2011, 52, 2376-2383. [CrossRef]

48. Ghosh, S.; Badruddoza, A.Z.M.; Hidajat, K.; Uddin, M.S. Adsorptive removal of emerging contaminants from water using superparamagnetic $\mathrm{Fe}_{3} \mathrm{O}_{4}$ nanoparticles bearing aminated beta-cyclodextrin. J. Environ. Chem. Eng. 2013, 1, 122-130. [CrossRef]

49. Wang, C.; Feng, L.; Yang, H.; Xin, G.; Li, W.; Zheng, J.; Tian, W.; Li, X. Graphene oxide stabilized polyethylene glycol for heat storage. Phys. Chem. Chem. Phys. 2012, 14, 13233-13238. [CrossRef] [PubMed]

50. Chen, J.P.; Yang, P.C.; Ma, Y.H.; Tu, S.J.; Lu, Y.J. Targeted delivery of tissue plasminogen activator by binding to silica-coated magnetic nanoparticle. Int. J. Nanomed. 2012, 7, 5137-5149. [CrossRef] [PubMed]

51. Hsu, H.L.; Chen, J.P. Preparation of thermosensitive magnetic liposome encapsulated recombinant tissue plasminogen activator for targeted thrombolysis. J. Magn. Magn. Mater. 2017, 427, 188-194. [CrossRef]

52. Wang, Y.; Yang, S.T.; Wang, Y.; Liu, Y.; Wang, H. Adsorption and desorption of doxorubicin on oxidized carbon nanotubes. Colloids Surf. B Biointerfaces 2012, 97, 62-69. [CrossRef] [PubMed]

53. Oishi, M.; Hayashi, H.; Iijima, M.; Nagasaki, Y. Endosomal release and intracellular delivery of anticancer drugs using ph-sensitive PEGylated nanogels. J. Mater. Chem. 2007, 17, 3720-3725. [CrossRef]

54. Lee, M.; Jeong, J.; Kim, D. Intracellular uptake and ph-dependent release of doxorubicin from the self-assembled micelles based on amphiphilic polyaspartamide graft copolymers. Biomacromolecules 2015, 16, 136-144. [CrossRef] [PubMed]

55. Zhang, R.Y.; Olin, H. Carbon nanomaterials as drug carriers: Real time drug release investigation. Mater. Sci. Eng. C Mater. Biol. Appl. 2012, 32, 1247-1252. [CrossRef]

56. Cai, W.; Chen, K.; He, L.; Cao, Q.; Koong, A.; Chen, X. Quantitative PET of EGFR expression in xenograft-bearing mice using ${ }^{64} \mathrm{Cu}$-labeled cetuximab, a chimeric anti-egfr monoclonal antibody. Eur. J. Nucl. Med. Mol. Imaging 2007, 34, 850-858. [CrossRef] [PubMed]

57. Mu, Q.; Su, G.; Li, L.; Gilbertson, B.O.; Yu, L.H.; Zhang, Q.; Sun, Y.P.; Yan, B. Size-dependent cell uptake of protein-coated graphene oxide nanosheets. ACS Appl. Mater. Interfaces 2012, 4, 2259-2266. [CrossRef] [PubMed]

58. Chertok, B.; David, A.E.; Yang, V.C. Polyethyleneimine-modified iron oxide nanoparticles for brain tumor drug delivery using magnetic targeting and intra-carotid administration. Biomaterials 2010, 31, 6317-6324. [CrossRef] [PubMed]

59. Yang, K.; Zhang, S.; Zhang, G.; Sun, X.; Lee, S.-T.; Liu, Z. Graphene in mice: Ultrahigh in vivo tumor uptake and efficient photothermal therapy. Nano Lett. 2010, 10, 3318-3323. [CrossRef] [PubMed]

60. Chu, M.; Shao, Y.; Peng, J.; Dai, X.; Li, H.; Wu, Q.; Shi, D. Near-infrared laser light mediated cancer therapy by photothermal effect of $\mathrm{Fe}_{3} \mathrm{O}_{4}$ magnetic nanoparticles. Biomaterials 2013, 34, 4078-4088. [CrossRef] [PubMed]

61. Maiello, E.; Gebbia, V.; Manzione, L.; Giuliani, F.; Morelli, F.; Arcara, C.; Grimaldi, A.; Colucci, G. Clinical results of EGFR-targeted therapies in advancedcolorectal cancer. EJC Suppl. 2008, 6, 64-69. [CrossRef]

62. Rivera, F.; Vega-Villegas, M.E.; Lopez-Brea, M.F. Cetuximab, its clinical use and future perspectives. Anticancer Drugs 2008, 19, 99-113. [CrossRef] [PubMed]

63. O'Neal, D.P.; Hirsch, L.R.; Halas, N.J.; Payne, J.D.; West, J.L. Photo-thermal tumor ablation in mice using near infrared-absorbing nanoparticles. Cancer Lett. 2004, 209, 171-176. [CrossRef] [PubMed]

64. Kirui, D.K.; Khalidov, I.; Wang, Y.; Batt, C.A. Targeted near-IR hybrid magnetic nanoparticles for in vivo cancer therapy and imaging. Nanomedicine 2013, 9, 702-711. [CrossRef] [PubMed]

(C) 2018 by the authors. Licensee MDPI, Basel, Switzerland. This article is an open access article distributed under the terms and conditions of the Creative Commons Attribution (CC BY) license (http:/ / creativecommons.org/licenses/by/4.0/). 
Article

\title{
Intratumoral Delivery of Doxorubicin on Folate-Conjugated Graphene Oxide by In-Situ Forming Thermo-Sensitive Hydrogel for Breast Cancer Therapy
}

\author{
Yi Teng Fong ${ }^{1,2,+}$, Chih-Hao Chen ${ }^{2,+}$ and Jyh-Ping Chen ${ }^{1,2,3,4, *}$ \\ 1 Department of Chemical and Materials Engineering, Chang Gung University, Taoyuan 33302, Taiwan; \\ evausatw@cgmh.org.tw \\ 2 Department of Plastic and Reconstructive Surgery and Craniofacial Research Center, \\ Chang Gung Memorial Hospital, Linkou, Kwei-San, Taoyuan 33305, Taiwan; cjh5027@cgmh.org.tw \\ 3 Research Center for Chinese Herbal Medicine and Research Center for Food and Cosmetic Safety, \\ College of Human Ecology, Chang Gung University of Science and Technology, Kwei-San, \\ Taoyuan 33302, Taiwan \\ 4 Department of Materials Engineering, Ming Chi University of Technology, Tai-Shan, \\ New Taipei City 24301, Taiwan \\ * Correspondence: jpchen@mail.cgu.edu.tw; Tel.: +886-3-211-8800 (ext. 5298) \\ + These authors contributed equally to this paper.
}

Received: 6 October 2017; Accepted: 7 November 2017; Published: 14 November 2017

\begin{abstract}
By taking advantage of the $\mathrm{pH}$-sensitive drug release property of graphene oxide (GO) after intracellular uptake, we prepared folic acid (FA)-conjugated GO (GOFA) for targeted delivery of the chemotherapeutic drug doxorubicin (DOX). GOFA-DOX was further encapsulated in an injectable in-situ forming thermo-sensitive hyaluronic acid-chitosan-g-poly ( $N$-isopropylacrylamide) (HACPN) hydrogel for intratumoral delivery of DOX. As the degradation time of HACPN could be extended up to 3 weeks, intratumoral delivery of GOFA-DOX/HACPN could provide controlled and targeted delivery of DOX through slow degradation HACPN and subsequent cellular uptake of released GOFA-DOX by tumor cells through interactions of GOFA with folate receptors on the tumor cell's surface. GOFA nano-carrier and HACPN hydrogel were first characterized for the physico-chemical properties. The drug loading experiments indicated the best preparation condition of GOFA-DOX was by reacting $0.1 \mathrm{mg}$ GOFA with $2 \mathrm{mg}$ DOX. GOFA-DOX showed $\mathrm{pH}$-responsive drug release with $\sim 5$ times more DOX released at $\mathrm{pH} 5.5$ than at $\mathrm{pH} 7.4$ while only limited DOX was released from GOFA-DOX/HACPN at pH 7.4. Intracellular uptake of GOFA by endocytosis and release of DOX from GOFA-DOX in vitro could be confirmed from transmission electron microscopic and confocal laser scanning microscopic analysis with MCF-7 breast cancer cells. The targeting effect of FA was revealed when intracellular uptake of GOFA was blocked by excess FA. This resulted in enhanced in vitro cytotoxicity as revealed from the lower half maximal inhibitory concentration (IC50) value of GOFA-DOX $(7.3 \mu \mathrm{g} / \mathrm{mL})$ compared with that of DOX $(32.5 \mu \mathrm{g} / \mathrm{mL})$ and GO-DOX $(10 \mu \mathrm{g} / \mathrm{mL})$. The flow cytometry analysis indicated higher apoptosis rates for cells treated with GOFA-DOX $(30 \%)$ compared with DOX ( $8 \%$ ) and GO-DOX (11\%). Animal studies were carried out with subcutaneously implanted MCF-7 cells in BALB/c nude mice and subject to intratumoral administration of drugs. The relative tumor volumes of control (saline) and GOFA-DOX/HACPN groups at day 21 were 2.17 and 1.79 times that at day 0 with no significant difference. In comparison, the relative tumor volumes of treatment groups at the same time were significantly different at 1.02, 0.67 and 0.48 times for DOX, GOFA-DOX and GOFA-DOX/HACPN groups, respectively. The anti-tumor efficacy was also supported by images from an in vivo imaging system (IVIS) using MCF-7 cells transfected with luciferase (MCF-7/Luc). Furthermore, tissue biopsy examination and blood analysis indicated that intratumoral delivery of DOX using GOFA-DOX/HACPN did not elicit acute toxicity. Taken together,
\end{abstract}


GOFA-DOX/HACPN could be deemed as a safe and efficient intratumoral drug delivery system for breast cancer therapy.

Keywords: thermo-sensitive hydrogel; graphene oxide; folic acid; intratumoral delivery; cancer therapy

\section{Introduction}

In recent years, an effective cancer treatment platform has always been the focus of developing advanced drug delivery systems based on different nano-sized drug carriers [1,2]. Such systems used liposomes and/or polymer nanoparticles as the drug carrier, combining triggered release of an anticancer drug under the characteristic environment of cancer cells and protect the drug until it enters the cell to increase the intracellular drug concentration [3]. Thus, the ideal drug delivery system should be not only to improve the treatment efficacy but also to decrease the systemic toxicity effects. Graphene, a novel two-dimensional (2D) honeycomb material, has been recognized as one of the most promising nanomaterials used as a filler in polymer matrices [4]. With a 2D planar structure composed of $\mathrm{sp}^{2}$ mixed-layer trajectories, graphene-based nanomaterials have been widely studied for applications in biotechnology [5]. When used as a drug carrier, graphene is usually modified to increase its hydrophilicity and reduce the thickness by converting it into an oxidized form (i.e., graphene oxide, GO) $[6,7]$. Indeed, GO was shown to be a functional nano-sized carrier for delivery of anticancer drugs based on $\pi-\pi$ stacking, such as camptothecin (camptothecin, CPT), camptothecin derivatives (SN38) and adriamycin (doxorubicin, DOX) [8]. The hydrogen bond interactions between GO and the drug can result in a large amount of drug being adsorbed onto GO due to its large specific surface area $[9,10]$. An added advantage of GO for chemotherapeutic drug delivery is the $\mathrm{pH}$-dependent drug release behavior, where enhanced drug release at a low $\mathrm{pH}$ value $(\mathrm{pH} 5.0$ to $\mathrm{pH}$ 5.5) will provide efficient intracellular drug release after its endocytosis by the cell for drug release in the endosome [11,12].

Targeted delivery of anticancer drugs for cancer therapy could be more effective than traditional chemotherapy. The targeting therapy could be divided into active targeting and passive targeting $[13,14]$. For active targeting therapy, the drug carrier is modified with a ligand or a monoclonal antibody on the surface to increase the ability of the carrier to be specifically recognized by diseased cells. Folic acid (FA) is a group of water-soluble vitamin B that exists in green leaves, vegetables and other plants. It is an important element for all cells and involved in DNA synthesis or cell division. Folic acid is transported into healthy cells or cancer cells through their folate receptors on cell surface. As cancer cells require more FA for maintaining cell differentiation and proliferation, there are over-expressed folate receptors on the cell membrane of cancer cells, compared with healthy and/or normal cells [15]. Thus, modifying an anticancer drug nano-carrier, such as GO, with FA could enhance its ability to be recognized and its intracellular uptake efficiency by cancer cells through ligand-mediated targeting drug delivery [16,17]. Previously, we have used FA-conjugated multi-walled carbon nanotubes (a 1D carbon nanomaterial) for targeted delivery of DOX to cancer cells [18].

In-situ forming thermo-sensitive hydrogel undergoes physical sol-to-gel phase transition as temperature increases. It can be easily administered via injection using a conventional syringe needle after in-situ gelation at the physiological temperature [19]. Poly(N-isopropylacrylamide) (PNIPAm) is one of the most studied thermo-sensitive hydrogel showing reversible sol-gel phase transition behavior around its lower critical solution temperature (LCST) at $\sim 32{ }^{\circ} \mathrm{C}[20,21]$. PNIPAm end capped with a carboxylic acid group could be synthesized for subsequent conjugating with carbohydrate polymers, e.g., chitosan and hyaluronic acid, to form injectable thermo-sensitive copolymer, hyaluronic acid-chitosan- $g$-poly( $N$-isopropylacrylamide) (HACPN) with a similar LCST to PNIPAm [22].

Compared to traditional intravenous administration of anticancer drugs, intratumoral drug delivery systems have the potential to enable the loading and release of insoluble anticancer 
drugs through in-situ forming thermo-sensitive hydrogel. This drug delivery system can deliver anticancer drugs locally to the tumor site, leading to low dose requirements and reduce multiple drug administration cycles, which could reduce or eliminate adverse effects of the drug due to local delivery and prevention of systemic drug uptake [23]. Injectable gelling depots with thermo-sensitive hydrogel and pre-shaped implant systems are two types of intratumoral delivery systems for anticancer drugs [24]. The injectable gelling depot based on in-situ phase separation of thermo-sensitive hydrogel has been shown to be less invasive and lead to less pain upon injection as compared to pre-formed implants, making them a desirable system for local administration of anticancer drugs [25]. A typical injectable gelling depot system is formulated by simple mixing of drug and polymer solution below the LCST of the polymer hydrogel. After injection, sol-gel transition occurs to transform the minimally viscous solution into a drug delivery gel depot. The advantage of this method is the avoidance of invasive surgery for implantation, a high water content of the hydrogel to improve the compatibility, biodegradability of the thermo-sensitive polymer for excretion from the body once achieving its intended purpose and flexibility of the design of the drug release rate by changing the formulation [26].

However, thermo-sensitive hydrogels present challenges in anticancer drug delivery applications, i.e., initial burst release [27]. The burst release may lead to systemic toxicity due to the high dosage of drug released. The main reasons for burst release stems from the fact that a solid gel is not formed immediately upon injection into the body. A highly hydrophilic drug trapped in the aqueous phase of the gel may diffuse into the body fluid uncontrollably fast before and after gelation induced by a temperature change. To solve the burst release problem, we postulate that embedding drug-loaded GO in in-situ forming HACPN hydrogel could provide an ideal drug delivery platform for intratumoral delivery of anticancer drugs. A key requirement of in-situ depot-forming systems for local delivery, and more specifically for intratumoral delivery, could be fulfilled easily by HACPN hydrogel with its injectability through standard gauge needles [28]. Therefore, we first prepared FA-conjugated GO as the targeted drug delivery carrier for doxorubicin (DOX) (GOFA-DOX). Then, GOFA-DOX was encapsulated into the thermo-sensitive and biodegradable polymer hydrogel HACPN for local drug delivery. We demonstrated that GOFA, with its high loading capacity for DOX, showed enhanced intracellular uptake by breast cancer cell MCF-7 and pH-responsive drug release. The targeted drug delivery in concomitant with the degradation of HACPN could alleviate burst DOX release and enhance cytotoxicity toward MCF-7 cells in vitro. Furthermore, an efficient and safe breast cancer therapy employing intratumoral delivery of GOFA-DOX/HACPN in xenograft tumor mouse models with MCF-7 implanted subcutaneously in nude mice could be expected (Figure 1).

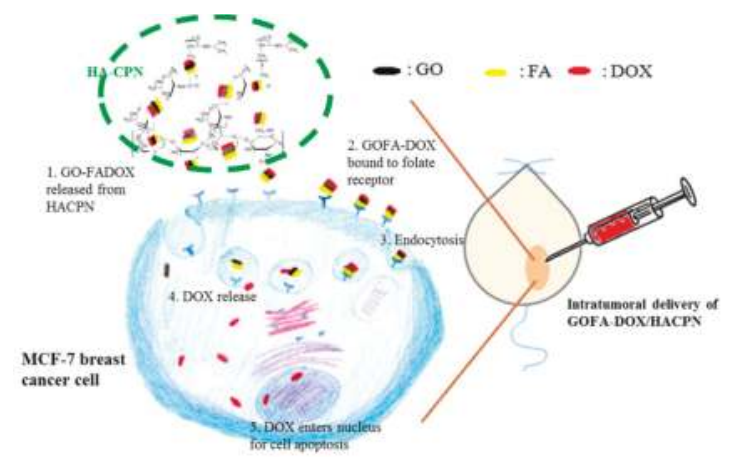

Figure 1. The schematic illustration of the antitumor effect by intratumoral delivery of DOX-loaded GOFA in HACPN hydrogel (GOFA-DOX/HACPN) in a xenograft tumor mouse model with MCF-7 cells implanted subcutaneously in nude mice. 


\section{Results and Discussion}

\subsection{Synthesis and Characterization of GO and GOFA}

The nano-sized GO was prepared by using commercial GO as raw material through modified Hummer method, followed by prolong $(30 \mathrm{~min})$ ultrasonication [29]. This reduced GO size and introduced abundant carboxyl groups for conjugating with FA. The morphology of as-prepared GO was characterized by transmission electron microscope (TEM) and atomic force microscope (AFM). As shown in Figure 2, the size of GO was 150 200 nm while the thickness was about $4.0 \pm 0.2 \mathrm{~nm}$, which was in agreement with previous studies [30]. Using 1-ethyl-3-(3-dimethylaminopropyl) carbodiimide (EDC) as a crosslinking agent, we synthesized GOFA by covalently conjugating GO with FA through amide bond formation between the amine groups of FA and carboxyl groups of GO in an aqueous solution. The EDC-mediated conjugation works by activating carboxyl groups for direct reaction with primary amines via amide bond formation. Because no portion of the EDC chemical structure becomes part of the final bond between GO and FA, it is considered a zero-length carboxyl-to-amine crosslinker. GOFA showed a light brownish color stable solution in phosphate buffered solution (PBS) with no aggregation occurred up to 1 day at $0.1 \mathrm{mg} / \mathrm{mL}$, ensuring proper suspension during DOX loading. After FA was conjugated to GO to form GOFA, the size remained the same but the thickness increased to $12.0 \pm 0.3 \mathrm{~nm}$ from TEM and AFM observation (Figure 2). The roughness also increased from $1.5 \pm 0.4 \mathrm{~nm}$ to $5.3 \pm 0.5 \mathrm{~nm}$. Controlling the size of GOFA within 200 to $500 \mathrm{~nm}$ was very important for its efficient intracellular uptake into cells [31].

The modified Hummer method used here oxidized commercial GO with concentrated sulfuric acid and introduced more oxygen molecules, including abundant carboxyl groups, to GO. An aqueous suspension of GO exhibits a zeta potential of $-33.0 \pm 1.1 \mathrm{mV}$, indicative of negatively charged surfaces caused by the presence of hydrophilic carboxyl groups. The zeta potential of GO changed to $-24.7 \pm 0.9 \mathrm{mV}$ after conjugation with FA as the carboxyl groups was consumed after reacting with the primary amine groups of FA. The changes in thickness, roughness and zeta potential indicated successful conjugation of FA with GO nano-sheet.

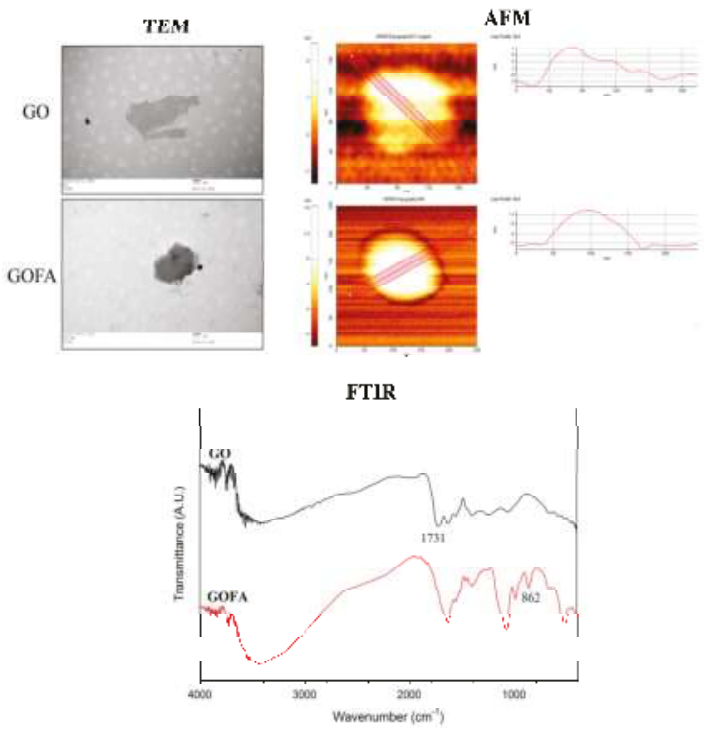

Figure 2. Transmission electron microscopic (TEM), atomic force microscopic (AFM) and Fourier transform infrared (FTIR) spectroscopic analysis of GO and GOFA. 
From Fourier transform infrared (FTIR) spectroscopy analysis, major peaks of GO at $3400 \mathrm{~cm}^{-1}$ $(\mathrm{OH}), 1731 \mathrm{~cm}^{-1}(\mathrm{C}=\mathrm{O}), 1640 \mathrm{~cm}^{-1}(\mathrm{C}=\mathrm{C}), 1246 \mathrm{~cm}^{-1}(\mathrm{C}-\mathrm{OH})$ and $1060 \mathrm{~cm}^{-1}(\mathrm{C}-\mathrm{O})$ were identified (Figure 2). After FA conjugation to GO, the absorption peaks at $1731 \mathrm{~cm}^{-1}$ disappeared due to consumption of carboxylic acid $\mathrm{C}=\mathrm{O}$ with concomitant appearance of the additional aromatic $\mathrm{C}-\mathrm{H}$ bending at $862 \mathrm{~cm}^{-1}$ due to FA. Taken together, the FTIR analysis indicated successful incorporation of FA in GOFA. This was also supported by quantitative analysis of the amount of FA conjugated to GO, which is $98.2 \mu \mathrm{g}$ FA/mg GOFA with $92.8 \%$ loading efficacy.

\subsection{Synthesis and Characterization of $H A C P N$}

Due to the toxicity of PNIPAm, copolymers containing PNIPAm and other biocompatible natural polymers were preferred for biomedical applications. Modification of PNIPAm by grafting with other biocompatible polymers could fortify the mechanical properties of the hydrogel and reduce its cytotoxicity [32]. Thus, the HACPN hydrogel is more practicable as an injectable hydrogel vehicle for drug delivery [33]. The relative compositions of chitosan, hyaluronic acid and PNIPAm in HACPN could be calculated to be $12.6 \%(w / w), 5.5 \%(w / w)$ and $81.9 \%(w / w)$, respectively [28]. The HACPN solution was free free-flowing at $25^{\circ} \mathrm{C}$ and transformed into gels at $37^{\circ} \mathrm{C}$ [32]. Furthermore, the solid hydrogel remained stationary when the sample vial was inverted, verifying the high structural strength of the injectable thermo-sensitive polymer hydrogel at the physiological temperature. The LCST was determined from the sol-gel phase transition by measuring the turbidity of a $10 \%(w / v)$ polymer solution. The relative absorbance of the polymer solution increased with temperature and the LCST could be calculated to be 30.5 and $30.3{ }^{\circ} \mathrm{C}$ for $5 \%$ and $10 \%(w / v)$ HACPN solutions, respectively, by defining the LCST being the temperature corresponding to half of the maximum change in the absorbance (Figure 3A). The gelling processes of HACPN was also thermo-reversible as subsequent cooling cycle resulted in gel-sol transition and fully reversible gel melting [28].

The phase transition kinetics analysis was carried out to investigate the gel formation time of HACPN solutions. As shown in Figure 3B, the relative absorbance rose sharply as the temperature was shifted from 25 to $37^{\circ} \mathrm{C}$. The gel formation kinetics of $5 \%$ HACPN was slower than that of $10 \%$ HACPN albeit both completed gel formation in less than $5 \mathrm{~min}$. The fast gel formation will ensure fast in-situ gel formation to entrap DOX-loaded GOFA and prevent burst release of the drug. It should be noted that the volume of polymer solution used here $(2 \mathrm{~mL})$ for in vitro gel forming kinetics measurements was much larger than the volume used for in vivo injection $(0.2 \mathrm{~mL})$. Therefore, we expect the gel formation time will be shorter than that shown in Figure 3B ( 4 min). With comparable LCST but faster gel formation kinetics, $10 \% \mathrm{HACPN}$ was chosen for further studies.

The effect of GOFA on the phase transition of HACPN was studied using differential scanning calorimetry (DSC). From DSC analysis (Figure 3C), the temperatures at the onsets of the differential scanning calorimetry (DSC) endotherms were at 28.70 and $29.53{ }^{\circ} \mathrm{C}$ for HACPN and GOFA/HACPN, respectively, while the corresponding peak temperatures were 29.95 and $30.07^{\circ} \mathrm{C}$, which could be referred to as the LCST [34]. Moreover, the enthalpy change of the phase transition, which was calculated by integration of peak area, increased from 0.9763 to $1.299 \mathrm{~J} / \mathrm{g}$ during the heating process of the DSC cycle, indicating the replacement of water molecules around the hydrophilic polar groups by GOFA at a temperature lower than the LCST and the endothermic heat caused by the dehydration of polar groups increased [35].

The drug release behaviors from a hydrogel matrix depended on several factors, such as diffusion through the matrix, osmosis, degradation or weight loss of the matrix and physical parameters of the polymer matrix [36]. Taking advantage of the weight loss of HACPN hydrogel is an attractive characteristic for intratumoral drug delivery since the hydrogel does not need to be removed after local application [37]. From the weight loss at $37^{\circ} \mathrm{C}$ in phosphate buffered saline (PBS), HACPN showed quick degradation rate initially with $\sim 65 \%$ remaining weight at day 7 (Figure 3D). After this period, the degradation rate slowed down moderately with $\sim 12 \%$ remaining weight at day 28 . The degradation 
of HACPN hydrogel in vitro implies that GOFA/DOX could be continuously released in vivo after intratumoral delivery, followed by intracellular uptake of the nano-drug by cancer cells.
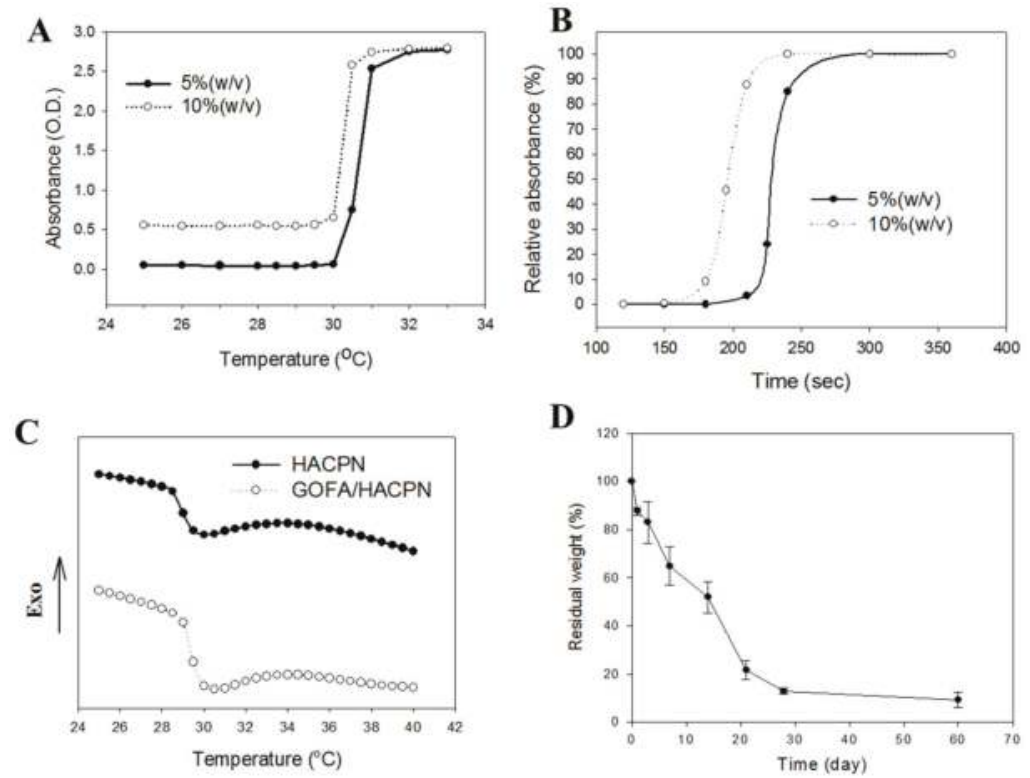

Figure 3. (A) Phase transition behavior of thermo-sensitive polymer HACPN at $5 \%$ and $10 \%(w / v)$ from 25 to $33{ }^{\circ} \mathrm{C}$; (B) Kinetics of phase transition of $5 \%$ and $10 \%(w / v)$ HACPN solutions during heating with instantaneous temperature change from 25 to $37^{\circ} \mathrm{C}$; (C) Thermal properties of HACPN and GOFA/HACPN with $0.1 \%(w / w)$ GOFA from differential scanning calorimetry; (D) The weight loss of $10 \%(w / v) \mathrm{HACPN}$ in $\mathrm{pH} 7.4 \mathrm{PBS}$ at $37^{\circ} \mathrm{C}$.

\subsection{DOX Loading and Release}

Drug loading and release behavior are the most important characteristics to evaluate a drug delivery system. Figure 4A shows the drug loading performance of GOFA. The high surface area and conjugate structure of GO could facilitate strong $\pi-\pi$ stacking interactions with DOX and to achieve high DOX loadings [9]. By increasing the amount of DOX used during drug loading, the loading content (the weight of DOX to the weight of GOFA) of DOX increased sharply and reached as high as $25 \mathrm{mg}$ DOX/mg GOFA when $3 \mathrm{mg}$ DOX reacted with $0.1 \mathrm{mg}$ GOFA. On the contrary, the DOX loading efficiency (the weight percentage of initial DOX bound to GOFA) decreased with increasing amount of DOX used and reduced from $95.5 \%$ to $37.6 \%$ when $3 \mathrm{mg}$ DOX was used. Thus, reacting $2.0 \mathrm{mg}$ DOX with $0.1 \mathrm{mg}$ GOFA (DOX/GOFA $=20$ ) was deemed the best condition for preparing GOFA-DOX considering both drug loading efficiency and loading content with the former being $51.2 \%$ and the latter being $14.2 \mathrm{mg} / \mathrm{mg}$. It should be noted the DOX loading content reported here is much higher than the values $(32 \mu \mathrm{g} / \mathrm{mg}$ and $1.84 \mathrm{mg} / \mathrm{mg}$ ) reported previously using FA-conjugate carbon nanotubes [18,38]. For DOX loading to GO, the loading contents reported previously were 2.35 and $0.294 \mathrm{mg} / \mathrm{mg}[10,39]$. These results indicated that GOFA is a highly efficient nano-carrier for loading and delivery of DOX.

The release of drug from GOFA-DOX at $37^{\circ} \mathrm{C}$ in PBS at pH 7.4 and 5.5 is presented in Figure 4B. The $\mathrm{pH}$ values for evaluating drug release were chosen based on the physiological and the endosomal $\mathrm{pH}$ value of cancer cells, respectively. The drug release curves showed that DOX loaded on GOFA was released at a slow and controlled manner at $\mathrm{pH} 7.4$, to the extent of $18.7 \%$ in $216 \mathrm{~h}$. The release rate 
of DOX was significantly enhanced at pH 5.5 and the amount of drug released was $89.4 \%$ within the same time period.

That the release rate of DOX at $\mathrm{pH} 5.5$ was significantly higher than that at $\mathrm{pH} 7.4$ may be caused by weakening of hydrogen bonds between DOX and GOFA. Noncovalent attachment of DOX to GOFA involves hydrogen bonds between - $\mathrm{COOH}$ of GOFA and -OH of DOX and between -OH of GOFA and $-\mathrm{OH}$ of DOX [18]. The degree of hydrogen bond interactions between DOX and GOFA is a function of the $\mathrm{pH}$ value. The $\mathrm{H}^{+}$in solution would compete with the hydrogen bond-forming group and weaken the hydrogen bond interactions at $\mathrm{pH} 5.5$, leading to greater release of DOX. Alternatively, the high release rate at acidic conditions may be caused by the amine $\left(-\mathrm{NH}_{2}\right)$ groups of DOX getting protonated to result in partial dissociation of hydrogel-bonding interaction [40]. The high drug loading and the $\mathrm{pH}$-sensitive release of DOX suggest that GOFA is a promising delivery vehicle for the anticancer drug.

The drug release behavior of DOX from GOFA-DOX/HACPN showed the same $\mathrm{pH}$ dependence as GOFA but is much slower than GOFA (Figure 4B). Thus, we can anticipate effective modulation of the burst release of DOX by entrapping GOFA-DOX in HACPN at the physiological pH extracellularly, followed by copious DOX release at the endosomal $\mathrm{pH}$ in cancer cells to exert enhanced cytotoxicity following the intracellular uptake of GOFA-DOX.

A

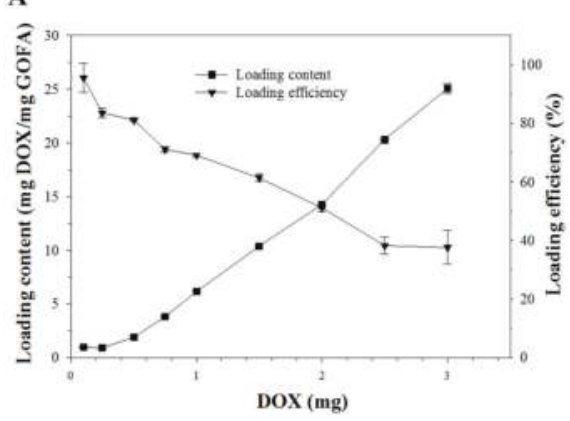

B

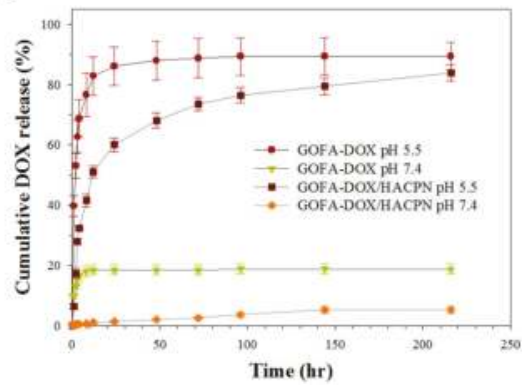

Figure 4. The loading and release of DOX. (A) Drug loading efficiency and drug loading content when $0.1 \mathrm{mg}$ GOFA was reacted with different amount of DOX; (B) Drug release from GOFA-DOX and GOFA-DOX/HACPN at $\mathrm{pH} 7.4$ and $\mathrm{pH} 5.5$ in PBS $\left(37^{\circ} \mathrm{C}\right)$.

\subsection{In Vitro Cell Culture}

\subsubsection{Cellular Uptake}

Eukaryotic cells could form endocytotic vesicles to enclose extracellular substances through invagination of their plasma membrane segments. The specific uptake of GOFA by MCF-7 cells could be strongly suggested by receptor-mediated endocytosis to show efficient and targeted delivery of DOX by GOFA-DOX [9]. Folate receptor is a common tumor marker expressed at high levels on the surfaces of various cancer cells, which can facilitate cellular internalization of GO through receptor-mediated endocytosis after conjugating FA to GO. Confocal microscopy revealed intracellular fluorescence corresponding to quantum dot (QD)-labeled GOFA when MCF-7 cells were exposed to GOFA for $1 \mathrm{~h}$ and quenched with trypan blue to eliminate the residual fluorescence bound to cell membrane (Figure 5A). When folate receptors on MCF-7 cell surface were blocked by FA before contacting with GOFA, less receptor-mediated intracellular uptake was expected for GOFA. Indeed, we observed drastically diminished intracellular fluorescence signal of GOFA by blocking with excess FA (Figure 5B). This difference is due to the efficient blockage of folate receptor on MCF-7 cell surface with free FA in solution, which competitively inhibited the affinity of folate receptor toward GOFA. Overall, our result was in agreement with previous studies that revealed folate receptor-dependent cellular uptakes by cancer cells for anticancer drug delivery [41]. 
Two possible mechanisms of cellular DOX uptake from nanoparticles have been suggested: (1) DOX is released from the nanoparticle outside the cells, or (2) DOX is carried by the nanoparticle and released inside the cells [42]. Folic acid modification could increase the cytotoxicity of DOX encapsulated in nanoparticles toward MCF-7 cells by minimizing extracellular DOX release [43]. Upon incubation of MCF-7 with free DOX at $37 \mathrm{C}$ for $1 \mathrm{~h}$, red fluorescence was found mostly confined within the nucleus of shrunken cells, where DOX is chelated with DNA (Figure 5C). For GOFA-DOX, green fluorescence of GOFA appears in the cytoplasm of shrunken cells (Figure 5D). This provides a direct evidence for endocytosis of GOFA, which accumulated in the cytoplasm after internalization. Red fluorescence was only observed in the cell nucleus, indicating DOX released from GOFA in the cytoplasm could translocate across the nuclear membrane to interact with DNA molecules in the cell nucleus (Figure 5D). That the red signal due to DOX is much stronger for GOFA-DOX than DOX also implied GOFA could facilitate DOX diffusion across the cell membrane through intracellular uptake of GOFA-DOX to enhance the cytotoxicity toward cancer cells. Taken together, the results suggest that DOX-loaded GOFA could be transported across cell membrane via endocytosis and DOX was subsequently released under the acidic intracellular environment.

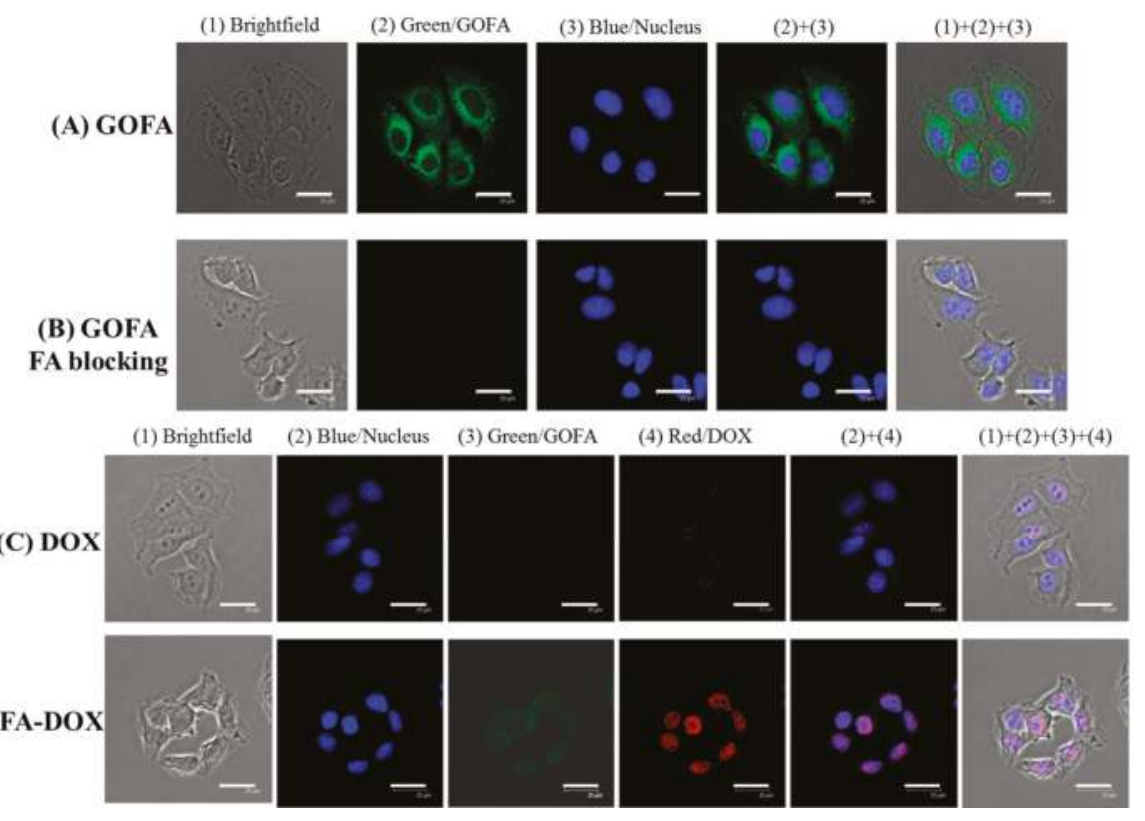

Figure 5. Confocal microscopy images of MCF-7 cells after incubated with GOFA for $1 \mathrm{~h}$ (A); incubated with $0.1 \mathrm{mg} / \mathrm{mL}$ folic acid for $1 \mathrm{~h}$ to block cell surface folate receptors and then treated with GOFA for $1 \mathrm{~h}(\mathbf{B})$; incubated with free DOX for $1 \mathrm{~h}(\mathbf{C})$; incubated with GOFA-DOX for $1 \mathrm{~h}(\mathbf{D})$. Bar $=25 \mu \mathrm{m}$.

Internalization of GOFA by MCF-7 cells was also observed by transmission electron microscope (TEM) to confirm endocytosis. Intracellular uptake was evident after contacting GOFA with cells, which were found within the endosomes in the cytoplasmic region (Figure 6). The presence of GOFA in close proximity to the nuclear region could be also observed. In vitro confocal and TEM images therefore strongly support efficient entry of GOFA into cancer cells through endocytosis after releasing from HACPN. It could be postulated that GOFA could potentially enhance the apoptotic effects of DOX via its efficient endocytosis by the cancer cells and increase the intracellular anticancer activity of the drug [44]. 


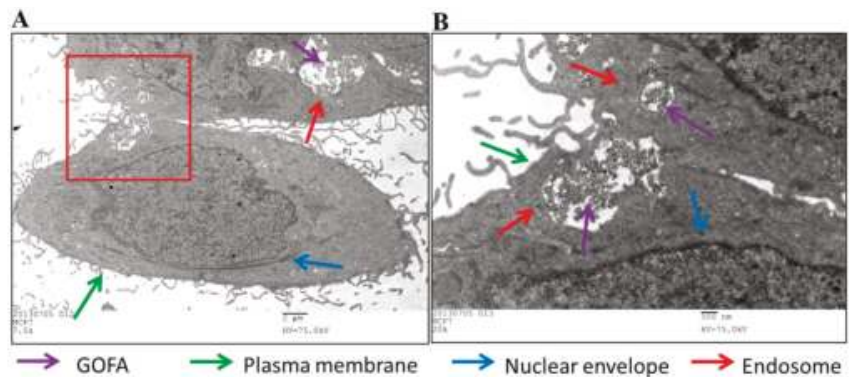

Figure 6. (A) Transmission electron microscope (TEM) micrographs of MCF-7 cells treated with GOFA for $1 \mathrm{~h}$. (B) is an enlarged view of the square in (A). (A) Bar $=2 \mu \mathrm{m},(\mathbf{B})$ Bar $=500 \mathrm{~nm}$.

\subsubsection{In Vitro Cytotoxicity and Biocompatibility Studies}

After confirming the successful entry of GOFA-DOX into the cells and release the drug, cell viability assay was used to compare the cytotoxicity of GO-DOX, GOFA-DOX and free DOX at different DOX concentrations toward MCF-7 cells (Figure 7A). When treated with an equivalent concentration of DOX, MCF-7 cells showed the lowest viability when treated with GOFA-DOX, followed by GO-DOX and free DOX. The IC50 values were calculated to be 7.3, 10 and $32.5 \mu \mathrm{g} / \mathrm{mL}$ for GOFA-DOX, GO-DOX and free DOX, respectively. This suggests GOFA-DOX can efficiently deliver the drug to the cell nucleus area due to the high cellular internalization of FA-conjugated GO via receptor-binding endocytosis. The biocompatibility of GOFA was confirmed over a broad concentration range using MCF-7 cells (Figure 7B), where the relative cell viability is above $90 \%$ up to $100 \mu \mathrm{g} / \mathrm{mL}$, which covers the concentrations of GOFA studied in Figure 7A, indicating cell cytotoxicity shown by GOFA-DOX was indeed from DOX released but not from the drug carrier itself.

A

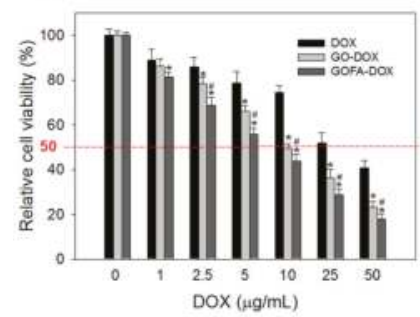

B

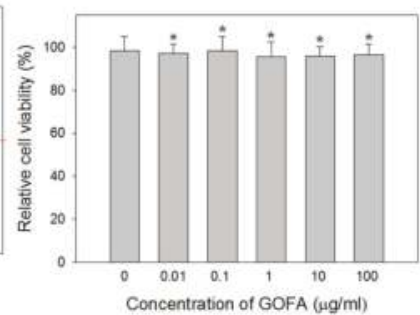

C

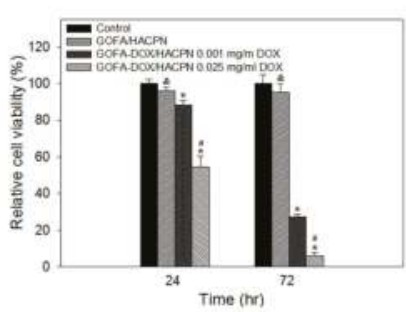

Figure 7. (A) Cytotoxicity of free DOX, GO-DOX and GOFA-DOX against MCF-7 cells. The cells were treated for $24 \mathrm{~h}$. The relative cell viability was compared to the control without DOX. ${ }^{*} p<0.05$ compared with DOX, ${ }^{\#} p<0.05$ compared with GO-DOX; (B) Viability of MCF-7 cells after incubated with different concentration of GOFA for $24 \mathrm{~h}$. The relative cell viability was compared to the control without GOFA. * $p>0.05$ compared with control; (C) Cell viability of MCF-7 cells after incubated with GOFA/HACPN and GOFA-DOX/HACPN at different DOX concentrations for 24 and $72 \mathrm{~h}$. The control is cell culture medium. \& $p>0.05$ compared with control, ${ }^{*} p<0.05$ compared with control, ${ }^{*} p<0.05$ compared with GOFA-DOX/HACPN $0.001 \mathrm{mg} / \mathrm{mL}$ DOX. Data are presented as mean \pm standard deviation (SD), $n=6$.

For the cytotoxicity of GOFA-DOX/HACPN toward MCF-7 cells, when cells were incubated at a low DOX concentration $(0.001 \mathrm{mg} / \mathrm{mL})$, cell survival rate was $90 \%$ after $24 \mathrm{~h}$ (Figure $7 \mathrm{C}$ ). When MCF-7 cells were cultured for $72 \mathrm{~h}$ in the presence of GOFA-DOX/HACPN, cell viability was further decreased to $\sim 30 \%$. At a higher DOX concentration (i.e., $0.025 \mathrm{mg} / \mathrm{mL}$ ), the same cytotoxicity effect could be 
observed. That the cytotoxicity of GOFA-DOX/HACPN was both DOX dose and time-dependent, indicating GOFA-DOX could be released from HACPN continuously to exert the cytotoxicity effect toward MCF-7 cells. The biocompatibility of GOFA/HACPN could be also observed from Figure 7C with the relative cell viability not significantly different from the control, indicating GOFA/HACPN does not elicit cytotoxicity toward MCF-7 cells in vitro.

\subsubsection{Cell Apoptosis Induced by DOX In Vitro}

Doxorubicin is known as an anthracycline antibiotic effective in treating a variety of cancers. It functions primarily at the DNA level by blocking the replication and transcription processes [45,46]. DOX also activates damage-inducible DNA repair and prevent the triggering of programmed cell death by spontaneous and induced DNA damage [47]. To confirm the cytotoxicity of GO-DOX and GOFA-DOX toward MCF-7 cells was induced by apoptosis as of free DOX and compare the apoptosis ratio, Annexin V-FITC/PI staining assays was performed and the apoptotic and necrotic cells were quantified by flow cytometry. The percentages of necrotic (Q1), late apoptotic (Q2), early apoptotic (Q3) and live cells (Q4) are shown in Figure 8. The flow cytometry analysis revealed that early and late apoptosis represented the major death mode of MCF-7 cells, which was caused by free DOX or DOX released form GO (GOFA). The ratio of apoptosis cells treated with GOFA-DOX was 30.3\%, compared with that of free DOX (8.6\%). Most importantly, it is worth noting that the ratio of apoptosis cells treated with GOFA-DOX was markedly higher than that in cells treated with GO-DOX $(11.2 \%)$, endorsing the targeting effect of FA. In general, the results of flow cytometry were consistent with the cell viability results by 3-(4,5-dimethyl-2-thiazolyl)-2,5-diphenyl-2H-tetrazolium bromide (MTT) assays (Figure 7A), underlining the importance of using GOFA to facilitate the entrance of DOX-loaded nano-carrier into the cells through endocytosis and subsequently release DOX that enters the nucleus to exert the cell cytotoxicity (Figure 5C,D). Furthermore, the FA-mediated intracellular uptake of GOFA could enhance the endocytosis of the nano-carrier to substantially increase the extent of cytotoxicity of DOX toward MCF-7 though cell apoptosis (Figure 5A,B).
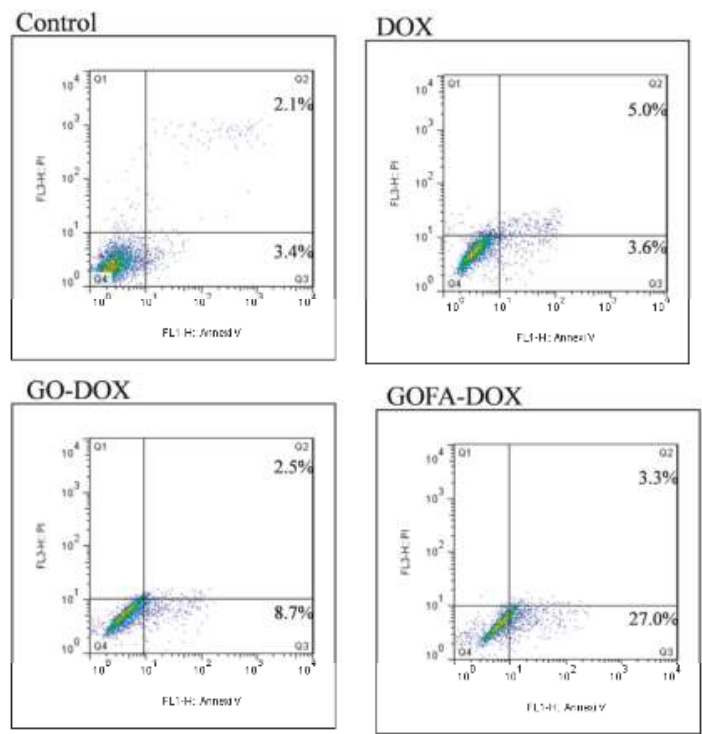

Figure 8. Flow cytometer analysis of the apoptotic and necrotic cells by Annexin V-FITC/PI staining (Q1: necrotic; Q2: late apoptotic; Q3: early apoptotic; Q4: live) after $24 \mathrm{~h}$ incubation with free DOX, GO-DOX and GOFA-DOX, respectively. The numbers in Q1 to Q3 indicate the percentage of cells after the treatment. 


\subsection{Animal Study}

\subsubsection{Antitumor Effect}

With an aim to improve antitumor therapeutic effects and to decrease the side effects of DOX, we have successfully demonstrated that GOFA nano-carrier could conjugate with DOX and be encapsulated in HACPN to enhance its cytotoxicity toward MCF-7 breast cells in vitro. To validate those data in vivo, we administered the DOX-loaded GOFA in HACPN by taking advantage of the in-situ gelling property of the thermo-sensitive hydrogel. All BALB/c nude mice with an aggressive subcutaneous MCF-7 cells tumor were injected intratumorally with formulations containing saline (control), GOFA/HACPN, free DOX, GOFA-DOX or GOFA-DOX/HACPN, followed by measuring the tumor size and mouse body weight. In order to successful determining the anti-tumor effects in vivo, the size of the tumor was controlled within $60-100 \mathrm{~mm}^{3}$ when the treatment started.

As shown in Figure 9A, the same trends of tumor growth were observed in the control group and the GOFA/HACPN group. The relative tumor volume increased rapidly during the treatment period and reached $2.17 \pm 0.02$ (control) and $1.79 \pm 0.16$ (GOFA/HACPN) at day 21 with no significant difference between groups. In contrast, the tumor growth rate was inhibited at different levels in all DOX-treated groups. The DOX, GOFA-DOX and GOFA-DOX/HACPN groups showed $0.82 \pm 0.10$, $0.67 \pm 0.02$ and $0.48 \pm 0.07$ relative tumor sizes at day 21, respectively, with significant difference among groups. Indeed, in vitro cytotoxicity results also endorsed the substantial enhancement of cytotoxicity of GOFA-DOX toward MCF-7 cells over free DOX at the same drug dosage (Figures 7A and 8). Intratumoral injection of DOX showed associated cytotoxic effects only at the early stage of treatment and short-term inhibition of tumor growth. The tumor volume rapidly dropped as early as 3 days after treatment and lasted for 4 days, followed by a rebound phenomenon in tumor volume at the later stage of treatment. For the GOFA-DOX group, with the targeting effect of FA, DOX could be more efficiently delivered to MCF-7 cells and the relative tumor volume could be significantly reduced throughout the test period after day 7 and showed minimal recovery 7 days after treatment. Nonetheless, the most efficient cytotoxic effect and continuous inhibition of tumor growth was observed only in the GOFA-DOX/HACPN group where the tumor size was continuously reduced up to 11 days to resulted in the highest tumor inhibition ratio of $52 \%$ (based on tumor volume changes) after 21 days, suggesting the in vivo anti-tumor efficacy using a combinatory GOFA-DOX/HACPN intratumoral drug delivery platform. These results demonstrated that thermo-sensitive HACPN hydrogel loading GOFA-DOX for cancer in-situ treatment could lead to more extensive destruction of tumor tissues and enhance the therapeutic efficiency. The enhanced intracellular uptake of GOFA-DOX contributed to the higher tumor-killing ability when compared with the free DOX dosage form. For comparison with GOFA-DOX, in-situ forming HACPN thermo-sensitive hydrogel can be retained around the tumor tissue and slowly released GOFA-DOX in concomitant with hydrogel degradation, which could raise local DOX concentration in the tumor and enhance the topical bioavailability of DOX for the best antitumor effect toward MCF-7 cells.

To assess the potential for adverse effects associated with treatments, mice were observed for changes in their body weight and appetite, for diarrhea and abnormal behavior over the course of treatments. Neither control nor drug-treated mice showed abnormalities in appetite and behavior throughout the 21 days observation period and there was no significant difference in weight for all treatment groups from the control (Figure 9B). 
A

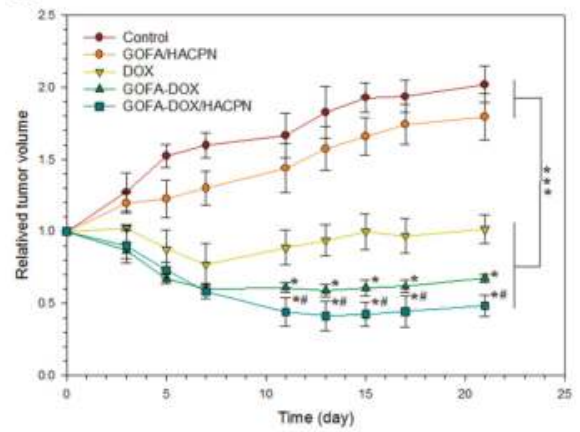

B

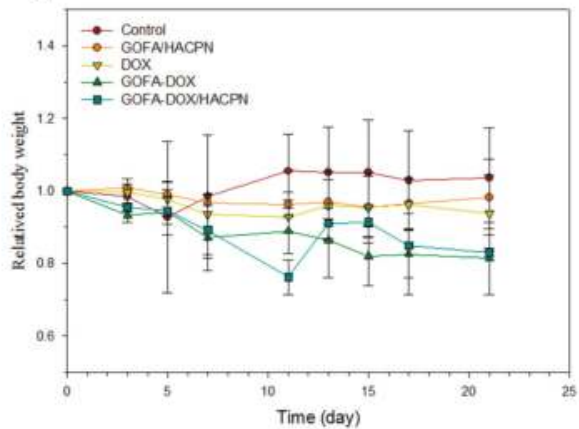

Figure 9. Antitumor activity induced by DOX in nude mice bearing MCF-7 cancer cells. DOX (30 mg $/ \mathrm{kg}$ ) was administered intratumorally and tumor volume (A) and body weight (B) changes were recorded. The data are shown as mean \pm standard deviation (SD), $n=6 .{ }^{*} p<0.05$ compared with DOX, ${ }^{\#} p<0.05$ compared with GOFA-DOX, ${ }^{* * *} p<0.001$.

\subsubsection{Histological and Systemic Toxicity Analysis}

At day 21, the tumors were harvested for histological analysis. As shown in Figure 10A, there was no evidence of necrosis in the H\&E staining slide for the tumor in the control group. Minimum necrosis was observed in the GOFA/HACPN group whereas some necrosis regions were observed in the free DOX and GOFA-DOX groups. There was significantly more necrosis regions in tumors treated with GOFA-DOX/HACPN when compared with other DOX-treated groups. Indeed, the H\&E staining revealed that the cavitation phenomenon in coagulative necrosis was more obvious in the GOFA-DOX/HACPN group (Figure 10A). These results demonstrated that intratumoral delivery of GOFA-DOX/HACPN enhanced the anti-tumor efficacy, suggesting it is an excellent treatment for breast cancer.

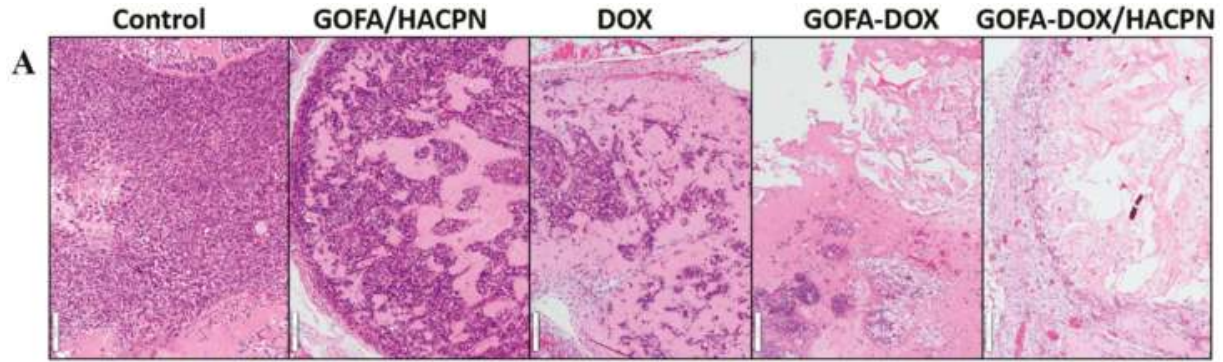

B

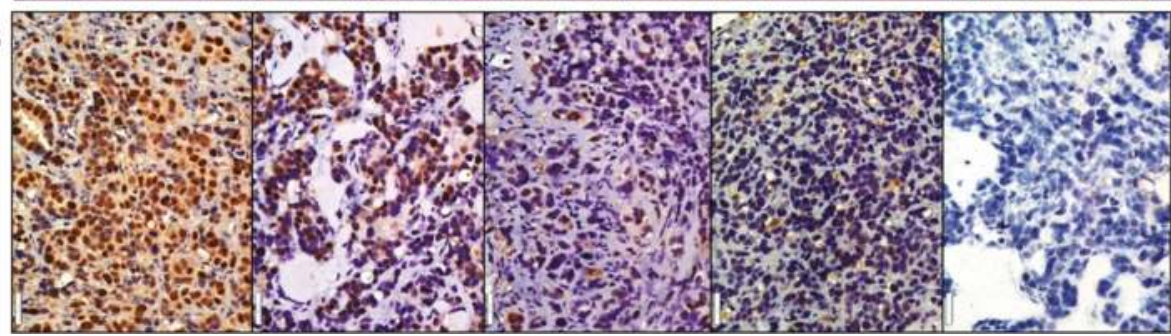

Figure 10. (A) H\&E (Bar $=100 \mu \mathrm{m})$ and $(\mathbf{B})$ proliferating cell nuclear antigen $(\mathrm{PCNA})$ immunohistochemical $($ Bar $=20 \mu \mathrm{m})$ staining of retrieved tumor tissues at day 21 . 
Improved tumor delivery of DOX should also inhibit proliferation of cancer cells. Immunohistochemical examination of tumor sections associated with the cell proliferation markerproliferating cell nuclear antigen (PCNA) clearly indicated that a greater number of actively proliferating tumor cells existed in tumor sections from the control and the GOFA/HACPN groups. In contrast, the tumor treated with DOX and GOFA-DOX showed weak PCNA immunoreactivity. The PCNA expression was the lowest in the GOFA-DOX/HACPN group than other groups (Figure 10B). Therefore, we conclude GOFA-DOX/HACPN can provide effective anticancer activity to effectively inhibit proliferation of cancer cells [48].

When the animals were euthanized, no gross abnormalities were observed in the treated mice. To further assess possible systemic toxicity, the major organs for the mice treated with GOFA-DOX/HACPN at day 21 were harvested for morphologic evaluation of H\&E-stained sections and compared with those in the control group. As shown in Figure 11, the GOFA-DOX/HACPN group did not reveal any observable differences from the control group based on the histological examination of heart, lung, liver, spleen and kidney biopsy. H\&E staining of the heart tissue sections showed striated cardiac muscles with the centrally placed nucleus. Normal alveoli without the sign of pulmonary fibrosis were seen in the lung sections. The histology of liver tissues revealed normal hepatocytes, central veins, portal triads and liver lobules. Red pulp and white pulp appeared in spleen samples. The kidney biopsy samples contained normal Bowman's capsule surrounding glomeruli as well as convoluted tubules. That the GOFA-DOX incorporated HACPN hydrogels exhibit reduced systemic toxicities could be due to the localized and delayed release of DOX encapsulated in HACPN at the tumor site for good biocompatibility and safety.

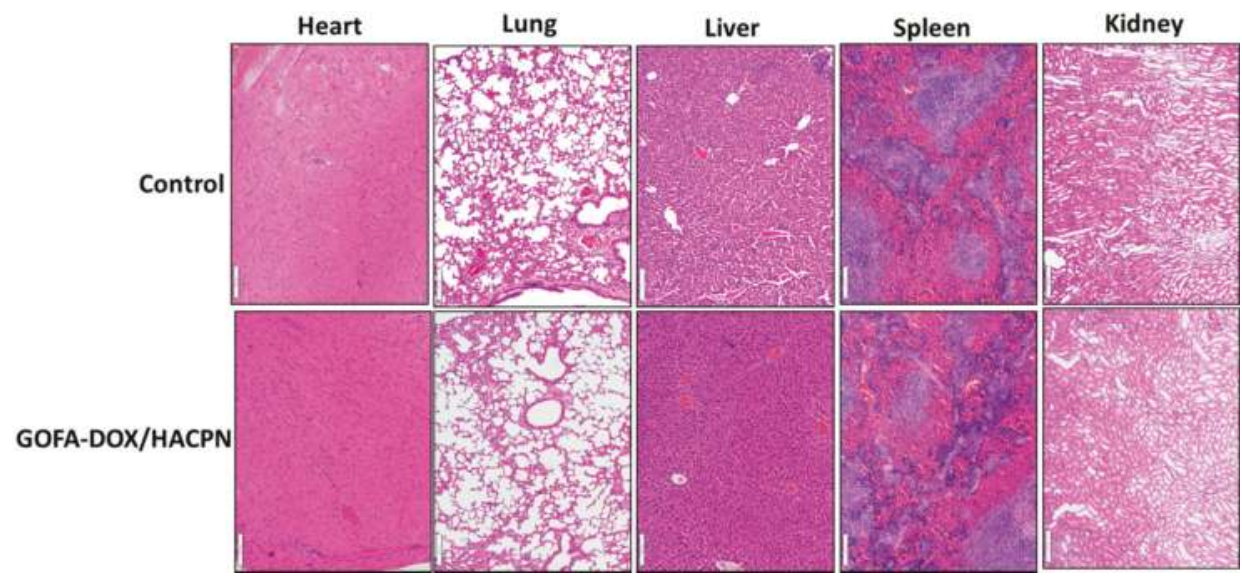

Figure 11. Histological examination of heart, lung, liver, spleen and kidney tissues by H\&E stain after euthanization at day 21. Tissue biopsy did not reveal any observable differences between the control and the GOFA-DOX/HACPN group. Bar $=100 \mu \mathrm{m}$.

On blood sampling of animals after the experiment, the application of GOFA-DOX/HACPN did not significantly alter the level of blood counts and hepatic or renal functions from hematologic study when compared with the control group (Table 1). These results were consistent with the overall health of mice from histological analysis.

Clinical applications of anticancer drugs are limited by side effects such as cardiac toxicity [49]. From the safety evaluation data in Figure 11 and Table 1, the intratumoral delivery of GOFA-DOX/HACPN appeared to be well tolerated by the animals. This could be suggested to be stemmed from combined effects of intratumoral injection and in-situ forming drug delivery system. The intratumoral delivery of DOX using GOFA-DOX/HACPN could provide a high local concentration 
of the antitumor drug and the in-situ forming HACPN hydrogel together with GOFA-DOX would eliminate the initial burst release of DOX to reduce systemic toxicity [50].

Considering the toxicity of GO, it is generally considered to be safe for in vivo applications [51]. For HACPN, the biodegradable components chitosan and HA are safe science chitosan is biodegradable predominantly by lysozyme and by bacterial enzymes in the colon in vertebrates [52] while HA could be degraded through step-wise enzymatic or non-enzymatic reactions in vivo [53]. For the non-biodegradable PNIPAm component in HACPN, it was reported that low molecular weight PNIPAm showed good biocompatibility in vivo by undergoing renal clearance [54]. By using PNIPAm polymers with a low molecular weight $(22 \mathrm{kDa})$ for HACPN synthesis [28], we did not expect the PNIPAm generated by HACPN degradation to exert any in vivo toxicity as it is below the renal cutoff [55].

Table 1. Blood analysis for evaluation of systemic toxicity.

\begin{tabular}{cccc}
\hline Item & Unit & Control & GOFA-DOX/HACPN \\
\hline \multicolumn{4}{c}{ Hematology } \\
\hline WBC & $10^{3}$ cells $/ \mu \mathrm{L}$ & $5.78 \pm 2.34$ & $2.9 \pm 0.6^{*}$ \\
RBC & $10^{6}$ cells $/ \mu \mathrm{L}$ & $8.57 \pm 0.51$ & $8.5 \pm 0.2^{*}$ \\
HGB & $\mathrm{g} / \mathrm{dL}$ & $13.30 \pm 0.87$ & $13.2 \pm 0.5^{*}$ \\
HCT & $\%$ & $41.77 \pm 2.23$ & $39.1 \pm 2.5^{*}$ \\
PLT & $10^{3}$ cells $/ \mu \mathrm{L}$ & $334.30 \pm 29.8$ & $279.5 \pm 37.5^{*}$ \\
\hline \multicolumn{3}{c}{ Clinical Chemistry } \\
\hline AST & $\mathrm{U} / \mathrm{L}$ & $254.5 \pm 19.1$ \\
ALT & $\mathrm{U} / \mathrm{L}$ & $102.50 \pm 0.71$ & $294 \pm 39.4^{*}$ \\
BUN & $\mathrm{mg} / \mathrm{dL}$ & $28.40 \pm 3.54$ & $32.1 \pm 3.1^{*}$ \\
CREA & $\mathrm{mg} / \mathrm{dL}$ & $0.12 \pm 0.01$ & $0.13 \pm 0.01 *$ \\
\hline
\end{tabular}

WBC: white blood cell; RBC: red blood cell; HGB: hemoglobin; HCT: hematocrit; PLT: platelet; AST: aspartate transaminase; ALT: alanine transaminase; BUN: blood urea nitrogen; CREA: creatinine Values are means \pm standard deviation (SD) of six independent measurements. ${ }^{*} p>0.05$ compared with control.

\subsubsection{IVIS for Bioluminescence Imaging (BLI) Intensity}

As residual hydrogel may influence the measurement of tumor volume, we further used a stably luciferase report gene-transfected MCF-7 cells (MCF-7/Luc) and in vivo imaging system (Xenogen IVIS-200, Caliper Life Sciences, Hopkinton, MA, USA) to determine the bioluminescence imaging (BLI) intensity of tumors formed from subcutaneous implanted MCF-7/Luc cells. It has been demonstrated that luciferase expression and bioluminescence does not affect tumor cell growth for MCF-7 cells [56]. For therapeutic effects from BLI imaging, the mean value of the normalized BLI signal intensity increased to $1738 \%$ in the control group after 21 days, reflecting an active tumor growth for MCF-7/Luc cells (Figure 12). Without any drug, the GOFA/HACPN treatment did not showed a significant difference in BLI signal from the control group, albeit with a lower mean BLI signal intensity of $1539 \%$. In the DOX-treated group, the mean values decreased to $35.3 \% 21$ days after single DOX administration, indicating that the cytotoxic effect of DOX affected tumor growth (Figure 12). In the GOFA-DOX group, the mean value further reduced to $25.0 \%$ with significant difference in BLI intensity from the DOX-treated group. However, a remarkable drop in normalized BLI signal intensity to 3.1\% was observed for the combinatory GOFA-DOX/HACPN group and the BLI signal was significantly different from all DOX-treated groups. In general, the antitumor effect from different treatments with IVIS imaging was consistent with that from tumor volume change shown in Figure 9A. 

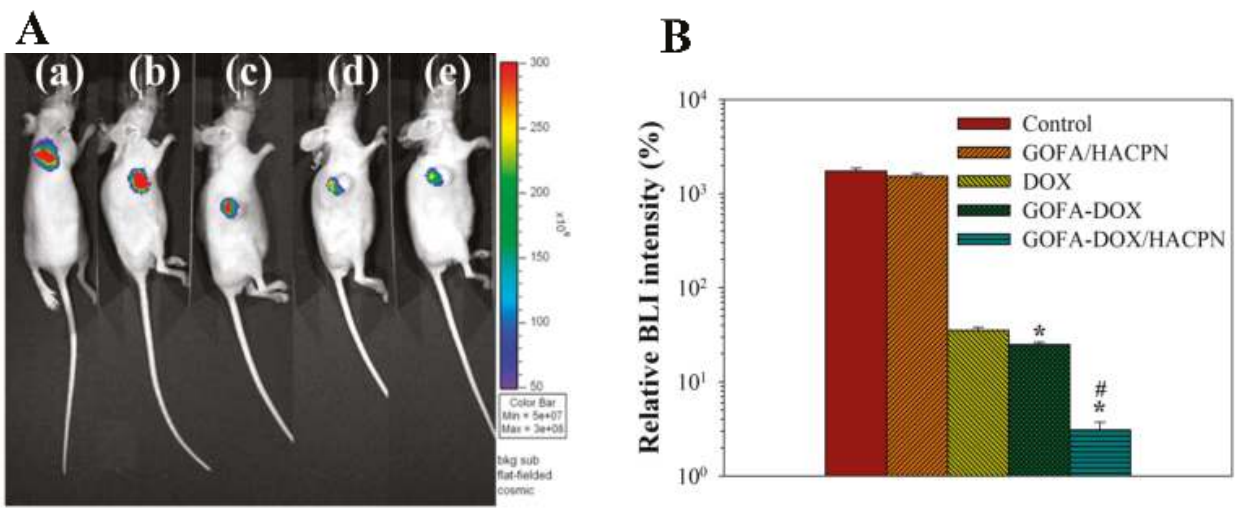

Figure 12. The bioluminescence imaging (BLI) of subcutaneously implanted MCF-7/Luc cells in nude mice. The BLI signal was measured at baseline (before treatment) and at day 21 after treatment. (A) Representative BLI obtained in the (a) control (saline), (b) GOFA/HACPN, (c) DOX, (d) GOFA-DOX and (e) GOFA-DOX/HACPN group by IVIS at day 21. (B) Plot of the relative BLI signal intensity at day 21 (mean $\pm \mathrm{SD}, n=6$ ). The relative BLI signal intensity (\%) was calculated from the total bioluminescent signal intensity at day 21 normalized by the total bioluminescent signal intensity at baseline. ${ }^{*} p<0.05$ compared with DOX, ${ }^{*} p<0.01$ compared with GOFA-DOX.

\section{Materials and Methods}

\subsection{Materials}

Graphene oxide (GO) (N002-PS) and quantum dots (QD) (QSA-490, CdSSe/ZnS core/shell QDs with amine group) were purchased from Angstron Materials (Dayton, OH, USA) and Ocean NanoTech (San Diego, CA, USA), respectively. N-isopropylacrylamide (NIPAM), azobisisobutyronitrile (AIBN), mercaptoacetic acid (MAA), chitosan (deacetylation degree $=98 \%$, molecular weight $=1.5 \times 10^{5} \mathrm{Da}$ ), 2-morpholinoethane sulfonic acid (MES), 3-(4,5-dimethyl-2-thiazolyl)-2,5-diphenyl-2H-tetrazolium bromide, (MTT), 2,4,6-trinitrobenzene sulfonic acid (TNBS) and 4',6-diamidino-2-phenylindole dihydrochloride (DAPI), folic acid (FA), doxorubicin (DOX) hydrochloride were purchased from Sigma-Aldrich (St. Louis, MO, USA). 1-ethyl-3-(3-dimethylaminopropyl) carbodiimide (EDC) and $N$-hydroxysuccinimide (NHS) were obtained from Acros (Geel, Belgium). Potassium salt of D-luciferin was obtained from Gold Biotechnology, Inc. (New Taipei City, Taiwan). Hyaluronic acid (HA, sodium hyaluronate) from Streptococcus zooepidemicus with an average molecular weight of $1.8 \times 10^{6} \mathrm{Da}$ was purchased from Bloomage Freda Biopharm Co. (Jinan, China). Minimum Essential Medium ( $\alpha$-MEM, ThermoFisher Scientific, Waltham, MA, USA) and fetal bovine serum (FBS, HyClone, Logan, UT, USA) were used for cell culture.

\subsection{Preparation and Characterization of GO and GOFA}

\subsubsection{Preparation of GO, GOFA and Quantum Dot (QD)-Labeled GO and GOFA}

The preparation and modification of GO followed the modified Hummers' method [4,57]. Briefly, $1 \mathrm{~g}$ of GO was stirred in $23 \mathrm{~mL}$ sulfuric acid for $12 \mathrm{~h}$, followed by slowly adding $3 \mathrm{~g} \mathrm{KMnO}_{4}$ below $20^{\circ} \mathrm{C}$. The temperature was increased to $40^{\circ} \mathrm{C}$ while stirring for another $30 \mathrm{~min}$. The temperature was increased to $80^{\circ} \mathrm{C}$ and stirred for another $45 \mathrm{~min}$. $46 \mathrm{~mL}$ of distilled deionized water $\left(\mathrm{ddH}_{2} \mathrm{O}\right)$ was added and the solution was heated to $98-105^{\circ} \mathrm{C}$ for $30 \mathrm{~min}$, followed by cooling down to room temperature for $1 \mathrm{~h}$. Additional $\mathrm{ddH}_{2} \mathrm{O}(140 \mathrm{~mL})$ and $10 \mathrm{~mL}$ of $30 \% \mathrm{H}_{2} \mathrm{O}_{2}$ were added and reacted for $5 \mathrm{~min}$ at $40{ }^{\circ} \mathrm{C}$. After the reaction, GO was washed three times with $5 \%$ hydrochloride acid by centrifugation and dialyzed against $\mathrm{ddH}_{2} \mathrm{O}$ till the $\mathrm{pH}$ become neutral. Nano-sized GO was obtained 
by sonicating for $30 \mathrm{~min}$ at $800 \mathrm{~W}$ and filtered with a $0.2 \mu \mathrm{m}$ filter and adjusted the final concentration of the GO solution to $0.2 \mathrm{mg} / \mathrm{mL}$ for future modification.

Folic acid (FA) molecules were conjugated to GO through carbodiimide-mediated covalent bonds formation between carboxyl groups in GO and amine groups in FA [9,58]. In short, $0.1 \mathrm{mg}$ GO was mixed with $6 \mathrm{mM}$ EDC and $6 \mathrm{mM}$ NHS in $10 \mathrm{~mL}$ pH 6 phosphate buffered saline (PBS) for $1.5 \mathrm{~h}$ to activate the carboxyl groups in GO. One milliliter of FA solution $(0.1 \mathrm{mg} / \mathrm{mL})$ in $\mathrm{pH} 7.4$ PBS was added to above solution and allowed to react at room temperature for $2 \mathrm{~h}$ to react the amine groups in FA with activated carboxyl groups in GO. After centrifugation at $14,000 \times \mathrm{g}$ for $30 \mathrm{~min}$, the product was washed several times with $\mathrm{ddH}_{2} \mathrm{O}$ to remove unreacted reagents and then dried at room temperature. The amount of FA immobilized to GO was determined by subtracting the amount of FA left in the reacting and washing solutions from the amount of FA initially added. The concentration of FA in the solution was determined by UV-Vis spectroscopy at $358 \mathrm{~nm}$.

For preparing QD-labeled GO or GOFA, $0.5 \mathrm{~mL}$ of GO or GOFA $(1 \mathrm{mg} / \mathrm{mL})$ was reacted with $20 \mu \mathrm{L}$ of $8 \mu \mathrm{M}$ QDs and $0.05 \mathrm{~mL}$ of $60 \mathrm{mM}$ EDC and $0.05 \mathrm{~mL}$ of $60 \mathrm{mM} \mathrm{NHS}$ for $90 \mathrm{~min}$. After centrifugation at $14,000 \times g$ for $30 \mathrm{~min}$, the product was washed several times with PBS and dispersed in PBS for use.

\subsubsection{Characterization of GO, GOFA and GOFA-DOX}

An atomic force microscope (AFM) (XE-70, Park Systems, Santa Clara, CA, USA) was used to analyze the surface topography, size and thickness of samples. Diluted GO or GOFA in alcohol were deposited onto a freshly cleaved Mica substrate and imaged after alcohol evaporation. Transmission electron microscopy (TEM) images were taken using JEM-2000EXII TEM (JEOL, Tokyo, Japan). The Fourier transform infrared (FTIR) spectra were recorded on a FT-730 FTIR spectrometer (Horiba, Japan) by mixing samples with $\mathrm{KBr}$ and scanned from 400 to $4000 \mathrm{~cm}^{-1}$ at $2.5 \mathrm{~mm} / \mathrm{s}$.

\subsection{Preparation and Characterization of HACPN Hydrogel}

\subsubsection{Synthesis of HACPN Hydrogel}

The HACPN temperature-sensitive hydrogel was synthesized as described previously $[28,59]$. Briefly, NIPAM and AIBN were purified by recrystallization in n-hexane and methanol, respectively. PNIPAM end-capped with a carboxyl group (PNIPAM-COOH) was synthesized in benzene by free radical polymerization of NIPAM and MAA (chain transfer agent) in the presence of AIBN (initiator). PNIPAM-COOH was reacted with chitosan in $0.1 \mathrm{M}$ MES buffer ( $\mathrm{pH}$ 5.0) containing NHS and EDC to get chitosan-g-PNIPAM (CPN) copolymer. By thermally induced precipitation, the CPN copolymer was recovered by centrifugation. For HACPN synthesis, CPN copolymer was further reacted with HA in $0.1 \mathrm{M}$ MES buffer ( $\mathrm{pH}$ 5.0) containing EDC and NHS to get HACPN. Residual HA was removed by thermal precipitation of $\mathrm{HACPN}$ at $50{ }^{\circ} \mathrm{C}$, followed by dialysis (molecular weight cut-off (MWCO) $300,000)$ at $4{ }^{\circ} \mathrm{C}$ and lyophilization.

\subsubsection{Characterization of HACPN Hydrogel}

To determine the LCST, $10 \%(w / v)$ polymer solutions $(5 \%$ or $10 \%(w / v))$ were prepared in $\mathrm{ddH}_{2} \mathrm{O}$. The sol-gel phase transition of the polymer solution was measured using an UV-Vis spectrophotometer (Spectronic 200, Thermo Scientific, Waltham, MA, USA) equipped with a circulator bath for temperature control. A semi-micro cuvette (10 mm light path) containing $2 \mathrm{~mL}$ of polymer solution was used. The absorbance of the polymer solution at $470 \mathrm{~nm}$ was recorded from 25 to $33^{\circ} \mathrm{C}$. The polymer solution was equilibrated at each test temperature for $60 \mathrm{~min}$. From the thermo-precipitation curve by plotting the absorbance at $470 \mathrm{~nm}\left(\mathrm{OD}_{470}\right)$ vs. temperature, the LCST of the polymer was defined as the temperature when the absorbance was half of the maximum value.

For sol-gel phase transition kinetics, $2 \mathrm{~mL}$ of $5 \%$ or $10 \%(w / v)$ of polymer solutions in $\mathrm{ddH}_{2} \mathrm{O}$ were put in a semi-micro cuvette and sealed with Parafilm. The samples were equilibrated in a 
$25^{\circ} \mathrm{C}$ incubator for $60 \mathrm{~min}$ and then placed in an UV-Vis spectrophotometer pre-equilibrated at $37^{\circ} \mathrm{C}$. The turbidity of polymer solution was recorded as a function of time up to $6 \mathrm{~min}$.

For differential scanning calorimetry (DSC) analysis, $10 \mathrm{mg}$ polymer solutions prepared in $\mathrm{ddH}_{2} \mathrm{O}$ were placed in a DSC aluminum pan and analyzed with a Q20 DSC (TA Instruments, New Castle, DE, USA). The scan rate was $1{ }^{\circ} \mathrm{C} / \mathrm{min}$ from 10 to $40{ }^{\circ} \mathrm{C}$ under $30 \mathrm{~mL} / \mathrm{min}$ nitrogen.

For degradation of HACPN, $0.2 \mathrm{~mL}$ of $10 \%(w / v)$ HACPN hydrogel $(20 \mathrm{mg}$ HACPN) was placed in a pre-weighed Millicell ${ }^{\circledR}$ cell culture insert (Millipore) and immediately gelled at $37^{\circ} \mathrm{C}$. Five milliliters of PBS ( $\mathrm{pH} 7.4,37^{\circ} \mathrm{C}$ ) was added to the HACPN gel and the cell insert was shaken at $50 \mathrm{rpm}$ in a $37^{\circ} \mathrm{C}$ incubator. At different time points, samples were removed and rapidly frozen at $-80{ }^{\circ} \mathrm{C}$, followed by freeze-drying and weighing to obtain the residual weight of HACPN. The in vitro degradation of $\mathrm{HACPN}$ was calculated from the following equation,

$$
\text { Residual weight }(\%)=\left(\frac{W_{t}}{W_{\mathrm{i}}}\right) \times 100 \%
$$

where $W_{\mathrm{i}}$ is the initial weight of HACPN and $W_{t}$ is the weight of HACPN at time $t$.

\subsection{DOX Loading and Release}

\subsubsection{Loading of DOX on GOFA}

A solution containing DOX (0.1-3.0 mg) and $0.1 \mathrm{mg}$ of GOFA was prepared in $1 \mathrm{~mL}$ PBS ( $\mathrm{pH}$ 7.4) and stirred at $4{ }^{\circ} \mathrm{C}$ for $24 \mathrm{~h}$ in dark. The GOFA-DOX were collected by ultracentrifugation $(14,000 \times g$ for $15 \mathrm{~min})$ and washed three times with PBS until the supernatant became color-free. The amount of unbound DOX in the solution was determined by measuring the absorbance at $490 \mathrm{~nm}$ $\left(\mathrm{OD}_{490}\right)$. The drug loading efficiency $(\%)$ and the drug loading content is defined as,

$$
\begin{aligned}
\text { Loading effcienct }(\%) & =\frac{\text { Weight of loaded DOX }(\mathrm{mg})}{\text { Weight of initial DOX }(\mathrm{mg})} \times 100 \% \\
\text { Loading content } & =\frac{\text { Weight of loaded DOX }(\mathrm{mg})}{\text { Weight of GOFA }(\mathrm{mg})}
\end{aligned}
$$

\subsubsection{In Vitro DOX Release from GOFA-DOX and GOFA-DOX/HACPN}

For drug release, $0.1 \mathrm{mg} / \mathrm{mL}$ GOFA-DOX was prepared in $1 \mathrm{~mL}$ of phosphate buffered saline (PBS) at pH 5.7 (endosomal $\mathrm{pH}$ ) or at $\mathrm{pH} 7.4$ (physiological $\mathrm{pH}$ ) at $1.8 \mathrm{mg} / \mathrm{mL}$ DOX. The solution was shaken at $50 \mathrm{rpm}$ and $37^{\circ} \mathrm{C}$, followed by ultracentrifugation to separate GOFA-DOX at pre-determined times [60]. All supernatant was removed and replenished with an equal volume of PBS of the same $\mathrm{pH}$ for further drug release studies. The concentration of DOX in the supernatant was quantified using an enzyme-linked immunosorbent assay (ELISA) reader at $490 \mathrm{~nm}$. The DOX release results were calculated in a cumulative manner by the following equation [43],

$$
\text { Cumulative Dox released }(\%)=\left(\frac{\text { Cumulative amout of DOX released }}{\text { Initial amount of DOX }}\right) \times 100 \%
$$

The DOX release from GOFA-DOX/HACPN hydrogel was determined for $10 \%(w / v)$ HACPN by dissolving $0.1 \mathrm{~g}$ HACPN in $1 \mathrm{~mL}$ GOFA-DOX solution (0.1 mg/mL in pH 7.4 PBS). $0.5 \mathrm{~mL}$ of HACPN solution was placed in Millicell ${ }^{\circledR}$ cell culture inserts fitted in a 6-well cell culture plate. $5 \mathrm{~mL}$ of PBS buffer ( $\mathrm{pH}=7.4$ ) was added to each well to totally immerse the copolymer hydrogel in the insert and the plate was incubated at $37^{\circ} \mathrm{C}$ by shaking at $50 \mathrm{rpm}$. At predetermined times, all solution in each well was removed for determination of the DOX concentration using an ELISA reader at $490 \mathrm{~nm}$ and an equal volume of PBS buffer ( $\mathrm{pH}$ 7.4) was added to calculate the cumulative DOX release by Equation (4). 


\subsection{In Vitro Cell Culture}

\subsubsection{Cell Line and Cell Culture Condition}

The MCF-7 human breast adenocarcinoma cell line (BCRC 60436) was obtained from the Bioresource Collection and Research Center (Hsinchu, Taiwan). The cells were cultured in $\alpha$-MEM medium supplemented with $10 \% \mathrm{FBS}$ at $37{ }^{\circ} \mathrm{C}$ in a humidified $\mathrm{CO}_{2}$ incubator containing $5 \% \mathrm{CO}_{2}$. MCF-7 cells were sub-cultured routinely by using trypsin-ethylenediaminetetraacetic acid (EDTA) (Gibco, Thermo Fisher Scientific, Waltham, MA, USA) when cells reached 80-90\% confluence.

The MCF-7/Luc cell line that could stably expresses firefly luciferase and neomycin-resistant genes was constructed from pGL4.51[luc2/CMV/Neo] plasmid vector (Promega, Madison, WI, USA) [56]. MCF-7 cells were transfected with the Luc-reporter vector and liposome (E2431, Promega) using standard protocols. Transfected cells were selected with $1 \mathrm{mg} / \mathrm{mL}$ G418 (Sigma-Aldrich, St. Louis, MO, USA) selection antibiotic for two weeks and the resistant colonies were isolated and tested for luciferase activity.

\subsubsection{Intracellular Uptake}

To evaluate the role of FA in cellular uptake of GOFA, MCF-7 cells were cultured in $0.5 \mathrm{~mL}$ $\alpha$-MEM supplemented with $10 \%$ FBS in 24 -well culture plates at $1 \times 10^{4}$ cells $/$ well. Cells were grown overnight in a humidified $\mathrm{CO}_{2}$ incubator at $37^{\circ} \mathrm{C}$ under $5 \% \mathrm{CO}_{2}$ atmosphere, washed with sterilized PBS and incubated with $0.5 \mathrm{~mL}$ QD-labeled GO or GOFA suspension $(0.1 \mathrm{mg} / \mathrm{mL})$ for $1 \mathrm{~h}$. Each testing samples were washed with PBS three times and fixed with $4 \%$ paraformaldehyde for $15 \mathrm{~min}$, followed by nuclear staining with DAPI. In a separate experiment, the cells were pre-treated with free FA $(1 \mathrm{mg} / \mathrm{mL})$ for $1 \mathrm{~h}$ to block the folate receptor on cell surface before incubated with QD-labeled GOFA. Possible fluorescence signals from extracellular QD-labeled GOFA bound to the surfaces of MCF-7 cells were quenched by trypan blue dye solution for $15 \mathrm{~min}$. Since trypan blue is excluded from entering live cells, all fluorescence signals observed will be only from GOFA taken intracellularly. The green fluorescence from QD and blue fluorescence from DAPI were examined under a confocal laser scanning microscope (Zeiss LSM 510 Meta, Oberkochen, Germany) with excitation/emission wavelength of $488 \mathrm{~nm} / 500-550 \mathrm{~nm}$ and $364 \mathrm{~nm} / 407-482 \mathrm{~nm}$, respectively.

To determine intracellular uptake of GOFA-DOX and release of DOX, MCF-7 cells were cultured in $0.5 \mathrm{~mL} \alpha$-MEM supplemented with $10 \%$ FBS in 24 -well culture plates at $1 \times 10^{4}$ cells / well. Cells were grown overnight in a humidified $\mathrm{CO}_{2}$ incubator at $37^{\circ} \mathrm{C}$ under $5 \% \mathrm{CO}_{2}$ atmosphere, washed with sterilized PBS and incubated with $0.5 \mathrm{~mL}$ DOX solution or GOFA-DOX suspension $(0.1 \mathrm{mg} / \mathrm{mL})$ for $1 \mathrm{~h}$. Each testing samples were washed with PBS three times and fixed with $4 \%$ paraformaldehyde for $15 \mathrm{~min}$, followed by nuclear staining with DAPI (blue) and examination under a confocal laser scanning microscope. The uptake of GOFA-DOX and release of DOX could be visualized by the green fluorescence of QD-labeled GOFA and the red fluorescence of DOX. The excitation wavelength is $543 / 488 / 364 \mathrm{~nm}$ (red/green/blue) and the emission wavelength is 550-650/500-550/407-482 nm (red/green/blue).

For transmission electron microscope (TEM) analysis, $1 \times 10^{5}$ of MCF-7 cells were grown on ThermoNox (Nunc, Roskilde, Denmark) coverslips and treated with GOFA for $24 \mathrm{~h}$. The cells were fixed in a mixture of $2.5 \%$ paraformaldehyde and $2 \%$ glutaraldehyde solution for $2 \mathrm{~h}$. Cells were rinsed in $0.1 \mathrm{M}$ sodium cacodylate buffer ( $\mathrm{pH} 7.4$ ) and post-fixed in 1.0\% osmium tetroxide for $30 \mathrm{~min}$. The cells were then dehydrated in a graded ethanol series (30\%,50\%,70\% with 3\% uranyl acetate, 80\%, $95 \%$ and $100 \%$ ) for $10 \mathrm{~min}$ at each concentration and followed by two changes in $100 \%$ propylene oxide. After infiltration and embedding in epoxy resins at $60^{\circ} \mathrm{C}$ for $48 \mathrm{~h}$, ultrathin sections (approximately $80 \mathrm{~nm}$ ) were examined under a FEI/Philips CM 120 TEM (Hillsboro, OR, USA). 


\subsubsection{In Vitro Cytotoxicity Assessment}

For in vitro cytotoxicity tests, MCF-7 cells were cultured in $\alpha$-MEM supplemented with $10 \%$ FBS in a 96-well culture plate at a seeding density of $1 \times 10^{4}$ cells/well and incubated overnight at $37{ }^{\circ} \mathrm{C}$ in a humidified $5 \% \mathrm{CO}_{2}$ atmosphere. After being rinsed with PBS (pH 7.4), the cells were incubated with $200 \mu \mathrm{L}$ of DOX solutions, GO-DOX or GOFA-DOX suspensions prepared in culture medium containing different DOX concentrations to determine the IC50 (half-maximum inhibitory concentration) value. Cell viability after $24 \mathrm{~h}$ was determined using MTT assays by adding $50 \mu \mathrm{L}$ MTT reagent to each well and incubated for $3 \mathrm{~h}$ at $37^{\circ} \mathrm{C}$. After removing the medium and MTT reagent, $200 \mu \mathrm{L}$ of dimethylsulfoxide was added to the well to dissolve the crystal produced and the absorbance was measured at $540 \mathrm{~nm}$ using a Synergy HT microplate reader (BioTek, Winooski, VT, USA). Each experiment was repeated six times. All procedures were finished in conditions devoid of light. Cell viability using cell culture medium and GO (GOFA) were taken as $100 \%$ for DOX and GO-DOX (GOFA-DOX), respectively. Control cytotoxicity experiments to confirm the biocompatibility of the drug-free carrier were carried out using MCF-7 cells by following the same procedure as described above within a concentration range of $0.01-100 \mu \mathrm{g} / \mathrm{mL}$ GOFA.

The cytotoxicity of GOFA-DOX/HACPN was determined in a double-chamber dish with MCF-7 cells cultured in $\alpha$-MEM supplemented with 10\% FBS in a 24-well culture plate at a seeding density of $1 \times 10^{4}$ cells/well and incubated overnight at $37{ }^{\circ} \mathrm{C}$ in a humidified $5 \% \mathrm{CO}_{2}$ atmosphere. The GOFA/HACPN solution was prepared by dissolving $0.1 \mathrm{~g}$ HACPN in $1 \mathrm{~mL}$ GOFA-DOX solution (0.1 mg GOFA in pH 7.4 PBS) with $0,0.001$ or $0.025 \mathrm{mg} / \mathrm{mL}$ DOX). $0.2 \mathrm{~mL}$ of the GOFA-DOX/HACPN solution was placed in Millicell ${ }^{\circledR}$ cell culture inserts and fitted in the 24-well cell culture plate. The relative cell viability was determined by MTT assays at 24 and $72 \mathrm{~h}$ by MTT assays as described above with cell culture medium as control.

\subsubsection{Analysis of Apoptosis Using Annexin V and Propidium Iodide Staining}

Apoptotic MCF-7 cells were identified with fluorescein isothiocyanate-labeled Annexin V (Annexin V-FITC, BD Biosciences, Franklin Lakes, NJ, USA). Propidium iodide (PI) was also used as a dead cell marker. MCF-7 $\left(5 \times 10^{5}\right.$ cells per well) were seeded in a six-well plate and cultured for $24 \mathrm{~h}$. After treatment with free DOX, GO-DOX and GOFA-DOX for $24 \mathrm{~h}$, the cells were harvested, trypsinized, washed with PBS and incubated with Annexin V-FITC and PI for $15 \mathrm{~min}$ at room temperature in the dark. The samples were immediately analyzed with the FACSCalibur flow cytometer (BD Biosciences, Franklin Lakes, NJ, USA) with the CellQuest software.

\subsection{Animal Studies}

\subsubsection{Xenograft Tumor Mouse Model}

All animal procedures were approved by the Institutional Animal Care and Use Committee of Chang Gung University (IACUC Approval No. CGU14-092). Female nude mice (BALB/ cAnN.Cg-Foxn1nu/CrlNarl, 4-6 weeks old, weighed between 20 and $25 \mathrm{~g}$ ) were purchased from the National Laboratory Animal Center (Taipei, Taiwan) and used for the in vivo animal studies. Mice were cared, housed and maintained in specific sterile environment in the Laboratory Animal Center, Chang Gung University. Estrogen-responsive MCF-7 xenograft tumor model was established and maintained by injecting $5 \times 10^{6} \mathrm{MCF}-7$ cells (in $0.1 \mathrm{~mL}$ of Matrigel Matrix High Concentration, BD Biosciences, Franklin Lakes, NJ, USA) subcutaneously into the backs of the 6-week-old mice after anesthetized with $5 \mathrm{mg} / \mathrm{kg}$ xylazine (Rompum, Bayer) and $0.8 \mathrm{mg} / \mathrm{kg}$ Tiletamin + Zolezepam (Zoletil 50, Virbac) [61]. Animals were used in experiments after 14 days when the tumor volumes reached $60 \sim 100 \mathrm{~mm}^{3}$. 


\subsubsection{In Vivo Antitumor Efficacy}

Thirty tumor-bearing mice were randomly divided into 5 groups with 6 mice in each group. Group 1, intratumoral injection with $200 \mu \mathrm{L}$ of saline (control); group 2, intratumoral injection with $200 \mu \mathrm{L}$ of $10 \%(w / v)$ GOFA/HACPN; group 3, intratumoral injection with $200 \mu \mathrm{L}$ of DOX solution (30 mg/kg of DOX); group 4, intravenous injection with $200 \mu \mathrm{L}$ of GOFA-DOX (30 mg/kg of DOX); group 5, intratumoral injection with $200 \mu \mathrm{L}$ of $10 \%(w / v)$ GOFA-DOX/HACPN (30 mg/kg of DOX). After administration, the tumor size and body weight was monitored continuously for 21 days. Tumor volumes were calculated based on the length and width of tumor (length $\times(\text { width })^{2} / 2$ ). The relative of tumor volume (\%) was calculated from $V_{t} / V_{0}$, where $V_{t}$ indicated the tumor volume at time $t$ and $V_{0}$ indicated the tumor volume at day 0 . The relative body weight (\%) was calculated according to $W_{t} / W_{0}$, where $W_{t}$ indicated the weight at time $t$ and $W_{0}$ indicated the weight at day 0 .

\subsubsection{Histological, Immunohistochemical, Hematologic and Biochemical Analysis}

After sacrificing, tumor tissues were immediately harvested and fixed in 10\% phosphate buffered formalin. The tissues were embedded in paraffin and sectioned $(8 \mu \mathrm{m})$, followed by hematoxylin and eosin (H\&E) staining. Paraffin-embedded tumor tissues were stained for proliferating cell nuclear antigen (PCNA) using N-Histofine ${ }^{\circledR}$ MOUSESTAIN KIT (Nichirei Biosciences Inc., Tokyo, Japan) following the manufacturer's protocol [62]. The primary antibody was mouse monoclonal anti-PCNA antibody (Abcam ab29).

To evaluate the systemic toxicity of GOFA-DOX/HACPN, major organs including hearts, livers, spleens, lungs and kidneys were harvested before euthanasia and embedded in paraffin and sectioned for H\&E staining. Blood samples were collected for hematologic analysis (white blood cell count, red blood cell count, hemoglobin and hematocrit) and biochemical analysis (aspartate aminotransferase, alanine aminotransferase, blood urea nitrogen and creatinine) of major organ functions. The mice in the control group (saline) were used as comparison.

\subsubsection{Bioluminescence Imaging (BLI) for In Vivo Evaluation of Anti-Tumor Efficacy}

MCF-7/Luc cells were injected subcutaneously into the backs of the 6-week-old mice following and animal were grouped as described for MCF-7 cells. The bioluminescence imaging (BLI) was performed using noninvasive in vivo imaging system (IVIS) (Xenogen IVIS-200, Caliper Life Sciences, Hopkinton, MA, USA). Mice were anesthetized with 1\% isoflurane in room air. D-Luciferin (Gold Biotechnology, New Taipei City, Taiwan) in PBS (15 mg/mL) was injected intraperitoneally at a dose of $150 \mathrm{mg} / \mathrm{kg}$ and images were acquired to determine the peak bioluminescence. The BLI intensity was determined at baseline (i.e., before treatment) and 21 days after treatment by measuring the total peak bioluminescent signal intensity through standardized regions of interest (ROIs) in tumor by using the Living Image ${ }^{\circledR} 4.0$ software (PerkinElmer, Waltham, MA, USA). The relative BLI (\%) was calculated from the total bioluminescent signal intensity at day 21 normalized by the total signal intensity at baseline.

\subsection{Statistical Analyses}

All data were reported as mean \pm standard deviation (SD). Statistical significances were analyzed by Statistical Product and Service Solutions (SPSS) one-way ANOVA Least Significant Difference (LSD) test and differences were considered significant at $p<0.05$.

\section{Conclusions}

In conclusion, we have confirmed the synthesis of the nano-sized anticancer drug carrier GOFA, the intracellular uptake of GOFA by endocytosis and the specific targeting effect of GOFA toward MCF-7 breast cancer cells. The high loading capacity of DOX on GOFA in addition to the pH-dependent drug release behavior could facilitate drug release after endocytosis and maintain a high drug 
concentration cytotoxic to MCF-7 cells. The temperature-sensitive in-situ forming hydrogel HACPN could provide fast sol-gel phase transition kinetics around the physiological temperature. The gelled HACPN could serve as a depot for continuous GOFA-DOX release during hydrogel degradation and offer a facile intratumoral delivery platform for the chemotherapeutic drug. Enhanced cytotoxicity of GOFA-DOX toward MCF-7 was confirmed through MTT assays and flow cytometry analysis, which could be ascribed to the FA-targeting effect. GOFA-DOX/HACPN also showed effective drug dosage and time-dependent cytotoxicity effects in vitro, suggesting its potential for in vivo anticancer therapy. From xenograft tumor mouse model with subcutaneously implanted MCF-7 (MCF-7/Luc) cells, tumor volume measurement and BLI signal intensity revealed the highest anticancer efficiency of GOFA-DOX/HACPN. H\&E staining and immunohistochemistry of tumor tissues confirmed this treatment could result in the best effect to induce tumor necrosis and reduction of expression of the tumor cell proliferating marker (PCNA). In addition, no side effects were detected from biopsy of major organs and blood analysis to endorse the safety of this treatment. Taken together, we could conclude the intratumoral delivery of GOFA-DOX/HACPN could be suggested as a safe and effective drug delivery system for breast cancer chemotherapy or potentially also applicable to treatment of other local solid tumors.

Acknowledgments: We would like to express our appreciation of financial supports provided by Change Gung Memorial Hospital (CMRPD3E0272, CMRPD2G0081 and BMRP249) and the Ministry of Science and Technology (NERPD2C0461, MOST-106-2221-E-182-056-MY3). The Microscope Core Laboratory in Change Gung Memorial Hospital, Linkou, is acknowledged for the assistance in microscopic studies.

Author Contributions: Chih-Hao Chen and Jyh-Ping Chen conceived and designed the experiments; Yi Teng Fong and Chih-Hao Chen performed the experiments; Yi Teng Fong and Chih-Hao Chen analyzed the data; Yi Teng Fong and Jyh-Ping Chen wrote the paper.

Conflicts of Interest: The authors declare no conflict of interest.

\section{References}

1. Govindan, B.; Swarna Latha, B.; Nagamony, P.; Ahmed, F.; Saifi, M.A.; Harrath, A.H.; Alwasel, S.; Mansour, L.; Alsharaeh, E.H. Designed synthesis of nanostructured magnetic hydroxyapatite based drug nanocarrier for anti-cancer drug delivery toward the treatment of human epidermoid carcinoma. Nanomaterials 2017, 7, 138. [CrossRef] [PubMed]

2. Martínez-Carmona, M.; Colilla, M.; Vallet-Regí, M. Smart mesoporous nanomaterials for antitumor therapy. Nanomaterials 2015, 5, 1906-1937. [CrossRef] [PubMed]

3. Debbage, P. Targeted drugs and nanomedicine: Present and future. Curr. Pharm. Des. 2009, 15, $153-172$. [CrossRef] [PubMed]

4. Lu, Y.-J.; Yang, H.-W.; Hung, S.-C.; Huang, C.-Y.; Li, S.-M.; Ma, C.; Chen, P.-Y.; Tsai, H.-C.; Wei, K.-C.; Chen, J.-P. Improving thermal stability and efficacy of BCNU in treating glioma cells using PAA-functionalized graphene oxide. Int. J. Nanomed. 2012, 7, 1737-1747.

5. Wang, Y.; Li, Z.; Wang, J.; Li, J.; Lin, Y. Graphene and graphene oxide: Biofunctionalization and applications in biotechnology. Trends Biotechnol. 2011, 29, 205-212. [CrossRef] [PubMed]

6. Yang, X.; Zhang, X.; Ma, Y.; Huang, Y.; Wang, Y.; Chen, Y. Superparamagnetic graphene oxide--Fe $\mathrm{O}_{4}$ nanoparticles hybrid for controlled targeted drug carriers. J. Mater. Chem. 2009, 19, 2710-2714. [CrossRef]

7. Sun, X.; Liu, Z.; Welsher, K.; Robinson, J.T.; Goodwin, A.; Zaric, S.; Dai, H. Nano-graphene oxide for cellular imaging and drug delivery. Nano Res. 2008, 1, 203-212. [CrossRef] [PubMed]

8. Liu, Z.; Robinson, J.T.; Sun, X.; Dai, H. Pegylated nanographene oxide for delivery of water-insoluble cancer drugs. J. Am. Chem. Soc. 2008, 130, 10876-10877. [CrossRef] [PubMed]

9. Zhang, L.; Xia, J.; Zhao, Q.; Liu, L.; Zhang, Z. Functional graphene oxide as a nanocarrier for controlled loading and targeted delivery of mixed anticancer drugs. Small 2010, 6, 537-544. [CrossRef] [PubMed]

10. Yang, X.; Zhang, X.; Liu, Z.; Ma, Y.; Huang, Y.; Chen, Y. High-efficiency loading and controlled release of doxorubicin hydrochloride on graphene oxide. J. Phys. Chem. C 2008, 112, 17554-17558. [CrossRef] 
11. Ma, N.; Zhang, B.; Liu, J.; Zhang, P.; Li, Z.; Luan, Y. Green fabricated reduced graphene oxide: Evaluation of its application as nano-carrier for $\mathrm{pH}$-sensitive drug delivery. Int. J. Pharm. 2015, 496, 984-992. [CrossRef] [PubMed]

12. Wu, S.Y.; An, S.S.; Hulme, J. Current applications of graphene oxide in nanomedicine. Int. J. Nanomed. 2015, 10, 9-24.

13. Bae, K.H.; Chung, H.J.; Park, T.G. Nanomaterials for cancer therapy and imaging. Mol. Cells 2011, 31, 295-302. [CrossRef] [PubMed]

14. Cho, K.; Wang, X.; Nie, S.; Shin, D.M. Therapeutic nanoparticles for drug delivery in cancer. Clin. Cancer Res. 2008, 14, 1310-1316. [CrossRef] [PubMed]

15. Wu, B.; Zhao, N. A Targeted nanoprobe based on carbon nanotubes-natural biopolymer chitosan composites. Nanomaterials 2016, 6, 216. [CrossRef] [PubMed]

16. Sahu, S.K.; Mallick, S.K.; Santra, S.; Maiti, T.K.; Ghosh, S.K.; Pramanik, P. In vitro evaluation of folic acid modified carboxymethyl chitosan nanoparticles loaded with doxorubicin for targeted delivery. J. Mater. Sci. Mater. Med. 2010, 21, 1587-1597. [CrossRef] [PubMed]

17. Yang, C.L.; Chen, J.P.; Wei, K.C.; Chen, J.Y.; Huang, C.W.; Liao, Z.X. Release of doxorubicin by a folate-grafted, chitosan-coated magnetic nanoparticle. Nanomaterials 2017, 7, 85. [CrossRef] [PubMed]

18. Lu, Y.J.; Wei, K.C.; Ma, C.C.; Yang, S.Y.; Chen, J.P. Dual targeted delivery of doxorubicin to cancer cells using folate-conjugated magnetic multi-walled carbon nanotubes. Colloids Surf. B Biointerfaces 2012, 89, 1-9. [CrossRef] [PubMed]

19. Liow, S.S.; Dou, Q.; Kai, D.; Karim, A.A.; Zhang, K.; Xu, F.; Loh, X.J. Thermogels: In situ gelling biomaterial. ACS Biomater. Sci. Eng. 2016, 2, 295-316. [CrossRef]

20. Rzaev, Z.M.; Dincer, S.; Pişkin, E. Functional copolymers of $N$-isopropylacrylamide for bioengineering applications. Prog. Polym. Sci. 2007, 32, 534-595. [CrossRef]

21. Okano, T.; Yamada, N.; Sakai, H.; Sakurai, Y. A novel recovery system for cultured cells using plasma-treated polystyrene dishes grafted with poly(N-isopropylacrylamide). J. Biomed. Mater. Res. 1993, 27, 1243-1251. [CrossRef] [PubMed]

22. Gil, E.S.; Hudson, S.M. Stimuli-responsive polymers and their bioconjugates. Prog. Polym. Sci. 2004, 29, 1173-1222. [CrossRef]

23. Fakhari, A.; Subramony, J.A. Engineered in-situ depot-forming hydrogels for intratumoral drug delivery. J. Control. Release 2015, 220, 465-475. [CrossRef] [PubMed]

24. Wolinsky, J.B.; Colson, Y.L.; Grinstaff, M.W. Local drug delivery strategies for cancer treatment: Gels, nanoparticles, polymeric films, rods and wafers. J. Control. Release 2012, 159, 14-26. [CrossRef] [PubMed]

25. Kempe, S.; Mäder, K. In situ forming implants—An attractive formulation principle for parenteral depot formulations. J. Control. Release 2012, 161, 668-679. [CrossRef] [PubMed]

26. Loh, X.J.; Li, J. Biodegradable thermosensitive copolymer hydrogels for drug delivery. Expert Opin. Ther. Pat. 2007, 17, 965-977. [CrossRef]

27. Wu, W.; Chen, H.; Shan, F.; Zhou, J.; Sun, X.; Zhang, L.; Gong, T. A novel doxorubicin-loaded in situ forming gel based high concentration of phospholipid for intratumoral drug delivery. Mol. Pharm. 2014, 11, 3378-3385. [CrossRef] [PubMed]

28. Chen, J.-P.; Cheng, T.-H. Preparation and evaluation of thermo-reversible copolymer hydrogels containing chitosan and hyaluronic acid as injectable cell carriers. Polymer 2009, 50, 107-116. [CrossRef]

29. Huang, Y.-S.; Lu, Y.-J.; Chen, J.-P. Magnetic graphene oxide as a carrier for targeted delivery of chemotherapy drugs in cancer therapy. J. Magn. Magn. Mater. 2017, 427, 34-40. [CrossRef]

30. Zhi, F.; Dong, H.; Jia, X.; Guo, W.; Lu, H.; Yang, Y.; Ju, H.; Zhang, X.; Hu, Y. Functionalized graphene oxide mediated adriamycin delivery and miR-21 gene silencing to overcome tumor multidrug resistance in vitro. PLoS ONE 2013, 8, e60034. [CrossRef] [PubMed]

31. Lu, C.-H.; Zhu, C.-L.; Li, J.; Liu, J.-J.; Chen, X.; Yang, H.-H. Using graphene to protect DNA from cleavage during cellular delivery. Chem. Commun. 2010, 46, 3116-3118. [CrossRef] [PubMed]

32. Chen, J.P.; Cheng, T.H. Thermo-responsive chitosan-graft-poly( $N$-isopropylacrylamide) injectable hydrogel for cultivation of chondrocytes and meniscus cells. Macromol. Biosci. 2006, 6, 1026-1039. [CrossRef] [PubMed]

33. Fang, J.Y.; Chen, J.P.; Leu, Y.L.; Hu, J.W. Temperature-sensitive hydrogels composed of chitosan and hyaluronic acid as injectable carriers for drug delivery. Eur. J. Pharm. Biopharm. 2008, 68, 626-636. [CrossRef] [PubMed] 
34. Feil, H.; Bae, Y.H.; Feijen, J.; Kim, S.W. Effect of comonomer hydrophilicity and ionization on the lower critical solution temperature of $N$-isopropylacrylamide copolymers. Macromolecules 1993, 26, 2496-2500. [CrossRef]

35. Gao, Y.; Yang, J.; Ding, Y.; Ye, X. Effect of urea on phase transition of poly(N-isopropylacrylamide) investigated by differential scanning calorimetry. J. Phys. Chem. B 2014, 118, 9460-9466. [CrossRef] [PubMed]

36. Kamath, K.R.; Park, K. Biodegradable hydrogels in drug delivery. Adv. Drug Deliv. Rev. 1993, 11, 59-84. [CrossRef]

37. Cho, J.K.; Hong, K.Y.; Park, J.W.; Yang, H.K.; Song, S.C. Injectable delivery system of 2-methoxyestradiol for breast cancer therapy using biodegradable thermosensitive poly(organophosphazene) hydrogel. J. Drug Target. 2011, 19, 270-280. [CrossRef] [PubMed]

38. Li, R.; Wu, R.A.; Zhao, L.; Hu, Z.; Guo, S.; Pan, X.; Zou, H. Folate and iron difunctionalized multiwall carbon nanotubes as dual-targeted drug nanocarrier to cancer cells. Carbon 2011, 49, 1797-1805. [CrossRef]

39. Zhou, T.; Zhou, X.; Xing, D. Controlled release of doxorubicin from graphene oxide based charge-reversal nanocarrier. Biomaterials 2014, 35, 4185-4194. [CrossRef] [PubMed]

40. Depan, D.; Shah, J.; Misra, R. Controlled release of drug from folate-decorated and graphene mediated drug delivery system: Synthesis, loading efficiency and drug release response. Mater. Sci. Eng. C 2011, 31, 1305-1312. [CrossRef]

41. Saul, J.M.; Annapragada, A.; Natarajan, J.V.; Bellamkonda, R.V. Controlled targeting of liposomal doxorubicin via the folate receptor in vitro. J. Control. Release 2003, 92, 49-67. [CrossRef]

42. Wong, H.L.; Rauth, A.M.; Bendayan, R.; Manias, J.L.; Ramaswamy, M.; Liu, Z.; Erhan, S.Z.; Wu, X.Y. A new polymer-lipid hybrid nanoparticle system increases cytotoxicity of doxorubicin against multidrug-resistant human breast cancer cells. Pharm. Res. 2006, 23, 1574-1585. [CrossRef] [PubMed]

43. Manaspon, C.; Viravaidya-Pasuwat, K.; Pimpha, N. Preparation of folate-conjugated Pluronic F127/chitosan core-shell nanoparticles encapsulating doxorubicin for breast cancer treatment. J. Nanomater. 2012, 2012, 22. [CrossRef]

44. Lee, D.-G.; Ponvel, K.M.; Kim, M.; Hwang, S.; Ahn, I.-S.; Lee, C.-H. Immobilization of lipase on hydrophobic nano-sized magnetite particles. J. Mol. Catal. B Enzym. 2009, 57, 62-66. [CrossRef]

45. Zunino, F.; Di Marco, A.; Zaccara, A.; Luoni, G. The inhibition of RNA polymerase by daunomycin. Chem.-Biol. Interact. 1974, 9, 25-36. [CrossRef]

46. Frederick, C.A.; Williams, L.D.; Ughetto, G.; Van der Marel, G.A.; Van Boom, J.H.; Rich, A.; Wang, A.-J. Structural comparison of anticancer drug-DNA complexes: Adriamycin and daunomycin. Biochemistry 1990, 29, 2538-2549. [CrossRef] [PubMed]

47. Meyn, M.S. Ataxia-telangiectasia and cellular responses to DNA damage. Cancer Res. 1995, 55, 5991-6001. [PubMed]

48. Kim, J.I.; Lee, B.S.; Chun, C.; Cho, J.-K.; Kim, S.-Y.; Song, S.-C. Long-term theranostic hydrogel system for solid tumors. Biomaterials 2012, 33, 2251-2259. [CrossRef] [PubMed]

49. Frishman, W.H.; Yee, H.C.M.; Keefe, D.; Sung, H.M.; Liu, L.L.; Einzig, A.I.; Dutcher, J. Cardiovascular toxicity with cancer chemotherapy. Curr. Probl. Cancer 1997, 21, 301-360. [CrossRef]

50. Luo, J.W.; Zhang, T.; Zhang, Q.; Cao, X.; Zeng, X.; Fu, Y.; Zhang, Z.R.; Gong, T. A novel injectable phospholipid gel co-loaded with doxorubicin and bromotetrandrine for resistant breast cancer treatment by intratumoral injection. Colloids Surf. B Biointerfaces 2016, 140, 538-547. [CrossRef] [PubMed]

51. Seabra, A.B.; Paula, A.J.; de Lima, R.; Alves, O.L.; Durán, N. Nanotoxicity of graphene and graphene oxide. Chem. Res. Toxicol. 2014, 27, 159-168. [CrossRef] [PubMed]

52. Kean, T.; Thanou, M. Biodegradation, biodistribution and toxicity of chitosan. Adv. Drug Deliv. Rev. 2010, 62, 3-11. [CrossRef] [PubMed]

53. Fakhari, A.; Berkland, C. Applications and emerging trends of hyaluronic acid in tissue engineering, as a dermal filler and in osteoarthritis treatment. Acta Biomater. 2013, 9, 7081-7092. [CrossRef] [PubMed]

54. Kohori, F.; Sakai, K.; Aoyagi, T.; Yokoyama, M.; Sakurai, Y.; Okano, T. Preparation and characterization of thermally responsive block copolymer micelles comprising poly( $N$-isopropylacrylamide- $b$-DL-lactide). J. Control. Release 1998, 55, 87-98. [CrossRef]

55. Patenaude, M.; Hoare, T. Injectable, degradable thermoresponsive poly( $N$-isopropylacrylamide) hydrogels. ACS Macro Lett. 2012, 1, 409-413. [CrossRef] 
56. Tiffen, J.C.; Bailey, C.G.; Ng, C.; Rasko, J.E.; Holst, J. Luciferase expression and bioluminescence does not affect tumor cell growth in vitro or in vivo. Mol. Cancer 2010, 9, 299. [CrossRef] [PubMed]

57. Hummers, W.S., Jr.; Offeman, R.E. Preparation of graphitic oxide. J. Am. Chem. Soc. 1958, 80, 1339. [CrossRef]

58. Huang, P.; Xu, C.; Lin, J.; Wang, C.; Wang, X.; Zhang, C.; Zhou, X.; Guo, S.; Cui, D. Folic acid-conjugated graphene oxide loaded with photosensitizers for targeting photodynamic therapy. Theranostics 2011, 1, 240-250. [CrossRef] [PubMed]

59. Liao, H.-T.; Chen, C.-T.; Chen, J.-P. Osteogenic differentiation and ectopic bone formation of canine bone marrow-derived mesenchymal stem cells in injectable thermo-responsive polymer hydrogel. Tissue Eng. Part C Methods 2011, 17, 1139-1149. [CrossRef] [PubMed]

60. Grenha, A.; Seijo, B.; Remunán-López, C. Microencapsulated chitosan nanoparticles for lung protein delivery. Eur. J. Pharm. Sci. 2005, 25, 427-437. [CrossRef] [PubMed]

61. Wang, T.; Hartner, W.C.; Gillespie, J.W.; Praveen, K.P.; Yang, S.; Mei, L.A.; Petrenko, V.A.; Torchilin, V.P. Enhanced tumor delivery and antitumor activity in vivo of liposomal doxorubicin modified with MCF-7-specific phage fusion protein. Nanomed. Nanotechnol. Biol. Med. 2014, 10, 421-430. [CrossRef] [PubMed]

62. Xie, Y.; Long, Q.; Wu, Q.; Shi, S.; Dai, M.; Liu, Y.; Liu, L.; Gong, C.; Qian, Z.; Wei, Y. Improving therapeutic effect in ovarian peritoneal carcinomatosis with honokiol nanoparticles in a thermosensitive hydrogel composite. RSC Adv. 2012, 2, 7759-7771. [CrossRef]

(C) 2017 by the authors. Licensee MDPI, Basel, Switzerland. This article is an open access article distributed under the terms and conditions of the Creative Commons Attribution (CC BY) license (http:/ / creativecommons.org/licenses/by/4.0/). 
Article

\title{
Enhanced Delivery of Therapeutic siRNA into Glioblastoma Cells Using Dendrimer-Entrapped Gold Nanoparticles Conjugated with $\beta$-Cyclodextrin
}

\author{
Jieru Qiu ${ }^{1,2}$, Lingdan Kong ${ }^{2}$, Xueyan Cao ${ }^{2}$, Aijun $\mathrm{Li}^{2}{ }^{2}$, Ping Wei ${ }^{2}$, Lu Wang ${ }^{2}$, \\ Serge Mignani ${ }^{3,4, *}$, Anne-Marie Caminade ${ }^{5,6}$, Jean-Pierre Majoral ${ }^{5,6, *}$ and Xiangyang Shi ${ }^{1,2,4, *}$ \\ 1 Department of Radiology, Shanghai Tenth People's Hospital, Tongji University School of Medicine, \\ Shanghai 200072, China; jieruq@outlook.com \\ 2 College of Chemistry, Chemical Engineering and Biotechnology, Donghua University, Shanghai 201620, \\ China; lingdankong@hotmail.com (L.K.); caoxy_116@dhu.edu.cn (X.C.); andrewaijun.lee@gmail.com (A.L.); \\ weiping876@hotmail.com (P.W.); wanglu2013@dhu.edu.cn (L.W.) \\ 3 Université Paris Descartes, PRES Sorbonne Paris Cité, CNRS UMR 860, Laboratoire de Chimie et de \\ Biochimie Pharmacologiques et Toxicologique, 45, rue des Saints Peres, 75006 Paris, France \\ 4 CQM-Centro de Química da Madeira, MMRG, Universidade da Madeira, Campus da Penteada, \\ 9020-105 Funchal, Portugal \\ 5 Laboratoire de Chimie de Coordination du CNRS, 205 Route de Narbonne, BP 44099, \\ 31077 Toulouse CEDEX 4, France; anne-marie.caminade@lcc-toulouse.fr \\ 6 Université de Toulouse, UPS, INPT, 31077 Toulouse CEDEX 4, France \\ * Correspondence: serge_mignani@orange.fr (S.M.); majoral@lcc-toulouse.fr (J.-P.M.); xshi@dhu.edu.cn (X.S.); \\ Tel.: +86-21-67792656 (X.S.)
}

Received: 8 January 2018; Accepted: 29 January 2018; Published: 27 February 2018

\begin{abstract}
We describe a safe and highly effective non-viral vector system based on $\beta$-cyclodextrin $(\beta-C D)$-modified dendrimer-entrapped gold nanoparticles (Au DENPs) for improved delivery small interfering RNA (siRNA) to glioblastoma cells. In our approach, we utilized amine-terminated generation 5 poly (amidoamine) dendrimers partially grafted with $\beta-C D$ as a nanoreactor to entrap $A u$ NPs. The acquired $\beta$-CD-modified Au DENPs (Au DENPs- $\beta$-CD) were complexed with two different types of therapeutic siRNA (B-cell lymphoma/leukemia-2 (Bcl-2) siRNA and vascular endothelial growth factor (VEGF) siRNA). The siRNA compression ability of the Au DENPs- $\beta$-CD was evaluated by various methods. The cytocompatibility of the vector/siRNA polyplexes was assessed by viability assay of cells. The siRNA transfection capability of the formed Au DENPs- $\beta$-CD vector was evaluated by flow cytometric assay of the cellular uptake of the polyplexes and Western blot assays of the $\mathrm{Bcl}-2$ and VEGF protein expression. Our data reveals that the formed Au DENPs- $\beta$-CD carrier enables efficiently delivery of siRNA to glioma cells, has good cytocompatibility once complexed with the siRNA, and enables enhanced gene silencing to inhibit the expression of Bcl-2 and VEGF proteins. The developed Au DENPs- $\beta$-CD vector may be used for efficient siRNA delivery to different biosystems for therapeutic purposes.
\end{abstract}

Keywords: PAMAM dendrimers; $\beta$-CD; gold nanoparticles; gene silencing; siRNA

\section{Introduction}

Gene therapy is becoming a promising strategy for cancer therapy by transfecting genetic materials (such as DNA [1-3], RNA [4,5] and antisense oligonucleotides [6,7]) into target cancer cells to achieve the therapeutic purposes. Among that, RNA interference has been considered as one of the most potential strategies for cancer therapy through silencing the specific genes up-regulated in cancer 
cells or involved in cell division [8,9]. Small interfering RNA (siRNA) has played a central role for RNA interference.

For efficient siRNA delivery, one has to consider to use a carrier system owing to the electrostatic repulsion of the negatively-charged cell membrane and the negatively-charged siRNA backbone [10,11]. For gene delivery, non-viral vectors are increasingly employed considering their better bio-safety profile than viral ones, relative ease to be synthesized, targeting specificity to cell/tissue after surface modification [12-14], structural diversity, and capacity to transfect plasmid of varying sizes $[15,16]$. The currently used non-viral vectors such as cationic lipids $[17,18]$, polymers $[12,19,20]$, polypeptides [21,22], and inorganic nanoparticles (NPs) $[23,24]$ can be used to form vector/DNA polyplexes at the nanoscale $[10,11,25]$. In any case, development of novel vector systems for safe and effective transfection of siRNA still remains a critical research area [26-32].

Poly(amidoamine) (PAMAM) dendrimers are a class of monodispersed macromolecules [33-35] with branched interior and well-fixed molecular conformation and controlled surface functionalities [36-39]. These properties of PAMAM dendrimers make them act as desired carrier systems for non-viral siRNA delivery [13,40-42]. In this direction, several studies have reported that by functional modifications of generation 5 (G5) PAMAM dendrimers via dendrimer periphery modification of polyethylene glycol chains [43] or entrapment of gold (Au) NPs within dendrimer internal cavities [44], the cytotoxicity of the vector has been significantly reduced, while the gene transfection efficiency has been prominently enhanced [14,44-47]. Previously, we have shown that the Au NP entrapment within G5 PAMAM dendrimers to form dendrimer-entrapped Au NPs (Au DENPs) is beneficial to reduce the cytotoxicity of dendrimers and simultaneously enhance the gene delivery efficiency [44]. On one hand, the entrapped $\mathrm{Au}$ NPs are able to compensate the dendrimer terminal amine cytotoxicity by reducing the density of amine groups, thus improving the cytocompatibility of the dendrimers; on the other hand, the Au NPs entrapped helps to maintain the globular conformation of the dendrimer, thereby enhancing the compaction capacity of DNA.

Recently, we have used $\beta$-cyclodextrin ( $\beta$-CD) to modify the surface of G5 PAMAM dendrimers and used the $\beta$-CD-modified G5 dendrimers for the synthesis of Au NPs within the dendrimers [48]. The prepared $\beta$-CD-modified Au DENPs (Au DENPs- $\beta-C D$ ) displayed weakened cytotoxicity and enhanced DNA compression capability, and enabled the enhanced transfection of plasmid DNA (pDNA) encoding either luciferase gene or enhanced the green fluorescent protein gene into 293T cells. The enhanced gene delivery efficiency could be resulted from the entrapped Au NPs. Meanwhile, the attached $\beta$-CD moieties might facilitate the release of pDNA or the siRNA complex from endosomes after endocytic uptake [49]. These promising results strongly stimulate us to further explore the performance of the Au DENPs- $\beta-C D$ to deliver siRNA to silence genes in cancer cells.

In this work, we prepared the Au DENPs- $\beta$-CD vector according to the procedure previously reported [48]. The prepared Au DENPs- $\beta$-CD were employed as a vector to compact two different types of siRNA including B-cell lymphoma 2 (Bcl-2) siRNA and vascular endothelial growth factor (VEGF) siRNA under the appropriate N/P (dendrimer terminal amine/siRNA phosphate) ratios for oncogene silencing (Scheme 1). The siRNA compaction ability of the vector was explored by gel electrophoresis, dynamic light scattering, and zeta potential measurements. The cytocompatibility of the prepared vector/siRNA polyplexes was also analyzed by cell viability assay. Furthermore, flow cytometry assay and confocal microscopic observations of cells were used to assess the efficiency of gene transfection of the vector/siRNA polyplexes. Finally, we used Western blot assay to prove the oncogene silencing efficiency of the Au DENPs- $\beta-C D /$ siRNA polyplexes in glioblastoma cancer cells. 


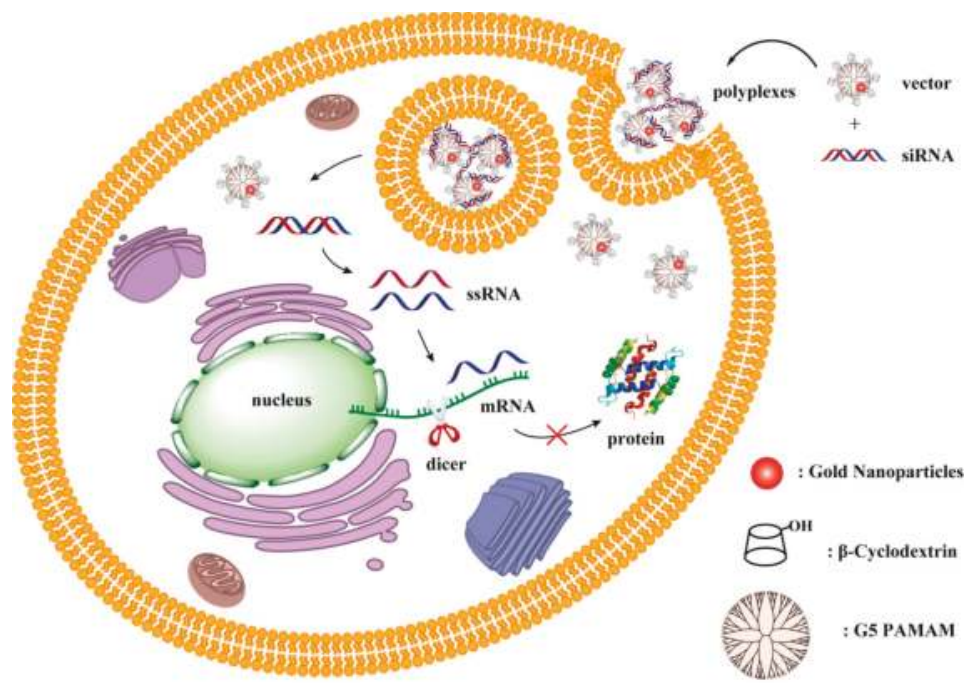

Scheme 1. Schematic illustration of the gene delivery process.

\section{Results and Discussion}

\subsection{Characterization of Vector/siRNA Polyplexes}

Herein, we aimed to explore the enhanced delivery efficiency of siRNA using the Au DENPs- $\beta$-CD (Q2) vector. Au DENPs without $\beta$-CD modification (Q1) and pristine $G 5 . \mathrm{NH}_{2}$ dendrimers (Q0) were used for comparison. We first checked the siRNA compaction capability of the vectors. Agarose gel retardation assay was used to analyze the obtained vector/siRNA polyplexes (Figure 1). Apparently, the migration of both siRNAs is able to be blocked at higher N/P ratios. For Bcl-2 siRNA, all vectors fully inhibit the siRNA migration at the N/P ratio of 2:1 or above (Figure 1a). For VEGF siRNA, Q0 and Q1 retard the siRNA migration at the N/P ratio of 2:1 or above (Figure 1b), similar to Bcl-2 siRNA. It seems that Q2 displays a better compaction capacity of VEGF siRNA than Q0 and Q1, and the siRNA migration can be completely retarded at the $\mathrm{N} / \mathrm{P}$ ratio above $1: 1$. Clearly, the conjugation of $\beta-C D$ onto G5 dendrimers is beneficial for enhanced siRNA compaction, in accordance with our previous study [48]. These results demonstrated that both Bcl-2 siRNA and VEGF siRNA could be efficiently compressed by the vectors at $\mathrm{N} / \mathrm{P}$ ratios greater than $2: 1$.

DLS and zeta potential measurements were utilized to characterize the vector/siRNA polyplexes (Figure 2 and Table S1, Supporting Information). Apparently, the hydrodynamic particle size of the vector/siRNA polyplexes decreases with the N/P ratio. This may be attributed to the situation that at a higher N/P ratio, more vector materials are present and the siRNA can be more compacted to have a smaller size. It appears that polyplexes composed of the vectors with Au NPs entrapped have a slightly larger size than those gained using dendrimers without the entrapment of Au NPs, which is different from the vector/pDNA in our earlier work [44]. This difference is probably owing to the much smaller molecular weight of siRNA, and the size of the polyplexes could be mainly derived from that of the vectors.

We determined the surface potentials of the vector/siRNA polyplexes under the given N/P ratios (Figure 3). Clearly, at the same N/P ratios, the surface potential of the polyplexes obeys the order of Q0/siRNA > Q1/siRNA > Q2/siRNA for both Bcl-2 siRNA (Figure 3a) and VEGF siRNA (Figure $3 b$ ). These data suggest that the modification of $\beta-C D$ on the dendrimer periphery and the entrapment of $\mathrm{Au}$ NPs within the dendrimer internal cavity reduce the density of dendrimer surface 
amines, thus decreasing the surface potentials of the formed polyplexes. This is beneficial for them to have an improved cytocompatibility (see below). However, the surface potentials of the Q1/siRNA and Q2/siRNA are still positively charged. Overall, the positive surface potential along with the appropriate hydrodynamic sizes of the polyplexes may allow them to be used for effective gene delivery [48].
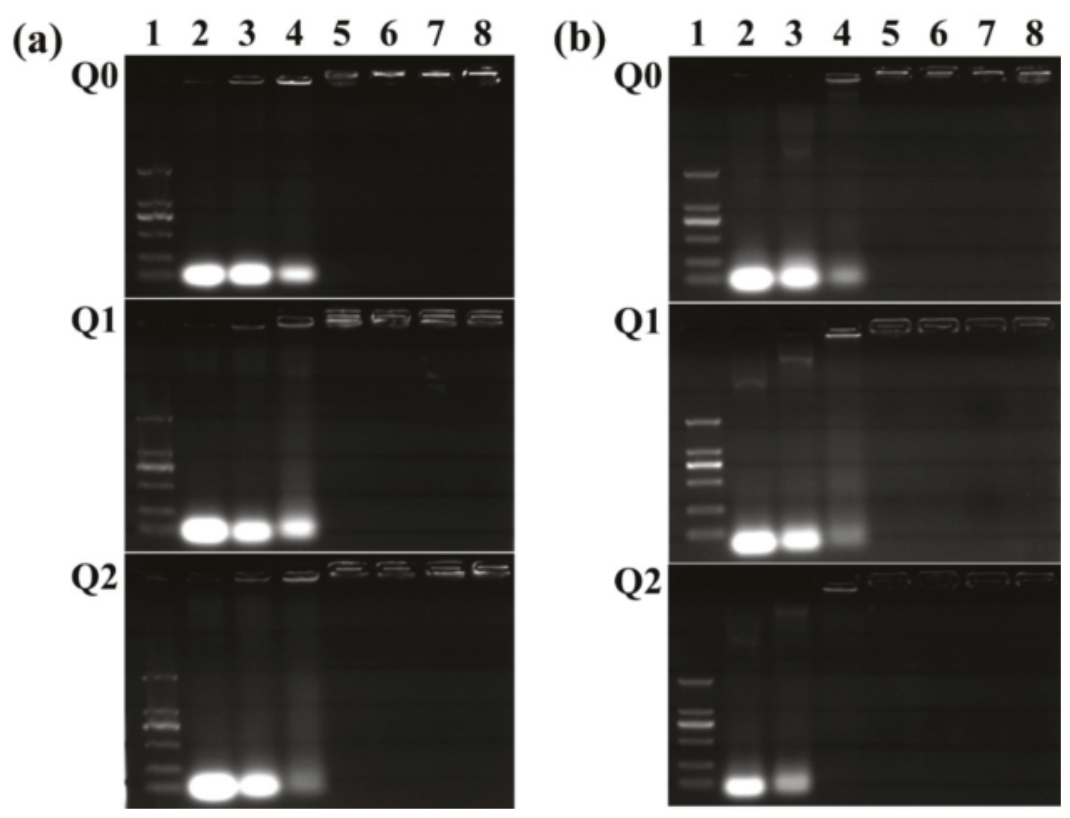

Figure 1. Gel retardation assay of B-cell lymphoma/leukemia-2 (Bcl-2) siRNA (a) and vascular endothelial growth factor (VEGF) siRNA (b) complexed with Q0, Q1 and Q2 at various N/P ratios, respectively. Lane 1: DNA marker; lane $2: \mathrm{N} / \mathrm{P}=0.25: 1$; lane $3: \mathrm{N} / \mathrm{P}=0.5: 1$; lane $4: \mathrm{N} / \mathrm{P}=1: 1$; lane 5 : $\mathrm{N} / \mathrm{P}=2: 1 ;$ lane $6: \mathrm{N} / \mathrm{P}=3: 1 ;$ lane $7: \mathrm{N} / \mathrm{P}=4: 1 ;$ and lane $8: \mathrm{N} / \mathrm{P}=5: 1$.
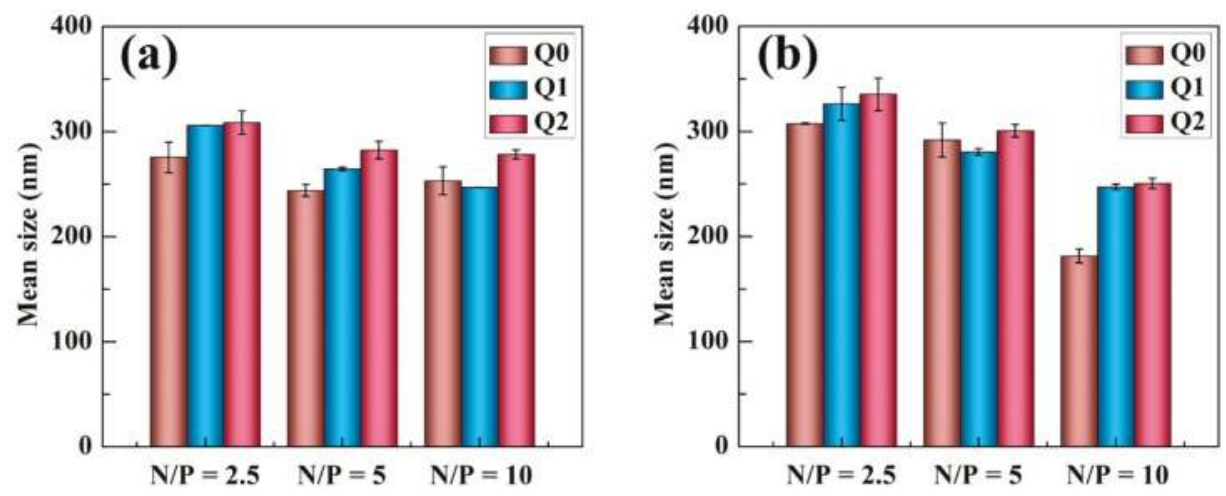

Figure 2. Mean hydrodynamic size of Bcl-2 siRNA (a) and VEGF siRNA (b) complexed with Q0, Q1, and Q2 at N/P ratios of 2.5:1, 5:1, or 10:1, respectively (mean $\pm \mathrm{SD}, n=3$ ). 

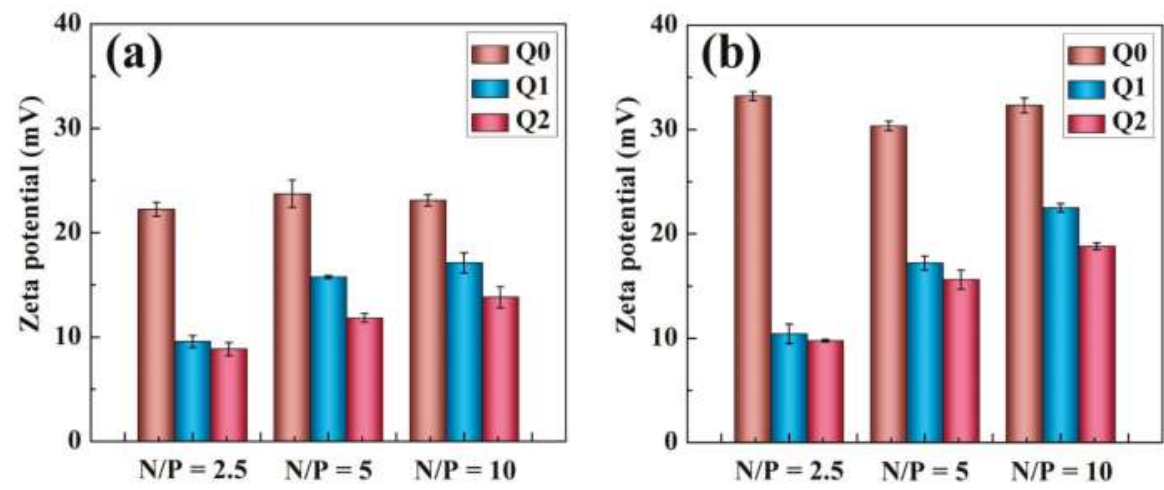

Figure 3. Surface potentials of Bcl-2 siRNA (a) and VEGF siRNA (b) complexed with Q0, Q1, and Q2 at $\mathrm{N} / \mathrm{P}$ ratios of 2.5:1, 5:1 or 10:1, respectively (mean $\pm \mathrm{SD}, n=3$ ).

\subsection{Cytotoxicity Assay}

MTT assay of cell viability was next carried out to test the cytotoxicity of vector/siRNA polyplexes (Figure 4). The cell viability is reduced with the vector concentration. The cytotoxicity of the vector/siRNA polyplexes obeys the order of Q2/siRNA $<\mathrm{Q} 1 /$ siRNA $<\mathrm{Q} 0 /$ siRNA at the same vector concentration for either Bcl2 siRNA (Figure 4a) or VEGF siRNA (Figure 4b). Even at the highest vector concentration of $2000 \mathrm{nM}$, the cells incubated with the Q2/ siRNA polyplexes still display a viability higher than $80 \%$, while the cells co-cultured with the Q0/siRNA polyplexes show a viability lower than $60 \%$. Our results suggest that $\mathrm{Q} 2$ could be adopted as a relatively 'safe' gene delivery vector when compared with Q0 and Q1. Our data emphasize that the dendrimer periphery modification with $\beta-C D$ and the internal loading of Au NPs are beneficial to compromise the cytotoxicity of G5 PAMAM dendrimers.
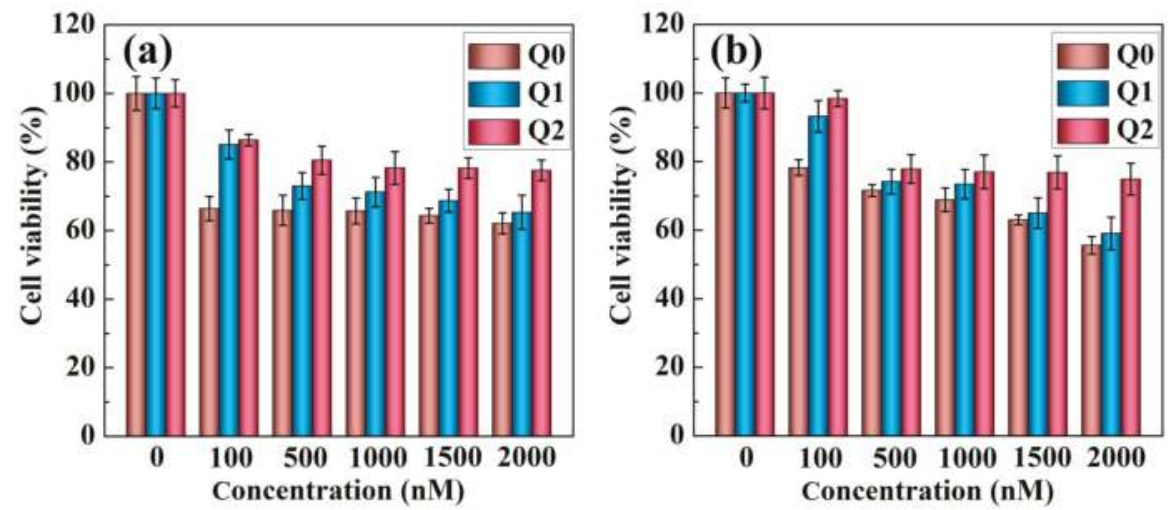

Figure 4. MTT viability assay of Uppsala 87 Malignant Glioma (U87MG) cells treated with the vector/Bcl-2 siRNA (a) and vector/VEGF siRNA; and (b) polyplexes under distinct vector concentrations (mean \pm SD, $n=6)$. 


\subsection{Uptake of Vector/siRNA Polyplexes by Cancer Cells}

The cellular uptake of the vector/siRNA polyplexes was investigated by flow cytometry analysis (Figure S1, Supporting Information). As shown in Figure 5, for both vector/Cy3-Bcl-2 siRNA and vector/Cy3-VEGF siRNA polyplexes, the percentages of fluorescent cells associated with the Cy3-labeled siRNA are relatively higher at the higher N/P ratios of the polyplexes. Under the same conditions, it appears that Bcl-2 siRNA (Figure 5a) can be more significantly uptaken by the U87MG cells than VEGF siRNA (Figure 5b). The percentage of cells having the Cy3 fluorescence signals after transfection by the vector/Cy3-Bcl-2 siRNA polyplexes is higher than $80 \%$ for all different vectors. The ability of vector to deliver Bcl-2 siRNA and VEGF siRNA follows the tendency of Q0<Q1<Q2 at $\mathrm{N} / \mathrm{P}$ ratios of 5 and 10. It should be noted that $\mathrm{Q} 2$ possesses a lower surface potential, thus being more liable to show enhanced transfection efficiency of genes at high N/P ratios.
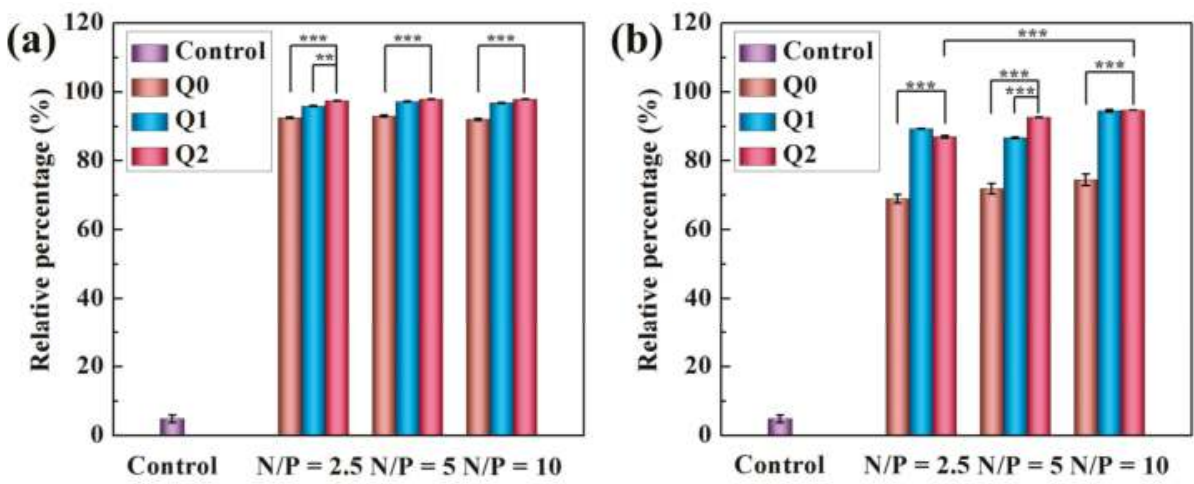

Figure 5. Flow cytometry analysis of U87MG cells transfected using vector/Cy3-Bcl-2 siRNA (a) and vector/Cy3-VEGF siRNA (b) polyplexes at the N/P ratios of 2.5:1, 5:1, and 10:1, respectively. Cells without treatment were used as control. Data are shown with mean $\pm \operatorname{SD}(n=3)$. For $(\mathbf{a}, \mathbf{b}), * *$ and $* * *$ mean that the $p$ values of statistical analyses are $<0.01$ and $<0.001$, respectively.

Confocal microscopic imaging was used to further study the transcellular pathways and localization of the vector/siRNA polyplexes at the N/P ratio of 5:1. As illustrated in Figure 6, control cells without treatment just display the Hoechst 33342-stained cell nuclei, which is blue fluorescent. The cells incubated with free Cy3-Bcl-2 siRNA without vector just displays the blue fluorescence associated to the Hoechst 33342 staining, similar to the control cells. This indicates that free Cy3-Bcl-2 siRNA is not able to be transfected into the cells due to its intrinsic negative charge. In contrast, Cy3-Bcl-2 siRNA complexed with all three different vectors can be transfected within the cancer cells, as red fluorescence signals in all cases can be seen in the cytoplasm of cells. The intensity of the red fluorescence signals of cells follows the order of $\mathrm{Q} 0<\mathrm{Q} 1<\mathrm{Q} 2$ under the same condition, suggesting that the siRNA delivery efficiency follows the same order, in agreement with the flow cytometry assay data. For the Cy3-VEGF siRNA delivery (Figure S2, Supporting Information), the same trend of cellular uptake of the polyplexes can be seen. 


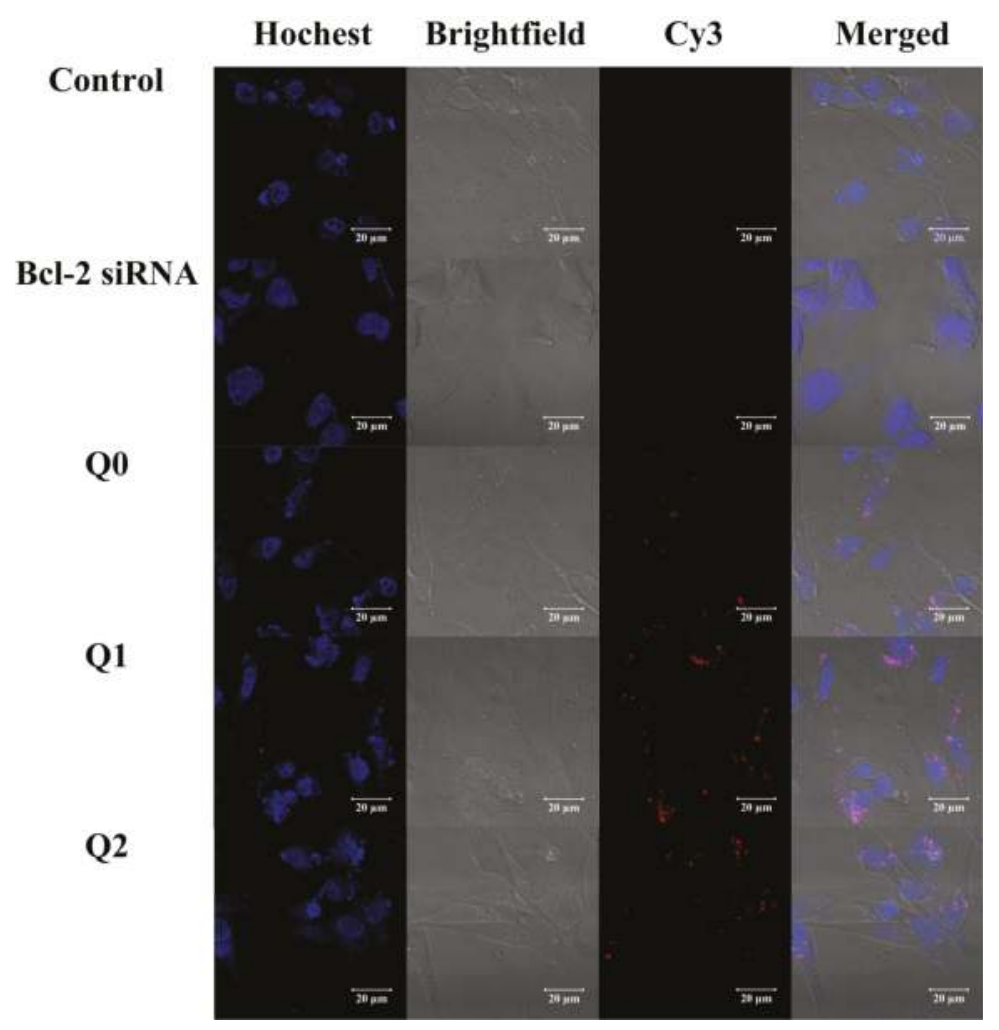

Figure 6. Confocal microscopic images $(63 \times)$ of U87MG cells showing the intracellular localization of the vectors/Cy3-Bcl-2 siRNA polyplexes that were prepared with an N/P of 5:1 (red: Cy3-labeled siRNA; blue: Hoechst 33342 stained cell nuclei).

\subsection{Gene Silencing with VEGF and Bcl-2 siRNAs}

With the goal to study the effective siRNA delivery using the designed vector systems, Western blot analysis was undertaken to explore the gene silencing capabilities of vector/siRNA polyplexes at the N/P ratio of 5:1. We used naked siRNA without any protection as a control and GAPDH protein was adopted as the reference protein. As shown in Figure 7a, the Bcl-2 gene is not able to be silenced by naked Bcl-2 siRNA, which is similar to the control cells. In contrast, decreased expression of Bcl-2 protein can be seen in cells treated with all vector/siRNA polyplexes, and the gene silencing efficacy follows the order of Q2 $>$ Q1 $>$ Q0. Similarly, VEGF siRNA is also able to be transfected after complexation with the vectors of Q0, Q1, and Q2 to lower the expression of VEGF protein (Figure 7b), and the gene silencing trend follows the same order. These results prove that the Au DENPs- $\beta-C D$ (Q2) possess excellent siRNA transfection ability and the formed polyplexes are able to silence the genes in cancer cells for effective gene therapy applications. 

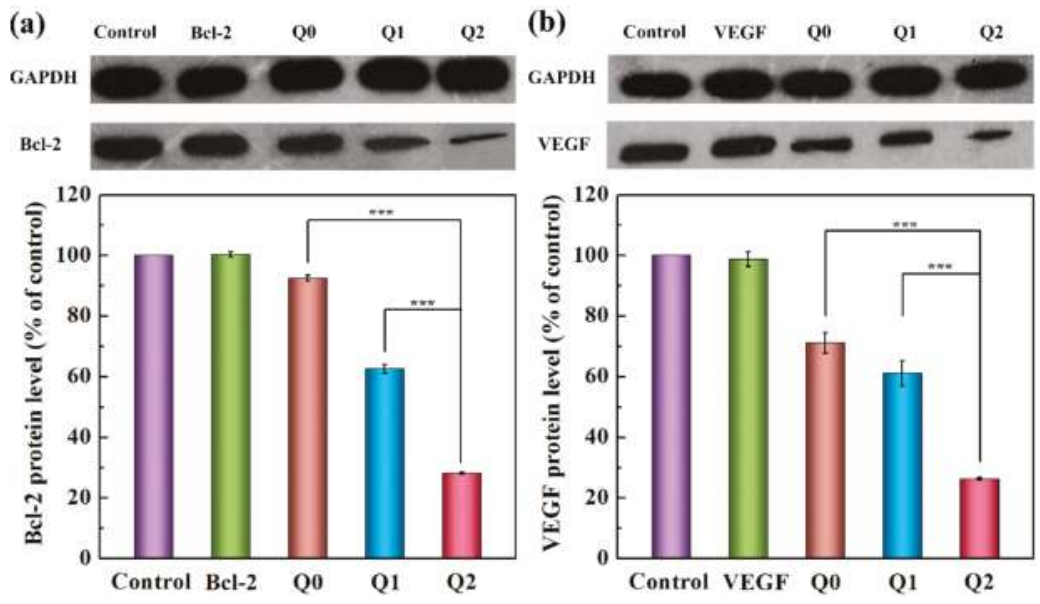

Figure 7. Relative Bcl-2 (a) and VEGF (b) protein expression levels in U87MG cells transfected with vector/siRNA polyplexes at an N/P ratio of 5:1. The GAPDH protein was used as a reference for the Western blot data. For $(\mathbf{a}, \mathbf{b}),{ }^{* * *}$ means that the $p$ values of statistical analyses are $<0.001$.

\section{Experimental Section}

\subsection{Synthesis of $A u$ DENPs- $\beta-C D$}

G5.NH $\mathrm{N}_{2}, \mathrm{Au}$ DENPs, and Au DENPs- $\beta$-CD were obtained using the same procedures described in our previous work [48]. For clarity, the structure of G5. $\mathrm{NH}_{2}$ PAMAM dendrimer and $\beta-\mathrm{CD}$ can be seen in Figure S3 (Supporting Information). Besides, for simplicity, the above materials were referred to as Q0, Q1, and Q2, respectively.

\subsection{Preparation of Vectors/siRNA Polyplexes}

Bcl-2 and VEGF siRNAs were respectively complexed with vectors with various N/P ratios. Both vectors and siRNA $(1 \mu \mathrm{g})$ were dissolved in phosphate buffered saline (PBS, $0.01 \mathrm{~mol} / \mathrm{L}, \mathrm{pH} 7.4)$ to reach an ultimate volume of $100 \mu \mathrm{L}$, then blended gently and incubated for $20 \mathrm{~min}$ at room temperature.

\subsection{Gene Silencing with VEGF and Bcl-2 siRNAs}

U87MG cells were incubated into 12-well flat-bottomed plates at a density of $1 \times 10^{5}$ cells / well as described above. When the cells were brought to a $60-70 \%$ confluence, the medium in each well was substituted with $1 \mathrm{~mL}$ of fresh DMEM containing $100 \mu \mathrm{L}$ of vector/siRNA polyplexes prepared using $1 \mu \mathrm{g}$ of siRNA at the N/P ratio of 5:1. After incubation for $4 \mathrm{~h}$, the cell medium was exchanged to fresh DMEM supplemented with 10\% FBS and the cells were then cultivated for additional $48 \mathrm{~h}$. Then, the cells were treated with pre-chilled PBS and digested with lysis buffer ( $400 \mu \mathrm{L} /$ well) for 30 min under ice bath. The lysates were centrifuged at $12,000 \mathrm{rpm}$ for $5 \mathrm{~min}$ at $4{ }^{\circ} \mathrm{C}$. Thereafter, the supernatants were collected for Western-blot assay according to protocols in our previous work [13]. Both the Bcl-2 and VEGF proteins were detected using a Western Lightning ${ }^{\circledR}$ Plus-ECL (Enhanced Chemiluminescence) Kit (PerkinElmer, Inc., Boston, MA, USA). More detailed information of experimental can be seen in Supporting Information.

\section{Conclusions}

To summarize, we used the synthesized Au DENPs- $\beta-C D$ as a carrier for highly efficient delivery of siRNA to glioblastoma cells. The Au DENPs- $\beta$-CD are much more efficient to compact siRNA under 
appropriate $\mathrm{N} / \mathrm{P}$ ratios, and exhibit lower cytotoxicity and better siRNA delivery efficiency than the pristine G5. $\mathrm{NH}_{2}$ dendrimers and the Au DENPs without $\beta$-CD modification. These results are related to the dendrimer surface modification of $\beta-C D$ and dendrimer internal cavity entrapment of Au NPs. In addition, with the assistance of the Au DENPs- $\beta-C D$ vector, both Bcl- 2 and VEGF siRNAs are able to be transfected to silence of glioblastoma cancer cells by downregulation of the respective proteins. Strongly, our study suggests that Au DENPs- $\beta$-CD may be employed as a prospective carrier for safe and effective transfection of siRNA to treat a variety of cancer cells based on specific siRNAs.

Supplementary Materials: The following are available online at http:/ /www.mdpi.com/2079-4991/8/3/131/s1. Figure S1: Flow cytometry analysis spectra; Figure S2: Confocal microscopic images; Figure S3: Molecular structures of G5.NH $\mathrm{NH}_{2}$ PAMAM dendrimers and $\beta$-CD; Table S1: Polydispersity index (PDI) of siRNA complexed with vectors.

Acknowledgments: This research is financially supported by the Science and Technology Commission of Shanghai Municipality (17540712000), the National Natural Science Foundation of China (81761148028 and 21773026, and 31400816), and the Fundamental Research Funds for the Central Universities (for Lu Wang, Xueyan Cao and Xiangyang Shi). Xiangyang Shi also thanks the support of the Sino-French Cai Yuanpei Programme, as well as the support by FCT-Fundaca õ para a Ciência e a Tecnologia (project No. PEst-OE/QUI/UI0674/2013, CQM, Portuguese Government funds) and by ARDITI-Agência Regional para o Desenvolvimento da Investigaca õ Tecnologia e Inovaca õ through the project No. M1420-01-0145-FEDER-000005-Centro de Quim ica da Madeira-CQM+ (Madeira 14-20).

Author Contributions: Xiangyang Shi designed the whole experiments; Jieru Qiu carried out the primary parts of the experiments, analyzed the data, and wrote the paper; Lingdan Kong performed some of the experiments of cell culture and edited the manuscript; Aijun Li, Ping Wei, Xueyan Cao, and Lu Wang contributed to some in vitro experiments; and Serge Mignani, Anne-Marie Caminade, Jean-Pierre Majoral, and Xiangyang Shi revised and proofread the whole manuscript.

Conflicts of Interest: No conflict of interest was declared by the authors.

\section{References}

1. Sonawane, N.D.; Szoka, F.C.; Verkman, A.S. Chloride accumulation and swelling in endosomes enhances DNA transfer by polyamine-DNA polyplexes. J. Biol. Chem. 2003, 278, 44826-44831. [CrossRef] [PubMed]

2. Pantarotto, D.; Singh, R.; McCarthy, D.; Erhardt, M.; Briand, J.P.; Prato, M.; Kostarelos, K.; Bianco, A. Functionalized carbon nanotubes for plasmid DNA gene delivery. Angew. Chem. Int. Edit. 2004, 43, 5242-5246. [CrossRef] [PubMed]

3. Farmer, H.; McCabe, N.; Lord, C.J.; Tutt, A.N.J.; Johnson, D.A.; Richardson, T.B.; Santarosa, M.; Dillon, K.J.; Hickson, I.; Knights, C.; et al. Targeting the DNA repair defect in BRCA mutant cells as a therapeutic strategy. Nature 2005, 434, 917-921. [CrossRef] [PubMed]

4. Borgheti-Cardoso, L.N.; Depieri, L.V.; Diniz, H.; Calzzani, R.A.J.; Fantini, M.C.D.; Iyomasa, M.M.; Vicentini, F.; Bentley, M. Self-assembling gelling formulation based on a crystalline-phase liquid as a non-viral vector for siRNA delivery. Eur. J. Pharm. Sci. 2014, 58, 72-82. [CrossRef] [PubMed]

5. Liu, H.M.; Li, Y.; Mozhi, A.; Zhang, L.; Liu, Y.L.; Xu, X.; Xing, J.M.; Liang, X.J.; Ma, G.H.; Yang, J.; et al. SiRNA-phospholipid conjugates for gene and drug delivery in cancer treatment. Biomaterials 2014, 35, 6519-6533. [CrossRef] [PubMed]

6. Van Hauwermeiren, F.; Vandenbroucke, R.E.; Grine, L.; Puimege, L.; Van Wonterghem, E.; Zhang, H.; Libert, C. Antisense oligonucleotides against TNFR1 prevent toxicity of TNF/IFN gamma treatment in mouse tumor models. Int. J. Cancer 2014, 135, 742-750. [CrossRef] [PubMed]

7. Itoh, M.; Nakaura, M.; Imanishi, T.; Obika, S. Target gene knockdown by $2^{\prime}, 4^{\prime}$-BNA/LNA antisense oligonucleotides in zebrafish. Nucleic Acid Ther. 2014, 24, 186-191. [CrossRef] [PubMed]

8. Putral, L.N.; Gu, W.Y.; McMillan, N.A.J. RNA interference for the treatment of cancer. Drug News Perspect. 2006, 19, 317-324. [CrossRef] [PubMed]

9. Izquierdo, M. Short interfering RNAs as a tool for cancer gene therapy. Cancer Gene Ther. 2005, 12, $217-227$. [CrossRef] [PubMed]

10. Aagaard, L.; Rossi, J.J. RNAi therapeutics: Principles, prospects and challenges. Adv. Drug Deliv. Rev. 2007, 59, 75-86. [CrossRef] [PubMed] 
11. Castano, S.; Delord, B.; Fevrier, A.; Lehn, J.M.; Lehn, P.; Desbat, B. Brewster angle microscopy and PMIRRAS study of DNA interactions with BGTC, a cationic lipid used for gene transfer. Langmuir 2008, 24, 9598-9606. [CrossRef] [PubMed]

12. Kong, L.D.; Qiu, J.R.; Sun, W.J.; Yang, J.; Shen, M.W.; Wang, L.; Shi, X.Y. Multifunctional PEI-entrapped gold nanoparticles enable efficient delivery of therapeutic siRNA into glioblastoma cells. Biomater. Sci. 2017, 5, 258-266. [CrossRef] [PubMed]

13. Kong, L.D.; Wu, Y.L.; Alves, C.S.; Shi, X.Y. Efficient delivery of therapeutic siRNA into glioblastoma cells using multifunctional dendrimer-entrapped gold nanoparticles. Nanomedicine 2016, 11, 3103-3115. [CrossRef] [PubMed]

14. Xiao, T.Y.; Hou, W.X.; Cao, X.Y.; Wen, S.H.; Shen, M.W.; Shi, X.Y. Dendrimer-entrapped gold nanoparticles modified with folic acid for targeted gene delivery applications. Biomater. Sci. 2013, 1, 1172-1180. [CrossRef]

15. Paleos, C.M.; Tziveleka, L.A.; Sideratou, Z.; Tsiourvas, D. Gene delivery using functional dendritic polymers. Expert Opin. Drug Deliv. 2009, 6, 27-38. [CrossRef] [PubMed]

16. Wu, J.; Yamanouchi, D.; Liu, B.; Chu, C.C. Biodegradable arginine-based poly(ether ester amide)s as a non-viral DNA delivery vector and their structure-function study. J. Mater. Chem. 2012, 22, 18983-18991. [CrossRef]

17. Stamatatos, L.; Leventis, R.; Zuckermann, M.J.; Silvius, J.R. Interactions of cationic lipid vesicles with negatively charged phospholipid-vesicles and biological-membranes. Biochemistry 1988, 27, 3917-3925. [CrossRef] [PubMed]

18. Behr, J.P.; Demeneix, B.; Loeffler, J.P.; Mutul, J.P. Efficient gene-transfer into mammalian primary endocrine-cells with lipopolyamine-coated DNA. Proc. Natl. Acad. Sci. USA 1989, 86, 6982-6986. [CrossRef] [PubMed]

19. Boussif, O.; Lezoualch, F.; Zanta, M.A.; Mergny, M.D.; Scherman, D.; Demeneix, B.; Behr, J.P. A versatile vector for gene and oligonucleotide transfer into cells in culture and in-vivo-polyethylenimine. Proc. Natl. Acad. Sci. USA 1995, 92, 7297-7301. [CrossRef] [PubMed]

20. Pack, D.W.; Hoffman, A.S.; Pun, S.; Stayton, P.S. Design and development of polymers for gene delivery. Nat. Rev. Drug Discov. 2005, 4, 581-593. [CrossRef] [PubMed]

21. Haralambidis, J.; Duncan, L.; Tregear, G.W. The solid-phase synthesis of oligonucleotides containing a 3'-peptide moiety. Tetrahedron Lett. 1987, 28, 5199-5202. [CrossRef]

22. Derossi, D.; Joliot, A.H.; Chassaing, G.; Prochiantz, A. The 3rd helix of the antennapedia homeodomain translocates through biological-membranes. J. Biol. Chem. 1994, 269, 10444-10450. [PubMed]

23. Kuriyama, S.; Mitoro, A.; Tsujinoue, H.; Nakatani, T.; Yoshiji, H.; Tsujimoto, T.; Yamazaki, M.; Fukui, T. Particle-mediated gene transfer into murine livers using a newly developed gene gun. Gene Ther. 2000, 7, 1132-1136. [CrossRef] [PubMed]

24. Srinivasan, C.; Lee, J.; Papadimitrakopoulos, F.; Silbart, L.K.; Zhao, M.H.; Burgess, D.J. Labeling and intracellular tracking of functionally active plasmid DNA with semiconductor quantum dots. Mol. Ther. 2006, 14, 192-201. [CrossRef] [PubMed]

25. Mintzer, M.A.; Simanek, E.E. Nonviral vectors for gene delivery. Chem. Rev. 2009, 109, 259-302. [CrossRef] [PubMed]

26. Guillot-Nieckowski, M.; Eisler, S.; Diederich, F. Dendritic vectors for gene transfection. New J. Chem. 2007, 31, 1111-1127. [CrossRef]

27. Li, S.; Huang, L. Nonviral gene therapy: Promises and challenges. Gene Ther. 2000, 7, 31-34. [CrossRef] [PubMed]

28. Itaka, K.; Kanayama, N.; Nishiyama, N.; Jang, W.D.; Yamasaki, Y.; Nakamura, K.; Kawaguchi, H.; Kataoka, K. Supramolecular nanocarrier of siRNA from peg-based block catiomer carrying diamine side chain with distinctive pk(a) directed to enhance intracellular gene silencing. J. Am. Chem. Soc. 2004, 126, 13612-13613. [CrossRef] [PubMed]

29. Minakuchi, Y.; Takeshita, F.; Kosaka, N.; Sasaki, H.; Yamamoto, Y.; Kouno, M.; Honma, K.; Nagahara, S.; Hanai, K.; Sano, A.; et al. Atelocollagen-mediated synthetic small interfering RNA delivery for effective gene silencing in vitro and in vivo. Nucleic Acids Res. 2004, 32, e109. [CrossRef] [PubMed]

30. Spagnou, S.; Miller, A.D.; Keller, M. Lipidic carriers of siRNA: Differences in the formulation, cellular uptake, and delivery with plasmid DNA. Biochemistry 2004, 43, 13348-13356. [CrossRef] [PubMed] 
31. Dalby, B.; Cates, S.; Harris, A.; Ohki, E.C.; Tilkins, M.L.; Price, P.J.; Ciccarone, V.C. Advanced transfection with lipofectamine 2000 reagent: Primary neurons, siRNA, and high-throughput applications. Methods 2004, 33, 95-103. [CrossRef] [PubMed]

32. Unnamalai, N.; Kang, B.G.; Lee, W.S. Cationic oligopeptide-mediated delivery of dsRNA for post-transcriptional gene silencing in plant cells. FEBS Lett. 2004, 566, 307-310. [CrossRef] [PubMed]

33. Tomalia, D.A.; Baker, H.; Dewald, J.; Hall, M.; Kallos, G.; Martin, S.; Roeck, J.; Ryder, J.; Smith, P. A new class of polymers-starburst-dendritic macromolecules. Polym. J. 1985, 17, 117-132. [CrossRef]

34. Tomalia, D.A.; Baker, H.; Dewald, J.; Hall, M.; Kallos, G.; Martin, S.; Roeck, J.; Ryder, J.; Smith, P. Dendritic macromolecules-synthesis of starburst dendrimers. Macromolecules 1986, 19, 2466-2468. [CrossRef]

35. Bielinska, A.U.; Chen, C.L.; Johnson, J.; Baker, J.R. DNA complexing with polyamidoamine dendrimers: Implications for transfection. Bioconjug. Chem. 1999, 10, 843-850. [CrossRef] [PubMed]

36. He, H.; Li, Y.; Jia, X.R.; Du, J.; Ying, X.; Lu, W.L.; Lou, J.N.; Wei, Y. PEGylated poly(amidoamine) dendrimer-based dual-targeting carrier for treating brain tumors. Biomaterials 2011, 32, 478-487. [CrossRef] [PubMed]

37. Shakhbazau, A.; Isayenka, I.; Kartel, N.; Goncharova, N.; Seviaryn, I.; Kosmacheva, S.; Potapnev, M.; Shcharbin, D.; Bryszewska, M. Transfection efficiencies of PAMAM dendrimers correlate inversely with their hydrophobicity. Int. J. Pharm. 2010, 383, 228-235. [CrossRef] [PubMed]

38. Zeng, F.W.; Zimmerman, S.C. Dendrimers in supramolecular chemistry: From molecular recognition to self-assembly. Chem. Rev. 1997, 97, 1681-1712. [CrossRef] [PubMed]

39. Bosman, A.W.; Janssen, H.M.; Meijer, E.W. About dendrimers: Structure, physical properties, and applications. Chem. Rev. 1999, 99, 1665-1688. [CrossRef] [PubMed]

40. Zhou, J.H.; Wu, J.Y.; Hafdi, N.; Behr, J.P.; Erbacher, P.; Peng, L. PAMAM dendrimers for efficient siRNA delivery and potent gene silencing. Chem. Commun. 2006, 22, 2362-2364. [CrossRef] [PubMed]

41. Nam, H.Y.; Nam, K.; Hahn, H.J.; Kim, B.H.; Lim, H.J.; Kim, H.J.; Choi, J.S.; Park, J.S. Biodegradable PAMAM ester for enhanced transfection efficiency with low cytotoxicity. Biomaterials 2009, 30, 665-673. [CrossRef] [PubMed]

42. Navarro, G.; de Ilarduya, C.T. Activated and non-activated PAMAM dendrimers for gene delivery in vitro and in vivo. Nanomed. Nanotechnol. Biol. Med. 2009, 5, 287-297. [CrossRef] [PubMed]

43. Hou, W.X.; Wei, P.; Kong, L.D.; Guo, R.; Wang, S.G.; Shi, X.Y. Partially PEGylated dendrimer-entrapped gold nanoparticles: A promising nanoplatform for highly efficient DNA and siRNA delivery. J. Mater. Chem. B 2016, 4, 2933-2943. [CrossRef]

44. Shan, Y.B.; Luo, T.; Peng, C.; Sheng, R.L.; Cao, A.M.; Cao, X.Y.; Shen, M.W.; Guo, R.; Tomas, H.; Shi, X.Y. Gene delivery using dendrimer-entrapped gold nanoparticles as nonviral vectors. Biomaterials 2012, 33, 3025-3035. [CrossRef] [PubMed]

45. Qi, R.; Gao, Y.; Tang, Y.; He, R.R.; Liu, T.L.; He, Y.; Sun, S.; Li, B.Y.; Li, Y.B.; Liu, G. PEG-conjugated PAMAM dendrimers mediate efficient intramuscular gene expression. AAPS J. 2009, 11, 395-405. [CrossRef] [PubMed]

46. Xiao, T.Y.; Cao, X.Y.; Hou, W.X.; Peng, C.; Qiu, J.R.; Shi, X.Y. Poly(amidoamine) dendrimers modified with 1,2-epoxyhexane or 1,2-epoxydodecane for enhanced gene delivery applications. J. Nanosci. Nanotechnol. 2015, 15, 10134-10140. [CrossRef] [PubMed]

47. Hou, W.X.; Wen, S.H.; Guo, R.; Wang, S.G.; Shi, X.Y. Partially acetylated dendrimer-entrapped gold nanoparticles with reduced cytotoxicity for gene delivery applications. J. Nanosci. Nanotechnol. 2015, 15, 4094-4105. [CrossRef] [PubMed]

48. Qiu, J.R.; Kong, L.D.; Cao, X.Y.; Li, A.J.; Tan, H.R.; Shi, X.Y. Dendrimer-entrapped gold nanoparticles modified with $\beta$-cyclodextrin for enhanced gene delivery applications. RSC Adv. 2016, 6, 25633-25640. [CrossRef]

49. Kihara, F.; Arima, H.; Tsutsumi, T.; Hirayama, F.; Uekama, K. In vitro and in vivo gene transfer by an optimized alpha-cyclodextrin conjugate with polyamidoamine dendrimer. Bioconjug. Chem. 2003, 14, 342-350. [CrossRef] [PubMed]

(c) 2018 by the authors. Licensee MDPI, Basel, Switzerland. This article is an open access article distributed under the terms and conditions of the Creative Commons Attribution (CC BY) license (http:/ / creativecommons.org/licenses/by/4.0/). 
Article

\title{
Gadolinium-Doped Gallic Acid-Zinc/Aluminium-Layered Double Hydroxide/Gold Theranostic Nanoparticles for a Bimodal Magnetic Resonance Imaging and Drug Delivery System
}

\author{
Muhammad Sani Usman ${ }^{1, *}$, Mohd Zobir Hussein ${ }^{1, *}$, Sharida Fakurazi ${ }^{2,3}$, \\ Mas Jaffri Masarudin ${ }^{4}$ and Fathinul Fikri Ahmad Saad ${ }^{5}$ \\ 1 Materials Synthesis and Characterization Laboratory, Institute of Advanced Technology (ITMA), \\ Serdang 43400, Selangor, Malaysia \\ 2 Laboratory of Vaccines and Immunotherapeutics, Institute of Bioscience, Serdang 43400, Selangor, Malaysia; \\ sharida.fakurazi@gmail.com \\ 3 Department of Human Anatomy, Faculty of Medicine and Health Sciences, Serdang 43400, \\ Selangor, Malaysia \\ 4 Department of Cell \& Molecular Biology, Faculty of Biotechnology and Biomolecular Sciences, \\ Serdang 43400, Selangor, Malaysia; masjaffri@upm.edu.my \\ 5 Centre for Diagnostic and Nuclear Imaging, Faculty of Medicine and Health Sciences, \\ Universiti Putra Malaysia, Serdang 43400, Selangor, Malaysia; ahmadsaadff@gmail.com \\ * Correspondence: muhusma@gmail.com (M.S.U.); mzobir@upm.edu.my (M.Z.H.); \\ Tel.: +60-1-0309-3348 (M.S.U.); +60-3-8946-8092 (M.Z.H.)
}

Received: 16 July 2017; Accepted: 25 August 2017; Published: 31 August 2017

\begin{abstract}
We have developed gadolinium-based theranostic nanoparticles for co-delivery of drug and magnetic resonance imaging (MRI) contrast agent using Zn/Al-layered double hydroxide as the nanocarrier platform, a naturally occurring phenolic compound, gallic acid (GA) as therapeutic agent, and $\mathrm{Gd}\left(\mathrm{NO}_{3}\right)_{3}$ as diagnostic agent. Gold nanoparticles (AuNPs) were grown on the system to support the contrast for MRI imaging. The nanoparticles were characterized using techniques such as Hi-TEM, XRD, ICP-ES. Kinetic release study of the GA from the nanoparticles showed about $70 \%$ of GA was released over a period of $72 \mathrm{~h}$. The in vitro cell viability test for the nanoparticles showed relatively low toxicity to human cell lines (3T3) and improved toxicity on cancerous cell lines (HepG2). A preliminary contrast property test of the nanoparticles, tested on a 3 Tesla MRI machine at various concentrations of GAGZAu and water (as a reference) indicates that the nanoparticles have a promising dual diagnostic and therapeutic features to further develop a better future for clinical remedy for cancer treatment.
\end{abstract}

Keywords: Zn/Al LDH; gallic acid; therapeutic; diagnostic; theranostic

\section{Introduction}

Nano-based materials or nanotechnology research has become a hot zone of material science research globally, due to the various advantages that come with nanomaterials [1], especially in numerous biomedical applications [2-6]. Chemotherapy remains the best choice of cancer treatment, due the availability of various anticancer agents. Nevertheless, the challenge of toxicities posed by these agents still exits [7]. Over a decade or so, various nanotechnology platforms have been explored in overcoming this challenge. Some of the areas of interest are the nanodrug delivery systems (NDDS). However, multimodal delivery systems (MDS) are recently gaining more attention [8], where drugs 
are simultaneously loaded along with other active agents on the same nanocarrier platform [7,9]. For instance, in theranostic research, the concept of MDS is employed where a nanocarrier is used as a delivery agent for therapeutic agents and diagnostic agents, such as magnetic resonance imaging (MRI) contrast agents [6], for a non-invasive concurrent delivery [10].

MRI is a non-invasive and non-ionizing important imaging tool used for cancer clinical diagnosis. Since the 1970s, MRI has been one of the most recognized powerful imaging techniques due to its high spatial resolution and tissue penetrating ability [8,11]. However, the use of MRI often requires contrast agents. Gadolinium-based (Gd) contrast agents are the commonly used contrast agents for MRI, which improve the $\mathrm{T} 1$ and $\mathrm{T} 2$ relaxation times of the images produced [8]. T1 and T2 relaxations are the main signals among others generated during MR imaging, which have distinctive grey-scale color contrasts reflecting the fluid and soft tissue composition of human subject. The signals represent spin-lattice relaxation and spin-spin relaxation for T1 and T2, respectively [12]. Zn/Al-layered double hydroxide (LDH) is one of the candidates capable of simultaneously intercalating and adsorbing theranostic agents due to their exchangeable interlayer anions. $\mathrm{LDH}$ is one of the group of two-dimensional layered structures materials [13] and has the general formula of $\left[\mathrm{M}_{1-x}^{2+} \mathrm{M}_{x}^{3+}(\mathrm{OH})_{2}\right]_{x}$ $\left.+\left[\mathrm{A}^{n-}\right] x / n \cdot m \mathrm{H}_{2} \mathrm{O}\right][14]$, where divalent and trivalent metal cations are represented by $\mathrm{M}^{2+}$ and $\mathrm{M}^{3+}$, respectively, and interlayer exchangeable anions are represented by $\left[\mathrm{A}^{n-}\right]$, and water as $x / n[8,15-17]$. Gallic acid is the therapeutic agent employed in this research; it is a naturally occurring polyhydroxyl phenolic compound, often found in different kinds of fruits. It is believed to have anticancer properties as well as other activities in a range of cells [18]. Although there are various research publications on drug intercalation using LDH in drug delivery as reviewed by Kura et al. [19], only a few works have so far been done on theranostic applications using LDH-based nanocarriers. Those articles have also been reviewed by Usman et al. [8], amongst which none has reported synthesis of theranostic nanocomposite using drug intercalation process.

Herein, we synthesized theranostic nanoparticles by Gd doping onto Zn/Al-LDH. Gallic acid was first intercalated into the interlayers of the LDH-Gd and AuNPs were then grown on the surface of the LDH nanoparticles. The LDH prepared via co-precipitation method was used as the nanocarrier, while Gd and AuNPs were used as the main contrast agent and booster for MRI, respectively.

\section{Results and Discussion}

The final GAGZAu nanoparticles were subjected to various characterizations as will be reported later, although the analyses were done at every step of the synthesis, starting with the LDH nanocarrier itself. Figure 1 is a representative of a typical multimodal theranostic setting, similar to a host-guest reaction in supramolecular chemistry, where a nano-carrier, a 2D host was first loaded with therapeutic agent (the first guest) by the intercalation process, gallic acid. Following the formation of pure phase, diagnostic agents (the second guests), Gd, and AuNPs were loaded. A third guest, a targeting agent, can be also loaded, resulting in the formation of a multimodal theranostic nanodelivery system [8]. However, the loading of a targeting agent will be done in our near future work. The mechanism of bonding between the $\mathrm{LDH}$ and the GA is via hydrogen bonding due the surplus $\mathrm{OH}$ groups in the anionic guest as well as ion exchange with the interlayer anions [20]. Whereas the contrast agents are bonded to the LDH through van der Waals forces of attraction. 


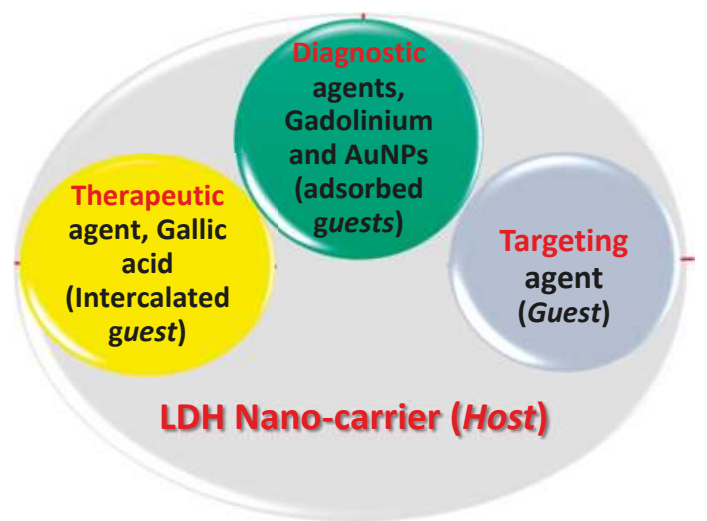

Figure 1. Schematic arrangement of GAGZAu nanocomposite in respect to theranostic delivery system in a typical host-guest relationship.

\subsection{X-ray Diffraction}

The diffractograms in Figure 2a indicate various patterns of the different stages of the nanocomposite synthesis, from the starting material to the final nanocomposite (A-E respectively). The diffractogram (A) represents the $\mathrm{Gd}\left(\mathrm{NO}_{3}\right)_{3}$, (B) represents $\mathrm{LDH},(\mathrm{C})$ is for gallic acid, which are all in a pristine state. Further, the pattern of GAGZA (D) represents the first stage of the formation of theranostic nanocomposite, that is, the anticancer drug was intercalated into the LDH/Gd (A) interlayers at this stage. This as a result shows increase in basal spacing up to $9.9 \AA$, that is much higher than $7.7 \AA$ of the LDH basal spacing; which strongly indicates the drug intercalation had taken place. In addition, the slight shift to a lower $2 \theta$ angle also implies the intercalation of the therapeutic agent GA into the interlayers of the LDH has taken place. The diffractogram of the theranostic GAGZAu (E) nanoparticles however, did not indicate most of the reflections of the LDH. This is presumably due to the surface coating of the AuNPs on the surface of the theranostic nanoparticles. Nonetheless, the pattern (Pattern 4-784) observed match with FCC (111, 200, and 220) of pure AuNPs [21].

\subsection{Drug Release Profile and Kinetics from GAGZA Nanocomposite}

The amount of drug loaded and in vitro drug release in the nanoparticles was calculated using a standard curve of the UV-Vis spectrometer at $\lambda_{\max }$ of the drug, $264 \mathrm{~nm}$. As seen in Figure $2 \mathrm{~b}$, the maximum percentage of about $60 \%$ of the drug is released over a period of $5000 \mathrm{~min}(84 \mathrm{~h})$ with $50 \%$ drug loading. The release was done using PBS buffer solution at $\mathrm{pH} 4.8$ and 7.4. The release in the slightly alkaline $\mathrm{pH}$ is observed to be significantly lower $(10 \%)$ than in the acidic $\mathrm{pH}(60 \%)$; which could be attributed to ion exchange occurring in the buffer media between the anions in the drug and the LDH nanocarrier [22]. Nonetheless, the sustained release profiles suggest safe release of the drug from the nanocarrier to the solution under acidity of $\mathrm{pH} 4.8$ and less release at the higher $\mathrm{pH}$ 7.4. The huge difference in the release pattern of the $\mathrm{pH}$ is attributed to the mechanism or behavior of the nanocarrier in buffer solutions, as it is a common attribute of LDH interlayers to dissolve in acidic media together with the anionic guest on the external surface of the LDH [15], hence resulting in more release of the intercalated guest. This indicates the suitability of the nanohybrid as a good candidate for anticancer research, as rightly reported in literature where $\mathrm{LDH}$ nanoparticles was reported to have penetrated the cervical cancer cells via mediated endocytosis [23]. Furthermore, to understand the mechanism of the drug release, the data from the release study was fitted to three different kinetics models, namely

$$
\text { Pseudo-first order: } \ln \left(q_{e}-q_{t}\right)=\ln q_{t}-k t
$$




$$
\begin{gathered}
\text { Pseudo-second order: } \frac{t}{q_{t}}=\frac{1}{k q_{e}^{2}}+\frac{t}{q} \\
\text { Parabolic diffusion: }\left(1-M_{t} / M_{o}\right) / t=k t^{-0.5}+b
\end{gathered}
$$

The parameters used in the fitting equations are the drug content in the nanocarrier during release which are represented as $M_{t}$ and $M_{0}$, the amount released at equilibrium and time $t$ designated as $q_{e}$ and $q_{t}$ respectively; and the release constant $k$ [15].

The three models as represented in Equations (1)-(3), gave different kinetic processes, the model that best describes the kinetic release of the gallic acid from the nanocomposite at both $\mathrm{pH}$ (7.4 and 4.8 ) is the pseudo-second order model, as expressed in Equation (2). The parameter $\frac{t}{q_{t}}$ is plotted against the time $t$, which gave correlation coefficients $\left(R^{2}\right)$ of 0.994 at both pH 7.4 and 4.8 (Figure 2c,d). The rate constants $(k)$ were determined to be $4.7 \times 10^{-2}$ and $8.5 \times 10^{-3} \mathrm{~g} / \mathrm{mg}$, for $\mathrm{pH} 7.4$ and 4.8 , respectively. These results are consistent with other reported findings on drug release using LDH nanocarriers [15] and other nanocarriers [24]. Table 1 is a compilation of the fitted data of correlation coefficients $\left(R^{2}\right)$, rate constants $(k)$, and half-lives $\left(t_{1 / 2}\right)$, as well as saturation points (\%) of gallic acid released from GAGZA at $\mathrm{pH} 7.4$ and 4.8 .

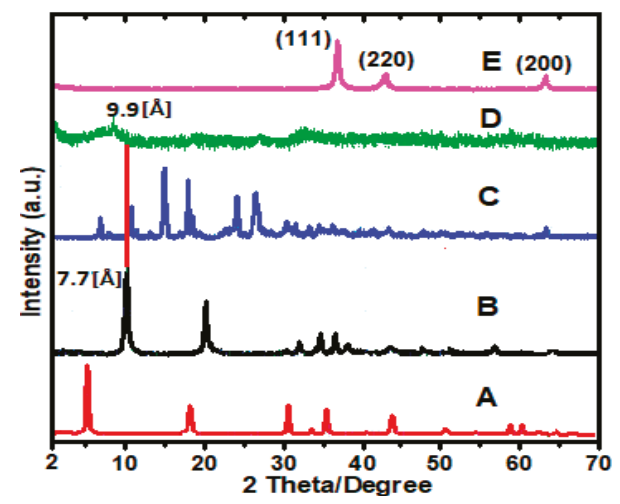

(a)

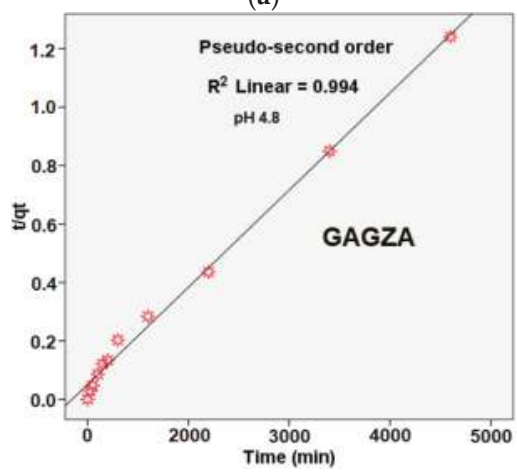

(c)

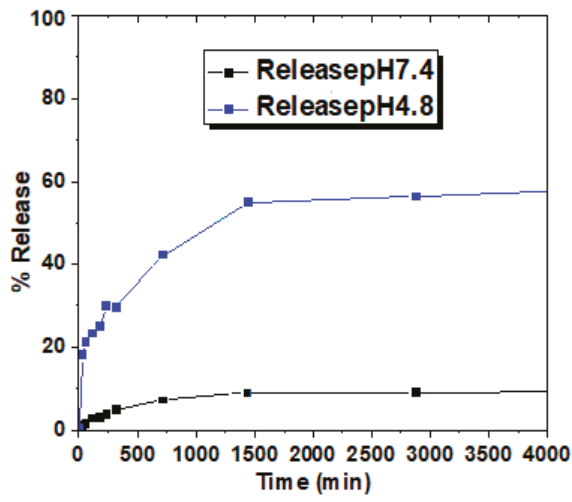

(b)

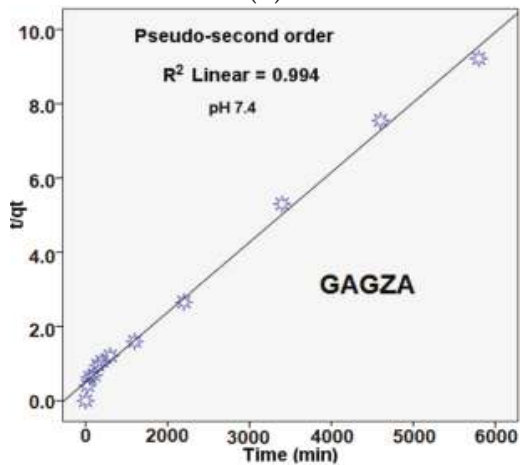

(d)

Figure 2. (a) X-ray diffractograms of (A) $\mathrm{Gd}\left(\mathrm{NO}_{3}\right)_{3}$, (B) $\mathrm{Zn} / \mathrm{Al}-\mathrm{LDH}$, (C) pure gallic acid, (D) gallic acid-Zn/Al-LDH-Gd nanocomposite (GAGZA), (E) gallic acid-Zn/Al-LDH/Gd-Au nanocomposite (GAGZAu); (b) Release profiles of gallic acid intercalated into Zn/Al-LDH-Gd nanoparticles (GAGZA) in phosphate-buffered solutions at $\mathrm{pH} 4.8$ and $\mathrm{pH}$ 7.4; (c) Data of gallic acid released from GAGZA obtained at $\mathrm{pH} 4.8$ fitted to pseudo-seconder order; (d) Data of gallic acid released from GAGZA obtained at 7.4 fitted to pseudo-seconder order. 
Table 1. Fitted data of correlation coefficients $\left(R^{2}\right)$, rate constants $(k)$, and half-lives $\left(t_{1 / 2}\right)$ of gallic acid released from GAGZA at $\mathrm{pH} 7.4$ and 4.8 .

\begin{tabular}{|c|c|c|c|c|c|c|}
\hline \multirow{2}{*}{$\begin{array}{l}\text { Medium } \\
\text { pH }\end{array}$} & \multirow{2}{*}{$\begin{array}{l}\text { Release Saturation } \\
\qquad(\%)\end{array}$} & \multirow{2}{*}{$\begin{array}{c}\left(R^{2}\right) \\
\begin{array}{c}\text { Pseudo-First } \\
\text { Order }\end{array}\end{array}$} & \multirow{2}{*}{$\begin{array}{c}\left(R^{2}\right) \\
\begin{array}{c}\text { Pseudo-Second } \\
\text { Order }\end{array}\end{array}$} & \multirow{2}{*}{$\begin{array}{c}\left(R^{2}\right) \\
\text { Parabolic } \\
\text { Diffusion }\end{array}$} & \multirow{2}{*}{$\begin{array}{c}\text { Rate Constant } \\
(k)\end{array}$} & \multirow{2}{*}{$\begin{array}{l}t_{1 / 2} \\
(\mathrm{~min})\end{array}$} \\
\hline & & & & & & \\
\hline 7.4 & 18 & 0.432 & 0.994 & 0 & $4.7 \times 10^{-2}$ & 520 \\
\hline 4.8 & 62 & 0.094 & 0.994 & 0.7 & $8.5 \times 10^{-3}$ & 400 \\
\hline
\end{tabular}

\subsection{Surface Morphology and Elemental Content Analysis}

The morphology of the nanoparticles was studied before and after the addition of AuNPs, that is for GAGZA and GAGZAu. Figure 3a depicts micrographs of GAGZAu and Figure 3c shows GAGZA micrographs. Though evenly distributed, the nanoparticles are observed to be agglomerated at dry state. The agglomeration may be due to surface energy, a phenomenon associated with small sized nanoparticles [25]. As observed in Figure 3a, the AuNPs coated on the GAGZA nanocomposite appears to have covered the LDH structure which has affected the thermal stability of the final GAGZAu nanocomposite as discussed in the TGA analysis chapter, as well as the MRI contrast due to increased surface area to volume ratio in the nanohybrid. The FESEM micrographs of the nanoparticles analyzed with EDX indicated the presence of the all the active elements in the nanoparticles ( $\mathrm{Zn}, \mathrm{Al}, \mathrm{O}, \mathrm{C}, \mathrm{Gd}$, and $\mathrm{Au})$.

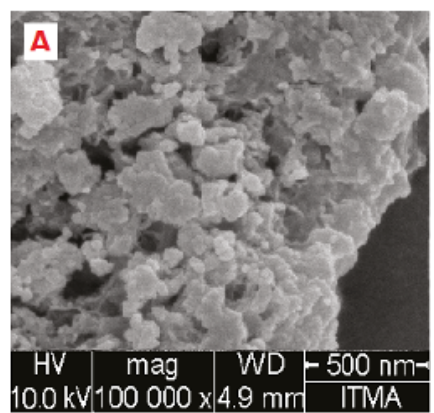

(a)

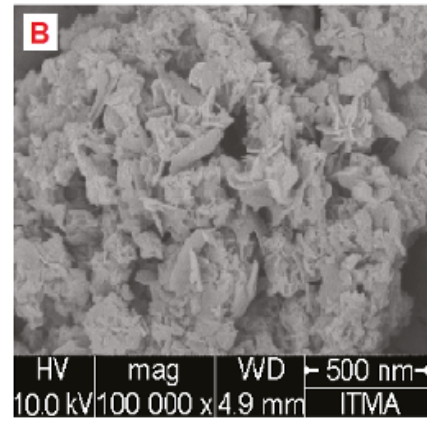

(c)

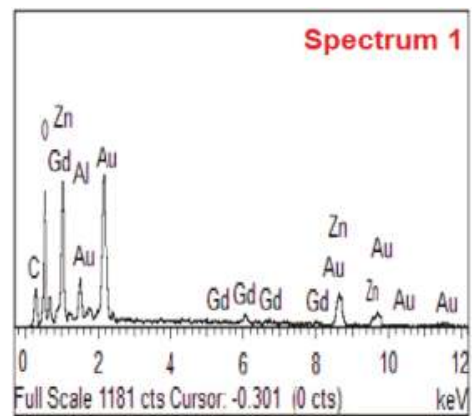

(b)

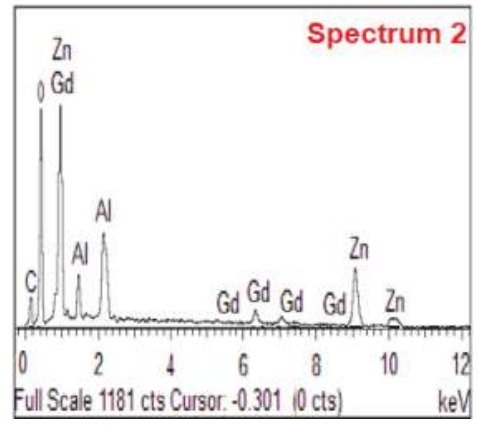

(d)

Figure 3. (a) Field emission scanning electron microscopy (FESEM) micrograph (A) and (b) Energy dispersive X-ray (EDX) spectrum (1) of gallic acid intercalated in LDH/Gd nanoparticles coated with AuNPs (GAGZAu); (c) micrograph (B); and (d) EDX spectrum (2) of gallic acid intercalated in LDH/Gd nanoparticles (GAGZA). 
The EDX spectra were generated via random capture of the whole area of the FESEM micrographs attached to the spectra. As anticipated, the elements contained in spectrum 1 (Figure $3 b$ ) obtained from GAGZAu contain various reflections of Au which appeared to dominate the Gd reflections in spectrum 2 (Figure 3d), indicting the coating of the LDH surface with AuNPs. The few reflections of $\mathrm{Gd}$ are also suggesting the presence of the element in the micrograph. However, as expected also, the spectrum 2 obtained from GAGZA micrograph, before the addition of AuNPs (Figure 3d) showed dominant reflections from $\mathrm{Gd}$ with no sign of Au signals, which confirms the initial formation of LDH-Gd nanocomposites. Likewise, the $\mathrm{Zn}$ and $\mathrm{Al}$ reflections which appeared in both spectra confirm the structure of $\mathrm{Zn} / \mathrm{Al}-\mathrm{Gd} \mathrm{LDH}$. Further, aside from the $\mathrm{C}$ and $\mathrm{O}$ signals that appeared in the spectra, which are likely from the intercalated GA drug, no other reflections are observed. This shows the high percentage of purity of the nanocomposite at various stages of synthesis. The results appear to be in conformity with ICP-ES elemental composition analysis carried out on the samples, which showed presence of all the intended elements in the nanocomposite.

\subsection{Size, Shape, and Distribution Analysis}

TEM was used to analyze size and shape/distribution of the nanoparticles. The GAGZA micrograph (Figure $4 \mathrm{~b}$ ) indicates various sizes of the nanoparticles in different shapes, including rod-shaped nanoparticles which are conspicuously seen throughout the micrographs at different magnifications. All the nanoparticles are found to be within the nanorange (1-100 nm) [1].

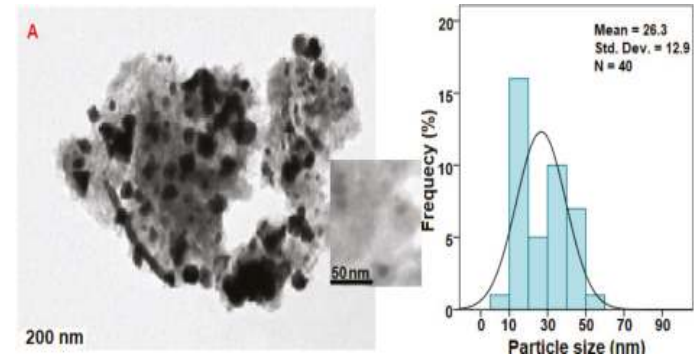

(a)

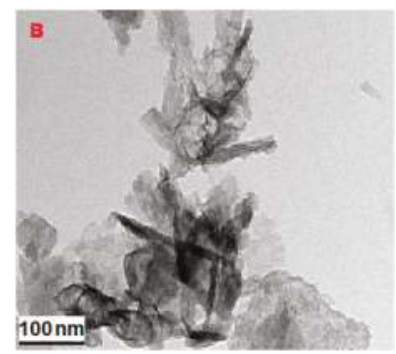

(b)

Figure 4. (a) Transmission electron microscopy (TEM) micrograph (A) and particle size distribution of gallic acid-intercalated in $\mathrm{Zn} / \mathrm{Al}-\mathrm{LDH} / \mathrm{Gd}$ nanoparticles coated with AuNPs (GAGZAu) and micrograph (B); (b) of gallic acid intercalated in Zn/Al-LDH/Gd nanoparticles (GAGZA).

The micrograph of the sample containing AuNPs (GAGZAu) (Figure 4a) evidently indicates the presence of the AuNPs in various sizes and shapes-such as hexagonal, triangular, and spherical shapes-thus confirming the growth of the AuNPs as indicated by other characterization results of the sample. The mean size of the AuNPs is approximately $26.3 \mathrm{~nm}$ as indicated in the histogram in Figure $4 \mathrm{a}$, which are predominantly evenly distributed on the surface of the LDH nanocomposite across all shapes and sizes.

\subsection{Chemical Interaction Studies (FT-IR Analysis)}

The chemical interactions and changes between the nanocarriers and nanoparticles were studied using FT-IR spectroscopy. The changes in functional groups, chemical bonds and shifts in wavenumbers are the indication that some of the interactions have taken place. For easy comparison, the analysis was done on the pristine samples and the nanoparticles. Figure 5 depicts the FT-IR spectra of the $\mathrm{Zn} / \mathrm{Al}-\mathrm{LDH}, \mathrm{Gd}\left(\mathrm{NO}_{3}\right)_{3}, \mathrm{GA}, \mathrm{GAGZA}$, and GAGZAu (A-E). The bands between 3307-3391 $\mathrm{cm}^{-1}$ which appear in all the FT-IR spectra are associated with $\mathrm{OH}$ stretching vibrations [26]; 1736 and $1702 \mathrm{~cm}^{-1}$ are characteristic absorptions of $\mathrm{C}=\mathrm{O} ; \mathrm{C}=\mathrm{C}$ aromatic ring stretching modes are represented 
by the bands 1541 and 1441, and 1541 and $1449 \mathrm{~cm}^{-1}$ in the GAGZA and GA spectra respectively; the band at $595 \mathrm{~cm}^{-1}$ represents bending vibration of $\mathrm{OH}$ carboxylic group. The bands at 1232, 1089, and $1025 \mathrm{~cm}^{-1}$ which appear in the GAGZA spectrum and at 1246 and $1026 \mathrm{~cm}^{-1}$ in the GA spectrum, are of $\mathrm{C}-\mathrm{O}$ stretching vibrations [27]. The nitrate group stretching mode appears as a band at 1384 $\mathrm{cm}^{-1}$ of the $\mathrm{Zn} / \mathrm{Al}$ spectrum; the band is noticeably absent in all other spectra; this is due to the loss of the nitrate anion in the bonding process, while $H_{2}$ bending vibration band can be seen at $1640 \mathrm{~cm}^{-1}$. Furthermore, as expected the spectra of GAGZAu (E) appeared to be similar to spectra D of GAGZA, with the only difference is blue-shift in the band positions to higher wavenumbers. Generally, there are all shifts in the absorptions of the bands which are as a result of the bonding that took place between the guests and the LDH host at different stages of synthesis.

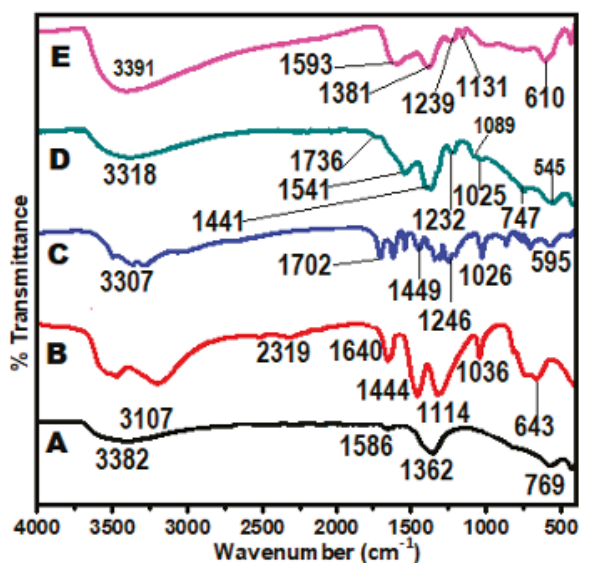

Figure 5. Fourier transform infrared spectroscopy (FT-IR) spectra (A) LDH, (B) $\mathrm{Gd}\left(\mathrm{NO}_{3}\right)_{3}$, (C) pure gallic acid, (D) gallic acid-Zn/Al-LDH/Gd nanoparticles (GAGZA), (E) Gallic acid-Zn/Al-LDH/Gd-Au nanoparticles (GAGZAu).

\subsection{Thermal Stability Analysis (TGA/DTG)}

The thermal stability of the nanoparticles and the pristine materials (GA and LDH) was tested with thermogravimetric and differential thermogravimetric analyses (TGA/DTG). To have more understanding of the thermal changes that occur, the TGA/DTG patterns of Zn/Al-LDH, GA, GAGZA, and GAGZAu were obtained as shown in Figure 6, and some key parameters have been highlighted in Table 2, which are: maximum peak temperature (Tmax), decomposition temperature range (Trange), and change in mass [(decomposed mass) Delta $\mathrm{m}$ ] [28]. The peak at $88^{\circ} \mathrm{C}$ which corresponds with weight loss of $5.9 \%$ in the $\mathrm{Zn} / \mathrm{Al}-\mathrm{LDH}$ thermogram (Figure 6a) is representative of physisorbed water loss on the surface and interlayer of the $\mathrm{LDH}$.

The second peak at $243{ }^{\circ} \mathrm{C}$ with $16.3 \%$ mass loss and the third peak with $8.7 \%$ weight loss are reflective of nitrate decomposition and metal hydroxide layers dehydroxylation. The GA thermogram in Figure $6 \mathrm{~b}$ shows three significant peaks, the first peak at $86^{\circ} \mathrm{C}$ with $8.8 \%$ weight loss is attributed to absorbed water, while the peak at $264^{\circ} \mathrm{C}$ which accounts to substantial weight loss of $41.0 \%$ is due to the dihydroxylation and decomposition of gallic acid structure, and lastly the one at $325^{\circ} \mathrm{C}(22.5 \%)$ which represents residue decomposition.

Figure $6 \mathrm{c}$ depicts the thermogram of the GAGZA nanoparticles. The peak at $112{ }^{\circ} \mathrm{C}$ which represents $10.6 \%$ weight loss is related to removal of water. The peak next to it at $250{ }^{\circ} \mathrm{C}$ representing $17.4 \%$ loss of weight is due to dehydroxylation of the intercalated gallic acid as well as partial decomposition of nitrate. The peak at $600{ }^{\circ} \mathrm{C}$ indicating $8.2 \%$ weight loss could be attributed to the decomposition of $\mathrm{Gd}\left(\mathrm{NO}_{3}\right)_{3}$ together with the nitrate ions of $\mathrm{LDH}$ layers in the nanocomposite. 
The sharp peak at $851{ }^{\circ} \mathrm{C}(8.3 \%)$ indicates the collapse of hydrotalcite-like layers and complete decomposition of the nanoparticles [29], which shows improved thermal stability that took place in comparison with the individual components. This is due to electrostatic attraction bonding that occurred between the negatively charged gallic acid functional groups and the positively charged LDH interlayer surfaces. Interestingly, the thermogram of the final nanocomposite which is the gold coated GAGZAu (Figure 6d), showed less thermal stability compared to the GAGZA thermogram. For instance, the first two peaks ( 99 and $198^{\circ} \mathrm{C}$ ) which represent loss of water and that of dihydroxylation respectively, appear to be at lower temperatures in comparison with GAGZA composite (112 and $250{ }^{\circ} \mathrm{C}$ ). The peak at $602{ }^{\circ} \mathrm{C}$ and $1.59 \%$ weight loss of GAGZAu is associated with nitrate ions decomposition in nanocomposite. The peak associated with AuNPs surface decomposition is at $334{ }^{\circ} \mathrm{C}$ [30], amounting to about $2.2 \%$ weight loss. Generally however, the nanohybrid appear to be less thermally stable after coating with the AuNPs as depicted in Table 2. Nonetheless, the AuNPs could be more thermally stable when synthesized separately in their pure nanoparticles form using capping agents. As reported in literature, thermal stability of AuNPs depends on certain factors, such as the capping or stabilizing agents used in the synthesis and the type of bonding that occur between them determine the thermal stability, thus, weak bonds result in less stability and vice versa [31-34]. In our case, the reduction in thermal stability after AuNPs coating is presumably due to weak interaction between the AuNPs and the LDH nanocomposite surface, since no capping agent was used for the AuNPs synthesis.

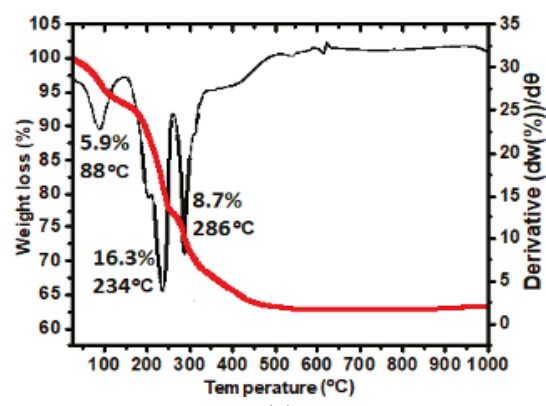

(a)

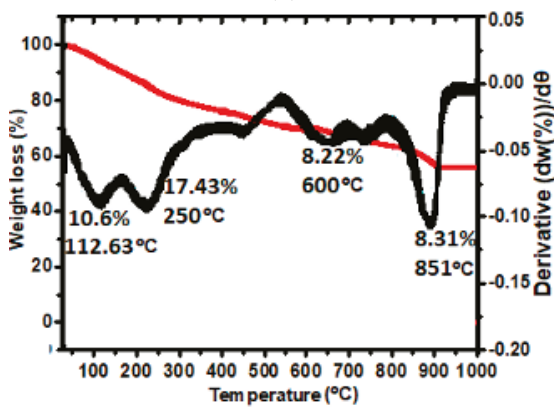

(c)

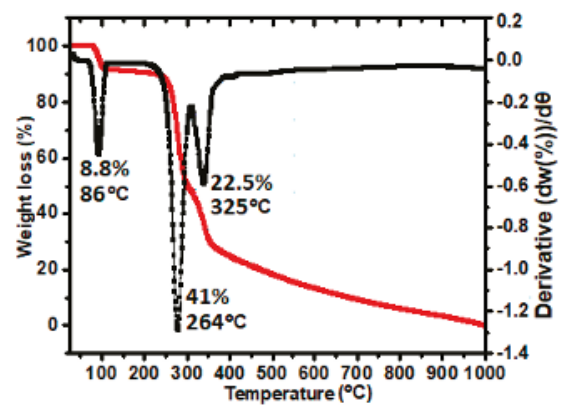

(b)

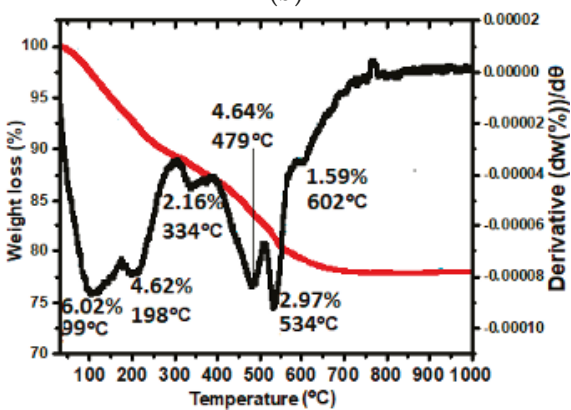

(d)

Figure 6. (a) Thermogravimetric and differential thermogravimetric analyses (TGA/DTG) thermograms of pure LDH; (b) pure gallic acid; (c) gallic acid-LDH/Gd nanoparticles (GAGZA); (d) gallic acid-LDH/Gd-Au nanoparticles (GAGZAu). 
Table 2. Maximum peak temperature (Tmax) decomposition temperature range (Trange) and change in mass (Delta $\mathrm{m}$ ).

\begin{tabular}{cccc}
\hline Sample & Tmax $\left({ }^{\circ} \mathrm{C}\right)$ & Trange $\left({ }^{\circ} \mathrm{C}\right)$ & Delta m (\%) \\
\hline (A) LDH & 234 & $88-286$ & 30.9 \\
(B) Gallic acid & 264 & $86-325$ & 72.3 \\
(C) GAGZA & 851 & $112-851$ & 44.6 \\
(D) GAGZAu & 534 & $99-602$ & 22.2 \\
\hline
\end{tabular}

\subsection{CHNS-ICP-ES Analyses}

The composition of the GAGZAu nanocomposite was determined by combining CHNS and ICP-ES analyses, the individual data acquired were used to estimate the percentage content of each element. As indicated in Table 3, the constituents of the nanocomposite have, as obtained from the results, indicated successful intercalation of the guest drug (gallic acid) into LDH interlayer gallery. Additionally, the mole ratio of the $\mathrm{Zn}^{2+} / \mathrm{Al}^{3+}$ in the GAGZAu nanocomposite and in the LDH was observed to be the same (0.1\%). The ICP-ES data also shows presence of $\mathrm{Gd}$ and $\mathrm{Au}$, indicating successful integration of Gd in the LDH-Gd block as well as coating of the surface with AuNPs. Moreover, the results are a validation of the EDX results reported earlier in this paper, which similarly confirms the presence of the aforesaid elements in the nanocarrier.

Table 3. Elemental analysis results for $\mathrm{Zn} / \mathrm{Al}$-layered double hydroxide (LDH) nanocarrier and GAGZAu nanocomposite.

\begin{tabular}{|c|c|c|c|c|c|c|c|c|c|}
\hline Sample & $\mathrm{C} \%$ & $\mathbf{H}^{\circ} \cdot$ & $\mathbf{N} \%$ & $\mathrm{Zn} \% \cdot$ & $\mathrm{Al} \% \cdot \bullet$ & $\mathrm{Gd} \%{ }^{*}$ & $\mathbf{A u} \% \bullet$ & $\mathrm{Zn}^{2+} / \mathrm{Al}^{3+} \% \cdot$ & Drug $\%$ \\
\hline $\mathrm{Zn} / \mathrm{Al}-\mathrm{LDH}$ & - & - & 7.3 & 45 & 5.2 & - & - & 0.1 & - \\
\hline GAGZA-Au & 8.714 & 2.186 & 0.4208 & 8.82 & 1.02 & 1.56 & 3.0 & 0.1 & 50 \\
\hline
\end{tabular}

\subsection{In Vitro Cytotoxicity Studies against HepG2 and $3 T 3$ Cell Lines}

The toxicities of the GAGZAu, the free drug and the nanocarrier were tested via cell viability study against liver cancer cell lines and normal human cell lines, HepG2 and 3T3, respectively. The cell lines were exposed to different concentrations of the aforementioned samples, starting with 0 (control) to $100 \mu / \mathrm{mL}$. As observed in Figure 7, the free drug, the LDH and the GAGZAu nanohybrid tested against the 3 T3 cell lines indicate nearly $100 \%$ cell viability in most of the concentrations. The 50 and $100 \mu / \mathrm{mL}$ dosage of the free drug however, shows slightly lower viability. This is expected as anticancer drugs are known to be cytotoxic and have certain undesirable side effects on normal cells $[35,36]$. Likewise, Gd-based contrast agent has been reported to have caused nephrogenic systemic fibrosis, which is associated with the toxicity of Gd [37,38]. Nevertheless, such toxicities are reduced when the anticancer agents and other agents are intercalated into LDH nanocarriers [39] or adsorbed on the surface, as observed in our case, the toxicities of GA and Gd have been virtually neutralized in the nanoparticles form, that is in the GAGZAu tested for the normal cell lines.

The HepG2 cell lines were similarly treated with different concentrations of the free drug, LDH and GAGZAu. Although the toxicity of the gallic acid against the HepG2 cell lines decreased in the nanoparticles form, the viability of the cells treated with GAGZAu still indicates cytotoxicity against HepG2 cell lines. Moreover, the LDH nanocarrier affects the therapeutic activity of the gallic acid; the nanoparticles could be more cytotoxic to other cancer cell lines. Nonetheless, the cells treated at $50 \mu / \mathrm{mL}$ of GAGZAu show the highest anticancer activity, which is due to higher release of the anticancer compounds contained inside the nanocomposite. Even though both 3T3 and HepG2 cells lines are non-phagocytic and have negatively charged cell surfaces, only the cancer cell lines will be susceptible to anticancer activity effects of the nanocomposite. The general mechanism of GA uptake by the cells is through electrostatic attraction which is prompted by cellular endocytosis between the 
positively charged GAGZAu surface and the negatively charged cell surface [20]. The individual specific mechanism through which the GAGZAu intake occurs in the 3T3 and HepG2 cannot be described via simple MTT assay alone, other more precise experiments such as flow cytometry have to be applied.

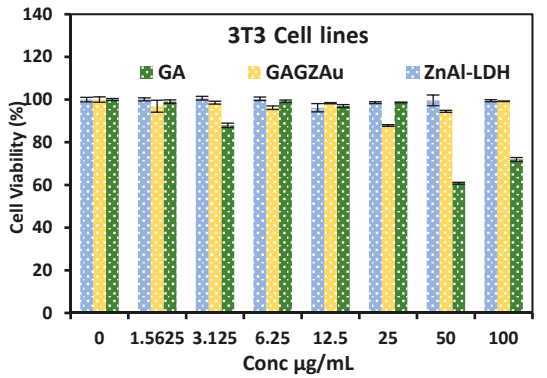

(a)

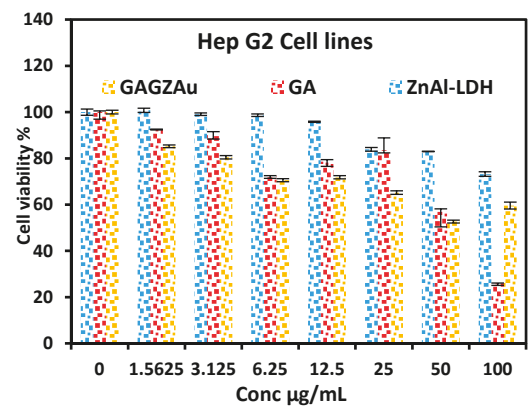

(b)

Figure 7. Cytotoxicity study of GAGZAu, LDH, and free drug at various concentrations exposed to (a) cancer cell lines (HepG2) and; (b) normal cell lines (3T3).

\subsection{Magnetic Resonance Imaging}

The magnetic resonance image of the samples was captured as shown in Figure 8, where five tubes were arranged, each representing GAGZAu nanoparticle solutions at different concentrations in order of increasing $\mathrm{Gd}^{3+}$ concentration; $0.2,0.5$, and $2.0 \mathrm{w} / \mathrm{v}, \mathrm{Gd}\left(\mathrm{NO}_{3}\right)_{3}$ and distilled water (as the reference). The average intensity of each tube was measured using Syngovia MRI software, and signal mean intensities were calculated. The signals intensities of each concentrate tube was documented to increase steadily and proportionally as the concentration of $\mathrm{Gd}^{3+}$ in the nanohybrid, that is 322.44, 297.70 , and 262.00 for 2.0, 0.5, and $0.2 w / v$ concentration, respectively. In addition, the R1 signal intensity of GAGZAu at the lowest dosage $(0.2 w / v)$ indicates higher R1 signal intensity $(262.00)$ than $\mathrm{Gd}\left(\mathrm{NO}_{3}\right)_{3}(235.45)$ at 0.5 concentration and the water reference (228.66). This is indicative that $\mathrm{R} 1$ signal increase is as a result of the formation of Gd-based nanoparticles. The boost occurred as a result of the shortening of the longitudinal relaxation time (T1) [40,41] due higher surface area to volume ratio of AuNPs coated on the surface of the nanoparticles, which improves water solubility [41] and molecule movement, and proton exchange within the $\mathrm{Gd}^{3+} / \mathrm{LDH}$ lattice [42,43]. The phenomenon is suspected to be connected with the change in structure of the nanohybrid after AuNPs surface coating, as observed in the GAGZAu TEM and FESEM micrographs. The free movement of water molecules through the nanohybrid results in shortening of the longitudinal relaxation time as well as reduces short circulation in the system, which in turn increases the R1 value of the recorded MR image. The longitudinal relaxation time as stated earlier in this work is responsible for the contrast effect of MR imaging [44]. Similar outcome was reported by previous works done using Gd/LDH-Au nanoparticles [8]. 


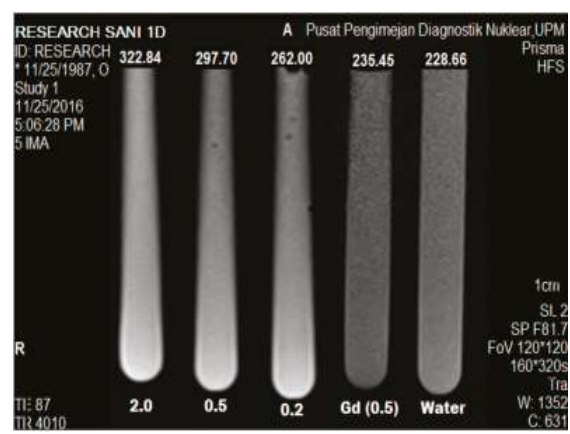

Figure 8. GAGZAu image at different $\mathrm{Gd}^{3+}$ concentrations $(2.0,0.5,0.2)$, $\mathrm{Gd}(0.5) w / v$ and water taken from magnetic resonance imaging MRI Prisma 3-Tesla machine.

\section{Materials and Methods}

\subsection{Materials}

Gallic acid with molecular weight of $170.12 \mathrm{~g} / \mathrm{mol}$ and $98 \%$ purity, sodium hydroxide molecular weight of $40.00 \mathrm{~g} / \mathrm{mol}$ and $98 \%$ purity and phosphate-buffered saline were purchased from Sigma-Aldrich (St. Louis, MO, USA). Zinc nitrate hexahydrate molecular weight of 297.47 $\mathrm{g} / \mathrm{mol}, 98 \%$ purity, and aluminium nitrate hexahydrate molecular weight of $375.13 \mathrm{~g} / \mathrm{mol}, 98 \%$ purity, were purchased from Systerm ChemPur (Shah Alam, Selangor Darul Ehsan, Malaysia). Gadolinium (III) nitrate hexahydrate and molecular weight of $451.4 \mathrm{~g} / \mathrm{mol}$ with $99.9 \%$ purity and tetrachloroauric(III) acid trihydrate, $393.83 \mathrm{~g} / \mathrm{mol}$ and $49 \%$ Au purity were purchased from Acros Organics (Morris Plains, NJ, USA). Sodium borohydride molecular weight of $37.83 \mathrm{~g} / \mathrm{mol}$, and $99 \%$ purity was purchased from Fluka Analytical (St. Gallen, Switzerland). All chemicals were used as received without further purification. Deionized water was used throughout the experiment.

\subsection{Synthesis of Gd-Zn/Al-Layered Double Hydroxide}

$\mathrm{Zn} / \mathrm{Al}$-layered double hydroxide was synthesized using $\mathrm{Zn}\left(\mathrm{NO}_{3}\right)_{2}$ and $\mathrm{Al}\left(\mathrm{NO}_{3}\right)_{3}$ at a molar ratio of $4: 1$ of $\mathrm{Zn}^{2+}$ to $\mathrm{Al}^{3+} . \mathrm{Gd}\left(\mathrm{NO}_{3}\right)_{3}(0.0008 \mathrm{M})$ was firstly dissolved in $250 \mathrm{~mL}$ deionized water before the addition of the $\mathrm{Zn} / \mathrm{Al}$ nitrate salts. Dropwise addition of $\mathrm{NaOH}(2 \mathrm{M})$ was immediately followed until a $\mathrm{pH}$ of 7 was reached. The synthesis was conducted under nitrogen flow and vigorous stirring. The slurry obtained at the end of the process was aged for $18 \mathrm{~h}$ at $70{ }^{\circ} \mathrm{C}$, centrifuged, washed with deionized water (three times), and oven dried at $60^{\circ} \mathrm{C}$.

\subsection{Loading of Gallic Acid into Gd-Zn/Al-LDH Nanoparticles (GAGZA)}

Briefly, gallic acid, $0.2 \mathrm{M}$ solution was prepared by dissolving $3.6 \mathrm{~g}$ of the drug into $50 \mathrm{~mL}$ deionized water while stirring and heating at $45^{\circ} \mathrm{C}$. Under continuous nitrogen flow with vigorous stirring, the drug solution was simultaneously added dropwise with $\mathrm{NaOH}(2 \mathrm{M})$ into the $250 \mathrm{~mL}$ solution of Gd-Zn/Al-layered double hydroxide. The solution was kept until pH 7 was reached and the drug was completely loaded. The mixture was then aged for $18 \mathrm{~h}$ at approximately $70{ }^{\circ} \mathrm{C}$. The resultant slurry obtained was filtered, washed/centrifuged using deionized water, and oven dried at $60{ }^{\circ} \mathrm{C}$ for $12 \mathrm{~h}$.

\subsection{Doping of Gold Nanoparticles (AuNPs) onto Zn/Al-Gd GA LDH (GAGZAu)}

Appropriate amount of GAGZA was ultrasonically dispersed for $5 \mathrm{~min}$, under gentle stirring; $2 \% \mathrm{HAuCl}_{4}(6 \mathrm{~mL})$ solution was added. After 5 min stirring, $0.125 \mathrm{M} \mathrm{NaOH}(4 \mathrm{~mL})$ was added; the dispersion was allowed to stir for $5 \mathrm{~min}$ before the temperature of the solution was raised to $60{ }^{\circ} \mathrm{C}$ 
and stirred for $24 \mathrm{~h}$ in dark conditions. The resulting precipitate was obtained after centrifuge/filtration, the mixture was re-dispersed in $30 \mathrm{~mL}$ deionized water; $1 \mathrm{M} \mathrm{NaBH}_{4}(20 \mathrm{~mL})$ was added and stirred for an hour. The final suspension obtained was washed six times using a centrifuge, filtered, and dried at $70{ }^{\circ} \mathrm{C}$ in an oven.

\subsection{Characterization}

An XRD-6000 (Shimadzu, Tokyo, Japan) X-ray diffraction (XRD) instrument was used for crystallographic analysis of the powdered samples. $\mathrm{CuK}_{\alpha}$ radiation $(\lambda=1.5418 \AA$ ) at scan speed of $4^{\circ} / \mathrm{min}$, using a range of $2-70{ }^{\circ} \mathrm{C}$ at $30 \mathrm{kV}$ and $30 \mathrm{~mA}$ was used in obtaining the XRD patterns. A ultraviolet-visible (UV-Vis) spectrophotometer (PerkinElmer, Singapore) (Lambda35) was used for the controlled release and optical property studies. Fourier transform infrared (FT-IR) spectra of the materials were obtained using a Thermo Nicolet, Nicolet 6700 model (Thermo Scientific, Waltham, MA, USA). The spectra were obtained using the potassium bromide $(\mathrm{KBr})$ discs at 10 ton pellet pressing and a resolution of $4 \mathrm{~cm}^{-1}$ over a range of $400-4000 \mathrm{~cm}^{-1}$. A PerkinElmer spectrophotometer (PerkinElmer, Wellesley, MA, USA) (model Optima2000DV) inductively coupled plasma atomic emission spectrometry (ICP-ES) was employed in studying the composition of zinc, aluminum, gadolinium, and gold content of the nanoparticles. A CHNS-932 LECO (LECO, St. Joseph, Michigan, USA) instrument was used in determining carbon, hydrogen, nitrogen, and sulphur (CHNS) content in the sample. A Mettler-Toledo instrument (METTLER TOLEDO, Shah Alam, Selangor, Malaysia) was used for thermogravimetric and differential thermogravimetric (TGA/DTG) analyses. A sample heating rate of $10{ }^{\circ} \mathrm{C} / \mathrm{min}$ and a range of $20-1000{ }^{\circ} \mathrm{C}$ were used in this work. The analysis was carried out at a continuous nitrogen flow at $50 \mathrm{~mL} / \mathrm{min}$ flow rate. High resolution transmission electron microscope (Hi-TEM) (FEI Tecnai TF20 X-Twin, Hillsboro, OR, USA) and FEI Nova NanoSEM 230 field emission scanning electron microscope (FESEM) (FEI, Hillsboro, OR, USA) were employed for shape/sizes analyses and morphological analyses, respectively while energy dispersive X-ray spectroscopy (EDX) (FEI, Hillsboro, OR, USA) was used for elemental analysis of the FESEM micrographs.

\subsection{Drug Release Study}

As mentioned earlier, gallic acid release from GAGZA was studied using a PerkinElmer Lambda 35 UV-Vis spectrophotometer (PerkinElmer, Singapore). Firstly, standard solutions of gallic acid at different concentrations were prepared. Appropriate amount of GAGZA was dissolved in $5 \mathrm{~mL}$ of $\mathrm{HCl}$ $(1 \mathrm{~mol} / \mathrm{L})$ and then diluted with $45 \mathrm{~mL}$ deionized water. The lambda max of the drug in the solution was found to be $264 \mathrm{~nm}$, which was used in determining the standard curve for the standard solutions and drug loading capacity of GA. Kinetic release of the loaded GA from GAGZA was done at pH 7.4 and 4.8 in a phosphate-buffered solution (PBS). Briefly, $25 \mathrm{mg}$ of the sample was dispersed in $30 \mathrm{~mL}$ of the PBS in tubes. The tubes were placed in an oil bath shaker at $37^{\circ} \mathrm{C}$ and $3 \mathrm{~mL}$ of the solutions were withdrawn and replaced with $3 \mathrm{~mL}$ of pure PBS at time intervals of $0.5,1.0,2.0,3.0,4.0,5.0,6.0,12.0$, $24.0,48.0,72.0,92.0$, and $120.0 \mathrm{~h}$. The release media extracted were analyzed at lambda max $=264 \mathrm{~nm}$ wavelength with a UV-Vis spectrophotometer (PerkinElmer, Singapore).

\subsection{Cell Culture}

The cell lines used for cancer study was HepG2 (human liver hepatocellular carcinoma cell line) and normal cell lines, 3T3 (standard fibroblast cell line) for toxicity study, which were obtained from ATCC. RPMI 1640 was used as a medium for cell lines growth, which contains $1 \%$ penicillin/streptomycin and 10\% fetal bovine serum (FBS). Cells culture was done at approximately $80 \%$ confluence, as adherent monolayers. Temperature was set at $37^{\circ} \mathrm{C}$ and in a $5 \% \mathrm{CO}_{2}$ humidified atmosphere. Cell harvest was done via trypsinization (in brief) with trypsin-EDTA solution. All reagents are research grade and were used as received. 


\subsection{MTT Cell Viability Assays}

RPMI 1640 was also used as a medium for the cancer cell lines and normal cells, which were grown in a humidified incubator at $37^{\circ} \mathrm{C}$ and $5 \% \mathrm{CO}_{2}$. The cells were grown and were harvested and counted. Prior to $24 \mathrm{~h}$ incubation, the cells were transferred to 96 -well plates $(1 \times 104$ cells $/$ well $)$ and then the GAGZAu nanoparticles, LDH, and free GA were added. The medium was kept for $24 \mathrm{~h}$ to allow the cells to attach to the surface before treatment. The cells containing the GAGZAu, Zn/Al-LDH, and free drug were administered and applied in different concentrations prior to treatment and $72 \mathrm{~h}$ incubation. For MTT, 5 mg of (3-[4,5-dimethylthiazol-2-yl]-2, 5-diphenyltetrazolium bromide was dissolved in PBS $(2 \mathrm{~mL})$. To each of the 96-well plates, $20 \mu \mathrm{L}$ of the MTT solution was added and incubated at $37^{\circ} \mathrm{C}$ for $3 \mathrm{~h}$ until formazan product was developed (purple-colored). Suction method was employed to remove the solution in each well containing media, unbound MTT, and dead cells; $100 \mu \mathrm{L}$ of DMSO was added to each well. The optical densities of the cells were obtained with the use of a microplate reader at $570 \mathrm{~nm}$. Prior to the measurements, the cells were shaken. All analyses were done in triplicate and the cell viabilities/increase was presented in percentage in reference to control cells.

\subsection{MR Imaging Analysis}

The GAGZAu nanocomposite was tested for MRI signal intensity using 3.0 T MRI clinical instrument (3.0 T Siemens Magnetom, Erlangen, Germany). Prior to the analysis, GAGZAu was prepared in various concentrations $(2.0,0.5$, and $0.2 \mathrm{w} / v)$ according $\mathrm{Gd}^{3+}$ concentration. $\mathrm{Gd}\left(\mathrm{NO}_{3}\right)_{3}$ $(0.5 w / v)$ and water together with samples were then placed in a $1 \mathrm{~mL}$ tube. The MR image was acquired by attaching the tubes to an MRI phantom, and then the phantom was placed in the instrument. The T1-weighted images of the samples were captured at TR/TE: (83/9000) $224 \times 220 \mathrm{~s}$, field of view (FOV): $120 \times 120$. The MR image was analyzed and signal intensities of the individual samples were extracted with Syngovia (MRI and CT reporting software, syngo MR E11, Siemens, Erlangen, Germany, 2013).

\section{Conclusions}

Gd-based nanocomposite (GAGZAu) was developed in this work, which was painstakingly analyzed to understand and ascertain its theranostic properties. The results obtained from different stages of the nanoparticles synthesis until the final nanocomposite GAGZAu shows the potentiality of the nanohybrid to be used as a theranostic bimodal delivery agent. The in vitro drug release study shows higher drug release in $\mathrm{pH} 4.8$ ( $\mathrm{pH}$ of cancer cells), indicating the capability of the platform to convey the GA into cancer cells and prevent premature release in the blood stream. Moreover, the nanocomposite shows reasonable cytotoxicity to HepG2 cancer cell lines and negligible toxicity to 3T3 normal cell lines. The preliminary MR imaging analysis conducted on the developed theranostic nanohydrid also indicates improved MRI contrast of T1-weighted image obtained as compared to pure $\mathrm{Gd}\left(\mathrm{NO}_{3}\right)_{3}$ and water. Based on the promising outcome of this work, further works such as in vivo testing could be done on the GAGZAu nanocomposite, which would improve its theranostic prospects, such as reducing artefact formations like short circulation and tissue specificity that are associated with gadolinium-based contrast agents as well as toxicities of chemotherapeutic agents.

Acknowledgments: The authors acknowledge Universiti Putra Malaysia (UPM) and the Ministry of Higher Education of Malaysia (MOHE) for providing the funds to conduct this research under NanoMITe grant Vot No. 5526300. We also acknowledge the assistance provided by Nor Kamalia Binti Abdul Jalil of Centre for Diagnostic and Nuclear Imaging, Universiti Putra Malaysia, during the MR imaging test of this research.

Author Contributions: Muhammad Sani Usman and Mohd Zobir Hussein conceived and designed the experiments; Muhammad Sani Usman performed the experiments; Sharida Fakurazi and Mas Jaffri Masarudin analyzed the data; Fathinul Fikri Ahmad Saad and Mohd Zobir Hussein contributed reagents/materials/analysis tools; Muhammad Sani Usman wrote the paper. All authors read and edited the paper before submission.

Conflicts of Interest: The authors declare no conflict of interest. 


\section{References}

1. Usman, M.S.; Ibrahim, N.A.; Shameli, K.; Zainuddin, N.; Yunus, W.M.Z.W. Copper nanoparticles mediated by chitosan: Synthesis and characterization via chemical methods. Molecules 2012, 17, 14928-14936. [CrossRef] [PubMed]

2. Kovanda, F.; Jindova, E.; Dousova, B.; Kolousek, D.; Plestil, J.; Sedlakova, Z. Layered double hydroxides intercalated with organic anions and their application in preparation of $1 \mathrm{dh}$ /polymer nanocomposites. Acta Geodyn. Geomater. 2009, 6, 111-119.

3. Swierczewska, M.; Liu, G.; Lee, S.; Chen, X. High-sensitivity nanosensors for biomarker detection. Chem. Soc. Rev. 2012, 41, 2641-2655. [CrossRef] [PubMed]

4. Yoo, D.; Lee, J.-H.; Shin, T.-H.; Cheon, J. Theranostic magnetic nanoparticles. Acc. Chem. Res. 2011, 44, 863-874. [CrossRef] [PubMed]

5. Xu, W.; Kattel, K.; Park, J.Y.; Chang, Y.; Kim, T.J.; Lee, G.H. Paramagnetic nanoparticle $\mathrm{T}_{1}$ and $\mathrm{T}_{2}$ MRI contrast agents. Phys. Chem. Chem. Phys. 2012, 14, 12687-12700. [CrossRef] [PubMed]

6. Jeong Kim, T.; Seok Chae, K.; Chang, Y.; Ho Lee, G. Gadolinium oxide nanoparticles as potential multimodal imaging and therapeutic agents. Curr. Top. Med. Chem. 2013, 13, 422-433. [CrossRef]

7. Usman, M.S.; Hussein, M.Z.; Fakurazi, S.; Ahmad Saad, F.F. Gadolinium-based layered double hydroxide and graphene oxide nano-carriers for magnetic resonance imaging and drug delivery. Chem. Cent. J. 2017, 11, 47. [CrossRef]

8. Cherry, S.R. Multimodality imaging: Beyond PET/CT and SPECT/CT. Semin. Nucl. Med. 2009, 39, 348-353. [CrossRef] [PubMed]

9. Srinivasan, M.; Rajabi, M.; Mousa, S.A. Multifunctional nanomaterials and their applications in drug delivery and cancer therapy. Nanomaterials 2015, 5, 1690-1703. [CrossRef] [PubMed]

10. Elgqvist, J. Nanoparticles as Theranostic Vehicles in Experimental and Clinical Applications-Focus on Prostate and Breast Cancer. Int. J. Mol. Sci. 2017, 18, 1102. [CrossRef] [PubMed]

11. Kim, K.S.; Park, W.; Hu, J.; Bae, Y.H.; Na, K. A cancer-recognizable MRI contrast agents using pH-responsive polymeric micelle. Biomaterials 2014, 35, 337-343. [CrossRef] [PubMed]

12. Campbell, J.L.; Arora, J.; Cowell, S.F.; Garg, A.; Eu, P.; Bhargava, S.K.; Bansal, V. Quasi-cubic magnetite/silica core-shell nanoparticles as enhanced MRI contrast agents for cancer imaging. PLoS ONE 2011, 6, e21857. [CrossRef] [PubMed]

13. Gwak, G.-H.; Kim, M.-K.; Oh, J.-M. Composites of quasi-colloidal layered double hydroxide nanoparticles and agarose hydrogels for chromate removal. Nanomaterials 2016, 6, 25. [CrossRef] [PubMed]

14. Zhang, Y.; Liu, X.; Zhang, C.; He, M.; Lu, X. Interlayer Structures and Dynamics of Arsenate and Arsenite Intercalated Layered Double Hydroxides: A First Principles Study. Minerals 2017, 7, 53. [CrossRef]

15. Barahuie, F.; Hussein, M.Z.; Arulselvan, P.; Fakurazi, S.; Zainal, Z. Drug delivery system for an anticancer agent, chlorogenate-Zn/Al-layered double hydroxide nanohybrid synthesised using direct co-precipitation and ion exchange methods. J. Solid State Chem. 2014, 217, 31-41. [CrossRef]

16. Saifullah, B.; Hussein, M.Z.; Hussein-Al-Ali, S.H.; Arulselvan, P.; Fakurazi, S. Sustained release formulation of an anti-tuberculosis drug based on para-amino salicylic acid-zinc layered hydroxide nanocomposite. Chem. Cent. J. 2013, 7, 72. [CrossRef] [PubMed]

17. Bullo, S.; Hussein, M.Z. Inorganic nanolayers: Structure, preparation, and biomedical applications. Int. J. Nanomed. 2015, 10, 5609. [CrossRef] [PubMed]

18. Dorniani, D.; Hussein, M.Z.B.; Kura, A.U.; Fakurazi, S.; Shaari, A.H.; Ahmad, Z. Preparation of $\mathrm{Fe}_{3} \mathrm{O}_{4}$ magnetic nanoparticles coated with gallic acid for drug delivery. Int. J. Nanomed. 2012, 7, 5745-5756. [CrossRef] [PubMed]

19. Kura, A.U.; Hussein, M.Z.; Fakurazi, S.; Arulselvan, P. Layered double hydroxide nanocomposite for drug delivery systems; bio-distribution, toxicity and drug activity enhancement. Chem. Cent. J. 2014, 8. [CrossRef] [PubMed]

20. Choi, S.-J.; Choi, G.E.; Oh, J.-M.; Oh, Y.-J.; Park, M.-C.; Choy, J.-H. Anticancer drug encapsulated in inorganic lattice can overcome drug resistance. J. Mater. Chem. 2010, 20, 9463-9469. [CrossRef]

21. Long, N.N.; Kiem, C.D.; Doanh, S.C.; Nguyet, C.T.; Hang, P.T.; Thien, N.D.; Quynh, L.M. Synthesis and optical properties of colloidal gold nanoparticles. J. Phys. Conf. Ser. 2009, 187, 012026. [CrossRef] 
22. Hussein, M.Z.B.; Zainal, Z.; Yahaya, A.H.; Wong Vui Foo, D. Controlled release of a plant growth regulator, $\alpha$-naphthaleneacetate from the lamella of $\mathrm{Zn}$-Al-layered double hydroxide nanocomposite. J. Control. Release 2002, 82, 417-427. [CrossRef]

23. Oh, J.-M.; Choi, S.-J.; Kim, S.-T.; Choy, J.-H. Cellular uptake mechanism of an inorganic nanovehicle and its drug conjugates: Enhanced efficacy due to clathrin-mediated endocytosis. Bioconjug. Chem. 2006, 17, 1411-1417. [CrossRef] [PubMed]

24. Dorniani, D.; Kura, A.U.; Hussein-Al-Ali, S.H.; Bin Hussein, M.Z.; Fakurazi, S.; Shaari, A.H.; Ahmad, Z. In vitro sustained release study of gallic acid coated with magnetite-PEG and magnetite-PVA for drug delivery system. Sci. World J. 2014, 416354. [CrossRef]

25. Raffi, M.; Mehrwan, S.; Bhatti, T.M.; Akhter, J.I.; Hameed, A.; Yawar, W.; ul Hasan, M.M. Investigations into the antibacterial behavior of copper nanoparticles against Escherichia coli. Ann. Microbiol. 2010, 60, 75-80. [CrossRef]

26. Kong, X.; Jin, L.; Wei, M.; Duan, X. Antioxidant drugs intercalated into layered double hydroxide: Structure and in vitro release. Appl. Clay Sci. 2010, 49, 324-329. [CrossRef]

27. Zhang, Z.; Liu, W.; Zheng, Y.; Jin, L.; Yao, W.; Gao, X. SGP-2, an acidic polysaccharide from Sarcandra glabra, inhibits proliferation and migration of human osteosarcoma cells. Food Funct. 2014, 5, 167-175. [CrossRef] [PubMed]

28. Chieng, B.W.; Ibrahim, N.A.; Yunus, W.M.Z.W.; Hussein, M.Z. Poly (lactic acid)/poly (ethylene glycol) polymer nanocomposites: Effects of graphene nanoplatelets. Polymers 2013, 6, 93-104. [CrossRef]

29. Ghotbi, M.Y.; bin Hussein, M.Z. Gallate-Zn-Al-layered double hydroxide as an intercalated compound with new controlled release formulation of anticarcinogenic agent. J. Phys. Chem. Solids 2010, 71, 1565-1570. [CrossRef]

30. Mukherjee, P.; Bhattacharya, R.; Bone, N.; Lee, Y.K.; Patra, C.R.; Wang, S.; Lu, L.; Secreto, C.; Banerjee, P.C.; Yaszemski, M.J. Potential therapeutic application of gold nanoparticles in B-chronic lymphocytic leukemia (BCLL): Enhancing apoptosis. J. Nanobiotechnol. 2007, 5, 4. [CrossRef] [PubMed]

31. Zarabi, M.F.; Arshadi, N.; Farhangi, A.; Akbarzadeh, A. Preparation and Characterization of Gold Nanoparticles with Amino Acids, Examination of Their Stability. Indian J. Clin. Biochem. 2014, 29, 306-314. [CrossRef] [PubMed]

32. King, S.R.; Shimmon, S.; Gentle, A.R.; Westerhausen, M.T.; Dowd, A.; McDonagh, A.M. Remarkable thermal stability of gold nanoparticles functionalised with ruthenium phthalocyanine complexes. Nanotechnology 2016, 27, 215702. [CrossRef] [PubMed]

33. Patra, J.K.; Baek, K.H. Novel green synthesis of gold nanoparticles using Citrullus lanatus rind and investigation of proteasome inhibitory activity, antibacterial, and antioxidant potential. Int. J. Nanomed. 2015, 10, 7253. [CrossRef]

34. Zawada, K.; Waldemar, T.; Elżbieta, M. A smart synthesis of gold/polystyrene core-shell nanohybrids using TEMPO coated nanoparticles. RSC Adv. 2014, 4, 23876-23885. [CrossRef]

35. Sugano, K.; Kansy, M.; Artursson, P.; Avdeef, A.; Bendels, S.; Di, L.; Ecker, G.F.; Faller, B.; Fischer, H.; Gerebtzoff, G. Coexistence of passive and carrier-mediated processes in drug transport. Nat. Rev. Drug Discov. 2010, 9, 597-614. [CrossRef] [PubMed]

36. Xu, Z.P.; Lu, G. Layered double hydroxide nanomaterials as potential cellular drug delivery agents. Pure Appl. Chem. 2006, 78, 1771-1779. [CrossRef]

37. Tian, X.; Shao, Y.; He, H.; Liu, H.; Shen, Y.; Huang, W.; Li, L. Nanoamplifiers synthesized from gadolinium and gold nanocomposites for magnetic resonance imaging. Nanoscale 2013, 5, 3322-3329. [CrossRef] [PubMed]

38. Thomsen, H.S. Nephrogenic systemic fibrosis: A serious late adverse reaction to gadodiamide. Nephrogenic systemic fibrosis: A serious late adverse reaction to gadodiamide. Eur. Radiol. 2006, 5, 2619-2621. [CrossRef] [PubMed]

39. Sparreboom, A.; Baker, S.D.; Verweij, J. Paclitaxel repackaged in an albumin-stabilized nanoparticle: Handy or just a dandy? J. Clin. Oncol. 2005, 23, 7765-7767. [CrossRef] [PubMed]

40. Atabaev, T.S.; Lee, J.H.; Shin, Y.C.; Han, D.-W.; Choo, K.S.; Jeon, U.B.; Hwang, J.Y.; Yeom, J.A.; Kim, H.-K.; Hwang, Y.-H. Eu, Gd-Codoped Yttria Nanoprobes for Optical and T1-Weighted Magnetic Resonance Imaging. Nanomaterials 2017, 7, 35. [CrossRef] [PubMed]

41. Le, W.; Cui, S.; Chen, X.; Zhu, H.; Chen, B.; Cui, Z. Facile synthesis of gd-functionalized gold nanoclusters as potential MRI/CT contrast agents. Nanomaterials 2016, 6, 65. [CrossRef] [PubMed] 
42. Zhang, L.; Liu, T.; Xiao, Y.; Yu, D.; Zhang, N. Hyaluronic acid-chitosan nanoparticles to deliver Gd-DTPA for MR cancer imaging. Nanomaterials 2015, 5, 1379-1396. [CrossRef] [PubMed]

43. Caravan, P. Strategies for increasing the sensitivity of gadolinium based MRI contrast agents. Chem. Soc. Rev. 2006, 35, 512-523. [CrossRef] [PubMed]

44. Shen, A.J.; Li, D.L.; Cai, X.J.; Dong, C.Y.; Dong, H.Q.; Wen, H.Y.; Dai, G.H.; Wang, P.J.; Li, Y.Y. Multifunctional nanocomposite based on graphene oxide for in vitro hepatocarcinoma diagnosis and treatment. J. Biomed. Mater. Res. A 2012, 100, 2499-2506. [CrossRef] [PubMed]

(C) 2017 by the authors. Licensee MDPI, Basel, Switzerland. This article is an open access article distributed under the terms and conditions of the Creative Commons Attribution (CC BY) license (http://creativecommons.org/licenses/by/4.0/). 
Article

\title{
MIL-100(Al) Gels as an Excellent Platform Loaded with Doxorubicin Hydrochloride for $\mathrm{pH}$-Triggered Drug Release and Anticancer Effect
}

\author{
Yuge Feng ${ }^{1}$, Chengliang Wang ${ }^{2}$, Fei Ke ${ }^{3}$, Jianye Zang ${ }^{2}$ and Junfa Zhu ${ }^{1, *}$ \\ 1 National Synchrotron Radiation Laboratory and Department of Chemical Physics, \\ University of Science and Technology of China, Hefei 230029, China; ygfeng@mail.ustc.edu.cn \\ 2 Hefei National Laboratory for Physical Sciences at Microscale, CAS Center for Excellence in \\ Biomacromolecules, Collaborative Innovation Center of Chemistry for Life Sciences, \\ and School of Life Sciences, University of Science and Technology of China, Hefei 230026, China; \\ wangcl@ustc.edu.cn (C.W.); zangjy@ustc.edu.cn (J.Z.) \\ 3 Department of Applied Chemistry and State Key Laboratory of Tea Plant Biology and Utilization, \\ Anhui Agricultural University, Hefei 230036, China; kefei@ahau.edu.cn \\ * Correspondence: jfzhu@ustc.edu.cn; Tel.: +86-551-6360-2064
}

Received: 26 May 2018; Accepted: 15 June 2018; Published: 19 June 2018

\begin{abstract}
Slow and controlled release systems for drugs have attracted increasing interest recently. A highly efficient metal-organic gel (MOGs) drug delivery carrier, i.e., MIL-100(Al) gel, has been fabricated by a facile, low cost, and environmentally friendly one-pot process. The unique structure of MIL-100(Al) gels has led to a high loading efficiency $(620 \mathrm{mg} / \mathrm{g})$ towards doxorubicin hydrochloride (DOX) as a kind of anticancer drug. DOX-loaded MOGs exhibited high stability under physiological conditions and sustained release capacity of DOX for up to three days (under acidic environments). They further showed sustained drug release behavior and excellent antitumor effects in in vitro experiments on HeLa cells, in contrast with the extremely low biotoxicity of MOGs. Our work provides a promising way for anticancer therapy by utilizing this MOGs-based drug delivery system as an efficient and safe vehicle.
\end{abstract}

Keywords: metal-organic gels; doxorubicin loading and release; $\mathrm{pH}$-responsiveness; anticancer effect

\section{Introduction}

Most anticancer chemotherapeutics are controlled at high doses to make up for their premature deterioration and non-specific absorption, which typically results in the development of dose-limited toxicity [1-4]. As alternatives, slow and controlled release systems for drugs have recently attracted increasing interest $[5,6]$. On the one hand, the continuous slow and sustained release of small amounts of drug, instead of several large doses, can weaken patient compliance [7]. On the other hand, delivering the drug by controlled release can reduce the side effects, thus improving therapeutic efficiency [8].

Metal-organic framework (MOFs) is a class of crystalline porous hybrids built from metal ions and organic linkers. Its large surface area, tunable pore size, adjustable composition and structure, and versatile functionality character, make it an ideal carrier for slow and controlled release drug delivery [9-15]. For instance, Horcajada et al. reported that MIL-100(Fe) nanoparticles could load anticancer drugs (doxorubicin, DOX) up to $9 \%$, and a sustained release in phosphate-buffered saline (PBS) within 14 days was observed [16]. Sun et al. reported Cu-metal organic frameworks (MOFs) with mixed ligands, MOFs-2 (40\% 1,3,5-benzene tricarboxylate, $60 \%$ isophthalic acid) and MOFs-3 (70\% 1,3,5-benzene tricarboxylate, $30 \%$ isophthalic acid), and their application as the transport vehicles for the delivery of DOX. The MOFs-2 showed the best performance in transport DOX as 
the consequence of highest loading capacity $(95 \mathrm{mg} / \mathrm{g}$ ). In weak acid solution ( $\mathrm{pH} 5.8)$, MOFs-2 released 20\% DOX in $80 \mathrm{~h}$ [17]. Vasconcelos et al. encapsulated the anticancer drug DOX in nano ZIF-8 with a loading capacity of $49 \mathrm{mg} / \mathrm{g}$, which exhibited a progressive release behavior [18]. However, every previous study has its own shortcomings including complicated synthesis routes, intrinsic biotoxicity, low loading capacity, short release time, and poor stability at a physiological pH of 7.4. The shortcomings limit their potential applications in clinical treatment, which requires high qualities of all the performance-indicators above-mentioned.

Metal-organic gels (MOGs), as the emerging carriers, are constructed by the self-assembly of metal ions and suitable ligands through various noncovalent interactions $[19,20]$. Compared with MOFs, MOGs possess lower density, higher surface area, larger porosity, and can be synthesized in gentle conditions such as cheap and clean solutions, low temperature and short reaction time [21-27]. Inspired by these outstanding features, herein, we designed a kind of MOG, i.e., MIL-100(Al) $\left(\mathrm{Al}_{3} \mathrm{O}(\mathrm{OH})\left(\mathrm{H}_{2} \mathrm{O}\right)_{2}(\mathrm{BTC})_{2} \cdot \mathrm{nH}_{2} \mathrm{O}\right)$ gels synthesized by a facile, low cost, and environmentally friendly one-pot process as the carrier for anticancer drug doxorubicin (DOX). It is encouraging that MIL-100(Al) gels exhibit high performance in all typical indicators. First, they involve a concise synthetic step, large loading capacity for DOX, and low biotoxicity. Second, DOX-loaded MOGs show a slow and sustainable releasing ability and high anticancer efficiency, thus providing a promising approach for clinical anticancer treatment.

\section{Materials and Methods}

\subsection{Materials and Methods}

1,3,5-Benzenetricarboxylic acid $\left(\mathrm{H}_{3} \mathrm{BTC}\right)$ was purchased from Sigma-Aldrich (St. Louis, MO, USA). Aluminum nitrate nonahydrate $\left(\mathrm{Al}\left(\mathrm{NO}_{3}\right)_{3} \cdot 9 \mathrm{H}_{2} \mathrm{O}\right)$ was obtained from Sinopharm (Shanghai, China) Chemical Reagent Co., Ltd., (Shanghai, China). Doxorubicin (DOX) was purchased from Aladdin Biotech Company (Shanghai, China). Other chemicals obtained from commercial suppliers were of analytical reagent. All chemicals were used without further purification.

The powder X-ray diffraction (PXRD) patterns was collected by using the theta rotating anode X-ray diffractometer with $\mathrm{Cu}$ target $(40 \mathrm{KV}, 200 \mathrm{~mA})$ from $2^{\circ}$ to $70^{\circ}$. The Fourier transform infrared spectroscopy (FTIR) spectrum was determined using a Magna-IR 750 spectrometer (Nicolet, Madison, WI, USA) in the range of $500-4000 \mathrm{~cm}^{-1}$ with a resolution of $4 \mathrm{~cm}^{-1}$. The morphologies of the sample were studied using a SIRION200 Schottky field emission scanning electron microscope (FEI, Hillsboro, OR, USA) and JEM-2100F transmission electron microscope (JEOL, Tokyo, Japan) at $200 \mathrm{kV}$, respectively. Nitrogen adsorption-desorption isotherms were carried out with a Micromeritics TriStar II 3020 adsorption analyzer (Micromeritics, Atlanta, GAM USA) at $77 \mathrm{~K}$. UV-Vis absorption spectra were carried out with a Shimadzu UV-1800 spectrophotometer (Shimadzu, Kyoto, Japan).

\subsection{Synthesis of MIL-100(Al) Gels}

In a typical synthesis procedure, aluminum nitrate nonahydrate $\left(\mathrm{Al}\left(\mathrm{NO}_{3}\right)_{3} \cdot 9 \mathrm{H}_{2} \mathrm{O}, 7.6 \mathrm{mmol}\right)$ and 1,3,5-Benzentricarboxylic acid $\left(\mathrm{H}_{3} \mathrm{BTC}, 5 \mathrm{mmol}\right)$ were added to $36 \mathrm{~mL}$ ethanol [28]. After stirring for $15 \mathrm{~min}$ at room temperature to dissolve the solid, the transparent mixture was transferred to a sealed container and heated to $120^{\circ} \mathrm{C}$ for one hour. The wet gels were dried in an oven at $80^{\circ} \mathrm{C}$. Finally, the obtained particles were washed by a Soxhlet extractor using ethanol as medium.

\subsection{Incorporation of $D O X$}

DOX-anticancer drug $(10 \mathrm{mg})$ was first dissolved in $4 \mathrm{~mL}$ deionized water and then the MIL-100(Al) gels $(10 \mathrm{mg}$ ) were added. The suspension was stirred for $24 \mathrm{~h}$ in the dark at room temperature. The obtained materials were then centrifuged, washed with deionized water several times, and dried under vacuum condition for further release tests. The supernatant was collected and measured by a UV-Vis spectrophotometer at a wavelength of $480 \mathrm{~nm}$ for the calculation of drug 
loading content and drug loading efficiency. The drug loading capacity was calculated as follows: drug loading capacity $=$ (weight of DOX in MIL-100(Al) gels/weight of nanoparticles). The drug loading efficiency was calculated by: Drug loading efficiency (wt \%) = (weight of DOX in MIL-100(Al) gels / weight of feeding DOX) $\times 100$. The delivery concentration of DOX was derived according to the standard curve which was obtained from measuring the UV-Vis adsorption spectra of DOX with different known concentrations in PBS buffer solution (shown in Figure S1) and then by plotting the absorbance as a function of DOX concentration (shown in Figure S2).

\subsection{Drug Release}

The drug release experiment was performed by soaking the sample in PBS buffer solutions $(\mathrm{pH}=7.4$ and $\mathrm{pH}=5.5)$ at $37^{\circ} \mathrm{C}$. Ten $\mathrm{mg}$ of DOX-loaded MIL-100(Al) gels (DOX-loaded MOGs) were suspended into $10 \mathrm{~mL}$ PBS solution. The mixture solution was stirred at the temperature of $37^{\circ} \mathrm{C}$ in a water bath. At predetermined time intervals, $3 \mathrm{~mL}$ of PBS solution was removed and assayed. The volume of each withdrawn sample was replaced by the same volume of fresh PBS solution. The amount of released DOX was calculated according to the absorption analyzed by the UV-Vis spectrophotometer at $480 \mathrm{~nm}$ and standard absorbance vis DOX concentration curve. The calibration experiment was performed using different known concentrations of DOX in PBS buffer solution (shown in Figure S1). The derived standard absorbance vis DOX concentration curve is shown in Figure S2.

\subsection{Cell Cytotoxicity of DOX-Loaded MOGs}

HeLa cells were used for cell viability assay. A 96-well plate was used for cell seeding with a total number of about $2 \times 10^{3}$ per well. The cells were first incubated overnight, and then the MIL-100(Al) gels and DOX-loaded MOGs were added in every well with a final concentration ranging from 0.1 $\mu \mathrm{g} / \mathrm{mL}$ to $100 \mu \mathrm{g} / \mathrm{mL}(0.1 \mu \mathrm{g} / \mathrm{mL}, 0.5 \mu \mathrm{g} / \mathrm{mL}, 1 \mu \mathrm{g} / \mathrm{mL}, 2.5 \mu \mathrm{g} / \mathrm{mL}, 5 \mu \mathrm{g} / \mathrm{mL}, 10 \mu \mathrm{g} / \mathrm{mL}, 25 \mu \mathrm{g} / \mathrm{mL}$, $50 \mu \mathrm{g} / \mathrm{mL}$, and $100 \mu \mathrm{g} / \mathrm{mL}$ ). Autoclave water was added and treated as the negative control. The cells were incubated with MOGs or DOX-loaded MOGs for 12, 24, 36, 48, and $72 \mathrm{~h}$, respectively. Later, all the medium in the wells were drawn and discharged, and additional MTT solution dissolved in the medium was used to treat the cells for another $4 \mathrm{~h}$. Finally, dimethyl sulfoxide (DMSO) was loaded to replace the medium and dissolve the crystals for further absorbance detection. The absorbance of each well was obtained at the wavelength of $590 \mathrm{~nm}$. Compared to the negative control, the cell viability was calculated. Each sample was repeated five times and the results presented as average values with error bars representing the standard deviation.

\subsection{Flow Cytometry}

HeLa cells $\left(2 \times 10^{5}\right)$ were seeded on a six-well plate and incubated overnight. The next day, cells were incubated with MIL-100(Al) gels $(12.5 \mu \mathrm{g} / \mathrm{mL})$, DOX-loaded MOGs $(12.5 \mu \mathrm{g} / \mathrm{mL})$, and autoclave water overnight, respectively. The cells were washed twice with 1X PBS followed by treatment with $1 \mathrm{X}$ trypsin for $5 \mathrm{~min}$ before quenching the cells with culture medium. Thereafter, the cells were washed twice with 1X PBS by centrifugation (1000 rpm, $5 \mathrm{~min}$ ), and 1X ANNEXIN binding buffer (100 $\mu \mathrm{L})$ was added to the cell together with PI-PE and ANNEXIN V-FITC conjugate. The cells were incubated in the dark for $20 \mathrm{~min}$. Then, they were immediately analyzed with a flow cytometer.

\subsection{Fluorescence Microscopy Images}

The fluorescence microscopy studies were performed on HeLa cells in a confocal dish with a total number of $4 \times 10^{5}$ per dish. MIL-100(Al) gels $(200 \mu \mathrm{L})$ and DOX-loaded MOGs $(200 \mu \mathrm{L})$ were added into each dish respectively, to give a final concentration of $12.5 \mu \mathrm{g} / \mathrm{mL}$ and the cells were incubated for $12 \mathrm{~h}$. Thereafter, the medium was removed and the cells were washed three times with 1X PBS. The treated cells were re-suspended in 1X PBS. Then, the ANNEXIN V-FITC conjugate was added $(25 \mu \mathrm{L})$, and the cells incubated for $15 \mathrm{~min}$ in the dark. Thereafter, the ANNEXIN containing PBS was 
removed and the cells were washed three times with 1X PBS before fixing them with paraformaldehyde solution ( $4 \%$ in $1 \mathrm{X}$ PBS, $1 \mathrm{~mL}$ ). After $20 \mathrm{~min}$, the formaldehyde solution was removed and the cells washed twice with 1 X PBS. In the end, the cells were incubated with Hoechst solution $(5 \mu \mathrm{g} / \mathrm{mL}$, $1 \mathrm{~mL}$ ) in $1 \mathrm{X}$ PBS in the dark for $15 \mathrm{~min}$, and washed with twice with 1X PBS to image.

\section{Results and Discussion}

\subsection{Morphology and Structure Characterization of MIL-100(Al) Gels}

Transmission electron microscope (TEM) images (Figure 1a,b) showed the irregular structure of the as-synthesized MIL-100(Al) gels. Powder x-ray diffraction (XRD) was applied to identify their microstructure. The result was similar with that of a previous report [29]. As depicted in Figure S3, the pattern for the gel sample revealed a low crystallinity as several broad peaks were observed. However, it also showed that the gel was closely related to the MIL-100(Al) crystal [30]. In each position where a peak appeared for the MIL-100(Al) crystal, there appeared a corresponding broad peak for the gel sample, implying that the gel and the MOF crystal had similar structures. The nitrogen adsorption-desorption isotherm, which was used to evaluate the porous properties of MIL-100(Al) gels, was between those of type-I and type-IV, suggesting the coexistence of micropores and mesopores in the MIL-100(Al) gels sample (Figure S4). The Brunauer-Emmett-Teller (BET) surface area and pore volume of the MIL-100(Al) gels were calculated to be $920 \mathrm{~m}^{2} / \mathrm{g}$ and $0.535 \mathrm{~cm}^{3} / \mathrm{g}$, respectively. They were slightly lower than those of MIL-100(Al) $\left(1214 \mathrm{~m}^{2} / \mathrm{g}\right.$ and $\left.0.77 \mathrm{~cm}^{3} / \mathrm{g}\right)$. The similar large surface area and high porosity of MIL-100(Al) gels may arise from the intrinsic nature of the MIL-100(Al) [31]. Thus, the large surface area and high porosity make this material a possible candidate for highly efficient drug loading.

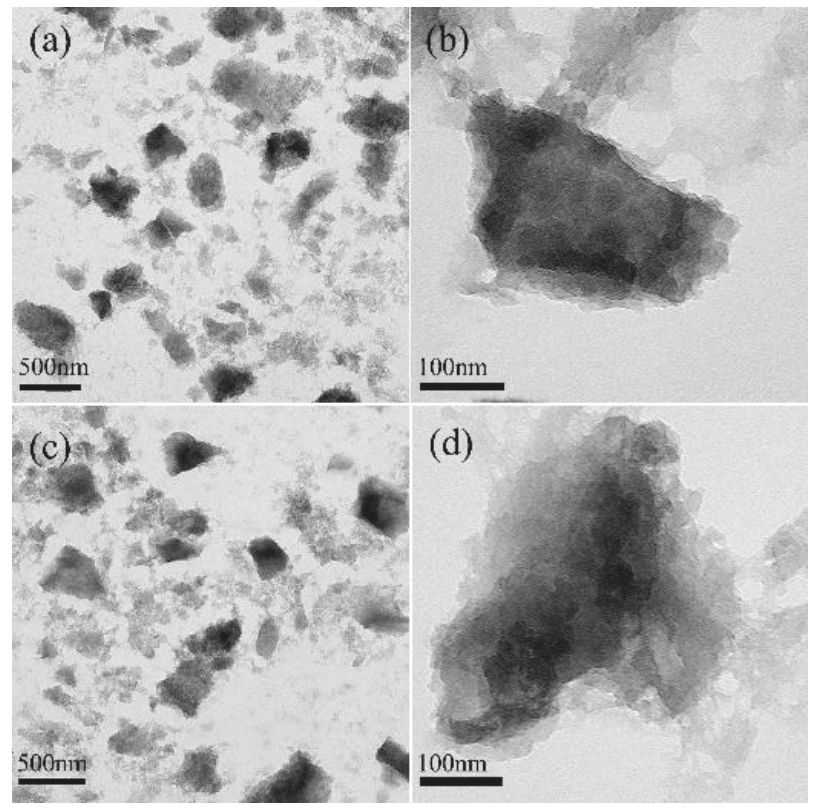

Figure 1. TEM images of (a,b) MIL-100(Al) gels. (c,d) DOX-loaded MIL-100(Al) gels. 


\subsection{Drug Loading and Release Behaviors}

The TEM images of DOX-loaded MOGs (Figure 1c,d) exhibited almost no change in morphology when compared with MIL-100(Al) gels. Figure $2 \mathrm{a}$ is the XRD patterns of MIL-100(Al) gels and DOX-loaded MIL-100(Al) gels (DOX-loaded MOGs). Both of them showed similar features before and after the drug adsorption, indicating that the porous structure of MIL-100(Al) gels was retained after the loading of DOX. Figure $2 \mathrm{~b}$ shows the FTIR spectra of MIL-100(Al) gels, DOX, and DOX-loaded MOGs. The peak at $3400 \mathrm{~cm}^{-1}$ was attributed to the $\mathrm{O}-\mathrm{H}$ stretching of MIL-100(Al) gels. In the FTIR spectrum of DOX, peaks at $1020 \mathrm{~cm}^{-1}$ and $3400 \mathrm{~cm}^{-1}$ were caused by $-\mathrm{NH}_{2}$ torsional vibration and $\mathrm{O}-\mathrm{H}$ stretching vibrations of DOX, respectively. In the case of the DOX-loaded MOGs, peaks of O-H stretching vibrations overlap were broadened and a new adsorption band at $1020 \mathrm{~cm}^{-1}$ owing to the torsional vibration of $-\mathrm{NH}_{2}$ from DOX was generated. This FTIR result indicated that MIL-100(Al) gels conjugated with DOX molecules successfully.
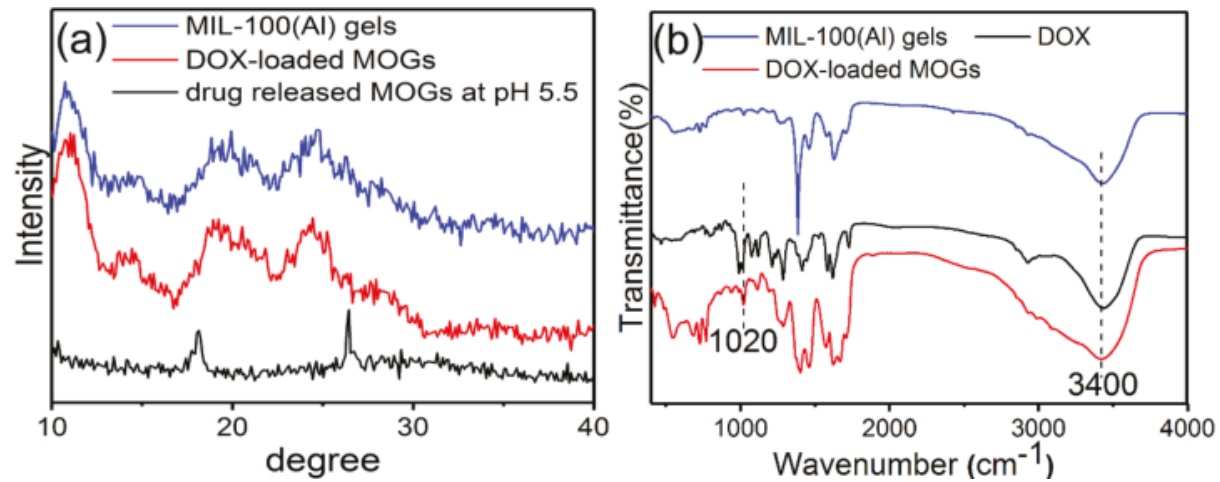

Figure 2. (a) Powder XRD patterns of MIL-100(Al) gels, DOX-loaded MOGs, and drug-released MOGs at pH 5.5; (b) FTIR spectra of MIL-100(Al) gels, DOX, and DOX-loaded MOGs.

It turns out that the loading capacity was reached up to $620 \mathrm{mg}$ of DOX per gram of the sample. This large DOX loading capacity and high loading efficiency $(62 \%)$ may be attributed to the ultrahigh porosity and enormous internal surface of MIL-100(Al) gels. The driving force of loading of DOX in MOGs may arise from the porous absorption and intermolecular forces. The latter most likely originated from the hydrogen bonds formed between the $-\mathrm{NH}_{2},-\mathrm{OH}$ groups in $\mathrm{DOX}$ and the surface active $-\mathrm{OH},-\mathrm{COOH}$ groups in MOGs [6,32].

The controlled drug release kinetics of DOX from DOX-loaded MOGs were investigated using UV-Vis adsorption spectra in PBS buffer solutions at $37^{\circ} \mathrm{C}$. Figure 3 is the DOX release profiles at two different $\mathrm{pH}$ values ( $\mathrm{pH}=7.4$ and 5.5). It can be seen that the release of DOX from DOX-loaded MOGs in $\mathrm{pH}=7.4$ only reached $10 \%$ within $100 \mathrm{~h}$. In contrast, the DOX release rate was significantly increased in $\mathrm{pH}=5.5$ and this release reached nearly $100 \%$ within $100 \mathrm{~h}$. This revealed that under acidic conditions, the drug can be released more easily. Under the weak acidic condition $(\mathrm{pH}=5.5)$, the drug delivery rate gradually decreased with time. Basically, the rate can be clearly divided into three regions: (i) an early rapid release within the first $10 \mathrm{~h}$; (ii) a slow release region in the time range between 10 and $60 \mathrm{~h}$; and (iii) a saturation region after $70 \mathrm{~h}$ [33]. The first rapid release was induced by the simple diffusion and dissolution of DOX molecules adsorbed onto the surface of MOGs. The second region revealed a gentle and steady release over a long time due to the desorption, diffusion, and dissolution processes of DOX molecules from channels in the gels to the solution. The last saturated drug release process could be attributed to host-guest interactions between the DOX molecules and the gels. The results revealed that the obtained MIL-100(Al) gels exhibited a high 
drug loading and long sustained release time under an acidic environment. To further understand the DOX release process from the DOX-loaded MOGs, TEM images were taken from DOX-loaded MOGs after $10 \mathrm{~h}, 50 \mathrm{~h}$, and $100 \mathrm{~h}$ in the release process at pH 5.5 (inset in Figure 3). They revealed the gradual collapse of the MIL-100(Al) gel structure during the procedure. The result was consistent with the XRD pattern of drug-released MOGs at pH 5.5 (Figure 2a), which showed the dissolution of MIL-100(Al) gels in an acidic environment. The reason is that MIL-100(Al) gels self-assemble through multiple non-covalent bonds under preparation conditions such as $\mathrm{H}$-bonds, $\pi-\pi$ stacking, electrostatic interactions, and other supramolecular weak interactions [20]. These non-covalent bonds are easily destroyed under acidic conditions, leading to the dissolution of MOGs. The excellent $\mathrm{pH}$-responsive release property may be attributed to the collapse of the MIL-100(Al) gel structure and the reduction of the interaction between DOX and MOGs in acidic conditions ( $\mathrm{pH}$ 5.5) [34]. In addition, DOX molecules tend to be more hydrophilic at lower $\mathrm{pH}$ values [35]. The other possible reason is that the protons can easily penetrate the pores in acidic buffer solution to protonate the amino group of DOX, resulting in the acceleration of drug release [36].

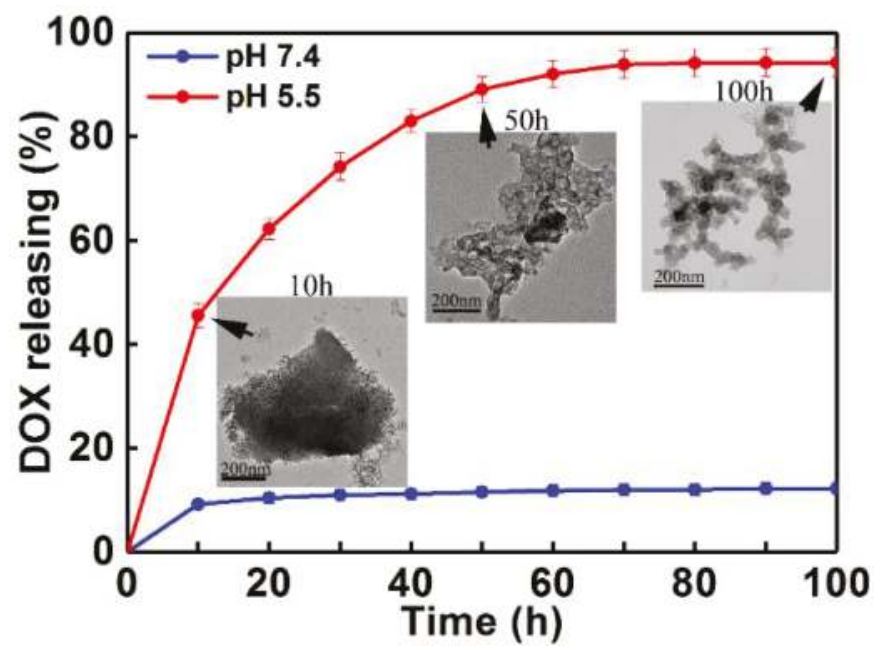

Figure 3. Drug release profiles for DOX-loaded MOGs in PBS buffer solution at $\mathrm{pH}=5.5$ and $\mathrm{pH}=7.4$ within $100 \mathrm{~h}$. (Inset are TEM images of DOX-loaded MOGs after $10 \mathrm{~h}, 50 \mathrm{~h}$, and $100 \mathrm{~h}$ in release process at $\mathrm{pH}$ 5.5.) Bars denote the standard deviation $( \pm \mathrm{SD}, n=5)$.

\subsection{Cell Cytotoxicity of DOX-Loaded MOGs}

After evaluating the drug loading and release ability of MOGs, in vitro cell viabilities of DOX-loaded MOGs and pure MIL-100(Al) gels on HeLa cells were investigated using the MTT (3-(4,5-Dimethylthiazol-2-yl)-2,5-diphenyltetrazolium bromide) assay. To study the biotoxicity of pure MIL-100(Al) gels and the therapeutic efficiency of DOX-loaded MOGs, HeLa cells were cultured with the DOX-loaded MOGs and pure MIL-100(Al) gels at concentrations ranging from $0.1 \mu \mathrm{g} / \mathrm{mL}$ to $100 \mu \mathrm{g} / \mathrm{mL}(0.1,0.5,1,2.5,5,10,25,50$, and $100 \mu \mathrm{g} / \mathrm{mL})$ for $24 \mathrm{~h}$. The results are exhibited in Figure 4. As can be seen, after $24 \mathrm{~h}$ incubation with HeLa cells, the pure MIL-100(Al) gels showed no obvious toxicity towards the HeLa cells even at the concentration of MIL-100(Al) gels as high as $100 \mu \mathrm{g} / \mathrm{mL}$. In contrast, the DOX-loaded MOGs showed high cytotoxicity on HeLa cells. As the concentration of DOX-loaded MOGs increased, the cell viability rapidly decreased. When the concentration of DOX-loaded MOGs reached $25 \mu \mathrm{g} / \mathrm{mL}$, only 20\% of HeLa cells survived. Therefore, the DOX could be efficiently released from the DOX-loaded MOGs to kill most of the tumor cells, demonstrating that 
the as-synthesized MIL-100(Al) gels hold great promise for application in the field of drug delivery system for cancer treatment.

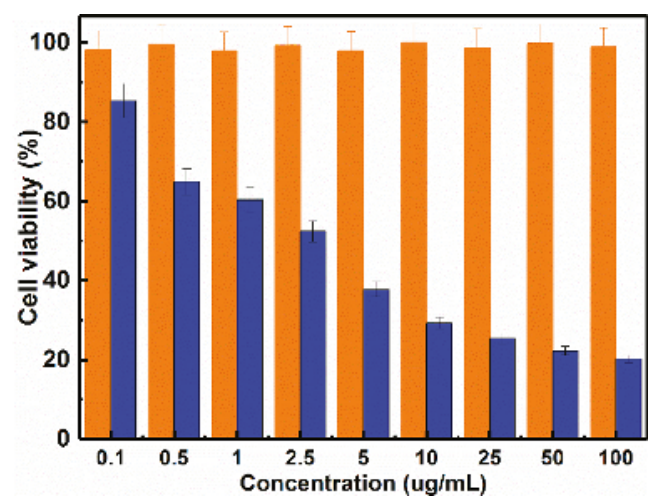

Figure 4. The effect of MIL-100(Al) gels and DOX-loaded MOGs with various concentrations on the cell viability of HeLa cells in $24 \mathrm{~h}$ (the orange and blue bars represent the viability of HeLa cancer cells incubated with MIL-100(Al) gels and DOX-loaded MOGs, respectively).

The in vitro drug release behavior of DOX-loaded MOGs on HeLa cells was also investigated. DOX-loaded MOGs and MOGs + free DOX with different concertation were studied. The results are shown in Figure 5a-f. Accordingly, the viability of cells incubated with DOX-loaded MOGs gradually decreased in the time range of $72 \mathrm{~h}$. This was in contrast with the sudden reduction behavior of the viability of cells incubated with MOGs + free DOX, in all the control experiment groups.
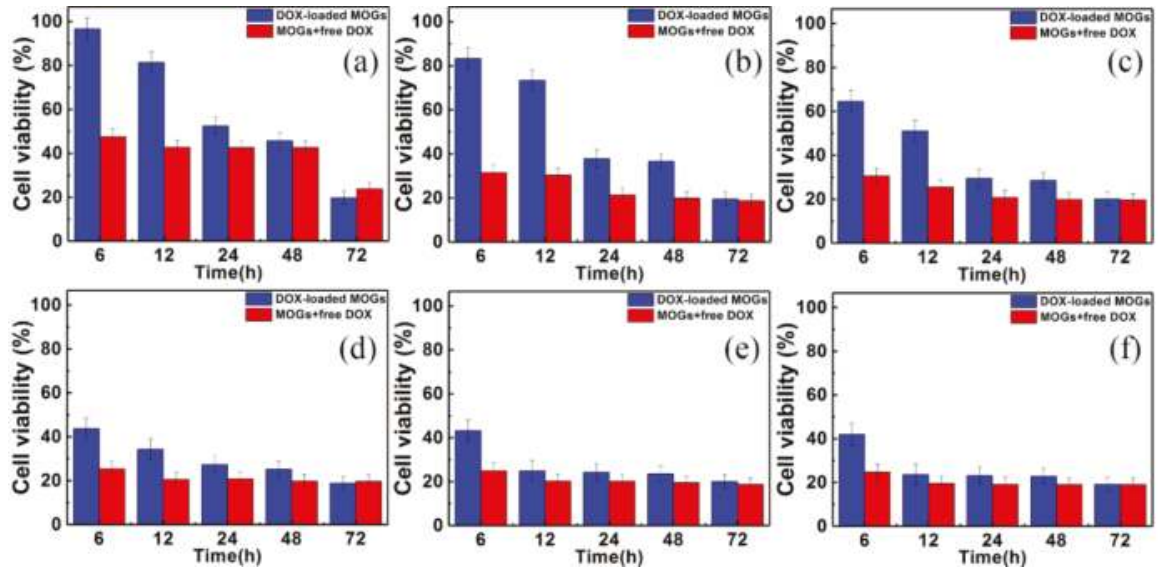

Figure 5. Cell viability of HeLa cells incubated with DOX-loaded MOGs and MOGs + free DOX for different time periods at concentrations of (a) $2.5 \mu \mathrm{g} / \mathrm{mL}$, (b) $5 \mu \mathrm{g} / \mathrm{mL}$, (c) $10 \mu \mathrm{g} / \mathrm{mL}$, (d) $25 \mu \mathrm{g} / \mathrm{mL}$, (e) $50 \mu \mathrm{g} / \mathrm{mL}$, and (f) $100 \mu \mathrm{g} / \mathrm{mL}$.

\subsection{Flow Cytometry}

In order to further investigate the apoptosis of the cells, we performed the flow cytometry analysis on HeLa cells with $12.5 \mu \mathrm{g} / \mathrm{mL}$ MIL-100(Al) gels and DOX-loaded MOGs. As shown in Figure 6, almost 
no necrotic and late apoptotic cells were observed in the control experiment (only containing pure autoclave water) $(1.49 \%)$ and MIL-100(Al) gels (1.88\%), revealing the low toxicity of this MOGs-based material. However, when the DOX-loaded MOGs were added, the percentage of apoptotic cells immediately became prominent $(89.9 \%)$. These results were in line with the MTT assay and further confirmed that apoptotic cell death arose from the DOX released from DOX-loaded MOGs.
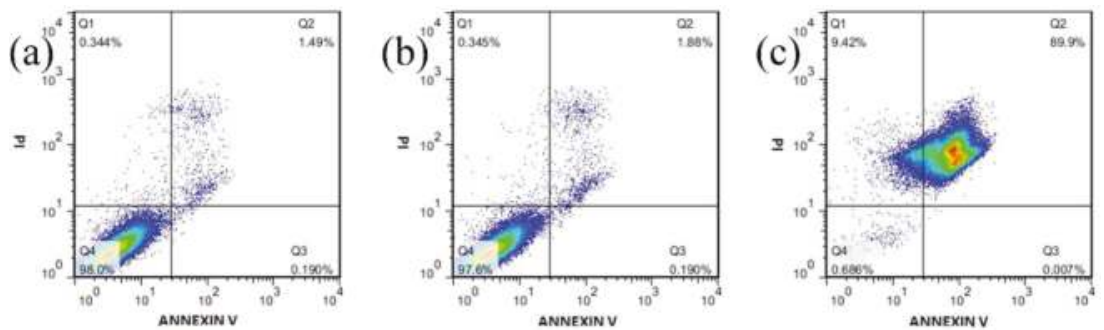

Figure 6. Flow cytometry experiments of HeLa cells when incubated with (a) Pure autoclave water as control, (b) MIL-100(Al) gels, and (c) DOX-loaded MOGs, respectively.

\subsection{Fluorescence Microscopy Images}

To further confirm the therapeutic efficiency of DOX-loaded MOGs, we performed confocal fluorescence microscopy for HeLa cells incubated with $12.5 \mu \mathrm{g} / \mathrm{mL}$ pure MIL-100(Al) gels and DOX-loaded MOGs for $24 \mathrm{~h}$, followed by staining the nucleus with DAPI and the apoptotic cells with Annexin V-FITC. The results are revealed in Figure 7. Herein, the green fluorescence was attributed to the apoptotic HeLa cells, while the blue and red fluorescence represented the living cell imaging and DOX released, respectively. For the HeLa cells incubated with pure MIL-100(Al) gels, only very small amounts of apoptotic HeLa cells were present (Figure 7c,d). In contrast, for the HeLa cells incubated with DOX-loaded MOGs, a large number of the HeLa cells were apoptotic (Figure 7g,h). This result again demonstrates the high efficiency of the DOX-loaded MOGs in cancer therapeutic treatment.
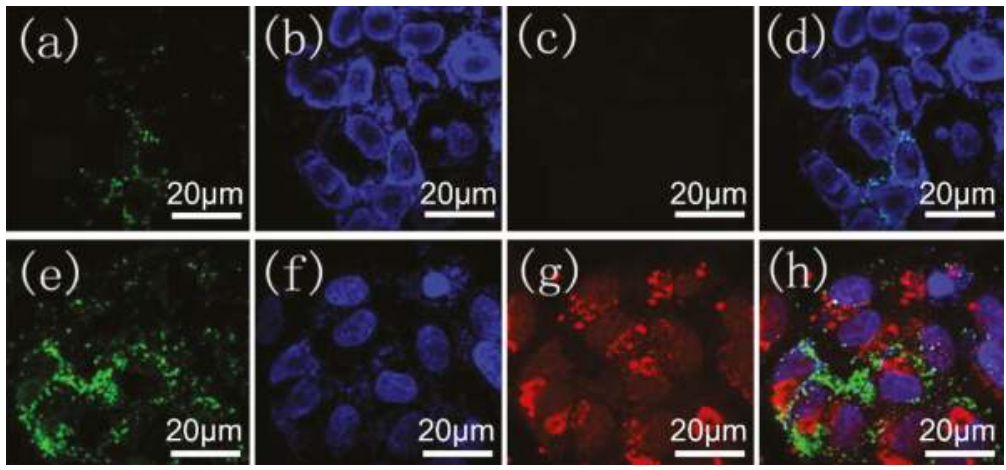

Figure 7. Confocal microscopy images of HeLa cells incubated with $12.5 \mu \mathrm{g} / \mathrm{mL}$ (a-d) MIL-100(Al) gels and (e-h) DOX-loaded MOGs, respectively. Blue fluorescence represents the living cell imaging. Red fluorescence represents the released DOX from DOX-loaded MOGs within the cancer cells. Green fluorescence represents the apoptosis of cells. $(\mathbf{d}, \mathbf{h})$ are the merged images of $(\mathbf{a}-\mathbf{c})$ and (e-g), respectively. 


\section{Conclusions}

On the basis of the methods reported in the previous work [5,6,19,20], we reported on a metal-organic gel (MOG)-based drug delivery system for anticancer therapy, i.e., MIL-100(Al) gels, which were synthesized by a facile, low cost, and environmentally friendly one-pot method. The anticancer drug doxorubicin hydrochloride (DOX) was successfully encapsulated in the MIL-100(Al) gels with high loadings $(620 \mathrm{mg} / \mathrm{g})$. Through the control experiments, the fabricated DOX-loaded MOGs were comparable with some previous pH-responsive drug delivery systems [16-18]. Specifically, the drug was not released at physiological condition (PBS, pH 7.4), but was released in a controlled manner at acidic conditions ( $\mathrm{pH} 5.5$ ) with approximately $100 \%$, after being delivered over three days. We also conducted in vitro experiments of DOX-loaded MIL-100(Al) gels (DOX-loaded MOGs) toward HeLa cells where it turned out that the DOX-loaded MOGs had excellent efficiency in killing the HeLa cells. The synthetic MIL-100(Al) gels here featured a concise synthetic step, large loading capacity for DOX, and low biotoxicity. Furthermore, the DOX-loaded MOGs showed slow and sustainable releasing ability and high anticancer efficiency. MIL-100(Al) gels exhibited high qualities of all the performance-indicators as above-mentioned, making DOX-loaded MOGs a promising anticancer approach for clinical application.

Supplementary Materials: The following are available online at http://www.mdpi.com/2079-4991/8/6/446/s1. Figure S1: UV-vis absorption spectra of DOX at different concentrations in PBS buffer solution, Figure S2: Calibration plot of standard DOX concentration, Figure S3: Powder XRD patterns of the as-synthesized MIL-100(Al) gels and the XRD pattern simulated from crystal structure data of MIL-100(Al), Figure S4: Nitrogen adsorption-desorption isotherm of MIL-100(Al) gel measured at $77 \mathrm{~K}$.

Author Contributions: Y.F. and J.Z. (Junfa Zhu) conceived and designed the experiments; Y.F. and C.W. performed the experiments; Y.F., C.W. and F.K. analyzed the data; J.Z. (Junfa Zhu) and J.Z. (Jianye Zang) contributed reagents/materials/analysis tools; Y.F. wrote the paper.

Funding: This research was funded by the National Key R\&D Program of China (2017YFA0403402), the Natural Science Foundation of China (Grants U1732272 and 21773222), the Key Program of Research and Development of Hefei Science Center of CAS (2017HSC-KPRD001), and the Collaborative Innovation Center of Suzhou Nano Science and Technology.

Acknowledgments: This work was supported by the National Key R\&D Program of China (2017YFA0403402), the Natural Science Foundation of China (Grants U1732272 and 21773222), the Key Program of Research and Development of Hefei Science Center of CAS (2017HSC-KPRD001), and the Collaborative Innovation Center of Suzhou Nano Science and Technology. Thanks to Jilong Wang and Fan Zheng for the assistance of in vivo cell experiments.

Conflicts of Interest: The authors declare no conflict of interest.

\section{References}

1. Jain, R.K.; Stylianopoulos, T. Delivering nanomedicine to solid tumors. Nat. Rev. Clin. Oncol. 2010, 7, 653-664. [CrossRef] [PubMed]

2. Davis, M.E.; Chen, Z.; Shin, D.M. Nanoparticle therapeutics: An emerging treatment modality for cancer. Nat. Rev. Drug Discov. 2008, 7, 771-781. [CrossRef] [PubMed]

3. Maeda, H.; Nakamura, H.; Fang, J. The EPR effect for macromolecular drug delivery to solid tumors: Improvement of tumor uptake, lowering of systemic toxicity, and distinct tumor imaging in vivo. Adv. Drug Deliv. Rev. 2013, 65, 71-79. [CrossRef] [PubMed]

4. Chen, Y.; Ai, K.; Liu, J.; Sun, G.Y.; Yin, Q.; Lu, L.H. Multifunctional envelope-type mesoporous silica nanoparticles for $\mathrm{pH}$-responsive drug delivery and magnetic resonance imaging. Biomaterials 2015, 60, 111-120. [CrossRef] [PubMed]

5. Chowdhuri, A.R.; Singh, T.; Ghosh, S.K.; Sahu, S.K. Carbon dots embedded magnetic nanoparticles @ chitosan @metal organic framework as a nanoprobe for $\mathrm{pH}$ sensitive targeted anticancer drug delivery. ACS Appl. Mater. Interfaces 2016, 8, 16573-16583. [CrossRef] [PubMed]

6. Su, Y.Y.; Teng, Z.; Yao, H.; Wang, S.J.; Tian, Y.; Zhang, Y.L.; Liu, W.F.; Tian, W.; Zheng, L.J.; Lu, N.; et al. A multifunctional PB@mSiO 2 -PEG/DOX nanoplatform for combined photothermal-chemotherapy of tumor. ACS Appl. Mater. Interfaces 2016, 8, 17038-17046. [CrossRef] [PubMed] 
7. Jalvandi, J.; White, M.; Gao, Y.; Truong, Y.B.; Padhye, R.; Kyratzis, I.L. Polyvinyl alcohol composite nanofibres containing conjugated levofloxacin-chitosan for controlled drug release. Mater. Sci. Eng. C 2017, 73, 440-446. [CrossRef] [PubMed]

8. Wang, D.D.; Zhou, J.J.; Chen, R.H.; Shi, R.H.; Zhao, G.Z.; Xia, G.L.; Li, R.; Liu, Z.B.; Tian, J.; Wang, H.J.; et al. Controllable synthesis of dual-MOFs nanostructures for $\mathrm{pH}$-responsive artemisinin delivery, magnetic resonance and optical dual-model imaging-guided chemo/photothermal combinational cancer therapy. Biomaterials 2016, 100, 27-40. [CrossRef] [PubMed]

9. Zhao, D.; Timmons, D.J.; Yuan, D.; Zhou, H.C. Tuning the Topology and Functionality of Metal-Organic Frameworks by Ligand Design. Acc. Chem. Res. 2011, 44, 123-133. [CrossRef] [PubMed]

10. Corma, A.; Garcia, H.; Llabres, F.X.; Xamena, I. Engineering Metal Organic Frameworks for Heterogeneous Catalysis. Chem. Rev. 2010, 110, 4606-4655. [CrossRef] [PubMed]

11. Keskin, S.; Kizilel, S. Biomedical Applications of Metal Organic Frameworks. Chem. Res. 2011, 50, 1799-1812. [CrossRef]

12. Yang, X.L.; Chen, X.H.; Hou, G.H.; Guan, R.F.; Shao, R.; Xie, M.H. A multiresponsive metal-organic framework: Direct chemiluminescence, photoluminescence, and dual tunable sensing applications. Adv. Funct. Mater. 2016, 26, 393-398. [CrossRef]

13. Kaur, R.; Kim, K.H.; Paul, A.K.; Deep, A. Recent advances in the photovoltaic applications of coordination polymers and metal organic frameworks. J. Mater. Chem. A 2016, 4, 3991-4002. [CrossRef]

14. Li, H.; Guo, K.; Wu, C.; Shu, L.; Guo, S.; Hou, J.; Zhao, N.; Wei, L.; Man, X.; Zhang, L. Controlled and Targeted Drug Delivery by a UV-responsive Liposome for Overcoming Chemo-resistance in Non-Hodgkin Lymphoma. Chem. Biol. Drug Des. 2015, 86, 783-794. [CrossRef] [PubMed]

15. He, Q.; Gao, Y.; Zhang, L.; Zhang, Z.; Gao, F.; Ji, X.; Li, Y.; Shi, J. A pH-responsive mesoporous silica nanoparticles-based multi-drug delivery system for overcoming multi-drug resistance. Biomaterials 2011, 32, 7711-7720. [CrossRef] [PubMed]

16. Nunzio, M.R.; Agostoni, V.; Cohen, B.; Gref, R.; Douhal, A. A “Ship in a Bottle" Strategy to Load a Hydrophilic Anticancer Drug in Porous Metal Organic Framework Nanoparticles: Efficient Encapsulation, Matrix Stabilizationand Photodelivery. J. Med. Chem. 2014, 57, 411-420. [CrossRef] [PubMed]

17. Sun, K.K.; Li, L.; Yu, X.L.; Liu, L.; Meng, Q.T.; Wang, F.; Zhang, R. Functionalization of mixed ligand metal-organic frame-works as the transport vehicles for drugs. J. Colloid Interface Sci. 2017, 486, 128-135. [CrossRef] [PubMed]

18. Vasconcelos, I.B.; Silva, T.G.; Militao, G.C.; Soares, T.A.; Rodrigues, N.M.; Rodrigues, M.O.; Freire, N.B.; Junior, S.A. Cytotoxicity and slow release of the anti-cancer drug doxorubicin from ZIF-8. RSC Adv. 2012, 2, 9437-9442. [CrossRef]

19. Sengupta, S.; Mondal, R. Metal-Organic-Particle-Supported Metallogel Formation Using a Nonconventional Chelating Pyridine-Pyrazole-Based Bis-Amide Ligand. Chem. Eur. J. 2013, 19, 5537-5541. [PubMed]

20. Zhang, J.; Su, C.Y. Metal-organic gels: From discrete to coordination polymers. Coord. Chem. Rev. 2013, 257, 1373-1408. [CrossRef]

21. Xiao, B.; Zhang, Q.; Huang, C.; Li, Y. Luminescent Zn(II)-terpyridine metal organic gel for visual recognition of anions. RSC Adv. 2015, 5, 2857-2860. [CrossRef]

22. Aiyappa, H.B.; Saha, S.; Wadge, P.; Banerjee, R.S. Fe(III) phytatemetallogel as a prototype anhydrous, intermediate temperature proton conductor. Chem. Sci. 2015, 6, 603-607. [CrossRef] [PubMed]

23. Huang, M.; Mi, K.; Zhang, J.H.; Liu, H.L.; Yu, T.T.; Yuan, A.; Kong, Q.; Xiong, S. MOF-derived bi-metal embedded N-doped carbon polyhedral nanocages with enhanced lithium storage. J. Mater. Chem. A 2017, 5, 266-274. [CrossRef]

24. Zhao, X.; Yuan, L.; Zhang, Z.Q.; Wang, Y.S.; Yu, Q.; Li, J. Synthetic Methodology for the Fabrication of Porous Porphyrin Materials with Metal-Organic-Polymer Aerogels. Inorg. Chem. 2016, 55, 5287-5296. [CrossRef] [PubMed]

25. Li, L.; Xiang, S.L.; Cao, S.Q.; Zhang, J.Y.; Ouyang, G.F.; Chen, L.P.; Su, C.Y. A synthetic route to ultralight hierarchically micro/mesoporousAl(III)-carboxylate metal-organic aerogels. Nat. Commun. 2013, 4, 1774-1782.

26. Mahmood, A.; Xia, W.; Mahmood, N.; Wang, Q.F.; Zou, R.Q. Hierarchical heteroaggregation of binary metal-organic gels with tunable porosity and mixed valence metal sites for removal of dyes in water. Sci. Rep. 2015, 5, 10556. [CrossRef] [PubMed] 
27. Sutar, P.; Maji, T.K. Coordination polymer gels: Soft metal-organic supramolecular materials and versatile applications. Chem. Commun. 2016, 52, 8055-8074. [CrossRef] [PubMed]

28. Liu, Y.R.; He, L.; Zhang, J.; Wang, X.; Su, C.Y. Evolution of spherical assemblies to fibrous networked Pd(II) metallo gels from a pyridine-based tripodal ligand and their catalytic property. Chem. Mater. 2009, 21, 557-563. [CrossRef]

29. Xia, W.; Zhang, X.; Xu, L.; Wang, Y.; Lin, J.; Zou, R. Facile and economical synthesis of metal-organicframework MIL-100(Al) gels for high efficiency removalof microcystin-LR. RSC Adv. 2013, 3, 11007-11013. [CrossRef]

30. Volkringer, C.; Popov, D.; Loiseau, T.; Ferey, G.; Burghammer, M.; Riekel, C.; Haouas, M.; Taulelle, F. Synthesis, Single-Crystal X-ray Microdiffraction, and NMR Characterizations of the Giant Pore Metal-Organic Framework Aluminum Trimesate MIL-100. Chem. Mater. 2009, 21, 5695-5697. [CrossRef]

31. Gjmez, G.P.; Cabello, C.P.; Opanasenko, M.; Horacek, M.; Cejka, J. Superior Activity of Isomorphously Substituted MOFs with MIL-100 (M = Al, Cr, Fe, In, Sc, V) Structure in the Prins Reaction: Impact of Metal Type. ChemPlusChem 2017, 82, 152-159.

32. Tan, S.Y.; Ang, C.Y.; Mahmood, A.; Qu, Q.; Li, P.; Zou, R.; Zhao, Y.L. Doxorubicin-Loaded Metal-Organic Gels for $\mathrm{pH}$ and Glutathione Dual-Responsive Release. ChemNanoMat 2016, 2, 504-508. [CrossRef]

33. Kayal, S.; Ramanujan, R.V. Doxorubicin loaded PVA coated iron oxide nanoparticles for targeted drug delivery. Mater. Sci. Eng. C 2010, 30, 484-490. [CrossRef]

34. Yang, X.; Grailer, J.J.; Rowland, I.J.; Javadi, A.; Hurley, S.A.; Matson, V.Z. Multifunctional Stable and $\mathrm{pH}$-Responsive Polymer Vesicles Formed by Heterofunctional Triblock Copolymer for Targeted Anticancer Drug Delivery and Ultrasensitive MR Imaging. ACS Nano 2010, 4, 6805-6817. [CrossRef] [PubMed]

35. Liu, J.; Zong, E.; Fu, H.; Zheng, S.; Xu, Z.; Zhu, D. Adsorption of aromatic compounds on porous covalent triazine-based framework. J. Colloid Interface Sci. 2012, 372, 99-107. [CrossRef] [PubMed]

36. Hu, X.; Hao, X.; Wu, Y.; Zhang, J.; Zhang, X.; Wang, P.C.; Zou, G.; Liang, X.J. Multifunctional Hybrid Silica Nanoparticles for Controlled Doxorubicin Loading and Release with Thermal and pH Dual Response. J. Mater. Chem. B 2013, 1, 1109-1118. [CrossRef] [PubMed]

(C) 2018 by the authors. Licensee MDPI, Basel, Switzerland. This article is an open access article distributed under the terms and conditions of the Creative Commons Attribution (CC BY) license (http:/ / creativecommons.org/licenses/by/4.0/). 
Article

\title{
Photo-Magnetic Irradiation-Mediated Multimodal Therapy of Neuroblastoma Cells Using a Cluster of Multifunctional Nanostructures
}

\author{
Rohini Atluri ${ }^{1,2}$, Rahul Atmaramani ${ }^{1,3}$, Gamage Tharaka ${ }^{4}$, Thomas McCallister ${ }^{1}$, Jian Peng ${ }^{4}$, \\ David Diercks ${ }^{5}$, Somesree GhoshMitra ${ }^{1}$ and Santaneel Ghosh ${ }^{1,4, *}$ \\ 1 Nano-Bio Engineering Laboratory, Southeast Missouri State University, Cape Girardeau, MO 63701, USA; \\ atluri.rohini@gmail.com (R.A.); rratmaramani1s@semo.edu (R.A.); tgmccallister@gmail.com (T.M.); \\ somesree@gmail.com (S.G.) \\ 2 Mechanical and Energy Engineering Department, University of North Texas, Denton, TX 76207, USA \\ 3 Department of Bioengineering, The University of Texas at Dallas, Richardson, TX 75080, USA \\ 4 Department of Physics and Engineering Physics, Southeast Missouri State University, Cape Girardeau, \\ MO 63701, USA; tharakarcbb13@gmail.com (G.T.); jpeng@semo.edu (J.P.) \\ 5 Department of Metallurgical and Materials Engineering, Colorado School of Mines, Golden, CO 80401, USA; \\ ddiercks@mines.edu \\ * Correspondence: sghosh@semo.edu; Tel.: +1-573-651-2393
}

Received: 24 July 2018; Accepted: 25 August 2018; Published: 29 September 2018

\begin{abstract}
The use of high intensity chemo-radiotherapies has demonstrated only modest improvement in the treatment of high-risk neuroblastomas. Moreover, undesirable drug specific and radiation therapy-incurred side effects enhance the risk of developing into a second cancer at a later stage. In this study, a safer and alternative multimodal therapeutic strategy involving simultaneous optical and oscillating (AC, Alternating Current) magnetic field stimulation of a multifunctional nanocarrier system has successfully been implemented to guide neuroblastoma cell destruction. This novel technique permitted the use of low-intensity photo-magnetic irradiation and reduced the required nanoparticle dose level. The combination of released cisplatin from the nanodrug reservoirs and photo-magnetic coupled hyperthermia mediated cytotoxicity led to the complete ablation of the B35 neuroblastoma cells in culture. Our study suggests that smart nanostructure-based photo-magnetic hybrid irradiation is a viable approach to remotely guide neuroblastoma cell destruction, which may be adopted in clinical management post modification to treat aggressive cancers.
\end{abstract}

Keywords: photo-magnetic actuation; cisplatin; nanoparticle; MYCN; multimodal therapy

\section{Introduction}

Neuroblastoma is a childhood cancer that is diagnosed at a median age of 17 months [1], with an incidence rate of 10.2 per million children under 15 years of age [2]. There are about seven hundred new cases each year in the United States, and in two out of three cases, the disease usually spreads to the lymph nodes or other parts of the body at the time of diagnosis. This is an embryonal tumor of the autonomic nervous systems [3], and it is the most common extra cranial tumor of childhood with long term survival rates of only about 15\% [4]. Theoretically, tumors can appear anywhere along the sympathetic nervous system, but in reality, a majority of the tumors are detected in the adrenal medulla [5]. Other sites for tumors include the upper chest, neck, and paraspinal spaces. Often, metastasis can be seen in regional lymph nodes and in the bone marrow, and during an advanced stage of the disease, it can infiltrate a local organ such as with a celiac axis tumor [6,7]. Overexpression and dominance of cell survival pathways are mainly responsible for the malignant transformation 
and metastasis of neural crest derived cells [8]. There are several factors that define specific cases of neuroblastoma, but high risk ones include stage, age, MYCN oncogene amplification, chromosome 11q status, metastasis, histologic category, and deoxyribonucleic acid (DNA) ploidy [5].

Due to biological heterogeneity of neuroblast tumors, different therapeutic strategies are pursued. While reduced intensity therapeutic approaches, such as surgery alone or in combination with moderate intensity chemotherapy, are the usual line of treatment for less aggressive tumors, high intensity chemo-radiotherapies are usually favored for tumors with more aggressive features [5]. For high risk neuroblastoma, the current treatment is divided into three phases: (1) induction of remission, (2) consolidation of remission, and (3) maintenance. The most commonly used induction regimen includes cycles of cisplatin and etoposide as well as alternate use of vincristine, doxorubicin, and cyclophosphamide [9]. Additionally, two types of radiation therapies are used: (1) external beam radiation therapy, and (2) Metaiodobenzylguanidine (MIBG) radiotherapy [10]. Myeloablative chemotherapy with autologous hematopoietic stem-cell rescue $[4,11]$ and isotretinoin with anti-GD2 immunotherapy [12] is also considered for high-risk neuroblastoma treatment.

Although the use of high-intensity chemo-radiotherapies have demonstrated only modest improvement in the treatment of high-risk neuroblastoma, undesirable side effects include mouth sores, nausea, hair loss, and most importantly, increased chance of infection [10]. In addition to these, there may be several drug-specific side effects, for example, cisplatin and carboplatin can affect kidneys [13], doxorubicin is a cardiotoxic agent [14], and cyclophosphamide can damage bladder as well as ovaries and testicles [15], which may affect future fertility. Short-term side effects of radiation therapy are nausea, diarrhea, burns, and fatigue [10], while long-term side effects may lead to damage in DNA, which has a risk of developing into a second cancer many years after completion of radiotherapy. Unfortunately, despite implementing all advanced treatment modalities, 50-60\% patients in high-risk groups have a relapse, and there is no known curative treatment available to date [5]. Use of anti-GD2 monoclonal antibodies to prevent relapse is a good example of an immunotherapeutic approach to lessen the side effects of chemo [16], as well as radiotherapies. A future trend is to develop antibody-based treatment guidelines as well as synergistic combination therapies.

From the above discussion, it is evident that innovative approaches possessing a novel therapeutic potential need to be implemented in order to overcome the existing challenges to treat high-risk neuroblastoma. An innovative technique that holds promise in the area of cancer diagnosis and therapeutics to perform precise drug delivery, multimodal therapy, and detection of circulating or residual cancer cells, all of which can play crucial roles in the treatment of high-risk neuroblastoma, is the development of novel nanostructures coupled with smart actuation strategies [17-24]. Nanostructured materials and smart surfaces carry excellent treatment potential for the development of novel clinical solutions because they can be designed to target/detect specific cancer cells and be remotely tuned to release measured doses of therapeutic agents, which in turn may improve treatment efficacy, decrease therapy time, and decrease the quantities of the therapeutic agent necessary for effective treatment by 10-50-fold [25]. In order to meet these goals cumulatively, "combinatorial therapeutics" approaches consisting of various nanostructures and advanced instrumentation are becoming one of the most exciting forefront fields, but it has been in its infancy until now. Oscillating magnetic field induced hyperthermia [26-28] or photothermal destruction of cancer cells [29] are among the most promising approaches among these; however, both fall short of addressing several concerns, including the use of high intensity magnetic or optical irradiation coupled with a lower yield at a clinically viable dose level. As discussed earlier, the rapid emergence of treatment resistance is a formidable challenge that needs a multimodal treatment approach, and unfortunately, the aforementioned approaches do not address this concern. Recently reported [30] "multimodal chemo-radiotherapy of glioblastoma" demonstrated encouraging outcomes, which has the potential of addressing this challenge; however, the technique needs further investigation before successful implementation, especially where the use of potent $\gamma$-rays is involved. 
Therefore, we set ourselves the goal of enhancing the treatment efficacy by combining a group of smart nanostructures, each of which are capable of performing a specific task with a novel strategy that has been unexplored thus far, namely simultaneous photo-magnetic actuation. In this study, three different types of nanostructures have been used to accomplish the objectives: (1) core-shell magnetic nanospheres (CSMNSs), (2) Polyvinylpyrollidone (PVP)-capped gold nanoparticles (AuNPs), and (3) cisplatin loaded thermo-responsive nanoparticles (CPNPs). The first two protagonists (i.e., the CSMNS and the AuNPs) induce a coupled hyperthermia and oxidative stress under the hybrid photo-magnetic irradiation, whereas the CPNPs cause sustained release of the imbibed cisplatin during the treatment. These augmented the cisplatin and photo-magnetic hyperthermia mediated cytotoxicity inducing mechanisms, and intensified the oxidative stress induced damage, all at a relatively lower irradiation and nanoparticle exposure level, which led to complete ablation of the B35 neuroblastoma cells in culture. Additionally, by using this technique, exposures to the high energy $\gamma$-rays have been avoided. Our study suggests that smart nanostructure-based photo-magnetic hybrid irradiation is a viable approach to remotely guide neuroblastoma cell destruction, which may be adopted as an efficient technique in clinical management post modification. Although we have explored this technique for neuroblastoma cell destruction in this study, it can be further modified and extended to treat other aggressive cancers.

\section{Materials and Methods}

\subsection{Photo-Magnetic Actuator Design}

A unique photo-magnetic actuator was designed to perform simultaneous optical and AC magnetic field stimulation of cultured mammalian cells or dispersed nanocarrier systems (Figure 1a,b). The incubator (Figure 1b) consisted of a sample chamber for placing TPP tissue culture tubes, AC/DC magnetic field generating coil, a cage for the placement of light-emitting diodes (LEDs) for low-level optical irradiation, and a high-performance glass window at the front wall of the incubator for transmitting the laser irradiation during moderate/high level optical stimulation. Inside the sample chamber, the B35 neuroblastoma cells were cultured or the nanocarriers were colloidally dispersed, as needed. The circuit utilized a capacitor bank in series with the inductor coil and a $0.5 \Omega$ resistor. A magnetic field in the range of $10-150$ Oe and $60-150 \mathrm{kHz}$ could be produced as needed by changing the capacitor and/or the coil inductance. A temperature controlling unit was attached to stabilize the incubator temperature in the range of $36-37^{\circ} \mathrm{C}$ during the experiments, and the top and the bottom panels of the incubator were designed to be removable to allow easy swapping of the samples. The incubator was attached to the base of the class 3B laser $(520 \mathrm{~nm}, 300 \mathrm{~mW})$, and a laser stop was placed to the rear of the incubator to inhibit reflection. Further, black absorbent tape material was used to confine the laser exposure to only necessary areas. A fiber optic thermometer was used to measure precise temperature change during heating of the nanocarriers.

\subsection{Nanocarrier Design}

Magnetite $\left(\mathrm{Fe}_{3} \mathrm{O}_{4}\right)$ core-polymeric shell nanospheres (CSMNS) were synthesized as reported in our previous work [31]. In brief, a double-layered shell consisting of a thermo-activated polymer network of poly(ethylene glycol) ethyl ether methacrylate-co-poly(ethylene glycol) methyl ether methacrylate (PEGEEMA-co-PEGMEMA) was synthesized first using a precipitation polymerization method. One batch of these designed spheres was used to induct the magnetic nanocrystals inside the outer shell, while the other batch was freeze dried and later loaded with the anticancer drug cisplatin (Sigma Aldrich, Bellefonte, PA, USA), as described below. Polyvinylpyrollidone (PVP)-capped gold nanoparticles $(0.05 \mathrm{mg} / \mathrm{mL}, 5 \mathrm{~nm}$ diameter) were obtained from nano Composix. All nanocarrier morphology was assessed by performing scanning and transmission electron microscopy (SEM and TEM: FEI NOVA 230 NANOSEM, Tustin, CA, USA, accelerating voltage 5-20 kV; Philips EM 420 TEM, Port Elizabeth, South Africa-120 kV electron beam) [31]. 


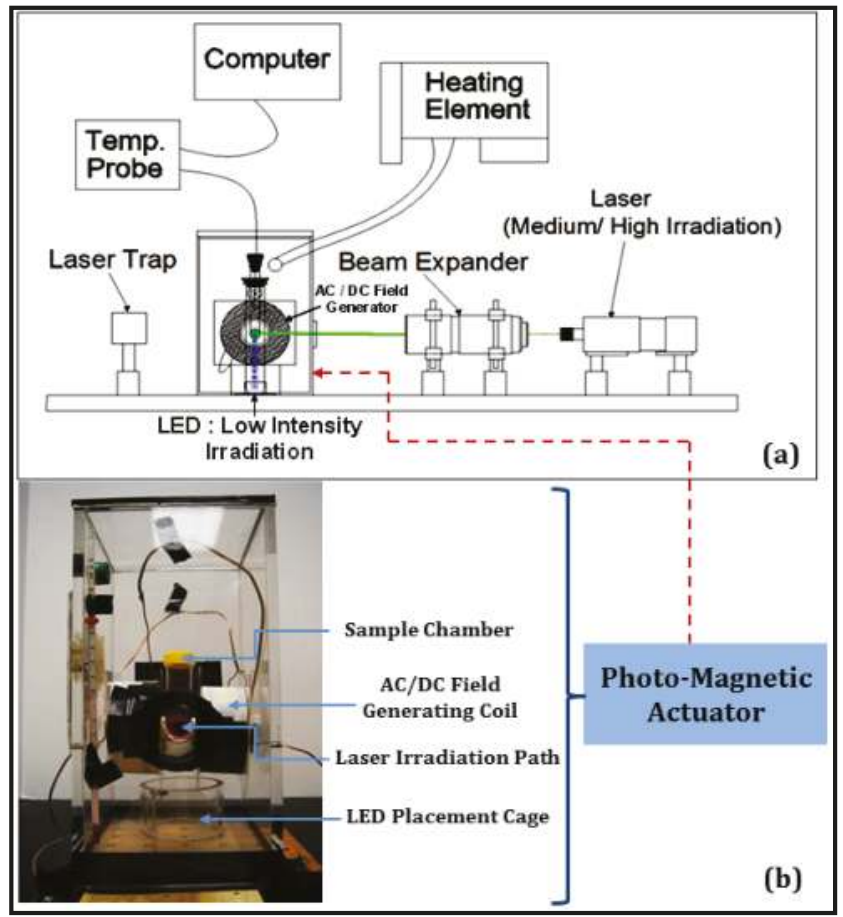

Figure 1. (a) Schematic of the experimental setup for the combined optical-AC magnetic field irradiation of nanocarriers and B35 neuroblastoma cells (electronics not shown). (b) Various components of the incubator with a TPP tissue culture tube mounted inside.

\subsection{Loading the Drugs in Polymeric Nanocarriers and Characterization of Release Profile}

An aqueous solution of cisplatin $(2 \mathrm{mg} / \mathrm{mL})$ was added to the previously prepared freeze-dried (non-magnetic) nanospheres. The solution was stirred for $24 \mathrm{~h}$ at room temperature and the cisplatin-loaded nanoparticles (CPNPs) were collected by centrifugation. A specialized diffusion chamber (PermeGear Static Franz cell,) with two compartments was used for the in vitro release kinetics measurement. The two compartments communicate through an opening $2 \mathrm{~cm}$ in diameter. A semipermeable membrane (mol. wt. cut-off 13,000 Da) was used to cover the opening. The CPNP solution was placed in the donor compartment and the receiver compartment was filled with the deionized (DI) water. To determine the concentration of the released cisplatin (at room temperature and at $\left.37^{\circ} \mathrm{C}\right)$ in the receiving compartment, samples were withdrawn at definite time intervals $(20,40$, 60,80 , and $100 \mathrm{~h}$ ) and the absorbance was measured using UV-visible spectroscopy at a wavelength of $301 \mathrm{~nm}$.

\subsection{Light Scattering and Magnetic Measurements}

Dynamic light scattering (DLS) measurements were performed to examine the volumetric transition behavior using a Malvern NanoZS system equipped with a helium-neon laser $(632.8 \mathrm{~nm})$ as the light source. The hydrodynamic radius distribution of the nanospheres in water was measured at a scattering angle of $60^{\circ}$. A magnetic property $[M(H)]$ of the nanospheres was measured using a Lakeshore model 7300 (Westerville, Ohio, USA) Vibrating Sample Magnetometer (VSM), at ambient temperature and at $38{ }^{\circ} \mathrm{C}$. 


\subsection{Cell Culture and Treatment}

B 35 rat neuroblastoma cells (ATCC, Manassas, VA, USA) were routinely cultured at $37^{\circ} \mathrm{C}$ in $5 \%$ $\mathrm{CO}_{2}$ and $85 \%$ relative humidity by using Dulbecco's modified Eagle's medium (DMEM, Invitrogen, Carlsbad, CA, USA) derived complete media that contains 90\% DMEM, and 10\% fetal bovine serum (FBS). For the experiments, about 10,000 cells $/ \mathrm{cm}^{2}$ were seeded in TPP tissue culture tube flasks $\left(10 \mathrm{~cm}^{2}\right.$ growth surface area) containing $2 \mathrm{~mL}$ of DMEM complete media and were allowed to grow for $48 \mathrm{~h}$ or more until a $70 \%$ confluence was observed. All the experiments were performed in triplicates.

For the treatment with nanoparticles, after $48 \mathrm{~h}$ of cell growth and attachment, the cells were washed with serum-free DMEM and were exposed to the NPs (various concentrations of MNPs (Magnetic Nano-Particle) and/or AuNPs), which were colloidally suspended in the culture media. During the nanoparticle exposure, cultures were placed into serum-free DMEM to prevent particle aggregation. After $4 \mathrm{~h}$ of exposure, the cells were washed with serum-free DMEM and were cultured back into $2 \mathrm{~mL}$ complete DMEM media until the beginning of the next exposure cycle. The treatment was repeated thrice for every $24 \mathrm{~h}$. At the end of the final exposure, live cell imaging was performed to assess the cell proliferation.

For the AC magnetic field exposure, optical irradiation, and hybrid optical-AC magnetic field exposure, the cells were cultured and exposed to the NPs as mentioned earlier. Immediately after the addition of NPs (MNPs and/or AuNPs), the cells were exposed to AC magnetic field exposure/optical irradiation/hybrid optical-AC magnetic field exposure (magnetic field intensity 60 Oe, frequency $120 \mathrm{kHz}$, laser power $300 \mathrm{~mW}$ ) for $15 \mathrm{~min}$. Following irradiation, the cells were placed in the incubator for $3 \mathrm{~h}$ and $45 \mathrm{~min}$ as part of the treatment. After $4 \mathrm{~h}$ of NP exposure and irradiation, the cells were washed with serum-free DMEM and were cultured back into $2 \mathrm{~mL}$ complete DMEM media until the beginning of the next exposure cycle. The treatment was repeated thrice for every $24 \mathrm{~h}$. At the end of the final exposure, live cell imaging was performed to assess cell proliferation.

For the treatment with cisplatin-loaded thermo-responsive nanoparticles (CPNPs), after $48 \mathrm{~h}$ of cell growth and attachment, the cells were washed with serum-free DMEM and were exposed to the CPNPs $(200 \mu \mathrm{g} / \mathrm{mL})$, which were colloidally suspended in the culture media for $4 \mathrm{~h}$. After $4 \mathrm{~h}$ of exposure, the cells were washed with serum-free DMEM and were cultured back into $2 \mathrm{~mL}$ complete DMEM media until the beginning of the next exposure cycle. The treatment was repeated thrice for every $24 \mathrm{~h}$. At the end of the final exposure, live cell imaging was performed to assess cell proliferation.

For hybrid optical-AC magnetic field exposure in the presence of CPNPs and NPs, the cells were treated (with CPNPs and NPs) as mentioned earlier. After the addition of the nanocarriers, the cells were exposed to hybrid optical-AC magnetic field exposure (magnetic field intensity $60 \mathrm{Oe}$, frequency $120 \mathrm{kHz}$, laser power $300 \mathrm{~mW}$ ) for $15 \mathrm{~min}$. Following irradiation, the cells were placed in the incubator for $3 \mathrm{~h}$ and $45 \mathrm{~min}$ as part of the treatment. After $4 \mathrm{~h}$ of nanocarrier exposure and irradiation, the cells were washed with serum-free DMEM and were cultured back into $2 \mathrm{~mL}$ complete DMEM media until the beginning of the next exposure cycle. The treatment was repeated thrice for every $24 \mathrm{~h}$. At the end of the final exposure, live cell imaging was performed to assess cell proliferation.

Nuclear morphology was assessed using confocal images captured through a $64 \times$ objective from cells (cultured on the coverglasses, which were inserted into the TPP tissue culture tube flasks and fixed) labeled with 4',6-diamidino-2-phenylindole (DAPI, Ex $=405 \mathrm{~nm}, \mathrm{Em}=450 / 35 \mathrm{~nm}$ ), following various treatments.

\subsection{Flow Cytometry Analysis: Annexin V Apoptosis Assay}

Upon treatment under various conditions, the cells were washed with serum-free DMEM, trypsinized, centrifuged, and suspended in $500 \mu \mathrm{L} 1 \times$ binding buffer. Cells were further incubated with FITC (Fluorescein isothiocyanate) Annexin V apoptosis detection reagent for $20 \mathrm{~min}$ at room temperature in darkness $(100 \mu \mathrm{L}$ of cell suspension was mixed with $5 \mu \mathrm{L}$ of FITC Annexin V and $5 \mu \mathrm{L}$ of PI), followed by flow cytometry analysis. 


\section{Results}

A simultaneous optical and AC magnetic field assisted therapeutic strategy was unexplored thus far, despite having a huge potential of generating synergetic effects, which may be especially beneficial for the destruction of aggressive cancer cells. This innovative setup (Figure 1a,b) enabled high-risk neuroblastoma cell exposure to varying combinations of optical and magnetic field excitation in the presence of specifically designed nanocarriers, thereby augmenting the positive outcomes of separate actuation strategies and the nanocarrier functionalities. The maximum field strength generated by the coils $(\approx 150$ Oe) is approximately 200 times weaker than that produced by a magnetic resonance imaging $(\mathrm{MRI})$ machine $\left(\approx 3 \times 10^{4} \mathrm{Oe}\right)$, which are known to be safe for use by people with medical implants such as pacemakers [32]. It may be noted that a Helmholtz coil-based design can be adopted for conducting experimentation with animal models and to obtain deeper penetration, a near infrared (NIR) laser can be used [22]. However, for low-level photo-magnetic therapy requiring LED irradiation in vivo, further modification is needed in the instrumentation.

No recognizable physicochemical interactions or clustering (and thereby precipitation) were observed among these three types of nanocarriers when they were (simultaneously) dispersed for $48 \mathrm{~h}$ in: (i) aqueous solution (DI $\mathrm{H}_{2} \mathrm{O}$ ), and in (ii) phosphate buffered saline (PBS). This indicates that the encapsulation (shell) formed by the polymerized, stable, and higher mechanical strength-possessing PEG-derivative biopolymer chains protected the embedded magnetic nanoparticles from being exposed to the proteins, salts, and other potential reactive agents present in the colloidal suspensions. Similarly, the polyvinylpyrollidone surface-tethered gold-nanoparticles were protected from potential (damaging) interactions with the media constituents, and therefore, did not facilitate agglomeration. The synthesized magnetic nanocarriers (CSMNSs) exhibited good colloidal stability, strong magnetic properties, and no precipitation after several days. From the SEM imaging, slightly oval shaped particles (arising from the surface roughness of the carbon film during sample preparation), were observed (Figure 2a). The mean diameter of the nanocarriers was found to be $268 \pm 24 \mathrm{~nm}$. Particle encapsulation was assessed using TEM imaging at $120 \mathrm{kV}$. The resulting TEM micrographs (Figure 2b) revealed that the magnetic nanocrystals were located near each other, which is very typical for magnetic nanoparticle-based systems, as observed earlier by several researchers [26,33,34]. Due to their size and structure, the nanomagnets were expected to exhibit super-paramagnetic behavior at a moderate field and frequency $(0-150 \mathrm{Oe}, 0-1000 \mathrm{kHz})$ range [31,35], which was assessed at $311 \mathrm{~K}$, or above the volumetric transition temperature (Figure 2c). No to minimal hysteresis response was observed, unlike the ferromagnetic nanoparticle-based systems [28,34], even after the volumetric shrinkage of the spheres, which indicated super-paramagnetic behavior and the absence of nanocrystal agglomeration at elevated temperatures. Under the measured field intensity of $60 \mathrm{Oe}$, created by a permanent magnet at the adjacent wall of the flask, the CSMNSs moved in the direction of the field and formed a film on the flask wall close to the magnet (Figure 2d). Almost all particles were completely separated from the solution, even with the application of a moderately intense field, which demonstrated their controllability under a magnetic field. It may be noted that the CSMNS response to an external magnetic field was much stronger than that of the individual magnetic nanodots due to a much higher magnetization value per carrier. Slight agitation brought the nanospheres back into the solution once the magnetic field was removed. This behavior further indicated that it will be possible to trap and maintain these nanocarriers in the targeted tissue regions without being washed away by the blood flow during in vivo applications. TEM imaging of the AuNPs demonstrated the particle distribution (Figure 2e) in the culture media and the high absorption in the range of $520 \pm 15 \mathrm{~nm}$ (Figure 2f) facilitated coupled hyperthermia under hybrid optical-AC magnetic field exposure, as assessed later. The CPNPs consisted of two polymer shells with varying degrees of hydrophilicity, as described in the previous section (nanocarrier design), the inner one having a diameter of $162 \pm 24 \mathrm{~nm}$ (not shown here). Multi-shell nanocarriers were designed to expand the volumetric transition range [31], which in turn facilitated the release of the imbibed therapeutic agents. Morphology of the CPNPs was assessed by performing SEM imaging (Figure $2 \mathrm{~g}$ ) and the mean diameter of the double shell nanocarriers was 
found to be $341 \pm 32 \mathrm{~nm}$. The temperature-dependent volumetric transition behavior of these cisplatin loaded nanocarriers is shown in Figure $2 \mathrm{~h}$, which demonstrates a broader $\left(31-38^{\circ} \mathrm{C}\right)$ volumetric transition range, and consequently, sustained release of the imbibed cisplatin (Figure 2i).
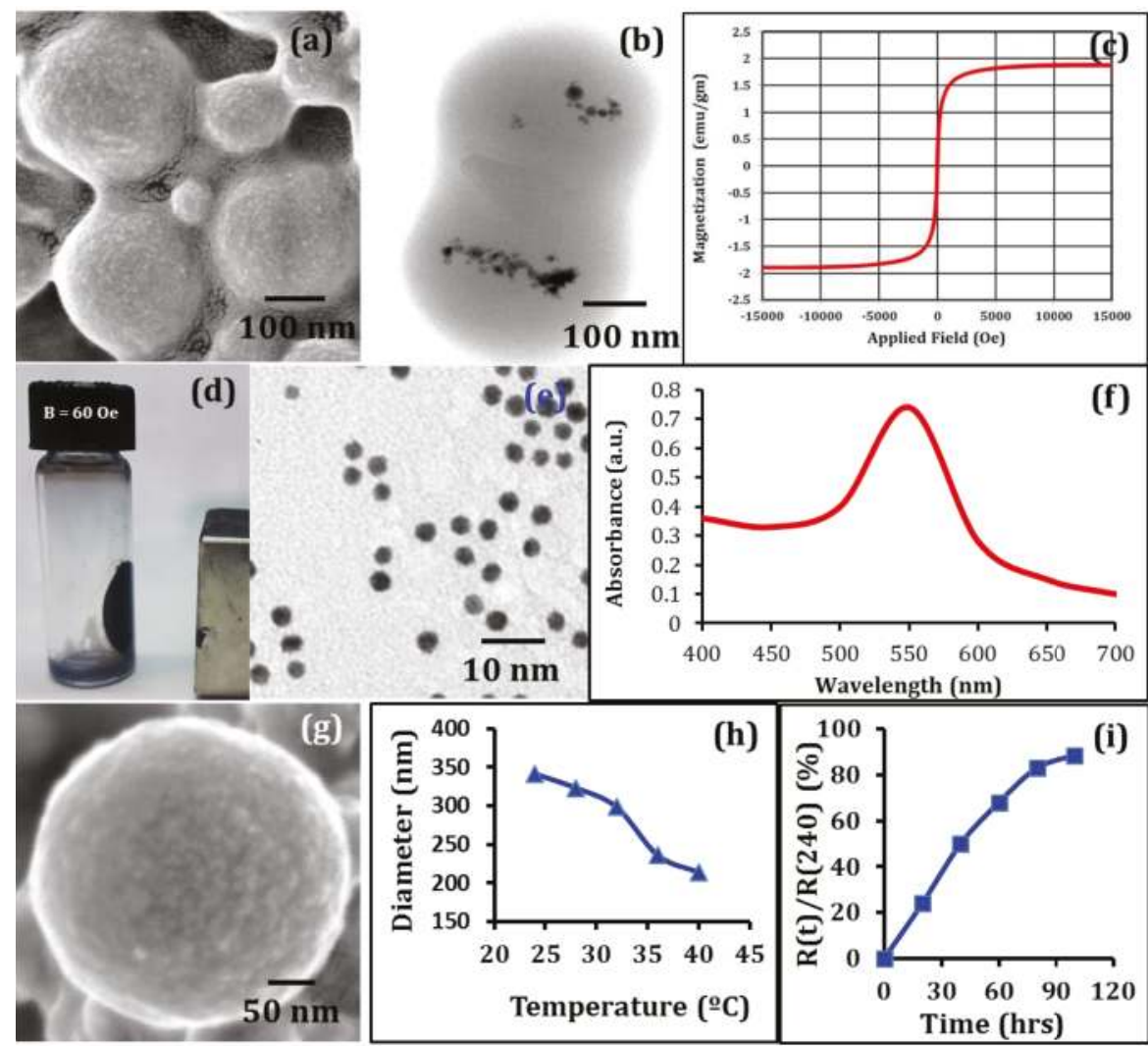

Figure 2. Morphology of designed CSMNSs: (a) SEM analysis demonstrating the polymer shell, and (b) TEM analysis demonstrating the distribution of the encapsulated MNPs. (c) Applied field vs magnetization plot for CSMNSs at $311 \mathrm{~K}$, demonstrating super-paramagnetic behavior, even at the collapsed state of the polymeric shell. (d) Response of the CSMNSs to an applied DC magnetic field of 60 Oe by a permanent magnet at the adjacent wall of the flask. Characterization of the AuNPs: (e) TEM analysis demonstrating the particle distribution in cell culture media, ruling out the possibility of agglomeration, and (f) UV-visible spectrum of the dispersed AuNPs in the culture media. (g) SEM imaging of the CPNP demonstrating nanocarrier morphology. (h) Temperature dependence of hydrodynamic diameter of the CPNPs. (i) Drug release profile from the CPNPs. R(t) represents the mass released at any time $\mathrm{t}$, and $\mathrm{R}(240)$ represents total mass released over $240 \mathrm{~h}$ (10 days).

The remote heating response of the nanocarriers was observed under AC magnetic fields (Figure 3a,b), optical irradiation (Figure 3c), and under hybrid optical-AC magnetic field exposure (Figure 3d). Upon field application, the nanocarrier-suspended culture media temperature increased in a concentration-dependent manner and reached a near steady state after approximately 20-30 min of irradiation. For AC magnetic field modulation, MNP concentration was varied between $200-400 \mu \mathrm{g} / \mathrm{mL}$, and the temperature change was observed to be in the range of $1.5-3.5 \mathrm{~K}$ at $40 \mathrm{Oe}$, and between $3-5 \mathrm{~K}$ at 60 Oe field intensities, respectively. The optical irradiation-induced temperature 
change was found to be in the range of 3.7 and $8 \mathrm{~K}$, respectively, when the concentration of the AuNPs were changed from 2 to $4 \mu \mathrm{g} / \mathrm{mL}$ in the culture media. A significantly stronger heating response was observed under the hybrid optical-AC magnetic field, in the range of 8-10.5 K, even with a mixture consisting of only $2 \mu \mathrm{g} / \mathrm{mL}$ AuNPs and $400 \mu \mathrm{g} / \mathrm{mL}$ MNPs. During all measurements, observed joule heating was found to be minimal, in the range of $0.5-1.25 \mathrm{~K}$. Observing the heating response under coupled optical-AC magnetic field and considering clinically viable dose levels of the nanocarriers, $400 \mu \mathrm{g} / \mathrm{mL}$ MNPs and $2 \mu \mathrm{g} / \mathrm{mL}$ AuNPs were chosen as the mixture composition for executing acute hyperthermia towards the development of a multi modal therapy for the destruction of the neuroblastoma cells.

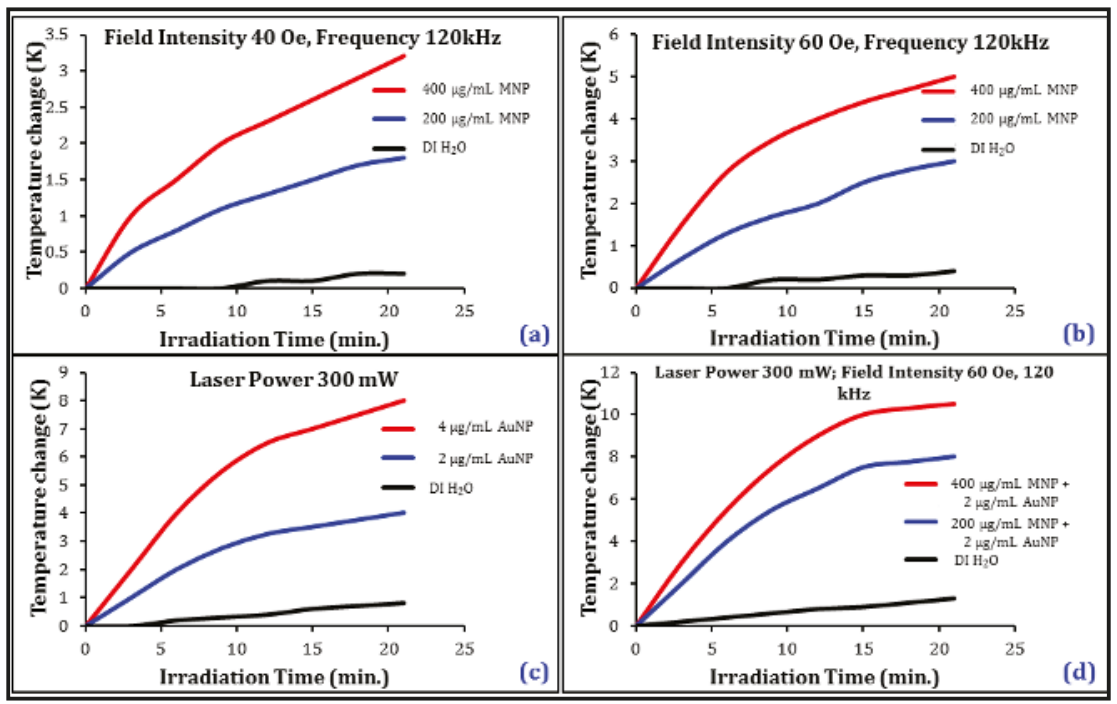

Figure 3. Remote heating response under AC magnetic field exposure as a function of CSMNS concentration at (a) $40 \mathrm{Oe}$, and (b) at $60 \mathrm{Oe}$. Frequency of the magnetic field was kept at $120 \mathrm{kHz}$. Heating response (c) under optical irradiation as a function of AuNP concentration, and (d) under hybrid optical-AC magnetic field irradiation using CSMNSs and AuNPs together in the media at various concentrations.

B35 neuroblastoma cell proliferation was observed post hyperthermia treatments and compared with the control (Figure 4a), and with only nanoparticle exposure (Figure $4 \mathrm{~b}$ ) conditions. The dose level of the CSMNSs and AuNPs used in this study were found to have a very low cytotoxicity, as observed in Figure $4 \mathrm{~b}$ and quantified later (Figure 4i). Hybrid optical and AC magnetic field irradiation did not inhibit cell proliferation in the absence of the nanocarriers, as observed in Figure 4c, although a slight reduction in cell proliferation was observed in the presence of the nanocarriers under separate (i.e., magnetic or optical) actuations (Figure 4d,e). Under combined photo-magnetic actuation in the presence of the nanocarriers, severe inhibition in proliferation with cytoplasmic blebbing and irregularities in shape were observed (Figure 4f), which even surpassed the culture condition with the CPNP exposure in the media (Figure 4g). Finally, complete ablation of the B35 neuroblastoma cells in culture was observed under photo-magnetic combined actuation in the presence of the magnetic, gold, and the cisplatin loaded nanocarriers (Figure 4h). One-way analysis of variance (ANOVA) depicted statistically significant differences $(p$-value $<0.01)$ in the cell density values between the control and hybrid photo-magnetic actuation in the presence of nanocarriers with and without the presence of the cisplatin loading, as well as between control and $200 \mu \mathrm{g} / \mathrm{mL}$ CPNP treatments (Figure 4i). 

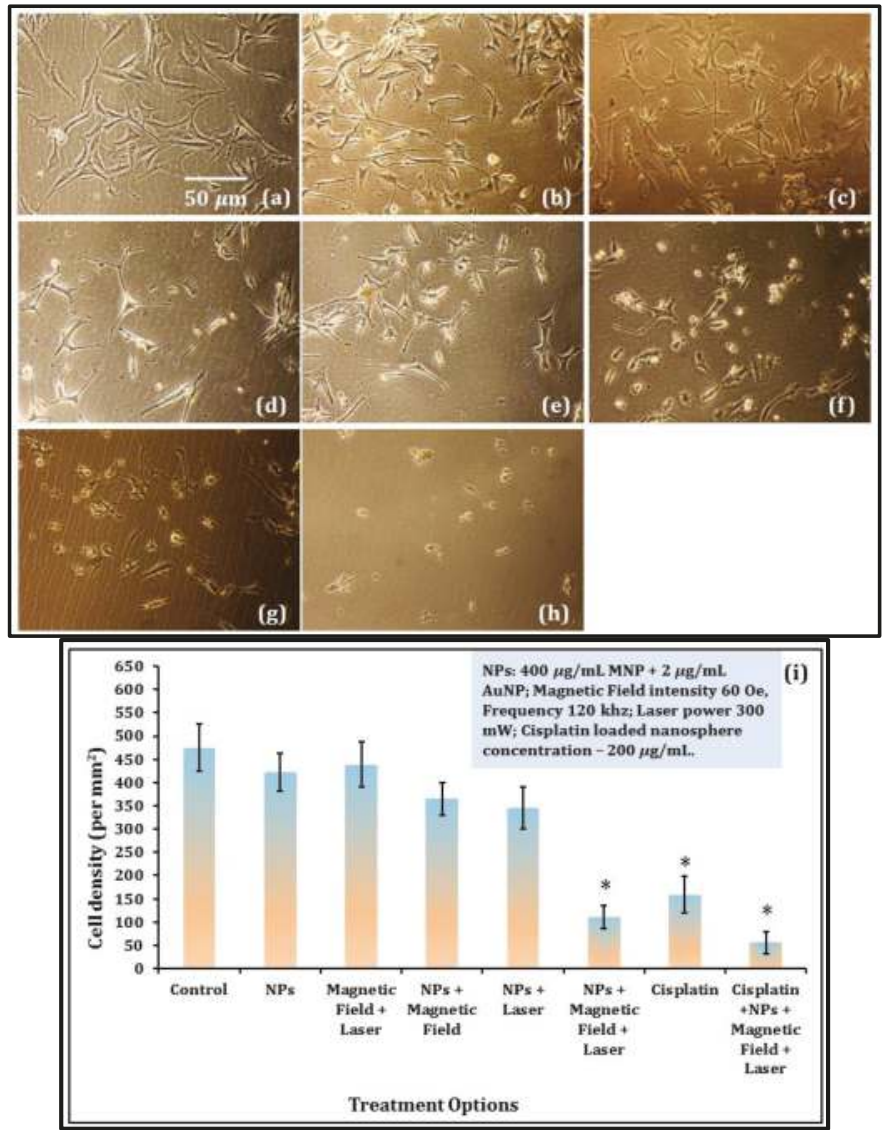

Figure 4. B35 neuroblastoma cell proliferation under the following conditions: (a) control; (b) presence of NPs $(400 \mu \mathrm{g} / \mathrm{mL} \mathrm{MNP}+2 \mu \mathrm{g} / \mathrm{mL}$ AuNP) in the culture media; (c) combined optical-AC magnetic field irradiation in the absence of NPs; (d) presence of NPs under AC magnetic field irradiation; (e) presence of NPs under optical irradiation; (f) combined optical-AC magnetic field irradiation in the presence of NPs; (g) presence of $200 \mu \mathrm{g} / \mathrm{mL}$ CPNPs; and (h) combined optical-AC magnetic field irradiation in the presence of NPs and CPNPS. The AC magnetic field intensity was 60 Oe, frequency was $120 \mathrm{kHz}$, and laser power was $300 \mathrm{~mW}$ (at $520 \mathrm{~nm}$ ). Scale bar is $50 \mu \mathrm{m}$ in (a), and is also applicable for (b-h). (i) Bar chart displaying quantification of average cell densities (cell number $/ \mathrm{mm}^{2}$ ), indicative of cell proliferation for B35 neuroblastoma cells under all treatment options. Data are means \pm SEM from four separate experiments and * indicates statistically significant differences, compared to cells cultured as the control, at $p<0.01$ (ANOVA and LSD post-hoc).

In apoptotic cells, the membrane phospholipid phosphatidylserine (PS) is translocated from the inner to the outer leaflet of the plasma membrane, thereby exposing PS to the external cellular environment. Annexin $\mathrm{V}$ is a $35-36 \mathrm{kDa} \mathrm{Ca}^{2+}$ dependent phospholipid-binding protein (conjugated to FITC) that has a high affinity for PS, and binds to cells with exposed PS. Staining with FITC Annexin V is typically used in conjunction with a vital dye, such as propidium iodide (PI) or 7-amino-actinomycin (7-AAD), to identify early apoptotic cells. Cells that are considered viable are FITC Annexin V and PI negative; cells that are in early apoptosis are FITC Annexin V positive and PI negative; and cells that are in late apoptosis or already dead are both FITC Annexin V and PI positive. Results 
demonstrated more than 95\% viable cells for the control (Figure 5a), post nanoparticle exposure (Figure 5b), and hybrid photo-magnetic irradiation in the absence of the nanocarriers (Figure 5c), thereby revealing the innate biocompatibility of the nanocarriers, as well as the irradiation exposure. Slight elevation of apoptosis (15-20\% in the suspended cells) was observed in the presence of the nanocarriers under separate (i.e., magnetic or optical) actuations (Figure $5 \mathrm{~d}$,e). However, $98 \%$ early /late apoptotic cells were observed under combined photo-magnetic actuation in the presence of the nanocarriers (Figure 5f), which was found to be significantly greater than that of the $200 \mu \mathrm{g} / \mathrm{mL}$ CPNP exposure (65\% apoptotic/necrotic cells, Figure $5 \mathrm{~g}$ ), demonstrating the extent of induced cytotoxicity by this hybrid actuation-nanocarrier combination. Figure $5 \mathrm{~h}$ demonstrates a severe degree of induced apoptosis (99\% apoptotic or necrotic cells) under photo-magnetic combined actuation in the presence of the magnetic, gold, and the cisplatin loaded nanocarriers. It should be noted that the apoptosis trend was found to be somewhat similar to the previously observed cell proliferation results.
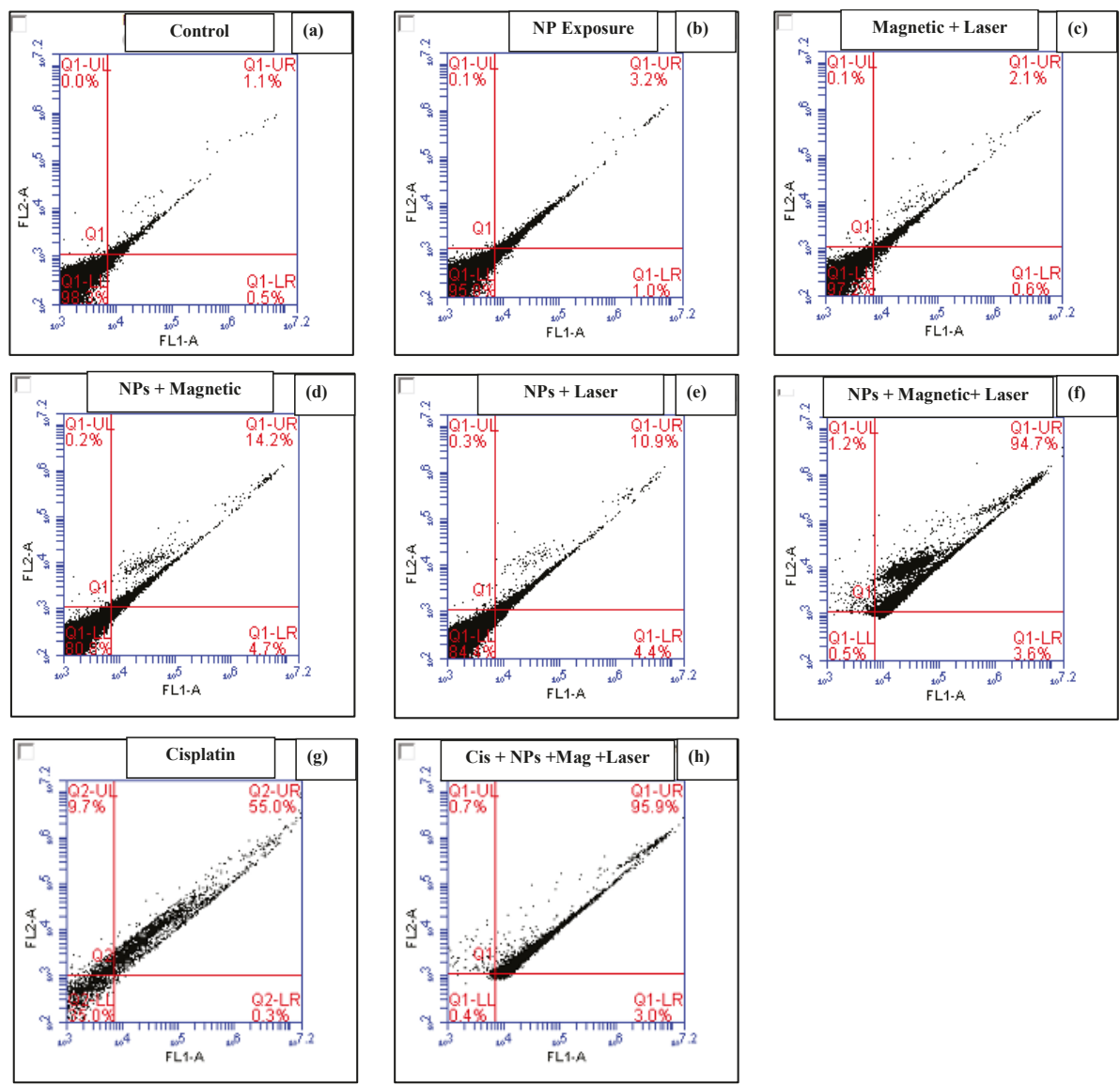

Figure 5. Apoptosis detection by the Annexin V assay. In four windows of each plot, the lower left indicates normal cells, the lower right indicates early apoptotic cells, the upper right indicates middle phase apoptotic cells, and the upper left indicates late phase apoptotic cells or necrotic cells. Irradiation/exposure parameters where applied: AC magnetic field intensity was 60 Oe, frequency was $120 \mathrm{kHz}$, and laser power was $300 \mathrm{~mW}$ (at $520 \mathrm{~nm})$; NPs: $(400 \mu \mathrm{g} / \mathrm{mL} \mathrm{MNP} \mathrm{+} 2 \mu \mathrm{g} / \mathrm{mL}$ AuNP); CPNPs $200 \mu \mathrm{g} / \mathrm{mL}$. 
Nuclear changes, such as condensation of the nucleus and/or DNA fragmentation, are the typical characteristics of later stages of the apoptotic program. Induction of apoptosis was further investigated by observing DAPI stained cell nuclei for the conditions that severely inhibited B35 neuroblastoma cell proliferation (Figure 6a-d). While in the control (Figure 6a), the cells had round and homogeneous nuclei, exposure to CPNPs $(200 \mu \mathrm{g} / \mathrm{mL})$ launched the apoptotic machinery of the cell, as observed from the deformed and condensed nuclei and apoptotic bodies (Figure 6b). Under combined photo-magnetic actuation in the presence of the gold and magnetic nanocarriers, severe chromatin condensation and nuclear fragmentation was evident (Figure 6c), indicating the potency of photo-magnetic hyperthermia-mediated cytotoxicity at a relatively lower irradiation and nanoparticle exposure level. Even a higher degree of damage was observed under photo-magnetic combined actuation in the presence of the CSMNSs, AuNPs, and CPNPs (Figure 6d), thereby demonstrating the effectiveness of the multimodal therapeutic strategy. Quantification of pyknotic nuclei, which is indicative of cell death [36], is displayed in Figure 6e, depicting statistically significant differences ( $p$-value $<0.01$ ) between the control and $200 \mu \mathrm{g} / \mathrm{mL}$ CPNP treatment, as well as between the control and hybrid photo-magnetic actuation in the presence of nanocarriers with and without the presence of the cisplatin loading.

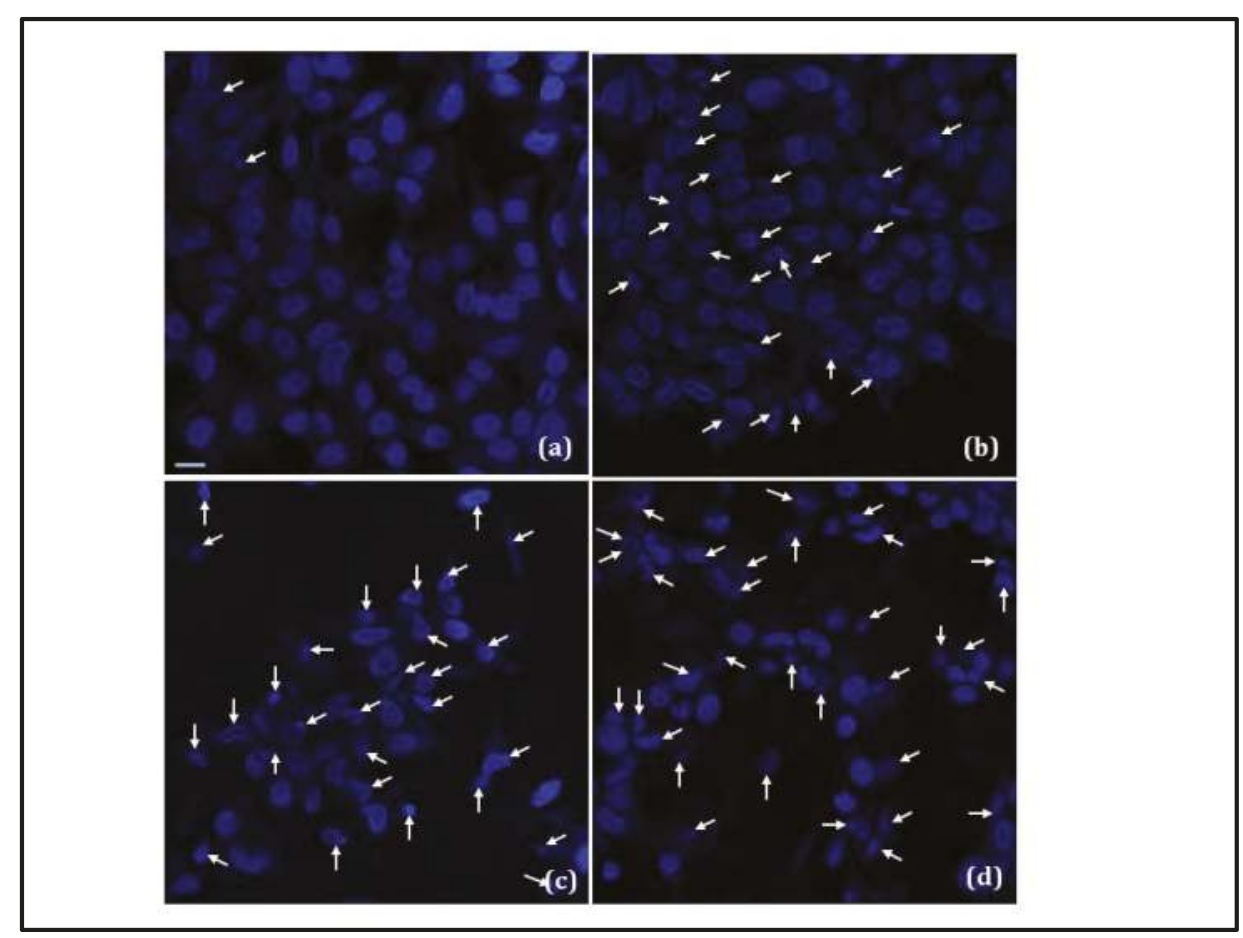

Figure 6. Cont. 


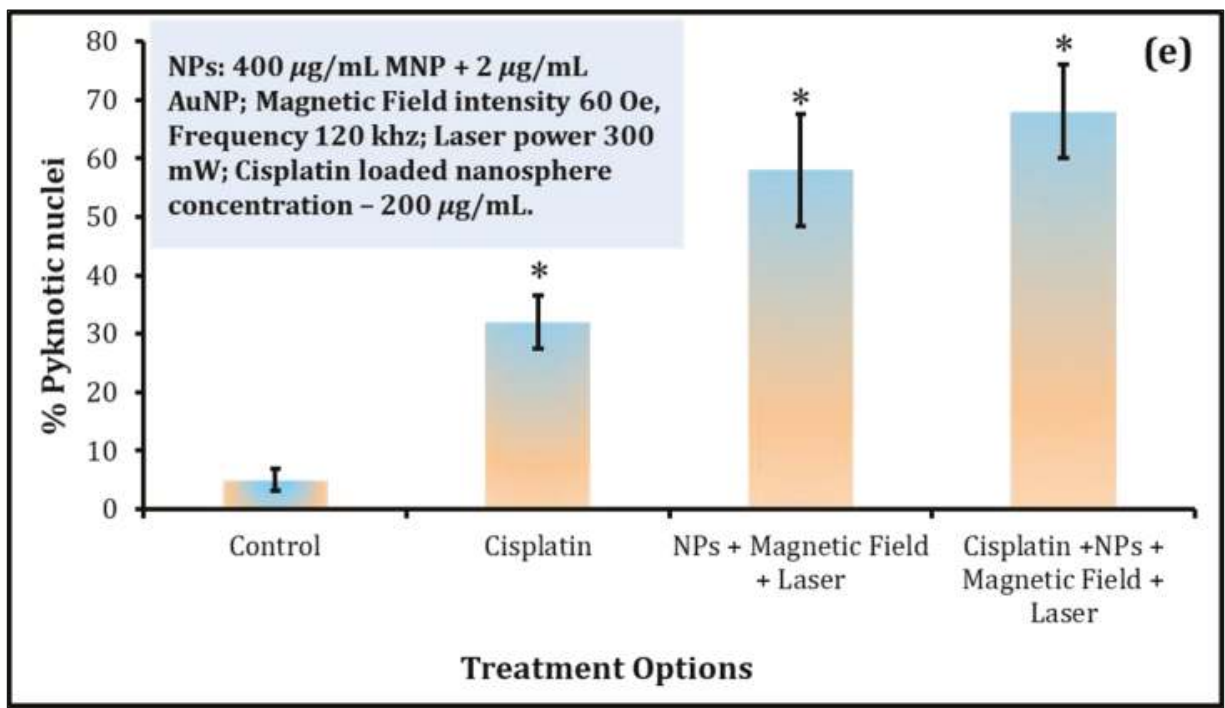

Figure 6. Nuclear condensation and fragmentation (white arrows) under the following conditions: (a) control, (b) presence of $200 \mu \mathrm{g} / \mathrm{mL}$ CPNPs, (c) combined optical-AC magnetic field irradiation in the presence of NPs $(400 \mu \mathrm{g} / \mathrm{mL} \mathrm{MNP}+2 \mu \mathrm{g} / \mathrm{mL}$ AuNP), and (d) combined optical-AC magnetic field irradiation in the presence of NPs and CPNPS. AC Magnetic field intensity was 60 Oe, frequency was $120 \mathrm{kHz}$, and laser power was $300 \mathrm{~mW}$ (at $520 \mathrm{~nm}$ ). Scale bar is $10 \mu \mathrm{m}$ in (a), and is also applicable for (b-d). (e) Bar chart displaying quantification of pyknotic nuclei, indicative of cell death. Data are means \pm SEM from four separate experiments and * indicates statistically significant differences, compared to cells cultured as the control, at $p<0.01$ (ANOVA and LSD post-hoc).

\section{Discussion}

Combined photo-magnetic stimulation has successfully been implemented on the cluster of complementing nanocarriers to develop a multimodal therapy to guide the neuroblastoma cell destruction (Figure 7). This novel strategy permitted the use of a less intense AC magnetic field in combination with optical irradiation during the treatment, thus removing the safety concerns associated with the AC magnetic field-assisted therapies. Although a green laser $(300 \mathrm{~mW})$ has been used in this study as the light source for the optical irradiation as a proof of concept, it can be replaced by a near infrared (NIR) laser to obtain deeper penetration, since the gold nanoparticles can be tuned to possess high NIR absorption [22]. The penetration depth of the optical irradiation can be further enhanced by the use of free-space or even a fiber-optic Bessel beam [37], thus eliminating the use of high-intensity radiotherapy, which has the potential to incur severe DNA damage and has a risk of developing into a second cancer at a later stage. Moreover, the treatment efficacy has been achieved at a reduced nanoparticle dose level [28,38]. In our recent reports [21,24], various strategies for targeting and delivery of therapeutic agents for the central nervous system (CNS)-related conditions have been identified: (i) endocytosis based, and (ii) laminin (or other disease specific surface proteins) binding peptide based. The later strategy is gaining huge traction for specific targeting at present, and coupled with the impressive development of the target-specific synthetic oligonucleotides/aptamer design [39], provides a viable option for delivery of these nanocarriers, since all these vectors can be surface-functionalized with appropriate functional groups (such as $-\mathrm{COOH},-\mathrm{NH}_{2}$, or $-\mathrm{SH}$ ) for the conjugation of biomolecules. Another recent work by Jeong et al. [40] demonstrated the feasibility of administering these types of nanocarriers intravenously to treat spinal cord injury in mice. Prior observations indicate that these aforementioned strategies will increase the 
concentration of the nanocarriers at the target tissue. Site-specific injection is also another route that needs to be explored with these types of nanocarriers depending on the location and accessibility of the tumor. In our previous studies $[24,31,41]$, the nanocarriers were found to be highly non-reactive, stable in physiological solutions, and were minimally toxic at even a higher dose level than the dose administered here. Reduced dose level can potentially render them as ideal candidates for photo-magnetic combination therapy.

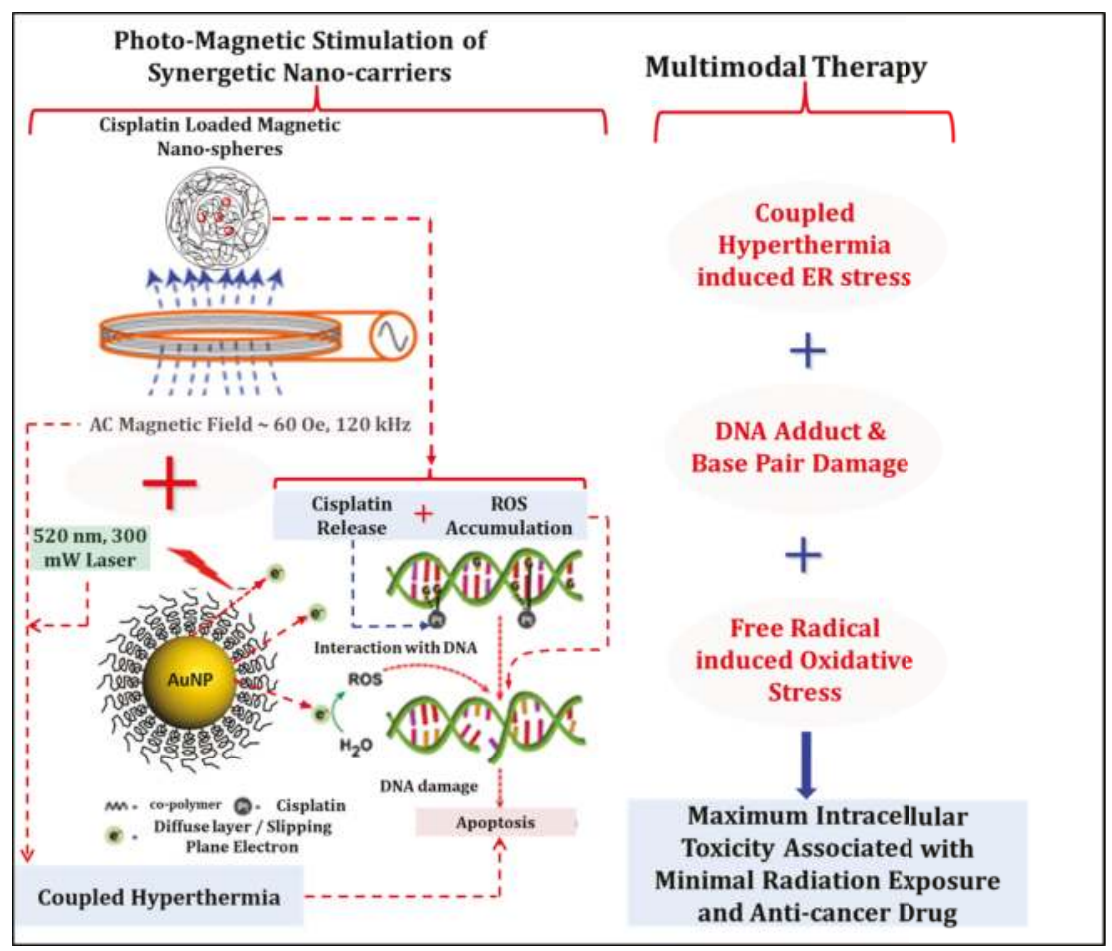

Figure 7. Photo-magnetic irradiation mediated multimodal therapeutic strategy of neuroblastoma cells using clusters of nanostructures: coupled hyperthermia, DNA damage, and reactive oxygen species (ROS) -induced apoptosis of B35 neuroblastoma cells in culture. Note that in this experiment, cisplatin has been loaded in a separate non-magnetic nanocarrier.

For tumorigenesis and malignant transformation, responsible molecular mechanisms are: (1) overexpression of cell survival pathways, and (2) downregulation of apoptosis [8]. The molecular factors of cell survival pathways include protein kinases (protein kinase B (AKT/PKB); anaplastic lymphoma kinase (ALK); phosphatidylinositide 3-kinases (PI3K); and focal adhesion kinase (FAK)), transcription factors (NF- $\mathrm{kB}, \mathrm{MYCN}$, and p53), and growth factors (insulin-like growth factor (IGF); epidermal growth factor (EGF); platelet-derived growth factor (PDGF); and vascular endothelial growth factor (VEGF)). Manipulation of the cell survival pathways may reduce the malignant potential of the tumor, which in turn may provide reduction of required dosages and the dose-related side effects of the conventional therapies in clinical practice. Moreover, since the presence of residual cancer cells in the hematopoietic compartment is the plausible explanation for tumor relapse [5], highly sensitive methods to detect and isolate rare circulating tumor cells may lead to improved treatment efficacy. The cluster of nanostructures used in this study carries the potential to act as effective modulators of these pathways and selectively target the tumor cells due to their controllability 
under hybrid photo-magnetic field and temperature-sensitive behavior. A temperature-dependent hydrophilic-hydrophobic transition behavior renders them suitable for drug delivery applications as well, in which triggered release is necessary.

Kinases are enzymes to phosphorylate, thus they act as on-off switches for activating other factors in cell signaling pathways. One well known kinase is AKT kinase, which regulates important cellular functions like cell growth, proliferation, survival, and angiogenesis [8,42]. In human tissue samples, it was observed that the AKT phosphorylation was more prevalent in primary neuroblastoma than in benign ganglioma or in normal adrenal tissue [8]. Downregulation of AKT to increase apoptosis is one of the many ways to address the neuroblastoma tumor growth, and two main strategies are being pursued: (1) long-term exposure of SH-SY5Y cells to interferon $\beta$, which decreased activation of the P13K-AKT pathway [43,44], thereby increasing the apoptosis, and (2) Rapamycin-induced mTOR (a downstream effector of AKT) inhibition [45], which is related to decreased tumor growth, angiogenesis, and increased apoptosis. Similarly, inhibition of FAK by siRNA [46] or small molecule inhibitors, such as NVP-TAE 226 [47] and Y15 [48] results in decreased cell survival, increased apoptosis, and G2 cell cycle arrest. NVP-TAE 226 (mol. wt. 468.94) and Y15 (mol. wt. 284.01) are ideal candidates to be loaded into these designed nanocarriers due to their low molecular weight and adequate water solubility, which will be extremely beneficial for controlled release into the tumor cells under photo-magnetic stimulation. Among transcription factors, NF- $\mathrm{kB}$ has important roles in neuroblastoma chemo-resistance as doxorubicin and VP16 have both been shown to trigger NF- $\mathrm{B}$ activation in neuroblastoma cells, inhibiting apoptosis [49]; nevertheless, siMYCN (siRNA against MYCN) has been found to increase caspase-3 mediated apoptosis [50]. Selective inhibition of MYCN can be achieved using an anti-gene peptide nucleic acid (PNA) [51], which can either be covalently attached to the nanocarrier surface, or can be loaded inside for on-demand release when the target site is reached. Targeted therapy to modulate the growth factors is another direction for the treatment of high risk neuroblastoma [52]. Imatinib, a tyrosine kinase inhibitor of PDGFR (PDGF receptor) has been shown to inhibit the growth of a number of human neuroblastoma cell lines in vitro and xenograft in vivo [53]. We recently demonstrated a nanocarrier mediated neurite growth factor (NGF) delivery to neuronal model cells for promoting neurite outgrowth [28,41]. A similar strategy can be adopted for the delivery of a selected growth factor mediated cell survival pathway modulators to the targeted cancer cells.

For high-risk neuroblastoma treatment, identification and targeting of the rare circulating tumor cells or removal of the nucleic acids from such cells is extremely important to prevent the tumor relapse. We have recently designed Förster resonance energy transfer (FRET)-based multifunctional nanocarriers [41], which are capable of performing organelle specific binding for detection of damaged cells and can provide on-demand release of a specific drug or a combination of drugs. Combined with the photo-magnetic actuation, these nanocarriers have the potential to perform detection at the single cell level, which may lead to a greater understanding of how to handle residual tumor cells. Further, since most of these aforementioned tasks can be performed with various types of magnetically controllable nanocarriers, it will be possible to prevent the diffusion out of the targeted area using a concentrated DC magnetic field during in vivo localization. Use of a Halbach cylinder [54] can extend the penetration depth of the applied magnetic field during clinical applications.

\section{Conclusions}

In conclusion, an optical and AC magnetic field-assisted therapeutic strategy for high risk neuroblastoma treatment was developed. Multifunctional nanostructures CSMNSs, AuNPs, and CPNPs at a reduced dose level were used to create coupled hyperthermia and induce sustained release of the imbibed cisplatin, which caused complete ablation of the B35 neuroblastoma cells. This enabled replacement of high energy $\gamma$-ray and high-intensity AC magnetic field exposure. The developed technique can potentially further combine the modulation of cell survival pathways and the detection of rare circulating tumor cells, thereby leading to a greater understanding 
and comprehensive solution to overcome the existing challenges to treat high-risk neuroblastoma. The results of this study suggest that photo-magnetic irradiation based multimodal therapy is a viable approach to remotely guide neuroblastoma cell destruction and the technique may be extended to treat other aggressive cancers.

Author Contributions: S.G. (Santaneel Ghosh) and S.G. (Somesree GhoshMitra) designed the experiments. T.M. synthesized and characterized the nanostructures, and R.A. (Rohini Atluri) and R.A. (Rahul Atmaramani) performed PC12 cell related experiments. D.D. performed the electron microscopy and the analysis. G.T. performed the photo-magnetic actuation of the nanocarriers and temperature regulation measurements. S.G. (Santaneel Ghosh) and J.P. supervised the design of the photo-magnetic actuator. S.G. (Santaneel Ghosh) directed the project and supervised this work. All authors have read and approved the final manuscript.

Acknowledgments: This work was supported by grants from the Research Corporation-Single Investigator Cottrell College Science Award (SG); Grants and Research Funding Committee, Southeast Missouri State University (SG). The authors declare no conflict of interests.

Conflicts of Interest: The authors declare no conflict of interests.

\section{References}

1. $\quad$ London, W.B.; Castleberry, R.P.; Matthay, K.K.; Look, A.T.; Seeger, R.C.; Shimada, H.; Thorner, P.; Brodeur, G.; Maris, J.M.; Reynolds, C.P.; et al. Evidence for an age cutoff greater than 365 days for neuroblastoma risk group stratification in the Children's Oncology Group. J. Clin. Oncol. 2005, 23, 6459-6465. [CrossRef] [PubMed]

2. Ries, L.A.; Smith, M.A.; Gurney, J.G.; Linet, M.; Tamra, T.; Young, J.L.; Bunin, G. Cancer Incidence and Survival among Children and Adolescents: United States SEER Program 1975-1995; NIH: Bethesda, MD, USA, 1999.

3. Hoehner, J.C.; Wester, T.; Pahlman, S.; Olsen, L. Localization of neurotrophins and their high-affinity receptors during human enteric nervous system development. Gastroenterology 1996, 110, 756-767. [CrossRef] [PubMed]

4. Matthay, K.K.; Villablanca, J.G.; Seeger, R.C.; Stram, D.O.; Harris, R.E.; Ramsay, N.K.; Swift, P.; Shimada, H.; Black, C.T.; Brodeur, G.M.; et al. Treatment of high-risk neuroblastoma with intensive chemotherapy, radiotherapy, autologous bone marrow transplantation, and 13-cis-retinoic acid. N. Engl. J. Med. 1999, 341, 1165-1173. [CrossRef] [PubMed]

5. Maris, J.M. Recent advances in neuroblastoma. N. Engl. J. Med. 2010, 362, 2202-2211. [CrossRef] [PubMed]

6. Rees, H.; Markley, M.A.; Kiely, E.M.; Pierro, A.; Pritchard, J. Diarrhea after resection of advanced abdominal neuroblastoma: A common management problem. Surgery 1998, 123, 568-572. [CrossRef] [PubMed]

7. Bousvaros, A.; Kirks, D.R.; Grossman, H. Imaging of neuroblastoma: An overview. Pediatr. Radiol. 1986, 16, 89-106. [CrossRef] [PubMed]

8. Megison, M.L.; Gillory, L.A.; Beierle, E.A. Cell survival signaling in neuroblastoma. Anticancer Agents Med. Chem. 2013, 13, 563-575. [CrossRef] [PubMed]

9. Kushner, B.H.; LaQuaglia, M.P.; Bonilla, M.A.; Lindsley, K.; Rosenfield, N.; Yeh, S.; Eddy, J.; Gerald, W.L.; Heller, G.; Cheung, N.K. Highly effective induction therapy for stage 4 neuroblastoma in children over 1 year of age. J. Clin. Oncol. 1994, 12, 2607-2613. [CrossRef] [PubMed]

10. American Cancer Society, Inc. Neuroblastoma. Available online: www.cancer.org/cancer/neuroblastoma (accessed on 25 August 2018).

11. Berthold, F.; Boos, J.; Burdach, S.; Erttmann, R.; Henze, G.; Hermann, J.; Klingebiel, T.; Kremens, B.; Schilling, F.H.; Schrappe, M.; et al. Myeloablative megatherapy with autologous stem-cell rescue versus oral maintenance chemotherapy as consolidation treatment in patients with high-risk neuroblastoma: A randomised controlled trial. Lancet Oncol. 2005, 6, 649-658. [CrossRef]

12. Yu, A.L.; Gilman, A.L.; Ozkaynak, M.F.; London, W.B.; Kreissman, S.G.; Chen, H.X.; Smith, M.; Anderson, B.; Villablanca, J.G.; Matthay, K.K.; et al. Anti-GD2 antibody with GM-CSF, interleukin-2, and isotretinoin for neuroblastoma. N. Engl. J. Med. 2010, 363, 1324-1334. [CrossRef] [PubMed]

13. Arany, I.; Safirstein, R.L. Cisplatin nephrotoxicity. Semin. Nephrol. 2003, 23, 460-464. [CrossRef]

14. Buzdar, A.U.; Marcus, C.; Blumenschein, G.R.; Smith, T.L. Early and delayed clinical cardiotoxicity of doxorubicin. Cancer 1985, 55, 2761-2765. [CrossRef]

15. Travis, L.B.; Curtis, R.E.; Glimelius, B.; Holowaty, E.J.; Van Leeuwen, F.E.; Lynch, C.F.; Hagenbeek, A.; Stovall, M.; Banks, P.M.; Adami, J.; et al. Bladder and kidney cancer following cyclophosphamide therapy for non-Hodgkin's lymphoma. J. Natl. Cancer Inst. 1995, 87, 524-530. [CrossRef] [PubMed] 
16. Barker, E.; Mueller, B.M.; Handgretinger, R.; Herter, M.; Yu, A.L.; Reisfeld, R.A. Effect of a chimeric anti-ganglioside GD2 antibody on cell-mediated lysis of human neuroblastoma cells. Cancer Res. 1991, 51, 144-149. [PubMed]

17. Islam, M.; Atmaramani, R.; Mukherjee, S.; Ghosh, S.; Iqbal, S.M. Enhanced proliferation of PC12 neural cells on untreated, nanotextured glass coverslips. Nanotechnology 2016, 27, 415501. [CrossRef] [PubMed]

18. Yuan, G.; Yuan, Y.; Xu, K.; Luo, Q. Biocompatible PEGylated $\mathrm{Fe}_{3} \mathrm{O}_{4}$ nanoparticles as photothermal agents for near-infrared light modulated cancer therapy. Int. J. Mol. Sci. 2014, 15, 18776-18788. [CrossRef] [PubMed]

19. You, C.C.; Miranda, O.R.; Gider, B.; Ghosh, P.S.; Kim, I.B.; Erdogan, B.; Krovi, S.A.; Bunz, U.H.; Rotello, V.M. Detection and identification of proteins using nanoparticle-fluorescent polymer "chemical nose" sensors. Nat. Nanotechnol. 2007, 2, 318-323. [CrossRef] [PubMed]

20. Mendes, R.; Pedrosa, P.; Lima, J.C.; Fernandes, A.R.; Baptista, P.V. Photothermal enhancement of chemotherapy in breast cancer by visible irradiation of Gold nanoparticles. Sci. Rep. 2017, 7, 11491-11498. [CrossRef] [PubMed]

21. GhoshMitra, S.; Ghosh, S. A novel nano-structure for central nervous system drug delivery:Sustained release of Therapeutic agents from Core-Multi-Shell nano-carriers. JSM Nanotechnol. Nanomed. 2016, 4, 1040.

22. Gu, L.; Koymen, A.R.; Mohanty, S.K. Crystalline magnetic carbon nanoparticle assisted photothermal delivery into cells using CW near-infrared laser beam. Sci. Rep. 2014, 4, 5106. [CrossRef] [PubMed]

23. Chowdhury, S.M.; Surhland, C.; Sanchez, Z.; Chaudhary, P.; Kumar, M.S.; Lee, S.; Peña, L.A.; Waring, M.; Sitharaman, B.; Naidu, M. Graphene nanoribbons as a drug delivery agent for lucanthone mediated therapy of glioblastoma multiforme. Nanomedicine Nanotechnology. Biol. Med. 2015, 11, 109-118.

24. GhoshMitra, S.; Diercks, D.R.; Mills, N.C.; Hynds, D.L.; Ghosh, S. Role of engineered nanocarriers for axon regeneration and guidance: Current status and future trends. Adv. Drug Deliv. Rev. 2012, 64, 110-125. [CrossRef] [PubMed]

25. Ellis-Behnke, R. Nano Neurology and the Four P's of Central Nervous System Regeneration: Preserve, Permit, Promote, Plasticity. Med. Clin. N. Am. 2007, 91, 937-962. [CrossRef] [PubMed]

26. Kumar, C.S.S.R.; Mohammad, F. Magnetic Nanomaterials for Hyperthermia-based Therapy and Controlled Drug Delivery. Adv. Drug Deliv. Rev. 2011, 63, 789-808. [CrossRef] [PubMed]

27. Orel, V.; Shevchenko, A.; Romanov, A.; Tselepi, M.; Mitrelias, T.; Barnes, C.H.; Burlaka, A.; Lukin, S.; Shchepotin, I. Magnetic properties and antitumor effect of nanocomplexes of iron oxide and doxorubicin. Nanomedicine Nanotechnology. Biol. Med. 2015, 11, 47-55.

28. Ghosh, S.; GhoshMitra, S.; Cai, T.; Diercks, D.R.; Mills, N.C.; Hynds, D.A.L. Alternating Magnetic Field Controlled, Multifunctional Nano-Reservoirs: Intracellular Uptake and Improved Biocompatibility. Nanoscale Res. Lett. 2010, 5, 195-204. [CrossRef] [PubMed]

29. Huang, X.; El-Sayed, I.H.; Qian, W.; El-Sayed, M.A. Cancer cell imaging and photothermal therapy in the near-infrared region by using gold nanorods. J. Am. Chem. Soc. 2006, 128, 2115-2120. [CrossRef] [PubMed]

30. Setua, S.; Ouberai, M.; Piccirillo, S.G.; Watts, C.; Welland, M. Cisplatin-tethered gold nanospheres for multimodal chemo-radiotherapy of glioblastoma. Nanoscale 2014, 6, 10865-10873. [CrossRef] [PubMed]

31. McCallister, T.; Gidney, E.; Adams, D.; Diercks, D.R.; Ghosh, S. Engineered, thermoresponsive, magnetic nanocarriers of oligo (ethylene glycol)-methacrylate-based biopolymers. Appl. Phys. Express 2014, 7, 117003. [CrossRef]

32. 3B Sci. Inc. 2015. Available online: https://www.a3bs.com/ (accessed on 25 August 2018).

33. Rubio-Retama, J.; Zafeiropoulos, N.E.; Serafinelli, C.; Rojas-Reyna, R.; Voit, B.; Cabarcos, E.L.; Stamm, M. Synthesis and Characterization of Thermosensitive PNIPAM Microgels Covered with Superparamagnetic $\gamma-\mathrm{Fe}_{2} \mathrm{O}_{3}$ Nanoparticles. Langmuir 2007, 23, 10280-10285. [CrossRef] [PubMed]

34. Ghosh, S.; Yang, C.; Cai, T.; Hu, Z.; Neogi, A. Oscillating magnetic field-actuated microvalves for micro-and nanofluidics. J. Phys. D 2009, 42, 135501. [CrossRef]

35. Fortin, J.P.; Wilhelm, C.; Servais, J.; Ménager, C.; Bacri, J.C.; Gazeau, F. Size-sorted anionic iron oxide nanomagnets as colloidal mediators for magnetic hyperthermia. J. Am. Chem. Soc. 2007, 129, 2628-2635. [CrossRef] [PubMed]

36. Adams, C.F.; Rai, A.; Sneddon, G.; Yiu, H.H.P.; Polyak, B.; Chari, D.M. Increasing magnetite contents of polymeric magnetic particles dramatically improves labeling of neural stem cell transplant populations. Nanomedicine Nanotechnology. Biol. Med. 2015, 11, 19-29.

37. Mohanty, S.K.; Mohanty, K.S.; Berns, M.W. Manipulation of mammalian cells using a single-fiber optical microbeam. J. Biomed. Opt. 2008, 13, 54047-54049. [CrossRef] [PubMed] 
38. Alkilany, A.M.; Murphy, C.J. Toxicity and cellular uptake of gold nanoparticles: What we have learned so far? J. Nanoparticle Res. 2010, 12, 2313-2333. [CrossRef] [PubMed]

39. Wagner, K.; Kautz, A.; Roder, M.; Schwalbe, M.; Pachmann, K.; Clement, J.H.; Schnabelrauch, M. Synthesis of oligonucleotide-functionalized magnetic nanoparticles and study on their in vitro cell uptake. Appl. Organometal. Chem. 2004, 18, 514-519. [CrossRef]

40. Jeong, S.J.; Cooper, J.G.; Ifergan, I.; McGuire, T.L.; Xu, D.; Hunter, Z.; Sharma, S.; McCarthy, D.; Miller, S.D.; Kessler, J.A. Intravenous immune-modifying nanoparticles as a therapy for spinal cord injury in mice. Neurobiol. Dis. 2017, 108, 73-82. [CrossRef] [PubMed]

41. GhoshMitra, S.; Diercks, D.R.; Mills, N.C.; Hynds, D.A.L.; Ghosh, S. Excellent biocompatibility of semiconductor quantum dots encased in multifunctional poly ( $N$-isopropylacrylamide) nanoreservoirs and nuclear specific labeling of growing neurons. Appl. Phys. Lett. 2011, 98, 103702. [CrossRef]

42. Song, G.; Ouyang, G.; Bao, S. The activation of Akt/PKB signaling pathway and cell survival. J. Cell. Mol. Med. 2005, 9, 59. [CrossRef] [PubMed]

43. Hennessy, B.T.; Smith, D.L.; Ram, P.T.; Lu, Y.; Mills, G.B. Exploiting the PI3K/AKT pathway for cancer drug discovery. Nat. Rev. Drug Discov. 2005, 4, 988-1004. [CrossRef] [PubMed]

44. Wang, L.; Yang, H.-J.; Xia, Y.-Y.; Feng, Z.-W. Insulin-like growth factor 1 protects human neuroblastoma cells SH-EP1 against MPP -induced apoptosis by AKT/GSK-3ß/JNK signaling. Apoptosis 2010, 15, 1470-1479. [CrossRef] [PubMed]

45. Johnsen, J.I.; Segerström, L.; Orrego, A.; Elfman, L.; Henriksson, M.; Kågedal, B.; Eksborg, S.; Sveinbjörnsson, B.; Kogner, P. Inhibitors of mammalian target of rapamycin downregulate MYCN protein expression and inhibit neuroblastoma growth in vitro and in vivo. Oncogene 2008, 27, 2910-2922. [CrossRef] [PubMed]

46. Beierle, E.A.; Trujillo, A.; Nagaram, A.; Kurenova, E.V.; Finch, R.; Ma, X.; Vella, J.; Cance, W.G.; Golubovskaya, V.M. N-MYC regulates focal adhesion kinase expression in human neuroblastoma. J. Biol. Chem. 2007, 282, 12503-12516. [CrossRef] [PubMed]

47. Beierle, E.A.; Trujillo, A.; Nagaram, A.; Golubovskaya, V.M.; Cance, W.G.; Kurenova, E.V. TAE226 inhibits human neuroblastoma cell survival. Cancer Investig. 2008, 26, 145-151. [CrossRef] [PubMed]

48. Beierle, E.A.; Ma, X.; Stewart, J.; Nyberg, C.; Trujillo, A.; Cance, W.G.; Golubovskaya, V.M. Inhibition of focal adhesion kinase decreases tumor growth in human neuroblastoma. Cell Cycle 2010, 9, 1005-1015. [CrossRef] [PubMed]

49. Ammann, J.U.; Haag, C.; Kasperczyk, H.; Debatin, K.; Fulda, S. Sensitization of neuroblastoma cells for TRAIL-induced apoptosis by NF-KB inhibition. Int. J. Cancer 2009, 124, 1301-1311. [CrossRef] [PubMed]

50. Kang, J.-H.; Rychahou, P.G.; Ishola, T.A.; Qiao, J.; Evers, B.M.; Chung, D.H. MYCN silencing induces differentiation and apoptosis in human neuroblastoma cells. Biochem. Biophys. Res. Commun. 2006, 351, 192-197. [CrossRef] [PubMed]

51. Tonelli, R.; Purgato, S.; Camerin, C.; Fronza, R.; Bologna, F.; Alboresi, S.; Franzoni, M.; Corradini, R.; Sforza, S.; Faccini, A.; et al. Anti-gene peptide nucleic acid specifically inhibits MYCN expression in human neuroblastoma cells leading to cell growth inhibition and apoptosis. Mol. Cancer Ther. 2005, 4, 779-786. [CrossRef] [PubMed]

52. Byrne, A.M.; Bouchier-Hayes, D.J.; Harmey, J.H. Angiogenic and cell survival functions of vascular endothelial growth factor (VEGF). J. Cell. Mol. Med. 2005, 9, 777. [CrossRef] [PubMed]

53. Beppu, K.; Jaboine, J.; Merchant, M.S.; Mackall, C.L.; Thiele, C.J. Effect of imatinib mesylate on neuroblastoma tumorigenesis and vascular endothelial growth factor expression. J. Natl. Cancer Inst. 2004, 96, 46-55. [CrossRef] [PubMed]

54. Riegler, J.; Lau, K.D.; Garcia-Prieto, A.; Price, A.N.; Richards, T.; Pankhurst, Q.A.; Lythgoe, M.F. Magnetic cell delivery for peripheral arterial disease: A theoretical framework. Med. Phys. 2011, 38, 3932-3943. [CrossRef] [PubMed]

(C) 2018 by the authors. Licensee MDPI, Basel, Switzerland. This article is an open access article distributed under the terms and conditions of the Creative Commons Attribution (CC BY) license (http:/ / creativecommons.org/licenses/by/4.0/). 


\title{
Trends towards Biomimicry in Theranostics
}

\author{
Michael Evangelopoulos ${ }^{1}$, Alessandro Parodi ${ }^{2}$, Jonathan O. Martinez ${ }^{1}$ and Ennio Tasciotti ${ }^{1,3, *}$ \\ 1 Center for Biomimetic Medicine, Houston Methodist Research Institute, Houston, TX 77030, USA; \\ mevangelopoulos@houstonmethodist.org (M.E.); jomartinez@houstonmethodist.org (J.O.M.) \\ 2 Department of Pharmacology, University of Illinois at Chicago, Chicago, IL 60607, USA; aparodi@uic.edu \\ 3 Department of Orthopedics \& Sports Medicine, Houston Methodist Hospital, Houston, TX 77030, USA \\ * Correspondence: etasciotti@houstonmethodist.org; Tel.: +1-713-441-7319
}

Received: 29 June 2018; Accepted: 20 August 2018; Published: 21 August 2018

\begin{abstract}
Over the years, imaging and therapeutic modalities have seen considerable progress as a result of advances in nanotechnology. Theranostics, or the marrying of diagnostics and therapy, has increasingly been employing nano-based approaches to treat cancer. While first-generation nanoparticles offered considerable promise in the imaging and treatment of cancer, toxicity and non-specific distribution hindered their true potential. More recently, multistage nanovectors have been strategically designed to shield and carry a payload to its intended site. However, detection by the immune system and sequestration by filtration organs (i.e., liver and spleen) remains a major obstacle. In an effort to circumvent these biological barriers, recent trends have taken inspiration from biology. These bioinspired approaches often involve the use of biologically-derived cellular components in the design and fabrication of biomimetic nanoparticles. In this review, we provide insight into early nanoparticles and how they have steadily evolved to include bioinspired approaches to increase their theranostic potential.
\end{abstract}

Keywords: biomimetic; bioinspired; cancer; multistage nanovectors; nanomedicine; nanoparticles; theranostics

\section{Introduction}

Over the past several decades, medicine has benefitted significantly from the use of imaging modalities to help guide diagnosis and treatment. While our ability to look inside the body was initially largely limited to what could be felt, the introduction of more advanced imaging systems (e.g., X-ray imaging) helped revolutionize the field of imaging and is now among medicine's leading diagnostic tools. Since then, imaging modalities to treat diseases have evolved from simple $\mathrm{X}$-rays to high resolution computer augmented virtual environments that allow physicians to navigate the various layers of the body in greater detail [1-4]. However, despite imaging systems evolving to generate great detail and delineate the complexity of the body, diagnosis and treatment algorithms continue to remain a two-step process, consequently limiting the onset of therapy [5]. More so, although nanotechnology has been introduced as an effective utility to concentrate a payload to a target site [6-8], thereby limiting toxicity to healthy tissue and other side effects, this approach continues to require two distinct steps to diagnose and treat disease. To mitigate these shortcomings, significant interest has been sparked towards the development of therapies that aim to combine diagnostic and therapeutic capabilities into a single agent.

This new class of treatment, referred to as theranostics, has led to the development of a large arsenal of therapeutic agents that offer a viable one-step treatment solution [9-11]. For example, nanomaterials capable of enhancing tumor imaging while concurrently delivering a therapy is only one application in which theranostic-based technologies are being exploited $[12,13]$. With the urgency 
required in the timely diagnosis and subsequent treatment of cancer, time-saving theranostic treatments have garnered tremendous support [5,14-16].

Recently, in an effort to further strengthen the effectiveness of theranostics, bioinspired approaches have been developed with a goal of providing biological-like behaviors to synthetic theranostic vectors. In this review, we outline the fundamental imaging modalities that have largely contributed to the development of theranostic-based therapies followed with a discussion on multi-step delivery vectors that have contributed to furthering efficacy for these imaging modalities. Lastly, a brief overview of bioinspired theranostic strategies is discussed.

\section{Nanoparticle-Based Theranostics}

\subsection{Iron Oxide Nanoparticles}

Iron Oxide nanoparticles (IONP) have generated tremendous momentum in nanomedicine due to their many beneficial properties [17]. Distinctive elements such as superparamagnetism, susceptibility to surface-modifications (e.g., polyethylene glycol, dextran, polypeptides, etc.), and high surface to volume ratios have proven highly useful, particularly for magnetic resonance imaging (MRI) and drug delivery [18-20]. Composed of ferrite nanocrystallites of magnetite and their oxidized counterpart maghemite, the last decade has witnessed considerable interest in these particles for theranostic applications. Specifically, it has been found that when IONP are reduced to a size of $<20 \mathrm{~nm}$, they become superparamagnetic in the presence of a magnetic field [21]. Conversely, when the magnetic field is turned off, the particles become highly dispersed [22]. In clinical applications, this feature is critical as the aggregation of particles can lead to detection and sequestration by the mononuclear phagocyte system (MPS), inhibiting IONP from reaching their target and significantly lowering their efficacy [23].

These features, coupled with the use of a magnetic field as a guiding mechanism, can be beneficial in a number of ways. For example, the total drug amount needed to achieve a clinical effect can be reduced, resulting in a decrease in the frequency of administration and minimal cytotoxic effects on healthy tissue [24]. Furthermore, when subjected to an alternating magnetic field, IONP have also been shown to dissipate heat, resulting in an increase in temperature in the surrounding area. This feature has been exploited in magnetic hyperthermia to kill cancer cells, resulting in an increase of over $10{ }^{\circ} \mathrm{C}$ at the injection site (Figure 1) [25]. Meanwhile, surface modifications (e.g., antibodies, dyes, chemotherapeutics) garnered beneficial properties for IONP by prolonging circulation [26] and increasing cancer-targeting abilities [27]. In one case, IONP were functionalized with cystine, the oxidized dimer of cysteine, to achieve improved biocompatibility and hydrophilicity [28]. In addition, cystine-functionalized IONP demonstrated versatility as a viable contrast agent for MRI, as well as ultrasonography, further exhibiting its potential for theranostic applications.
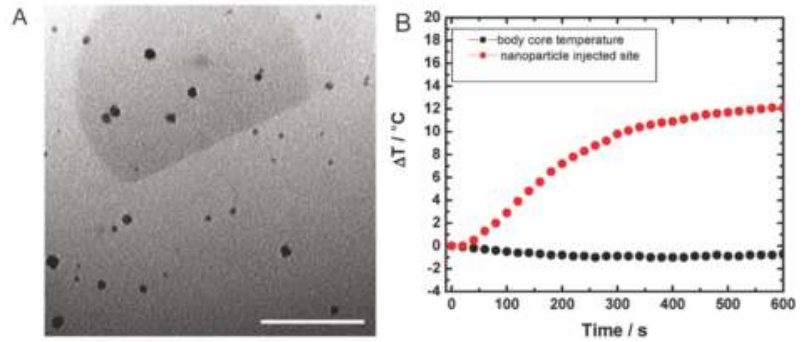

Figure 1. (A) Transmission electron microscope image of IONP fabricated with a dopamine-anchored shell, scale bar, $100 \mathrm{~nm}$; (B) Quantitative analysis depicted the temperature changes at the nanoparticle injection site versus the body core as measured with a fiber optic temperature probe. Images reproduced from [25], with permission from BioMed Central Ltd., 2010. 
While multifunctional nanoparticles have recently gained significant attention, improvements still need to be made in the loading ability of nanoparticles into the drug carrier. Yoon et al. reported that IONP co-loaded with the chemotherapeutic, paclitaxel, into micelles, showed promising results as a candidate for the combined imaging and treatment of cancer [29]. These results show micelles, encapsulated with both a chemotherapeutic payload and imaging agent, were able to inhibit the growth of a tumor in vivo by more than $50 \%$ compared to a control group, thereby demonstrating this coupled approach as a promising theranostic tool. Nevertheless, limitations of IONP continue to exist. For example, the physiological environment of the body causes drug-conjugated IONP to suddenly release the payload upon administration, thereby limiting its effectiveness at the intended site. Efforts to mitigate the adverse release of payloads have been achieved through the incorporation of layer-by-layer fabrication using oppositely charged polymers [30]. This attempt exhibited the development of a stabilized IONP formulation while also achieving the simultaneous loading of naturally-derived compounds.

In general, multi-modal systems incorporating IONP have drawn considerable attention for their magnetic and photothermal properties. In more recent efforts, merging polymer responsive materials with IONP have exhibited desirable properties through the manipulation of environmental factors to achieve therapeutic potency and imaging potential [31]. A more comprehensive analysis has recently been conducted by Pellegrino and coworkers discussing the current state of magnetic-based stimuli-responsive systems [32]. Nevertheless, the cytotoxicity of IONP is still debated, with some reports revealing increased toxicity (i.e., disruption of cell cytoskeleton) [33] and others demonstrating no toxicity (i.e., no increase of reactive oxygen species) [34]. Additionally, although IONP were successful in generating initial buzz under familiar names such as Feridex, they ultimately failed commercially due to adverse side effects and lack of diagnostic utility [35]. Despite this, a resurgence of their use has been found in the treatment of iron deficiency with more recent efforts exploiting the use of ferromagnetic IONP (i.e., permanent magnetism) for diagnostic imaging, thereby reaffirming the multitude of applications possible with IONP.

\subsection{Gold Nanoparticles}

Similar to IONP, gold-based nanoparticles have also gained significant popularity over the past decade, seeing applications ranging from optical bioimaging to detection of cancer. Features such as high surface area to volume ratio coupled with cytocompatibility and stability have made gold an ideal candidate for photothermal therapy [36]. In addition to these properties, ease of synthesis and conversion of heat using near-infrared (NIR) light have enabled the use of gold (e.g., nanoshells, nanorods, hollow gold) [37] for a variety of photo-triggered treatments. Specifically, using surface plasmon resonance for photodynamic therapy has drawn particular interest. In particular, exploitation of the combined resonant oscillation of free electrons present on the particle surface, thereby outputting a sharp absorption band, has led to the use of gold nanoparticles in a variety of imaging and therapeutic applications [38]. More so, the ability to conjugate antibodies onto the nanoparticle surface paved the way for direct electron microscopic visualization while minimal toxicity and light scattering efficiency opened the door for a multitude of biomedical applications. Khlebtsov et al. have shown promising results of multifunctional nanoparticles consisting of gold-loaded hematoporphyrin-doped silica particles as an antimicrobial therapeutic [39]. Others have also shown promising applications of gold-based nanoparticles as antibiotic [40] and vaccine [41] delivery systems.

Despite numerous advantageous features, concern over their cytotoxicity still remains. A study designed to evaluate the cytotoxic effects by Soenen et al. [42] revealed that high concentrations $(200 \mathrm{nM})$ led to the formation of reactive oxygen species, resulting in a $20 \%$ decrease in cell viability after $24 \mathrm{~h}$. Nevertheless, the same study exhibited that a concentration of $100 \mathrm{nM}$ showed negligible toxicity. To mitigate toxicity, Choi et al. [43] designed a gold-loaded nanocarrier that was shown to increase circulation time and tumor accumulation while minimizing disruption of metabolic activity and cell viability. The ability to localize more gold to the tumor site through an increase in circulation 
enables a hyperthermia-based approach to be more effective and reveals a promising tool for translation into the clinic.

Although great success has been observed with gold nanoparticles using in vitro and in vivo models, lack of homogeneity in human cancer prevents gold from showing the same success in the clinic. In addition, the high cost associated with development of gold nanoparticles remains as another barrier preventing clinical translation [35,44]. For this reason, continued investigation in the scale-up for commercialization and clinical trials needs to be re-evaluated and optimized to meet the demand of the clinic. However, as is often the case with nanoparticles, delineation of nanoparticle accumulation at the target site can often be difficult to assess in clinical trials, serving as a barrier to their proper investigation.

\subsection{Quantum Dots}

Showing similar rise in popularity are non-metal theranostics such as quantum dots (QD), colloidal particles that can range in size from 1 to $10 \mathrm{~nm}$ in diameter $[45,46]$. These semiconductor nanocrystals, synthesized using a cadmium selenide (CdSe) core with a zinc sulfide layer to maintain desirable crystallinity and homogeneity, are able to emit light and exhibit distinctive optical qualities that are not found in organic dyes or florescent probes [47]. These qualities include exhibiting high luminescence, a more stable and restricted emission spectrum, and a broader excitation field [45,48]. This is helpful in monitoring long-term studies such as the interactions of multi-labeled biological markers in cells. Additionally, the ability to fine-tune the fluorescence emission of QD from ultraviolet to near-infrared wavelengths has exhibited beneficial properties for studying the extravasation of cancer cells in vivo. For example, conjugating antibodies that target different tumor markers onto QD allows for the real-time imaging of cancer cells as they metastasize [47].

Additionally, surface modification of QD can provide further benefits. To create water-stabilized QD with increased photostability and enhanced functionality, Medintz et al. were able to use ligand exchange to replace hydrophobic capping ligands with hydrophilic bifunctional ligands [49]. These aqueous QD can be used for fluorescence imaging or to trace receptor mediated trafficking in live cells and for long term labeling of endosomes without any drastic harmful effects [50]. After successful in vitro studies, Gao et al. developed a copolymer coated QD to target and image prostate cancer in vivo [51]. Using this method, the tumor could be actively probed by the antibody conjugated QDs and imaged in live animals. Further tuning the size to favor rapid clearance from the body and applications calling for high sensitivity have the potential to make QD an integral part of imaging the human body.

Nevertheless, caution must be taken when using QD in vivo. Many studies indicate that the use of cadmium is toxic and that it possesses DNA-damaging properties. Other groups suggest that the use of cadmium in the cellular environment also results in the formation of reactive oxygen species that contributes to cell death. Thus to prevent or reduce these harmful effects, passivation can be used to protect the core from oxidation and lower the toxic effects [52]. Nevertheless, more recent efforts have aimed to harness the diagnostic potential of QD and couple them with a chemotherapeutic such as doxorubicin, a commonly used anthracycline drug. In a study performed by Bagalkot et al., QD were used to develop a QD-aptamer-doxorubicin conjugate capable of targeting cancer cells (Figure 2) [53]. This approach harnesses the targeting potential of the aptamer specifically selected to localize at prostate cancer cells expressing the antigen. Following binding to the target, the conjugated doxorubicin is released, resulting in the activation of the QD core, consequently allowing for the simultaneous imaging of the cancer cells. However, to be properly translated into the clinic, significant work still needs to be performed investigating the toxicity of QD. As it currently stands, QD translation into in vivo models often portrays difficulty in identifying the dominant and compensation mechanism employed [54], spurring a need for a multi-modal QD system. In addition, further evaluation of toxicity is needed before QD can reach clinical translation status. 


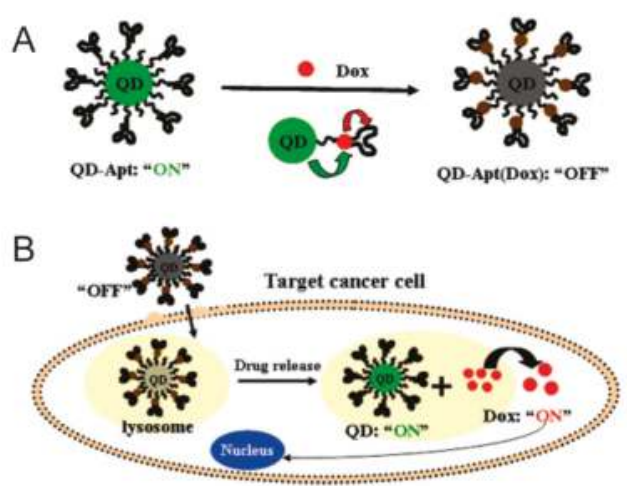

Figure 2. (A) Schematic illustration demonstrating the Bi-FRET-based QD-aptamer-doxorubicin nanoparticle. This approach results in the simultaneous quenching of QD and doxorubicin; QD fluorescence is quenched by doxorubicin while doxorubicin fluorescence is quenched by QD; (B) Schematic illustration depicting the internalization via the PSMA endocytosis pathway. Internalization results in the release of doxorubicin from the conjugated nanoparticle, thereby resulting in cell death and the triggering of QD fluorescence. Images reproduced from [53], with permission from American Chemical Society, 2007.

\section{Multistage Nanovectors}

Despite all the advantages first-generation nanoparticles provide $[55,56]$, the many biological obstacles they are required to overcome have led to the development of several delivery vectors designed to decouple the multitude of tasks required to bypass these barriers [57-59]. Previously, our group introduced multistage nanovectors (MSV) [60,61], engineered to systemically shield, transport and reliably deliver therapeutic and imaging agents, thereby making them ideal for theranostics applications [62,63]. Designed using porous silicon due to its biocompatibility and degradability $[64,65]$, well-established fabrication techniques make it possible to uniquely control parameters such as shape, size, and porosity that can aid in the strategic negotiation of biological barriers $[56,57,66]$. As one example, mathematical modeling has revealed that MSV exhibit superior margination and adhesion during systemic circulation, favoring the release of a payload into the extracellular space $[67,68]$. In addition, functionalization of the MSV surface with biological moieties (e.g., antibodies, aptamers, phages) can further aid in the negotiation of biological barriers such as avoidance of MPS and targeting of inflamed vasculature $[8,69]$. This versatility, combined with the ability to control the release kinetics of a payload [70], makes MSV a promising tool for theranostics applications [71,72]. Furthermore, porous silicon as a material has been extensively studied for various medical applications including diagnostics, drug delivery, implantables, and tissue engineering [73,74].

\section{Nanoparticle Loading into Multistage Nanovectors}

The nano-sized pores of MSV facilitate the loading and retention of several types of nanoparticles that effectively bestow MSV with novel therapeutic and diagnostic functions [75]. For example, loading MSV with liposomes containing small interfering RNA (siRNA) directed against the EphA2 oncoprotein resulted in the sustained delivery of siRNA and silencing of the protein in ovarian tumors for up to three weeks, substantially extending the silencing impact of free liposomes that previously required biweekly administration to achieve a similar response [76]. This work was further expanded to demonstrate an enhanced tumor response by combining chemotherapy (e.g., Paclitaxel and Docetaxel) with sustained EphA2 siRNA delivery using MSV [77]. This approach resulted in a significant reduction in tumor burden with complete inhibition of tumor growth when combined with chemotherapy in two different tumor models, including a highly aggressive and chemoresistant model 
(i.e., HeyA8-MDR). In addition, this approach of MSV/siRNA was validated in treating breast cancer by delivering siRNA-targeting ataxia telangiectasia mutated (ATM) genes using liposomes [78] or by modifying the surface of MSV with polyethyleneimine to form nanocomplexes within the pores to deliver ATM [79], STAT3, and GRP78 siRNA [80] inducing significant reduction in cancer stem cells. MSV loading with paclitaxel micelles exhibited a similar sustained delivery and suppressed tumor growth with a single administration, confirming the sustained release characteristics of MSV upon loading with nanoparticles [81].

Lastly, a cooperative thermal therapy approach for breast cancer was demonstrated by loading NIR responsive hollow gold nanoparticles into MSV [82]. This approach enabled a two-fold increase in heat generation and more efficient cell killing independent of genetic mutations expressed by the breast cancer cells (i.e., HER2 vs triple-negative) (Figure 3). This cooperative effect was generated due to the collective electromagnetic dipole-dipole coupling of gold nanoparticles within MSV, resulting in a coherent thermal spot-source allowing for more efficient heat dissipation and increased energy transfer and heat production.
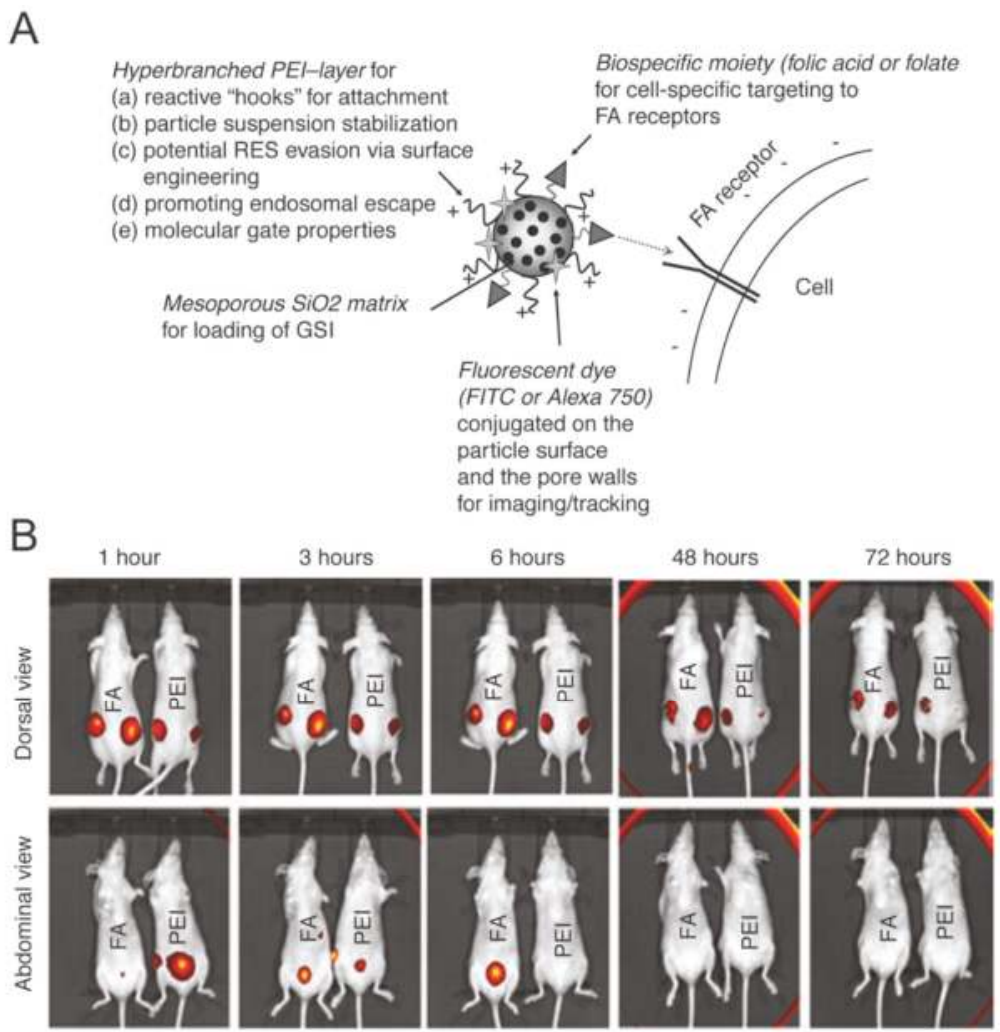

Figure 3. (A) Schematic illustration depicting the mesoporous silica nanoparticle matrix functionalized with a folate targeting moieties and fluorescent dyes; (B) Dorsal (top) and abdominal (bottom) in vivo images of tumor-bearing mice treated with non-conjugated mesoporous silica nanoparticles (PEI) and folate conjugated nanoparticles (FA) over a $72 \mathrm{~h}$ time period. Dorsal images depict nanoparticle accumulation in the tumor while abdominal images depict accumulation in the bladder. Mice were each inoculated with two tumors. Images reproduced from [82], with permission from Cell Press, 2011. 
The diagnostic potential of MSV was further evaluated by investigating emerging properties upon loading with contrast agents. The loading of MSV with gadolinium-based contrast agents (Magnevist, spherical fullerenes and carbon nanotubes encapsulating gadolinium ions) revealed a 50-fold increase in the relaxivity of MRI compared to clinically available contrast agents and, thus, significantly enhanced the $\mathrm{T}_{1}$ contrast possible [83]. This improved relaxivity and contrast enhancement was attributed to geometric confinement of the contrast agents within the pores of MSV. This confining effect resulted in an increased tumbling rate, thus inhibiting the ability of the contrast agents to rotate freely and effectively, reducing the mobility of the water molecules. The impact of confinement was studied by loading Magnevist in MSV with various pore sizes and demonstrated that smaller pores bestowed greater relaxivity enhancement [84].

In addition to gadolinium, MSV loaded with superparamagnetic iron oxide nanoparticles (SPION) demonstrated increased negative contrast suitable for $\mathrm{T}_{2}$-weighted MRI compared to free SPION [85]. Furthermore, MSV have been successfully loaded with fluorescent QD [86] and carbon nanotubes [87] with their surface allowing for the covalent attachment of NIR fluorescent dyes, radioactive molecules, and therapeutic agents [88]. The flexible and versatile nature of MSV has the potential to generate theranostic agents by co-loading nanoparticles that individually provide therapeutic (e.g., siRNA, micelles, gold) or diagnostic (e.g., gadofullerenes, gadonanotubes, SPION, QD) action and thus whose combination would result in treatment and imaging. Alternatively, the surface of MSV could be used to attach diagnostic and therapeutic agents, permitting one to use the full porous matrix to load a nanoparticle payload. Furthermore, any current or future theranostic nanoparticle smaller than $100 \mathrm{~nm}$ can be incorporated into MSV with relative ease, enabling advanced generations of theranostic agents.

\section{Bio-Inspired Theranostics}

Recently, bio-inspired approaches have gained increasing popularity in overcoming the current limitations of drug delivery systems such as biocompatibility, toxicity, and targeting [89,90]. FDA-approved Abraxane, albumin-bound paclitaxel, represents the first example of a bio-inspired approach and has been shown to improve circulation time while reducing unwanted side effects of chemotherapy. Harnessing albumin's innate ability to transport hydrophobic molecules and interact with endothelial cells has led to Abraxane exhibiting increased efficacy of paclitaxel, thereby demonstrating itself as an effective adjuvant therapy. This manipulation of biological matter and its incorporation into synthetic carriers and payloads was proposed to both improve the delivery of drugs and assist in accumulation of imaging agents. As such, theranostics based on the mimicry or incorporation of biological components were developed to exploit all levels of biological complexity.

It is therefore not only important to select a material that works compatibly when administered but to also consider rational design when engineering drug delivery vectors. Although nanoparticle design has traditionally centered on the use of spherically-shaped particles due to ease of synthesis, more recent efforts have been biologically inspired, leading to the design of vehicles that are strategically shaped to optimally travel within the blood stream and overcome biological barriers. In the preceding case (Section 3), MSV were designed to mimic the size and shape of red blood cells to increase margination towards vessel walls. Similarly, other efforts have drawn inspiration from bacteria's worm-like structure (e.g., filomicelles) [91]. Specifically, the elongated shape of filomicelles and nanoworms have shown great promise as delivery vehicles both for chemotherapeutic delivery [92] and imaging applications [93]. In addition, hyper-branched polymeric structures have also been designed to covalently link drug molecules to a substrate, providing controlled drug release mediated through degradable linkages [94]. Nevertheless, although shape has played a pivotal role in drug delivery carrier design, other efforts have leveraged physical incorporation of biological components. As such, this section will highlight some key aspects of bio-inspired theranostics such as enzymatic substrates, natural-derived transporters, viruses, and cells. 


\subsection{Proteases}

Proteases (e.g., caspases, metalloproteases (MMP), furin) have been identified as a component of the tumor environment that is commonly overexpressed and, thus, is a prime tool to exploit for the development of bio-inspired strategies. Recently, nanoformulated protease substrates were proposed as a new research tool to investigate proteolytic activity in the intra- and extra-cellular space. These substrates work by taking advantage of the cleavage of monomeric units that polymerize after cleavage, functioning as an enhanced fluorescent signal or theranostic agent $[95,96]$. Another strategy designed by Kim et al. involved the use of MMP and cathepsin B as an activation mechanism for fluorescent nanoprobes [97]. In this way, the imaging of a tumor area can be enhanced knowing that proteolitic enzymes are readily present in the tumor microenvironment, thereby leading to the cleavage of the imaging probe and higher specificity of imaging agents. Wong et al. developed a QD-loaded gelatin multistage nanoparticle designed to degrade in the presence of MMP-2, a protease highly expressed in the tumor microenvironment, thereby releasing smaller sized QD that readily diffuse into the tumor [98].

Cathepsins, monomeric proteases, have also been identified as viable targets to be employed in targeted-based therapies. Typically activated in low $\mathrm{pH}$ environments such as lysosomes, cathepsins have been abundantly expressed in various malignant tumors and are known to increase cancer cell recruitment. In one strategy, PEG was combined with cathepsin B to form a liposomal nanoparticle that facilitates the targeting of cathepsin B expressing cancer cells, allowing the release of a therapeutic payload at a target site [99]. Cathepsin was similarly used in an effort to mitigate the unwanted side effects of chemotherapeutic camptothecin derivatives [100]. When cathepsin B was conjugated onto a camptothecin derivative, similar anti-tumor effects were observed without any toxic effects. This method demonstrates considerable promise in the use of proteases to develop viable bioinspired strategies.

\subsection{Lipoproteins}

Similar to proteases, lipoprotein-based nanoparticles have also been extensively evaluated as a suitable bioinspired approach for the transport of theranostic payloads [101]. This class of nanoparticles is biochemically synthesized by the body and governs the transport of lipids, enabling fats to be carried in the blood stream. Additionally, lipoproteins possess innate biocompatibility properties, inspiring the design of long circulating particles aimed at improving the transport of hydrophobic payloads. Unique properties such as their small size $(<40 \mathrm{~nm})$ and amphiphilic nature favor their diffusion, in addition to their payload, deeper into the tumor mass. As such, low-density (LDL) and high-density (HDL) lipoprotein-based carriers have been developed to exploit these properties and increase the delivery of therapeutic and imaging agents through weak chemical interactions (i.e., covalent bonds) and the exchange of a hydrophobic core with a payload of interest.

For example, LDL conjugated with radiolabelled tracers was shown to accumulate in the tumor within $24 \mathrm{~h}$ of injection, shedding light to the abnormal traffic of these molecules and lipid metabolism during cancer [102]. Furthermore, LDL has been shown to possess great propensity in accommodating a variety of agents for photodynamic therapy (e.g., NIR-molecules [103-105]) and can further be modified to target cancer cells. For example, Zheng et al. showed that by conjugating a tumor-homing molecule through a lysine substitution and coupling LDL with folate, accumulation of LDL in cancer cells is improved [106]. Conversely, HDL-based delivery systems rely on the over expression of their natural receptor, scavenger receptor class B type I, in many cancer cells $[107,108]$. It was hypothesized that HDL could represent a major source of cholesterol for growing neoplastic lesions [109]. This led to increased interest in HDL-based carriers and the loading of chemotherapeutics (e.g., paclitaxel) [110] and NIR agents capable of generating reactive oxygen species under light irradiation, resulting in the killing of cancer cells. 


\subsection{Viral \& Cellular Vesicles}

Further inspiration for suitable bioinspired approaches was found by imitating the working mechanism of viruses. Their enhanced ability to target and integrate their genome into the DNA of human cells makes them a promising tool for drug delivery. In particular, adenoviral particles were investigated as ideal carriers for gene therapy in vivo with recent efforts focused on coupling these carriers with metallic particles for improved imaging and curative properties. Specifically, iron particles were shown to readily absorb onto the adenovirus surface resulting in a hybrid particulate with promising theranostic properties. To further refine and standardize the hybridization process, Everts et al. modified the surface of adenoviral vectors with gold nanoparticles [111]. This led to the ability to use the adenoviral vector for its tumor-associated antigen homing ability and the gold nanoparticles for their ablation properties.

Conversely, inspiration drawn directly from cells found in the body (i.e., erythrocytes, leukocytes, mesenchymal stem cells) have also gained increasing prominence. Over the past two decades, erythrocytes have been investigated for their biocompatibility, prolonged circulation, and their desirable isolation and manipulation properties. In addition, the ability to load a payload into the cellular body through concentration gradients makes erythrocytes a promising carrier. Methotrexate, a chemotherapeutic used to treat inflammatory diseases, loaded into erythrocytes, represents one of the first examples to successfully inhibit cancer growth. The loading of photo-triggered hematoporphyrin derivatives into erythrocytes has also been shown to provide antibody-mediated delivery of the derivatives with increased efficacy [112]. For prolonged circulation and decreased clearance of IONP, Markov et al. designed a protocol that incorporates IONP into erythrocytes that demonstrated considerable improvements in imaging properties of IONP for MRI [113]. In a similar strategy, $\mathrm{Hu}$ et al. incorporated erythrocyte cellular membrane to coat poly (lactic-co-glycolic acid) (PLGA) particles (Figure 4) [114]. Following functionalization with an erythrocyte shell, it was reported that PLGA particles remained in circulation for three days following administration in vivo, demonstrating promising potential as a delivery vector. This approach was later further optimized to combine a hybrid erythrocyte/platelet-derived membrane to provide increased circulation and marry the two distinct functions of each donor cell source [115].

Similarly, cell-derived vesicles known as exosomes have also garnered significant interest due to their small size and protein function. As such, exosomes have been reported as vesicles that facilitate transport of biological materials (e.g., proteins, mRNA) to different tissues by utilizing vascular systems [116]. This has led to attempts to isolate exosomes and load them with therapeutic payloads (e.g., siRNA) to exploit their natural tropism, in addition to their biocompatibility and prolonged circulation, thereby making them a promising tool for theranostics [117]. Despite this, exosomes still lack many of the proteins needed for targeting cancer and overcoming biological barriers to actively target inflammation. Leukocytes, on the other hand, are decorated with many essential proteins needed for bypassing the MPS, communicating with the endothelial layer, and reaching an inflammatory site.

Mesenchymal stem cells (MSC), often favored due to their innate ability to home to inflammation, have also been considering as a unique tool for drug delivery and as a theranostic system. When previously doped with hyaluronic acid, MSC displayed a substantial increase in homing to inflammation when evaluated in vivo using an inflamed ear animal model [118]. To exploit the innate homing observed with MSC, our group functionalized MSV with a photosensitizer and allowed MSC to internalize our nanoparticles [119]. In a breast cancer animal model, MSC demonstrated successful homing to the tumor, thereby facilitating precise photodynamic therapy using a low power laser source. This method resulted in a $70 \%$ decrease in tumor cell viability following photodynamic activation, demonstrating cell-based drug delivery as a versatile therapeutic strategy.

Inspired by the innate biological properties of leukocytes, our group developed a tool designed to mimic leukocytes while exploiting the MSV as our foundation. By coating MSV with freshly isolated leukocyte membranes, our group was able to prolong circulation, avoid MPS uptake, and communicate with the endothelium through critical surface markers [72]. Specifically, it was demonstrated that 
over 150 transmembrane proteins were successfully grafted onto the MSV particle [120] while still maintaining the bioactivity necessary to facilitate vascular permeability [121]. In addition, it was demonstrated that when MSV were functionalized with cellular membrane derived from a syngeneic cell source, prolonged circulation was achieved with a delay in sequestration in vivo [122].

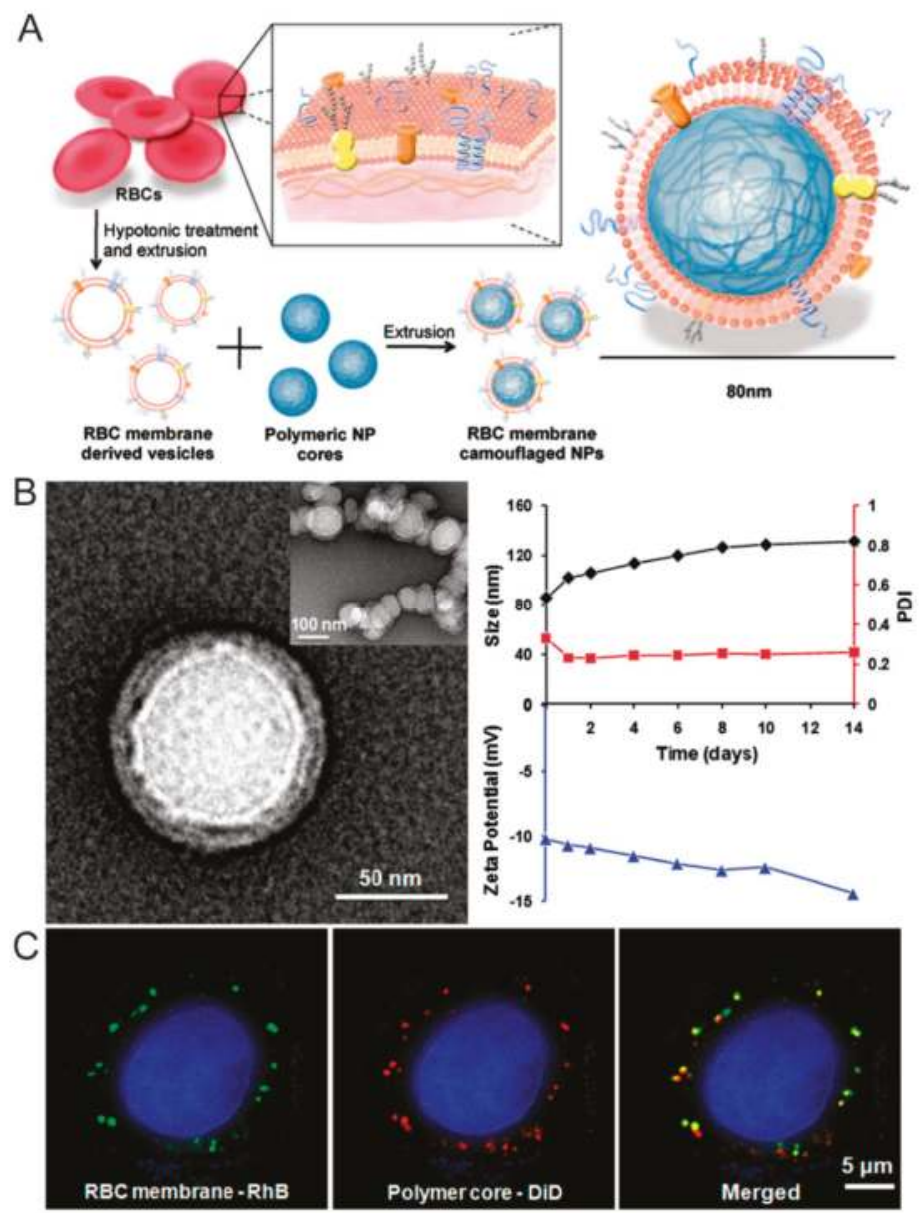

Figure 4. (A) Schematic illustration demonstrating the fabrication of erythrocyte-coated PLGA nanoparticles; (B) Transmission electron microscope images of erythrocyte-functionalized PLGA nanoparticles and DLS measurements depicted nanoparticle size (black), PDI (red), and zeta potential over $14 \mathrm{~d}$; (C) Fluorescent microscope images depicting the colocalization of erythrocyte membranes (green) and PLGA cores (red) following internalization by cervical cancer HeLa cells after $6 \mathrm{~h}$. Images reproduced from [114], with permission from National Academy of Sciences, 2011.

More recent efforts have incorporated leukocyte proteins directly into a proteolipid formulation, resulting in proteoliposomal vesicles dubbed leukosomes [123]. In this approach, the targeting potential and extended circulation of leukocytes can be granted to all classes of drugs capable of being loaded into liposomal core or within the liposomal bilayer (i.e., hydrophobic, hydrophilic, and amphiphilic). Using leukosomes, a 5-fold increase in targeting inflamed vasculature was displayed when compared to liposomes in as little as $1 \mathrm{~h}$ following intravenous administration, with an 8-fold 
increase being observed at $24 \mathrm{~h}$ (Figure 5). These features ultimately allow for greater accumulation at the inflammation site with minimal cytotoxicity to healthy cells, making them promising tools for further evaluation for theranostic-based therapy. Further evaluation of this bioinspired tool revealed a 16-fold increase in breast cancer accumulation relative to liposomes with similar significance also observed in an atherosclerotic plaque animal model [124]. In an effort to evaluate the potential imaging applications using MRI, leukosome bilayers were functionalized with gadolidium chelating phospholipids. This revealed a linear increase in contrast as the leukosome concentration increased, representing promise as an imaging modality and theranostic tool.
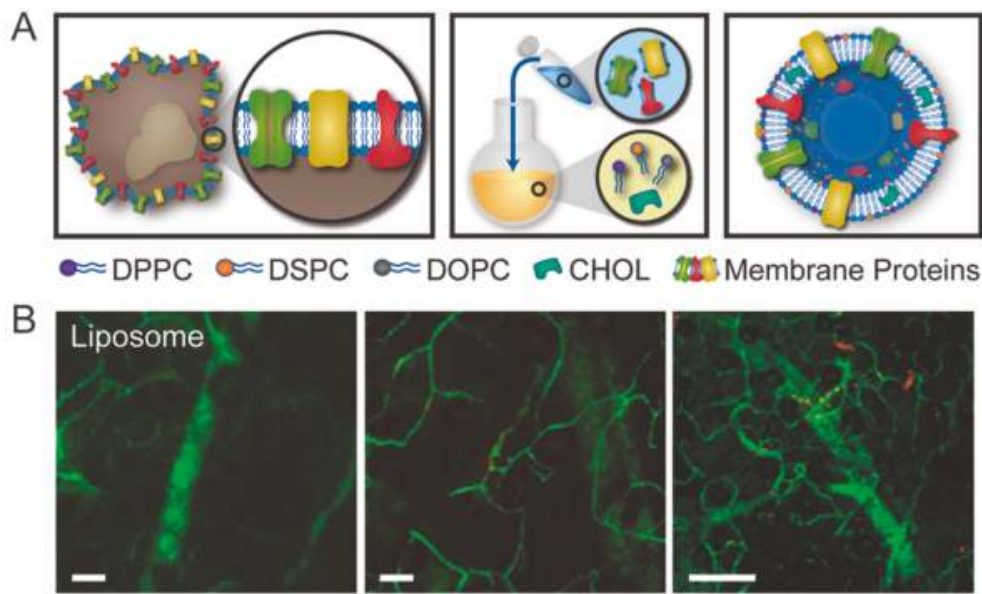

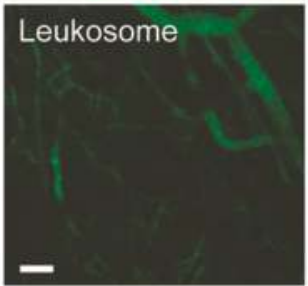

Control

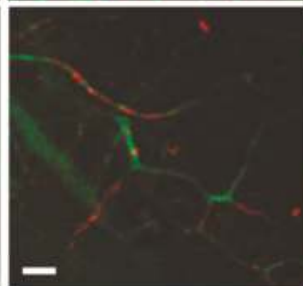

Inflamed (1 h)

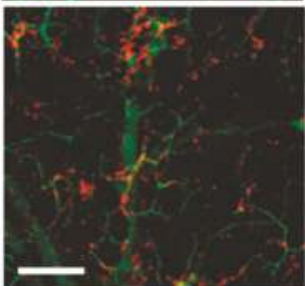

Inflamed (24 h)
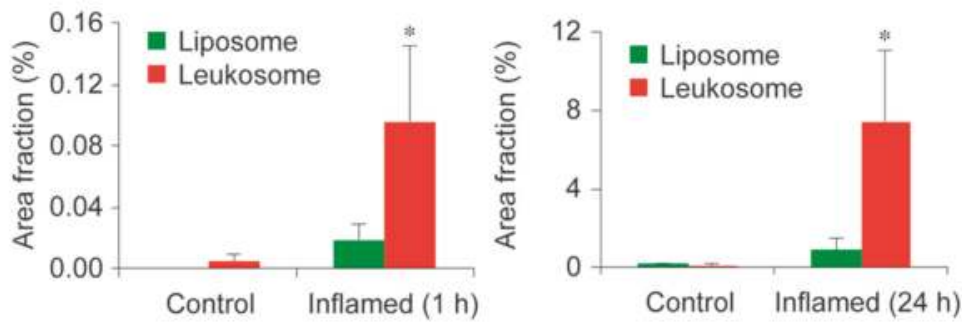

Figure 5. (A) Schematic illustration representing the synthesis and formulation of leukosome nanoparticles; (B) Intravital microscope images comparing liposome and leukosome accumulation in a lipopolysaccharide-inflamed mouse ear at $1 \mathrm{~h}$ and $24 \mathrm{~h}$. Quantitative analysis was performed by calculating the area fraction covered by nanoparticles. Error bars represent the mean $\pm \mathrm{SD}$ of a minimum of ten fields of view from three mice. Images reproduced from [123], with permission from Springer Nature, 2016. 
As with many clinical therapeutics, ease of translation and scalability remains a valid concern. As such, our group exhibited development of leukosome particles using a commercially available microfluidic system did not hinder production and provided similar grafting compared to traditional thin layer evaporation [125]. Specifically, we demonstrated a comparable transfer of proteins onto the liposomal surface with more efficiency in protein integration observed (i.e., $90 \%$ protein integration). In addition, leukosomes were found to remain stable up to one month following fabrication, highlighting the validity of the micro-fluidic system in nanoparticle generation. Particularly, the use of the NanoAssemblr micro-fluidic system was showcased as a promising tool to be used in the fabrication of biomimetic nanoparticles up to $5 \mathrm{~mL}$ with scalability to larger micro-fluidic systems (i.e., $1 \mathrm{~L}$ batches) made possible with relative ease. Although further studies are still needed, bioinspired theranostics have displayed great promise as therapeutic and diagnostic tools, supplementing an already vast arsenal.

\section{Conclusions and Future Perspectives}

Over the past several years, nanotechnology has spurred the development of a multitude of delivery vehicles and the exploration of a variety of imaging modalities. Theranostics have recently been introduced as a means to unify the dual-step process typically required to diagnose and treat disease. Through the development of one-step theranostic platforms, it is now possible to visualize the disease while simultaneously providing therapy, allowing for the ability to tailor a therapeutic regimen to accommodate the adaptations of the disease and minimize toxicity to healthy tissue. Herein, we briefly highlighted how inorganic nanoparticles have been employed in the use of theranostic-based application (for further reading on the subject see $[126,127]$ ). However, to further maximize the efficiency of these theranostic platforms, it is critical to incorporate bioinspired approaches that can be strategically optimized to provide even greater targeting potential and accumulation of a payload. As mentioned in this review, bioinspired approaches have been created to not only harness the innate properties typically presented by the cells of the body, but to offer unique approaches to delivery therapeutic cargoes that display hydrophobic characteristics such as in the case of Abraxane.

In addition, although this review has focused primarily on a select number of nanotechnologies, it is important to note that other materials have also shown promising results as theranostic and biomimetic systems. For example, graphene, carbon nanotubes, and polymeric nanoparticles have garnered significant interest from the scientific community, with trends on social media also highlighting their popularity [128]. In the case of graphene, much work has been performed showcasing the photothermal abilities along with various targeted delivery strategies $[129,130]$. In addition, the use of other inorganic nanoparticles (e.g., halloysites) have also seen promising use in the stabilization of otherwise agglomerate-prone nanoparticles [131,132]. Overall, with the convergence of theranostic technologies and bioinspired approaches, a new wave of one-step solutions that offer personalized and precision-based technologies can be realized.

Nevertheless, to effectively translate current biomimetic theranostics into the clinic, further investigation into several components is still needed. First and foremost, the issue of scalability remains the primary barrier for translation into the clinic. As the incorporation of biological matter into nanoparticles requires refined and intricate decoration, scalability may not always be a case of simply doubling the materials required for fabrication. In addition, an issue that currently plagues nanoparticle success is lack of homogeneity between patient to patient, opposite of what is commonly observed in small animal models. This is further complicated by the observation of phenomena which are observed in animal models (e.g., enhanced permeability and retention) yet lack sufficient proof in humans. Although significant strides have been made in the translation of the various nanoparticles discussed into preclinical and clinical trials [35], additional work is still needed. Specifically, it is imperative that to effectively continue investigation, careful selection and examination of animal models is employed. 
Author Contributions: M.E., A.P. and J.O.M. wrote the manuscript; M.E. and A.P. edited the manuscript: M.E. reorganized and supervised the manuscript preparation process; E.T. provided funding and final review; All authors provided discussion and accepted the final manuscript.

funding: The research was funded by the George and Angelina Kostas Charitable Foundation, William Randolph Hearst Foundation, The Cullen Trust for Health Care, the National Institutes of Health (1R21CA173579-01A1), Cancer Prevention \& Research Institute of Texas (RP170466 and RP180394), NCI and the Office of Research on Women's Health (1R56CA213859-01A1) and the Robert J. Kleberg, Jr. and Helen C. Kleberg Foundation.

Acknowledgments: The authors would like to thank Iman K. Yazdi, Joseph S. Fernandez-Moure, Shilpa Scaria, and Sarah Hmaidan for valuable feedback.

Conflicts of Interest: The authors declare no conflict of interest.

\section{References}

1. Hara, M.; Shokur, S.; Yamamoto, A.; Higuchi, T.; Gassert, R.; Bleuler, H. Virtual environment to evaluate multimodal feedback strategies for augmented navigation of the visually impaired. In Proceedings of the 2010 Annual International Conference of the IEEE Engineering in Medicine and Biology, Buenos Aires, Argentina, 31 August-4 September 2010; pp. 975-978.

2. Hamacher, A.; Kim, S.J.; Cho, S.T.; Pardeshi, S.; Lee, S.H.; Eun, S.J.; Whangbo, T.K. Application of virtual, augmented, and mixed reality to urology. Int. Neurourol J. 2016, 20, 172-181. [CrossRef] [PubMed]

3. Kim, K.H. The potential application of virtual, augmented, and mixed reality in neurourology. Int. Neurourol J. 2016, 20, 169-170. [CrossRef] [PubMed]

4. Sun, G.C.; Wang, F.; Chen, X.L.; Yu, X.G.; Ma, X.D.; Zhou, D.B.; Zhu, R.Y.; Xu, B.N. Impact of virtual and augmented reality based on intraoperative magnetic resonance imaging and functional neuronavigation in glioma surgery involving eloquent areas. World Neurosurg. 2016, 96, 375-382. [CrossRef] [PubMed]

5. Mujar, M.; Dahlui, M.; Yip, C.H.; Taib, N.A. Delays in time to primary treatment after a diagnosis of breast cancer: Does it impact survival? Prev. Med. 2013, 56, 222-224. [CrossRef] [PubMed]

6. Rosenblum, D.; Joshi, N.; Tao, W.; Karp, J.M.; Peer, D. Progress and challenges towards targeted delivery of cancer therapeutics. Nat. Commun. 2018, 9, 1410. [CrossRef] [PubMed]

7. Fernandez-Moure, J.S.; Evangelopoulos, M.; Colvill, K.; Van Eps, J.L.; Tasciotti, E. Nanoantibiotics: A new paradigm for the treatment of surgical infection. Nanomedicine (Lond) 2017, 12, 1319-1334. [CrossRef] [PubMed]

8. Peer, D.; Karp, J.M.; Hong, S.; Farokhzad, O.C.; Margalit, R.; Langer, R. Nanocarriers as an emerging platform for cancer therapy. Nat. Nanotechnol. 2007, 2, 751-760. [CrossRef] [PubMed]

9. Muthu, M.S.; Leong, D.T.; Mei, L.; Feng, S.S. Nanotheranostics-application and further development of nanomedicine strategies for advanced theranostics. Theranostics 2014, 4, 660-677. [CrossRef] [PubMed]

10. Penet, M.F.; Chen, Z.; Kakkad, S.; Pomper, M.G.; Bhujwalla, Z.M. Theranostic imaging of cancer. Eur. J. Radiol. 2012, 81, 124-126. [CrossRef]

11. Kelkar, S.S.; Reineke, T.M. Theranostics: Combining imaging and therapy. Bioconj. Chem. 2011, 22, 1879-1903. [CrossRef] [PubMed]

12. Fan, Z.; Fu, P.P.; Yu, H.; Ray, P.C. Theranostic nanomedicine for cancer detection and treatment. J. Food Drug Anal. 2014, 22, 3-17. [CrossRef] [PubMed]

13. Sumer, B.; Gao, J. Theranostic nanomedicine for cancer. Nanomedicine (Lond) 2008, 3, 137-140. [CrossRef] [PubMed]

14. Ruddy, K.J.; Gelber, S.; Tamimi, R.M.; Schapira, L.; Come, S.E.; Meyer, M.E.; Winer, E.P.; Partridge, A.H. Breast cancer presentation and diagnostic delays in young women. Cancer 2014, 120, 20-25. [CrossRef] [PubMed]

15. Radzikowska, E.; Roszkowski-Sliz, K.; Chabowski, M.; Glaz, P. Influence of delays in diagnosis and treatment on survival in small cell lung cancer patients. Adv. Exp. Med. Biol. 2013, 788, 355-362. [PubMed]

16. Evangelopoulos, M.; Tasciotti, E. Bioinspired approaches for cancer nanotheranostics. Nanomedicine (Lond) 2017, 12, 5-7. [CrossRef] [PubMed] 
17. Laurent, S.; Forge, D.; Port, M.; Roch, A.; Robic, C.; Vander Elst, L.; Muller, R.N. Magnetic iron oxide nanoparticles: Synthesis, stabilization, vectorization, physicochemical characterizations, and biological applications. Chem. Rev. 2008, 108, 2064-2110. [CrossRef] [PubMed]

18. Dilnawaz, F.; Singh, A.; Mohanty, C.; Sahoo, S.K. Dual drug loaded superparamagnetic iron oxide nanoparticles for targeted cancer therapy. Biomaterials 2010, 31, 3694-3706. [CrossRef] [PubMed]

19. Jun, Y.W.; Lee, J.H.; Cheon, J. Chemical design of nanoparticle probes for high-performance magnetic resonance imaging. Angew. Chem. Int. Ed. Engl. 2008, 47, 5122-5135. [CrossRef] [PubMed]

20. Yu, M.K.; Jeong, Y.Y.; Park, J.; Park, S.; Kim, J.W.; Min, J.J.; Kim, K.; Jon, S. Drug-loaded superparamagnetic iron oxide nanoparticles for combined cancer imaging and therapy in vivo. Angew. Chem. Int. Ed. Engl. 2008, 47, 5362-5365. [CrossRef] [PubMed]

21. Zou, P.; Yu, Y.; Wang, Y.A.; Zhong, Y.; Welton, A.; Galban, C.; Wang, S.; Sun, D. Superparamagnetic iron oxide nanotheranostics for targeted cancer cell imaging and ph-dependent intracellular drug release. Mol. Pharm. 2010, 7, 1974-1984. [CrossRef] [PubMed]

22. Wang, L.S.; Chuang, M.C.; Ho, J.A. Nanotheranostics-A review of recent publications. Int. J. Nanomed. 2012, 7, 4679-4695.

23. Lam, T.; Pouliot, P.; Avti, P.K.; Lesage, F.; Kakkar, A.K. Superparamagnetic iron oxide based nanoprobes for imaging and theranostics. Adv. Colloid Interface Sci. 2013, 199-200, 95-113. [CrossRef] [PubMed]

24. Indira, T.K.; Lakshmi, P.K. Magnetic nanoparticles-A review. Int. J. Pharm. Sci. Nanotechnol. 2010, 3, 1035-1042.

25. Balivada, S.; Rachakatla, R.S.; Wang, H.; Samarakoon, T.N.; Dani, R.K.; Pyle, M.; Kroh, F.O.; Walker, B.; Leaym, X.; Koper, O.B.; et al. A/C magnetic hyperthermia of melanoma mediated by iron(0)/iron oxide core/shell magnetic nanoparticles: A mouse study. BMC Cancer 2010, 10, 119. [CrossRef] [PubMed]

26. Sandiford, L.; Phinikaridou, A.; Protti, A.; Meszaros, L.K.; Cui, X.; Yan, Y.; Frodsham, G.; Williamson, P.A.; Gaddum, N.; Botnar, R.M.; et al. Bisphosphonate-anchored pegylation and radiolabeling of superparamagnetic iron oxide: Long-circulating nanoparticles for in vivo multimodal (t1 mri-spect) imaging. ACS Nano 2013, 7, 500-512. [CrossRef] [PubMed]

27. Rosen, J.E.; Chan, L.; Shieh, D.-B.; Gu, F.X. Iron oxide nanoparticles for targeted cancer imaging and diagnostics. Nanomed. Nanotechnol. Biol. Med. 2012, 8, 275-290. [CrossRef] [PubMed]

28. Dolci, S.; Domenici, V.; Vidili, G.; Orecchioni, M.; Bandiera, P.; Madeddu, R.; Farace, C.; Peana, M.; Tiné, M.R.; Manetti, R.; et al. Immune compatible cystine-functionalized superparamagnetic iron oxide nanoparticles as vascular contrast agents in ultrasonography. RSC Adv. 2016, 6, 2712-2723. [CrossRef]

29. Yoon, H.Y.; Saravanakumar, G.; Heo, R.; Choi, S.H.; Song, I.C.; Han, M.H.; Kim, K.; Park, J.H.; Choi, K.; Kwon, I.C.; et al. Hydrotropic magnetic micelles for combined magnetic resonance imaging and cancer therapy. J. Control. Release 2012, 160, 692-698. [CrossRef] [PubMed]

30. Mancarella, S.; Greco, V.; Baldassarre, F.; Vergara, D.; Maffia, M.; Leporatti, S. Polymer-coated magnetic nanoparticles for curcumin delivery to cancer cells. Macromol. Biosci. 2015, 15, 1365-1374. [CrossRef] [PubMed]

31. Espinosa, A.; Di Corato, R.; Kolosnjaj-Tabi, J.; Flaud, P.; Pellegrino, T.; Wilhelm, C. Duality of iron oxide nanoparticles in cancer therapy: Amplification of heating efficiency by magnetic hyperthermia and photothermal bimodal treatment. ACS Nano 2016, 10, 2436-2446. [CrossRef] [PubMed]

32. Mai, B.T.; Fernandes, S.; Balakrishnan, P.B.; Pellegrino, T. Nanosystems based on magnetic nanoparticles and thermo-or ph-responsive polymers: An update and future perspectives. Acc. Chem. Res. 2018, 51, 999-1013. [CrossRef] [PubMed]

33. Gupta, A.K.; Gupta, M. Cytotoxicity suppression and cellular uptake enhancement of surface modified magnetic nanoparticles. Biomaterials 2005, 26, 1565-1573. [CrossRef] [PubMed]

34. Muldoon, L.L.; Sandor, M.; Pinkston, K.E.; Neuwelt, E.A. Imaging, distribution, and toxicity of superparamagnetic iron oxide magnetic resonance nanoparticles in the rat brain and intracerebral tumor. Neurosurgery 2005, 57, 785-796. [CrossRef] [PubMed]

35. Anselmo, A.C.; Mitragotri, S. Nanoparticles in the clinic. Bioeng. Transl. Med. 2016, 1, 10-29. [CrossRef] [PubMed] 
36. Chen, J.; Glaus, C.; Laforest, R.; Zhang, Q.; Yang, M.; Gidding, M.; Welch, M.J.; Xia, Y. Gold nanocages as photothermal transducers for cancer treatment. Small 2010, 6, 811-817. [CrossRef] [PubMed]

37. Young, J.K.; Figueroa, E.R.; Drezek, R.A. Tunable nanostructures as photothermal theranostic agents. Ann. Biomed. Eng. 2012, 40, 438-459. [CrossRef] [PubMed]

38. Amendola, V.; Pilot, R.; Frasconi, M.; Marago, O.M.; Iati, M.A. Surface plasmon resonance in gold nanoparticles: A review. J. Phys. Condens. Matter 2017, 29, 203002. [CrossRef] [PubMed]

39. Khlebtsov, B.N.; Tuchina, E.S.; Khanadeev, V.A.; Panfilova, E.V.; Petrov, P.O.; Tuchin, V.V.; Khlebtsov, N.G. Enhanced photoinactivation of staphylococcus aureus with nanocomposites containing plasmonic particles and hematoporphyrin. J. Biophotonics 2013, 6, 338-351. [CrossRef] [PubMed]

40. Rai, A.; Prabhune, A.; Perry, C.C. Antibiotic mediated synthesis of gold nanoparticles with potent antimicrobial activity and their application in antimicrobial coatings. J. Mater. Chem. 2010, 20, 6789-6798. [CrossRef]

41. Lin, A.Y.; Lunsford, J.; Bear, A.S.; Young, J.K.; Eckels, P.; Luo, L.; Foster, A.E.; Drezek, R.A. High-density sub-100-nm peptide-gold nanoparticle complexes improve vaccine presentation by dendritic cells in vitro. Nanoscale Res. Lett. 2013, 8, 72. [CrossRef] [PubMed]

42. Soenen, S.J.; Manshian, B.; Montenegro, J.M.; Amin, F.; Meermann, B.; Thiron, T.; Cornelissen, M.; Vanhaecke, F.; Doak, S.; Parak, W.J.; et al. Cytotoxic effects of gold nanoparticles: A multiparametric study. ACS Nano 2012, 6, 5767-5783. [CrossRef] [PubMed]

43. Choi, W.I.; Kim, J.Y.; Kang, C.; Byeon, C.C.; Kim, Y.H.; Tae, G. Tumor regression in vivo by photothermal therapy based on gold-nanorod-loaded, functional nanocarriers. ACS Nano 2011, 5, 1995-2003. [CrossRef] [PubMed]

44. Arvizo, R.; Bhattacharya, R.; Mukherjee, P. Gold nanoparticles: Opportunities and challenges in nanomedicine. Expert Opin. Drug Deliv. 2010, 7, 753-763. [CrossRef] [PubMed]

45. Madani, S.Y.; Shabani, F.; Dwek, M.V.; Seifalian, A.M. Conjugation of quantum dots on carbon nanotubes for medical diagnosis and treatment. Int. J. Nanomed. 2013, 8, 941-950.

46. Xu, G.; Mahajan, S.; Roy, I.; Yong, K.T. Theranostic quantum dots for crossing blood-brain barrier and providing therapy of hiv-associated encephalopathy. Front. Pharm. 2013, 4, 140. [CrossRef] [PubMed]

47. Shekhar, N.; Rao, M.E.B. Quantum dot: Novel carrier for drug delivery. Int. J. Res. Pharm. Biomed. Sci. 2011, $2,448-458$.

48. Pisanic, T.R., II; Zhang, Y.; Wang, T.H. Quantum dots in diagnostics and detection: Principles and paradigms. Analyst 2014, 139, 2968-2981. [CrossRef] [PubMed]

49. Medintz, I.L.; Clapp, A.R.; Mattoussi, H.; Goldman, E.R.; Fisher, B.; Mauro, J.M. Self-assembled nanoscale biosensors based on quantum dot FRET donors. Nat. Mater. 2003, 2, 630-638. [CrossRef] [PubMed]

50. Li, H.; Duan, Z.W.; Xie, P.; Liu, Y.R.; Wang, W.C.; Dou, S.X.; Wang, P.Y. Effects of paclitaxel on EGFR endocytic trafficking revealed using quantum dot tracking in single cells. PLoS ONE 2012, 7, e45465. [CrossRef] [PubMed]

51. Gao, X.; Xing, Y.; Chung, L.K.; Nie, S. Quantum dot nanotechnology for prostate cancer research. In Prostate Cancer, Chung, L.K., Isaacs, W., Simons, J., Eds.; Humana Press: New York, NY, USA, 2007; pp. 231-244.

52. Bae, W.K.; Joo, J.; Padilha, L.A.; Won, J.; Lee, D.C.; Lin, Q.; Koh, W.K.; Luo, H.; Klimov, V.I.; Pietryga, J.M. Highly effective surface passivation of pbse quantum dots through reaction with molecular chlorine. J. Am. Chem. Soc. 2012, 134, 20160-20168. [CrossRef] [PubMed]

53. Bagalkot, V.; Zhang, L.; Levy-Nissenbaum, E.; Jon, S.; Kantoff, P.W.; Langer, R.; Farokhzad, O.C. Quantum dot-aptamer conjugates for synchronous cancer imaging, therapy, and sensing of drug delivery based on bi-fluorescence resonance energy transfer. Nano Lett. 2007, 7, 3065-3070. [CrossRef] [PubMed]

54. Fang, M.; Peng, C.W.; Pang, D.W.; Li, Y. Quantum dots for cancer research: Current status, remaining issues, and future perspectives. Cancer Biol. Med. 2012, 9, 151-163. [PubMed]

55. Balasubramanian, K.; Evangelopoulos, M.; Brown, B.S.; Parodi, A.; Celia, C.; Iman, K.Y.; Tasciotti, E. Ghee butter as a therapeutic delivery system. J. Nanosci. Nanotechnol. 2017, 17, 977-982. [CrossRef] [PubMed]

56. Yazdi, I.K.; Ziemys, A.; Evangelopoulos, M.; Martinez, J.O.; Kojic, M.; Tasciotti, E. Physicochemical properties affect the synthesis, controlled delivery, degradation and pharmacokinetics of inorganic nanoporous materials. Nanomedicine (Lond) 2015, 10, 3057-3075. [CrossRef] [PubMed]

57. Blanco, E.; Shen, H.; Ferrari, M. Principles of nanoparticle design for overcoming biological barriers to drug delivery. Nat. Biotechnol. 2015, 33, 941-951. [CrossRef] [PubMed] 
58. Khaled, S.Z.; Cevenini, A.; Yazdi, I.K.; Parodi, A.; Evangelopoulos, M.; Corbo, C.; Scaria, S.; Hu, Y.; Haddix, S.G.; Corradetti, B.; et al. One-pot synthesis of ph-responsive hybrid nanogel particles for the intracellular delivery of small interfering rna. Biomaterials 2016, 87, 57-68. [CrossRef] [PubMed]

59. Wolfram, J.; Shen, H.; Ferrari, M. Multistage vector (msv) therapeutics. J. Control. Release 2015, 219, 406-415. [CrossRef] [PubMed]

60. Tasciotti, E.; Liu, X.; Bhavane, R.; Plant, K.; Leonard, A.D.; Price, B.K.; Cheng, M.M.; Decuzzi, P.; Tour, J.M.; Robertson, F; , et al. Mesoporous silicon particles as a multistage delivery system for imaging and therapeutic applications. Nat. Nanotechnol. 2008, 3, 151-157. [CrossRef] [PubMed]

61. Martinez, J.O.; Brown, B.S.; Quattrocchi, N.; Evangelopoulos, M.; Ferrari, M.; Tasciotti, E. Multifunctional to multistage delivery systems: The evolution of nanoparticles for biomedical applications. Chin. Sci. Bull. 2012, 57, 3961-3971. [CrossRef] [PubMed]

62. Ferrari, M. Frontiers in cancer nanomedicine: Directing mass transport through biological barriers. Trends Biotechnol. 2010, 28, 181-188. [CrossRef] [PubMed]

63. Shen, J.; Wu, X.; Lee, Y.; Wolfram, J.; Yang, Z.; Mao, Z.W.; Ferrari, M.; Shen, H. Porous silicon microparticles for delivery of sirna therapeutics. J. Vis. Exp. 2015, 95, 52075. [CrossRef] [PubMed]

64. Martinez, J.O.; Evangelopoulos, M.; Chiappini, C.; Liu, X.; Ferrari, M.; Tasciotti, E. Degradation and biocompatibility of multistage nanovectors in physiological systems. J. Biomed. Mater. Res. Part A 2014, 102, 3540-3549. [CrossRef] [PubMed]

65. Martinez, J.O.; Boada, C.; Yazdi, I.K.; Evangelopoulos, M.; Brown, B.S.; Liu, X.; Ferrari, M.; Tasciotti, E. Short and long term, in vitro and in vivo correlations of cellular and tissue responses to mesoporous silicon nanovectors. Small 2013, 9, 1722-1733. [CrossRef] [PubMed]

66. Chiappini, C.; Tasciotti, E.; Fakhoury, J.R.; Fine, D.; Pullan, L.; Wang, Y.C.; Fu, L.; Liu, X.; Ferrari, M. Tailored porous silicon microparticles: Fabrication and properties. Chemphyschem 2010, 11, 1029-1035. [CrossRef] [PubMed]

67. Decuzzi, P.; Godin, B.; Tanaka, T.; Lee, S.Y.; Chiappini, C.; Liu, X.; Ferrari, M. Size and shape effects in the biodistribution of intravascularly injected particles. J. Control. Release 2010, 141, 320-327. [CrossRef] [PubMed]

68. Hossain, S.S.; Zhang, Y.; Liang, X.; Hussain, F.; Ferrari, M.; Hughes, T.J.; Decuzzi, P. In silico vascular modeling for personalized nanoparticle delivery. Nanomedicine (Lond) 2013, 8, 343-357. [CrossRef] [PubMed]

69. Martinez, J.O.; Evangelopoulos, M.; Karun, V.; Shegog, E.; Wang, J.A.; Boada, C.; Liu, X.; Ferrari, M.; Tasciotti, E. The effect of multistage nanovector targeting of vegfr2 positive tumor endothelia on cell adhesion and local payload accumulation. Biomaterials 2014, 35, 9824-9832. [CrossRef] [PubMed]

70. Martinez, J.O.; Evangelopoulos, M.; Bhavane, R.; Acciardo, S.; Salvatore, F.; Liu, X.; Ferrari, M.; Tasciotti, E. Multistage nanovectors enhance the delivery of free and encapsulated drugs. Curr. Drug Targets 2015, 16, 1582-1590. [CrossRef] [PubMed]

71. Shen, H.; Rodriguez-Aguayo, C.; Xu, R.; Gonzalez-Villasana, V.; Mai, J.; Huang, Y.; Zhang, G.; Guo, X.; Bai, L.; Qin, G.; et al. Enhancing chemotherapy response with sustained epha2 silencing using multistage vector delivery. Clin. Cancer Ees. 2013, 19, 1806-1815. [CrossRef] [PubMed]

72. Parodi, A.; Quattrocchi, N.; van de Ven, A.L.; Chiappini, C.; Evangelopoulos, M.; Martinez, J.O.; Brown, B.S.; Khaled, S.Z.; Yazdi, I.K.; Enzo, M.V.; et al. Synthetic nanoparticles functionalized with biomimetic leukocyte membranes possess cell-like functions. Nat. Nanotechnol. 2013, 8, 61-68. [CrossRef] [PubMed]

73. Tasciotti, E.; Cabrera, F.J.; Evangelopoulos, M.; Martinez, J.O.; Thekkedath, U.R.; Kloc, M.; Ghobrial, R.M.; Li, X.C.; Grattoni, A.; Ferrari, M. The emerging role of nanotechnology in cell and organ transplantation. Transplantation 2016, 100, 1629-1638. [CrossRef] [PubMed]

74. Scavo, M.P.; Gentile, E.; Wolfram, J.; Gu, J.; Barone, M.; Evangelopoulos, M.; Martinez, J.O.; Liu, X.; Celia, C.; Tasciotti, E.; et al. Multistage vector delivery of sulindac and silymarin for prevention of colon cancer. Colloids Surf. B Biointerfaces 2015, 136, 694-703. [CrossRef] [PubMed]

75. Godin, B.; Gu, J.; Serda, R.E.; Bhavane, R.; Tasciotti, E.; Chiappini, C.; Liu, X.; Tanaka, T.; Decuzzi, P.; Ferrari, M. Tailoring the degradation kinetics of mesoporous silicon structures through pegylation. J. Biomed. Mater. Res. Part A 2010, 94, 1236-1243. [CrossRef] [PubMed] 
76. Tanaka, T.; Mangala, L.S.; Vivas-Mejia, P.E.; Nieves-Alicea, R.; Mann, A.P.; Mora, E.; Han, H.D.; Shahzad, M.M.; Liu, X.; Bhavane, R.; et al. Sustained small interfering rna delivery by mesoporous silicon particles. Cancer Res. 2010, 70, 3687-3696. [CrossRef] [PubMed]

77. Alvarez, S.D.; Derfus, A.M.; Schwartz, M.P.; Bhatia, S.N.; Sailor, M.J. The compatibility of hepatocytes with chemically modified porous silicon with reference to in vitro biosensors. Biomaterials 2009, 30, $26-34$. [CrossRef] [PubMed]

78. Barnes, T.J.; Jarvis, K.L.; Prestidge, C.A. Recent advances in porous silicon technology for drug delivery. Ther. Deliv. 2013, 4, 811-823. [CrossRef] [PubMed]

79. Zhang, M.; Xu, R.; Xia, X.; Yang, Y.; Gu, J.; Qin, G.; Liu, X.; Ferrari, M.; Shen, H. Polycation-functionalized nanoporous silicon particles for gene silencing on breast cancer cells. Biomaterials 2014, 35, 423-431. [CrossRef] [PubMed]

80. Shen, J.; Xu, R.; Mai, J.; Kim, H.C.; Guo, X.; Qin, G.; Yang, Y.; Wolfram, J.; Mu, C.; Xia, X.; et al. High capacity nanoporous silicon carrier for systemic delivery of gene silencing therapeutics. ACS Nano 2013, 7, 9867-9880. [CrossRef] [PubMed]

81. Xu, W.; Ganz, C.; Weber, U.; Adam, M.; Holzhuter, G.; Wolter, D.; Frerich, B.; Vollmar, B.; Gerber, T. Evaluation of injectable silica-embedded nanohydroxyapatite bone substitute in a rat tibia defect model. Int. J. Nanomed. 2011, 6, 1543-1552. [CrossRef] [PubMed]

82. Mamaeva, V.; Rosenholm, J.M.; Bate-Eya, L.T.; Bergman, L.; Peuhu, E.; Duchanoy, A.; Fortelius, L.E.; Landor, S.; Toivola, D.M.; Linden, M.; et al. Mesoporous silica nanoparticles as drug delivery systems for targeted inhibition of notch signaling in cancer. Mol. Ther. 2011, 19, 1538-1546. [CrossRef] [PubMed]

83. Ananta, J.S.; Godin, B.; Sethi, R.; Moriggi, L.; Liu, X.; Serda, R.E.; Krishnamurthy, R.; Muthupillai, R.; Bolskar, R.D.; Helm, L.; et al. Geometrical confinement of gadolinium-based contrast agents in nanoporous particles enhances t1 contrast. Nat. Nanotechnol. 2010, 5, 815-821. [CrossRef] [PubMed]

84. Sethi, R.; Ananta, J.S.; Karmonik, C.; Zhong, M.; Fung, S.H.; Liu, X.; Li, K.; Ferrari, M.; Wilson, L.J.; Decuzzi, P. Enhanced mri relaxivity of $\mathrm{gd}(3+)$-based contrast agents geometrically confined within porous nanoconstructs. Contrast Media Mol. Imaging 2012, 7, 501-508. [CrossRef] [PubMed]

85. Ferrati, S.; Mack, A.; Chiappini, C.; Liu, X.; Bean, A.J.; Ferrari, M.; Serda, R.E. Intracellular trafficking of silicon particles and logic-embedded vectors. Nanoscale 2010, 2, 1512-1520. [CrossRef] [PubMed]

86. Martinez, J.O.; Chiappini, C.; Ziemys, A.; Faust, A.M.; Kojic, M.; Liu, X.; Ferrari, M.; Tasciotti, E. Engineering multi-stage nanovectors for controlled degradation and tunable release kinetics. Biomaterials 2013, 34, 8469-8477. [CrossRef] [PubMed]

87. Godin, B.; Gu, J.; Serda, R.E.; Ferrati, S.; Liu, X.; Chiappini, C.; Tanaka, T.; Decuzzi, P.; Ferrari, M. Multistage mesoporous silicon-based nanocarriers: Biocompatibility with immune cells and controlled degradation in physiological fluids. Newslett. Control. Release Soc. 2008, 25, 9-11.

88. Tasciotti, E.; Godin, B.; Martinez, J.O.; Chiappini, C.; Bhavane, R.; Liu, X.; Ferrari, M. Near-infrared imaging method for the in vivo assessment of the biodistribution of nanoporous silicon particles. Mol. Imaging 2011, 10, 56-68. [CrossRef] [PubMed]

89. Parodi, A.; Molinaro, R.; Sushnitha, M.; Evangelopoulos, M.; Martinez, J.O.; Arrighetti, N.; Corbo, C.; Tasciotti, E. Bio-inspired engineering of cell- and virus-like nanoparticles for drug delivery. Biomaterials 2017, 147, 155-168. [CrossRef] [PubMed]

90. Molinaro, R.; Corbo, C.; Livingston, M.; Evangelopoulos, M.; Parodi, A.; Boada, C.; Agostini, M.; Tasciotti, E. Inflammation and cancer: In medio stat nano. Curr. Med. Chem. 2017. [CrossRef]

91. Truong, N.P.; Whittaker, M.R.; Mak, C.W.; Davis, T.P. The importance of nanoparticle shape in cancer drug delivery. Expert Opin Drug Deliv. 2015, 12, 129-142. [CrossRef] [PubMed]

92. Truong, N.P.; Quinn, J.F.; Whittaker, M.R.; Davis, T.P. Polymeric filomicelles and nanoworms: Two decades of synthesis and application. Polym. Chem. 2016, 7, 4295-4312. [CrossRef]

93. Esser, L.; Truong, N.P.; Karagoz, B.; Moffat, B.A.; Boyer, C.; Quinn, J.F.; Whittaker, M.R.; Davis, T.P. Gadolinium-functionalized nanoparticles for application as magnetic resonance imaging contrast agents via polymerization-induced self-assembly. Polym. Chem. 2016, 7, 7325-7337. [CrossRef] 
94. Fuchs, A.V.; Bapat, A.P.; Cowin, G.J.; Thurecht, K.J. Switchable $19 \mathrm{f}$ mri polymer theranostics: Towards in situ quantifiable drug release. Polymer Chem. 2017, 8, 5157-5166. [CrossRef]

95. Cao, C.-Y.; Chen, Y.; Wu, F.-Z.; Deng, Y.; Liang, G.-L. Caspase-3 controlled assembly of nanoparticles for fluorescence turn on. Chem. Commun. 2011, 47, 10320-10322. [CrossRef] [PubMed]

96. Chen, Y.; Liang, G. Enzymatic self-assembly of nanostructures for theranostics. Theranostics 2012, 2, $139-147$. [CrossRef] [PubMed]

97. Yhee, J.Y.; Kim, S.A.; Koo, H.; Son, S.; Ryu, J.H.; Youn, I.C.; Choi, K.; Kwon, I.C.; Kim, K. Optical imaging of cancer-related proteases using near-infrared fluorescence matrix metalloproteinase-sensitive and cathepsin b-sensitive probes. Theranostics 2012, 2, 179-189. [CrossRef] [PubMed]

98. Wong, C.; Stylianopoulos, T.; Cui, J.; Martin, J.; Chauhan, V.P.; Jiang, W.; Popovic, Z.; Jain, R.K.; Bawendi, M.G.; Fukumura, D. Multistage nanoparticle delivery system for deep penetration into tumor tissue. In Proceedings of the National Academy of Sciences, Washington, DC, USA, 8 February 2011; Volume 108, pp. 2426-2431.

99. Mikhaylov, G.; Klimpel, D.; Schaschke, N.; Mikac, U.; Vizovisek, M.; Fonovic, M.; Turk, V.; Turk, B.; Vasiljeva, O. Selective targeting of tumor and stromal cells by a nanocarrier system displaying lipidated cathepsin b inhibitor. Angew. Chem. Int. Ed. 2014, 53, 10077-10081. [CrossRef] [PubMed]

100. Zhang, X.; Tang, K.; Wang, H.; Liu, Y.; Bao, B.; Fang, Y.; Zhang, X.; Lu, W. Design, synthesis, and biological evaluation of new cathepsin $b$-sensitive camptothecin nanoparticles equipped with a novel multifuctional linker. Bioconj. Chem. 2016, 27, 1267-1275. [CrossRef] [PubMed]

101. Ng, K.K.; Lovell, J.F.; Zheng, G. Lipoprotein-inspired nanoparticles for cancer theranostics. Acc. Chem. Res. 2011, 44, 1105-1113. [PubMed]

102. Corbin, I.R.; Li, H.; Chen, J.; Lund-Katz, S.; Zhou, R.; Glickson, J.D.; Zheng, G. Low-density lipoprotein nanoparticles as magnetic resonance imaging contrast agents. Neoplasia 2006, 8, 488-498. [CrossRef] [PubMed]

103. Li, H.; Marotta, D.E.; Kim, S.; Busch, T.M.; Wileyto, E.P.; Zheng, G. High payload delivery of optical imaging and photodynamic therapy agents to tumors using phthalocyanine-reconstituted low-density lipoprotein nanoparticles. J. Biomed. Opt. 2005, 10, 41203. [CrossRef] [PubMed]

104. Song, L.; Li, H.; Sunar, U.; Chen, J.; Corbin, I.; Yodh, A.G.; Zheng, G. Naphthalocyanine-reconstituted ldl nanoparticles for in vivo cancer imaging and treatment. Int. J. Nanomed. 2007, 2, 767-774.

105. Zheng, G.; Li, H.; Zhang, M.; Lund-Katz, S.; Chance, B.; Glickson, J.D. Low-density lipoprotein reconstituted by pyropheophorbide cholesteryl oleate as target-specific photosensitizer. Bioconj. Chem. 2002, 13, 392-396. [CrossRef]

106. Zheng, G.; Chen, J.; Li, H.; Glickson, J.D. Rerouting lipoprotein nanoparticles to selected alternate receptors for the targeted delivery of cancer diagnostic and therapeutic agents. In Proceedings of the National Academy of Sciences, Washington, DC, USA, 23 November 2005; Volume 102, pp. 17757-17762.

107. Mooberry, L.K.; Nair, M.; Paranjape, S.; McConathy, W.J.; Lacko, A.G. Receptor mediated uptake of paclitaxel from a synthetic high density lipoprotein nanocarrier. J. Drug Target. 2010, 18, 53-58. [CrossRef] [PubMed]

108. Cao, W.; Ng, K.K.; Corbin, I.; Zhang, Z.; Ding, L.; Chen, J.; Zheng, G. Synthesis and evaluation of a stable bacteriochlorophyll-analog and its incorporation into high-density lipoprotein nanoparticles for tumor imaging. Bioconj. Chem. 2009, 20, 2023-2031. [CrossRef] [PubMed]

109. Fiorenza, A.M.; Branchi, A.; Sommariva, D. Serum lipoprotein profile in patients with cancer. A comparison with non-cancer subjects. Int. J. Clin. Lab. Res. 2000, 30, 141-145. [CrossRef] [PubMed]

110. McConathy, W.J.; Nair, M.P.; Paranjape, S.; Mooberry, L.; Lacko, A.G. Evaluation of synthetic/reconstituted high-density lipoproteins as delivery vehicles for paclitaxel. Anti-Cancer Drugs 2008, 19, 183-188. [CrossRef] [PubMed]

111. Everts, M.; Saini, V.; Leddon, J.L.; Kok, R.J.; Stoff-Khalili, M.; Preuss, M.A.; Millican, C.L.; Perkins, G.; Brown, J.M.; Bagaria, H.; et al. Covalently linked au nanoparticles to a viral vector: Potential for combined photothermal and gene cancer therapy. Nano Lett. 2006, 6, 587-591. [CrossRef] [PubMed]

112. McHale, A.P.; McHale, M.L.; Blau, W. The effect of hematoporphyrin derivative and human erythrocyte ghost encapsulated hematoporphyrin derivative on a mouse myeloma cell line. Cancer Biochem. Biophys. 1988, 10, 157-164. [PubMed] 
113. Markov, D.E.; Boeve, H.; Gleich, B.; Borgert, J.; Antonelli, A.; Sfara, C.; Magnani, M. Human erythrocytes as nanoparticle carriers for magnetic particle imaging. Phys. Med. Biol. 2010, 55, 6461-6473. [CrossRef] [PubMed]

114. Hu, C.M.; Zhang, L.; Aryal, S.; Cheung, C.; Fang, R.H.; Zhang, L. Erythrocyte membrane-camouflaged polymeric nanoparticles as a biomimetic delivery platform. In Proceedings of the National Academy of Sciences, Washington, DC, USA, 5 July 2011; Volume 108, pp. 10980-10985.

115. Dehaini, D.; Wei, X.; Fang, R.H.; Masson, S.; Angsantikul, P.; Luk, B.T.; Zhang, Y.; Ying, M.; Jiang, Y.; Kroll, A.V.; et al. Erythrocyte-platelet hybrid membrane coating for enhanced nanoparticle functionalization. Adv. Mater. 2017, 29, 1606209. [CrossRef] [PubMed]

116. Johnsen, K.B.; Gudbergsson, J.M.; Skov, M.N.; Pilgaard, L.; Moos, T.; Duroux, M. A comprehensive overview of exosomes as drug delivery vehicles-endogenous nanocarriers for targeted cancer therapy. Biochim. Biophys. Acta-Rev. Cancer 2014, 1846, 75-87. [CrossRef] [PubMed]

117. Tan, A.; Rajadas, J.; Seifalian, A.M. Exosomes as nano-theranostic delivery platforms for gene therapy. Adv. Drug Deliv. Rev. 2013, 65, 357-367. [PubMed]

118. Corradetti, B.; Taraballi, F.; Martinez, J.O.; Minardi, S.; Basu, N.; Bauza, G.; Evangelopoulos, M.; Powell, S.; Corbo, C.; Tasciotti, E. Hyaluronic acid coatings as a simple and efficient approach to improve msc homing toward the site of inflammation. Sci. Rep. 2017, 7, 7991. [PubMed]

119. Nakki, S.; Martinez, J.O.; Evangelopoulos, M.; Xu, W.; Lehto, V.P.; Tasciotti, E. Chlorin e6 functionalized theranostic multistage nanovectors transported by stem cells for effective photodynamic therapy. ACS Appl. Mater. Interfaces 2017, 9, 23441-23449. [PubMed]

120. Corbo, C.; Parodi, A.; Evangelopoulos, M.; Engler, D.A.; Matsunami, R.K.; Engler, A.C.; Molinaro, R.; Scaria, S.; Salvatore, F.; Tasciotti, E. Proteomic profiling of a biomimetic drug delivery platform. Curr. Drug Targets 2015, 16, 1540-1547. [PubMed]

121. Palomba, R.; Parodi, A.; Evangelopoulos, M.; Acciardo, S.; Corbo, C.; de Rosa, E.; Yazdi, I.K.; Scaria, S.; Molinaro, R.; Furman, N.E.; et al. Biomimetic carriers mimicking leukocyte plasma membrane to increase tumor vasculature permeability. Sci. Rep. 2016, 6, 34422. [CrossRef] [PubMed]

122. Evangelopoulos, M.; Parodi, A.; Martinez, J.O.; Yazdi, I.K.; Cevenini, A.; van de Ven, A.L.; Quattrocchi, N.; Boada, C.; Taghipour, N.; Corbo, C.; et al. Cell source determines the immunological impact of biomimetic nanoparticles. Biomaterials 2016, 82, 168-177. [CrossRef] [PubMed]

123. Molinaro, R.; Corbo, C.; Martinez, J.O.; Taraballi, F.; Evangelopoulos, M.; Minardi, S.; Yazdi, I.K.; Zhao, P.; De Rosa, E.; Sherman, M.B.; et al. Biomimetic proteolipid vesicles for targeting inflamed tissues. Nat. Mater. 2016, 15, 1037-1046. [CrossRef] [PubMed]

124. Martinez, J.O.; Molinaro, R.; Hartman, K.A.; Boada, C.; Sukhovershin, R.; De Rosa, E.; Kirui, D.; Zhang, S.; Evangelopoulos, M.; Carter, A.M.; et al. Biomimetic nanoparticles with enhanced affinity towards activated endothelium as versatile tools for theranostic drug delivery. Theranostics 2018, 8, 1131-1145. [CrossRef] [PubMed]

125. Molinaro, R.; Evangelopoulos, M.; Hoffman, J.R.; Corbo, C.; Taraballi, F.; Martinez, J.O.; Hartman, K.A.; Cosco, D.; Costa, G.; Romeo, I.; et al. Design and development of biomimetic nanovesicles using a microfluidic approach. Adv. Mater. 2018, 30, e1702749. [PubMed]

126. Xie, J.; Lee, S.; Chen, X. Nanoparticle-based theranostic agents. Adv. Drug Deliv. Rev. 2010, 62, 1064-1079. [CrossRef] [PubMed]

127. Medarova, Z.; Pham, W.; Farrar, C.; Petkova, V.; Moore, A. In vivo imaging of sirna delivery and silencing in tumors. Nat. Med. 2007, 13, 372-377. [CrossRef] [PubMed]

128. Sechi, G.; Bedognetti, D.; Sgarrella, F.; Van Eperen, L.; Marincola, F.M.; Bianco, A.; Delogu, L.G. The perception of nanotechnology and nanomedicine: A worldwide social media study. Nanomedicine (Lond) 2014, 9, 1475-1486. [CrossRef] [PubMed]

129. Zhang, Y.; Li, Y.; Ming, P.; Zhang, Q.; Liu, T.; Jiang, L.; Cheng, Q. Ultrastrong bioinspired graphene-based fibers via synergistic toughening. Adv. Mater. 2016, 28, 2834-2839. [CrossRef] [PubMed]

130. Orecchioni, M.; Cabizza, R.; Bianco, A.; Delogu, L.G. Graphene as cancer theranostic tool: Progress and future challenges. Theranostics 2015, 5, 710-723. [CrossRef] [PubMed] 
131. Mingliang, D.; Baochun, G.; Demin, J. Newly emerging applications of halloysite nanotubes: A review. Polym. Int. 2010, 59, 574-582.

132. Jana, S.; Kondakova, A.V.; Shevchenko, S.N.; Sheval, E.V.; Gonchar, K.A.; Timoshenko, V.Y.; Vasiliev, A.N. Halloysite nanotubes with immobilized silver nanoparticles for anti-bacterial application. Colloids Surf. B Biointerfaces 2017, 151, 249-254. [CrossRef] [PubMed]

(C) 2018 by the authors. Licensee MDPI, Basel, Switzerland. This article is an open access article distributed under the terms and conditions of the Creative Commons Attribution (CC BY) license (http:/ / creativecommons.org/licenses/by/4.0/). 
Article

\title{
Systemic Administration of Polyelectrolyte Microcapsules: Where Do They Accumulate and When? In Vivo and Ex Vivo Study
}

\author{
Nikita A. Navolokin ${ }^{1,2}$, Sergei V. German ${ }^{1,3}$, Alla B. Bucharskaya ${ }^{2}$, Olga S. Godage ${ }^{2}$, \\ Viktor V. Zuev ${ }^{2}$, Galina N. Maslyakova ${ }^{1,2}$, Nikolaiy A. Pyataev ${ }^{4}$, Pavel S. Zamyshliaev ${ }^{4}$, \\ Mikhail N. Zharkov ${ }^{4}$, Georgy S. Terentyuk ${ }^{1,2}$, Dmitry A. Gorin ${ }^{1,3}$ and Gleb B. Sukhorukov 1,5,* \\ 1 Remote Controlled Theranostic Systems Lab, Saratov State University, Saratov 410012, Russia; \\ nik-navolokin@yandex.ru (N.A.N.); gsv0709@mail.ru (S.V.G.); gmaslyakova@yandex.ru (G.N.M.); \\ vetklinikanew@mail.ru (G.S.T.); gorinda@mail.ru (D.A.G.) \\ 2 Scientific Research Institute of Fundamental and Clinical Uronephrology, Saratov Medical State University, \\ Saratov 410000, Russia; allaalla_72@mail.ru (A.B.B.); olgabess@yandex.ru (O.S.G.); \\ zuev.viktor.sgmu@gmail.com (V.V.Z.) \\ 3 Biophotonics Laboratory, Skoltech Center for Photonics and Quantum Materials, Skolkovo Institute of \\ Science and Technology, Moscow 121205, Russia \\ 4 Laboratory of Pharmacokinetics and Targeted Drug Delivery, Medicine Institute, National Research Ogarev \\ Mordovia State University, Saransk 430005, Russia; pyataevna@mail.ru (N.A.P.); \\ zamyshlyaev@gmail.com (P.S.Z.); mikhail.zharkov.92@mail.ru (M.N.Z.) \\ 5 School of Engineering and Materials Science, Queen Mary University of London, London E1 4NS, UK \\ * Correspondence: g.sukhorukov@qmul.ac.uk; Tel.: +44-20-78825508
}

Received: 27 September 2018; Accepted: 7 October 2018; Published: 10 October 2018

\begin{abstract}
Multilayer capsules of 4 microns in size made of biodegradable polymers and iron oxide magnetite nanoparticles have been injected intravenously into rats. The time-dependent microcapsule distribution in organs was investigated in vivo by magnetic resonance imaging (MRI) and ex vivo by histological examination (HE), atomic absorption spectroscopy (AAS) and electron spin resonance (ESR), as these methods provide information at different stages of microcapsule degradation. The following organs were collected: Kidney, liver, lung, and spleen through $15 \mathrm{~min}, 1 \mathrm{~h}$, $4 \mathrm{~h}, 24 \mathrm{~h}, 14$ days, and 30 days after intravenous injections (IVIs) of microcapsules in a saline buffer at a dosage of $2.5 \times 10^{9}$ capsule per $\mathrm{kg}$. The IVI of microcapsules resulted in reversible morphological changes in most of the examined inner organs (kidney, heart, liver, and spleen). The capsules lost their integrity due to degradation over $24 \mathrm{~h}$, and some traces of iron oxide nanoparticles were seen at 7 days in spleen and liver structure. The morphological structure of the tissues was completely restored one month after IVI of microcapsules. Comprehensive analysis of the biodistribution and degradation of entire capsules and magnetite nanoparticles as their components gave us grounds to recommend these composite microcapsules as useful and safe tools for drug delivery applications.
\end{abstract}

Keywords: polymer microcapsules; magnetite nanoparticles; biodistribution; magnetic resonance imaging; electron spin resonance spectroscopy; histological examination; atomic absorption spectroscopy; intravenous injections

\section{Introduction}

Novel drug delivery systems have been in the focus of research in bio-nanotechnology in the past decades. Substantial progress in biomedicine and applied chemistry resulted in the development of reasonably effective delivery systems aimed to bring bioactive compounds via chemical targeting to a particular site of the body, organs and tissues. The major demand in the area is how to direct the vesicles 
to the tumor site, which remains challenging due to side effects. Most of the elaborated delivery systems are "passive" in terms of external navigation and control over their delivery. Recent developments in nanobiotechnology have made an essential contribution, as they deal with fabrication of constructs enabling multimodal functioning, carrying bioactive molecules and being visible and addressable externally. Logically, if a delivery system represents a sort of vesicle in order to make it visible and addressable, these vesicles should also incorporate nanoparticles such as magnetite nanoparticles, which can be seen by full-body imaging techniques such as magnetic resonance imaging (MRI).

Among the technologies available so far for drug delivery, in general, there are a limited number of techniques enabling multifunctionality. Multifunctionality in this particular context is the combination of the following: Ability to carry bioactive substances, navigate to a specific site, be biodegradable after deploying the cargo, and susceptible to external activation and visualization. Obviously, the components of these multifunctional delivery systems should be responsive to local media or external stimuli. Use of externally guided nanostructured carriers for drug delivery is a promising method in bio-nanotechnology, which can be used in areas such as diagnostics of tumors [1,2] for enhanced contrast at MRI visualization [3,4], targeted delivery of drugs to specific organs and tissues [5-7] and for magnetic hyperthermia of tumors [8-10]. This research has been undertaken to illustrate the promise of addressed delivery to particular sites in the body with the help of magnetic nanoparticles externally navigated with a magnetic field [11], which might also work as an accomplishing method with biological targeting performed by conjugation of nanoparticles with tumor-specific antibodies, followed by accumulation of nanoparticles in the targets [12].

In light of the development of multifunctional delivery systems more than a decade ago, the principles of layer-by-layer ( $(\mathrm{bl})$ assembly were applied to construct micron and submicron sized delivery systems, where various components can be simply tailored via incorporation of responsive and charge species as shell components of the capsules [13].

These capsules, proposed as delivery systems a while ago, were intensively studied mostly for their physical and chemical properties. At present, these capsules can be made of a defined size in a range from about $100 \mathrm{~nm}$ to several microns, contain various bioactive molecules including proteins, nucleic acids as well as small molecules, and can be externally addressed via a magnetic field, light or ultrasound $[14,15]$. These capsules can be taken up by various cells types, including endothelial cells, mesenchymal stem cells, microphages, neuroblastoma and others [16-18]. The mechanism of cell uptake is relevant to endocytosis and, as most reports have demonstrated, there is a minimal or absent effect on cell viability. Various cell types showed high percentages of survival at an excess of capsules per cell ratio. Capsule degradation inside the cells varied from a few to up to $24 \mathrm{~h}$, depending on the cell type and capsule composition. The release of encapsulated materials inside the cells can be gradual or triggered externally if light is used to open the capsules while inside the cells and releases the cargo to cytoplasm [19-23].

Despite the intense study on capsule properties and their interaction with cells, there is a lack of reported data on how the capsules would behave if administered systemically in vivo. So far, there have been few reports on $\mathrm{lbl}$ capsules administered in vivo either via subcutaneous injection or nasal gavage [24-27]. There are attempts for MRI imaging of iron oxide modified capsules. However, there are no systematic studies of $\mathrm{lbl}$ capsule distribution in organs or at what time point they are accumulated in a particular part of the body once they are introduced systemically.

The aim of this study was to examine capsule distribution in vivo upon systemic delivery via the tail and to explore major organs, such as the liver, lung, heart, spleen, and kidney for capsule presence at different time points in rats. Particular attention was given to evaluating for how long the capsules and debris of capsule degradation were present in these organs and what their degradation times were. A detailed analysis of capsule fate in vivo is very complex and requires various methods for the unambiguous identification of capsules and their components. In order to facilitate capsule identification, capsules were made of biodegradable polymers to ensure their degradation was modified with magnetite nanoparticles sandwiched between the layers. Complex 
analysis was conducted in vivo using MRI visualization and on ex vivo samples using atomic absorption spectroscopy (AAS), electron spin resonance (ESR) for detection of iron as an element and as superparamagnetic nanoparticles, respectively, and direct histology visualization of selected organs.

\section{Materials and Methods}

\subsection{Magnetic Microcapsule Preparation}

Magnetic microcapsules were prepared using the layer-by-layer technique [28]. Poly-L-arginine hydrochloride (Parg, MW $\sim 70 \mathrm{kDa}$ ), dextran sulfate sodium salt (Dex, MW 70 kDa), and sodium chloride (anhydrous) were used without further purification and were purchased from Sigma-Aldrich $\mathrm{GmbH}$, Germany. The water used in all experiments was prepared in a UVOI-1M purification system (Mediana-filter, Moscow, Russia) and had a resistivity higher than $14 \mathrm{M} \Omega \bullet \mathrm{cm}$.

The following materials were used for the microcapsule preparation: $\mathrm{CaCO}_{3}$ microparticles (diameter, $4 \pm 0.7 \mu \mathrm{m}$ ), poly-L-arginine and dextran sulfate sodium salt diluted in $0.15 \mathrm{M} \mathrm{NaCl}$ water solution; magnetite hydrosol (diameter, $13 \pm 5 \mathrm{~nm}$ and zeta potential, $-31 \pm 9 \mathrm{mV}$ measured by the DLS method) (Figure S1). In this work, the method described previously by Massart was used for iron oxide nanoparticle synthesis [29]. Synthesis was carried out using the setup described in reference [30].

The nanocomposite polyelectrolyte shells were formed on the surface of calcium carbonate microparticles. Polyelectrolyte shells were prepared by $\mathrm{lbl}$ assembly technique via alternate treating microparticles in solutions of oppositely charged polyelectrolytes and nanoparticles. These were poly-L-arginine (Parg), dextran sulfate sodium salt (Dex) and magnetite nanoparticles (MNPs). The consecutive adsorption of Parg and MNPs was repeated three times and finally, the capsules had the following composition: Parg/Dex/(Parg/MNPs) 3 /Parg/Dex (Figure 1a). The microcapsule with each freshly deposited layer was washed two times with deionized water before starting the next deposition step. Optical and transmission electron microscopy (TEM) images of magnetic microcapsules are presented in Figure 1b. The concentration of the microcapsules was determined using a hemocytometer and it was of the order of $5 \times 10^{8} \mathrm{~mL}^{-1}$.
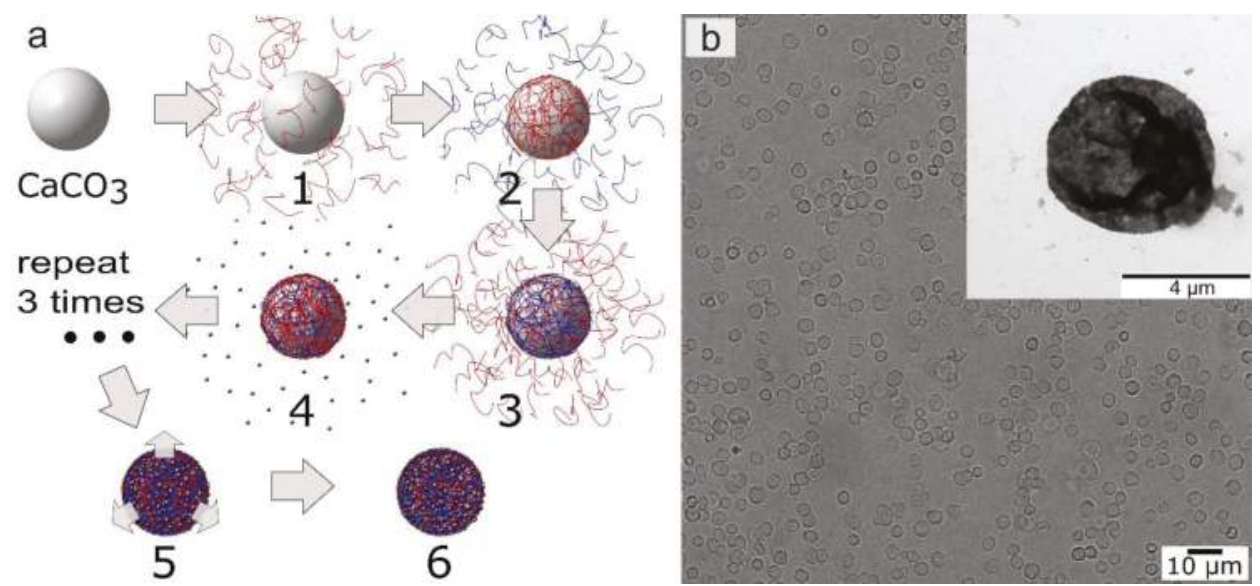

Figure 1. (a) Scheme of microcapsule preparation: 1, 3-adsorption of Parg, 2-adsorption of Dex, 4-adsorption of magnetite nanoparticles (MNP)s, 5-dissolution of core, 6-magnetic polyelectrolite microcapsule. (b) Optical and transmission electron microscopy (TEM) (inset figure) images of biodegradable microcapsules containing magnetite MNPs.

The polyelectrolyte composites containing this type of magnetite nanoparticles exhibit the superparamagnetic behavior which was shown on the planar polyelectrolyte composite coatings. [31]. 
Variation of the volume fraction of inorganic nanoparticles led us to control the physical properties of microcapsule shells as well as MRI contrast. Contrast enhancement of magnetic microcapsules increases with increasing average distance between magnetite nanoparticles in the shell [32]. In agreement with the analyses of some already published articles, we can conclude that size stability of such type of microcapsule in vitro is very high [33].

\subsection{Dynamic Light Scattering, Atomic Force Microscopy, and Transmission Electron Microscopy}

The measurements of the zeta-potential and size distribution of nanoparticles were performed using a Zetasizer Nano-ZS instrument (Malvern Instruments Ltd., Malvern, UK).

Atomic force microscopy (AFM) images of microcapsules were obtained with a Ntegra Spectra microscope (NT-MDT, Zelenograd, Moscow, Russia) in tapping mode. For image acquisition, NSG10 probes from NT-MDT with a resonant frequency of about $220 \mathrm{kHz}$, a force constant of 3.1-37.6 N/m and a tip curvature below $10 \mathrm{~nm}$ were used. Samples were prepared by drying a drop of the microcapsule suspension on the cover glass slide surface. All image processing was done with Gwyddion software [34].

Transmission electron microscopy (TEM) images were obtained using a Libra-120 transmission electron microscope (Carl Zeiss, Jena, Germany) operating at $120 \mathrm{kV}$. The samples were prepared by deposition of a capsule suspension onto a formvar film supported by the copper grid.

\subsection{Animal Study. Ex Vivo Organ Preparation}

Animal experiments were performed in accordance with the University's Animal Ethics Committee and the relevant international agency [35] in Core Facilities of Saratov State Medical University. In experiments, 42 white outbred male rats weighing $200 \pm 20 \mathrm{~g}$ were used. Thirty-six rats were intravenously injected with a single dose of a microcapsule suspension dispersed in physiological saline at $2.5 \times 10^{9}$ capsules per $\mathrm{kg}$. Then, the animals were randomly divided into 6 groups of 6 rats in each group; the control group consisted of 6 rats. The duration of the experiment was different in different groups; i.e., the lifetime of the animals after administration of the microcapsules was $15 \mathrm{~min}$, $1 \mathrm{~h}, 4 \mathrm{~h}, 24 \mathrm{~h}, 7$ days and 30 days. These time intervals were chosen as they are most frequently used for the biodistribution study [36].

An MRI study was performed and after that, the animals were decapitated. The following organs were collected: Kidney, liver, lung, and spleen at the indicated time points after microcapsule administration. The time dependence of microcapsule and iron distribution inside the rats was investigated by histological examination, AAS and ESR.

\subsection{Magnetic Resonance Imaging}

Magnetic resonance imaging in vivo was performed using a Philips Achieva 1.5T high field MRI scanner with a phased array coil. Immobilization of animals was carried out for $60 \mathrm{~min}$ in the supine position with the fixation of the limbs. Zoletil 50 (Virbac, France) was administered intramuscularly at a dose of $40 \mu \mathrm{g} / \mathrm{kg}$ for anesthesia. T1 and T2-weighted quick "Spin Echo" protocols (Turbo Spin Echo-TSE), and T1-weighted "Fast Field Echo" (is equal to the "Gradient Echo") were used. The presence of contrast agents in the test object which mainly reduces the longitudinal relaxation time T1 (substances containing gadolinium, for example, gadobutrol [37]), in the tissue causes a hyperintense signal on T1-weighted images (lighter staining). Contrast agents which mainly reduce the transverse relaxation time T2 (iron oxides) cause a hypointense signal on T2-weighted images. After in vivo MRI study, the animals were decapitated.

\subsection{Histological Examination}

The sampling of internal organs (spleen, liver, kidneys, lungs, and heart) for morphological studies and determination of microcapsule accumulation were conducted after removing the animals from the experiment. Samples of internal organs were fixed in a $10 \%$ solution of buffered neutral 
formalin for morphological examination and subjected to standard wiring alcohol. The standard histological techniques with hematoxylin and eosin staining were used.

The capsules were counted in 10 fields of vision in each section of organ, but not less than in 3 sections, with an increase of 774 on Microvizor medical of transmitted light mVizo-103 (LOMO, St. Petersburg, Russia). The standard magnification allows one to obtain more objective data and to compare them, so it will be possible to study the dynamics of microcapsule movement and determine the time points for the accumulation of microcapsules in the organs.

\subsection{Atomic Absorption Spectrometry}

A Thermo Scientific iCE 3500 instrument (Thermo Scientific, Bartlesville, OK, USA) was used for the quantitative determination of iron in the tumor. The operating principle of the method is based on the transfer of elements defined in the atomic state. Fiery atomizer was used in the work. The element concentration was determined by the intensity of the light absorption with the characteristic wavelength of atomic vapor of the element. The wavelength was $248.3 \mathrm{~nm}$ for Fe, the slit width was $0.2 \mathrm{~nm}$, and the lamp current was $75 \%$. A hollow cathode lamp was used as the light source. A standard sample of metal ions (GSO 7330-96, Saint Petersburg, Russia) was used for the calibration of the spectrometer.

\subsection{Quantitative Magnetite Content Analysis via Electron Spin Resonance (ESR) Spectroscopy}

In order to evaluate microcapsules presence in organs, a quantitative magnetite content analysis of ex vivo samples was performed using the ESR method according to the procedure described by Chertok et al. [38] with modification given below in this section.

The modified procedure of ESR spectroscopy in this study is based on the recording of ferromagnetic resonance spectra reflecting the magnetite content in a specimen. The paramagnetic peaks of the ionized iron become totally smooth and really cannot influence the intensity and other characteristics of the signal. Thus, the endogenous iron does not interfere with determination of ferromagnetic capsules. Furthermore, the constant distribution of magnetite over the capsules and the uniform environment for the incorporated magnetite (the polyelectrolytes surrounding the magnetite) guarantee that the resonance field and the spectrum forms are not different for any specimens containing microcapsules. This makes it possible to calibrate the spectrometer with in vitro specimens of a microcapsules suspension and to measure the microcapsule and magnetite content in ex vivo specimens without further corrections, including the control correction.

Before ESR analysis, pieces of extracted organs weighing 150-200 mg were dried in a vacuum oven and fixed to the quartz rod. After that, they were inserted into a recording unit (block) of the ESR spectrometer (The scheme is shown in Supporting Information (Figure S3)).

ESR spectra were obtained using a CMS $8400 \mathrm{X}$-band ESR spectrometer (Adani, Belarus) with the following parameters: Resonant frequency, $\sim 9.2 \mathrm{GHz}$; center field, $3100 \mathrm{G}$; sweep width, $3400 \mathrm{G}$; modulation amplitude, $1 \mathrm{G}$.

In our studies, the ESR method originally proposed in the paper [38] has been modified: ESR spectra were recorded in dry samples at room temperature $\left(21^{\circ} \mathrm{C}\right)$ in contrast to low-temperature $\left(-128^{\circ} \mathrm{C}\right)$ measurements in frozen samples used by Chertok et al. This modification makes the recording easier to use without significant loss of accuracy. The obtained calibration curve for the contain/signal relationship have proved the relation to be linear in the investigated concentration range (from 0.5 to $20 \mu \mathrm{g}$ of magnetite per sample) for dry capsules. The calibration curve is given in SI (Figure S4).

Spectra were recorded as the first derivative of absorbed microwave power $(\mathrm{P})$ versus the applied magnetic field $(\mathrm{B})$ and are given as $(\mathrm{dP} / \mathrm{dB})$. The double integral of the collected spectra $\left(\iint(\mathrm{dP} / \mathrm{dB}) \mathrm{dBdB}\right)$ is known to be proportional to the number of resonating electronic spins in a measured sample. Double integral values were obtained from spectra using the EPRCMD 4.0 program (Adani, Minsk, Belarus). 
The concentration of magnetite in the samples was obtained with the help of a calibration curve, which was made using samples with the known content of magnetite in form of a dried suspension of magnetite microcapsules of known concentration. The samples were dried in vacuum at ESR-neutral substrate and then investigated by the procedure mentioned above.

Control experiments, conducted with blood and tissue samples without any magnetite in the system, showed no ferromagnetic signal; therefore, the background correction was negligible and was not taken into account (Figure S5). It should be noted that the addition of blood and organ homogenates to the calibration samples does not alter the shape of the spectra (Figure S6) and the resonance field. This fact underpins the possibility of application of the ESR method to the quantitative analysis of magnetite microcapsules in ex vivo samples.

\section{Results}

\subsection{In Vivo MRI Study of Intravenously Injected Capsules}

Initial assessment of capsule distribution was done by MRI. Magnetite nanoparticles mainly reduce the transverse relaxation time $\mathrm{T} 2$ and cause the darker staining of corresponding marked tissue areas on T2-weighted images (Figure 2). The microcapsules with magnetite NPs in the shell do not enhance contrast in the region of interest ROI compared to magnetite hydrosol in the same concentration, but upon enzyme degradation liberated nanoparticles enhance contrast in magnetic resonance (MR) images (Figure 2, Figure S2).

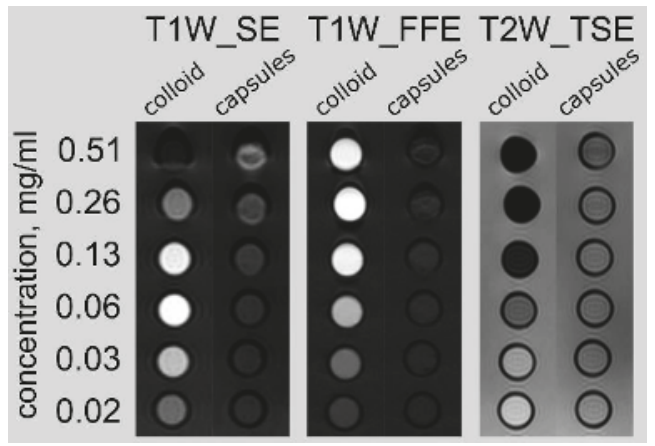

Figure 2. The MRI contrast of the magnetite colloid and magnetic microcapsules at a different concentrations of magnetite in the probe tubes. Different pulse sequences are presented from left to right: T1 weighted "Spin-echo" (T1W_SE), T1 weighted "Fast Field Echo" (T1W_FFE), and T2 weighted "Turbo Spin Echo" (T2W_TSE).

Figure 3 shows the T1 and T2 weighted MR images of rats obtained $24 \mathrm{~h}$ after injection of microcapsules containing magnetite nanoparticles. Solid orange lines indicate liver in a rat after microcapsule injection. Dotted orange lines indicate liver in a control rat. Magnetite distributed in liver leads to a decrease in the MR signal intensity in the region of interest (ROI) in the T1 weighted MR images (Figure 3a). This can be explained by the fact that the concentration of magnetite in the ROI was higher than $0.4 \mathrm{mg} / \mathrm{mL}$. At high concentrations of magnetite nanoparticles, the effect of the T2 relaxation process on the measured MR signal intensity was higher than the effect of the T1 relaxation process. This leads to a decrease in the MR signal intensity in the T1 weighted images. The T2 relaxation time affects the MR signal intensity in the T1 weighted images because in clinical MRI the images are weighted by T1 and T2 but not calculated from only T1 or T2 relaxation times. Pure T1 and T2 images are not useful in clinical MRI, because the T1 and T2 values could not be applied for differential diagnosis or characterization of pathology [39]. 


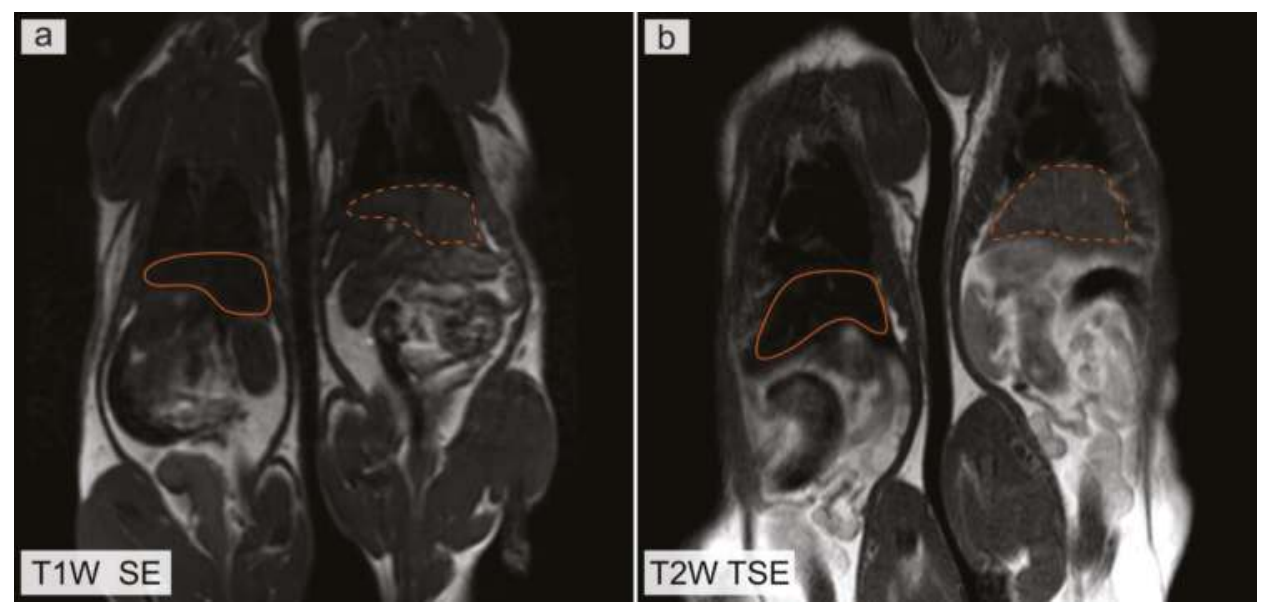

Figure 3. Magnetic resonance (MR) images of rats obtained $24 \mathrm{~h}$ after injection of a microcapsule suspension. (a) T1 weighted MR image. (b) T2 weighted image. The rat on the right is a control rat, without injection of microcapsules.

The average magnetite nanoparticles concentration in the liver is less than $1 \mathrm{mg} / \mathrm{mL}$, taking into account volume of the rat's liver so artifacts in MR images are not observed.

According to MRI investigation, immediately after intravenous administration of microcapsules, the contrast of the region of interest is not observed. This fact is related to the high volume fraction of magnetite NPs in the microcapsules used. Microcapsules with a high volume fraction of magnetite NPs have no effect on the MR signal intensity, but upon enzyme degradation the liberated nanoparticles enhance contrast (Figure 2, Figure S2) [32]. It was established that the dependence of the MR signal on the volume fraction of magnetite was related to the interparticle distance (d) in the microcapsule shell (Figure S2). The further histological study demonstrated that the microcapsules were destroyed in the liver within $24 \mathrm{~h}$ and the realized magnetite nanoparticles exhibited contrast properties within 7 days (Figure 3).

Then, the distribution of the microcapsules in the organs was analyzed postmortem at selected time points by the three methods mentioned above: AAS, histology, and ESR. Appropriate qualitative and quantitative assay methods need to be established and be sensitive enough to detect the presence of microcapsules in cells and tissues.

\subsection{Comparative Analysis of Histology Data with AAS and ESR}

The time dependence of microcapsule and iron distribution inside the internal organs of rats after intravenous injection (IVI) of biodegradable microcapsules was investigated by histological examination, AAS, and ESR.

Liver. At the histologic examination the content of the microcapsules increased most $1 \mathrm{~h}$ after IVI, while pronounced changes were noted in the form of circulatory disorders and dystrophy of hepatocytes. Four hours after IVI, the number of whole capsules decreased, but the amount of pigment increased (Figure 4a,b). At the same time, the morphological changes in the tissue were less pronounced, although there were signs of an allergic reaction with eosinophils in the lumen of the vessels. Twenty-four hours after IVI of microcapsules, the dissolution of the capsules in the Kupffer cells was noted and the hepatocytes with the release of its contents into the cytoplasm of a cell, eosinophilia was not already marked. A week later, the content of the pigment was large, and the whole capsules were only between hepatocytes or their fragments. A month later a normalized structure of the liver was observed, and the pigment was absent. According to AAS, the maximum 
amount of iron in the liver was observed $1 \mathrm{~h}$ after IVI of microcapsules. According to ESR analysis, the dynamics of magnetite distribution had a different character. Starting at a relatively small fraction at first time point of $15 \mathrm{~min}$ it consistently increased over $24 \mathrm{~h}$ and reached a maximum at the end of the first day after administration. After a week, the concentration of magnetite in the liver dropped 7-fold lower than that at the maximum (Figure 5).
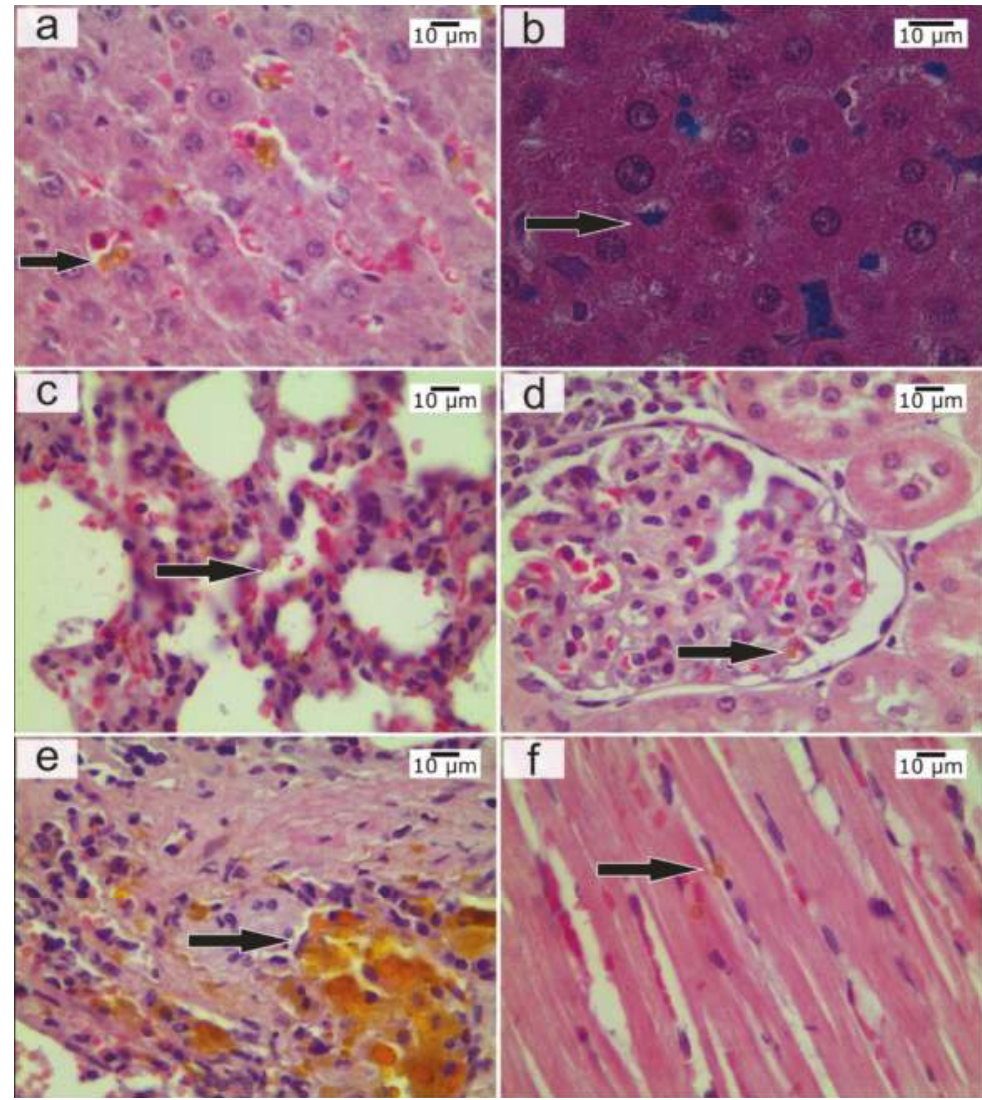

Figure 4. (a) Liver $4 \mathrm{~h}$ after intravenous injection (IVI) of the microcapsules-the conglomerates of the microcapsules in sinusoids. Hematoxylin and eosin (H\&E), magnification $774 \times$. (b) Liver $4 \mathrm{~h}$ after IVI of microcapsules, the conglomerates of the microcapsules were painted in blue. Prussian blue staining, magnification $1199.7 \times$. (c) Lung $15 \mathrm{~min}$ after IVI of the microcapsules, microcapsules in capillaries of lung tissue. H\&E, magnification $774 \times$. (d) Kidneys $15 \mathrm{~min}$ after IVI of the microcapsules-the microcapsules in vascular loops of glomeruli. H\&E, magnification 774×. (e) Spleen one day after IVI of the microcapsules-the microcapsules and magnetite were observed in spleen tissue. H\&E, magnification $774 \times$. (f) Heart $1 \mathrm{~h}$ after IVI of microcapsules-the individual microcapsules in myocardium. H\&E, magnification $774 \times$. The arrow indicates microcapsules or their clusters in the organs.

Lung. At the histological examination, the maximum changes appeared $4 \mathrm{~h}$ after IVI of microcapsules in the form of pronounced congestion of large vessels, focal hemorrhages, and peribronchial eosinophilic infiltration. The severity of these changes was reduced after $24 \mathrm{~h}$. A large number of capsules were also noted $15 \mathrm{~min}$ after IVI of microcapsules in an average amount of $8.75 \pm 1.03$ units in the field of view 
in the lumen of medium caliber vessels, between the bronchi and in the stroma (Figure 4c). One week after IVI of microcapsules, the severity of the allergic reactions increased with the involvement of the bronchi and blood vessels. One month after IVI of the microcapsules, the appearance of a large number of lymphocytes in the lungs was noted, which were in the form of widespread infiltrates located around the main bronchus. Infiltrates occupied the area in several fields of view at the lowest magnification eye field. There was pronounced hyperplasia of the muscular layer of vessels of various sizes, with ring-shaped lymphoid infiltration around blood vessels of all calibers. The area of perivascular infiltration was significantly less than that around the bronchi. According to AAS, the maximum amount of iron in the lungs was observed $4 \mathrm{~h}$ after IVI of microcapsule suspension. According to ESR analysis in lungs, the concentration of magnetite was highest in the early stages of ex vivo analysis (between $15 \mathrm{~min}$ and $4 \mathrm{~h}$ after administration). It was significantly decreased at the time point of $24 \mathrm{~h}$, and the magnetite was not determined in the lungs in the subsequent phases of observation for week and month time (Figure 5). Unfortunately, it was not confirmed by MRI, because normal lung tissue has low proton density; therefore, magnetite-containing microcapsules were not visualized in lungs by MRI in vivo.

It should also be noted that in the lungs, a marked allergic reaction was observed during all time intervals, which was manifested by the appearance of perivascular lymphoid infiltration, and further abrupt thickening of the vessel walls, as well as more pronounced hyperplasia of bronchial lymphoid tissue, which was observed one month after the intravenous administration of the capsules. The absence of marked toxicity in the internal organs after IVI of microcapsules are consistent with our data obtained earlier [32].

Spleen. At the histological examination the maximum changes occurred $4 \mathrm{~h}$ after IVI of microcapsules in the form of pronounced congestion, increase in the number of microcapsules (up to 9 in the field of view in the white pulp. In red pulp, up to 4). After one day, the largest accumulation of microcapsules was noted, and there were also indirect signs of their degradation (Figure 4e). An important fact is that the signs of degradation were observed at all time intervals. After one week, single capsules were observed in the white pulp, and the pigment was located diffusely. One month after, the pigment disappeared in the red pulp and it remained in the white pulp. According to AAS, the maximum amount of iron in the spleen was observed after $4 \mathrm{~h}$. According to ESR, the dynamics of magnetite accumulation in the spleen was similar to that in the liver (increasing in the first day with subsequent decreasing), but after $24 \mathrm{~h}$, the concentration of magnetite in the spleen was two times higher than that in the liver (Figure 5).

Kidneys. At the histological examination, the maximum changes were observed $24 \mathrm{~h}$ after injection in the form of hemorrhages in the cortex, dilatation of capillary loops of the glomeruli, and marked degradation of the capsules with accumulation of content in the epithelium of convoluted tubules. This does not allow us to make an unambiguous conclusion: The capsules pass through the urinary filter and their contents are reabsorbed from the urine back into the tubules or capsules entered into the epithelium through the capillaries which nourish epithelium. The maximum content of whole capsules was observed in the first time points after IVI-in $15 \mathrm{~min}$ and $1 \mathrm{~h}$ (Figure $4 \mathrm{~d}$ ). After one week, the whole capsules were not detected, but the appearance of magnetite in the epithelium of convoluted tubules was noted. After one month, a normal structure of the kidney and the absence of pigment were observed. According to AAS, the maximum amount of iron in the kidneys was observed after $15 \mathrm{~min}$. According to ESR analysis in kidneys the absence of magnetite may be explained as follows: The concentration of magnetite in kidneys is lower than the limit of determination even at the time of first measurement (Figure 5).

Heart. At the histological examination the maximum changes were observed within $1 \mathrm{~h}$ after administration in the form of marked edema, single diapedetic hemorrhages, swelling and necrosis of cardiomyocytes. The maximum content of the capsules was up to 2-3 in the field of view (Figure 4f). Four hours after IVI of microcapsules, the severity of changes was reduced, and capsules were not detected; moderate swelling and granular degeneration were saved to the week after the introduction 
and after a month, the normal structure of the myocardium was seen. AAS and ERS investigations were not carried out in the heart tissue.

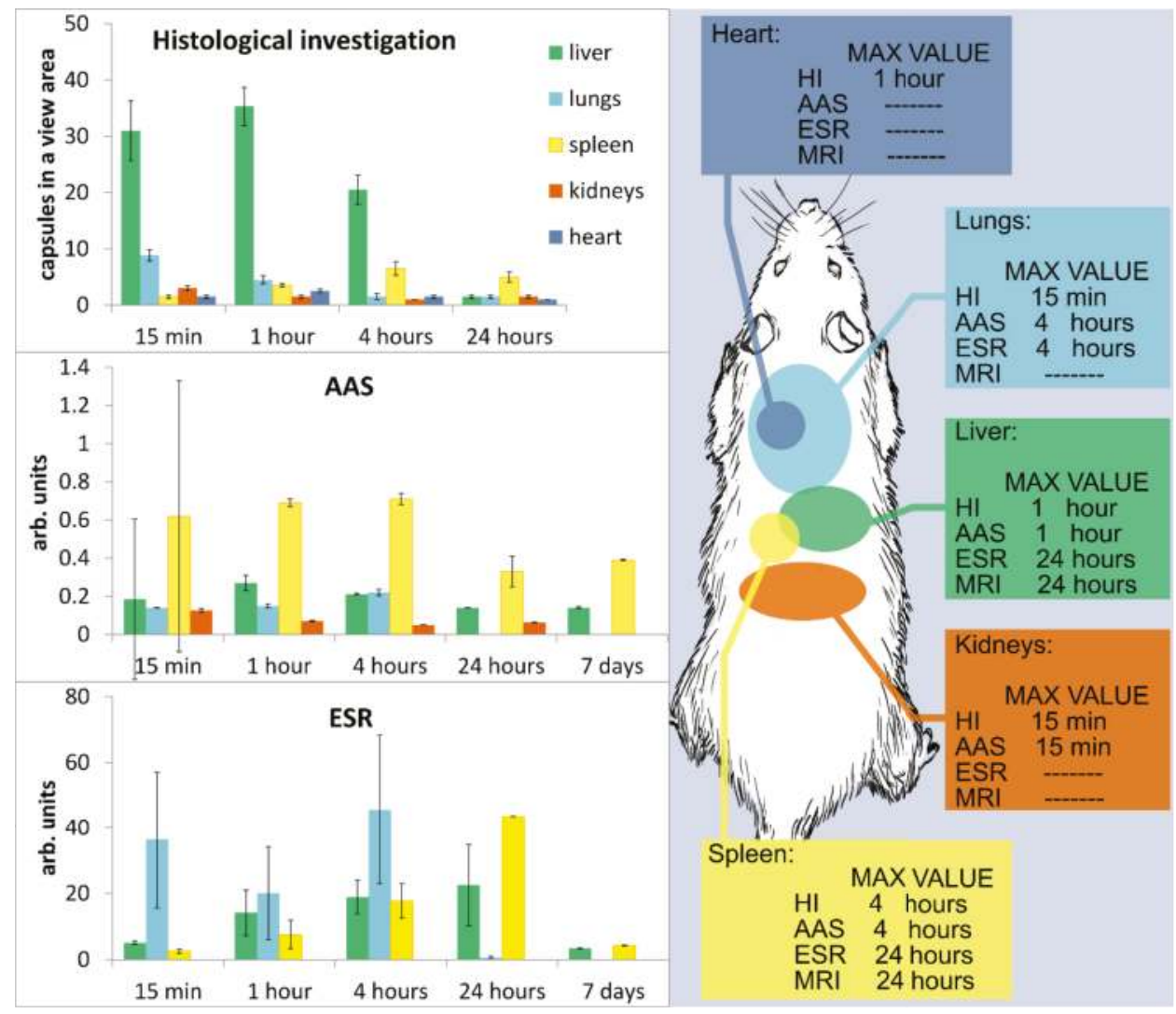

Figure 5. Biodistribution of magnetic microcapsules at intravenous injections. Left side: Microcapsule biodistribution data obtained by histological investigation, atomic absorption spectrometry (AAS) and electron spin resonance (ESR). Right side: maximum accumulation of microcapsules and MR signal for each organ observed.

\section{Discussion}

Since the nanocomposite microcapsules are multicomponent systems consisting of three components (cationic and anionic polyelectrolytes and inorganic nanoparticles), the components have different biodegradation times and as a result, the polymer shells are degraded more quickly than the magnetite nanoparticles. Therefore, as far as the degradation of the magnetic capsule is concerned, one should consider it as a multistep process. There is an initial state before biodegradation starts, then it is likely the polymer shell degradation occurs, releasing magnetite nanoparticles which later degrade, and iron ions could be free from the nanoparticles. Such a complex process of degradation requires different complementary methods for evaluating the biodistribution of magnetic microcapsules. Morphological methods, such as histology, allow comprehensive determination of the quantitative content of capsules in sections of internal organs, time points the capsules appear there, maximum accumulation and the delocalization of whole capsules between internal organs, and, at the end, to evaluate complete capsule destruction and elimination of their components at certain time 
points after intravenous administration. ESR allows evaluation of the biodistribution of magnetite nanoparticles once they are intact either in capsules or released from capsules but still intact and exhibit superparamagnetic properties. MRI makes possible the visualization of magnetite nanoparticles before and after polymer shell degradation, since these peculiarities of MRI capsule degradation imaging are discussed in detail [32]. After the beginning of capsule destruction, the morphological method ceases to be adequate for further quantification, since the capsules cannot be identified any longer. Since capsule integrity is lost, one can follow the fate of magnetite nanoparticles released from the destroyed capsules by using the MRI (in vivo) and ESR (ex vivo) methods. Both of these methods can monitor magnetite nanoparticles till their degradation, leaving only iron ions, which cannot be detected any longer by MRI and ESR. Along with that, AAS allows detection of iron element biodistribution at all stages of capsule accumulation and degradation, including monitoring of iron before and after microcapsule and nanoparticle degradation. In addition, the complexity of application of these methods makes it possible to identify more clearly the time periods of biodegradation of capsules with magnetite nanoparticles in certain organs.

Comparative analysis of microcapsule biodistribution showed that a significant correlation was observed between the temporal dynamics of microcapsule content in the liver, spleen, and kidneys, according to the histological and AAS data. At histological examination, the maximum amount of magnetite microcapsules was obtained in the kidneys and lungs at $15 \mathrm{~min}$, in the liver and heart at $1 \mathrm{~h}$, and in the spleen at $24 \mathrm{~h}$ after IVI of microcapsules. At AAS the maximum amount of magnetite microcapsules was observed in the kidneys at $15 \mathrm{~min}$, in the liver at $1 \mathrm{~h}$, and in the spleen and lungs at $4 \mathrm{~h}$ after IVI of microcapsules.

ESR analysis demonstrated the magnetite distribution dynamics in various tissues. Magnetite was found in the lungs, liver, and spleen and was not detected in the kidney at the selected time point. According to ESR analysis, the maximum of magnetite accumulation developed in the lungs after $4 \mathrm{~h}$, and in the liver and spleen at $24 \mathrm{~h}$ after intravenous administration of capsules, Biodegradation of the capsules and the release of their content begin on the first day after administration of the capsules. Additionally, the examined organs showed no presence of magnetite 30 days after IVI of microcapsules. Although the discrepancy of the results obtained by ESR and MRI could be explained by the sensitivity of both methods to magnetite nanoparticle conditions and the integrity of the microcapsule shells. According to the histological investigation, the microcapsules were degraded within $24 \mathrm{~h}$, which resulted in the different behavior of MRI and ESR signals.

The differences in the tissue distributions of magnetite and microcapsules can be explained by the action of several factors. Firstly, our study has demonstrated a significant accumulation of magnetite in the tissues with a highly developed reticuloendothelial system (liver and spleen). These data are consistent with the data from other studies [40,41], in which it was shown that nanoparticles are actively phagocytosed and accumulated in the organs with a large content of tissue macrophages.

Another factor which plays an important role in biodistribution may be the specific features of particle passage through the microcirculatory system. We assume that early-stage accumulation and the subsequent rapid decrease in the particle concentration in lungs is caused by mechanical embolization of some pulmonary capillaries with microcapsules at their first passage. The embolization is possible because the diameter of the capsules is close to the size of the pulmonary capillaries. The properties of microcirculation can also contribute to the accumulation of the microcapsules and magnetite in the liver and spleen. These organs contain open sections of the circulatory system, which makes possible the transition of the microcapsules from the blood flow to the interstitium.

\section{Conclusions}

In this study, we showed what happens with polyelectrolyte capsules modified with magnetic nanoparticles when they are systemically administered. The intravenous administration of microcapsules brings about changes in tissue morphology in most organs (kidney, heart, liver, spleen), but it is reversible and after a month, the structure of the tissue is completely restored. 
Whole capsules were not observed demonstrating their complete degradation, and the pigment indicating iron disappeared. Although the timeline of organ localization for capsules is coherent for other delivery systems, showing at first the accumulation in liver with traces of iron oxide seen in the spleen after 7 days, the overall picture illustrates the applicability of using these capsules for systemic delivery without visible pathological observation.

The reported data gave us more understanding about the distribution of capsules in the animal body in the dynamic time frames over hours and days and provide information about what organ and when one could expect the capsules potentially bearing bioactive cargo. The polyelectrolyte microcapsules, being on the research agenda for decades, can deliver the substance of interest to organs at a certain time after injection. Thus, the long-standing potential for application of these capsules can be further explored on particular delivery to organs. The magnetic nanoparticles have not been used here as their magnetic properties, but their addressing with magnetic field and/or electromagnetic irradiation is subject for further study where the expectations of multifunctional microcapsules to be used as multimodal drug delivery systems could be fulfilled.

Supplementary Materials: The following are available online at http://www.mdpi.com/2079-4991/8/10/812/s1, Figure S1: Magnetite nanoparticle size distribution measured by DLS; Figure S2: Dependence of MRI contrast on interparticle distance d, illustrated by TEM images of MNPs, microcapsules after enzyme degradation and initial microcapsules.; Figure S3: The sample preparation process for ESR spectroscopy; Figure S4: Chart for mass of magnetite-ESR area under curve dependence; Figure S5: Comparison of ESR spectra of liver from animals exposed and not exposed to microcapsules; Figure S6: Comparison of ESR spectra of microcapsules suspension in the water and liver homogenate.

Author Contributions: Conception and design of study, D.A.G., G.N.M. and G.B.S.; investigation, N.A.N., S.V.G., A.B.B., O.S.G., V.V.Z., M.N.Z., G.S.T. and P.S.Z.; analysis and interpretation of the experimental data, N.A.N., S.V.G., A.B.B., V.V.Z., G.N.M., N.A.P., P.S.Z. and G.S.T.; writing the manuscript, A.B.B., S.V.G., O.S.G., P.S.Z., M.N.Z. and N.A.P.; writing and revising of the manuscript, N.A.N., G.N.M., D.A.G. and G.B.S.; supervision, G.B.S.

Funding: This work was supported by the Government of the Russian Federation (grant 14.Z50.31.0004 to support scientific research projects implemented under the supervision of leading scientists at Russian Institutions and Russian Institutions of Higher Education).

Acknowledgments: In this section you can acknowledge any support given which is not covered by the author contribution or funding sections. This may include administrative and technical support, or donations in kind (e.g., materials used for experiments).

Conflicts of Interest: The authors declare no conflict of interest.

\section{References}

1. Stark, D.D.; Weissleder, R.; Elizondo, G.; Hahn, P.F.; Saini, S.; Todd, L.E.; Wittenberg, J.; Ferucci, J.T. Superparamagnetic Iron Oxide: Clinical Application as A Contrast Agent for MR Imaging of the Liver. Radiology 1988, 168, 297-301. [CrossRef] [PubMed]

2. Krishnan, K.M. Biomedical Nanomagnetics: A Spin Through Possibilities in Imaging, Diagnostics, and Therapy. IEEE Trans. Magn. 2010, 46, 2523-2558. [CrossRef] [PubMed]

3. Rosen, J.E.; Chan, L.; Shieh, D.B.; Gu, F.X. Iron Oxide Nanoparticles for Targeted Cancer Imaging and Diagnostics. Nanomed.-Nanotechnol. 2012, 8, 275-290. [CrossRef] [PubMed]

4. Ito, A.; Honda, H.; Kobayasi, T. Medical Application of Functionalized Magnetic Nanoparticles. J. Biosci. Bioeng. 2005, 100, 1-11. [CrossRef] [PubMed]

5. Suzuki, M.; Honda, H.; Kobayashi, T.; Wakabayashi, T.; Yoshida, J.; Takahashi, M. Development of a Target Directed Magnetic Resonance Contrast Agent Using Monoclonal Antibody-Conjugated Magnetic Particles. Brain Tumor Pathol. 1996, 13, 127-132.

6. Gaumet, M.; Vargas, A.; Gurny, R.; Delie, F. Nanoparticles for Drug Delivery: The Need for Precision in Reporting Particle Size Parameters. Eur. J. Pharm. Biopharm. 2008, 69, 1-9. [CrossRef] [PubMed]

7. Kievit, F.M.; Zhang, M. Surface Engineering of Iron Oxide Nanoparticles for Targeted Cancer Therapy. Acc. Chem. Res. 2011, 44, 853-862. [CrossRef] [PubMed] 
8. Johannsen, M.; Gneveckow, U.; Thiesen, B.; Taymoorian, K.; Cho, C.H.; Waldofner, N.; Scholz, R.; Jordan, A.; Loening, S.A.; Wust, P. Thermotherapy of Prostate Cancer Using Magnetic Nanoparticles: Feasibility, Imaging, And Three-Dimensional Temperature Distribution. Eur. Urol. 2007, 52, 1653-1661. [CrossRef] [PubMed]

9. Ito, A.; Tanaka, K.; Honda, H.; Abe, S.; Yamaguchi, H.; Kobayashi, T. Complete Regression of Mouse Mammary Carcinoma with a Size Greater than $15 \mathrm{~mm}$ by Frequent Repeated Hyperthermia Using Magnetite Nanoparticles. J. Biosci. Bioeng. 2003, 96, 364-369. [CrossRef]

10. Wu, K.; Wang, J.-P. Magnetic Hyperthermia Performance of Magnetite Nanoparticle Assemblies under Different Driving Fields. AIP Adv. 2017, 7, 056327. [CrossRef]

11. Estelrich, J.; Escribano, E.; Queralt, J.; Busquets, M.A. Iron Oxide Nanoparticles for Magnetically-Guided And Magnetically-Responsive Drug Delivery. Int. J. Mol. Sci. 2015, 16, 8070-8101. [CrossRef] [PubMed]

12. Wankhede, M.; Bouras, A.; Kaluzova, M.; Hadjipanayis, C.G. Magnetic Nanoparticles: an Emerging Technology for Malignant Brain Tumor Imaging and Therapy. Expert Rev. Clin. Pharmacol. 2012, 5, 173-186. [CrossRef] [PubMed]

13. Timin, A.; Gao, H.; Voronin, D.; Gorin, D.; Sukhorukov, G. Inorganic/Organic Multilayer Capsule Composition for Improved Functionality and External Triggering. Adv. Mater. Interfaces 2017, 4, 1600338. [CrossRef]

14. Becker, A.L.; Johnston, A.P.; Caruso, F. Layer-by-layer-assembled Capsules and Films for Therapeutic Delivery. Small 2010, 6, 1836-1852. [CrossRef] [PubMed]

15. Delcea, M.; Möhwald, H.; Skirtach, A.G. Stimuli-Responsive LbL Capsules and Nanoshells for Drug Delivery. Adv. Drug Deliv. Rev. 2011, 63, 730-747. [CrossRef] [PubMed]

16. Zebli, B.; Susha, A.S.; Sukhorukov, G.B.; Rogach, A.L.; Parak, W.J. Magnetic Targeting and Cellular Uptake of Polymer Microcapsules Simultaneously Functionalized with Magnetic and Luminescent Nanocrystals. Langmuir 2005, 21, 4262-4265. [CrossRef] [PubMed]

17. De Geest, B.G.; Vandenbroucke, R.E.; Guenther, A.M.; Sukhorukov, G.B.; Hennink, W.E.; Sanders, N.N.; Demmster, J.; De Smedt, S.C. Intracellularly Degradable Polyelectrolyte Microcapsules. Adv. Mater. 2006, 18, 1005-1009. [CrossRef]

18. Yu, W.; Zhang, W.; Chen, Y.; Song, X.; Tong, W.; Mao, Z.; Gao, C. Cellular Uptake of Poly(Allylamine Hydrochloride) Microcapsules with Different Deformability and Its Influence on Cell Functions. J. Colloid Interface Sci. 2016, 465, 149-157. [CrossRef] [PubMed]

19. De Geest, B.G.; Sanders, N.N.; Sukhorukov, G.B.; Demeester, J.; De Smedt, S.C. Release Mechanisms for Polyelectrolyte Capsules. Chem. Soc. Rev. 2007, 36, 636-649. [CrossRef] [PubMed]

20. Loretta, L.; Rivera-Gil, P.; Abbasi, A.Z.; Ochs, M.; Ganas, C.; Zins, I.; Sönnichsen, C.; Parak, W.J. LbL Multilayer Capsules: Recent Progress and Future Outlook for Their Use in Life Sciences. Nanoscale 2010, 2, 458-467. [CrossRef]

21. Bédard, M.F.; De Geest, B.G.; Skirtach, A.G.; Möhwald, H.; Sukhorukov, G.B. Polymeric Microcapsules with Light Responsive Properties for Encapsulation and Release. Adv. Colloid Interface Sci. 2010, 158, 2-14. [CrossRef] [PubMed]

22. Abbaspourrad, A.; Carroll, N.J.; Kim, S.H.; Weitz, D.A. Polymer Microcapsules with Programmable Active Release. J. Am. Chem. Soc. 2013, 135, 7744-7750. [CrossRef] [PubMed]

23. Ambrosone, A.; Marchesano, V.; Carregal-Romero, S.; Intartaglia, D.; Parak, W.J.; Tortiglione, C. Control of Wnt/ $\beta$-Catenin Signaling Pathway in Vivo via Light Responsive Capsules. ACS Nano 2016, 10, 4828-4834. [CrossRef] [PubMed]

24. De Koker, S.; De Geest, B.G.; Cuvelier, C.; Ferdinande, L.; Deckers, W.; Hennink, W.E.; DeSmedt, S.C.; Mertens, N. In Vivo Cellular Uptake, Degradation, and Biocompatibility of Polyelectrolyte Microcapsules. Adv. Funct. Mater. 2007, 17, 3754-3763. [CrossRef]

25. Zheng, C.; Zhang, X.G.; Sun, L.; Zhang, Z.P.; Li, C.X. Biodegradable and Redox-Responsive Chitosan/poly (L-aspartic acid) Submicron Capsules for Transmucosal Delivery of Proteins and Peptides. J. Mater. Sci. Mater. Med. 2013, 24, 931-939. [CrossRef] [PubMed]

26. Voronin, D.V.; Sindeeva, O.A.; Kurochkin, M.A.; Mayorova, O.; Fedosov, I.V.; Semyachkina-Glushkovskaya, O.; Gorin, D.A.; Tuchin, V.V.; Sukhorukov, G.B. In Vitro and In Vivo Visualization and Trapping of Fluorescent Magnetic Microcapsules in a Bloodstream. ACS Appl. Mater. Interfaces 2017, 9, 6885-6893. [CrossRef] [PubMed] 
27. Yi, Q.; Li, D.; Lin, B.; Pavlov, A.M.; Luo, D.; Gong, Q.; Song, B.; Ai, H.; Sukhorukov, G.B. Magnetic Resonance Imaging for Monitoring of Magnetic Polyelectrolyte Capsule In Vivo Delivery. Bionanoscience 2014, 4, 59-70. [CrossRef]

28. Donath, E.; Sukhorukov, G.B.; Caruso, F.; Davis, S.A.; Möhwald, H. Novel Hollow Polymer Shells by Colloid-Templated Assembly of Polyelectrolytes. Angew Chem. Int. Ed. Engl. 1998, 37, 2201-2205. [CrossRef]

29. Massart, R. Preparation of Aqueous Magnetic Liquids in Alkaline and Acidic Media. IEEE Trans. Magn. 1981, 17, 1247-1248. [CrossRef]

30. German, S.V.; Inozemtseva, O.A.; Markin, A.V.; Metvalli, K.; Khomutov, G.B.; Gorin, D.A. Synthesis of Magnetite Hydrosols in Inert Atmosphere. Colloid J. 2013, 75, 483-486. [CrossRef]

31. Dincer, I.; Tozkoparan, O.; German, S.V.; Markin, A.V.; Yildirim, O.; Khomutov, G.B.; Gorin, D.A.; Venig, S.B.; Elerman, Y. Effect of the Number of Iron Oxide Nanoparticle Layers on the Magnetic Properties of Nanocomposite LbL Assemblies. J. Magn. Magn. Mater. 2012, 324, 2958-2963. [CrossRef]

32. German, S.V.; Bratashov, D.N.; Navolokin, N.A.; Kozlova, A.A.; Lomova, M.V.; Novoselova, M.V.; Burilova, E.A.; Zuev, V.V.; Khlebtsov, B.N.; Bucharskaya, A.B.; et al. In vitro and in vivo MRI Visualization of Nanocomposite Biodegradable Microcapsules with Tunable Contrast. Phys. Chem. Chem. Phys. 2016, 18, 32238-32246. [CrossRef] [PubMed]

33. Zyuzin, M.V.; Díez, P.; Goldsmith, M.; Carregal-Romero, S.; Teodosio, C.; Rejman, J.; Feliu, N.; Escudero, A.; Almendral, M.J.; Linne, U.; et al. Comprehensive and Systematic Analysis of the Immunocompatibility of Polyelectrolyte Capsules. Bioconjug. Chem. 2017, 28, 556-564. [CrossRef] [PubMed]

34. Nečas, D.; Klapetek, P. Gwyddion: An Open-Source Software for SPM Data Analysis. Open Phys. 2012, 10, 181-188. [CrossRef]

35. International Guiding Principles for Biomedical Research Involving Animals. December 2012. CIOMS\&ICLAS. Available online: https:/ / olaw.nih.gov/sites/default/files/Guiding_Principles_2012.pdf (accessed on 3 October 2014).

36. Yang, L.; Kuang, H.; Zhang, W.; Aguilar, Z.P.; Wei, H.; Xu, H. Comparisons of the Biodistribution and Toxicological Examinations after Repeated Intravenous Administration of Silver and Gold Nanoparticles in Mice. Sci. Rep. 2017, 7, 3303. [CrossRef] [PubMed]

37. Huppertz, A.; Rohrer, M. Gadobutrol, a Highly Concentrated Mr-Imaging Contrast Agent: Its Physicochemical Characteristics and the Basis for Its Use in Contrast-Enhanced MR Angiography and Perfusion Imaging. Eur. Radiol. 2004, 14, M12-M18. [PubMed]

38. Chertok, B.; Cole, A.J.; David, A.E.; Yang, V.C. Comparison of Electron Spin Resonance Spectroscopy and Inductively-Coupled Plasma Optical Emission Spectroscopy for Biodistribution Analysis of Iron-Oxide Nanoparticles. Mol. Pharm. 2010, 7, 375e85. [CrossRef] [PubMed]

39. Rinck, P.A. Magnetic Resonance in Medicine: The Basic Textbook of the European Magnetic Resonance Forum, 4th ed.; Wiley-Blackwell: Berlin, Germany, 2001; p. 252.

40. Arami, H.; Khandhar, A.; Liggitt, D.; Krishnan, K.M. In Vivo Delivery, Pharmacokinetics, Biodistribution and Toxicity of Iron Oxide Nanoparticles. Chem. Soc. Rev. 2015, 44, 8576-8607. [CrossRef] [PubMed]

41. Patil, U.S.; Adireddy, S.; Jaiswal, A.; Mandava, S.; Lee, B.R.; Chrisey, D.B. In Vitro/in Vivo Toxicity Evaluation and Quantification of Iron Oxide Nanoparticles. Int. J. Mol. Sci. 2015, 16, 24417-24450. [CrossRef] [PubMed]

(C) 2018 by the authors. Licensee MDPI, Basel, Switzerland. This article is an open access article distributed under the terms and conditions of the Creative Commons Attribution (CC BY) license (http:/ / creativecommons.org/licenses/by/4.0/). 
Article

\title{
Transferrin Functionalized Liposomes Loading Dopamine HCl: Development and Permeability Studies across an In Vitro Model of Human Blood-Brain Barrier
}

\author{
Antonio Lopalco ${ }^{1}$, Annalisa Cutrignelli ${ }^{1, *}$, Nunzio Denora ${ }^{1,2}$, Angela Lopedota ${ }^{1}$, \\ Massimo Franco ${ }^{1}$ and Valentino Laquintana ${ }^{1}$ \\ 1 Department of Pharmacy-Drug Sciences, University of Bari “Aldo Moro”, 4 E. Orabona st, 70125 Bari, Italy; \\ antonio.lopalco@uniba.it (A.L.); nunzio.denora@uniba.it (N.D.); angelaassunta.lopedota@uniba.it (A.L.); \\ massimo.franco@uniba.it (M.F.); valentino.laquintana@uniba.it (V.L.) \\ 2 Institute for Physical and Chemical Processes (IPCF)-CNR, SS Bari, 4 E. Orabona st, 70125 Bari, Italy \\ * Correspondence: annalisa.cutrignelli@uniba.it; Tel.: +39-080-544-2766; Fax: +39-080-544-2767
}

Received: 3 March 2018; Accepted: 16 March 2018; Published: 20 March 2018

\begin{abstract}
The transport of dopamine across the blood brain barrier represents a challenge for the management of Parkinson's disease. The employment of central nervous system targeted ligands functionalized nanocarriers could be a valid tactic to overcome this obstacle and avoid undesirable side effects. In this work, transferrin functionalized dopamine-loaded liposomes were made by a modified dehydration-rehydration technique from hydrogenated soy phosphatidylcoline, cholesterol and 1,2-stearoyl-sn-glycero-3-phosphoethanolamine- $N$-[carboxy(poly(ethylene glycol)-2000)]. The physical features of the prepared liposomes were established with successive determination of their endothelial permeability across an in vitro model of the blood-brain barrier, constituted by human cerebral microvascular endothelial cells (hCMEC/D3). Functionalized dopamine-loaded liposomes with encapsulation efficiency more than $35 \%$ were made with sizes in a range around $180 \mathrm{~nm}$, polydispersity indices of 0.2 , and positive zeta potential values $(+7.5 \mathrm{mV})$. Their stability and drug release kinetics were also evaluated. The apparent permeability $\left(\mathrm{P}_{\mathrm{e}}\right)$ values of encapsulated dopamine in functionalized and unfunctionalized liposomes showed that transferrin functionalized nanocarriers could represent appealing non-toxic candidates for brain delivery, thus improving benefits and decreasing complications to patients subjected to L-dopa chronical treatment.
\end{abstract}

Keywords: dopamine; liposomes; drug delivery; transferrin; hCMEC/D3 cells; blood brain barrier

\section{Introduction}

The delivery of active pharmaceutical ingredients to the central nervous system (CNS) represents the most important challenge for the management of the symptoms of Parkinson's disease (PD) and other neurodegenerative disorders, because of the various defensive barriers surrounding the brain $[1,2]$. It is well established that many CNS-active molecules, such as dopamine (DA), do not penetrate across the blood-brain barrier (BBB) to enter the CNS, because of their high polarity, ionized state at physiological $\mathrm{pH}$ and/or the deficiency of endogenous cellular membrane transporters located within the brain endothelium, which forms the blood vessel walls [3-5]. Only small molecules with adequate hydrophilic/lipophilic balance and molecular weight can be absorbed passively into the CNS, if not substrates for the ABC (ATP-binding cassette) transporters efflux pumps. Different methodologies have been developed to raise the delivery of therapeutics for CNS diseases, including the development of CNS-targeted pro-drugs or co-drugs [6-9] and functionalized nanocarriers with uptake-facilitating ligands [10-12]. 
Until today, the most successful therapy for the management of PD is represented by L-dopa (LD), a bioprecursor of DA, that crosses the BBB through the active transport mechanism for amino acids and, once in the brain, is metabolized and transformed to DA by the enzyme dopa decarboxylase [13-15]. Even though LD improves the PD manifestations in the early phases of the disorder, an excessive peripheral LD bioconversion into DA from within the peripheral nervous system produces several unwanted secondary effects. In detail, clinical and preclinical investigations have shown that LD long-term use is associated with anomalous spontaneous movements, psychiatric complications and DA- or LD-induced neurotoxicity [16-18].

In this context, to overcome these disadvantages, a promising strategic delivery system to enhance BBB penetration by DA is the use of nanocarriers such as liposomes (LPs) decorated with uptake-facilitating ligands (Figure 1). In particular, the active targeting approach could be reached using LPs decorated with transferrin ( $\beta$-1 glycopeptide) (Tf), a hydrophilic carrier that regulates the extracellular iron level in human fluid by binding and sequestering it. In fact, Tf receptor, a dimeric transmembrane glycoprotein, certainly represents a successful target molecule since it as well as being overexpressed in different malignant cells that require high levels of iron for their growth is also localized on the endothelia surface of brain capillaries that comprise the BBB [19-21]. Numerous researchers used the targeting to Tf receptor for improving the BBB transport of drugs [22,23].

In this study, we have encapsulated the hydrophilic drug dopamine hychloride (DA.HCl) into Tf functionalized and unfunctionalized LPs (DA.HCl-LPs). These nanocarriers were made by a dehydrationrehydration technique and their particle sizes, polydispersity index, zeta potential and encapsulation efficiency values were determined. Their stability and drug-release behavior were also evaluated. An additional goal in this work was to study the permeability of the functionalized and unfunctionalized DA.HCl-LPs across an in vitro model of the BBB, constituted by human cerebral microvascular endothelial cells (hCMEC/D3), using a well-established procedure.

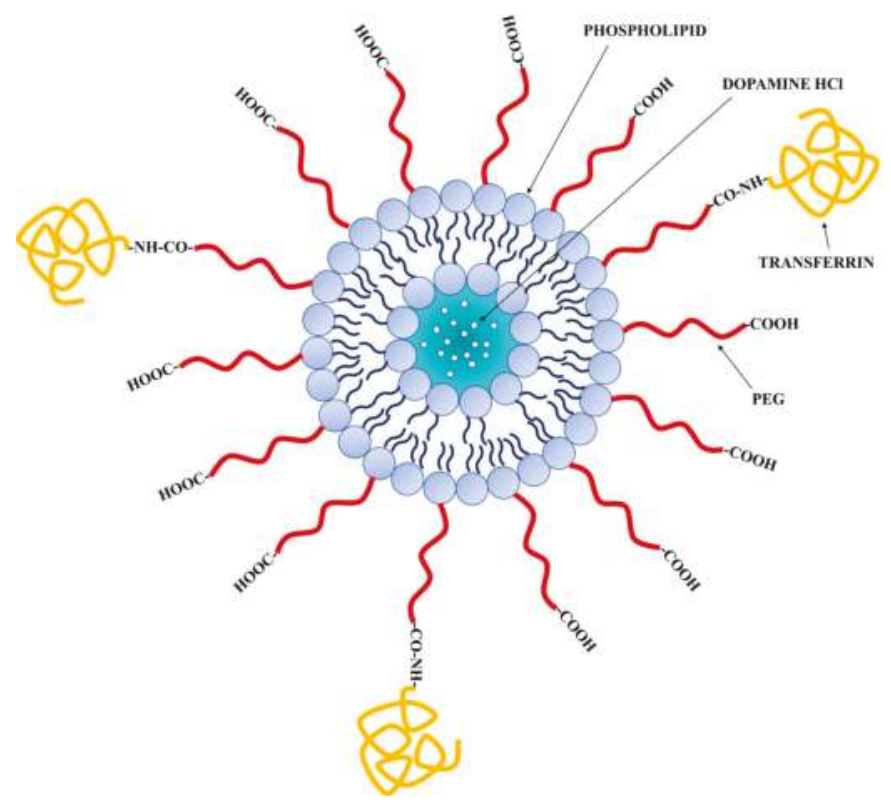

Figure 1. Schematic representation of functionalized DA.HCl-LPs. LPs are made of a phospholipid bilayer, which encloses an aqueous center. The aqueous space incorporates the hydrophilic DA. $\mathrm{HCl}$. Hydrophilic polymer polyethylene glycol (PEG) coats the ligand-targeted LPs. 


\section{Materials and Methods}

\subsection{Materials}

Dopamine hydrochloride (DA $\mathrm{HCl}, \mathrm{MW}=189.64 \mathrm{~g} / \mathrm{mol}$ ), cholesterol (Chol), Triton X-100, $N$-(3-dimethylamino-propyl)- $N$ '-ethylcarbodiimide hydrochloride (EDC), $N$-hydroxysulfosuccinimide (S-NHS) and Tranferrin (Tf) were bought from Sigma-Aldrich (Milan, Italy).

Hydrogenated soy phosphatidylcoline (Phospholipon 90H, PC) was a gift of Natterman Phospholipids $\mathrm{GmbH}$ (Koeln, Germany). 1,2-stearoyl-sn-glycero-3-phosphoethanolamine- $N$-[carboxy(poly(ethylene glycol)-2000)] (DSPE-PEG $2000-\mathrm{COOH}$ ) was purchased from Avanti Polar Lipids (Alabaster, AL, USA).

For cellular transport studies luciferin yellow was bought from Sigma-Aldrich (Milan, Italy); Transwell ${ }^{\circledR}$ permeable supports were from Corning (Corning, NY, USA). All the media and supplements for cell culture were bought from Life Technologies, Thermo Fisher Scientific (Waltham, MA, USA). Other materials used in this study were of analytical grade.

\subsection{Quantification of $\mathrm{DA} \cdot \mathrm{HCl}$}

High-performance liquid chromatography (HPLC) analysis was used to detect and quantify DA. HCl. The HPLC station and the column were the same previously described by Lopedota et al. [24] making a change to the mobile phase which in this case was constituted by 90/10 v/v $0.020 \mathrm{M}$ potassium phosphate buffer $(\mathrm{pH} 2.8) /$ acetonitrile mixture. The flow rate was kept at $1.0 \mathrm{~mL} / \mathrm{min}$, the eluent was continuously monitored at a wavelength of $280 \mathrm{~nm}$ and in these conditions DA.HCl retention time was about $6.5 \mathrm{~min}$. Calibration curves were obtained solubilizing DA. $\mathrm{HCl}$ in the same mobile phase and were linear over the tested concentration range (from $0.85 \mathrm{mg} / \mathrm{mL}\left(4.48 \times 10^{-3} \mathrm{M}\right.$ ) to $\left.0.0085 \mathrm{mg} / \mathrm{mL}\left(4.48 \times 10^{-5} \mathrm{M}\right)\right)$.

\subsection{Preparation of Unfunctionalized LPS}

Unfunctionalized LPs were made using the dehydration-rehydration method with a slight modification [25]. Briefly, PC/Chol in 7/3 molar ratio were solubilized in a chloroform/methanol $(2 / 1 \mathrm{v} / \mathrm{v})$ mixture and the solvents were removed by a rotary evaporator at $55{ }^{\circ} \mathrm{C}$ until a lipid film was obtained. The film was stored under vacuum for $3 \mathrm{~h}$ to guarantee whole elimination of the organic solvents and then rehydrated in the dark with a DA. $\mathrm{HCl}$ solution in phosphate buffer $\mathrm{pH}=4.5$. To avoid oxidation of $\mathrm{DA} \cdot \mathrm{HCl}$ all subsequent manipulations of the liposomal suspension were carried out in the absence of light. The resulting LPs were sized by sonication (Branson Sonifier 150, Danbury, CT, USA) alternating three cycles of $60 \mathrm{~s}$ each with three cooling cycles of $60 \mathrm{~s}$ in an ice bath. The liposomal suspension was freeze-dried for $24 \mathrm{~h}$ and then subjected to a controlled rehydration process with demineralized water. The un-loaded drug was removed by ultracentrifugation at 45,000 rpm for $50 \mathrm{~min}$ at $4{ }^{\circ} \mathrm{C}$ (Beckman L7-55, Life Science, Boston, MA, USA) and the obtained pellet was suspended in phosphate buffer $\mathrm{pH}=4.5$. Finally, dimension, zeta potential and encapsulation efficiency of the obtained vesicles were determined.

\subsection{Preparation of Tf Functionalized LPS}

The preparation of Tf functionalized LPs was conducted using the procedure described by Paszko et al. [26]. In detail, the initial composition of PC/Chol 7/3 molar ratio was integrated with the $2.5 \mathrm{~mol} \%$ of DSPE-PEG $2000-\mathrm{COOH}$ and LPs were prepared following the procedure described in the previous paragraph.

Then, LPs suspension was incubated for $10 \mathrm{~min}$ at room temperature with S-NHS and EDC, both dissolved in PBS $\mathrm{pH}=4.5$. Finally, $120 \mathrm{mg}$ of $\mathrm{Tf}$ per $\mathrm{mmol}$ of lipid were added and incubated for $12 \mathrm{~h}$ at $4{ }^{\circ} \mathrm{C}$ to allow the formation of an amide bond between the carboxyl and amine groups of PEGylated lipids and Tf, respectively. The unbound Tf was separated from functionalized vesicles by ultracentrifugation at 50,000 rpm for $2 \mathrm{~h}$, at $4{ }^{\circ} \mathrm{C}$ (Beckman L7-55, Life Science, Boston, MA, USA). 
The recovered pellet containing LPs was suspended in PBS $\mathrm{pH}=4.5$ and stored in the dark until further manipulations.

In order to investigate the density of Tf on the LPs surface a BCA assay kit was used, evaluating the percentage of Tf exposed on external LPs surface compared to the total amount of Tf used for the conjugation. The absorbance at $595 \mathrm{~nm}$ was recorded (PerkinElmer 2030 multilabel reader Victor TM X3, Waltham, MA, USA) and the protein concentration was determined by comparison to a standard curve $(0.5$ to $30 \mu \mathrm{g} / \mathrm{mL})$.

\subsection{Physicochemical Characterization of LPS}

For the determination of vesicles dimension and polydispersity index (P.I.) a Zetasizer Nano ZS (Malvern Instrument Ltd., Worcestershire, UK) was used and suspensions were appropriately diluted with demineralized water. The zeta potentials were investigated by laser Doppler velocimetry using the same instrument and diluting all samples with a $1 \mathrm{mM} \mathrm{KCl}$ solution to keep the ionic strength constant [27].

Experiments were performed in triplicate and the results were reported with the corresponding standard deviation.

\subsection{Quantification of $\mathrm{DA} \cdot \mathrm{HCl}$ into $\mathrm{LPS}$}

The quantity of DA. $\mathrm{HCl}$ encapsulated in liposomal vesicles was expressed as the difference between the total quantity solubilized in the LPs medium and the quantity of non-encapsulated $\mathrm{DA} \cdot \mathrm{HCl}$ recovered in the aqueous suspending medium after centrifugation at 45,000 rpm for $50 \mathrm{~min}$ at $4{ }^{\circ} \mathrm{C}$ (Beckman L7-55, Life Science, Boston, MA, USA). DA.HCl content was determined by HPLC using the calibration curve obtained as explained in Section 2.2. Results are expressed as encapsulation efficiency (EE) determined as actual drug loading/theoretical drug loading $\times 100$ [28]. Experiments were performed in triplicate.

\subsection{Freeze-Fracture Electron Microscopy}

A sample of DA-HCl-LPs was examined by transmission electron microscopy after freeze-fracture in the presence of $20 \%$ of glycerol as cryoprotectant. In detail, a drop of liposome dispersion, deposited in a small gold pan, was quickly frozen in liquid nitrogen. A freeze-replica apparatus at $-100{ }^{\circ} \mathrm{C}$ (FR-7000A, Hitachi Science Co., Tokyo, Japan) was used to fracturing the sample and replica was realized by platinum-carbon shadowing and examined with a JEM-1200EX (Japan Electron Co., Tokyo, Japan) transmission electron microscope.

\subsection{In Vitro Release Studies}

$1 \mathrm{~mL}$ of Tf functionalized and unfunctionalized LPs suspension containing DA. $\mathrm{HCl}$ was put into dialysis sacs (cut-off $3000 \mathrm{MW}$ ) and dialyzed against $50 \mathrm{~mL}$ of phosphate buffer $\mathrm{pH}=4.5$ supplemented with $\alpha$-tocopherol $0.005 \mathrm{M}$ to avoid $\mathrm{DA} \cdot \mathrm{HCl}$ oxidation in the release medium. The dialysis was conducted at $37^{\circ} \mathrm{C}$ in a shaker bath, $100 \mu \mathrm{L}$ of external medium were removed at predetermined times interval and analyzed by HPLC for DA. $\mathrm{HCl}$ content, and $100 \mu \mathrm{L}$ of phosphate buffer were added in order to preserve the sink condition. The experiment was conducted on both functionalized and unfunctionalized LPs for at least three times.

\subsection{Stability Studies}

LPs stability was evaluated by measuring size and polydispersity index by means of light scattering for one month, after appropriate dilution with demineralized water. 


\subsection{Culture of hCMEC/D3 Cells and Endothelial Permeability Experiments}

The in vitro model of the BBB, constituted by human cerebral microvascular endothelial cell line hCMEC/D3 was obtained from Dr. PO Couraud, Inserm, Paris, France. Culture of these cells was realized as reported by Lopalco et al. in a previous study. [2]. Briefly, cells at passage numbers between 25 and 30 were cultivated onto polyester Transwell ${ }^{\circledR}$ inserts and grown in supplemented media. Cell barrier integrity was verified prior to perform endothelial permeability experiments by means of trans-endothelial electrical resistance (TEER) using an EndOhm meter. Monolayers of human cerebral microvascular endothelial cells with TEER values between 65 and $89 \mathrm{Ohm} \cdot \mathrm{cm}^{2}$ were used in this study. The transport of Tf functionalized and unfunctionalized DA-LPs was examined at a concentration of $50 \mu \mathrm{g} / \mathrm{mL}$ of DA. $\mathrm{HCl}$ in LPs. The endothelial permeability of the nano-systems was performed as reported by Lopalco et al. [2]. The quantity of $\mathrm{DA} \cdot \mathrm{HCl}$ that had passed through the lipid membrane, constituted by the cell monolayer, was determined using HPLC. In order to determine the apparent permeability values across blank Transwell ${ }^{\circledR}$ inserts, experiments were performed in triplicate without seeding cells in the inserts.

Luciferin yellow transport studies were performed in the same manner explained earlier, except that the sample volumes were $200 \mu \mathrm{L}$. The cumulative quantity of luciferin yellow transported was measured by determining the fluorescence of the samples in phenol red-free DMEM at $\lambda_{\mathrm{ex}}=480 \mathrm{~nm}$ and $\lambda_{\mathrm{em}}=530 \mathrm{~nm}$ using an FLX800 microplate reader (BioTek Instruments, Inc., Winooski, VT, USA) [29]. A Gen5 ${ }^{\mathrm{TM}}$ software (BioTek Instruments, Inc., Winooski, VT, USA) was used for the acquisition of the data. The relative quantity of luciferin yellow per unit of volume of solution in the basal chamber was then determined from calibration standards made by serial dilution of the luciferin yellow.

\subsection{Statistical Analysis}

Statistical evaluation of data has been made using GraphPad Prism version 5.0 (San Diego, CA, USA) and statistical significance $(p<0.05)$ determined using a one-way analysis of variance (ANOVA) followed by the Bonferroni post hoc tests.

\section{Results and Discussion}

\subsection{LPS Characterization}

LPs containing DA. $\mathrm{HCl}$ and functionalized with Tf were prepared, as described, using a modification of the Kirby and Gregoriadis procedure since this method is well known to improve entrapment of water soluble drugs [30]. Tf was conjugated to the carboxyl group of PEG on the LPs PC/Chol/DSPE-PEG-COOH surface to obtain PC/Chol/DSPE-PEG-CO-Tf according to the procedure described in the Section 2.4. Then, the fully characterization in terms of dimension, polydispersity index, zeta potential, drug loading and Tf coupling efficiency was carried out. Results are summarized in Table 1.

Table 1. Particle size \pm SD, polydispersity index (PDI), zeta potential, and percent of encapsulation efficiency (EE\%) of DA.HCl-LPs unfunctionalized and functionalized with Tf.

\begin{tabular}{ccccc}
\hline Formulation & Size $(\mathbf{n m})$ & PDI & Zeta Potential (mV) & (EE\%) \\
\hline unfunctionalized DA·HCl-LPs & $162.4 \pm 3.2$ & 0.20 & $+4.8 \pm 0.9$ & $41.5 \pm 2.9$ \\
Tf functionalized DA·HCl-LPs & $181.7 \pm 7.8$ & 0.20 & $+7.5 \pm 1.2$ & $35.4 \pm 1.8$ \\
\hline
\end{tabular}

As can be seen, there is a difference between Tf functionalized and unfunctionalized LPs in terms of size and $\mathrm{EE} \%$. In particular, unfunctionalized LPs exhibit a mean diameter of $162.4 \pm 3.2 \mathrm{~nm}$ and a $\mathrm{EE} \%$ of $41.5 \pm 2.9 \%$ while for Tf functionalized LPs we found a value of mean diameter equal to $181.7 \pm 7.8$ and a $\mathrm{EE} \%$ of $35.4 \pm 1.8 \%$. This behavior is quite in agreement with data found in literature [20,31], the coupling of Tf or other ligands on the surface of liposomal vesicles leads to a slight increase in size, although the values are not different from the statistical point of view $(p>0.05)$. 
In all cases the PDI was equal to 0.2 and this value indicates the existence of a very uniform liposomal population in terms of dimensional distribution.

The charge on the LPs was found to be positive and small for the two formulations (values in a range from +4.8 to $+7.5 \mathrm{mV}$ ), with a slight increase for Tf functionalized LPs. This behavior could be ascribed to the existence of positive charged functional groups of Tf. Regarding the coupling efficiency of Tf, it was found to be equal to $48.8 \pm 2.6 \%$, compared to the total amount of Tf used for the conjugation.

In order to determine the stability of the obtained liposomal preparations, their size and PDI were evaluated one a week for 1 month, keeping them at $4{ }^{\circ} \mathrm{C}$. Results are shown in Table 2.

Table 2. Particle size \pm SD and PDI vales of DA.HCl-LPs unfunctionalized and functionalized with Transferrin.

\begin{tabular}{ccccccccc}
\hline Formulation & Week & $\mathbf{1}$ & Week & $\mathbf{2}$ & Week & $\mathbf{3}$ & Week & $\mathbf{4}$ \\
\cline { 2 - 7 } & Size $(\mathbf{n m})$ & PDI & Size $(\mathbf{n m})$ & PDI & Size $(\mathbf{n m})$ & PDI & Size (nm) & PDI \\
\hline $\begin{array}{c}\text { unfunctionalized } \\
\text { DA.HCl-LPs } \\
\begin{array}{c}\text { Tf functionalized } \\
\text { DA.HCl-LPs }\end{array}\end{array}$ & $168.4 \pm 2.4$ & 0.20 & $165.4 \pm 1.8$ & 0.25 & $159.4 \pm 3.5$ & 0.19 & $160.7 \pm 1.2$ & 0.21 \\
\hline
\end{tabular}

It is evident that no significant variations in terms of size and PDI are highlighted, so it is possible to state that vesicles are stable and can be used for next studies.

Moreover, after one month we determined by HPLC the DA. $\mathrm{HCl}$ amount in LPs after vesicles disruption with $0.1 \%$ Triton X-100 and filtration with $0.22 \mu \mathrm{m}$ cellulose acetate membrane filter (Millipore ${ }^{\circledR}$, Milan, Italy). It was found equal to $98.2 \%$ of the initial amount with no significant loss due to drug oxidation.

Figure 2 shows the freeze fracture electron micrograph and the size distribution of unfunctionalized DA.HCl-LPs. Freeze fracture electron microscopy is a powerful technique in the characterization of nanosystems such as micelles, quantum dots, unilamellar and multilamellar liposomes, niosomes and drug crystals because it allows to distinguish between bilayer and non- bilayer structure [32]. Moreover, freeze fracture electron microscopy remains a key tool for investigation of bilayer organization, since it allows to determine the multilamellarity of liposomal systems [32]. As can be seen by micrograph, unfunctionalized DA.HCl-LPs appeared as SUV (small unilamellar vesicles), as expected having used sonication to homogenize the size distribution, with no ripples on the surface and a fairly uniform distribution in terms of size, according to what has been seen through DLS analysis.

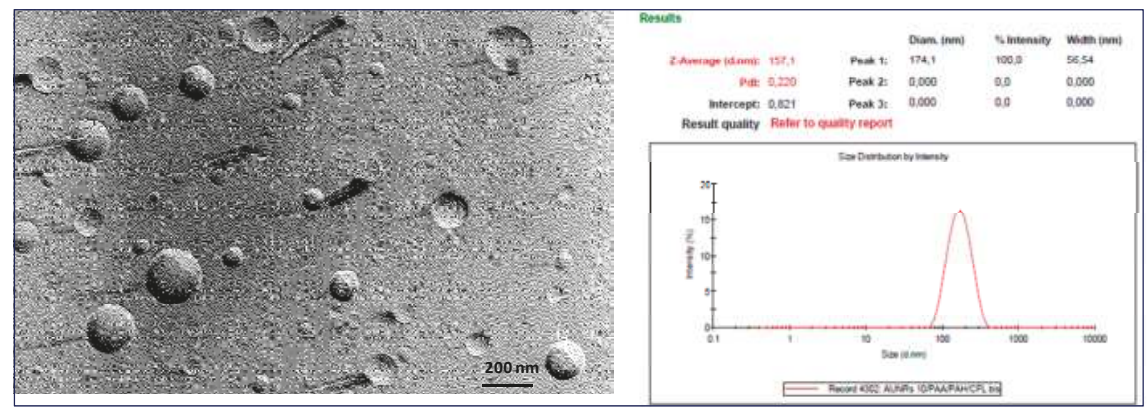

Figure 2. Freeze fracture electron micrograph and size distribution of unfunctionalized DA.HCl-LPs. 


\subsection{In Vitro Release Studies}

In vitro release studies were carried out by dialysis and the obtained cumulative release profiles are reported in Figure 3. The percentage of DA. $\mathrm{HCl}$ released was found to be $59.0 \pm 4.2 \%$ and $68.4 \pm 2.9 \%$ for Tf functionalized and unfunctionalized LPs, respectively, after a period of $24 \mathrm{~h}$, without any burst effect. The lower value found for functionalized LPs can be explained by the presence of Tf bound on the LPs surface which results in a decrease in the liposomal membrane permeability, slowing down drug release. This behavior is perfectly in line with what has been reported in the literature $[20,22]$.

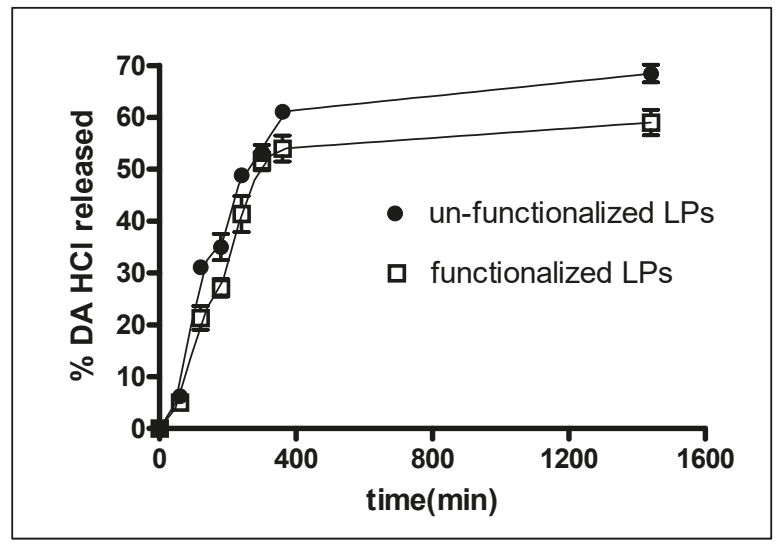

Figure 3. Release profiles of DA. $\mathrm{HCl}$ from LPs. Data are the mean of three determination.

\subsection{In Vitro Transport Analysis}

In vitro transport of formulations across the BBB was investigated using human hCMEC/D3 cell monolayers. The paracellular permeability $\left(\mathrm{P}_{\mathrm{e}}\right)$ of luciferin yellow was evaluated to exclude alterations of the tight junction properties triggered by LPs. In the presence of both functionalized and unfunctionalized LPs the $P_{e}$ value of luciferin yellow was $1.12 \pm 0.18 \times 10^{-3} \mathrm{~cm} / \mathrm{min}$, suggesting no adverse effect on cell monolayer integrity. The data in Table 3 show that the functionalization of LPs with Tf provide a higher permeability across the monolayer compared to unfunctionalized LPs. In detail, the permeability value registered for Tf functionalized DA.HCl-LPs turned out to be equal to $4.97 \pm 0.41 \times 10^{-3} \mathrm{~cm} / \mathrm{min}$ versus $0.92 \pm 0.24 \times 10^{-3} \mathrm{~cm} / \mathrm{min}$ found for unfunctionalized DA.HCl-LPs, with an increase of about 5 fold. The presence of $\mathrm{Tf}$ on the surface of LPs allows vesicles to exploit a mechanism of receptor-mediated endocytosis by means of the Tf receptor which is expressed on the endothelium of the cerebral capillaries (Figure 4). Five steps can describe the mechanism proposed in Figure 4. Initially, LPs decorated with transferrin bind specifically to endothelial receptor (1), resulting in their uptake or endocytosis (2). Intracellularly, LPs are transported in vesicles, that move through the endothelial cytoplasm in apical to basal direction (3), escaping degradation in lysosomes. When the opposing membrane is reached, the vesicle opens towards the basolateral compartment and releases LPs (4). The vesicle with the receptor moves through the endothelial cytoplasm in basal to apical direction $(5)[33,34]$.

Table 3. hCMEC/D3 permeability values $\left(\mathrm{P}_{\mathrm{e}}\right)$ of DA.HCl-LPs, functionalized DA.HCl-LPs and luciferin yellow \pm standard deviation (SD).

\begin{tabular}{cc}
\hline Formulation & $\mathbf{P}_{\mathbf{e}} \pm \mathbf{S D}(\mathbf{c m} / \mathbf{m i n})$ \\
\hline Unfunctionalized DA·HCl-LPs & $0.92 \pm 0.24 \times 10^{-3}$ \\
Tf Functionalized DA.HCl-LPs & $4.97 \pm 0.41 \times 10^{-3}$ \\
Luciferin yellow & $1.12 \pm 0.18 \times 10^{-3}$ \\
\hline
\end{tabular}




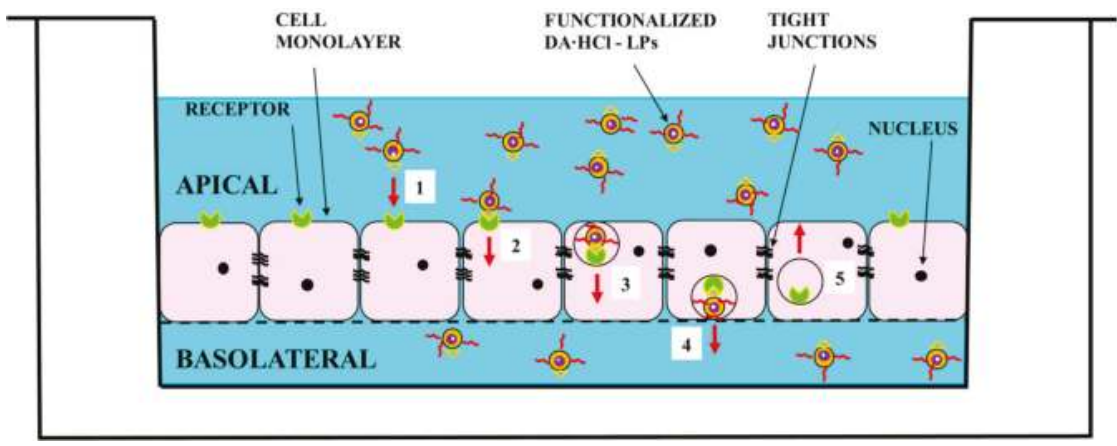

Figure 4. Representation of the endogenous Tf receptor-mediated transcytosis of DA.HCl loaded Tf functionalized LPs across an in vitro model of human BBB composed of hCMEC/D3 cell monolayers.

\section{Conclusions}

The transport of $\mathrm{DA} \cdot \mathrm{HCl}$ across the $\mathrm{BBB}$ represents one of the main missions for the management of Parkinson's disease. The employment of CNS targeted Tf functionalized nanoparticles such as LPs could offer a stratagem to overcome this obstacle. In this work, we have prepared both unfunctionalized and Tf functionalized LPs using a method well known to improve the capturing into the vesicles of hydrophilic drugs. Then, we evaluated their dimension, zeta potential, drug loading, Tf coupling efficiency and drug-release behavior. Finally, the permeability $\left(\mathrm{P}_{\mathrm{e}}\right)$ through a cellular model of BBB was studied, highlighting how these vesicles are able to permeate through the cell membrane by exploiting a receptor-mediated endocytosis mechanism. The absence of cytotoxicity and the validated technique of preparation make LPs appealing candidates for brain delivery, thus improving benefits and decreasing complications to patients subjected to LD chronical treatment.

Acknowledgments: This study was funded by the Inter-University Consortium for Research (C.I.R.C.M.S.B.) and the University of Bari Aldo Moro.

Author Contributions: Annalisa Cutrignelli, Valentino Laquintana and Antonio Lopalco conceived and designed the experiments; Antonio Lopalco performed the experiments; Nunzio Denora analyzed the data; Angela Lopedota and Massimo Franco contributed reagents/materials/analysis tools; Annalisa Cutrignelli and Antonio Lopalco wrote the paper.

Conflicts of Interest: The authors declare no conflict of interest.

\section{References}

1. Spuch, C.; Navarro, C. Liposomes for targeted delivery of active agents against neurodegenerative diseases (Alzheimer's disease and Parkinson's Disease). J. Drug Deliv. 2011, 2011, 469679. [CrossRef] [PubMed]

2. Lopalco, A.; Ali, H.; Denora, N.; Rytting, E. Oxcarbazepine-loaded polymeric nanoparticles: Development and permeability studies across in vitro models of the blood-brain barrier and human placental trophoblast. Int. J. Nanomed. 2015, 10, 1985-1996.

3. Bjorklund, A.; Dunnett, S.B. Dopamine neuron system in the brain: An update. Trends Neurosci. 2007, 30, 194-202. [CrossRef] [PubMed]

4. Denora, N.; Cassano, T.; Laquintana, V.; Lopalco, A.; Trapani, A.; Cimmino, C.S.; Laconca, L.; Giuffrida, A.; Trapani, G. Novel codrugs with GABAergic activity for dopamine delivery in the brain. Int. J. Pharm. 2012, 437, 221-231. [CrossRef] [PubMed]

5. Cassano, T.; Lopalco, A.; de Candia, M.; Laquintana, V.; Lopedota, A.; Cutrignelli, A.; Perrone, M.; Iacobazzi, R.M.; Bedse, G.; Franco, M.; et al. Oxazepam-Dopamine Conjugates Increase Dopamine Delivery into Striatum of Intact Rats. Mol. Pharm. 2017, 14, 3178-3187. [CrossRef] [PubMed]

6. Di Stefano, A.; Sozio, P.; Iannitelli, A.; Cerasa, L.S. New drug delivery strategies for improved Parkinson's disease therapy. Expert Opin. Drug Deliv. 2009, 6, 389-404. [CrossRef] [PubMed] 
7. Laquintana, V.; Denora, N.; Cutrignelli, A.; Perrone, M.; Iacobazzi, R.; Annese, C.; Lopalco, A.; Lopedota, A.; Franco, M. TSPO ligand-methotrexate prodrug conjugates: Design, synthesis, and biological evaluation. Int. J. Mol. Sci. 2016, 17, 967. [CrossRef] [PubMed]

8. Iacobazzi, R.M.; Lopalco, A.; Cutrignelli, A.; Laquintana, V.; Lopedota, A.; Franco, M.; Denora, N. Bridging Pharmaceutical Chemistry with Drug and Nanoparticle Targeting to Investigate the Role of the 18-kDa Translocator Protein TSPO. ChemMedChem 2017, 12, 1261-1274. [CrossRef] [PubMed]

9. Beesu, M.; Caruso, G.; Salyer, A.C.; Shukla, N.M.; Khetani, K.K.; Smith, L.J.; Fox, L.M.; Tanji, H.; Ohto, U.; Shimizu, T.; et al. Identification of a Human Toll-Like Receptor (TLR) 8-Specific Agonist and a Functional Pan-TLR Inhibitor in 2-Aminoimidazoles. J. Med. Chem. 2016, 59, 3311-3330. [CrossRef] [PubMed]

10. Denora, N.; Laquintana, V.; Lopalco, A.; Iacobazzi, R.M.; Lopedota, A.; Cutrignelli, A.; Iacobellis, G.; Annese, C.; Cascione, M.; Leporatti, S.; et al. In vitro targeting and imaging the translocator protein TSPO. J. Control. Release 2013, 172, 1111-1125. [CrossRef] [PubMed]

11. Laquintana, V.; Denora, N.; Lopalco, A.; Lopedota, A.; Cutrignelli, A.; Lasorsa, F.M.; Agostino, G.; Franco, M. Translocator protein ligand-PLGA conjugated nanoparticles for 5-fluorouracil delivery to glioma cancer cells. Mol. Pharm. 2014, 11, 859-871. [CrossRef] [PubMed]

12. Annese, C.; Abbrescia, D.I.; Catucci, L.; D'Accolti, L.; Denora, N.; Fanizza, I.; Fusco, C.; La Piana, G. Site-dependent biological activity of valinomycin analogs bearing derivatizable hydroxyl sites. J. Pept. Sci. 2013, 19, 751-757. [CrossRef] [PubMed]

13. Dawson, T.M.; Dawson, V.L. Molecular pathways of neurodegeneration in Parkinson's disease. Science 2003, 302, 819-822. [CrossRef] [PubMed]

14. Warren Olanow, C. Levodopa/dopamine replacement strategies in Parkinson's disease: Future directions. Mov. Disord. 2008, 23, S613-S622. [CrossRef] [PubMed]

15. Nutt, J.G.; Woodward, W.R. Levodopa pharmacokinetics and pharmacodynamics in fluctuating parkinsonian patients. Neurology 1986, 36, 739-744. [CrossRef] [PubMed]

16. Asanuma, M.; Miyazaki, I.; Ogawa, N. Dopamine- or L-DOPA-induced neurotoxicity: The role of dopamine quinone formation and tyrosinase in a model of Parkinson's disease. Neurotox. Res. 2003, 5, 165-176. [CrossRef] [PubMed]

17. Borah, A.; Mohanakumar, K.P. L-DOPA induced-endogenous 6-hydroxydopamine is the cause of aggravated dopaminergic neurodegeneration in Parkinson's disease patients. Med. Hypothesis 2012, 79, 271-273. [CrossRef] [PubMed]

18. Lopalco, A.; Douglas, J.; Denora, N.; Stella, V. Determination of pKa and hydration constants for a series of $\alpha$-keto-carboxylic acids using nuclear magnetic resonance spectrometry. J. Pharm. Sci. 2016, 105, 664-672. [CrossRef] [PubMed]

19. Leto, I.; Coronnello, M.; Righeschi, C.; Bergonzi, M.C.; Mini, E.; Bilia, A.R. Enhanced efficacy of artemisinin loaded in transferrin-conjugated liposomes versus stealth liposomes against HCT-8 colon cancer cells. ChemMedChem 2016, 11, 1745-1751. [CrossRef] [PubMed]

20. Sonali; Singh, R.P.; Singh, N.; Sharma, G.; Vijayakumar, M.R.; Koch, B.; Singh, S.; Singh, U.; Dash, D.; Pandey, B.L.; et al. Transferrin liposomes of docetaxel for brain-targeted cancer applications: Formulation and brain theranostics. Drug Deliv. 2016, 23, 1261-1271. [CrossRef] [PubMed]

21. Nogueira-Librelotto, D.R.; Codevilla, C.F.; Farooqi, A.; Rolim, C.M.B. Transferrin-Conjugated Nanocarriers as Active-Targeted Drug Delivery Platforms for Cancer Therapy. Curr. Pharm. Des. 2017, 23, 454-466. [CrossRef] [PubMed]

22. Ulbrich, K.; Hekmatara, T.; Herbert, E.; Kreuter, J. Transferrin- and transferrin receptor-antibody-modified nanoparticles enable drug delivery across the blood-brain barrier (BBB). Eur. J. Pharm. Biopharm. 2009, 71, 251-256. [CrossRef] [PubMed]

23. Li, Y.; He, H.; Jia, X.; Lu, W.L.; Lou, J.; Wei, Y. A dual-targeting nanocarrier based on poly(amidoamine) dendrimers conjugated with transferrin and tamoxifen for treating brain gliomas. Biomaterials 2012, 33, 3899-3908. [CrossRef] [PubMed]

24. Lopedota, A.; Trapani, A.; Cutrignelli, A.; Laquintana, V.; Denora, N.; Franco, M.; Trapani, G.; Liso, G. Effect of CDs on physico-chemical and release properties of Eudragit RS 100 microparticles containing glutathione. J. Incl. Phenom. Macrocycl. Chem. 2007, 57, 425-432. [CrossRef] 
25. Cutrignelli, A.; Lopedota, A.; Denora, N.; Laquintana, V.; Tongiani, S.; Franco, M. Characterization and release studies of liposomal gels containing glutathione/cyclodextrins complexes potentially useful for cutaneous administration. J. Pharm. Sci. 2014, 103, 1246-1254. [CrossRef] [PubMed]

26. Pasko, E.; Vaz Gisela, M.F.; Ehrhardt, C.; Senge, M.O. Trasferrin conjugation does not increase the efficiency of liposomal Foscan during in vitro photodynamic therapy of oesophageal cancer. Eur. J. Pharm. Sci. 2013, 48, 202-210. [CrossRef] [PubMed]

27. Denora, N.; Lopedota, A.; Perrone, M.; Laquintana, V.; Iacobazzi, R.M.; Milella, A.; Fanizza, E.; Depalo, N.; Cutrignelli, A.; Lopalco, A.; et al. Spray-dried mucoadhesives for intravesical drug delivery using $\mathrm{N}$-acetylcysteine- and glutathione-glycol chitosan conjugates. Acta Biomater. 2016, 43, 170-184. [CrossRef] [PubMed]

28. Lopedota, A.; Cutrignelli, A.; Laquintana, V.; Denora, N.; Iacobazzi, R.M.; Perrone, M.; Fanizza, E.; Mastrodonato, M.; Mentino, D.; Lopalco, A.; et al. Spray dried chitosan microparticles for intravesical delivery of celecoxib: Preparation and characterization. Pharm. Res. 2016, 33, 2195-2208. [CrossRef] [PubMed]

29. De Campos, R.P.; Siegel, J.M.; Fresta, C.G.; Caruso, G.; Fracassi da Silva, J.A.; Lunte, S.M. Indirect detection of superoxide in RAW 264.7 macrophage cells using microchip electrophoresis coupled to laser induced fluorescence detection. Anal. Bioanal. Chem. 2015, 407, 7003-7012. [CrossRef] [PubMed]

30. Kirby, C.; Gregoriadis, G. Dehydration-Rehydration vesicles: A simple method for high yield drug entrapment in liposomes. Nat. Biotechnol. 1984, 2, 979-984. [CrossRef]

31. Anabousi, S.; Bakowsky, U.; Schneider, M.; Huwer, H.; Lehr, C.M.; Ehrhardt, C. In vitro assessment of transferrin-conjugated liposomes as drug delivery systems for inhalation therapy of lung cancer. Eur. J. Pharm. Sci. 2006, 29, 367-374. [CrossRef] [PubMed]

32. Bibi, S.; Kaur, R.; Henriksen-Lacey, M.; McNeil, S.E.; Wilkhu, J.; Lattmann, E.; Christensen, D.; Mohammed, A.R.; Perrie, Y. Microscopy imaging of liposomes: From coverslips to environmental SEM. Int. J. Pharm. 2011, 417, 138-150. [CrossRef] [PubMed]

33. Erazo-Oliveras, A.; Muthukrishnan, N.; Baker, R.; Wang, T.Y.; Pellois, J.P. Improving the endosomal escape of cell-penetrating peptides and their cargos: Strategies and challenges. Pharmaceuticals 2012, 5, 1177-1209. [CrossRef] [PubMed]

34. Gao, W.; Hu, C.M.J.; Fang, R.H.; Zhang, L. Liposome-like nanostructures for drug delivery. J. Mater. Chem. B 2013, 1, 6569-6589. [CrossRef] [PubMed]

(C) 2018 by the authors. Licensee MDPI, Basel, Switzerland. This article is an open access article distributed under the terms and conditions of the Creative Commons Attribution (CC BY) license (http:/ / creativecommons.org/licenses/by/4.0/). 
Article

\title{
Preparation, Characterization, and Preliminary In Vitro Testing of Nanoceria-Loaded Liposomes
}

\author{
Agostina Grillone ${ }^{1, *}$, Tianshu Li ${ }^{2}$, Matteo Battaglini ${ }^{1,3}$, Alice Scarpellini ${ }^{4}$, Mirko Prato ${ }^{5}$, \\ Shinji Takeoka ${ }^{6}$ and Gianni Ciofani ${ }^{1,7, *}$ \\ 1 Smart Bio-Interfaces, Istituto Italiano di Tecnologia, Viale Rinaldo Piaggio 34, 56025 Pontedera, Italy; \\ matteo.battaglini@iit.it \\ 2 Research Organization for Nano \& Life innovation, Waseda University, 2-2 Wakamatsu-cho, Shinjuku-ku, \\ Tokyo 162-8480, Japan; tianshuli@aoni.waseda.jp \\ 3 The Biorobotics Institute, Scuola Superiore Sant'Anna, Viale Rinaldo Piaggio 34, 56025 Pontedera, Italy \\ 4 Electron Microscopy Facility, Istituto Italiano di Tecnologia, Via Morego 30, 16163 Genova, Italy; \\ alice.scarpellini@iit.it \\ 5 Materials Characterization Facility, Istituto Italiano di Tecnologia, Via Morego 30, 16163 Genova, Italy; \\ mirko.prato@iit.it \\ 6 Department of Life Science and Medical Bioscience, Graduate School of Advanced Science and \\ Engineering (TWIns), Waseda University, 2-2 Wakamatsu-cho, Shinjuku-ku, Tokyo 162-8480, Japan; \\ takeoka@waseda.jp \\ 7 Department of Mechanical and Aerospace Engineering, Politecnico di Torino, Corso Duca degli Abruzzi 24, \\ 10129 Torino, Italy \\ * Correspondence: agostina.grillone@iit.it (A.G.); gianni.ciofani@iit.it (G.C.); \\ Tel.: +39-050-883019 (A.G. \& G.C.)
}

Received: 4 August 2017; Accepted: 14 September 2017; Published: 16 September 2017

\begin{abstract}
Cerium oxide nanoparticles (nanoceria), well known for their pro- and antioxidant features, have been recently proposed for the treatment of several pathologies, including cancer and neurodegenerative diseases. However, interaction between nanoceria and biological molecules such as proteins and lipids, short blood circulation time, and the need of a targeted delivery to desired sites are some aspects that require strong attention for further progresses in the clinical application of these nanoparticles. The aim of this work is the encapsulation of nanoceria into a liposomal formulation in order to improve their therapeutic potentialities. After the preparation through a reverse-phase evaporation method, size, Z-potential, morphology, and loading efficiency of nanoceria-loaded liposomes were investigated. Finally, preliminary in vitro studies were performed to test cell uptake efficiency and preserved antioxidant activity. Nanoceria-loaded liposomes showed a good colloidal stability, an excellent biocompatibility, and strong antioxidant properties due to the unaltered activity of the entrapped nanoceria. With these results, the possibility of exploiting liposomes as carriers for cerium oxide nanoparticles is demonstrated here for the first time, thus opening exciting new opportunities for in vivo applications.
\end{abstract}

Keywords: cerium oxide nanoparticles; liposomes; drug delivery

\section{Introduction}

In cerium oxide, Ce owns the peculiar ability to easily switch between two oxidation states, $\mathrm{Ce}^{3+}$ and $\mathrm{Ce}^{4+}$, through the loss of electrons and/or oxygen, thus giving origin to crystalline defects or vacancies on the surface of the material [1]. At a nanoscale level, due to the higher surface/volume ratio, this phenomenon is more evident, thus making cerium oxide nanoparticles (nanoceria) more reactive with respect to the bulk material. The discovery of the excellent catalytic activities of nanoceria and their ability to act as free radicals scavengers have opened new perspectives in the biomedical 
fields and, more specifically, in all those scenarios where oxidative stress plays a crucial role in the pathogenesis of diseases [2]. Previous studies have shown that nanoceria are able to neutralize reactive oxygen species (ROS), including superoxide anions, peroxide radicals, and hydroxyl radicals, by mimicking the activity of enzymes involved in antioxidant defenses such as superoxide dismutase and catalase [3]. The biological activities of cerium oxide nanoparticles were assessed in vitro on several cell culture models such as cardiac [4], neuronal [5], and stem cells [6]; in vivo, nanoceria showed strong antioxidant properties by decreasing both nitric oxide and peroxynitrite formation in a murine model of ischemic cardiomyopathy [7], and they slowed down the progression of retinal degeneration in mouse and rat models $[8,9]$, promoted the regression of retinal vascular lesions in mice [10], and inhibited weight gain in rats [11].

Another peculiar feature of cerium oxide nanoparticles is their ability to act as a pro-oxidant agent at acidic $\mathrm{pH}$ values [12]. Several research groups reported that, where tumor microenvironment is acidic, nanoceria triggers ROS accumulation [12], possess cytotoxic and anti-invasive properties [13,14], and sensitize cells to radiotherapy [15]. Anticancer activity of nanoceria was studied in vitro for the treatment of breast, pancreas, ovarian, lung, and colon cancer cells [15-17].

Despite the significant promises of nanoceria, several challenges still need to be addressed before a translational exploitation into clinical practice. First of all, nanoceria dispersions are often unstable in aqueous solutions and in high ionic media, quickly precipitating and forming aggregates that hinder their in vivo administration [18] or at least that heavily affect their transport and biodistribution [19]. The interaction of nanoparticles with proteins moreover triggers recognition by phagocytic cells, thus inducing retention in the reticuloendothelial system (mainly in the spleen and in the liver), with a consequent reduction of blood circulation half-life [20]. Additionally, proteins adsorbed on the surface of nanoceria may also modify their surface chemistry and thus their physicochemical properties, in addition to the hydrodynamic size and the surface charge that determine cellular uptake and subcellular localization [21-23].

The goal of this study is the investigation of the possibility of exploiting the advantages of a liposomal drug delivery system in order to increase the therapeutic index of nanoceria. Liposomes are promising vectors that allow for the incorporation of hydrophilic and hydrophobic drugs due to their amphiphilic nature and vescicular structure [24]. Liposomes composed of phospholipids are biocompatible and biodegradable, with a diameter in the range of 50-200 $\mathrm{nm}$, and they generally do not undergo a rapid systemic clearance [24]. Surface modifications by means of polymeric chains as polyethylene glycol (PEG), in fact, provide a stealth layer that reduces their uptake by the immune system, thus prolonging the persistence of the liposomes in the blood circulation [24]. In addition, the use of liposomes can promote a selective delivery of the payload into targeted cells/tissues upon the functionalization of their surface with antibodies, antigens, or small molecules capable of binding specific receptors on the cell membrane $[25,26]$. Furthermore, such a targeting strategy can be also exploited for the crossing of biological barriers, thus allowing compartments otherwise inaccessible, such as the central nervous system, to be reached [27].

In this work, nanoceria-loaded liposomes were prepared through a reverse-phase evaporation method, extruded with membrane filters, and finally purified with gel permeation chromatography. Obtained hybrid nanovectors were extensively investigated in terms of lipid concentration, size distribution, Z-potential, morphology, and loading efficiency. Finally, preliminary in vitro studies have been carried out on normal human dermal fibroblasts to investigate biocompatibility and unaltered antioxidant activity of the entrapped nanoceria.

\section{Results}

\subsection{Characterization of Liposomes}

Empty liposomes and nanoceria-loaded liposomes were prepared by a reverse-phase evaporation method in order to obtain a high loading amount of nanoceria. Size and Z-potential were assessed 
before biological testing, and obtained results are summarized in Table 1. Free nanoceria present an average diameter of $12 \pm 1 \mathrm{~nm}$ and a Z-potential of $32.0 \pm 3.8 \mathrm{mV}$. Empty liposomes and nanoceria-loaded liposomes have a hydrodynamic size of about $165 \pm 42 \mathrm{~nm}$ and $230 \pm 10 \mathrm{~nm}$, respectively. As expected, analyses revealed a negative Z-potential of $-41.0 \pm 11.2 \mathrm{mV}$ for empty liposomes because of the presence of the anionic lipid (1,5-dihexadecyl- $N$-succinyl-L-glutamate, DHSG), while nanoceria-loaded liposomes present a positive surface charge of $30.8 \pm 0.4 \mathrm{mV}$ deriving from the adsorption of cerium oxide nanoparticles on the surface of negatively charged liposomes. Values obtained from inductively coupled plasma mass spectroscopy (ICP-MS) revealed $6 \mathrm{mg} / \mathrm{mL}$ of complexed nanoceria for a dispersion of $9 \mathrm{mg} / \mathrm{mL}$ of nanoceria-loaded liposomes, highlighting a loading efficiency of $12 \%$. The samples were found stable for many weeks since the preparation, resulting into a variation of the hydrodynamic size $<15 \%$ after one month of storage.

Morphology of the samples was confirmed by transmission electron microscopy (TEM) images. Figure 1a shows the monodispersed cerium oxide nanoparticles used in this work, while Figure 1b highlights the formation of well-defined spherical liposomes, and suggests the presence of cerium oxide nanoparticles complexed to the liposomes, both inside the lipid vesicles and on their surface, as also confirmed by the increment of the Z-potential.

The analysis of the total antioxidant capacity (TAC) of nanoceria-loaded liposomes and empty liposomes was assessed and expressed in terms of Trolox equivalents, a water-soluble vitamin E analog that serves as an antioxidant standard [28]. The TAC of $7 \mu \mathrm{g}$ of nanoceria-loaded liposomes was found significantly higher $\left(6.14 \pm 0.34 \mathrm{nmol} ;{ }^{*} p<0.05\right)$ with respect to the negligible effect of the same quantity of empty liposomes $(0.09 \pm 0.03 \mathrm{nmol})$, showing strong retained efficiency of the encapsulated nanoceria.

Table 1. Characterization of nanoceria, liposomes, and nanoceria-loaded liposomes dispersions.

\begin{tabular}{cccc}
\hline Sample & Size $(\mathbf{n m})$ & Polydispersity Index & Z-Potential $(\mathbf{m V})$ \\
\hline Nanoceria & $12 \pm 1$ & $0.156 \pm 0.010$ & $32.0 \pm 3.8$ \\
Empty liposomes & $165 \pm 42$ & $0.147 \pm 0.006$ & $-41.0 \pm 11.2$ \\
Nanoceria-loaded liposomes & $230 \pm 10$ & $0.263 \pm 0.023$ & $30.8 \pm 0.4$ \\
\hline
\end{tabular}

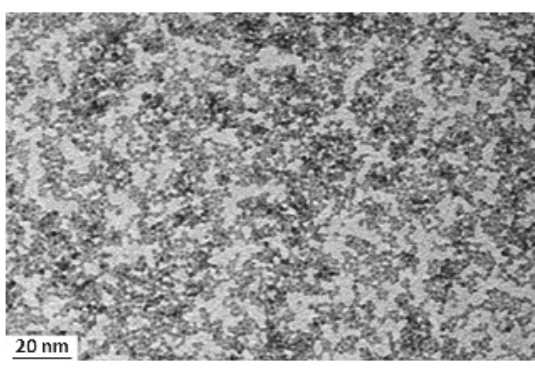

(a)

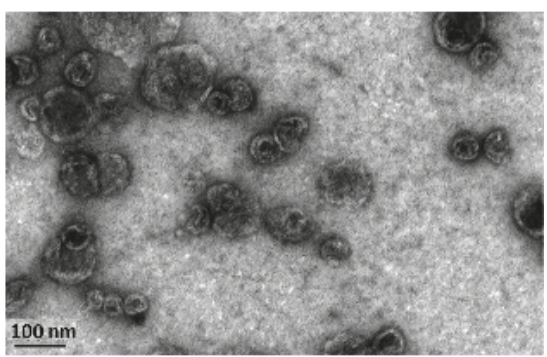

(b)

Figure 1. TEM imaging of free nanoceria (a) and of nanoceria-loaded liposomes (b).

\subsection{In Vitro Studies}

Biocompatibility of empty liposomes and of nanoceria-loaded liposomes was investigated on normal human dermal fibroblast (NHDF) cell line by a PicoGreen assay. As shown in Figure 2a, results indicate good cytocompatibility for all the samples up to a concentration of $200 \mu \mathrm{g} / \mathrm{mL}$ and after $48 \mathrm{~h}$ of treatment. No significant variation of fluorescence intensity, and therefore of number of cells in the samples, was in fact detected in the different cultures, thus demonstrating no cytotoxic effects of all of the formulations. 
Confocal microscopy was instead used to verify the cellular uptake of nanoceria-loaded liposomes, and Figure $2 \mathrm{~b}$ clearly shows strong internalization by NHDF cells after $48 \mathrm{~h}$ of incubation, with a strong accumulation of nanoceria-loaded liposomes (in red) in the perinuclear area of the cells (cell membranes stained in green, nuclei in blue).

To demonstrate unaltered antioxidant activity of entrapped nanoceria, reactive oxygen species (ROS) formation was assessed. NHDF cells were stimulated with $1 \mathrm{mM} \mathrm{H}_{2} \mathrm{O}_{2}$ for the intracellular generation of ROS, after a pre-incubation with increasing concentrations of nanoceria-loaded liposomes and empty liposomes as a control. Figure 3 shows that the treatment for $45 \mathrm{~min}$ with $1 \mathrm{mM} \mathrm{H}_{2} \mathrm{O}_{2}$ induced an increase in the ROS production of about $56 \%$ with respect to non-treated cells, which was hindered by the pre-incubation with nanoceria-loaded liposomes in a dose-dependent manner. This demonstrates a maintained antioxidant activity of cerium oxide nanoparticles encapsulated in the liposomes.

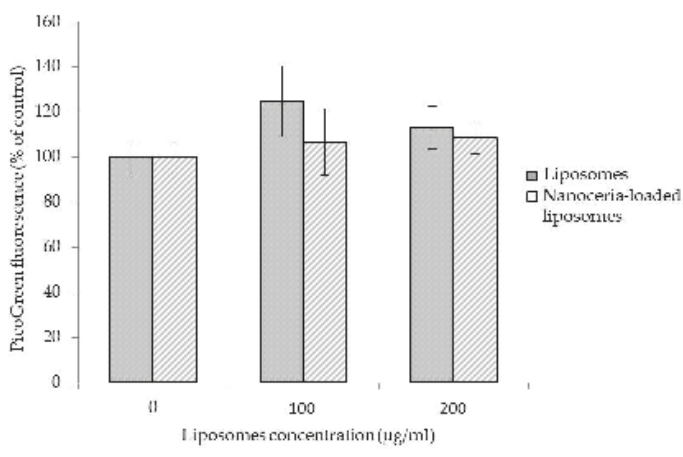

(a)

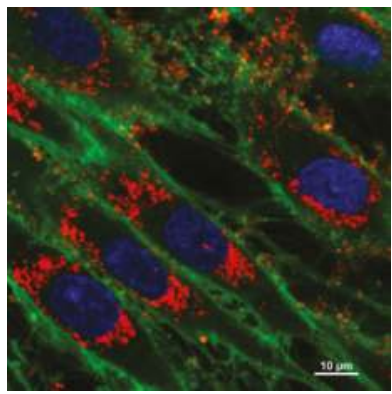

(b)

Figure 2. PicoGreen assay on NHDF cells after $48 \mathrm{~h}$ of incubation with increasing concentrations of empty liposomes and nanoceria-loaded liposomes (a); confocal image showing nanoceria-loaded liposomes (in red) up-taken by NHDF cells after $48 \mathrm{~h}$ of incubation; nanoceria-loaded liposomes are stained in red, cell membranes in green, and nuclei in blue (b).

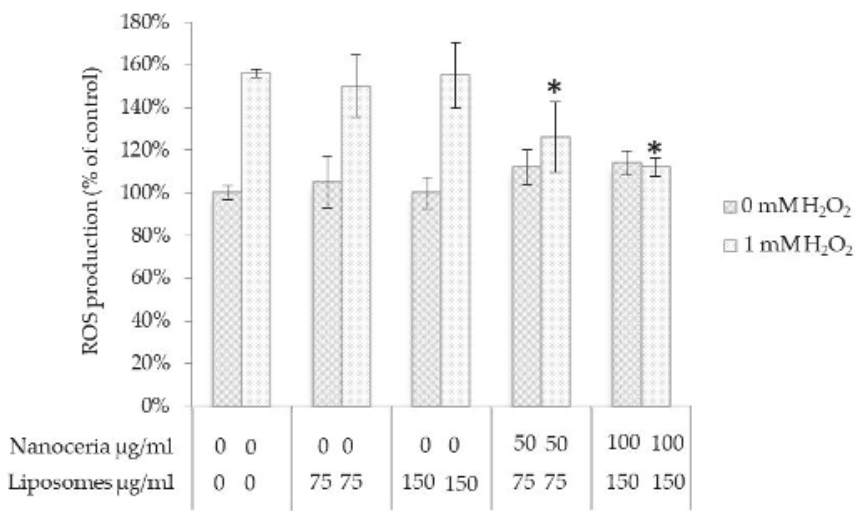

Figure 3. Quantitative evaluation of reactive oxygen species levels in NHDF cells treated with empty liposomes and nanoceria-loaded liposomes, with and without $\mathrm{H}_{2} \mathrm{O}_{2}$ pro-oxidant insult; ${ }^{*} p<0.05$. 


\section{Discussion}

The excessive and non-balanced production of free radicals, a process known as oxidative stress, can damage various cell components such as proteins, lipids, and DNA, causing many different diseases [29]. Neurodegenerative disorders, cancer, atherosclerosis, hypertensions, autoimmune diseases, diabetes, and obesity are just some of the pathological conditions associated with oxidative stress [30].

A way to restore the cell redox status could be the use of cerium oxide nanoparticles, the ability of which, as ROS scavengers, has been demonstrated by countless studies in the literature [31,32]. However, though efforts have been made to improve the stability and the biodistribution of nanoceria in vivo through polymeric coatings or surface modifications with ligand moieties, to date only one work reports the use of drug delivery systems as a multi-stage strategy for increasing the therapeutic potential of nanoceria [33]. In this research, the authors obtained cerium oxide nanoparticles encapsulation in poly(lactide-co-glycolide) microspheres, without however confirming the ROS scavenging activity of entrapped nanoceria in vitro [33].

As a similar approach, our objective was focused on the investigation of a strategy to load nanoceria into a drug delivery platform, namely, liposomes, that traditionally gained considerable interest in nanomedicine because of many advantageous features. Their high biocompatibility, the possibility of controlling their physicochemical properties, their ability to entrap molecules in both an aqueous core and a lipid bilayer, and, most importantly, the specific targeting to a desired site through an appropriate surface functionalization are only some of the properties that make liposomes an efficient drug carrier [34].

Most of the studies about the encapsulation of small inorganic nanoparticles in liposomes concern quantum dots [35], silica nanoparticles [35], and magnetic nanoparticles [36]. Extensively studied, megnetoliposomes are an interesting example of a multifunctional liposomes/nanoparticles hybrid platform, and they can be exploited as contrast agents in magnetic resonance imaging, for magnetically guided targeting delivery, or for generating heat when exposed to an alternating magnetic field [37].

A study of interaction between liposomes and nanoceria has been approached by Liu et al., who exploited phosphocoline-based liposomes as a model of the cell membrane, but focusing their investigations only on the interaction between nanoceria and biological membranes [38].

In the present work, we demonstrate for the first time that nanoceria can be encapsulated inside liposomes preserving their antioxidant activities. The final lipid composition has been the result of an extensive procedure of optimization, which took into account the stability of the preparation, the encapsulation yield, and the biocompatibility of the nanovectors. Particular attention has also been dedicated to the ease of purification of the final products. The presented formulation was an optimal compromise among all these considered factors.

Thus, nanoceria-loaded liposomes, well-tolerated by fibroblasts, can be extensively internalized by the cells and preserved strong antioxidant activities. The proposed strategy is therefore extremely promising for improving the biodistribution and the in vivo targeting: the encapsulation into liposomes could in fact protect nanoceria by the surface absorption of blood proteins that can affect the interaction with cells, while at the same time protecting the surface chemistry of the nanoparticles and therefore their catalytic activities. Moreover, the PEGylation of the liposome surface and their stability deriving from favorable electrostatic interactions could represent an advantage in overcoming the fast clearance from the blood circulation, by shielding liposomes from immunoglobulins and proteins of the complement system, which act as signals for recognition by the mononuclear phagocytic system. Liposomal lipids could also be used for several strategies of functionalization with targeting moieties, thus avoiding a direct link of ligands on the nanoparticle surface that could hinder their catalytic activities while, at the same time, enabling the targeting and crossing of biological barriers, such as the blood-brain barrier, which represents the major obstacle of nanoceria delivery to the central nervous system. Finally, the capacity of nanocarriers such as liposomes to act as multi-functional vectors for the delivery of multiple cargos offers an interesting stimulus for alternative therapeutic 
strategies. As an example, co-encapsulation of nanoceria and imaging contrast enhancers such as magnetic nanoparticles could make the liposomes an actual theranostic nanoplatform suitable in all those scenarios where nanoceria can play an important medical action.

\section{Materials and Methods}

\subsection{Preparation of Lipid Mixture and Liposomes}

For the liposome preparation, a lipid anionic mixture of 1,2-dipalmitoyl-sn-glycero-3-phosphocholine (DPPC), cholesterol, 1,5-dihexadecyl-N-succinyl-L-glutamate (DHSG), and 1,2-distearoylsn-glycero-3phosphoethanolamine- $N$-[monomethoxy poly(ethylene glycol) (5000)] (PEG-DSPE) at a molar ratio of 5:5:1:0.03 was used. DPPC and cholesterol were purchased from Nippon Fine Chemicals (Osaka, Japan), PEG-DSPE from NOF Corporation (Tokyo, Japan), and DHSG was in-house synthesized in laboratory $[39,40]$.

A mixture was prepared by dissolving those lipid components (total $100 \mathrm{mg}$ ) in $t$-butylalcohol $(20 \mathrm{~mL})$; the mixed solution was then freeze-dried overnight, and powder was then used for liposome preparation.

Nanoceria-loaded liposomes were prepared by a reverse-phase evaporation method. More specifically, $10 \mathrm{mg}$ of mixed lipid powder was dissolved in ethanol, and $50 \mathrm{mg}$ of nanoceria was then added $\left(47,232\right.$ from Alfa Aesar, Ward Hill, MA, USA), presenting a $\mathrm{Ce}^{3+} / \mathrm{Ce}^{4+}$ ratio of $\sim 1.6$, please see characterization reported in Figure S1, Supplementary Materials). After the solvent at $40{ }^{\circ} \mathrm{C}$ was removed by rotary evaporation under reduced pressure, the obtained dried lipid-nanoceria mixed film was hydrated and dispersed in $1 \mathrm{~mL}$ of water at room temperature for $3 \mathrm{~h}$ through stirring.

The liposome dispersion thereafter underwent two extrusion cycles through polycarbonate filters of a $200 \mathrm{~nm}$ pore size (Whatman ${ }^{\circledR}$ Nuclepore ${ }^{\mathrm{TM}}$ Track-Etched Membranes, Maidstone, UK). In order to separate un-loaded nanoceria from the liposome dispersion, suspension was purified through gel permeation chromatography using a Sephadex G-100 column and deionized water as eluent.

Each fraction containing liposomes was collected and analyzed in terms of size, Z-potential, nanoceria content, and lipid concentration. The same procedure was used for empty liposomes preparation, without nanoceria addition. Lipid concentration of the liposomes was calculated from the concentration of cholesterol using a cholesterol assessment kit (Abcam, Cambridge, UK) according to the manufacturer's instruction.

\subsection{Liposomes Characterization}

Particle size distribution and Z-potential of nanoceria, empty liposomes, and nanoceria-loaded liposomes were investigated with a Nano Z-Sizer (Malvern Instrument, Malvern, UK). For both analyses, each measurement was performed three times. Nanoceria content was calculated by means of elemental analysis performed through inductively coupled plasma mass spectroscopy (ICP-MS, Thermo Scientific, Waltham, MA) analysis, and the obtained value was used to determine the encapsulation efficiency through the following equation:

$$
\% \mathrm{EE}=[(\text { nanoparticles added }- \text { free nanoparticles }) / \text { nanoparticles added }] \times 100,
$$

Transmission electron microscopy (TEM) was performed in order to analyze sample morphology. For negative staining, $10 \mu \mathrm{L}$ of the nanoceria-loaded liposomes dispersion or of free nanoceria solution was placed on carbon-coated 200 mesh copper grids for $5 \mathrm{~min}$ and then stained with a $1 \%$ uranyl acetate solution. Thereafter, grids were washed three times with water to remove the excess of staining and allowed to air-dry. Transmission electron microscopy of the samples was performed using a JEOL JEM-1011 microscope (JEOL Ltd., Tokyo, Japan) equipped with a tungsten thermionic gun operating at a $100 \mathrm{kV}$ accelerating voltage. TEM images were acquired with a $11 \mathrm{Mp}$ Orius $1000 \mathrm{CCD}$ camera (Gatan, Pleasanton, CA, USA). 
The antioxidant efficiency of nanoceria-loaded liposomes was evaluated through a specific assay (the Total Antioxidant Capacity Assay Kit, Sigma, Saint Louise, MO, USA) that allows for the determination of the antioxidant capacity of a substance in terms of Trolox equivalents. Trolox is a water-soluble vitamin E analog [28] and was used as a standard antioxidant in order to obtain a calibration curve following the manufacturer's instruction. $\mathrm{A} \mathrm{Cu}^{2+}$ working solution was added to dispersions of empty liposomes, nanoceria-loaded liposomes (in both cases corresponding to an amount of $7 \mu \mathrm{g}$ of nanovectors), and to all the Trolox standard samples. In the presence of antioxidants, $\mathrm{Cu}^{2+}$ ions are converted to $\mathrm{Cu}^{+}$ions, which react with a colorimetric probe giving an absorbance peak at $570 \mathrm{~nm}$. This peak, assessed after $90 \mathrm{~min}$ of incubation through a microplate reader (Victor3, PerkinElmer, Waltham, MA, USA), is proportional to the total antioxidant capacity.

\subsection{Cell Cultures}

The normal human dermal fibroblast (NHDF) cell line was purchased from Lonza (Basel, Switzerland) and cultured in Dulbecco's Modified Eagle's Medium (DMEM) supplemented with $10 \%$ fetal bovine serum (FBS) and 1\% penicillin-streptomycin. Cells were grown at $37{ }^{\circ} \mathrm{C}$ in an atmosphere containing $5 \% \mathrm{CO}_{2}$ and passaged by trypsinization with $0.5 \%$ trypsin/ ethylenediaminetetraacetic (EDTA).

\subsection{Cytotoxicity of Nanoceria-Loaded Liposomes and Empty Liposomes}

The biocompatibility of nanoceria-loaded liposomes and empty liposomes was tested in terms of cell proliferation by the Quant-IT ${ }^{\mathrm{TM}}$ PicoGreen ${ }^{\circledR}$ dsDNA assay (Molecular Probes, Eugene, OR, USA), enabling cell number quantification upon evaluation of nucleic acids concentration. Cells were seeded at a density of $6 \times 10^{3}$ cells $/ \mathrm{cm}^{2}$ in 24 -well plates and incubated for $24 \mathrm{~h}$ at $37{ }^{\circ} \mathrm{C}$ and $5 \% \mathrm{CO}_{2}$. The medium was then replaced with fresh medium containing empty liposomes or nanoceria-loaded liposomes with different concentrations $(0,100$, and $200 \mu \mathrm{g} / \mathrm{mL})$. After $48 \mathrm{~h}$ since the beginning of the treatment, cells were lysed and incubated with the appropriate reagents according the manufacturer's instructions. Finally, fluorescence was measured in 96-well black plates through a microplate reader (Victor3, PerkinElmer, Waltham, MA; excitation 485 nm, emission $535 \mathrm{~nm}$ ).

\subsection{Cellular Uptake Investigation}

Internalization of nanoceria-loaded liposomes into NHDF cells was investigated by confocal microscopy. Cells were seeded at a density of $3 \times 10^{3}$ cell $/ \mathrm{cm}^{2}$ in Ibidi $\mu$-Dishes ( $35 \mathrm{~mm}$, Ibidi) and after $24 \mathrm{~h}$ they were treated with nanoceria-loaded liposomes at a concentration of $100 \mu \mathrm{g} / \mathrm{mL}$ for $48 \mathrm{~h}$. The liposomes were previously stained with a lipophilic red-fluorescent dye (1:200 dilution, Dil, Molecular Probes, Eugene, OR). Finally, cells were rinsed with PBS and treated for 10 min with CellMask, a green-fluorescent dye for labeling cell membranes (1:1000 dilution, Invitrogen, Carlsbad, CA, USA), and with Hoechst 33342 (5 $\mu \mathrm{g} / \mathrm{mL}$, Invitrogen) for nucleus counterstaining. A confocal microscope (C2s, Nikon, Tokyo, Japan) was therefore used for the acquisition of the images.

\subsection{Intracellular Antioxidant Activity Evaluation}

In order to investigate the antioxidant activity of nanoceria-loaded liposomes, $2^{\prime}, 7^{\prime}$ dichlorodihydrofluorescein diacetate $\left(\mathrm{H}_{2}\right.$ DCF-DA) Cellular Reactive Oxygen Species Detection Assay Kit (Life Technologies) was used. $\mathrm{H}_{2}$ DCF-DA is a fluorogenic dye that is able to diffuse through cell membrane and to intracellularly interact with hydroxyl, peroxyl, and other ROS. More specifically, after its cell internalization, $\mathrm{H}_{2}$ DCF-DA is deacetylated by cellular esterases to a non-fluorescent compound, which is later oxidized by ROS into $2^{\prime}, 7^{\prime}$-dichlorofluorescein (DCF), a fluorescent compound that thus becomes a direct indicator of the intracellular ROS levels. NHDF cells were seeded in a 24-well plate at a density of $6 \times 10^{3}$ cell $/ \mathrm{cm}^{2}$, incubated for $24 \mathrm{~h}$, and then treated for $48 \mathrm{~h}$ with dispersions of empty liposomes or nanoceria-loaded liposomes at different concentrations $(0,75$, and $150 \mu \mathrm{g} / \mathrm{mL})$, respectively containing 0,50 , and $100 \mu \mathrm{g} / \mathrm{mL}$ of nanoceria. In order to induce 
intracellular ROS accumulation, cells were treated with $1 \mathrm{mM} \mathrm{H}_{2} \mathrm{O}_{2}$ for $45 \mathrm{~min}$ at $37^{\circ} \mathrm{C}$ in a complete medium, and finally incubated with $100 \mu \mathrm{M} \mathrm{H} \mathrm{H}_{2}$ DCF-DA in a serum-free medium at $37{ }^{\circ} \mathrm{C}$ in the dark for $30 \mathrm{~min}$. After cell lysis through three freezing/thawing cycles, fluorescence was quantified with a microplate reader (Victor3, Perkin Elmer, Waltham, MA; excitation $485 \mathrm{~nm}$, emission $535 \mathrm{~nm}$ ).

\subsection{Statistical Analyses}

Data were analyzed with one-way ANOVA followed by Bonferroni's post hoc test or two-tailed unpaired $t$-test through KaleidaGraph (Synergy Software). In all experiments, performed in triplicate, data with a $p$-value $<0.05$ were considered statistically significant.

\section{Conclusions}

Liposomes were demonstrated to be an excellent platform for nanoceria encapsulation without altering antioxidant properties of the nanoparticles. Nanoceria-loaded liposomes showed good biocompatibility, a regular spherical shape, nanometric size, and preserved antioxidant activity in vitro. Further investigations will be needed in order to modify the liposome surface with appropriate ligands for a targeted delivery. The encapsulation of nanoceria into a liposomal drug delivery system could improve the pharmacokinetic profile of nanoceria in vivo and represents a stimulus for new strategies of nanotechnology-based therapies.

Supplementary Materials: The following are available online at http:/ www.mdpi.com/2079-4991/7/9/276/s1, Figure S1: XPS analysis of free nanoceria.

Author Contributions: Agostina Grillone and Tianshu Li designed and performed experiments; Matteo Battaglini, Alice Scarpellini and Mirko Prato contributed to the analysis tools; Shinji Takeoka and Gianni Ciofani conceived experiments and wrote the paper.

Conflicts of Interest: The authors declare no conflict of interest.

\section{References}

1. Das, S.; Dowding, J.M.; Klump, K.E.; Mcginnis, J.F.; Self, W.; Seal, S. Cerium oxide nanoparticles: Applications and prospects in nanomedicine. Nanomedicine 2013, 8, 1483-1508. [CrossRef] [PubMed]

2. Karakoti, A.; Singh, S.; Dowding, J.M.; Seal, S.; Self, W.T. Redox-active radical scavenging nanomaterials. Chem. Soc. Rev. 2010, 39, 4422-4432. [CrossRef] [PubMed]

3. Celardo, I.; Pedersen, J.Z.; Traversa, E.; Ghibelli, L. Pharmacological potential of cerium oxide nanoparticles. Nanoscale 2011, 3, 1411-1420. [CrossRef] [PubMed]

4. Niu, J.; Wang, K.; Kolattukudy, P.E. Cerium oxide nanoparticles inhibits oxidative stress and nuclear factor- $\mathrm{kB}$ Activation in $\mathrm{H} 9 \mathrm{c} 2$ cardiomyocytes exposed to cigarette smoke extract. Pharmacology 2011, 338, 53-61. [CrossRef]

5. Schubert, D.; Dargusch, R.; Raitano, J.; Chan, S.W. Cerium and yttrium oxide nanoparticles are neuroprotective. Biochem. Biophys. Res. Commun. 2006, 342, 86-91. [CrossRef] [PubMed]

6. Pagliari, F.; Mandoli, C.; Forte, G.; Magnani, E.; Pagliari, S.; Nardone, G.; Licoccia, S.; Minieri, M.; Di Nardo, P.; Traversa, E. Cerium oxide nanoparticles protect cardiac progenitor cells from oxidative stress. ACS Nano 2012, 6, 3767-3775. [CrossRef] [PubMed]

7. Niu, J.; Azfer, A.; Rogers, L.M.; Wang, X.; Kolattukudy, P.E. Cardioprotective effects of cerium oxide nanoparticles in a transgenic murine model of cardiomyopathy. Cardiovasc. Res. 2007, 73, 549-559. [CrossRef] [PubMed]

8. Kong, L.; Cai, X.; Zhou, X.; Wong, L.L.; Karakoti, A.S.; Seal, S.; McGinnis, J.F. Nanoceria extend photoreceptor cell lifespan in tubby mice by modulation of apoptosis/survival signaling pathways. Neurobiol. Dis. 2011, 42, 514-523. [CrossRef] [PubMed]

9. Chen, J.; Patil, S.; Seal, S.; McGinnis, J.F. Rare earth nanoparticles prevent retinal degeneration induced by intracellular peroxides. Nat. Nanotechnol. 2006, 1, 142-150. [CrossRef] [PubMed] 
10. Zhou, X.; Wong, L.L.; Karakoti, A.S.; Seal, S.; McGinnis, J.F. Nanoceria inhibit the development and promote the regression of pathologic retinal neovascularization in the Vldlr knockout mouse. PLoS ONE 2011, 6. [CrossRef] [PubMed]

11. Rocca, A.; Moscato, S.; Ronca, F.; Nitti, S.; Mattoli, V.; Giorgi, M.; Ciofani, G. Pilot in vivo investigation of cerium oxide nanoparticles as a novel anti-obesity pharmaceutical formulation. Nanomed. NBM 2015, 11, 1725-1734. [CrossRef] [PubMed]

12. Wason, M.S.; Zhao, J. Cerium oxide nanoparticles: Potential applications for cancer and other diseases. Am. J. Transl. Res. 2013, 5, 126-131. [PubMed]

13. Alili, L.; Sack, M.; Karakoti, A.S.; Teuber, S.; Puschmann, K.; Hirst, S.M.; Reilly, C.M.; Zanger, K.; Stahl, W.; Das, S.; et al. Combined cytotoxic and anti-invasive properties of redox-active nanoparticles in tumor-stroma interactions. Biomaterials 2011, 32, 2918-2929. [CrossRef] [PubMed]

14. Alili, L.; Sack, M.; von Montfort, C.; Giri, S.; Das, S.; Carroll, K.S.; Zanger, K.; Seal, S.; Brenneisen, P. Downregulation of tumor growth and invasion by redox-active nanoparticles. Antioxid. Redox Signal. 2013, 19, 765-778. [CrossRef] [PubMed]

15. Wason, M.S.; Colon, J.; Das, S.; Seal, S.; Turkson, J.; Zhao, J.; Baker, C.H. Sensitization of pancreatic cancer cells to radiation by cerium oxide nanoparticle-induced ROS production. Nanomed. NBM 2013, 9, 558-569. [CrossRef] [PubMed]

16. Asati, A.; Santra, S.; Kaittanis, C.; Perez, J.M.; Florida, O. Surface-charge-dependent cell localization and cytotoxicity of cerium oxide nanoparticles. Technology 2010, 32826, 5321-5331. [CrossRef] [PubMed]

17. Lin, W.; Huang, Y.-W.; Zhou, X.-D.; Ma, Y. Toxicity of cerium oxide nanoparticles in human lung cancer cells. Int. J. Toxicol. 2006, 25, 451-457. [CrossRef] [PubMed]

18. Nanda, H.S. Surface modification of promising cerium oxide nanoparticles for nanomedicine applications. RSC Adv. 2016, 6, 111889-111894. [CrossRef]

19. Yokel, R.A.; Hussain, S.; Garantziotis, S.; Demokritou, P.; Castranova, V.; Cassee, F.R. The yin: An adverse health perspective of nanoceria: Uptake, distribution, accumulation, and mechanisms of its toxicity. Environ. Sci. Nano 2014, 1, 406-428. [CrossRef] [PubMed]

20. Wang, B.; He, X.; Zhang, Z.; Zhao, Y.; Feng, W. Metabolism of nanomaterials in vivo: Blood circulation and organ clearance. Acc. Chem. Res. 2013, 46, 761-769. [CrossRef] [PubMed]

21. Walkey, C.; Das, S.; Seal, S.; Erlichman, J.; Heckman, K.; Ghibelli, L.; Traversa, E.; McGinnis, J.F.; Self, W.T. Catalytic properties and biomedical applications of cerium oxide nanoparticles. Environ. Sci. Nano 2015, 2, 33-53. [CrossRef] [PubMed]

22. Patila, S.; Sandbergb, A.; Heckertc, E.; Selfc, W.; Seala, S. Protein adsorption and cellular uptake of cerium oxide nanoparticles as a function of zeta potential. Biomaterials 2007, 28, 4600-4607. [CrossRef] [PubMed]

23. Dowding, J.M.; Das, S.; Kumar, A.; Dosani, T.; McCormack, R.; Gupta, A.; Sayle, T.X.; Sayle, D.C.; von Kalm, L.; Seal, S.; et al. Cellular interaction and toxicity depend on physicochemical properties and surface modification of redox-active nanomaterials. ACS Nano 2013, 7, 4855-4868. [CrossRef] [PubMed]

24. Wang, X.; Wang, Y.; Chen, Z.G.; Shin, D.M. Advances of cancer therapy by nanotechnology. Cancer Res. Treat. 2009, 41, 1-11. [CrossRef] [PubMed]

25. Wicki, A.; Witzigmann, D.; Balasubramanian, V.; Huwyler, J. Nanomedicine in cancer therapy: Challenges, opportunities, and clinical applications. J. Control. Release 2015, 200, 138-157. [CrossRef] [PubMed]

26. Li, T.; Amari, T.; Semba, K.; Yamamoto, T.; Takeoka, S. Construction and evaluation of pH-sensitive immunoliposomes for enhanced delivery of anticancer drug to ErbB2 over-expressing breast cancer cells. Nanomed. NBM 2017, 13, 1219-1227. [CrossRef] [PubMed]

27. Jain, K.K. Nanobiotechnology-based strategies for crossing the blood-Brain barrier. Nanomedicine 2012, 7, 1225-1233. [CrossRef] [PubMed]

28. Poljsak, B.; Raspor, P. The antioxidant and pro-oxidant activity of vitamin C and trolox in vitro: A comparative study. J. Appl. Toxicol. 2008, 28, 183-191. [CrossRef] [PubMed]

29. Aruoma, O.I. Free radicals, oxidative stress, and antioxidants in human health and disease. JAOCS 1998, 75, 199-212. [CrossRef]

30. Emerit, J.; Edeas, M.; Bricaire, F. Neurodegenerative diseases and oxidative stress. Biomed. Pharmacother. 2004, 58, 39-46. [CrossRef] [PubMed]

31. Xu, C.; Qu, X. Cerium oxide nanoparticle: A remarkably versatile rare earth nanomaterial for biological applications. NPG Asia Mater. 2014, 6, e90. [CrossRef] 
32. Nelson, C.B.; Johnson, M.E.; Walker, M.L.; Riley, K.R.; Sims, C.M. Antioxidant cerium oxide nanoparticles in biology and medicine. Antioxidants 2016, 5, 15. [CrossRef] [PubMed]

33. Singh, V.; Singh, S.; Das, S.; Kumar, A.; Self, W.T.; Seal, S. A facile synthesis of PLGA encapsulated cerium oxide nanoparticles: Release kinetics and biological activity. Nanoscale 2012, 4, 2597. [CrossRef] [PubMed]

34. Gregoriadis, G. Engineering liposomes for drug delivery: Progress and problems. Trends Biotechnol. 1995, 13, 527-537. [CrossRef]

35. Chen, C.S.; Yao, J.; Durst, R.A. Liposome encapsulation of fluorescent nanoparticles: Quantum dots and silica nanoparticles. J. Nanopart. Res. 2006, 8, 1033-1038. [CrossRef]

36. Pradhan, P.; Giri, J.; Rieken, F.; Koch, C.; Mykhaylyk, O.; Döblinger, M.; Banerjee, R.; Bahadur, D.; Plank, C. Targeted temperature sensitive magnetic liposomes for thermo-chemotherapy. J. Control. Release 2010, 142, 108-121. [CrossRef] [PubMed]

37. Kulshrestha, P.; Gogoi, M.; Bahadur, D.; Banerjee, R. In vitro application of paclitaxel loaded magnetoliposomes for combined chemotherapy and hyperthermia. Colloids Surf. B Biointerfaces 2012, 96, 1-7. [CrossRef] [PubMed]

38. Liu, Y.; Liu, J. Adsorption of nanoceria by phosphocholine liposomes. Langmuir 2016, 32, 13276-13283. [CrossRef] [PubMed]

39. Sou, K.; Naito, Y.; Endo, T.; Takeoka, S.; Tsuchida, E. effective encapsulation of proteins into size-controlled phospholipid vesicles using freeze-thawing and extrusion. Biotechnol. Prog. 2003, 19, 1547-1552. [CrossRef] [PubMed]

40. Takeoka, S.; Mori, K.; Ohkawa, H.; Sou, K.; Tsuchida, E. Synthesis and assembly of poly(ethylene glycol)-Lipids with mono-, di-, and tetraacyl chains and a poly(ethylene glycol) chain of various molecular weights. J. Am. Chem. Soc. 2000, 122, 7927-7935. [CrossRef]

(C) 2017 by the authors. Licensee MDPI, Basel, Switzerland. This article is an open access article distributed under the terms and conditions of the Creative Commons Attribution (CC BY) license (http:/ / creativecommons.org/licenses/by/4.0/). 


\section{MDPI}

St. Alban-Anlage 66

4052 Basel

Switzerland

Tel. +41616837734

Fax +41 613028918

www.mdpi.com

Nanomaterials Editorial Office

E-mail: nanomaterials@mdpi.com www.mdpi.com/journal/nanomaterials

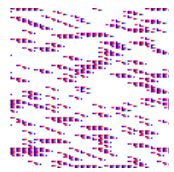



MDPI

St. Alban-Anlage 66

4052 Basel

Switzerland

Tel: +41 616837734

Fax: +41 613028918 